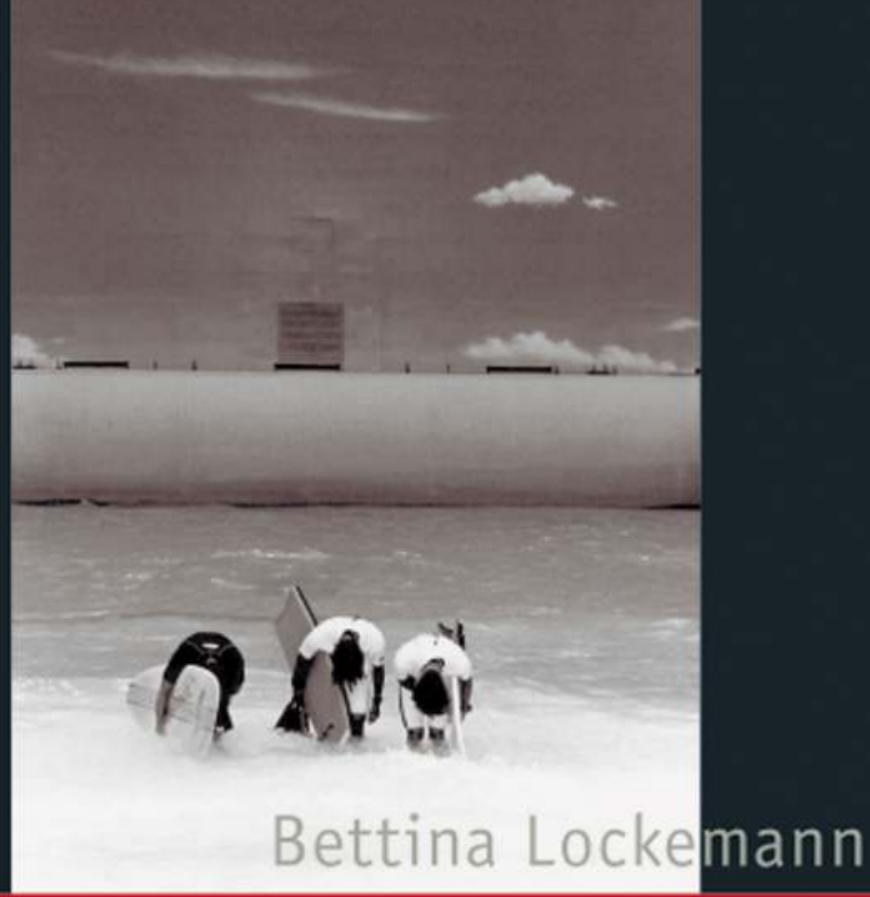

\title{
DAS FREMDE SEHEN
}

Der europäische Blick auf Japan in der künstlerischen Dokumentarfotografie

[transcript] Kultur-und Medientheorie 
Bettina Lockemann

Das Fremde sehen 
Bettina Lockemann (Dr. phil.) ist Künstlerin und Kunstwissenschaftlerin. Sie lehrt künstlerische Fotografie und Kunsttheorie u.a. in Stuttgart und Zürich. 


\author{
Bettina Lockemann \\ Das Fremde sehen. \\ Der europäische Blick auf Japan \\ in der künstlerischen Dokumentarfotografie
}


Als Dissertation angenommen im Dezember 2007 an der Staatlichen Akademie der Bildenden Künste Stuttgart im Fachbereich Kunstwissenschaft.

Erstgutachter war Prof. Dr. Hans Dieter Huber, Zweitgutachter war Prof. Dr. Rolf Sachsse.

Bibliografische Information der Deutschen Nationalbibliothek Die Deutsche Nationalbibliothek verzeichnet diese Publikation in der Deutschen Nationalbibliografie; detaillierte bibliografische Daten sind im Internet über http://dnb.d-nb.de abrufbar.

(C) 2008 transcript Verlag, Bielefeld

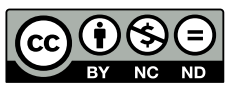

This work is licensed under a Creative Commons Attribution-NonCommercial-NoDerivatives 3.0 License.

Umschlaggestaltung: Kordula Röckenhaus, Bielefeld

Umschlagabbildung: (C) Elisabeth Neudörfl, entnommen aus dem Band: Neudörfl, Elisabeth (2002): Future World, Kat. (Sprengel Museum Hannover), Hannover Lektorat \& Satz: Bettina Lockemann Druck: Majuskel Medienproduktion GmbH, Wetzlar

$$
\text { ISBN 978-3-8376--1040-6 }
$$

Gedruckt auf alterungsbeständigem Papier mit chlorfrei gebleichtem Zellstoff.

Besuchen Sie uns im Internet: http://www.transcript-verlag.de

Bitte fordern Sie unser Gesamtverzeichnis und andere Broschüren an unter: info@transcript-verlag.de 


\section{INHALT}

$\begin{array}{ll}\text { Vorwort } & 7\end{array}$

$\begin{array}{lr}\text { Einleitung } & 9\end{array}$

\section{TEIL I: THEORETISCHE GRUNDLAGEN}

1. Der Blick auf das Fremde. Annäherung an ein Begriffsfeld 19

1.1. Das Fremde und das Andere 20

1.1.1. Das Fremde 20

1.1.2. Das Andere $\quad 25$

1.2. Begegnung mit dem Fremden $\quad 27$

1.2.1. Annäherung an das kulturell Fremde 27

1.2.2. Der ethnozentrische Blick 32

1.2.3. Kategorisierungen und Stereotype 33

1.3. Darstellungen des Fremden 42

1.3.1. Konstruktion des Anderen $\quad 42$

1.3.2. Repräsentation $\quad 45$

2. Konkrete Fremde. Das europäische Bild Japans 53

2.1. Die Relation Europa - Japan 54

2.1.1. Japan als Gegenstand der Wissenschaft 54

2.2. Europäisch-japanische Begegnungen $\quad 57$

2.2.1. Historischer Überblick $\quad 57$

2.2.2. Europäische Sichtweisen Japans 63

2.3. Stereotype Japanbilder $\quad 73$

2.3.1. Fremd- und Selbstbilder $\quad 73$

2.3.2. Visuelle Klischees $\quad 80$

3. Wann ist Fotografie dokumentarisch? 85

3.1. Herleitung des Begriffs $\quad 86$

3.2. Grundprobleme der Dokumentarfotografie $\quad 88$

3.2.1. Das Verhältnis zwischen Bild und Welt 89

3.2.2. Fotografie und Wahrheit 95

3.2.3. Bedeutung und Sichtbarkeit in der Dokumentarfotografie 99

3.2.4. Intention und Wirkung 106

4. Gebrauchsweisen der Dokumentarfotografie 113

4.1. Künstlerische Dokumentarfotografie 116

4.1.1. Beschreibung versus Interpretation 118

4.1.2. Verschiedene Ansätze 120

4.1.3. Frühe künstlerische Dokumentarfotografie 121

4.1.4. Der Fotograf als Autor 125

4.1.5. Kontextualisierung und Präsentation 127

4.2. Angewandte Dokumentarfotografie $\quad 130$

4.2.1. Reisefotografie 130

4.2.2. Ethnografische Fotografie 138

4.2.3. Journalistische Fotografie 145 
1. Japan nach 1945. Dokumentarfotografische Sichtweisen auf Nachkriegsjapan

2. Zeitgenössische dokumentarfotografische Sichtweisen auf Japan 181

2.1. Japan und die Düsseldorfer Becher-Schule 183

2.1.1. Die erste Generation $\quad 183$

2.1.2. Heiner Schilling 184

2.2. European Eyes on Japan 194

2.2.1. Naomi Tereza Salmon 195

2.2.2. Hans van der Meer 199

2.2.3. Margherita Spiluttini 202

2.3. Verschiedene Strategien der Annäherung an Japan 205

3. Paul Graham: Empty Heaven 211

3.1. Das Buch 213

3.2. Die Eingangssequenz $\quad 214$

3.3. Angeeignete Bildwelten 221

3.4. Künstliche Natur $\quad 231$

3.5. Menschenbilder $\quad 234$

3.5.1. Frauenporträts $\quad 234$

3.5.2. Bürokraten 238

3.6. Sequenzen und Tableaus $\quad 240$

3.7. Bewertung 242

4. Elisabeth Neudörfl: Future World 249

4.1. Das Buch 251

4.2. Die Eingangssequenzen $\quad 253$

4.2.1. Der westliche Einstieg 253

4.2.2. Der japanische Einstieg 258

4.3. Verdichtete Stadt 262

4.4. Sicherheit 267

4.5. Freizeit 272

4.6. Menschenbilder 275

4.6.1. Menschengruppen $\quad 275$

4.6.2. Porträts 279

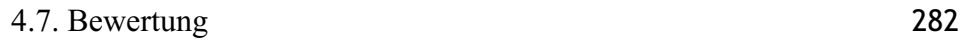

5. Auswertung der Gespräche mit japanischen Fotografie-Experten 287

5.1. Gespräche über Paul Grahams Empty Heaven 290

5.2. Gespräche über Elisabeth Neudörfls Future World 297

$\begin{array}{ll}\text { Schlussbemerkung } & 303\end{array}$

$\begin{array}{ll}\text { Literaturverzeichnis } & 311\end{array}$ 


\section{VORWORT}

Die vorliegende Dissertation setzt sich mit dem europäischen Blick auf Japan jenseits von Stereotypen und Klischees auseinander. Auch wenn bereits im Titel Japan und Europa als Regionen vorgestellt werden, die sich gegenseitig fremd sind, kann die Behauptung, Europa und Japan seien jeweils als Einheiten zu betrachten, kaum die Vielschichtigkeit beider Regionen treffend beschreiben. Vor dem Hintergrund der jeweils anderen Region überwiegen dennoch innere Gemeinsamkeiten, die hier mit den gewählten Begriffen Japan und Europa benannt werden. Auch wenn eine Überwindung von Stereotypen intendiert ist, ist nicht garantiert, dass sie vollkommen gelingt. Manche Begrifflichkeiten und Schlussfolgerungen mögen verkürzte Sichtweisen beinhalten, die die Vielschichtigkeiten und Differenzierungen nicht in vollem Umfang widerspiegeln. Ich habe mich bemüht, an Stellen, wo eine Differenzierung notwendig erscheint, sie auch zu treffen. An anderen Stellen habe ich, um eine allgemeinere Lesart zu betonen, auf solche Differenzierungen zugunsten der Lesbarkeit verzichtet. Weil es kaum möglich scheint, sämtliche Voreingenommenheiten und stereotype Annahmen $\mathrm{zu}$ überwinden, möchte ich um Nachsicht bitten, sollten sie doch einmal durchscheinen.

Im Text sind japanische Namen entsprechend der japanischen Konvention in umgekehrter Reihenfolge genannt: zuerst der Nachname gefolgt vom Vornamen. Englischsprachige Zitate habe ich - wenn nicht anders gekennzeichnet - selbst ins Deutsche übersetzt, um den Lesefluss zu verbessern. Die Interviews, die ich mit japanischen Fotografie-Expertinnen und -Experten geführt habe, können in der vollständigen Fassung im Internet von der Verlagswebsite herunter geladen werden (vgl. http://www.transcript-verlag.de/ ts1040/ts1040.php).

Ich habe mich in den Formulierungen der Einfachheit halber für die männliche Form entschieden, möchte aber betonen, dass sie die weibliche Form immer gleichberechtigt mit einschließt. Der Text ist in der neuen deutschen Rechtschreibung verfasst. Zitate sind in der originalen Schreibweise belassen, weshalb sich manchmal eine Kombination verschiedener Rechtschreibungen innerhalb eines Satzes oder Absatzes nicht vermeiden lässt.

Diese Arbeit wäre ohne die Unterstützung zahlreicher Menschen nicht zustande gekommen. Mein besonderer Dank gilt meinem Doktorvater Hans Dieter Huber, ohne dessen Vertrauen und Anregung ich diese Arbeit nie begonnen hätte. Gleichermaßen danke ich meinem Zweitgutachter Rolf Sachsse für die umfassende fachliche Unterstützung. Die Staatliche Akademie der Bildenden Künste Stuttgart hat das Projekt mit einem Graduiertenstipendium unterstützt. Einen dreimonatigen Forschungsaufenthalt in Japan ermöglichte ein Promotionsstipendium des Deutschen Instituts für Japanstudien in Tokyo. Danken möchte ich dessen Direktor Florian Coulmas sowie der Leiterin des Goethe-Instituts Osaka, Petra Matusche. Weiterhin danke ich meinen japani- 
schen Interviewpartnerinnen und -partnern: Aya Tomoka, Enari Tsuneo, Iizawa Kôtarô, Ikeda Yuko, Kasahara Michiko, Kikuta Mikiko, Matsumoto Kaoru, Oshima Naruki, Saiga Yuji mit seinen Studenten und Yoshihara Mieko. Danken möchte ich auch Cathy und Stefan Hotes, Elisabeth Neudörfl, Paul Graham, Claudia Olk, Erdmute und Hans-Friedrich Lockemann, Christoph Löhr sowie allen Kolleginnen und Kollegen, die durch Gespräche und Anregungen nachhaltig zum Gelingen dieser Arbeit beigetragen haben. 


\section{EINLEITUNG}

Als der amerikanische Gesandte Commodore Matthew Perry 1853 in Japan landet, um das seit fast 250 Jahren für Fremde weitgehend unzugängliche Land zur Öffnung seiner Häfen zu bewegen, wird er vom Fotografen Eliphalet M. Brown Junior begleitet. Dieser beginnt umgehend damit, Japaner und Japanerinnen in ihren fremd anmutenden Kleidern zu porträtieren sowie exotische Landschaften und Architekturen zu dokumentieren. ${ }^{1}$ Browns fotografischer Einsatz ist nicht zuletzt auf das eindringliche Plädoyer François Aragos zurückzuführen, der 1839 Louis Jacques Mandé Daguerres Erfindung der französischen Akademie der Wissenschaften vorstellt und sogleich die Dokumentation fremder Länder und ihrer Kulturgüter als eine der sinnfälligen Gebrauchsweisen des neuen Mediums Fotografie benennt (vgl. Arago 1980: 51f.).

Aufgrund des Erfolges der Perry-Mission siedeln sich in den der Öffnung folgenden Jahren zahlreiche Europäer in Japan an. Als einer der ersten in Yokohama ansässigen Fotografen schafft Felice Beato »einen >visuellen Code< von Japan, der einerseits dem europäischen enzyklopädischen Erfassen der >Fremde` und der Sehnsucht nach dem Einfachen und Anderen [entspricht], andererseits eine maßgebliche Rolle bei der Prägung der Themen und Motive« spielt (Delank 1996: 283). Beatos zweibändiges Albenwerk Photographic Views of Japan von 1868 setzt thematische Maßstäbe und dient lange Zeit als Vorbild in der Japanfotografie. Die vorrangig für den westlichen Markt angefertigten Fotografien bedienen die Sehnsucht nach der geheimnisvoll erscheinenden japanischen Exotik. »Beliebte Motive [sind] - damals wie heute bekannte Bauwerke, landschaftlich schöne Orte, >typisch Japanisches` wie Frauen im Kimono und Samurai in Rüstung, die Darstellung künstlerischer oder handwerklicher Aktivitäten [und] religiöser Zeremonien« (Delank 2003: 2). Die japanische Art sich zu kleiden und zu frisieren oder die Methoden des Handwerks gelten als ebenso abbildungswürdig wie die fremden Naturschönheiten und Architekturen, die sehr anders als europäische anmuten. Durch die umfangreiche Bildproduktion wird eine spezifische Sichtweise auf Japan etabliert. Diese Bildwelten beeinflussen die westliche Japanrezeption und prägen bis heute unser Japanbild. ${ }^{2}$ Auch wenn insbesondere seit dem Ende des Zweiten Weltkrieges zahlreiche neue Themenbereiche die Japandarstellungen erweitert haben und heute das zeitgenössische Japan mitsamt seiner technologischen Avanciertheit sowie seinen Subkulturen repräsentieren,

1 Browns Fotografien wurden später durch einen Brand zerstört, so dass heute nur einige wenige Motive in Form von Kupferstichen erhalten sind, die zur Illustration des Perry-Berichts eingesetzt wurden.

2 Der Begriff des Japanbildes bezeichnet unsere Vorstellungen von Japan und vereint Wissen, Annahmen und mentale Bilder; das Japanbild ist nicht zu verwechseln mit fotografischen Abbildungen. 
scheinen die klischeehaften Darstellungen japanischer Fremdheit bis in die Gegenwart hinein zu überwiegen.

Die Beziehungen zwischen Europa und Japan beginnen jedoch nicht erst mit der Öffnung Japans ab 1853. Bereits seit dem sechzehnten Jahrhundert bestehen erste Kontakte, die auch während der fast 250 Jahre währenden Abschließung Japans nicht abreißen. Seit Beginn der Beziehungen entstehen Wechselwirkungen kultureller Art. Die Europäer sind insbesondere vom japanischen Kunsthandwerk begeistert. Als in Meißen im achtzehnten Jahrhundert die Porzellanproduktion aufgenommen wird, werden zunächst traditionelle japanische Muster nachgeahmt (vgl. Impey 1993: 162). Umgekehrt beeinflussen westliche Wissenschaften die japanische Forschung. Die so genannten Rangaku (holländische Wissenschaften) werden in Japan aufmerksam rezipiert. Die Rangaku umfassen vor allem die naturwissenschaftlichen Bereiche der Physik, Chemie, Astronomie, Botanik und Optik, technisches Wissen wie Vermessungs- und Waffenkunde, aber auch Geografie und Geschichte. Als wichtigste Disziplin steht jedoch die westliche Medizin im Mittelpunkt (vgl. Tadashi 1993: 94). Die Rangaku bilden die Grundlagen für zahlreiche nach der japanischen Öffnung übernommene Neuerungen aus den westlichen Ländern. In der Bildenden Kunst ist insbesondere die Perspektive eine aus Europa eingeführte Erfindung, mit der japanische Künstler seit dem achtzehnten Jahrhundert experimentieren (vgl. Screech 1993: 128ff.).

Die Fähigkeit der japanischen Kultur, Einflüsse aus anderen Kulturen in die eigene $\mathrm{zu}$ integrieren, wirkt sich bis heute auf die europäische Japanrezeption aus. Als einziger nicht-westlicher Vertreter unter den führenden Industrienationen der Welt oszilliert Japan aus europäischer Sicht zwischen Fremdheit und Vertrautheit. Lebensstandard und Stand der Industrialisierung wirken in Europa sehr vertraut, während die traditionelle Kultur als fremd und anders wahrgenommen wird. Weil Japan nie kolonisiert war, sondern durch eine weitgehend eigenständige Industrialisierungsleistung $\mathrm{zu}$ den westlichen Nationen aufschließen konnte, ohne zuvor von ihnen ausgebeutet zu werden, nimmt Japan eine Sonderstellung unter den asiatischen Ländern ein. Denn in Europa empfindet man Japan nicht als absolut fremd - wie weniger entwickelte asiatische Staaten - noch ist es so vertraut wie andere christlich-europäisch geprägte Länder, beispielsweise in Südamerika. Weil es in den historischen Kontakten zwischen Japan und Europa, im Vergleich zu Regionen, zwischen denen koloniale Beziehungen bestanden, keine extremen Hierarchien gibt, können sich Japaner und Europäer grundsätzlich auf Augenhöhe gegenüber treten. Dies trifft zwar nicht pauschal für den gesamten historischen Zeitraum der Begegnung vom sechzehnten Jahrhundert bis heute zu, dennoch wird Japan von Anbeginn des Kontakts in Bereichen von Kultur und Gesellschaft als ähnlich entwickelt betrachtet wie europäische Nationen. In der Aufklärung - beispielsweise bei Voltaire - wird es sogar als Vorbild für ein Europa gesehen, das moralisch zu verkommen droht (vgl. Friese 1990: 37).

Da sich Japan erst kurz nach der Erfindung der Fotografie gegenüber dem Ausland öffnet, wird die Fotografie zu einer wichtigen Zeugin der Wandlung Japans von einer feudalen hin zu einer modernen Industriegesellschaft. Aus diesem Grund zeigen frühe Fotografien ein weitgehend traditionelles Japan, das sich nach und nach verändert. Allerdings interessieren sich westliche Fotografen auch während der zunehmenden Industrialisierung hauptsächlich für Traditionelles, während japanische Fotografen unter anderem die Industrialisierungsleistung dokumentieren, beispielsweise die Er- 
schließung der nördlichen Hauptinsel Hokkaido (vgl. Kinoshita 2003: 31ff.). ${ }^{3}$ Für den westlichen Markt fertigen in der Frühzeit der Fotografie allerdings auch japanische Fotografen Bilder vom exotischen Japan an. Die verschiedenen Bildwelten deuten auf unterschiedliche Interessen in der Japandarstellung hin. Heute lässt sich eine solche thematische Trennung der bildnerischen Interessen von japanischer und europäischer Seite nicht aufrecht erhalten, dennoch wirken insbesondere die historisch entwickelten westlichen Präferenzen in der Vermittlung Japans bis in die Gegenwart hinein.

Das beeinflusst auch die europäischen Vorstellungen von Japan. Widmet sich die Literaturwissenschaft seit langem in großem Umfang der Untersuchung der Entwicklung des Japanbildes in der europäischen Literatur, fehlen ähnliche Erkenntnisse für die Rolle der Fotografie. Ohne eine breit angelegte historische Untersuchung des europäischen Japanbildes innerhalb der Fotografiegeschichte vornehmen zu wollen, werden die historischen Grundlagen, vor deren Hintergrund sich auch visuelle Vorstellungen von Japan in Europa entwickelt haben, in der vorliegenden Studie untersucht. Dies bildet die Ausgangsbasis für die Betrachtung der Entwicklungen in der Japanfotografie seit dem Ende des Zweiten Weltkrieges.

Über einen langen Zeitrum hinweg wird der Fotografie, insbesondere ihren dokumentarischen Gebrauchsweisen, die Fähigkeit zugesprochen, eine authentische Darstellung der Realität zu ermöglichen. Aus diesem Grund gilt sie auch als geeignet, sich mit fremden Kulturen zu beschäftigen und deren Besonderheiten wahrheitsgemäß zu übermitteln. Im kritischen Diskurs kann diese Annahme jedoch nicht aufrecht erhalten werden. Die Fotografie vermag eine wahrheitsgemäße Wiedergabe der Welt nicht zu leisten. Wenn eine authentische Abbildung nicht möglich ist, was bedeutet das für die fotografische Annäherung an das Fremde? Kann Fotografie überhaupt eine glaubhafte Darstellung des Fremden leisten? Und welche Möglichkeiten bieten verschiedene dokumentarfotografische Ansätze für die Darstellung des Fremden? Die Erkenntnis der Unmöglichkeit objektiver Beschreibungen des Fremden - beispielsweise in der Ethnologie - führt zu der Annahme, dass eine subjektive Herangehensweise Fremdheitsdarstellungen ermöglichen kann, die dem Fremden als Fremdes gerecht werden. Hier wird ein besonderes Augenmerk auf die Kunst gelegt, die zur Überwindung der Krise der (ethnografischen) Repräsentation einen Ausweg zu versprechen scheint. Folgen angewandte dokumentarfotografische Praktiken in der Regel dem Wirklichkeitsversprechen der Fotografie, indem sie vermeintlich objektive Belege für beschreibbare Gegebenheiten liefern, operieren künstlerische Gebrauchsweisen der Dokumentarfotografie in einem großen Freiraum. Hier wird die mediale Bedingtheit des Mediums reflektiert und mit Wirkungen experimentiert. Dieser erweiterte Handlungsspielraum künstlerischer Formen der Dokumentarfotografie deutet auf interessante Auseinandersetzungen mit dem Fremden, weshalb diese Praktiken im Zentrum der Untersuchung stehen.

Weil die zeitgenössischen europäischen Japandarstellungen in der künstlerischen Dokumentarfotografie auf eine langjährige Tradition aufbauen, ist es interessant, auch fotografische Positionen aus dem Zeitraum der 1950er bis in die 1980er Jahre hinein zu betrachten. Die Projekte der international nam-

3 Hokkaido war zuvor hauptsächlich vom Volk der Ainu bewohnt - während der Meiji-Restoration übernimmt die japanische Regierung die Insel zur nördlichen Absicherung gegen Russland. 
haften Fotografen Werner Bischof, William Klein und Ed van der Elsken verfolgen verschiedene dokumentarfotografische Strategien im Umgang mit Japan. Ihre weitgehend künstlerischen Annäherungen zeugen sowohl von sich verändernden fotografischen Voraussetzungen im Umgang mit dem Fremden als auch von Veränderungen der japanischen Gesellschaft seit dem Zweiten Weltkrieg. Alle drei Projekte sind als Künstlerbücher publiziert worden.

Das monografische Künstlerbuch ist eine Publikationsform, der im Rahmen der vorliegenden Arbeit eine besondere Bedeutung zukommt. Vom Künstler selbst konzipiert und gestaltet fasst es in der Regel alle zu einem Projekt gehörenden Fotografien als Einheit zusammen. Über die Bildauswahl, das Layout und die Einbeziehung von Texten entscheidet der Künstler selbst. Insofern stellt das Künstlerbuch eine autonome Kunstform dar, die nicht von redaktionellen Erwägungen eines Kurators beeinflusst ist. Es ist davon auszugehen, dass das Künstlerbuch ein Projekt vollständig und im vom Künstler intendierten Sinne enthält, weshalb es als ideale Form gesehen werden kann, die über Intention und Haltung des Künstlers Aufschluss gibt.

Ausschlag gebend für die Auswahl der vorgestellten Fotografen und Fotografinnen sind verschiedene Parameter: Grundprämisse ist die konsequente Anwendung einer künstlerischen Dokumentarfotografie, deren Intention es ist, sich anlässlich der zeitgenössischen japanischen Kultur und Gesellschaft intensiv mit Fragen des Fremden zu befassen. Insofern ist die Fremdheit gegenüber Japan Bedingung der Auswahl. Aus diesem Grund werden weder Europäer berücksichtigt, die in Japan, noch Japaner, die in Europa leben. Die Fremdheitserfahrung ist ein wichtiges Kriterium, denn in der Auseinandersetzung mit dem Fremden durchdringt sie sich mit der Selbsterfahrung: Beide sind nicht voneinander zu trennen. Weiterhin ist der Bereich der behandelten Motive entscheidend. Berücksichtigt werden Arbeiten, die sich verschiedenen japanischen Motivwelten widmen. Sie beinhalten beispielsweise Porträts, Architektur und Landschaften oder beschäftigen sich mit Menschendarstellungen im Zusammenhang mit Innen- und Außenräumen. Nur so scheint gewährleistet, dass ein vielschichtiges Bild der japanischen Gesellschaft sichtbar wird. Arbeiten, die sich ausschließlich mit Architekturen, Landschaften oder Porträts beschäftigen, finden keine Berücksichtigung. Es geht insgesamt um die Erörterung der Frage, welche Möglichkeiten eine künstlerische Dokumentarfotografie bereithält, um Fremdes als Fremdes zu thematisieren und so möglicherweise ein über Klischees und Stereotypen hinausweisendes Japanbild zu zeigen. Dies scheint mitunter dadurch gewährleistet, dass unterschiedliche Elemente der zeitgenössischen japanischen Kultur innerhalb der einzelnen Arbeit berücksichtigt werden.

Im Zentrum der Betrachtung der zeitgenössischen Auseinandersetzung mit Japan stehen deshalb zwei Künstlerbücher. Paul Grahams und Elisabeth Neudörfls Arbeiten werden als Fallbeispiele für einen aufgeschlossenen Umgang mit dem Fremden untersucht. Beide Arbeiten sind sehr unterschiedlich konzipiert und zeugen von einem konsequenten Einsatz der künstlerischen Dokumentarfotografie. Diese beiden Fotografen werden beispielhaft betrachtet, weil sie sich über einen längeren Zeitraum in Japan aufhalten und sich intensiv mit der japanischen Kultur auseinandersetzen. Graham fotografiert Porträts, greift auf historisches Bildmaterial zurück, untersucht Innenräume sowie ausgewählte Situationen des Außenraums. Neudörfl konzentriert sich auf Porträts und urbane Situationen, fotografiert aber auch Landschaften sowie besonders gestaltete Freizeitumgebungen. Die Kombination von Men- 
schendarstellungen mit anderen Motivgruppen ermöglicht einen umfassenden Einblick in die japanische Gesellschaft. Beide Fotografen haben ihre Arbeiten ausschließlich als Auseinandersetzung mit Japan konzipiert und als monografische Werke jeweils in Form eines Künstlerbuchs publiziert. Innerhalb der geschlossenen Form des Künstlerbuchs, in dem zahlreiche Fotografien zueinander in Beziehung gesetzt werden, lassen sich die Fotografien einzeln und in der Zusammenstellung sowie im Hinblick auf die Intentionen der Künstler zusammenhängend untersuchen.

Ziel der Arbeit ist es herauszufinden, welche Möglichkeiten eine zeitgenössische künstlerische Dokumentarfotografie besitzt, um einen über Klischees hinausweisenden Umgang mit dem Fremden zu leisten. Das Thema Fremdheit bedarf als Konkretisierung der Auswahl einer spezifischen fremden Kultur. Der europäische Blick auf Japan ist nicht das einzig mögliche Beispiel für die Untersuchung der Sicht auf das Fremde. Japan ist aber deshalb interessant, weil es oft als sehr anders, wenn nicht sogar exotisch, wahrgenommen wird; es gibt zahlreiche Japanklischees. Andererseits kann Japan als eine der weltweit führenden Industrienationen den europäischen Ländern gegenüber als gleichwertig gelten. Weil es erst parallel zur Erfindung der Fotografie von Ausländern - beispielsweise Reisenden, Handelsvertretern oder Wissenschaftlern - besucht werden kann, spielt die Fotografie in der Entdeckung und Erforschung Japans für den Westen eine entscheidende Rolle. Deshalb unterscheidet sich das Verhältnis Europas zu Japan von dem zu anderen Kulturen, die ebenfalls Gegenstand einer Betrachtung des Fremden sein können. ${ }^{4}$ Weil insbesondere seit den 1990er Jahren zahlreiche europäische Fotografen in Japan fotografiert haben, steht umfangreiches Material zur Verfügung. Im Umkehrschluss bietet sich auch die gegenläufige Untersuchung des japanischen Blicks auf Europa an. Es findet sich jedoch keine vergleichbar umfangreiche japanische Auseinandersetzung mit Europa. Zudem bietet die Analyse der europäischen Arbeiten so reichhaltiges Material, dass die Berücksichtigung des Blicks in umgekehrte Richtung Inhalt weiterer Untersuchungen sein muss.

Viele europäische Japanfotografien zeigen heute ein Land, das durch einen tiefen Riss zwischen Tradition und Moderne gekennzeichnet ist. Zeitgenössische Darstellungen verweisen hauptsächlich auf Aspekte der boomenden Metropolenregion Tokyo, auf postmoderne oder extravagante Architekturen, auf technologisch Avanciertes, auf die Manga- und Game-Kultur, kurz: auf alles, was anders ist. Im Gegensatz dazu haben Fotografen wie Paul Graham und Elisabeth Neudörfl, die eine künstlerische Dokumentarfotografie betreiben, andere Ansätze und eigene Ansprüche. Sie vertreten ein Japanbild, das Klischees kritisch befragt und möglicherweise neue Sichtweisen etabliert. Damit initiieren diese Positionen im besten Fall beim Publikum ein Nachdenken über die eigenen Vorstellungen der fremden Kultur. Anhand dieser Japandarstellungen können Möglichkeiten und Grenzen des Dokumentarischen exemplarisch aufgezeigt werden.

Zur Entwicklung der Fragestellung ist es notwendig, zunächst einen theoretischen Apparat zu erarbeiten. Am Anfang steht die Auseinandersetzung

4 Die Berücksichtigung kolonialer Sichtweisen und Konflikte, wie sie in der Beziehung zu China beispielsweise zu thematisieren wären, lenkt den Blick wesentlich stärker auf das Politische, was nach meiner Einschätzung der Betrachtung der Fotografien Raum nähme. 
mit Fragen nach dem Fremden und Fremdheit. Untersucht wird auch die Bildung von Stereotypen, die den Blick auf das Fremde verstellen. Denn sie versuchen, es mit Hilfe von Beschreibungen festzulegen, was dem Fremden in seiner schillernden Diversität nicht gerecht werden kann. ${ }^{5}$ Weil Japan als Beispiel von Fremdheit herangezogen wird, ist die Untersuchung der langjährigen Beziehungen zwischen Europa und Japan ebenso relevant für die Fragestellung wie die Beschäftigung mit konkreten Klischees und Stereotypen, wie sie Japan und der japanischen Gesellschaft von europäischer Seite aus zugeschrieben werden. Weiterhin sind die Möglichkeiten der Dokumentarfotografie auszuloten. Welche Ansätze bietet sie auf, um sich mit Realität und im konkreten Fall mit der Realität des Fremden anlässlich einer fremden Kultur auseinanderzusetzen? Dazu gehört eine eingehende begriffliche Untersuchung der Grundvoraussetzungen der Dokumentarfotografie ebenso wie die Unterscheidung verschiedener dokumentarfotografischer Ansätze, die sich mit dem Fremden beschäftigen. Diese theoretischen Grundlagen bilden die Ausgangsbasis für die Betrachtung der zeitgenössischen Arbeiten der künstlerischen Dokumentarfotografie als Fallbeispiele für den Umgang mit dem Thema des Blicks auf das Fremde, die im zweiten Teil der Arbeit erfolgt.

Im ersten Teil der Arbeit werden in vier Kapiteln die theoretischen Grundlagen des Themas erarbeitet. Als Ausgangspunkt ist im ersten Kapitel das Fremde Gegenstand der Betrachtung. ${ }^{6}$ Thematisiert wird seine begriffliche Unterscheidung vom Anderen sowie der Umgang mit ihm. Hier sind insbesondere auch ethnologische Methoden relevant, die auf vielen Feldern der interkulturellen Begegnungen nutzbar gemacht werden können. Ethnozentrismus, Stereotypen und Vorurteile verstellen scheinbar den Blick auf das Fremde, weshalb die Umstände ihrer Entstehung genau beleuchtet werden. Weil das Fremde nicht ohne mediale Vermittlungen, sei es durch ethnografische Monografien oder fotografische Bilder, in Abwesenheit zur Anschauung gebracht werden kann, geht es schließlich um die Möglichkeiten seiner Repräsentation. Seine Vermittlung erweist sich jedoch als außerordentlich schwierig, was im Bereich der Ethologie zu einer Krise geführt hat. Welche alternativen Repräsentationsmöglichkeiten des Fremden stehen zur Verfügung?

Das zweite Kapitel führt Japan als konkrete Fremde ein und bietet einen Überblick über die komplexen Beziehungen zwischen Europa und Japan sowie die Entwicklung des europäischen Japanbildes seit den ersten Berichten Marco Polos bis in die Gegenwart hinein. Ausgehend von der Annahme, dass die heutige europäische Sicht auf Japan noch immer zumindest teilweise von stereotypen Wahrnehmungen beeinflusst ist, werden japanische Selbst- und Fremdbilder auf ihre Wandlungsfähigkeit hin untersucht. Mittels der Analyse visueller Japan-Klischees und deren historischer Entwicklung werden die bis

5 Das Fremde schillert: Es entzieht sich der Bewertung und vermag Aufmerksamkeit zu erregen, indem es zugleich anziehend wie abstoßend wirkt, ohne dass es zunächst möglich ist zu bestimmen, ob Repulsion oder Attraktion überwiegen. Das Fremde wirkt charismatisch. »Bemerkenswert ist die Tatsache, daß [...] der Forscher von einer Attraktion ausgeht, die sein >Gegenstand ‘ auf ihn ausübt. Allerdings kann die kulturelle Fremderfahrung auch von einer Repulsion ausgehen oder von einer Mischung aus Attraktion und Repulsion« (vgl. Waldenfels 1997: 103; Hervorhebung im Original).

6 Weil die theoretischen Grundlagen im ersten Kapitel umfassend diskutiert werden, möchte ich an dieser Stelle auf Quellenangaben verzichten. Die hier verwendeten Begriffe sind dort ausführlich belegt. 
in die Gegenwart hineinreichenden Auswirkungen der über Jahrhunderte tradierten Vorstellungen auf die westlichen Darstellungen Japans deutlich.

Das dritte Kapitel geht der Frage nach, wann Fotografie als dokumentarisch bezeichnet werden kann. Unter bildwissenschaftlichen Gesichtspunkten werden der Weltbezug sowie Fragen nach der Relevanz des Wahrheitsbegriffs für die Dokumentarfotografie erörtert. Das Wirklichkeitsversprechen der Fotografie, das eine authentische Repräsentation der Welt möglich erscheinen lässt, gilt als nicht einlösbar. Die >indexikalische Spurく verweist auf die letzte Bastion der in der Frühzeit der Fotografie empfundenen Realitätsnähe. Weil dokumentarische Fotografie sowohl in künstlerischen als auch in angewandten Kontexten praktiziert wird, sind die Ansprüche an Ansätze und Ziele sehr vielschichtig. Eine allgemeine Definition, die alle Bereiche und alle Intentionen über den historischen Zeitrahmen mit einschließt, kann nicht gegeben werden. Die thematischen Voraussetzungen geben nur wenig Aufschluss über dokumentarische Praktiken. Anhand von inhaltlichen Interessen und Fragen nach der fotografischen Haltung werden dokumentarische Strategien in der Auseinandersetzung mit dem Fremden als Fremdes betrachtet. Die Rede von der Krise der Repräsentation macht deutlich, dass sich zeitgenössische Dokumentarfotografie selbstkritisch mit ihren medialen Bedingtheiten und Möglichkeiten auseinandersetzen muss, um mögliche Auswege aus der Krise aufzuzeigen.

Das vierte Kapitel unterscheidet zwischen künstlerischen und angewandten Gebrauchsweisen der Dokumentarfotografie. Diese Trennung erscheint sinnvoll, weil angewandte Strategien sich dem Fremden mit anderen Intentionen nähern als künstlerische. Die Grundvoraussetzungen der künstlerischen Dokumentarfotografie manifestieren sich unter anderem in der Unterscheidung zwischen beschreibenden und interpretierenden Annäherungen an die Welt, es sind aber auch verschiedene Teilbereiche weiter auszudifferenzieren. Neben einem historischen Überblick über die Entwicklung der künstlerischen Dokumentarfotografie werden Fragen nach der Autorschaft des Fotografen sowie der Zusammenfügung von Fotografien zu Serien und Sequenzen innerhalb eines Kontextes thematisiert. Für den angewandten Bereich werden Reisefotografie, ethnografische Fotografie und journalistische Fotografie unterschieden. So weit möglich werden Bezüge zur historischen und zeitgenössischen Japanfotografie hergestellt. Historische Entwicklungen sowie Themenwahl und Darstellungsformen werden analysiert und so die grundsätzlichen Unterschiede zur Annäherung an Fremdes in der künstlerischen Dokumentarfotografie herausgearbeitet.

Der zweite Teil der Arbeit beginnt mit einem Überblick über drei fotografische Positionen, die in der Zeit zwischen den 1950er und den 1980er Jahren in Japan fotografiert worden sind. Diese vorrangig im Feld der künstlerischen Dokumentarfotografie angesiedelten Arbeiten werden auf ihre verschiedenen Ansätze der Japanfotografie hin untersucht. Die Betrachtung folgt der Annahme, dass sich in dieser Zeit nicht nur die japanische Gesellschaft nachhaltig verändert, sondern sich damit einhergehend auch die Grundvoraussetzungen der Annäherung an Japan wandeln. Untersucht werden insofern die Wahl der Themen und die visuellen Strategien der Fotografen. Werner Bischof fotografiert zu Beginn der 1950er Jahre noch das amerikanisch besetzte Japan und verfolgt einen allgemeinen Ansatz. William Klein widmet sich zehn Jahre später ausschließlich der Metropole Tokyo. Ed van der Elsken fotografiert über einen Zeitraum von fast 30 Jahren in Japan und lässt die Veränderungen innerhalb der japanischen Gesellschaft sichtbar werden. Die- 
ses Kapitel vermittelt zwischen der historischen und der gegenwärtigen fotografischen Auseinandersetzung mit Japan.

Das zweite Kapitel des zweiten Teils widmet sich verschiedenen Formen der europäischen künstlerischen Dokumentarfotografie im Japan der Gegenwart. Zunächst wird untersucht, in welcher Form sich Vertreter der Düsseldorfer Becher-Schule - beispielsweise Thomas Struth und Heiner Schilling in ihren Fotografien mit Japan als Fremdes auseinandersetzen. Einen weiteren Aspekt des europäischen Blicks auf Japan zeigt das noch andauernde Projekt European Eyes on Japan. Die Grundvoraussetzungen dieses Projekts sowie verschiedene fotografische Ansätze werden anhand von drei beispielhaft ausgewählten Arbeiten - von Naomi Salmon, Hans van der Meer und Margherita Spiluttini - analysiert. Untersucht werden auch verschiedene fotografische Strategien im Umgang mit dem fremden Japan sowie Möglichkeiten zur Überwindung voreingenommener Sichtweisen.

Im dritten und vierten Kapitel werden zwei Künstlerbücher ausführlich analysiert. Ausgehend von den Möglichkeiten, die ein in einem Künstlerbuch vollständig im Sinne des Künstlers repräsentiertes Projekt bietet, lassen sich Rückschlüsse auf die Ansätze und Intentionen der Fotografen ziehen. Das dritte Kapitel widmet sich ganz Paul Grahams Empty Heaven. In einer umfangreichen Analyse werden die gewählten Motivgruppen auf ihre Bedeutungen hin untersucht. Analysiert werden Grahams Verhältnis zum Japanthema und seine eingesetzten visuellen Strategien. Welche inhaltlichen Schwerpunkte wählt er für seine Arbeit? Wie integriert er die verschiedenen Motivkomplexe wie Porträts, reproduzierte Gemälde und Fotografien, Ansichten von kitschigen Gegenständen, Naturdarstellungen? Welche Rolle spielen traditionelle Japanthemen und wie verhält sich seine Arbeit in Bezug auf etablierte Japanklischees? Welches Japanbild können Paul Grahams Fotografien vermitteln? Wie thematisiert er Fremdheit? Diskutiert werden nicht nur die kulturellen Bedeutungen des Abgebildeten, sondern auch die Art der Umsetzung und die Anordnung der Fotografien im Buch.

Das vierte Kapitel beschäftigt sich mit Elisabeth Neudörfls Künstlerbuch Future World. Parallel zum vorangegangenen Kapitel stehen Fragen nach Intention und Annäherung an das Fremde im Mittelpunkt sowie die Analyse der eingesetzten Strategien zur Darstellung des Fremden. Eine eingehende Untersuchung der kulturellen Besonderheiten des in den Fotografien Dargestellten widmet sich den obigen Fragen und bettet Neudörfls Arbeit ein in den allgemeinen theoretischen Kontext des ersten Teils dieser Abhandlung. Themenwahl und Art der Umsetzung werden auf ihre Möglichkeiten hin befragt, etwas über die zeitgenössische japanische Kultur zu vermitteln und Fremdes als Fremdes sichtbar zu machen.

Das fünfte und letzte Kapitel untersucht die japanische Rezeption der Arbeiten von Paul Graham und Elisabeth Neudörfl. Weil die Analyse der europäischen Positionen in dieser Abhandlung aus einem europäischen Blickwinkel heraus erfolgt, kann sie keinen Aufschluss über die Beurteilung aus japanischer Sicht geben. Aus diesem Grund werden japanische FotografieExperten - Kuratoren, Galeristen, Fotografen, Professoren, Kritiker - nach ihren Eindrücken von Grahams und Neudörfls Japanprojekten befragt. Das Kapitel fasst deren Ansichten in Bezug auf den thematischen Ansatz, die gewählten Motive und die Strategien der Japandarstellung zusammen. Es geht darum herauszufinden, ob Japaner die Darstellungen als ihrer Kultur angemessen oder aber als stereotyp und klischeehaft wahrnehmen. 


\section{TEIL I:}

Theoretische GRUNDLAGEN 



\section{Der Blick Auf dAS FREMde ANNÄHERUNG AN EIN BEGRIFFSFELD}

Bevor konkret fotografische Abbildungen Japans analysiert werden, sollen in diesem Kapitel zunächst die theoretischen Grundlagen des Blicks auf das Fremde untersucht werden. Dies geschieht in drei Schritten. Im ersten Schritt geht es um die Frage, worum es sich genau handelt, wenn wir von dem Fremden sprechen? Kann man es (wissenschaftlich) erkennen und lässt es sich theoretisch beschreiben? Die Relation des Fremden zum Eigenen scheint hier von großer Bedeutung, was wiederum Fragen der Identität und Alterität aufwirft. Weiterhin ist zu untersuchen, wie sich das Fremde vom Anderen unterscheidet. Gibt es Parallelen zwischen dem Fremden und dem Anderen oder ist das Andere das Fremde oder das Fremde das Andere? Diese Fragestellungen öffnen ein sehr breites Untersuchungsfeld, das in ganz unterschiedlichen Forschungsgebieten wie beispielsweise der Philosophie, der Soziologie, der Germanistik, den Kulturwissenschaften, der Anthropologie und der Ethnologie untersucht worden ist und wird. Im Rahmen dieser Studie können lediglich einige grundsätzliche Probleme umrissen werden, um die Voraussetzungen für die Untersuchung zeitgenössischer fotografischer Darstellungen Japans aus europäischer Sicht zu schaffen.

Nach der Auseinandersetzung mit der Begriffskonstellation des Fremden, Eigenen und Anderen folgt im nächsten Schritt die Beschäftigung mit der Fremderfahrung, der Begegnung mit dem Fremden. Hier lohnt sich zunächst ein Blick zur Ethnologie, die als Wissenschaft vom kulturell Fremden prädestiniert dafür ist, Konzeptionen zur Annäherung an das Fremde bereitzustellen. Gleichzeitig werden in der Ethnologie auch zahlreiche Probleme diskutiert, die die Annäherung an das Fremde und der wissenschaftliche Anspruch einer objektiven Darstellung des Fremden mit sich bringen. Wie kann sich der ethnologische Beobachter seinem Gegenstand als Fremdem annähern? Welche Voraussetzungen lenken seinen Blick und beeinflussen somit seine Wahrnehmung? Welche Mechanismen kommen in der Betrachtung des Fremden zum Tragen? Inwieweit beeinflusst die eigene Sozialisation die Auseinandersetzung mit dem Fremden? Hier stellen sich einerseits Fragen nach der Ethnozentrik des Blicks, andererseits auch solche nach der Entstehung einer vorgeprägten Wahrnehmung, die sich in Form von Stereotypen und Vorurteilen äußert. Welche Rolle spielen Stereotypen und wie wirken sie sich auf die Wahrnehmung des Fremden aus?

Der dritte Abschnitt widmet sich der Darstellung des Fremden. Das Fremde wird nie ausschließlich im direkten Kontakt erfahren. Die Begegnungen mit dem Fremden werden in vielen Fällen dokumentiert; durch Aufzeichnung und Verschriftlichung entsteht eine Distanz. In der Ethnologie werden wissenschaftliche Texte verfasst, aber auch Diplomaten, Reisende, Schriftsteller, Journalisten und Künstler setzen ihre Begegnungen mit dem 
Fremden in Texte oder Bilder, möglicherweise auch in Musik um. Diese Darstellungen des Fremden sind für diejenigen, die keine direkten Erfahrungen mit dem Fremden machen können, die einzige Möglichkeit, am Fremden einer Begegnung mit dem Fremden - teilzuhaben. Zugleich prägt die lange Tradition, in der über Jahrhunderte Darstellungen des Fremden geschaffen wurden, die Auseinandersetzung mit dem Fremden nachhaltig. Die Darstellungen sind jedoch nicht Abziehbilder des Fremden, sie sind vielmehr Repräsentationen, die auf Abwesendes verweisen. Das Fremde kann so, aber auch anders gezeigt werden; die Darstellung ist abhängig von ihrem Autor. Wenn jedoch der Autor die Darstellung bestimmt und nicht der beobachtete Gegenstand, ist dann nicht jede Repräsentation eine Konstruktion? Ist eine authentische Wiedergabe des Fremden überhaupt möglich, wenn die Repräsentation eine Reduzierung von Komplexität voraussetzt? Geht dabei die Fremdheit des Fremden nicht verloren? Und schließlich: Repräsentationen kommen zum Tragen, wenn der repräsentierte Gegenstand abwesend ist. Kann die Repräsentation des Fremden ein Ersatz für seine fehlende Präsenz sein? Kann sie selbst eine Fremderfahrung ermöglichen?

\subsection{Das Fremde und das Andere}

\subsubsection{Das Fremde}

Das Begriffsfeld des Fremden schließt die Begriffe fremd, der Fremde, die Fremde, das Fremde und Fremdheit ebenso mit ein wie weitere mit fremd zusammengesetzte Begriffe. Hier - bei diesen Komposita ${ }^{1}-$ ist man sogleich mit dem Problem konfrontiert, dass es kaum möglich ist, das Fremde als solches zu umreißen, da es immer nur im Zusammenhang mit seinem Gegenstück, dem Vertrauten oder Eigenen, gesehen werden kann. Das, was dem Einen fremd ist, kann jemand Anderem vertraut sein. Der Begriff fremd lässt sich nur in Bezug zum eigenen Standpunkt sinnvoll verwenden. Fremdheit ist einerseits abhängig von der jeweiligen Situation und damit okkasionell und andererseits relational, weil sie sich immer auf das Ich oder die eigene Kultur bezieht. Fremdheit ist demzufolge immer ein »Ausdruck für eine Relation" (Waldenfels 1989: 44). Sie ist keine »kategoriale Eigenschaft von Dingen, Kulturen, dem eigenen oder einem anderen Ich« (Därmann 2002: 29f.; vgl. Waldenfels 2002: 161). Untersucht man den Blick auf das Fremde, geht es zwangsläufig immer um den okkasionellen Bezug von Fremdem und Eigenem. Das heißt: Der Blick ist immer abhängig vom situativen, raumzeitlichen, womöglich moralischen Standpunkt des Individuums - oder auch nur dem der Gewohnheit.

Der Begriff der Fremdheit weist zudem drei verschiedene Bedeutungsebenen auf. Sie können unterschieden werden als die Fremdheit des Ortes außerhalb des eigenen Bereiches liegend -, die Fremdheit des Besitzes - einem Anderen zugehörend - und die Fremdheit der Art - im Sinne einer fremdartigen Beschaffenheit (vgl. Waldenfels 1997: 20). Den verschiedenen Bedeutungsebenen liegt eine Besonderheit der deutschen Sprache zu Grunde, die nur einen Begriff kennt, während beispielsweise im Englischen die Ter-

Z.B. Fremdwort, Fremdstoff, Fremdsprache. 
mini foreign, alien und strange für die unterschiedlichen Ebenen gebräuchlich sind. Die Komplexität des Begriffs muss von daher immer mitgedacht werden. Um Fremdheit zu erfassen, können die verschiedenen Merkmale unabhängig voneinander variieren. Es müssen nicht alle drei Merkmale gleichzeitig vorliegen, um einen Zustand der Fremdheit zu erzeugen.

Fremd $»$ ist eine Ableitung von dem im Niederhochdeutsch untergegangenen gemeingermanischen Adverb fram >vorwärts, weiter; von - weg [ [...] und bedeutete ursprünglich >entfernt`, dann >unbekannt, unvertraut« (Drosdowski 1989: 204). Das topografische Moment wird in der ursprünglichen Bedeutung betont, heute scheint es primär noch in der Verwendung des Begriffs die Fremde auf, mit dem auf topografisch Entferntes verwiesen wird. Der Ort als ein Aspekt der Begegnung mit dem Fremden scheint nach wie vor von großer Relevanz für den Begriff der Fremdheit zu sein: Der Beobachter einer fremden Kultur begibt sich dorthin, verlässt seinen eigenen angestammten Platz und tauscht ihn mit der Fremde. Nur dort lässt sich die fremde Kultur in ihren zahlreichen Facetten beobachten, lassen sich Zusammenhänge beispielsweise zwischen lokaler Geografie, Kommunikationsweisen, Sitten und Gebräuchen herstellen.

Allerdings wird diese Erklärung nicht der Rolle gerecht, die der Begriff der Fremdheit im Umfeld der zeitgenössischen Theorie spielt. Der Ort des Fremden sollte nicht ausschließlich als ein konkret geografischer aufgefasst werden, sondern auch im übertragenen Sinne. Um den Topos des Fremden und seine Bedeutung in einer allgemeinen Dimension zu erfassen, möchte ich mich eingehender mit dem phänomenologischen Ansatz von Bernhard Waldenfels beschäftigen (vgl. Waldenfels 1997). ${ }^{2}$ Waldenfels bezieht sich in seiner Topografie insbesondere auf die Phänomenologie Edmund Husserls, der das Wesen des Fremden in der »bewährbaren Zugänglichkeit des original Unzugänglichen« verortet (Husserl 1987: 117). Für Waldenfels ist diese paradoxe Umschreibung Husserls signifikant: Sie verdeutlicht die Schwierigkeit, das Wesen des Fremden zu erfassen.

Seinen Platz hat das Fremde außerhalb des Eigenen. Das Eigene kann als eine Ordnung verstanden werden, die gegeben ist und zunächst nicht hinterfragt werden muss. Wo diese Ordnung an Grenzen gelangt, weil Dinge, Erfahrungen oder Wahrnehmungen hier nicht eingeordnet und verortet werden können, beginnt das Fremde. Es ist gekennzeichnet durch eine NichtZugehörigkeit seines Ortes, da er außerhalb des Eigenen liegt. Dieser Ort des Fremden ist nicht geografisch zu verstehen, da er nicht einfach aufgesucht werden kann. Wäre dies möglich, würde sich Fremdheit im selben Moment auflösen, in dem eine direkte Begegnung mit dem Fremden stattfindet. Es ließe sich in die Ordnung des Eigenen integrieren, es wäre nunmehr verstanden und bekannt. Derart wäre die jeweilige Fremdheit nicht mehr vorhanden. Nach dieser Definition wäre Fremdheit ein Defizit, das sich beheben ließe. Soll aber die theoretische Konzeption des Fremden thematisiert werden, ist es wichtig, das Fremde als Fremdes zu begreifen. Hier unterscheidet sich der Ansatz von Waldenfels maßgeblich von anderen Ansätzen, die Fremdes auch unter dem Aspekt des noch Fremden sehen und insofern implizieren, dass eine Überwindung der Fremdheit grundsätzlich möglich ist (vgl. z.B. Hogrebe 1993; Kristeva 1990; Därmann 2002). Hier ließe sich zwischen »radikaler Fremdheit« und »relativer Fremdheit«, unterscheiden, wobei radikale Fremd-

2 Der Titel des Werks lautet: »Topographie des Fremden«. 
heit diejenige ist, die nicht überwunden werden kann, während relative Fremdheit das Unbekannte, Unvertraute oder Noch-nicht-Verstandene bezeichnet (vgl. Därmann 2002: 29f.). Waldenfels verweist außerdem darauf, dass »radikale Fremdheit nicht zu verwechseln [ist] mit absoluter und totaler Fremdheit« (Waldenfels 1997: 37), da ein total »Fremdes, das das Sein als solches und im ganzen unterhöhlt« (ebd.: 16), nicht existiert. Er begründet dies damit, dass alles »Außer-ordentliche« auf bestimmte Ordnungen bezogen bleibt, über die es hinausgeht (ebd.: 37). Die radikale Form der Fremdheit »betrifft all das, was außerhalb jeder Ordnung bleibt und uns mit Ereignissen konfrontiert, die nicht nur eine bestimmte Interpretation, sondern die bloße Interpretationsmöglichkeit in Frage stellen « (ebd.: 36f.). Obwohl jede Interpretationsmöglichkeit in Frage gestellt wird, bleibt die Ordnung Bezugspunkt der radikalen Fremdheit. Beide bilden zusammen eine Differenz. Beispielsweise kann plötzlich in Frage stehen, ob eine fremde Sprache, die ganz anders ist als unsere, tatsächlich eine Sprache und damit Möglichkeit der Verständigung ist. Sie deshalb als radikal fremd zu betrachten, bedeutet, sie weiterhin in Bezug auf unsere Sprache, unsere Ordnung zu sehen; trotz radikalen Zweifels daran festzuhalten, dass es sich um eine Sprache handelt und nicht um ein bloßes Geräusch. Wäre sie hingegen absolut fremd, so wäre die Frage nach der Interpretationsmöglichkeit niemals aufgekommen. Sie wäre als Sprache unerkannt geblieben und nur als Geräusch wahrgenommen worden.

Das Fremde lässt sich nicht in die Ordnung des Eigenen integrieren. Das heißt zunächst, dass hier die ursprüngliche - geografische - Bedeutung von Fremdheit an ihre Grenzen stößt: Auch in der Fremde behält das Fremde seinen Charakter der Abwesenheit. Wir sind mit einem Paradox konfrontiert, denn es ist unmöglich, sich mit einem Abwesenden zu beschäftigen. ${ }^{3}$ Waldenfels bezeichnet dies als das »Paradox der Husserlschen Bestimmung, « in dem sich die Zugänglichkeit des Fremden »als Zugänglichkeit eines Unzugänglichen erweist. Der Ort des Fremden in der Erfahrung ist streng genommen ein Nicht-Ort. Das Fremde ist nicht einfach anderswo, es ist das Anderswo (Waldenfels 1997: 26; Hervorhebung im Original). Dieses Anderswo des Fremden ist durch eine Schwelle vom Eigenen getrennt, »ähnlich wie Schlafen von Wachen, Gesundheit von der Krankheit, Alter von der Jugend « (ebd.: 21). Es ist nicht möglich, gleichzeitig auf beiden Seiten der Schwelle zu stehen. Der Ort des Eigenen und der Ort des Fremden sind grundsätzlich nicht identisch.

Die Schwierigkeit, das Fremde genauer zu fassen, liegt auch in seiner vermeintlichen Negativität (vgl. Kristeva 1990: 104). Weil es selbst keine genuinen Eigenschaften besitzt und sich nicht in bestimmte Kategorien einordnen lässt, wird es mit dem bezeichnet, was es nicht ist. So überrascht die Beschreibung des Fremden als ein Zustand, dem drei Verneinungen zugrunde liegen, nicht: »1. Die Verneinung einer Zugehörigkeit. 2. Die Verneinung eines Wissens. 3. Die Verneinung einer Vertrautheit« (Hogrebe 1993: 358f.; vgl. zu Punkt 1. auch Menne 1972: Spalte 1102). Der Komplex der Zugehörigkeit betrifft die oben erwähnte zweite Bedeutungsebene des Besitzes. Das Fremde ist einem anderen zugehörig und befindet sich somit nicht in meinem Besitz. Im übertragenen Sinne ist es kein Bestandteil meiner eigenen Ordnung. In der

3 Das Abwesende kann jedoch durch Symbolsysteme anwesend sein (vgl. dazu den Abschnitt 1.3.2. Repräsentation). 
»Verneinung eines Wissens« wird nichts vom Gegenstand selbst behauptet, sondern der Sprecher behauptet von sich, dass er nicht weiß, was das Fremde ist und wie er mit der Wahrnehmung des als fremd Empfundenen umgehen kann. Der Sprecher bemerkt, dass etwas nicht in seine vertraute Ordnung passt. Hier zeigt sich erneut, dass sich das Fremde der Definition anhand spezifischer Kategorien entzieht. Wird bereits durch die Verneinung die Tatsache betont, dass etwas nicht zutrifft, so wird hier nichts mehr vom Gegenstand selbst behauptet, sondern der Sprecher macht Aussagen über seinen Zugang zum Gegenstand. ${ }^{4}$ Die Relation zum Sprecher oder Beobachter wird deutlich, zudem bestätigt sich damit, dass der Beobachter des Fremden stets selbst von der Fremdheit betroffen ist. Die »Verneinung eines Wissens« bezieht sich nicht zwangsläufig auf das Wissen um die Zugehörigkeit. Besteht ein Wissen um die Zugehörigkeit, dehnt sich das Nicht-Wissen auf detaillierte Aspekte der Zugehörigkeit aus. So ist das Wissen darum, dass jemand Japaner ist und demzufolge nicht meinem Kulturkreis angehört, nicht gleichzeitig damit verbunden, alle Aspekte der japanischen Kultur erfassen zu können. Das Wissen um die Zugehörigkeit offenbart ein tiefer gehendes NichtWissen und bestätigt somit die bestehende Fremdheit. Die »Verneinung der Vertrautheit « nimmt schließlich Bezug auf die etymologische Begriffsdefinition und benennt die dritte Bedeutungsebene des Fremden, nämlich die der anderen Art oder Fremdartigkeit.

In Hogrebes Erläuterung offenbart sich ein Widerspruch zum Ansatz von Waldenfels, da hier die Sonderfälle etwas »mir fremd geworden«, »mir noch fremd « und schließlich mir »nicht mehr fremd « angeführt werden (Hogrebe 1993: 358f.; Hervorhebung im Original). »In diesem letzten Spezialfall löst sich die Fremdheit auf, hat durch Umgang und Bekanntschaft eine Entfremdung des Fremden stattgefunden« (ebd.; Hervorhebung B.L.). Hogrebe geht insofern davon aus, dass prinzipiell eine Überwindung von Fremdheit möglich ist. Eine radikale Fremdheit, wie sie Andere formulieren, benennt Hogrebe nicht. Die Entfremdung des Fremden stellt sozusagen einen Sonderfall der Verneinung dar, weil es sich um eine doppelte Verneinung handelt. Dort, wo einstmals Fremdheit war, ist nun Vertrautheit. Danach wäre Fremdheit dem Unbekannten ähnlich, das bekannt wird. Die Besonderheit des Fremden als Fremdes verschwindet damit aber aus dem Blickfeld.

Das Fremde durch eine negative Abgrenzung definieren zu wollen, stellt den Versuch dar, das Fremde als etwas klar vom Eigenen Abweichendes zu benennen. Das Eigene stellt aber lediglich das Bezugssystem für die Wahrnehmung des Fremden zur Verfügung, was nicht gleichbedeutend damit ist, dass sich beides deutlich voneinander unterscheidet, das Fremde zum Eigenen eine Differenz bildet. Denn das Fremde schillert: ${ }^{5}$ Es weist in sich unterschiedliche Nuancen und Bedeutungsebenen auf, die nicht klar zu erfassen sind. Das Fremde lässt sich nicht festlegen, Okkasionalität und Relationalität lassen die Erfahrung des Fremden zu einem Prozess werden, der nie abgeschlossen ist und stets entsprechend der Gegebenheiten variiert.

4 Eben im Zugang liegt die Fremdheit. Das radikal Fremde ist kein Gegenstand. Dies steht im Unterschied zum absolut Fremden, eines Gegenstands, zu dem kein Mensch einen Zugang hat.

5 Zum Ausdruck »schillern« vgl. Anmerkung 5 der Einleitung auf Seite 14. Das Fremde wirkt charismatisch, weil es nicht festzulegen ist. Dadurch erregt es Aufmerksamkeit als (psychologischer) Begleitumstand der Okkasionalität. 
Wenn das Fremde nicht klar benannt werden kann, ohne dass es ähnlich dem Unbekannten seine Bedeutung als Fremdes verliert, muss - nach Waldenfels - ein Blickwechsel vollzogen werden. »So lange wir fragen, was das Fremde ist und bedeutet, wozu es da ist und woher es kommt, ordnen wir es in ein Vorwissen oder Vorverständnis, ob wir es wollen oder nicht« (Waldenfels 1997: 108; Hervorhebung im Original). Eine solche Annäherung an das Fremde führt zwangsläufig dazu, dass wir versuchen, es zu erfassen und zu erklären. »Die Situation ändert sich, wenn wir darauf verzichten, geradewegs $\mathrm{zu}$ bestimmen, was das Fremde ist, und wenn wir statt dessen das Fremde nehmen als das, worauf wir antworten und unausweichlich zu antworten haben, also als Aufforderung, Herausforderung, Anreiz, Anruf, Anspruch oder wie immer die Nuancen lauten mögen« (Waldenfels 1997: 108f.; Hervorhebung im Original). Das Fremde dient also als Anreiz der Auseinandersetzung, vor dem auch das Eigene zu hinterfragen ist, weil es mit dem Fremden einen Bezugspunkt erhält. Weil bei allen Betrachtungen des Fremden das Eigene als Ausgangspunkt stets mit definiert ist, dient es als Folie, vor der das Fremde untersucht wird. Der Beobachter als untersuchende Instanz ist immer selbst von der Fremdheit betroffen (vgl. Därmann 2002: 30; Waldenfels 1989: 47). Eigenes bildet einen Kontrast zum Fremden. Gleichzeitig entsteht aber auch das Eigene erst in der Begegnung mit dem Fremden. So lange keine Konfrontation mit dem Fremden stattfindet, bleibt das Eigene unbenannt und als Gegebenes unhinterfragt. Erst durch die Begegnung mit dem Fremden lässt sich das Eigene als das Vertraute näher umreißen und zum Fremden in Beziehung setzen. So wird die Untersuchung des Fremden gleichzeitig zu einer Untersuchung des Eigenen, da das eine sich im anderen widerspiegelt.

\section{Das Exotische als Spielart des Fremden}

Das Exotische ist eine besondere Erscheinungsform des Fremden, von dem es nicht klar unterschieden wird. Es gilt als »besonders farbige Spielart des Fremden« und liegt in jedem Fall außerhalb der eigenen Kulturgemeinschaft, worauf die Vorsilbe exo verweist (Trauzettel 1995: 1). Bedeutet exotisch eigentlich nur »fremdländisch" (Drosdowski 1989: 168), ist das Exotische anders als das Fremde - stark affektiv aufgeladen, da es auf die geheimnisvolle Seite des Fremden verweist. Das Exotische entsteht erst mit seinem Sprachgebrauch im achtzehnten Jahrhundert und ist nur als historisches Phänomen zu erschließen. Es »kristallisiert sich zu oszillierenden Gestalten im neunzehnten Jahrhundert, bis dass es in unserem [dem zwanzigsten] Jahrhundert fortschreitend und unaufhaltsam verdirbt und verkommt « (Trauzettel 1995: 3). Mit dem Aufkommen des Massentourismus wird es zu einem Klischee, denn das Gefühl des Exotischen ist nicht »jener kaleidoskopische $\mathrm{Zu}$ stand des Touristen oder des gewöhnlichen Zuschauers« (Segalen 1994: 44). Exotische Länder einfach bereisen und Exotisches in Form von Andenken massenhaft besitzen zu können, entkleidet das Exotische seiner Unnahbarkeit. Denn das Exotische erhält seine Berechtigung durch seine Unerreichbarkeit. ${ }^{6}$ Das Exotische ist die Projektion des absolut Fremden innerhalb des radikal Fremden und erhält so seine besondere Anziehungskraft. Sein Reiz

6 »Alles Exotische hatte den Reiz der Sensation; der Ausstellungswert eines musealen Schauobjekts und die von ihm entfachte Neugier wuchsen im Maße dessen, was für das Aufspüren, Erlangen und Transportieren an Aufwendungen erbracht worden ist« (Honold 2006: 33). 
liegt darin, es in seiner Fremdheit zu belassen und es von allen Versuchen der Erklärung und des rationalen Verstehen-wollens frei zu sprechen. Das NichtVerstehen ist Bedingung und Ausgangspunkt des Exotischen, nur so erhält es sein undurchdringliches und geheimnisvolles Wesen.

Victor Segalen versucht zu Beginn des zwanzigsten Jahrhunderts das Phänomen des Exotischen als theoretische Konzeption im Begriff Exotismus $\mathrm{zu}$ fassen. Er verweist darauf, dass das Exotische mental gekoppelt ist mit den Tropen, der glühenden Sonne und Palmen beziehungsweise dem Fernöstlichen. Es gibt »wenig Polar-Exotismus« (Segalen 1994: 31). Er versucht jedoch, den Begriff Exotismus globaler anzusiedeln und von seiner geografischen Bedeutung zu befreien. Für Segalen existiert beispielsweise auch ein historischer Exotismus. Sowohl Vergangenheit als auch Zukunft entziehen sich der Zugänglichkeit ebenso wie das exotisch Fremde. »Der Exotismus ist [...] keine Anpassung; es ist also nicht das vollkommene Begreifen eines Nicht-Ich, das man sich einverleiben könnte, sondern die scharfe, unmittelbare Wahrnehmung einer ewigen Unverständlichkeit. Von diesem Eingeständnis der Undurchdringbarkeit wollen wir ausgehen « (Segalen 1994: 44). Segalens Formulierung legt nahe, dass sein Konzept des Exotismus dem der radikalen Fremdheit bei Waldenfels ähnelt. Das Exotische verkörpert für Segalen etwas Entferntes, das nicht verstanden werden kann. Im Exotismus geht es nicht darum, Unbekanntes auf Bekanntes zu reduzieren, »also wie subtil auch immer, die eigene Kultur als Maßstab für die fremde zu setzen« (Geiger 1995: 50). Das Wechselspiel zwischen Fremdem und Eigenem bleibt im Exotischen erhalten, da es sich jeglicher Aneignung entzieht.

Der gängige Sprachgebrauch ist von Segalens Abstraktion des Konzepts Exotismus jedoch weitgehend unberührt geblieben. Nach wie vor verbindet man das Exotische mit südlichen geografischen Regionen. Das Exotische übt eine starke Anziehungskraft aus, die Distanz zum Fremden wird in ihm zelebriert. Das Exotische wird zum Faszinosum und zur Bedrohung gleichermaßen, da es als attraktiv und als beunruhigend zugleich empfunden wird (vgl. Trauzettel 1995: 4). Das Exotische als das absolut Nicht-Identische verkörpert Sehnsüchte nach dem, was unerreichbar ist. Als Projektionsfläche für Wünsche und Sehnsüchte ist es Anlass zur »Flucht vor sich selbst« (ebd.). Die Wahrnehmung des Exotischen bezieht sich nur auf dessen Oberfläche. Dadurch wird es verkannt, denn das Äußere wird mit seinem Inneren verwechselt. Die radikale Fremdheit des Exotischen ist unüberwindbar.

\subsubsection{Das Andere}

Das Begriffsfeld des Anderen wird hier eingeführt, weil im ethnologischen Diskurs die Begriffe fremd und anders häufig synonym verwendet werden, obwohl sie unterschiedliche Bedeutungen aufweisen. Für die vorliegende Arbeit ist eine Unterscheidung jedoch maßgeblich. Die verschiedenen Implikationen der beiden Begriffsfelder werden in der ethnologischen Literatur nur selten reflektiert (vgl. z.B. Fuchs/Berg 1995: 9). Das liegt vermutlich an der starken Orientierung der deutschen Ethnologie an den englischen und französischen Schwesternwissenschaften, in deren Sprachgebrauch die Unterscheidung zwischen fremd und anders nicht gemacht wird, sondern anders in der Bedeutung des deutschen fremd gebraucht wird und so die unterschiedlichen Implikationen dieses Begriffs einschließt. Die Ethnologen Eberhard Berg und Martin Fuchs konstatieren, dass sich der englische und französische Sprach- 
gebrauch vom Anderen durchgesetzt habe, während im deutschen noch oft vom Fremden die Rede sei. Sie merken an, dass sich die Begriffe fremd und anders in weiten Teilen decken, obwohl sie unterschiedliche Dimensionen der Reflexion erschließen. Die Reflexionsebenen werden jedoch im Einzelnen nicht genauer umschrieben (vgl. Fuchs/Berg 1995: 9). Laut Berg und Fuchs betont »das Bild vom Anderen [...] die Beziehung, die die Ethnologie zu ihrem Gegenüber unterhält« (ebd.). Der Philosoph Bernhard Waldenfels, der sich in ethnologischen Zusammenhängen um eine genaue Differenzierung der Begriffe bemüht, merkt hier an, es sei schwerlich gerechtfertigt, »das Motiv der Andersheit auf ein >Bild k zu reduzieren." Es sei vielmehr zu fragen, »was das `Gegenüberく von einem bloßen Gegenstand und selbst noch von einem bloßen alter ego unterscheidet « (Waldenfels 2002: 161; Anmerkung 22). In der vorliegenden Arbeit ist eine Unterscheidung des Fremden vom Anderen wichtig, weil das Andere als Gegenstück zum Selben ${ }^{7}$ eine Auseinandersetzung eröffnet, die nicht mit dem Diskurs des Fremden und Eigenen identisch ist. Deshalb sollen an dieser Stelle die Unterschiede der beiden Begriffsfelder herausgearbeitet werden.

Der Begriff des Fremden ist kein Grundbegriff der klassischen Philosophie (Waldenfels 1997: 16). Seit Platon beschäftigen sich jedoch Philosophen mit der Bedeutung des Anderen (vgl. Theunissen 1971; Meinhardt 1971). Weil eine eingehende philosophische Untersuchung der unterschiedlichen Bedeutungen beider Begriffe in diesem Rahmen nicht zu leisten ist, möchte ich hier lediglich auf die sehr plausible Differenzierung von Waldenfels eingehen: Anderes entsteht in der einfachen Abgrenzung vom Selben. Die Abgrenzung erfolgt durch einen neutralen Beobachter, der das Eine vom Anderen unterscheidet. Das Eine wird als das Andere des Anderen gesehen. Diese Art der Abgrenzung ist reversibel, als Operation könnte sie als »a = nicht $b$ « oder $» b=$ nicht $a \ll$ betrachtet werden (Waldenfels 1997: 20). Es ist aber nicht $\mathrm{a}$, das sich selbst von $\mathrm{b}$ unterscheidet, sondern wir sind es, die diese Unterscheidung treffen. »Die Unterscheidung vollzieht sich im Medium eines Allgemeinen, das uns erlaubt, zwischen verschiedenen Früchten oder Möbelstücken zu unterscheiden. [...] Eines ist in diesen Fällen von anderen verschieden, weil es von ihm unterschieden wird aufgrund einer `spezifischen Differenz nicht aber weil es sich selbst von anderem unterscheidet« (Waldenfels 1997: 21; Hervorhebung im Original). Das Fremde hingegen wird vom Eigenen nicht durch einen neutralen Beobachter unterschieden, sondern das Selbst erkennt das Fremde vor dem Hintergrund des Eigenen. Die Wahrnehmung des Fremden unterliegt einem Prozess der permanenten Grenzverschiebung, der Schaffung von unscharfen Übergängen zwischen Fremdem und Eigenem durch das Selbst und bildet damit den Unterschied zur bloßen Unterscheidung des Anderen vom Selben durch Dritte. Dies gilt ebenso für die Geschlechterdifferenz wie für kulturelle Unterschiede.

»Es gibt keinen neutralen >dritten Menschen`, der voraussetzungslos zwischen Mann und Frau unterscheiden könnte, da doch zunächst der Mann sich von der Frau und diese sich vom Mann unterscheidet. Ebenso gibt es keinen kulturellen Schiedsrichter, der europäische und fernöstliche Kultur äußerlich voneinander unterscheiden könnte, da Europäer zunächst sich von Japanern und diese sich von Europäern unter-

7 »Anderes [...] - wie in Platons Sophistes - [entsteht] durch Abgrenzung vom Selben« (Waldenfels 1997: 20f.; Hervorhebung im Original). 
schieden haben müssen, bevor der Schiedsspruch einsetzen kann« (Waldenfels 1997: 21f.; Hervorhebung im Original; vgl. auch Waldenfels 2002: 161).

Während es sich beim Anderen um eine einfach zu beobachtende Verschiedenheit von Nicht-Identischem handelt, bezieht sich das Fremde immer auf das Eigene, was bedeutet, dass der Unterscheidende selbst von der Unterscheidung betroffen ist. In der Bestimmung des Anderen findet eine reversible Form der Abgrenzung statt. Fremdheit hingegen ist bestimmt von der Kontrastierung mit dem Eigenen durch das betroffene Selbst (vgl. Waldenfels 2002: 161). Der okkasionelle Charakter des Fremden verweist auf einen Prozess, in dem es keine endgültige und festgelegte Form der Fremdheit gibt. Im Umgang mit Fremdheit ist eine permanente Beweglichkeit zu verzeichnen, während eine einmal getroffene Unterscheidung des Einen vom Anderen dauerhafte Gültigkeit besitzt.

Das Andere unterliegt - im Gegensatz zum Fremden - kategorialen Bestimmungen, die willkürlich gewählt werden, um es vom Selben zu unterscheiden. Die Abgrenzung des Anderen vom Selben beinhaltet demzufolge eine Differenz, die die Andersartigkeit des Anderen bestätigt. Eine einmal getroffene Unterscheidung fixiert die Differenz und gibt keinen Raum für Neubestimmungen. Während das Fremde verschiedene Nuancen aufweist, die in einem permanenten Prozess des Abgleichens mit dem Eigenen betrachtet werden, unterliegt das Andere festgelegten Kategorien. Es kann in seiner Andersartigkeit erfasst und beschrieben werden, was mit dem Fremden nicht gelingt. Während das Fremde changiert, ist das Andere fixiert.

\subsection{Begegnung mit dem Fremden}

\subsubsection{Annäherung an das kulturell Fremde}

In diesem Abschnitt sollen Annäherungsweisen an das kulturell Fremde untersucht werden. Die Ethnologie - die »Wissenschaft vom kulturell Fremden $\aleph^{8}$ - kann Konzeptionen der Betrachtung und Beschreibung des Fremden aufzeigen. Ihr Forschungsgebiet umfasst fremde Kulturen, wobei sie sich über lange Zeit hauptsächlich mit relativ geschlossenen, meist schriftlosen, außerhalb des europäisch-nordamerikanischen Kulturraums liegenden Gesellschaften befasst hat (vgl. Kohl 1993: 93). Die japanische Kultur fällt traditionell nicht in ihren Bereich, da sie als Schriftkultur über ihre schriftlichen Zeugnisse durch historisch-philologisch orientierte Wissenschaften erschlossen wird. Für die japanische Kultur wäre demzufolge hauptsächlich die Japanologie zuständig, die sich vorrangig mit der japanischen Literatur beschäftigt. Mittlerweile grenzt sich die Ethnologie jedoch weniger in ihrem Forschungsgegenstand von Fächern wie der Japanologie ab, sondern in ihrer Methode. Japan ist durchaus ein Arbeitsfeld für Ethnologen, was durch zahlreiche ethnologische Publikationen zur japanischen Kultur bestätigt wird.

Die Ethnologie, ähnlich den ihr verwandten Feldern der Kulturwissenschaft und Kulturanthropologie, geht von einem erweiterten Kulturbegriff aus und beobachtet ein breites Spektrum gesellschaftlichen Verhaltens. Der briti- 
sche Kulturwissenschaftler Stuart Hall definiert Kultur nicht als die großartige Tradition (»great tradition«) der Literatur, sondern

"ssowohl als die Bedeutungen und Werte, welche innerhalb spezifischer sozialer Gruppen und Klassen auf der Basis ihrer gegebenen historischen Bedingungen und Beziehungen entstehen und mittels denen sie ihre Existenzbedingungen $>$ handhaben , mit ihnen umgehen, als auch als die gelebten Traditionen und Praktiken, durch welche solche >Deutungen` ausgedrückt und verkörpert werden« (Hall 1999: 24f.; Hervorhebung im Original).

Diese Definition ist eine von vielen, die versuchen, einen umfassenden Kulturbegriff zu entwickeln, der sich nicht nur auf Bereiche von Kunst, Musik, Literatur und Wissenschaft bezieht. Bereits im neunzehnten Jahrhundert definiert der britische Ethnologe E.B. Tylor Kultur als ein komplexes Ganzes, das »der Mensch als Mitglied der Gesellschaft erworben hat« (Tylor 1871; zit. nach: Kohl 1993: 130; Hervorhebung B.L.). Wichtig ist hierbei, dass Kultur nicht etwas von der Natur Gegebenes, sondern etwas in der Gesellschaft Erworbenes ist, das sich der Einzelne im Laufe seiner Sozialisation aneignen muss. Dieser Kulturbegriff erlaubt es beispielsweise, Formen des $\mathrm{Zu}-$ sammenlebens, der Arbeit und des Alltags ebenso als kulturelle Phänomene $\mathrm{zu}$ betrachten wie Produkte der Hochkultur; er lässt so einen umfassenden Blick auf die beobachtete Gesellschaft zu. Die Ethnologie befasst sich mit der Beobachtung und Beschreibung fremder Kulturen in ihren Alltäglichkeiten und Ritualen unter den gegebenen geografischen Bedingungen. Sie ist mit zahlreichen Problemen konfrontiert, die in Diskursen zur »Krise der ethnographischen Repräsentation " ${ }^{9}$ auf breiter Ebene diskutiert werden. Diese Diskurse weisen auf Schwierigkeiten in der Beobachtung und Beschreibung des kulturell Fremden hin, die auch für die hier vorliegende Abhandlung von Interesse sind. In der Erörterung von Fragen der Repräsentation im Abschnitt 1.3.2. wird darauf näher eingegangen.

Wie bereits festgestellt, lässt sich das Fremde als Fremdes kaum definieren, weshalb der Kontakt mit ihm und die Relation zum Eigenen Schlüsselmomente darstellen. Das Fremde nimmt auf Ordnungen des Eigenen Bezug, es ist »relational« (Kohl 1993: 95). Waldenfels unterscheidet zwischen relational und relativ. Während relativ einen Bezug nur für mich oder für uns, aber nicht einen Bezug schlechthin bezeichnet, bedeutet relational allgemein in Bezug auf Anderes bestimmt (vgl. Waldenfels 1997: 37; Anmerkung 15). Die Ordnung des Eigenen bleibt der Bezugspunkt, in dessen Relation das Fremde untersucht wird. Die Funktionsweisen dieser Ordnung bestimmen unseren Umgang mit dem Fremden. Das Eigene - in Form von bewährten Mechanismen der Wahrnehmung oder Beurteilung - wird durch den Kontakt mit dem Fremden grundsätzlich in Frage gestellt.

In der Ethnologie findet der Kontakt mit dem Fremden im Rahmen der Feldforschung statt, die von Bronislaw Malinowski während eines Forschungsaufenthalts zu Beginn des zwanzigsten Jahrhunderts als Methode der teilnehmenden Beobachtung entwickelt wird. Zuvor hatten Ethnologen weitgehend Berichte von Missionaren, Kolonialbeamten, Handelsreisenden und Entdeckern ausgewertet, ohne eigene Feldforschung zu betreiben. Malinowski konzipiert »das Untersuchungs feld « des Ethnographen als eine räumlich

9 So der Untertitel einer von Berg/Fuchs 1993 herausgegebenen Publikation. 
begrenzte Einheit, deren voneinander abhängige Einzelelemente stetig aufeinander einwirken und daher nur in ihrem Gesamtzusammenhang studiert werden können « (Kohl 1993: 110). Dies bezieht die geografischen Gegebenheiten ebenso mit ein wie Sprache und Kommunikation, alltägliches Leben und Rituale. Die Beobachtung beschränkt sich jedoch nicht auf eine passive visuelle Wahrnehmung, vielmehr ist sie ein durch theoretisches Vorwissen geleitetes und zielgerichtetes Hinsehen. Das wissenschaftliche Gerüst des Ethnologen lenkt seinen Blick und unterscheidet ihn dadurch vom ethnologischen Laien. Nach Malinowski ist das Erlernen der fremden Sprache und die Teilnahme an der Lebenspraxis der beobachteten Kultur unerlässlich. Das Ziel der ethnologischen Feldforschung besteht darin, »den Standpunkt des Eingeborenen, seinen Bezug zum Leben zu verstehen und sich seine Sicht seiner Welt vor Augen zu führen« (Malinowski 1979: 49; Hervorhebung im Original). Dazu ist eine umfassende Eingliederung in die zu beobachtende Gesellschaft erforderlich. Malinowski geht sogar so weit zu fordern, Kontakte zu Mitgliedern der eigenen Kultur während des Forschungsaufenthaltes ruhen zu lassen (vgl. ebd.: 28). Die Idealvorstellung der teilnehmenden Beobachtung hat sich in der Folge zu dem bestimmenden Paradigma der modernen Ethnologie entwickelt. Dass die Beobachtung eines komplexen Systems mehr zum Verständnis beiträgt als das Herausgreifen einzelner Details, liegt auf der Hand. Trotzdem ist die Konzeption der teilnehmenden Beobachtung nicht unproblematisch, weil allein die Anwesenheit des Ethnologen die Situation in der beobachteten Kultur beeinflusst.

Die Ethnologie hat aus der teilnehmenden Beobachtung heraus eine Methode entwickelt, Gegebenheiten »aus der distanzierten Sicht eines von außen kommenden Beobachters zu betrachten« (Kohl 1993: 95). Diese Methode kann sowohl auf fremde Kulturen als auch auf soziale Gruppierungen innerhalb der eigenen Gesellschaft oder Kultur angewendet werden. Wichtig ist jedoch die Distanz des Beobachters zum beobachteten Gegenstand, die sich in der Gegebenheit von Fremdheit ausdrückt. Hier offenbart sich ein grundlegendes Problem der Ethnologie, denn der Forscher im Feld begibt sich in die zu erforschende Kultur. Er ist dort als teilnehmender Beobachter präsent und beeinflusst durch seine Anwesenheit als Fremder den Untersuchungsgegenstand, indem er soziale Kontakte zu Angehörigen der beobachteten Kultur unterhält. Die ursprüngliche Fremdheit ist einem Prozess der Aufweichung unterworfen. Denn der Forscher ist bemüht, die Fremdheit zu durchdringen und ein Verständnis für die fremde Kultur zu entwickeln, um auf Grundlage der erhobenen empirischen Daten die fremde Kultur beschreiben zu können. Die Fremdheit muss zu einem gewissen Grad einer Vertrautheit weichen. Das Fremde geht der Ethnologie als Untersuchungsgegenstand jedoch verloren, wenn sich die Distanz des Beobachters auflöst. Arbeitet die Wissenschaft vom kulturell Fremden an der Auflösung der Fremdheit selbst, zerstört sie in gewisser Weise ihre Arbeitsgrundlage: das Fremde als Fremdes. Waldenfels bezeichnet das Unterfangen einer Wissenschaft vom Fremden, das gegen sich selbst gerichtet ist und mit seinem Erfolg untergeht, als Paradox (vgl. Waldenfels 1997: 96f., 108f.). »Wenn die Erfahrung der Fremdheit in der Zugänglichkeit des Unzugänglichen besteht, wie könnte dann ein Zugänglichwerden oder Zugänglichmachen aussehen, das die Unzugänglichkeit des Fremden wahrt? Eine solche Möglichkeit liegt nicht auf der Hand « (Waldenfels 1997: 95). Um zu verhindern, dass das kulturell Fremde als der Gegenstand der Forschung verloren geht, benennt der Ethnologe Karl-Heinz 
Kohl »Fremdheit als methodisches Prinzip« der Ethnologie (Kohl 1993: 94). Wenn Fremdheit zur Methode wird und nicht sachliches Attribut ist, lässt sich das Problem der Auflösung des Gegenstands gewissermaßen umgehen. Denn so lange das Fremde als Fremdes betrachtet wird, bleibt die Distanz zum beobachteten Gegenstand und somit der Gegenstand selbst in seiner Fremdheit erhalten, auch wenn ein gewisser Grad an Vertrautheit erlangt wird. »Etwas wird fremd, indem es als fremd betrachtet wird « (Waldenfels 1997: 102). Die Haltung des Beobachters in Relation zum Gegenstand ist demzufolge von großer Bedeutung.

Ähnlich sieht das auch Alois Wierlacher. Die Kritik am

»Paradox der Ethnologen, fremde Kulturen ließen sich nur um den Preis ihrer Zerstörung erkennen, entstammt einem sehr problematischen Begriff von Erkenntnis und erfasst wie alle Paradoxe nur scheinbare Widersprüche. Wahrscheinlich können wir fremde Kulturen, die wir thematisieren, sehr wohl begreifen, aber nicht in toto verstehen, wenn wir unter /Verstehen das Nachvollziehen fremder Logiken verstehen. Es bleibt immer ein inkommensurabler Rest kultureller Fremdheit und Eigenheit« (Wierlacher 1993: 47f.; Hervorhebung im Original).

Entsprechend dieser Kritik ist es weder möglich, ein Maß an Vertrautheit zu erlangen, das die Fremdheit vollständig aufhebt, noch ist es möglich, den Gegenstand der ethnologischen Untersuchung, das Fremde, vollständig zu zerstören. Allerdings bleibt Wierlacher einem Denken verhaftet, bei dem das Fremde als Anderes behandelt wird. Zwar versteht er Fremdheit nicht direkt als Gegenstand, der kategorial zu beschreiben wäre. Dennoch wird Fremdheit bei ihm zum Untersuchungs-Gegenstand: Fremd sind die Logiken, also die kategorialen Bestimmungen fremder Kulturen selbst. Die fremden Kategorien kann man wohl annäherungsweise begreifen, jedoch nicht vollständig verstehen. $^{10}$

Das Erkennen oder das Verstehen des Fremden, das durch die Situation der Beobachtung angestrebt wird, braucht die Distanz, die durch die Begegnung von Eigenem mit Fremdem markiert ist, denn "gerade das NichtVertraute wird oft besser erkannt« (Landmann 1975: 193). Fiele dieser Zusammenhang fort, könnte das Fremde nicht mehr als Fremdes beschrieben werden. Der Beobachter befände sich auf derselben Ebene wie der beobachtete Gegenstand. Damit wäre zugleich die Motivation hinfällig, Fremdes und nicht Eigenes zu untersuchen. Bei der Beobachtung des Fremden geht es also nicht um eine Identifikation mit dem beobachteten Gegenstand, sondern um die Anerkennung des bestehenden Abstands und ein tiefer gehendes Verständnis desselben. »Verstehen ist nicht das sich Identifizieren mit dem Anderen, wobei die Distanz zu ihm verschwindet, sondern das Vertrautwerden in der Distanz, die das Andere als das Andere und Fremde zugleich sehen lässt« (Plessner 1953: 215).

10 Gegenstände werden Kategorien »unterworfen«. Kategorien aber kann man nicht anderen Kategorien unterwerfen - unterschiedliche Kategoriensysteme stehen auf derselben Ebene. Deshalb kann man das eine System weder durch das andere beschreiben (unterwerfen) wie einen Gegenstand, noch kann man die Welt »verstehen « wie sie die Benutzer anderer Systeme sehen. Man kann allenfalls das Zusammenspiel dieser Kategorien »begreifen«, etwa mittels »bewährbarer« Thesen über das Unzugängliche. 
Fremdheit steht in engem Zusammenhang mit Erfahrung. Waldenfels spricht von Erfahrungsstrukturen und Erfahrungsordnungen, die das Fremdartige ausmachen. Die Fremderfahrung markiert den Bereich des Kontakts mit dem Fremden. Die ethnografische Erfahrung findet in der Regel im Feld auf dem Gebiet der zu beschreibenden fremden Kultur statt. Hier treffen Beobachter und Beobachtete aufeinander. Die Literaturwissenschaftlerin Mary Louise Pratt bezeichnet dieses Terrain als »contact zone«, die sie als sozialen Raum beschreibt, »in dem disparate Kulturen, oftmals in sehr asymmetrischen Beziehungen von Dominanz und Subordination - wie Kolonialismus, Sklaverei oder deren Nachwirkungen, wie sie heute überall auf dem Globus gelebt werden, aufeinander treffen, miteinander kollidieren und streiten « (Pratt 1992: 4). In der contact zone besteht eine zeitliche und räumliche Kopräsenz vormals getrennter Individuen, deren Bahnen sich nun kreuzen. Für Pratt liegt die Besonderheit dieses Begriffs darin, dass hier Kolonialisten und Kolonisierte beziehungsweise Reisende und Bereiste nicht voneinander getrennt betrachtet werden. Die Gleichzeitigkeit der Interaktion und des ineinander greifenden Verständnisses unterliegt den gegebenen Machtverhältnissen (ebd.: 6f.). In diesem Bereich des Kontakts muss der Beobachter gleichzeitig mit dem Beobachteten thematisiert werden, auch wenn beide nicht auf derselben Ebene stehen. Meist befindet sich der Forscher in einer dominanten Position, da er die Sichtweise festlegt und bestimmt, wie die beobachtete Kultur repräsentiert wird. Pratts Sicht der contact zone unterscheidet sich nachhaltig von der herkömmlichen ethnologischen Erfahrung, die lange Zeit darum bemüht war, den Beobachter selbst nicht mit zu thematisieren. Der Rahmen der Beobachtung wird immer von den Voraussetzungen des Beobachters bestimmt. Für eine adäquate Beobachtung und Beschreibung des Fremden ist eine Einbeziehung beider Seiten im Sinne einer contact zone unerlässlich. Hier begegnen sich Eigenes und Fremdes aus unterschiedlichen Perspektiven.

Die Anwesenheit des Ethnologen im Feld bestätigt die Aussagen von Waldenfels, dass Fremdheit sich stets auf das Individuum bezieht. Der Forscher soll objektiv das Fremde beobachten, analysieren und auswerten, ist jedoch gleichzeitig als Subjekt von dieser Fremdheit betroffen. Er ist »Instrument der Beobachtung und Beobachter in einem « (Kohl 1993: 114). Er muss sich mit den physischen und psychischen Gegebenheiten der Fremde arrangieren und trotzdem die Wissenschaftlichkeit und Objektivität der Mission wahren. Die Fremderfahrung wird zur Selbsterfahrung. Man könnte von einer »zweiten Sozialisation« sprechen, die der Feldforscher durchläuft (ebd.: 111). Dies gilt natürlich nur sehr eingeschränkt, da der Forscher bereits sozialisiert ist und diese erste Sozialisation nicht negieren kann. Er bringt seine eigene kulturelle Prägung ebenso mit wie sein theoretisches Vorwissen und muss die Beobachtungen zu diesen Faktoren in Beziehung setzen. Ob in einer solchen Situation überhaupt eine Objektivität der Beobachtung und Beschreibung erreicht werden kann, ist fraglich. So haben Malinowskis posthum veröffentlichte Tagebücher gezeigt, dass der Forschungsalltag oft weit von den eingeforderten Prämissen der Theorie entfernt ist, da sich die subjektiven Empfindungen nicht unbedingt von den Bedingungen im Feld trennen lassen (vgl. Malinowski 1986; Kohl 1993: 114ff.).

»Da wir die uns umgebende Wirklichkeit immer nur selektiv wahrnehmen können, hängt es wesentlich von der Ausbildung, dem Vorwissen, den Voreingenommen- 
heiten und nicht zuletzt auch der Persönlichkeit des Feldforschers ab, was er sieht und was seiner Aufmerksamkeit entgeht. [...] Bemüht er sich aber, sich seiner inneren Konflikte, Emotionen und auch Sehnsüchte bewußt zu werden, dann kann es ihm auch gelingen, jene Verzerrungen [die durch persönliche Konflikte zustandekommen] zu neutralisieren« (Kohl 1993: 117f.).

Die Beobachtung und die Erhebung empirischer Daten vor Ort ist nur ein Teil der ethnologischen Arbeit. Die hieraus gewonnenen Erkenntnisse müssen noch - meist in schriftlicher Form - fixiert werden. Die Auswertung der ethnologischen Feldforschung mündet in der Regel in einen Text, der die untersuchte Kultur beschreibt und interpretiert. Dies ist neben den die Wahrnehmung des Beobachters prägenden Vorbedingungen ein weiteres Hindernis im Rahmen der Auseinandersetzung mit fremden Kulturen. Bevor auf die Probleme der Darstellung des Fremden im Abschnitt 1.3. näher eingegangen wird, sollen zunächst einige Faktoren eingehender betrachtet werden, die die Sicht des Beobachters beeinflussen.

\subsubsection{Der ethnozentrische Blick}

In der Begegnung mit dem Fremden bringt der Betrachter immer seine eigene Sozialisation und Kultur als Bezugssystem ein. Sie bilden die Ausgangsbasis der Betrachtung. Der Blick ist nie neutral, weil er immer vom Eigenen ausgeht. Daraus resultiert mitunter das Problem einer fehlenden Objektivität. Dies kann im Terminus des Ethnozentrismus gefasst werden. Im Ethnozentrismus wird das eigene kulturelle Raster auf eine Weise an die fremde Kultur angelegt, die Abweichendes nicht gelten lässt. Das Fremde wird so auf die eigenen Bilder, Vorstellungen und Wertschätzungen zurückgeführt (vgl. Waldenfels 1997: 49). Ethnozentrismus ist in ausgeprägter Form bei geschlossenen und kulturell homogenen Gesellschaften zu finden und ist $\gg$ mithin gekennzeichnet durch eine Mißachtung oder zumindest durch ein tiefes Desinteresse an allem, was von den eigenen kulturellen Selbstverständlichkeiten abweicht« (Kohl 1993: 32). Dies geschieht zunächst, um die eigene Lebensform zu verteidigen. Dagegen ist grundsätzlich nichts einzuwenden, denn es bringt das Selbstwertgefühl zum Ausdruck, ohne das keine Gesellschaft auskommt. Allerdings bleibt es selten dabei, häufig wird die eigene Kultur zu der einzig richtigen Lebensform verklärt und damit jede Andersartigkeit der fremden Kultur negativ bewertet. So kann eine ethnozentrische Sichtweise beispielsweise zu Fremdenhass führen.

Der Eurozentrismus stellt eine gesonderte Form des Ethnozentrismus dar, da er nicht aus dem Bewusstsein einer geschlossenen Wir-Gruppe heraus entsteht. »Im Eurozentrismus sind die kulturellen Differenzen der verschiedenen europäischen Völker vielmehr bereits aufgehoben. Eine seiner Grundlagen ist die nicht mehr an eine bestimmte Kultur gebundene, sondern die einzelnen Kulturen gewissermaßen transzendierende christliche Religion mit ihrem Missionsgebot« (Kohl 1993: 32). Das Sendungsbewusstsein, das in diesem Missionsgebot liegt, zieht sich unrühmlich durch die gesamte westliche Kolonialgeschichte. Der Eurozentrismus der Kolonisatoren sorgt dafür, dass sie sich stets den so genannten Primitiven überlegen fühlen und ihnen nicht nur die christliche Religion, sondern oftmals auch einen westlichen Lebensstil aufdrängen. Von außen betrachtet stellen die Europäer eine homogene Gruppe dar, die in den kolonisierten Ländern ähnliche Ziele verfolgen, unabhängig 
von den Differenzen, die innerhalb Europas zur Zeit des Kolonialismus durchaus vorhanden sind.

Eine eurozentrische Aneignung oder Ausgrenzung fremder Kulturen bewirkt in den betroffenen Kulturen mitunter eine Tendenz, dem europäischen Universalitätsanspruch etwas Eigenkulturelles entgegen zu setzen. Es entsteht das »Bestreben, eine `Eigenidentität zu konstruieren. Die Japaner antworteten auf die eurozentrische Orientalisierung mit einer Selbstorientalisierung im Sinne eines Japanzentrismus. Sie erklärten sich selbst zu einer unbegreifbaren und einzigartigen Nation und Kultur « (Mae 2001: 259). ${ }^{11}$ Der Eurozentrismus löst in Japan die Gegenbewegung des Japanzentrismus aus und beeinflusst so in direkter Weise sowohl die Außenwahrnehmung Japans als auch das Selbstverständnis der japanischen Kultur. Die lange Tradition des Eurozentrismus hat den Umgang mit sämtlichen außereuropäischen Völkern beeinflusst und wirkt sich noch heute auf die europäische Wahrnehmung fremder Kulturen aus.

»Begegnungen zwischen Kulturen beginnen selten beim Punkt Null, bei der tabula rasa. Fast jede Begegnung ist - meist unbewußt - mitgeprägt durch frühere Kontakte oder durch die im kollektiven Gedächtnis bewahrte geschichtliche Erfahrung mit der anderen Kultur. Fast jeder Kulturkontakt ist somit geprägt durch eigene oder tradierte Vorerfahrungen, die ihren konkreten Niederschlag und Ausdruck in spezifischen Bildern des jeweils Fremden gefunden haben« (K. Roth 1998: 30).

Diese Bilder des Fremden finden ihren Ausdruck oft in Stereotypen oder Vorurteilen. Lediglich ein bewusster Umgang mit den Voreingenommenheiten des eigenen Blicks und seiner eurozentrischen Perspektive, kann helfen, eine Sichtweise zu entwickeln, die dem beobachteten Gegenstand gerecht wird.

»Uns bleibt nur die Möglichkeit, unsere Verwurzelung in unserer eigenen Kultur klar zu erkennen und ein Gespür zu entwickeln für unsere Abhängigkeit von den eigenen gesellschaftlichen Normen, im Denken, Empfinden und Handeln. Paradox ausgedrückt heißt dies: Erst wenn wir bewußte Eurozentriker sind, vermögen wir das Fremde unvoreingenommen, d.h. unverstellt durch unsere unbewußten Vorurteile, wahrzunehmen. So gesehen, wäre Eurozentrismus geradezu die Bedingung der Erkenntnis« (Hijiya-Kirschnereit 1988: 210).

\subsubsection{Kategorisierungen und Stereotype}

Die Wahrnehmung des Fremden ist stets durch Vorwissen und Erwartungen geprägt. Das Wissen hat bewusste und unbewusste Bestandteile, die auf eigenen direkten und medial oder gesellschaftlich vermittelten Erfahrungen mit dem Fremden beruhen. An dieser Stelle sollen Schemata, Stereotypen und Vorurteile diskutiert werden. Zentral ist hier der Begriff des Stereotyps, der sich partiell mit den anderen Begriffen überschneidet. Man kann die Begriffe als eine Art Steigerungsform ansehen. Grundlegend sind zunächst Schemata oder Kategorisierungen, die die Wahrnehmung ordnen und es ermöglichen, Erfahrungen in das bestehende Ordnungssystem einzufügen (vgl. Donahue

11 Zum japanischen Selbstbild vgl. auch Teil I, Abschnitt 2.3.1. 
1998: 72f.). ${ }^{12}$ Während in der Social Identity Theory der Begriff Kategorie Anwendung findet, wird in der Kognitionspsychologie von Schemata gesprochen, die zur Beschreibung und Erklärung der Ordnung und Regelhaftigkeit kognitiver Vorgänge verwendet werden (vgl. Herrmann 1992: Sp. 1261). Die Begriffe werden hier synonym verwendet. Schemata sind für den Prozess der Wahrnehmung unerlässlich, sie dienen der Ordnung von Erfahrungen. "Schemata sind abstrakte Wissensstrukturen, die die definierenden Aspekte und relevanten Attribute eines gegebenen Konzepts spezifizieren. Schemata verleihen sozialer Information Bedeutung und unterstützen unaufwändige und effiziente Informationsverarbeitung « (Stangor/Schaller 2000: 66). Schemata sind nicht für alle Zeiten festgelegt, sie sind flexibel und ihre Zuschreibungen sind wandelbar (vgl. Pickering 2001: 3). Darin unterscheiden sie sich von Stereotypen. Vorurteile wiederum bilden eine Steigerung von Stereotypen. Sie sind grundsätzlich verzerrend und negieren jegliche Objektivität. In ihrer Starrheit sind sie die Grundlage von Rassismus und übertriebenem Nationalismus. Zwischen den Polen von Schema und Vorurteil ist der Begriff des Stereotyps angesiedelt, der eine gewisse Ambivalenz aufweist. Stereotypisierung ist mehr als nur ein Hilfsmittel zur Ordnung der Wahrnehmung und legt den Grundstein zur Vorurteilsbildung.

Stereotyp ist eine $»$ gelehrte Neubildung zu griechisch stereos $>$ starr, fest

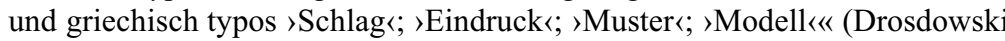
1989: 709). Der Begriff Stereotypie erscheint zunächst im Bereich des Buchdrucks als Bezeichnung für die Herstellung von Druckplatten, später wird er in der übertragenen Bedeutung von »feststehend, sich ständig wiederholend; leer, abgedroschen« verwendet (ebd.; vgl. auch Schönpflug 1998: Sp. 135). Stereotypen und Stereotypenbildung sind vor allem in der Sozialpsychologie ausgiebig erforscht worden, sie sind aber auch in der kulturwissenschaftlichen und medienwissenschaftlichen Auseinandersetzung mit dem Fremden von großer Bedeutung. Viele verschiedene Ansätze und Strömungen der Forschung, die in ihrer Komplexität hier unmöglich wiedergegeben werden können, haben dazu geführt, dass es keine einheitliche Definition oder auch nur eine Einigkeit über die Entstehung und Funktionsweisen von Stereotypen gibt. Es existieren zudem unterschiedliche Ansichten darüber, ob Stereotypen grundsätzlich negativ zu bewerten sind (vgl. z.B. Donahue 1998: 90; Bausinger 1988: 160), wie der alltägliche Sprachgebrauch suggeriert; oder ob es auch positive oder wenigstens neutrale Aspekte der Stereotypenbildung gibt (vgl. z.B. Bergler/Six 1972: 1371; Gilman 1985: 17f.; K. Roth 1998: 33), beispielsweise weil sie zur Sicherung der eigenen Identität gegenüber anderen notwendig sind. Ein kursorischer Überblick über dieses komplexe Gebiet soll hier die wichtigsten Elemente verdeutlichen.

Ungeachtet der zahlreichen Unterschiede in den Definitionen des Stereotyps ist zunächst festzuhalten, dass Stereotypen weit verbreitete Charakterzuschreibungen von Personen aufgrund ihrer Gruppenzugehörigkeit sind. Die Zuschreibungen reduzieren und negieren die individuellen, aber übertreiben, vereinfachen und fixieren die der Gruppe zugeschriebenen Eigenschaften über einen langen Zeitraum hinweg. Stereotypen sind gemeinhin resistent gegenüber abweichenden Erfahrungen. Stereotypen markieren Unterscheidungen

12 Dyer 1980: 28, verwendet den Begriff type im Sinne von Schema oder Kategorie. Die drei Begriffe werden wiederholt synonym verwendet, es lässt sich kaum eine differenzierte Unterscheidung der Bedeutung ausmachen. 
und schreiben sie fest (vgl. z.B. Hall 2002: 258; Haslam 1997: 119; Fleischmann 1999: 106). Zu betonen ist ebenfalls, dass Stereotypen einen affektiven Gehalt besitzen, also mit Emotionen aufgeladen sind.

Die erste Verwendung im Rahmen einer theoretischen Abhandlung über Wahrnehmung und Wahrnehmungsgewohnheiten findet der Begriff bei dem amerikanischen Publizisten Walter Lippmann, der 1922 das Buch Public Opinion veröffentlicht. Lippmann beschäftigt sich hier ausführlich mit den Bedingungen der modernen Welt, die durch einen Verlust der individuellen Erfahrungsmöglichkeiten geprägt ist. Um ausreichende Informationen über die komplex gewordene Welt zu erhalten, muss auf Medien zurückgegriffen werden, die mitunter ungenau und manipulativ sind. Manipuliert wird in den Medien nach Lippmann nicht in böser Absicht, sondern eher aus kommerziellen Gründen. So gehen die Medien den Weg des geringsten Widerstands und passen sich den gängigen Auffassungen an (vgl. Pickering 2001: 18). Lippmann formuliert Gedanken über Wahrnehmungsmöglichkeiten in einer Welt, in der die direkte Erfahrung nur noch einen geringen Bruchteil dessen ausmacht, worüber wir im Bilde sind. Er verwendet die Begriffe Stereotyp oder auch Typen im Sinne von Verallgemeinerungen, die eine schnelle Wahrnehmung von Sachverhalten ermöglichen. „Denn der Versuch, alle Dinge frisch und im Detail zu sehen statt als Typen und Verallgemeinerungen, erschöpft und kommt bei eiligen Angelegenheiten praktisch überhaupt nicht in Frage« (Lippmann 1964: 67).

Stereotypen ermöglichen eine Ökonomisierung der Wahrnehmung, die in einer schnelllebigen Zeit vollständig und in Ruhe nicht mehr zu leisten ist. Zudem spricht Lippmann der direkten Erfahrung nur noch eine Nebenrolle zu. »Wir werden über die Welt bereits unterrichtet, bevor wir sie sehen. Wir stellen uns die meisten Dinge vor, bevor wir unsere Erfahrungen damit machen. Und diese vorgefaßten Meinungen beherrschen aufs stärkste den ganzen Vorgang der Wahrnehmung, es sei denn, die Erziehung habe sie uns in aller Deutlichkeit bewußt gemacht« (ebd.: 68). Unsere Weltsicht ist demnach eine vermittelte, die lediglich durch einen bewussten Akt der Reflexion nicht zu einer unreflektierten Übernahme der herrschenden Meinungen führt. Lippmann formuliert dies als Tatsache ohne negative Wertung. Die Ökonomie der Wahrnehmung verlangt nach der Entwicklung detailreduzierender Systeme.

Lippmann spricht in seiner Definition der Stereotypensysteme drei wichtige Punkte an. Zunächst beschreibt er sie als ein »geordnetes, mehr oder minder beständiges Weltbild « (ebd.: 71), das unvollständig sein mag, aber eine Möglichkeit der Weltsicht darstellt. Stereotypen sind eine Methode, um der »Unordnung der Wirklichkeit eine Ordnung unterzuschieben« (ebd.: 72). Stereotypen bilden demzufolge ein ordnendes System zur Wahrnehmung von Welt und sind als solche unvermeidbar, da sie uns helfen, die Komplexität zu reduzieren. »Es ist die Projektion unseres eigenen Weltbewußtseins, unserer eigenen Stellung und unserer eigenen Rechte auf die Welt« (ebd.). Die Projektion, von der Lippmann spricht, ist der zweite wichtige Punkt. Sie ist an das Individuum gebunden, das das eigene Wertsystem auf das Wahrgenommene anwendet. Dies ließe sich mit dem ethnozentrischen Blick vergleichen, der die eigenen Wertmaßstäbe an die Wahrnehmung des Fremden legt und so $\mathrm{zu}$ Urteilen gelangt. Wichtig ist jedoch, dass dieser Individualisierung die vorgefertigten Meinungen zu Grunde liegen, die als Informationsquellen genutzt werden. Gesellschaftliche und individuelle Prozesse unterliegen somit 
einer Wechselwirkung. Als drittes bezeichnet er Stereotypen als »die Festung unserer Tradition, « hinter der wir uns sicher fühlen können (ebd.). Dieser dritte Punkt betrifft die Identität und die Zugehörigkeit zu einer Gruppe, Gesellschaft oder Kultur. Stereotypen stärken das Bewusstsein der eigenen Identität.

Lippmann sieht Stereotypensysteme als bedingt wandelbar und beschreibt bereits einige Funktionsweisen von Stereotypen, die später in empirischen Untersuchungen von Psychologen bestätigt worden sind (vgl. z.B. Yzerbyt/Rocher/Schadron 1997). So gibt er an, dass sich in der Erfahrung einer Situation die stereotypische Wahrnehmung mit der direkten Wahrnehmung überlagert. Wird die stereotype Vorstellung bestätigt, verstärkt sich in der Folge dieses Modell. Wird es hingegen in Frage gestellt, gibt es zwei verschiedene Möglichkeiten des Umgangs, die er der Flexibilität des Wahrnehmenden zuschreibt. Entweder wird das nicht mit dem Stereotyp kohärente Erlebnis als Ausnahme abgetan. Oder es erschüttert das Stereotyp so weitgehend, dass dieses in der Folge modifiziert wird oder es sogar zu einem grundsätzlichen Misstrauen »allen überkommenen Betrachtungsweisen des Lebens« gegenüber kommt (Lippmann 1964: 75). Lippmann sieht die Stereotypen also als ein grundsätzlich starres und unflexibles System, das aber in besonderen Fällen eine Modifikation zulässt. Im Umgang mit stereotypischer Wahrnehmung verweist Lippmann darauf, dass es wichtig ist, unsere Meinungen als »Teilerfahrungen« anzusehen, die durch Stereotypen beeinflusst sind. Nur so könne sich Toleranz entwickeln, da wir sonst unsere eigene Sehweise für absolut hielten (vgl. ebd.: 93). Die Gefahren, die eine stereotypische Wahrnehmung birgt, sind Lippmann durchaus bewusst. So entsteht ein Dilemma, da Stereotypen einerseits als notwendige Helfer im Umgang mit der Welt gebraucht werden, aber gleichzeitig die Gefahr bergen, Vorurteile und Intoleranz zu fördern. Diese Zweischneidigkeit hat die Stereotypenforschung in der Folge zunächst aus den Augen verloren, da Stereotypen wiederholt gleichgesetzt werden mit Vorurteilen und somit eine grundsätzlich negative Bedeutung bekommen (vgl. Manz 1968: 4; Pickering 2001: 25). Lange Zeit wird an der Hypothese festgehalten, dass Stereotypen immer einen wahren Kern (»kernel of truth «) beinhalten, da man von der Annahme ausgeht, dass, so verkürzt Stereotypen die Welt auch darstellen mögen, sie von zutreffenden Beobachtungen herrühren, die im Laufe der Zeit verzerrt werden (vgl. z.B. Yzerbyt/Rocher/Schadron 1997: 35). So können Schlussfolgerungen aus empirischen Daten Auslöser für eine stereotype Wahrnehmung sein. Die These des wahren Kerns scheint zunächst plausibel, würde worauf der Kulturwissenschaftler Michael Pickering hinweist - jedoch zu der absurden Konsequenz der Billigung von weißem Rassismus mit der Begründung führen, dass Afro-Amerikaner im Kern doch so sind, wie rassistische Stereotype behaupten (vgl. Pickering 2001: 25; Oakes/Reynolds 1997). Sind empirische Daten Grundlage eines Stereotyps, wird in der Begründung des wahren Kerns die Möglichkeit einer fehlerhaften Interpretation ausgeschlossen.

Nach Lippmanns theoretischer Grundlegung beginnen Wissenschaftler damit, empirische Studien durchzuführen (vgl. Manz 1968: Kap. 1). Der Psychologe Gordon Allport führt 1954 eine Unterscheidung zwischen Kategorisierung und Stereotypisierung ein. Kategorisierung sieht er als rationale Maßnahme der Verallgemeinerung und Vereinfachung, die nur zu Vorurteilen führt, wenn zusätzliches Wissen nicht eine Modifikation einleitet. Ein 
Stereotyp ist eine »übertriebene Überzeugung, die mit einer Kategorie in $\mathrm{Zu}$ sammenhang steht. Seine Funktion ist die Rechtfertigung (Rationalisierung) unseres Verhaltens in Bezug auf diese Kategorie« (Allport 1958; zit. nach: Pickering 2001: 10). Stereotype sind starr und unbeweglich. Nach Allport wird die irrationale Stereotypisierung nur in Individuen mit Charakterschwächen zum Problem (vgl. Pickering 2001: 26; Allport 2000). Die Pathologisierung der Stereotypisierung hat zur Folge, dass immer wieder von nützlichen Kategorien gesprochen wird, die sich jederzeit modifizieren lassen, und von schlechten Stereotypen, die einen selbst nicht betreffen, sondern nur jene, die ignorant und voller Vorurteile sind. Pickering weist jedoch darauf hin, dass allein die Tatsache, dass Sozialwissenschaftler und Psychologen Gruppen bilden und diese untersuchen, eine Vorverurteilungsstrategie zweiten Grades (»second-order prejudicing strategy«) impliziert (Pickering 2001: 27). Pickering betont, dass niemand frei ist von Stereotypen, selbst wenn sie bewusst reflektiert werden.

Mit dem Ansatz der sozialen Kognition der siebziger Jahre wird der pathologische Ansatz zurückgedrängt. Es wird deutlich, dass Diskriminierung ein soziales Phänomen ist. Henri Tajfel entwickelt mit anderen die Soziale Identitätstheorie (Social Identity Theory, SIT) und leitet damit eine Wende zum Sozialen in der Stereotypenforschung ein. Er schreibt Gruppen eine soziale Identität zu und bringt Stereotypen und Vorurteile mit dem Verhalten zwischen unterschiedlichen Gruppen in Verbindung. Das Prinzip der Gruppenzugehörigkeit ist für die Social Identity Theory entscheidend. Gruppen fungieren hier als eine Form der Kategorisierung. Sie existieren nur, wenn sich Gruppenmitglieder nicht ausschließlich als Individuen, sondern als Mitglieder einer Gruppe identifizieren. In der Gruppe gibt es eine geteilte soziale Identität, die es ermöglicht, das Eigene Gemeinsame von dem Anderen und Fremden abzugrenzen. »Die Vorstellung von >unserer $<$ Gemeinschaft betrifft entweder implizit oder explizit die Vorstellung von >ihnen`, von denen >wir uns unterscheiden" (Billig 1995: 66). Tajfel spricht davon, dass Menschen eine positive soziale Identität oder Selbstwahrnehmung benötigen. Um diese positive Identität zu erhalten, vergleichen sich Gruppen mit kontrastierenden Außengruppen (outgroups) und sie suchen Vergleichsebenen, die ihnen für diesen Zweck geeignet scheinen (vgl. Tajfel 1981: 256; Billig 1995: 66; Yzerbyt u.a. 1997). Wichtig ist, dass in der Social Identity Theory Kategorisierung und Stereotypisierung nicht mehr - wie in den früheren Forschungen - als individueller und unter Umständen pathologischer Prozess angesehen wird, sondern als ein natürliches Phänomen, das in sozialen Zusammenhängen entsteht. Hier wird dem Rechnung getragen, dass Stereotypen in der Regel von einer großen Gruppe geteilt werden. Gruppenorientierte Selbstwahrnehmung löst in der sozialen Kategorisierung die Individualisierung innerhalb der Gruppe ab.

Es lassen sich drei Stufen im Prozess der Gruppenidentifikation beschreiben. Zunächst kategorisieren sich Individuen als Teil einer Gruppe (ingroup), legen sich so eine soziale Identität zu und unterscheiden sich von den relevanten Außengruppen. Dann lernen sie die stereotypen Normen kennen, die mit dieser Identität zusammenhängen. Als drittes wenden sie diese Normen in ihrem Verhalten an; so wird ihr normatives Verhalten eine hervorstechendere Eigenschaft als ihre Gruppenzugehörigkeit. In dieser Form schafft die Social Identity Theory eine Verbindung zwischen Selbstidentifikation und Stereotypisierung (vgl. Billig 1995: 66). 
Bei Tajfel stellen Stereotypen einen Bereich der sozialen Kategorisierung dar. Er definiert sie als »übersimplifiziertes mentales Bild einer Kategorie von Personen, Institutionen oder Ereignissen, das von einer großen Anzahl Menschen geteilt wird. Stereotypen werden gemeinhin, aber nicht notwendigerweise, von Vorurteilen begleitet« (Stallybrass 1977; zit. nach: Tajfel/Forgas 2000: 57). Ohne diese Präzision hat Lippmann bereits Ähnliches formuliert. Es geht dabei um die Konstitution von Identität der eigenen Gruppe, bei Lippmann als gesellschaftlich verankerte Traditionen und Werte gefasst, und um die Projektion nach außen, auf die Anderen. Damit lässt sich die soziale Dimension der Stereotypen besser verstehen. Für den Umgang mit dem Fremden ist diese soziale Dimension besonders wichtig, weil sich rassistische und nationalistische Stereotypen in der Regel durch eine positive Wertung der eigenen Identität im Gegensatz zu der Minderwertigkeit anderer ethnischer Gruppen oder Nationalitäten konstituieren.

So wichtig die sozialpsychologischen Ansätze der Stereotypenforschung sind, weisen sie doch einige Schwächen auf, die wiederholt kritisiert werden. Häufig wird übersehen, dass das Wissen um die eigene Gruppe und die individuellen Besonderheiten innerhalb der eigenen Gruppe wesentlich höher ist als die Information über eine Außengruppe, da wesentlich mehr Kontakt zu Mitgliedern der eigenen Gruppe als zu denen anderer Gruppen besteht. Mitglieder der eigenen Gruppe werden wesentlich stärker individualisiert, während die Mitglieder der anderen Gruppe eher über Stereotypen und Verallgemeinerungen beschrieben werden (vgl. Ellemers/Knippenberg 1997: 212). Der soziale Kontext ist von großer Wichtigkeit für die Entstehung von Stereotypen. Die Kritik richtet sich auch gegen den Universalismus der Social Identity Theory, der die spezifische Bedeutung sozialer Kategorien vernachlässigt. So wären beispielsweise nationale Gruppen zu unterscheiden von religiösen, politischen, ethnischen, geschlechtlichen oder Jugendgruppen, die alle unterschiedliche Formen der Identifikation bereitstellen. Durch die Konzentration auf die individuelle Kategorisierung werden Faktoren wie die der nationalen Identitätsbildung vernachlässigt. Hinzu kommt, dass die Forschungen nicht in einen historisch soziologischen Kontext eingebettet sind (vgl. Billig 1995: 66f.; Pickering 2001: 44). Stereotypen sind gesellschaftlich und kulturell verankert, ohne dass die Ursprünge erkennbar wären. Die Existenz von Stereotypen hat häufig eine lange historische Tradition, die kaum nachvollziehbar ist, da die stereotypen Vorstellungen über indirekte Quellen wie Eltern, Freunde, Lehrer, politische oder religiöse Leitbilder und ganz besonders durch die Massenmedien vermittelt werden (vgl. Stangor/Schaller 2000: 68). Aber auch die Literatur, Bilder und kulturelle Artefakte jeglicher Art können Stereotypen transportieren. Die Inhalte der Stereotypen unterliegen gesellschaftlich-politischen Entwicklungsprozessen, so dass sie über Generationen hinweg durchaus einen Wertewandel erfahren können. Diese Prozesse sind jedoch sehr langwierig, denn die Resistenz von Stereotypen gegenüber Veränderung ist eines ihrer kennzeichnenden Merkmale.

Die inhaltlichen Wertigkeiten von Stereotypen deuten sich bereits im Vergleich zwischen den positiven Wertungen der eigenen Gruppe und den eher negativen Bewertungen der fremden Gruppe an. Stereotypen schreiben nicht nur dem Fremden in verzerrender Weise Eigenschaften zu, auch das Eigene unterliegt Kriterien der Verallgemeinerung, die stereotypische Ansätze aufweisen. Auch hier werden Eigenschaften verkürzt und undifferenziert dargestellt, wobei dies meist in einer idealisierten Form stattfindet, denn das Ei- 
gene ist das Normale und kann nicht, ohne Schaden zu nehmen, negativ bewertet werden. Eine negative Selbstwahrnehmung hätte grundlegende Selbstzweifel zur Folge und müsste zu einer Hinterfragung der eigenen Werte und Normen führen. Es ist wesentlich einfacher, das Fremde in Bezug zum Eigenen abzuwerten, um sich selbst ein positives Selbstwertgefühl zu erhalten. »Im Bild von der anderen Gruppe erscheinen die der eigenen Gruppe fehlenden, doch beneideten Eigenschaften stets vergrößert und manchmal verzerrt. Diese der eigenen Gemeinschaft mangelnden, in der konkurrierenden Gruppe jedoch blühenden Eigenschaften erhalten dann zumeist einen negativen Wertakzent« (Suppan 1998: 14f.). Ähnlich verhält es sich mit negativen Eigenschaften der eigenen Gruppe. Sie werden entweder zu Tugenden verklärt oder aber feindlichen Gruppen angelastet. Die negativen Stereotypen der Fremdgruppe können jedoch auch romantisch verklärt ins Gegenteil gewendet werden. So gibt es immer den guten Wilden, der in seiner Unzivilisiertheit eine Freiheit lebt, von der der zivilisierte Europäer nur träumen kann. Die Verklärung im Exotischen stellt jedoch ebenfalls eine Verzerrung der Realität dar. Hier werden Sehnsüchte und Wünsche auf den Anderen projiziert, was eine objektive Wahrnehmung ebenso verhindert wie negative Stereotype.

Wie Stereotypen tatsächlich entstehen, ist kaum geklärt. Sie fungieren als eine Form der sozialen Kontrolle (vgl. Pickering 2001: 5). Wenn man das Eigene als eine Form der Ordnung ansieht, die durch die Konfrontation mit dem Fremden hinterfragt wird, können Schematisierungen als ein Weg gesehen werden, die Ordnung aufrecht zu erhalten. Stereotypen als verschärfte Form der Schematisierung verhindern jedoch flexibles Denken, was dazu führt, dass die Situation der Begegnung und somit auch die Machtverhältnisse in dieser Begegnung festgeschrieben werden. Stuart Hall beschreibt, dass Stereotypenbildung unter großen Ungleichheiten der Machtverteilung auftritt (vgl. Hall 2002: 258). Die Gruppe, die die Macht ausübt, grenzt mittels Stereotypen andere Gruppen aus und festigt somit ihre Position als überlegen. Stereotypen entstehen in der Begegnung mit dem Fremden. Erst in dieser Begegnung wird das Eigene erkannt und kann vom Fremden differenziert werden. Um die Identität zu stärken, werden Vergleiche zum Fremden gezogen und diese mit Wertungen versehen.

Dementsprechend ist es nicht verwunderlich, dass zahlreiche Stereotypen, die für fremde Völker und Ethnien bestehen, auf die imperiale Vergangenheit der Kolonialzeit zurückzuführen sind. Homi K. Bhabha beschreibt das Stereotyp als »fixierte Form des kolonialen Subjekts, « das »die koloniale Beziehung erleichtert und eine diskursive Form des ethischen und kulturellen Gegensatzes etabliert, in deren Termini die koloniale Macht dann ausgeübt wird « (Bhabha 2000: 116; Hervorhebung im Original). Die kolonisierten Subjekte sind durch die auf Stereotypen basierenden Ideologien bekannt, so dass diskriminierende und autoritäre Formen der Kontrolle als angemessen angesehen werden (vgl. ebd.: 123). Stereotypen helfen dabei, die einmal etablierten Machtverhältnisse zu legitimieren und sorgen für strikte Grenzziehungen zwischen dem Eigenen und dem Anderen. Sie definieren, wer sich innerhalb und wer sich außerhalb dieser Grenzen befindet. Richard Dyer sieht hierin die wichtigste Funktion von Stereotypen, denn sie definieren »die Grenzen von akzeptablem und rechtmäßigem Verhalten [...] und bestehen auf Grenzen an exakt solchen Punkten, wo in der Realität keine sind « (Dyer 1993: 16). Durch ihren realitätsverzerrenden Charakter bewirken Stereotypen die Manifestierung von Unterscheidungen an Stellen, wo sie der Machtkons- 
tellation, nicht aber möglichen Interaktionsformen zwischen verschiedenen Gruppierungen dienen. Stereotypen sind somit eine Form des Ethnozentrismus, da sie Normen der eigenen Kultur an andere Kulturen anlegen und diese mit einer Wertung versehen. Der wertende Charakter der Stereotypen sorgt für die soziale Kontrolle. In solch zementierten Machtkonstellationen ist es möglich, dass die unterdrückte Gruppe die negativen Stereotypen in ihr Selbstbild übernimmt und sich so mit den Gegebenheiten arrangiert. Um sich jedoch gegen die Unterdrückung zu wehren, ist die Wiedererlangung eines positiven Selbstbildes notwendig, was beispielsweise durch die Umwertung negativer Werte geschehen kann. ${ }^{13}$

Die Konzeption von Stereotypen und stereotypischer Wahrnehmung ist von Bedeutung, da sie in Bezug auf die Wahrnehmung eine wichtige Funktion innehaben. »Stereotypen sind kognitive Formeln, verfestigte Überzeugungen, die der Umweltassimilation und Lebensbewältigung dienen. Es sind historisch-wandelbare, aber doch ziemlich stabile Alltagskategorisierungen, Typisierungen der Umwelt, die aber dadurch, daß sie Verhalten steuern, auf die Realität zurückwirken, Realität beeinflussen und erzeugen können « (K. Roth 1998: 23). Die Wechselwirkung mit der Realität macht sie zum interessanten Faktor in der Wahrnehmung des Fremden. Es geht um die Bilder in den Köpfen, die die Wahrnehmung des Fremden beeinflussen. In der sozialpsychologischen Stereotypenforschung werden meist Gruppen mit bestimmten Attributen in Verbindung gebracht. Beispielsweise werden ausgewählte ethnische Gruppen von den Versuchspersonen mit Adjektiven bezeichnet, die über die vorhandenen stereotypen Vorstellungen Auskunft geben. ${ }^{14}$ Auf die Problematik dieses Verfahrens haben Wissenschaftler wiederholt hingewiesen, da diese Attribute (trait terms) in einem anderen Kontext ihre Bedeutung verlieren oder unterschiedliche Bedeutungen annehmen können (vgl. z.B. Reicher/Hopkins/Condor 1997: 115). Zudem beziehen sich diese Attribute immer speziell auf Personengruppen.

\section{Mentale Bilder}

Die Vorstellungen über fremde Kulturen beschränken sich nicht ausschließlich auf die Charakterisierungen der Völker, sondern beziehen sich wesentlich umfassender auf kulturelle Äußerungen jeglicher Art. So ist es nicht überraschend, dass der Begriff Bild oder image in diesem Zusammenhang häufig verwendet wird, um die Vorstellungen und das Wissen, das über Fremdgruppen zur Verfügung steht, zu benennen. Die Vorstellungen oder Bilder sind nicht geleitet durch Wissen, das Gültigkeit besitzt, sondern sie gründen sich häufig auf Annahmen, von deren Wahrheitsgehalt ausgegangen wird. Es handelt sich also um eine Art subjektives Wissen, das nicht nach-

13 So entwickelten die rassistisch unterdrückten Afro-Amerikaner in der Civil Rights Bewegung den Slogan black is beautiful und kehrten damit die Negativität des Begriffs black um, der in der Verwendung der Weißen mit Schmutz in Verbindung gebracht wurde. Erst mit der Umwertung der Stereotypen und der Wiedererlangung eines positiven Selbstbildes war es möglich, an der Machtkonstellation zu rütteln.

14 In der Studie von Katz/Braly 1933 suchten Versuchspersonen aus einer Liste von Adjektiven die für sie passend scheinenden Adjektive aus und ordneten sie bestimmten Nationalitäten zu. Dieses Eigenschaftslistenverfahren wurde von nachfolgenden Forschern weiter ausdifferenziert (vgl. Manz 1968: 22ff.). 
prüfbar ist. Dieses subjektive Wissen kann auch Stereotypen und Vorurteile beinhalten, die das persönliche Bild der Welt prägen. Dieses Bild ist auch für das Verhalten verantwortlich (vgl. Boulding 1987: 5f.). Das image ist jedoch nicht von vornherein gleichzusetzen mit stereotypen Vorstellungen. Erst wenn es mit Wertungen in Verbindung gebracht wird, kann man von der Entstehung von Stereotypen sprechen. Nur wenn Unterscheidungen getroffen werden, die etwas als besser oder schlechter in Bezug auf die eigene Gruppe bewerten, entwickelt sich der für stereotype Sichtweisen signifikante emotionale Gehalt (vgl. ebd.: 11). Je nachdem, wie flexibel Bilder auf die Einflüsse der Umwelt, persönliche Erfahrungen und Informationen jeglicher Art reagieren und sich modifizieren lassen, können Bilder als Wahrnehmungshilfen oder auch als Träger von Vorurteilen dienen. Das persönliche Bild ist jedoch auch beeinflusst von gesellschaftlichen Faktoren. Kenneth Boulding spricht vom "public image « (ebd.: 64), das von Mitgliedern einer Gruppe geteilt wird und deren persönliches Bild mit beeinflusst. Hier sind Parallelen zur Funktion von Stereotypen zu beobachten. Erhält das Bild von einer fremden Kultur eine die Komplexität reduzierende Funktion, die das Fremde auf bestimmte Fremdheitsfaktoren und wesentliche Merkmale reduziert, wird das, was übrig bleibt, zum Klischee (vgl. Suhrbier 1995: 14). Das Klischee beinhaltet die Dinge, die eine Differenz zur eigenen Kultur darstellen. Wahrnehmungstheorien weisen nach, dass das Außergewöhnliche im Alltag eher wahrgenommen wird als das Selbstverständliche (vgl. z.B. G. Roth 1998: 107). Dies gilt auch für die Wahrnehmung fremder Kulturen, die meist in ihrer Differenz zur eigenen Kultur gesehen werden, während mögliche Ähnlichkeiten und Parallelen keine Beachtung finden (vgl. K. Roth 1998: 31). So bleibt das Normale einer fremden Kultur im Klischee häufig unberücksichtigt.

Bilder im Kopf, Klischees, Stereotypen oder Vorurteile beeinflussen die Wahrnehmung des Fremden. »Wir sehen, was wir wahrzunehmen gelernt haben und zu erwarten gewohnt sind und suchen deshalb in der Realität selektiv eher nach Hinweisen, die unsere Erwartungen bestätigen, als nach Falsifizierungen. Entgegengesetzte Erfahrungen und Informationen werden gerne unterdrückt, ignoriert oder als >Ausnahme von der Regel` abgetan « (K. Roth 1998: 32). Für die Wahrnehmung des Fremden bedeutet das zweierlei: Zunächst beherrschen Differenzen zum Eigenen verstärkt die Vorstellung vom Anderen. Diese Vorstellung steuert die Wahrnehmung des Fremden, so dass es eher zu einer Bestätigung der Vorstellung kommt, als dass diese widerlegt und in der Folge modifiziert wird. Dies erklärt auch die Erfahrungsresistenz von Stereotypen, werden ihnen widersprechende Erfahrungen doch häufig als Ausnahmen von der Regel abgetan. So können Stereotypen oder klischeehafte Vorstellungen zu »self-fulfilling prophecies« (ebd.; Fleischmann 1999: 127) werden, die lediglich die vorhandenen Bilder bestätigen und somit zur Auslassung wichtiger Faktoren führen. Sie können in einem Spannungsverhältnis zur erfahrbaren Realität stehen. Stereotypen und Klischees simulieren eine Kohärenz des Fremden, was die Wahrnehmung von Differenzen innerhalb der fremden Kultur verhindert. In der Beobachtung wird eine Einheitlichkeit erwartet, die mögliche Widersprüche unterdrückt. Stereotypen können insofern als eine kollektive »Erkenntnisbarriere « (Hansen 2000: 321) angesehen werden, die nur eine standardisierte Wahrnehmung des jeweiligen Fremden erlauben. Auch in der Social Identity Theory sind Kategorisierung und Stereotypisierung »aktive Konstruktionen, die der Umwelt auferlegt werden und unsere Wahrnehmung sowie die Interpretation eingehender Informatio- 
nen beeinflussen « (Tajfel/Forgas 2000: 49). Bewusst oder unbewusst beeinflussen Stereotypen und Klischees die Wahrnehmung und wirken sich somit auf die Darstellungen des Fremden in Texten und Bildern aus. Weil Stereotypen Kategorisierungen vornehmen, die dem Fremden in seiner Fremdheit nicht gerecht werden, verhindern Stereotypen eine differenzierte - sozusagen offene - Wahrnehmung. Durch Stereotypen wird das Fremde zum Anderen. Es wird auf Differentes fixiert, weil die Stereotypen den Blick auf die vielschichtigen Nuancen des Fremden verstellen. Dies wirkt wiederum auf die Vorstellungen des Fremden, so dass hier ein Kreislauf entsteht, der noch eingehend zu untersuchen ist.

\subsection{Darstellungen des Fremden}

\subsubsection{Konstruktion des Anderen}

Nach der Untersuchung der Parameter, die die Wahrnehmung des Fremden beeinflussen, soll nun die in Darstellungen manifestierte Wahrnehmung eingehend betrachtet werden. ${ }^{15}$ Die Beobachtungen, die aus dem Blick auf das Fremde resultieren, benötigen zu dessen Vermittlung eine Form.

Weil das Fremde relational und okkasionell ist, lässt es sich kaum fixieren. Der Versuch, seine verschiedenen Nuancen zu berücksichtigen, offenbart schnell, dass eine Darstellung aller Aspekte niemals gelingen kann. Denn das Fremde entzieht sich der Festlegung. Jegliche Form von Darstellung wird zur Fixierung. Wird das Fremde ausschließlich als vom Eigenen abweichend gesehen und klar abgegrenzt, wird es zum Anderen: Es wird als Anderes konstruiert. »Konzeptionen des Anderen und die Strukturen der Differenz und Ähnlichkeit, die sie mobilisieren, existieren nicht in einer natürlichen Form. Das unberührte, wirklich Andere dort draußen, das erst noch gefunden werden muss, gibt es nicht. Der Ort des Anderen befindet sich primär in der Sprache« (Pickering 2002: 72). Um das Fremde benennen und damit erzeugen zu können, bedarf es einer Form der Darstellung, die in der Regel sprachlich ist; die Möglichkeit einer bildlichen Darstellung ist hier zunächst mit einbezogen. In der sprachlichen Unterscheidung des Eigenen vom Fremden wird eine Differenz zum Anderen erst erzeugt. Das Andere besitzt keine objektive Realität. »Stattdessen ist es ein Bild, eine Wahrnehmung, die von dessen Inhaber eher subjektiv auf der Basis von vergangenen Zusammenhängen und Erfahrungen konstruiert wird, als eine objektive Aufzeichnung der Realität >da draußen< zu sein« (Befu 1992: 17).

Dieser Prozess der Konstruktion des Anderen durch den Diskurs wird mit dem Begriff othering beschrieben, der seinen Ursprung in den angloamerikanischen Cultural Studies hat und nicht übersetzbar ist. »Othering bezeichnet die Einsicht, dass die Anderen nicht einfach gegeben sind, auch niemals einfach gefunden oder angetroffen werden - sie werden gemacht « (Fabian 1995: 327; Hervorhebung im Original; vgl. auch Hardt/Negri 2002: 138). Othering beschreibt den Prozess des Machens oder Bezeichnens. Das

15 Darstellungen bedürfen einer sprachlichen Form. Als Darstellungen gelten Texte oder Bilder. Auf bildliche Darstellungsformen des Fremden wird erst in Teil I, Kap. 4 und besonders in Teil II ausführlich eingegangen, weshalb sie in diesem Kapitel zwar erwähnt, aber nicht präzisiert werden. 
othering hat eine ideologische Funktion. Es versucht, die selbst konstruierte Beziehung zwischen Eigenem und Anderem zu fixieren und ihr damit Stabilität zu verleihen. Um dies zu erreichen, muss die Konstruktion wiederholt bestätigt werden (vgl. Pickering 2002: 72f.). Indem Machtverhältnisse, Stereotypen oder Vorurteile perpetuiert werden, behaupten sie in der gesetzten Andersartigkeit Dauerhaftigkeit. Der Terminus othering bezeichnet ebenfalls die Ungleichheit, die zwischen denjenigen Subjekten herrscht, die das Andere konstruieren (»those who do the othering «) und denjenigen Objekten, die zu den Anderen gemacht werden (»those who are othered «). Die Macht liegt demzufolge bei denen, die das othering aktiv betreiben. Erstere »besetzen einen privilegierten Raum, in dem sie sich im Gegensatz zu den Anderen definieren können, die somit als different gekennzeichnet sind; diese Kennzeichnung verstärkt und verlängert die betreffende Ungleichheit, indem sie sie zu bekräftigen und beweisen scheint« (Pickering 2002: 73). Othering geschieht immer in Form von Darstellungen. Seien sie verbal, schriftlich fixiert oder bildhaft, das Andere wird erst zum Anderen, wenn dies thematisiert wird. Dazu ist eine Form notwendig. Die Darstellung ist insofern Teil der Konstruktion des Anderen.

Verschiedene Studien, die die historische Entwicklung der Beziehungen zwischen Europäern und den Anderen untersuchen, weisen nach, dass die Entwicklung der europäischen Wissenschaften ganz nachhaltig zu dieser Konstruktion des Anderen beigetragen hat. Entwicklungsdenken und die Idee eines linearen Voranschreitens der Menschheit von einer primitiven hin zu einer modernen Gesellschaft lassen schon früh die Idee reifen, dass Fortschritt das ist, was die Europäer von den primitiven Anderen unterscheidet. So wurden die primitiven Völker erst aus einer eurozentrischen Fortschrittsperspektive und deren diskriminierender Anwendung heraus erschaffen. Die Existenz von primitiven Völkern ist eine ideologische Konstruktion und keine Tatsache. »Fortschritt produziert Primitive, Primitive beweisen nicht den Fortschritt. Primitive sind Fortschritt, die dunkle, samtige, notwendige Rückseite des Konzepts« (McGrane 1989: 99). Auch die Natur wird seit dem achtzehnten Jahrhundert nicht mehr als gegeben angesehen, sie verlangt vielmehr nach dem Eingreifen der Menschheit. So werden nicht nur Pflanzen aus ihrem Kontext entfernt, gesammelt, umgepflanzt, klassifiziert und mit europäischen Namen belegt (vgl. Pratt 1992: 31). Die entstehende Ordnung, die der Mensch in das vermeintliche Chaos der Schöpfung bringt, ist eine gemachte, aus europäischer Sicht angelegte, die mitunter bestehende Zusammenhänge negiert und selbst neue schafft. Aus einem solchen Blickwinkel werden lange Zeit auch fremde Völker beobachtet und eingeordnet; ihnen werden spezifische Eigenschaften zugewiesen, die sie von den europäischen Völkern abgrenzen, wobei die Unterschiede innerhalb Europas in dieser Konzeption nivelliert werden. Die Wissenschaften behaupten im achtzehnten und frühen neunzehnten Jahrhundert jedoch, die Ordnungen aus der Natur herauszulesen. Sie sind sich ihrer konstruierenden Funktion nicht bewusst. ${ }^{16}$

$16 »$ Natural history conceived of the world as a chaos out of which the scientist produced an order. It is not, then, simply a question of depicting the planet as it was. [...] From another perspective, however, natural history is not transformative in the least. That is, as it understands itself, it undertakes to do virtually nothing in or to the world « (Pratt 1992: 30ff.; Hervorhebung im Original). 
Diese Art des Diskurses über das Fremde wird unter Behauptung von Wissenschaftlichkeit über lange Zeit hinweg geprägt. Da die europäische Begegnung mit dem Fremden sich über Jahrhunderte auf der Ebene der Kolonisation und des Imperialismus bewegt, sind die historischen Machtkonstellationen, die die Darstellungen des Fremden bestimmen, klar definiert. Hinzu kommt die Annahme, dass die Anderen nicht für sich selbst sprechen können, da sie aufgrund ihrer fehlenden Entwicklung dazu nicht in der Lage sind. Die Europäer avancieren so zur Deutungsmacht, die durch wissenschaftlichen Fortschritt für zahlreiche Phänomene Erklärungen generiert, die die Darstellungsweisen der Anderen prägen. Die Europäer werden zu beobachtenden Subjekten, während die Anderen durch die Beobachtung zu Objekten der Erkenntnis gemacht werden.

Die Konstruktion des Anderen beruht auf einer sehr langen Tradition, die auf frühe Kontakte mit dem Fremden zurückgeht. Verschiedene Autoren hinterfragen die Textproduktion und die damit verbundene Konstruktion des Anderen über die Jahrhunderte hinweg (vgl. Said 1995; McGrane 1989; Pratt 1992). Edward Said untersucht in seiner umfangreichen Studie über den Orientalismus die historische Entwicklung des Systems Orient/Okzident, das sowohl viel zur Konzeption der Selbstwahrnehmung Europas als auch der Fremdwahrnehmung des Orients durch die Europäer - des nahen, mittleren und fernen Ostens - beigetragen hat (vgl. Said 1995). Said vertritt die These der Konzeption und Konstruktion des Orients durch die Europäer. Einige zentrale Gedankengänge verdeutlichen die komplexen Zusammenhänge von Vorstellungen und Phantasien, realen Begegnungen, wissenschaftlichen Erkenntnissen und imperialen Machtstrukturen, die den Umgang mit dem Anderen prägen. Said führt die verschiedenen Aspekte in der Betrachtung des Fremden, die sowohl von Überlegenheitsdenken und stereotypischer Wahrnehmung als auch von Mythen, exotischen Vorstellungen und Sehnsüchten geprägt ist, zusammen:

»Orientalismus ist die Disziplin, durch die der Orient als ein Thema des Lernens, der Entdeckung und der Praxis systematisch untersucht worden ist (und wird). Zusätzlich habe ich den Begriff jedoch gebraucht, um die Sammlung von Träumen, Bildern und Worten zu benennen, die jedem zugänglich ist, der von dem östlich der trennenden Markierung Liegenden zu sprechen versucht« (Said 1995: 73).

Der von Said verwendete Begriff des Orientalismus umfasst somit sehr unterschiedliche Gebiete. Der Bereich der wissenschaftlichen Untersuchung, dem Objektivität zugeschrieben wird, wird in Verbindung gebracht mit der Phantasie, der Literatur und der Kunst, die sich eine Vorstellung vom Orient machen und ebenfalls zu dessen Repräsentation beitragen. Wissenschaftliche und künstlerische Annäherungen an den Orient lassen sich - nach Said nicht immer eindeutig voneinander trennen, da die Vorstellungen und Phantasien des grundsätzlich Anderen auch die wissenschaftlichen Anschauungen mit geprägt haben. Orientalismus kann demzufolge als die »Institution für den Umgang mit dem Orient [diskutiert werden. Orientalismus] geht mit ihm [dem Orient] um, indem er Behauptungen über ihn macht, Sichtweisen autorisiert, ihn beschreibt, ihn lehrt, ihn besiedelt, ihn regiert: Kurz zusammengefasst [dient] der Orientalismus als westlicher Stil der Dominanz, Neuordnung und Machtausübung über den Orient« (Said 1995: 3). Orientalismus ist der Diskurs, der den Orient erzeugt und ihn damit dominiert. 
Die Konstruktion des Anderen wird durch den Diskurs gesteuert. Er verbindet die verschiedenen hier diskutierten Annahmen. Dem Diskurs liegt eine historische Entwicklung zugrunde, denn über Jahrhunderte hinweg gibt es Kontakte zum Orient, sei es in Form von Handel oder in kriegerischer Auseinandersetzung. Seit jeher werden Unterscheidungen zwischen dem Orient und dem Okzident gemacht, die auf die extreme Andersartigkeit des Orientalen abzielen. Die Akzeptanz dieser gesetzten Andersartigkeit macht es möglich, jegliche Beobachtungen darauf aufzubauen und somit die Andersartigkeit zu manifestieren. Eine wichtige Rolle nehmen hier textliche Repräsentationen ein. Der wissenschaftliche Orientalismus beruht lange Zeit auf Textstudien; der Orientalist reist nicht selbst in die Gebiete seines Interesses, um vor Ort Erkenntnisse zu sammeln (vgl. Said 1995: 52). Das Interesse gilt meist lediglich der historischen Kultur und nicht der gegenwärtigen Situation. Neben den historischen Texten wird auf Erfahrungsberichte von Kolonialbeamten oder Reisenden zurückgegriffen. Die wissenschaftlichen Texte, die aus dieser Annäherung an das Fremde entstehen, übernehmen häufig die überlieferten stereotypischen Vorstellungen, was wiederum von den Kolonialregierungen zur Rechtfertigung des Umgangs mit den Einheimischen aufgegriffen wird (vgl. ebd.: 76f.). Die Wissenschaft rechtfertigt bereits vorab die koloniale Herrschaft und ist nicht erst eine Rationalisierung der Kolonialherrschaft im Nachhinein. ${ }^{17}$ Die Wissenschaft, deren Erkenntnisse keine aus erster Hand erworbenen sind, übt lange Zeit einen nachhaltigen Einfluss auf die realen Gegebenheiten der Begegnung mit dem Fremden aus.

Europa und der (vordere) Orient können auf eine besonders lange historische Tradition des Kontakts zurückblicken. Trotzdem können die Ausführungen Saids partiell auch auf den Kontakt der Europäer zu anderen Weltregionen übertragen werden, da diese zunächst fast immer aus der überlegenen imperialen Perspektive heraus betrachtet werden. Auch wenn es - wie im Fall Japans - nicht zu einer Kolonisierung gekommen ist, wird das Fremde stets beobachtet, untersucht und bewertet; diese Wahrnehmungen werden textlich dargelegt. $^{18}$

\subsubsection{Repräsentation}

Über einen langen Zeitraum hinweg haben Text- und Bildproduktionen die Vorstellungen der Europäer über das Fremde geprägt; sie wirken sich bis heute auf dessen Wahrnehmung aus. Das Interesse an der Entdeckung des Fremden initiiert ein Interesse an dessen Darstellung, denn lange Zeit ist Reisen nur wenigen Privilegierten vorbehalten. Erst in der Darstellung kann das Fremde überhaupt einer breiten Bevölkerungsschicht zugänglich gemacht werden.

Darstellungen des Fremden sind Repräsentationen. Sie sind keine Spiegelbilder des Fremden, sondern eher Interpretationen des Gesehenen und Erfahrenen. Dies wird häufig übersehen. Oft werden Darstellungen des Fremden als objektiv aufgefasst, insbesondere wenn sie als Ergebnisse wissenschaftli-

17 »To say simply that Orientalism was a rationalization of colonial rule is to ignore the extent to which colonial rule was justified in advance by Orientalism, rather than after the fact « (Said 1995: 39).

$18 \mathrm{Zu}$ den europäischen Japanbeziehungen vgl. Teil I, Kap. 2. 
cher Forschung präsentiert werden. ${ }^{19}$ Das betrifft sowohl die Produktion, als auch die Rezeption. Repräsentationen in diesem Sinne sind das, was im vorhergehenden Abschnitt allgemein beschrieben wird: Sie sind Konstruktionen des Anderen, sie fixieren ihren Gegenstand. Diese Theorie der Repräsentation als Spiegelbild ist gemäß Charles Taylor über lange Zeit das vorherrschende Modell: »Eine Repräsentation [...] ist die Wiedergabe einer unabhängigen Realität« (Taylor 1995: 54). In diesem Sinne werden die Darstellungen als Spiegelbilder, als Abbilder von Urbildern betrachtet. Ausgeblendet wird dabei das, was man die konstruktive Seite nennen kann, das Errichten von Darstellungen. Denn »rationales Denken, das nach Erkenntnis der Welt strebt, versucht Repräsentationen zu errichten« (ebd.). Repräsentationen sind dementsprechend konstruiert.

Für diese konstruktive Analyse der Darstellung als Repräsentation spielt es keine Rolle, ob es sich um wissenschaftliche oder künstlerische Repräsentationen handelt, die jedoch unterschiedliche Ansprüche verfolgen. Die Repräsentationen beruhen nicht ausschließlich auf direkten Wahrnehmungen, sondern oft auf Vergangenem, auf indirekten Erfahrungen und in der eigenen Gesellschaft vertretenen Stereotypen und Vorurteilen. Die repräsentierende Darstellung des Fremden wird aus all diesen Faktoren heraus konstruiert. In der Betrachtung von Repräsentationen des Fremden sollte diese Tatsache stets mitgedacht werden.

Die Erfahrungen mit dem Fremden werden aus unterschiedlichen Gründen aufgezeichnet. Sie finden ihren Niederschlag in wissenschaftlichen Abhandlungen, den Medien, der Literatur und in der Kunst. Die Darstellungen sind nach meinem Ermessen - Repräsentationen des Fremden und ersetzen oftmals eine direkte Erfahrung. Zwar sind wir gelegentlich direkt mit dem Fremden konfrontiert, wenn wir uns aus unserem angestammten Umfeld hinaus bewegen, doch durch Bilder, Filme, Bücher, Zeitschriften, Zeitungen, Fernsehen und Erzählungen haben wir einen wesentlich stärkeren Kontakt zum Fremden als durch unsere eigene, direkte Erfahrung. »Was wir über unsere Gesellschaft, ja über die Welt, in der wir leben, wissen, wissen wir durch die Massenmedien« (Luhmann 1996: 9). Dies ist für die Begegnungen mit dem Fremden in Form von Repräsentationen von großer Relevanz. Wie bereits Walter Lippmann anmerkt, besitzen wir wesentlich mehr Informationen aus zweiter als aus erster Hand, weshalb der Frage der Repräsentation große Bedeutung zukommt. Medien und Massenmedien besitzen hier eine zentrale Funktion. Wie Dinge beschrieben und diskutiert werden und wie Ereignisse in Bildern gezeigt werden, beeinflusst in hohem Maße die Sichtweisen derjenigen, die Bilder und Texte rezipieren. Wobei dies nicht bedeutet, dass eine mediale Darstellung automatisch einen Konsens erzeugt. Vielmehr gibt es unterschiedliche Lesarten und konträre Ansichten, die ebenfalls in den Prozess der Bedeutungskonstitution einfließen. Über mediale Repräsentationen werden Meinungen gebildet und Stereotypen kolportiert, aber möglicherweise auch in Frage gestellt. Es werden Weltbilder erzeugt, die mehr oder weniger fest in der Gesellschaft verankert sind und damit Einfluss auf unseren Umgang mit der Welt und auf unsere Vorstellung von der Welt ausüben.

19 So z.B. die von Engelbert Kaempfer angefertigten Tafeln, die Flora und Fauna Japans genauso skizzieren wie mythische Fabelwesen. Hier fließen einerseits eigens mitgebrachte Vorstellungen ein, andererseits prägen sie bis heute das Bild der Fremde als fabelhafte Landschaften (vgl. Kaempfer 1964). 
Eine umfassende philosophische Untersuchung des Begriffs der Repräsentation und seiner Entwicklungen kann an dieser Stelle nicht geleistet werden. Es ist nicht ganz klar, ob es sich um einen neueren »Kunstterminus« (Taylor 1995: 54) oder um einen klassischen Terminus der Erkenntnistheorie handelt. ${ }^{20}$ Hier soll das Begriffsfeld aus Sicht der anglo-amerikanischen Cultural Studies und Visual Cultural Studies untersucht werden, in dem Repräsentation ein zentraler Begriff ist. Im Deutschen umfasst der Begriff Repräsentation je nach Kontext die verschiedenen Bedeutungsebenen von Vorstellung, Darstellung, Abbild, Bild oder Stellvertretung (vgl. Scheerer u.a. 1992: Sp. 790). Während sich die Bedeutungsebenen Vorstellung und Darstellung auch auf gesellschaftliche Prozesse beziehen, legen Bild und Abbild einen Zusammenhang mit der Kunst nahe. Die Bedeutung der Stellvertretung steht vorrangig im juristischen und politischen Gebrauch. Insgesamt durchdringen und überlagern sich die verschiedenen Bedeutungsebenen, so dass keine eindeutige Differenzierung möglich ist; sie scheint hier auch nicht unbedingt notwendig. Repräsentation impliziert immer die Abwesenheit des repräsentierten Gegenstands, unabhängig davon, welche spezifische Bedeutung zum Tragen kommt. Der Gegenstand selbst ist nicht verfügbar, weshalb seine Repräsentationen den Platz des Originals einnehmen. Eine Ähnlichkeit zum Gegenstand, wie sie die Bedeutung Bild oder Abbild andeuten, ist jedoch für Repräsentationen nicht zwingend. Wichtig ist die Betonung der Differenz zwischen der Wirklichkeit und ihrer Repräsentation. Die direkte Erfahrung der Wirklichkeit erfordert Präsenz, also die Anwesenheit sowohl des Betrachters als auch des Betrachteten zur selben Zeit im selben Raum. Die Repräsentation hingegen steht in Abwesenheit des beobachteten Gegenstands für denselben. Die Repräsentation ist etwas Geschaffenes, das die Realität der Erfahrung transformiert und diese gestaltend umsetzt (vgl. Fabian 1995: 338).

Stuart Hall schreibt der Repräsentation eine zentrale Bedeutung in der Kultur zu. Ausgehend von den konstruktivistischen Theorien von Ferdinand de Saussure, Roland Barthes und Michel Foucault umreißt er sehr plausibel die Bedeutung des Repräsentationsbegriffes für die Cultural Studies (vgl. Hall 2002: Einführung und Kap. 1). Repräsentationen nehmen eine Schlüsselposition in der Kommunikation innerhalb einer Kultur ein, wobei der in Abschnitt 1.2.1. eingeführte erweiterte Kulturbegriff von Stuart Hall zum Tragen kommt. Um sich innerhalb einer Kultur verständigen zu können, ist es notwendig, dass Bedeutungen allen Mitgliedern einer Kultur zugänglich sind. Geteilte Bedeutung (shared meaning) heißt jedoch nicht, dass es für Dinge oder Ereignisse nur eine allgemeingültige Bedeutungsebene gibt, die die Vielfältigkeit von Interpretationsmöglichkeiten vereinheitlicht, die selbstverständlich innerhalb einer Kultur existieren. »Wenn man sagt, dass zwei Menschen derselben Kultur angehören, heißt dies, dass sie die Welt etwa in derselben Weise interpretieren und dass sie sich selbst, ihre Gedanken und Gefühle über die Welt zum gegenseitigen Verständnis ausdrücken können« (Hall 2002: 2). Diese kulturelle Kommunikation wird getragen von Sprache, die Hall als repräsentationales System beschreibt. Sprache bedeutet hier nicht nur gesprochene oder geschriebene Sprache, sie umfasst in Halls Konzeption ebenso die Bereiche Bilder, Musik und sogar Objekte, wenn wir sie als Systeme, Zeichen und Symbole verwenden, um Bedeutung zu konstituieren (vgl.

20 Vgl. dazu den umfassenden Artikel Repräsentation im historischen Wörterbuch der Philosophie: Scheerer u.a. 1992: Sp. $790-853$. 
ebd.: 1). Repräsentation ist für Hall demnach »der Prozess, in dem Mitglieder einer Kultur Sprache (grob definiert als jedes System, das Zeichen einsetzt, jedes signifizierende System) verwenden, um Bedeutung zu konstituieren « (ebd.: 61). Repräsentation verbindet demnach drei verschiedene Systeme: »die Welt der Dinge, Menschen, Ereignisse und Erfahrungen; die konzeptuelle Welt - die Welt der mentalen Konzeptionen in unseren Köpfen und schließlich die Zeichen, die in Sprachen organisiert sind und für diese Konzepte stehen oder sie kommunizieren« (ebd.). Um zwischen diesen unterschiedlichen Systemen zu vermitteln, wird ein Code benötigt, der besagt, welches Wort oder welches andere Zeichen (Signifikant) für welches Konzept (Signifikat) benutzt wird. ${ }^{21}$ Diese Systeme sind nicht für alle Zeit fixiert, vielmehr konstituiert sich Bedeutung zwischen ihnen aus einer spezifischen historischen Konstellation heraus. So lässt sich erklären, dass es in der Verwendung von Sprache zu Bedeutungsverschiebungen kommen kann. Der Code bildet die Ebene des Konsenses, die bewirkt, dass Kommunikation, so fehlerhaft sie auch sein mag, funktioniert, weil Übereinstimmung darüber herrscht, welche Bedeutungen welchem Konzept zugeschrieben werden.

Ein zentraler Aspekt dieses Modells ist die Frage nach der Herkunft von Bedeutung. Bedeutung ist kein natürlicher Bestandteil der Dinge selbst, vielmehr wird diese erst im Zusammenspiel der verschiedenen Systeme - im Raum der Sprache, des Codes - konstituiert. Die Dinge besitzen keine Bedeutung, die unabhängig von ihren Repräsentationen existiert. Der Prozess der Bedeutungskonstitution ist Bestandteil der Kultur. Bedeutung wird erzeugt, indem Dinge repräsentiert werden. ${ }^{22}$ Sie werden beschrieben, es werden Geschichten über sie erzählt, Bilder von ihnen produziert, Gefühle mit ihnen assoziiert, sie werden klassifiziert und konzeptualisiert und mit Werten belegt (vgl. Hall 2002: 3). Erst in der Repräsentation entsteht Bedeutung, weshalb der Form, beziehungsweise der Art und Weise der Repräsentation, eine immense Wichtigkeit zukommt.

Repräsentation kann als »prozeßhafter, kontingenter Vorgang, der sich zwischen mindestens zwei Seiten abspielt, " gesehen werden (Fuchs/Berg 1995: 14). Der Verweis auf die Kontingenz von Repräsentation macht deutlich, dass ihre Form nicht zwingend ist - sondern zu bewerten in Abhängigkeit zu den Bedingungen ihrer Entstehung. Repräsentationen können für sich nicht beanspruchen, dem repräsentierten Gegenstand oder Ereignis äquivalent zu sein. Sie sind demnach stets kritisch zu betrachten. Eine solch kritische Bewertung von Repräsentationen des Fremden ist deshalb schwierig, weil das dargestellte Fremde in einem doppelten Sinne abwesend ist: Es ist nicht nur anderswo, es ist das Anderswo. Es liegt in der Fremde und ist - als Fremdes - original unzugänglich. Dies verschärft das Problem der objektiven Repräsentation. Man kann auch von einer $»$ Verunsicherung [...] der etablierten

21 Der Gebrauch des Begriffs Code präzisiert den über das Linguistische hinausgehenden erweiterten Sprachbegriff. Code wird verstanden als bewegliches Regelsystem, als Konvention, als soziologisches Pendant zum linguistischen Begriff der Sprache (vgl. Barthes 1983: 19).

22 Für die genuin sprachliche Bedeutung hat Charles Taylor das konkretisiert: »Wörter sind dabei [bei der Errichtung von Repräsentationen] unentbehrliche Werkzeuge. [...] Hieraus resultiert natürlich eine stark designativ orientierte Auffassung von Bedeutung. Wörter besitzen eine Bedeutung, weil sie für Dinge stehen. [...] Die Bedeutung eines Wortes besteht in dem, was es bezeichnet. Bedeutung ist Bezeichnung, Designation« (Taylor 1995: 54f.). 
Humanwissenschaften« (Därmann 2005a: 21) sprechen, die von dieser Doppelung der Abwesenheit ausgeht: Wie kann eine Repräsentation als »bewährbare Zugänglichkeit des original Unzugänglichen« aussehen? ${ }^{23}$

Hier setzt die philosophische Kritik an humanwissenschaftlichen Repräsentationsformen an. Aspekte des Wissens und der Wissensproduktion in Verbindung mit Machtaspekten rücken ins Zentrum einer kritischen Analyse des Repräsentationsbegriffs, die die »kulturelle Hegemonie bestimmter Diskurse und Sprachen « und »das Erkenntnisprivileg, die Interpretationsmacht, die sich ihrem Gegenstand aufprägt, « als Problemfeld der Wissenschaften ins Bewusstsein rückt (Fuchs/Berg 1995: 72). Die Repräsentation ist prinzipiell nie in der Lage, den repräsentierten Gegenstand - ob Person oder Kultur exakt zu reproduzieren. Trotzdem wird sie, besonders wenn sie eine abbildhafte Ähnlichkeit mit dem repräsentierten Gegenstand verbindet, leicht mit diesem verwechselt. Die ihr inhärente Gefahr liegt darin, dass sie als objektive Stellvertretung des Originals angesehen wird. Sie weist jedoch »eine trügerische, das Ursprüngliche entstellende Macht« auf, »die mehr zu tun scheint als bloß zu repräsentieren« (Därmann 2002: 14). Inwieweit wird sie ihrem Gegenstand gerecht? Es gibt keine Möglichkeit, die Genauigkeit von Repräsentationen zu bestimmen. Husserl schreibt, sie müssen bewährbar sein. Dem schließt sich auch Fabian an. Er schlägt vor, Repräsentationen über ihre Nützlichkeit zu überprüfen: »Eine gute Repräsentation ist eine, die funktioniert. Und als Beweis für das Funktionieren gilt die Tatsache, daß eine Repräsentation uns [damit sind Rezipienten innerhalb einer Kultur gemeint] befähigt, gemeinsam auf die Welt einzuwirken« (Fabian 1995: 336). Mit diesem Modell wird abermals versucht, die originale Unzugänglichkeit des Fremden auf einer Ebene von Gegenständlichkeit zu behandeln, was dem Aspekt der Fremdheit jedoch nicht gerecht wird.

Das Problem einer objektiven Repräsentation des Fremden hat in der Ethnologie, deren Aufgabe darin besteht, als Wissenschaft vom Fremden dieses analytisch zu erfassen, zu interpretieren und zugänglich zu machen, zu einer Krise geführt, die seit den achtziger Jahren des zwanzigsten Jahrhunderts als Krise der ethnografischen Repräsentation auf breiter Ebene diskutiert wird.

»Die extreme interne Widersprüchlichkeit der Ethnologie, auf der einen Seite Wissenschaft sein zu wollen, auf der anderen Seite aber aufgrund der ethnographischen Forschungsmethodik eine saubere Trennung zwischen Subjekt und Objekt, zwischen Ethnologie und Beobachtungsobjekt, nicht bewerkstelligen zu können, spiegelt sich sehr deutlich in der Geschichte der Ethnologie wider« (Jamme 2002: 191).

Dies wird in den unterschiedlichen historischen Formen der ethnografischen Darstellung deutlich. Analysieren die Ethnologen im neunzehnten Jahrhundert vom heimatlichen Schreibtisch aus die Dokumente der Kolonialverwaltungen, ohne selbst in Kontakt mit den fremden Völkern getreten zu sein, werden aus den teilnehmenden Beobachtungen in der ersten Hälfte des zwanzigsten Jahrhunderts heraus Monografien geschrieben, die den Beobachter

23 Auch Husserl, der das Paradox der Fremdrepräsentation selbst so radikal formuliert hat, findet zu keiner Lösung auf diese Frage: »Ähnlich wie das Paradox der persönlichen Fremderfahrung entschärft Husserl auch das Paradox kultureller Fremderfahrung« (Waldenfels 1997: 94). 
weitgehend eliminieren. Seit den sechziger Jahren des zwanzigsten Jahrhunderts wird die Repräsentation der Fremderfahrung durch den ethnografischen Text zunehmend zum Problem. »Auf das Problematischwerden der ethnographischen Textualität an sich antwortet man mit einem experimentellen >Schreiben«" (Jamme 2002: 196; vgl. z.B. Tyler 1991). Collagetechniken lassen »die Schnitte und Brüche des Forschungsprozesses sichtbar werden « (Jamme 2002: 198). So verwischen zunehmend die Grenzen zwischen wissenschaftlicher Abhandlung und literarisch-poetischen Versuchen der Darstellung, was Christoph Jamme dazu veranlasst zu fragen, ob nicht möglicherweise die Kunst Lösungswege aus dem Dilemma anbieten kann. Das Medium der Repräsentation muss in der Theorie der Fremderfahrung reflektiert werden. »Es macht einen Unterschied, ob wir eine theoretische Abhandlung oder ein Reisetagebuch oder einen Roman schreiben bzw. ein Bild malen« (ebd.: 200). Jede Form der Repräsentation stellt eine Übersetzung der Fremderfahrung dar, eine Übersetzung von einem Symbolsystem in ein anderes. Dies ist auch Aufgabe der Kunst, woraus Jamme schlussfolgert:

»Nur die Kunst kann das Fremde so darstellen, daß es nicht vergewaltigt wird. Kunst macht Ernst mit der Einsicht, daß Fremd- und Selbsterfahrung nicht zu trennen sind; als Absage an die Herrschaft des Ichs über das Fremde liegt einzig in der Kunst die Möglichkeit der Versöhnung mit dem Fremden in Schönheit [...]. Die Kunst macht aber auch darauf aufmerksam, daß in jeder interkulturellen Verständigung eine interpretative Problematik liegt« (Jamme 2002: 200f.; Hervorhebung im Original).

Im Gegensatz zur Wissenschaft der Ethnologie hat die Kunst wesentlich gröBere Freiräume der Darstellung des Fremden, denn sie behauptet keine Objektivität, sie ist radikal subjektiv. Die Äußerungen eines Künstlersubjekts, das auf kreative gestalterische Art neue Realitäten in Form von Bildern oder Texten schafft, können zwar mit einer objektiv wahrnehmbaren Realität verwechselt werden, der Verweis auf die Kunst macht jedoch jeglichen Objektivitätsanspruch zunichte. Ohne auf empirische Daten zurückgreifen zu müssen, kann der Künstler möglicherweise eine angemessenere Repräsentation der Fremderfahrung und damit des Fremden leisten, als dies in vermeintlich wissenschaftlichen Darstellungen möglich ist. Kunst möchte nicht objektiv repräsentieren, sie kann Fremderfahrung aber subjektiv erfahrbar machen.

Jamme lässt jedoch die Rezeptionsproblematik durch den Betrachter außen vor. Die Interpretation der künstlerischen Äußerung, sei es als bildende Kunst, als Literatur oder Poesie oder auch als darstellende Kunst, stellt einen weiteren Übersetzungsprozess dar, der möglicherweise schwieriger zu bewerkstelligen ist als die Interpretation einer wissenschaftlichen Abhandlung, da die Lesarten diverser sind und die Subjektivität der Äußerungen eine subjektive und damit individualisierte Rezeption zur Folge haben muss. Die bildliche oder sprachliche, künstlerische Repräsentation ist einerseits bereits Interpretation und muss andererseits erneut interpretiert werden. Wo Kommunikation durch gesprochene oder schriftliche Sprache - so sie sich nicht im poetisch Abstrakten verliert - noch relativ klar definiert scheint, löst sich die Eindeutigkeit in anderen Kommunikationssystemen zunehmend auf. Wird beispielsweise über Bilder kommuniziert, ist der Interpretationsspielraum deutlich breiter und die Ebene des Konsenses über die Bedeutung schwindet. Wenn Repräsentation eine Form der Interpretation durch den Wahrnehmen- 
den und Beschreibenden wird, dann sind Repräsentationen des Fremden demzufolge Interpretationen des Fremden. Interpretationen sind vielschichtig und können lediglich Annäherungen sein. Ob sie jedoch an die Wirklichkeit der Fremderfahrung heranreichen, die sie ohnehin nie vollständig abbilden können, ist fraglich.

Darstellungen des Fremden sind nicht gleichzusetzen mit dem Fremden schlechthin. Eine Darstellung des Fremden bedeutet eine bestimmte Lesart eines gezielt ausgewählten Fremden durch eine Person in einem Kontext. Diese Interpretation des Fremden wird durch den Betrachter oder Leser erneut interpretiert, so dass es an mehreren Stellen zu Bedeutungsverschiebungen kommen kann. Sowohl der Betrachter, der sich der direkten Erfahrung des Fremden aussetzt, als auch der Rezipient, der an den interpretierten Erfahrungen des Betrachters teilhat, bringen Vorstellungen und Erfahrungen aus ihrer eigenen kulturellen Sozialisation in die Interpretation mit ein. Der Ethnologe James Clifford bemerkt bezugnehmend auf Roland Barthes dazu, »daß das Vermögen eines Textes, einen kohärenten Sinn zu erzeugen, weniger von den gewollten Absichten eines schaffenden Autors abhängt als von der schöpferischen Tätigkeit eines Lesers« (Clifford 1995: 149f.). Da Kommunikation niemals eindeutig ist, kann es an der Schnittstelle zwischen dem Fremden und dessen Beobachter, zwischen der Beobachtung und ihrer sprachlichen Fixierung und zwischen Text und Leser Missverständnisse geben. Sowohl Beobachter als auch Leser greifen auf Erfahrungen, Wissen, Vorstellungen und gesellschaftliche stereotype Annahmen zurück, die die jeweiligen Interpretationen beeinflussen. Die künstlerische Repräsentation ist der Versuch, mit diesem Wissen umzugehen.

\section{Zusammenfassung}

Fremdheit ist keine kategoriale Eigenschaft sondern Ausdruck einer Relation zum Eigenen. In der theoretischen Beschäftigung mit Fremdheit ist man deshalb immer mit einem original Unzugänglichen beschäftigt. Das Fremde kann als etwas gesehen werden, das Fragen an das Eigene stellt und Antworten provoziert. Der Begriff des Anderen wird vielfach synonym für den des Fremden verwendet. Während die Wahrnehmung des Fremden vor dem Hintergrund des Eigenen jedoch prozesshaft ist und einem ständigen Wandel unterliegt, stellt eine einmal durch eine neutrale Instanz getroffene Unterscheidung des Anderen vom Selben eine bleibende Größe dar. Das Andere ist im Gegensatz zum Fremden fixiert.

Die Ethnologie als Wissenschaft vom kulturell Fremden hat beispielhafte Methoden für die Annäherung an das Fremde entwickelt. Ausgehend von einem erweiterten Kulturbegriff ermöglicht sie die Beobachtung des Fremden in allen Bereichen. Sie nutzt Fremdheit als Methode, um die Distanz zum Gegenstand zu wahren und ihn so besser untersuchen zu können. Gleichzeitig steht sie aber auch für die Probleme im Umgang mit dem Fremden, denn in der teilnehmenden Beobachtung wird die Wahrnehmung stark von Vorwissen und Erfahrung geleitet, was einer neutralen wissenschaftlichen Beobachtung entgegensteht. Um dieses Problem zu umgehen, wird mit der Theorie der contact zone versucht, den Beobachter gemeinsam mit dem Beobachteten $\mathrm{zu}$ thematisieren und eventuelle Voreingenommenheiten $\mathrm{zu}$ berücksichtigen. Dies ist elementar, um den Ethnozentrismus, der die eigene Kultur als Maßstab anlegt, zu überwinden. Im Ethnozentrismus bündeln sich wiederholt Stereotypen und daraus resultierende Vorurteile der eigenen Gesellschaft gegen- 
über dem Fremden. Stereotypen sind vereinfachende, meist negative Aussagen über Fremdgruppen. Stereotypen erfüllen eine soziale Funktion und tragen dazu bei, die positive Einschätzung der eigenen Gruppe zu stärken. Sie dienen so der Aufrechterhaltung von Machtstrukturen. Als ein angenommenes, empirisch nicht zu bestätigendes Wissen wirken sie sich auf die Wahrnehmung des Fremden aus.

Die Wahrnehmung des Fremden resultiert in seiner Darstellung oder Repräsentation, die es zu fixieren droht. Wird zwischen Fremdem und Eigenem hauptsächlich die Differenz betont, wird das Fremde als Anderes in der Darstellung konstruiert. Repräsentationen sind Stellvertreter, die für das Abwesende stehen. Texte und Bilder repräsentieren das Fremde, indem sie es zeigen und die Wahrnehmung aus erster Hand durch eine medial vermittelte ersetzen, die häufig für objektiv gehalten wird. Es besteht die Gefahr, dass Repräsentationen mit dem Repräsentierten verwechselt werden.

Künstlerische Repräsentationen versuchen, einen Ausweg zu finden, indem sie - statt das Fremde zu fixieren - die Fremderfahrung erfahrbar machen. Eine eingehende Analyse des bestehenden Bildes des Fremden sowie eine permanente Hinterfragung der Beweggründe und Motivationen in der Darstellung des Fremden, können zu einer veränderten Wahrnehmung des Fremden und damit auch zu veränderten Repräsentationen führen. Eine Sensibilisierung der Wahrnehmung für Abweichungen, feine Differenzierungen, aber auch Ähnlichkeiten in der direkten Erfahrung, kann zum Gelingen beitragen. 


\section{KONKRETE FREMDE DAS EUROPÄISCHE BILD JAPANS}

Japan liegt von Europa aus gesehen am anderen Ende der Welt. Die erhebliche geografische Distanz lässt auf eine kulturelle schließen, denn bis ins Mittelalter hinein existieren keine direkten kulturellen Wechselbeziehungen zwischen Europa und Japan. Dies ändert sich mit der Ankunft der ersten Portugiesen im Jahr 1543, mit der zunächst eine Zeit des regen Austauschs beginnt, die jedoch nicht lange anhält. Weil Japan aber trotz einiger Phasen, in denen es stark vom Westen beeinflusst wird, seine kulturelle Eigenständigkeit wahrt, kann man aus europäischer Sicht Japan auch heute als fremd bezeichnen.

Sind das Fremde und Andere bislang auf einer abstrakten Ebene untersucht worden, soll in diesem Kapitel Japan als konkretes Beispiel für Fremde vorgestellt werden. Was bedeutet der Begriff Fremdheit, wenn er auf ein Land wie Japan angewendet wird? Lassen sich die im ersten Kapitel etablierten Parameter des Umgangs mit dem Fremden anhand der Entwicklung der europäischen Begegnung mit Japan konkretisieren? Eine Schwierigkeit besteht darin, sowohl Europa als auch Japan als homogenes Ganzes zu begreifen. Die Beziehungen der verschiedenen europäischen Länder zu Japan haben sich im Lauf der Jahrhunderte unterschiedlich entwickelt, so dass sich daraus variierende Japanbilder ergeben. Weil der europäische Blick jedoch generell durch die christliche Religion geprägt ist, lassen sich Parallelen in der Japanbetrachtung der verschiedenen europäischen Nationen erkennen.

Gleichermaßen ist es schwierig, den modernen Industriestaat Japan mit seinen rund 127 Millionen Einwohnern als Einheit zu begreifen. Lange Zeit wird Japan in seiner Gesamtheit betrachtet, um ein Verständnis für dieses immer wieder unverständlich scheinende Land zu entwickeln. Bis in die 1990er Jahre hinein beschreiben zahlreiche Autoren Japan eher als homogene Kultur und versuchen, die japanische Mentalität als solche zu erläutern (vgl. Kreiner 1994). Inzwischen differenziert sich die westliche Betrachtung der japanischen Kultur in zahlreiche Bereiche aus, was einerseits an der zunehmenden Partikularisierung der japanischen Gesellschaft selbst, andererseits aber auch an einem veränderten westlichen Verständnis im Umgang mit fremden Kulturen liegen mag.

Der Entwurf eines allgemeinen europäischen Japanbildes birgt die Gefahr, sich in die Falle des Ethnozentrismus zu begeben, also Japan als das fremde unverständliche Andere zu postulieren und damit stereotype Vorstellungen von Japan zu perpetuieren. Ein die europäischen Japanvorstellungen bündelndes und repräsentierendes Japanbild kann nur ausschnitthaft und ungenau sein. Aufgrund der Komplexität japanologischer Forschungen kann im Rahmen dieser Arbeit lediglich ein kleiner Abriss über die europäische Wahrnehmung und Darstellung Japans gegeben werden. Es ist jedoch ange- 
bracht, die historische Entwicklung des heutigen Japanbildes nachzuzeichnen. In der Offenlegung von Stereotypen und klischeehafter Wahrnehmung ist es möglich, das europäische Japanbild kritisch zu befragen. Dies ist im Hinblick auf die später zu untersuchenden fotografischen Darstellungen Japans unerlässlich. Mit dem Wissen um das allgemeine Japanbild ist es möglich, die zeitgenössischen Sichtweisen auf Japan zu kontextualisieren und ihre Grundlagen sowie ihr Wirken zu verstehen.

\subsection{Die Relation Europa - Japan}

Wie bereits im ersten Kapitel erörtert, ist das Fremde nicht isoliert zu sehen, denn es wird immer vor dem Hintergrund des Eigenen betrachtet. Das Vergleichen ist ein abstrakter und selektiver Prozess, der »immer entlang bestimmter Gesichtspunkte erfolgt, die von außen an eine vielschichtige Wirklichkeit herangetragen werden und die Auswahl der [...] Phänomene steuert, die in Hinblick auf Gemeinsamkeiten und Unterschiede untersucht werden sollen. Erkenntnisziel sind Beschreibung und Erklärung von Übereinstimmung und Abweichung« (Weber 2002: 31). Denken ist »ohne die implizite Suche nach Ähnlichkeiten und Unterschieden undenkbar« (ebd.). So ist es unmöglich, Japan losgelöst von anderen Kulturen - insbesondere der eigenen - zu untersuchen. Implizit oder explizit bildet der eigene kulturelle Hintergrund den Vergleichsrahmen, vor dem Japan gesehen wird (vgl. Sugimoto 2002: 23). Amerikaner oder Koreaner werden demzufolge ein anderes Bild von Japan haben als Deutsche oder Engländer. Die Begründung dafür liegt in der »Kultur, dem Wertesystem oder der Weltsicht der jeweiligen Gesellschaft, eine andere wäre ihre hegemoniale Ideologie. Die spezifischen historischen, politischen und wirtschaftlichen Beziehungen des Landes mit Japan wären ein weiteres Kriterium. Schließlich ist die Organisation der Wissenschaft in dem entsprechenden Land ein Faktor« (Befu 1994: 34).

\subsubsection{Japan als Gegenstand der Wissenschaft}

Auch wenn hier nicht einzig die wissenschaftliche Auseinandersetzung mit Japan in Betracht gezogen werden soll, zeigen sich im Hinblick auf die Ausrichtung der akademischen Disziplinen der Japanbetrachtung interessante Unterschiede. Nach einer Beschreibung von Befu Harumi aus dem Jahr 1994 beschäftigt sich die Japanologie in Deutschland primär mit der Betrachtung, Untersuchung und Beschreibung Japans. Im internationalen Kontext spricht man von Japanese Studies. Zentrales Element dieser Wissenschaften ist der Blick von außen. Die Forschungsschwerpunkte und -ansätze differieren jedoch nach Befu zum Teil erheblich. Die deutsche Japanologie legt einen Schwerpunkt auf die Lektüre originalsprachlicher, oftmals literarischer Texte, weshalb das Erlernen der japanischen Schriftsprache einen großen Teil der Ausbildung ausmacht. Die amerikanischen Japanese Studies hingegen sind eher empirisch/behavioristisch orientiert. Schwerpunkte werden beispielsweise durch sozialwissenschaftliche und anthropologische Theorien gesetzt, so dass empirische Studien vor Ort durchgeführt werden können. Für eine mündliche Kommunikation ausreichende Sprachkenntnisse sind selbstverständlich, genügen jedoch oftmals nicht zur philologischen Auswertung japanischer Textquellen. Entsprechend unterschiedlich werden Forschungsfragen 
formuliert und ausgearbeitet (vgl. Befu 1994: 36). Diese Betrachtung mag zutreffend gewesen sein. Die deutsche Japanologie unterliegt jedoch einem Wandlungsprozess und entwickelt sich weg von einer reinen Literatur- hin zu einer komplexen Regionalwissenschaft, die sich mit sehr unterschiedlichen Themenbereichen auseinandersetzt. Unabhängig vom Forschungsansatz wird Japan oftmals als Fremdes wahrgenommen. Die kulturwissenschaftliche Japanforschung ist jedoch bemüht, transkulturelle Aspekte in die Forschung einzuführen.

»Das Beispiel des Verhältnisses zwischen Japan und dem Westen zeigt, wie durch ein zu eurozentrisches Verständnis von Interkulturalität die >Andersheit` und >Fremdheit` zu stark betont werden. [...] Deshalb ist für die Japanforschung der Wechsel und Übergang zu dem neuen Kulturparadigma der Transkulturalität, wie er sich zur Zeit in den Kulturwissenschaften vollzieht, von großer Bedeutung« (Mae 2001: 258f.)

Dementsprechend gilt: Nicht allein durch den Vergleichshorizont der eigenen Kultur ist die notwendige Distanz zum Forschungsgegenstand zu etablieren, sondern gleichfalls sind dessen eurozentrische Grundlagen kritisch zu befragen.

Vor dem Einsetzen des Paradigmenwechsels innerhalb des japanologischen Forschungsansatzes betrachten westliche Wissenschaftler Japan eher im Hinblick auf kulturelle Differenzen, als dass sie nach Ähnlichkeiten suchen. Das dem Eigenen Vergleichbare lässt sich vermutlich mit bereits bekannten und als universal gültig angenommenen Theorien erklären, weshalb es weniger interessant scheint als das vom Eigenen Abweichende. Letzteres wirkt merkwürdig oder exotisch und erzeugt so ein grundlegendes wissenschaftliches Interesse (vgl. Befu 1994: 38). Dies entspricht der theoretischen Annahme, dass die Wahrnehmung des Fremden häufig eine Negation beinhaltet. Das Fremde wird zum nicht-identischen Anderen, weil der beschriebene Zustand des Fremden eine Differenz markiert. »Im Blickfeld westlicher Wissenschaftler wird Japan als das >Andere eine Spezies genannt Exotica japonica« (ebd.; Hervorhebung im Original). Vergleichbar mit Europäern interessieren sich Wissenschaftler asiatischer Länder auch für kulturelle Unterschiede zwischen der japanischen und ihrer eigenen Kultur, sie legen einen weiteren Schwerpunkt jedoch auf die Untersuchung kultureller Ähnlichkeiten (vgl. ebd.). ${ }^{1}$ Die eigene Kultur und deren auch historische - Beziehungen zu Japan leiten das Interesse und den Blick in der Auseinandersetzung mit der fremden Kultur, was sich wiederum auf die Wahrnehmung des Eigenen auswirkt. »Das Studium Japans dient mittels Selbstreflexion und Vergleich zur Vertiefung des Wissens über uns selbst und zur Erweiterung des Verständnisses unserer Kultur und Gesellschaft« (Kreiner 1994: 47f.). Japan wird somit zur Projektionsfläche und zum Korrektiv. Das Wissen um den eigenen kulturellen Hintergrund als Voraussetzung der Wahrnehmung Japans ist schon allein zur Entwicklung eines Be-

1 Zur Geschichte der deutschen Japanologie vgl. auch Schneider 1990; Lewin 1967. Auch in der deutschen Japanologie verändert sich der Arbeitsschwerpunkt. Das Deutsche Institut für Japanstudien Tokyo beschäftigt sich beispielsweise mit gesellschaftlichen Entwicklungen, die Parallelen in Japan und Deutschland aufweisen, wie beispielsweise der Forschungsschwerpunkt $>$ Herausforderungen des demographischen Wandels` verdeutlicht. 
wusstseins möglicher Voreingenommenheiten durch eurozentrische Sichtweisen notwendig.

Wie bereits im ersten Kapitel dargelegt, ist die Wahrnehmung des Eigenen ungleich differenzierter als die des Fremden. Japan ist seit jeher - wohl auch aufgrund seiner Insellage und seiner besonderen Entwicklung - als einzigartiges und homogenes kulturelles System wahrgenommen worden, ohne beispielsweise Unterschiede zwischen sozialen Gruppen oder geografischen Regionen zu untersuchen. Diese Art der Japanbetrachtung ist vor dem Hintergrund der Vergleichsperspektive zu sehen. Der Kulturvergleich birgt jedoch einige Probleme. Wird die eigene Kultur als Bewertungsmaßstab angelegt und werden aufgrund dieses Maßstabs Werturteile über die fremde Kultur gefällt, kann von einer ethnozentrischen Perspektive gesprochen werden. Um eine solche zu vermeiden, ist in der ersten Hälfte des zwanzigsten Jahrhunderts die These des Kulturrelativismus entwickelt worden, die davon ausgeht, »daß jede Kultur ihre eigenen autonomen Werte besitze, und daß das Verstehen einer fremden Kultur so lange unmöglich bleibe, wie die Wertmaßstäbe einer bestimmten Kultur als allgemeingültig beansprucht werden« (Aoki 1996: 29). Der Begriff Kulturrelativismus geht auf die amerikanischen Kulturanthropologen Franz Boas, Ruth Benedict und andere zurück und kritisiert das bis dahin auf einer einseitigen und damit ethnozentrischen Sicht beruhende Verständnis anderer Kulturen (vgl. ebd.). Die Einzigartigkeit der betrachteten Kultur wird im Kulturrelativismus betont, gleichzeitig wird versucht, die eigenen kulturellen Werte nicht als Bewertungskriterium auf die beobachtete fremde Kultur anzuwenden. Der Verzicht auf Bewertungen der anderen Kultur führt bei den Kulturrelativisten jedoch oft zu einer verklärenden Sicht des Anderen und damit zu einer Art invertiertem Rassismus, der sich gegen die eigene - westliche Kultur - richtet (vgl. Jarman 1998: 22; Geertz 1984: 271). Einige Kritiker des Kulturrelativismus verstehen die Behauptung der kulturellen Einzigartigkeit als eine Form der Ideologie, die zu Nationalismus und Chauvinismus führen kann. Sie plädieren für eine Abkehr der verallgemeinernden Betrachtung und möchten Kultur als einen Bereich der unendlichen Interpretationsmöglichkeiten und damit unendlichen Differenzierungen untersucht wissen. Da der Kulturrelativismus im Allgemeinen holistisch vorgeht, wird ihm in einer unendlich differenzierten Herangehensweise die Basis entzogen. Denn der Bezugspunkt der Relation liegt innerhalb der spezifischen Kultur. Wird diese nun nicht mehr als einheitliches Ganzes wahrgenommen, entfällt er, »denn wir verlieren den Zugriff auf die Möglichkeit, die Frage zu beantworten: >relativ wozu?« (Mohanty 1998: 240). Auch eine solche Sichtweise ist jedoch nicht unumstritten, da die Praxis der Kulturbetrachtung ganz ohne Bezugspunkt kaum umsetzbar erscheint. »Der zwischengesellschaftliche Kulturrelativismus [betont] die Wichtigkeit von Unterschieden und die Vielfalt kultureller Perspektiven zwischen Gesellschaften sowie er gleichermaßen Ethnozentrismus und kultureller Hegemonie bestimmter Gesellschaften begegnet« (Sugimoto 2002: 29; Hervorhebung B.L.).

Die Schwierigkeiten im Umgang mit dem Vergleichsrahmen der eigenen Kultur und dem daraus resultierenden Relativismus spiegeln sich auch im europäischen Japandiskurs wider. Japanische Kultur und Gesellschaft werden bis in die Gegenwart hinein häufig als absolut einzigartig und homogen aufgefasst und beschrieben, teilweise wird überhaupt die Möglichkeit eines Verstehens aufgrund der extremen kulturellen Andersartigkeit geleugnet. Entsprechend fordert der Japanologe Josef Kreiner Mitte der 1990er Jahre die 
Absage an »statische, monistische und oberflächliche Versuche der Interpretation, die Japan als monolithisches Phänomen behandeln, ohne historischen Wandel und regionale Unterschiede zu berücksichtigen. [...] All diese Modelle der Interpretation müssen durch einen mehrdimensionalen und flexiblen Ansatz ersetzt werden - als Analoge zur >Fuzzy<-Technologie« (Kreiner 1994: 52). Dies bedeutet nichts weniger als die Forderung nach einem Wandel der westlichen Wahrnehmung der japanischen Kultur und Gesellschaft, die nun als ein komplexes und heterogenes System anerkannt werden soll, das es verdient, in seinen einzelnen Bereichen genau untersucht zu werden. ${ }^{2}$ Eine solche Einstellung sollte im Rahmen der wissenschaftlichen Auseinandersetzung seit langem selbstverständlich sein, Kreiners Aufforderung macht jedoch Defizite deutlich. Prägen oberflächliche Betrachtungen bereits die Tradition wissenschaftlicher Untersuchungen der japanischen Kultur, liegt es nahe, dass die allgemeine europäische Wahrnehmung Japans erst recht auf Verallgemeinerungen beruht, die sich teilweise bereits vor Jahrhunderten etabliert haben.

\subsection{Europäisch-japanische Begegnungen}

\subsubsection{Historischer Überblick}

In diesem Abschnitt werden zunächst die historischen Entwicklungen der japanisch-europäischen Begegnungen überblicksartig zusammengefasst. Wie sich die Ereignisse auf das europäische Japanbild niederschlagen, wird im Abschnitt 2.2.2. genauer untersucht.

Die europäische Wahrnehmung und Einschätzung Japans beruht auf Kontakten, die bis ins Mittelalter zurückdatieren. Lange bevor die ersten Europäer im sechzehnten Jahrhundert japanischen Boden betreten, bringt Marco Polo gegen Ende des dreizehnten Jahrhunderts das Wissen um ein entferntes Land namens Zipangu aus China mit. ${ }^{3}$ Polo erwähnt sagenhaften Reichtum und macht Angaben zu geografischen Bedingungen, Politik, Wirtschaft, Religion, Brauchtum und Geschichte sowie das angenehme Äußere und die guten Manieren der Einwohner Zipangus. Sein Wissen stammt aus chinesischen und mongolischen Quellen und vermischt Fakten mit Mythen. Polo selbst hat Japan nie betreten, sein Bericht findet jedoch weite Verbreitung. Er wird in zahlreiche europäische Sprachen übersetzt und prägt das europäische Japanbild über lange Zeit. Obwohl auch Kannibalismus und Götzenanbetung Erwähnung finden, werden von europäischer Seite bereits vor den ersten direkten Kontakten Paradiesvorstellungen auf dieses am Rand der damals bekannten Welt liegende Land projiziert (vgl. Reichert 1993: 25; Kreiner 1993: 18).

2 Zu Fragen der sozialwissenschaftlichen japanologischen Forschung vgl. auch Sugimoto 2002: 23ff.

3 Der Name Zipangu für Japan geht auf das chinesische Ri-ben-guo (Land der aufgehenden Sonne) zurück und entspricht der Bedeutung des japanischen Originals (Nihon/Nippon) mehr als die durch einen mehrfachen Übersetzungsprozess gegangene Bezeichnung >Japan` (vgl. Reichert 1993: 25). 
Als erste Europäer betreten 1543 schiffbrüchige portugiesische Kaufleute japanischen Boden, ihnen folgen weitere portugiesische und kurz darauf spanische Kaufleute sowie jesuitische Missionare (vgl. Cooper 1993; Pohl 2002: 46ff.). Die entfernte Lage Japans macht ein militärisches Auftreten europäischer Mächte unmöglich, so dass sich die Europäer der örtlichen Gesetzgebung anzupassen haben. Anders als in anderen Gebieten der Welt stehen die Europäer hier unter japanischer Kontrolle (vgl. Cooper 1993; Breger 1990: 19). Detailliertes Wissen über Japan gelangt im sechzehnten Jahrhundert vorwiegend aus Berichten der jesuitischen Missionare nach Europa. ${ }^{4}$ Die Jesuiten werden von den japanischen Lehnsfürsten (daimyo) mit Respekt behandelt und verfügen über gute Kontakte zu den Fürstenhäusern. Dadurch sind sie sehr gut über die politischen, wirtschaftlichen und kulturellen Belange Japans informiert. In jährlich erscheinenden Missionsberichten teilen sie ihr Wissen, ihre Beobachtungen und Reflexionen über Japan der europäischen Öffentlichkeit mit. Neben Kirchenfragen behandeln die Berichte ausführlich die Gegebenheiten des Landes und zeugen noch heute von ausgezeichnetem Faktenwissen. Die - nach Coopers Einschätzung - literarisch teilweise sehr guten, tiefgründigen Beschreibungen und Analysen der japanischen Kultur offenbaren ein »Interesse an japanischen Dingen [...], das weit über die apostolischen Erfordernisse eines eifrigen Missionars« hinausgeht (Cooper 1993: 50). Sie finden weite Verbreitung und werden von gebildeten Europäern begierig aufgenommen. Auch von japanischen Kunstgegenständen, beispielsweise von Lackarbeiten und Porzellan, ist man in Europa begeistert. Die erste Phase des Kontakts zwischen Europa und Japan ist geprägt von einer beiderseitigen positiven Aufgeschlossenheit gegenüber der fremden Kultur, die mitunter auch durch kommerzielle Interessen geleitet wird.

Eine zweite Phase der europäischen Japanrezeption beginnt mit den japanischen Christenverfolgungen und der daran anschließenden, fast 250 Jahre währenden Abschottung des Landes (sakoku). Politische Entwicklungen führen zu Beginn des siebzehnten Jahrhunderts zu einer Verschiebung der Machtverhältnisse in Japan und im Jahr 1603 zur Gründung des TokugawaShogunats, das dem Kaiser nur noch repräsentative Funktionen zuschreibt (vgl. Pohl 2002: Kap. 5.6). Das Christentum wird wegen seines Einflusses auf die Fürstenhäuser und der befürchteten Schwächung der zentralen Shogunatsregierung 1614 verboten. Japanische Christen müssen ab 1622 dem Christentum abschwören. Tun sie es nicht, werden sie gefoltert oder hingerichtet. Die Missionare werden des Landes verwiesen. Nach der Niederschlagung eines letzten Christenaufstands bei Shimbara 1637 wird es katholischen Christen generell verboten, sich in Japan aufzuhalten. Auch Japaner dürfen nicht mehr ins Ausland reisen. Jeglicher Kontakt zu Europa wird eingestellt. Die einzige Ausnahme bildet eine niederländische Handelsvertretung auf der künstlichen Insel Dejima (auch Deshima) im Hafen von Nagasaki. Die bevorzugte Behandlung der Holländer beruht auf deren Verzicht auf Missionstätigkeiten, die als dem Handel abträglich betrachtet werden. Aufgrund ihres protestantischen Pragmatismus und der Ablehnung des römischen Katholizismus unterstützen sie die japanische Regierung bei der Niederschlagung des Christenaufstands von Shimbara (vgl. Vos 1993). 
Auf europäischer Seite ist im Zeitalter der Aufklärung das Japan betreffende Informationsbedürfnis weiterhin sehr groß. Unter Verwendung der Missionsberichte werden im siebzehnten Jahrhundert nach Ansicht Frieses scharfsinnige Japanbücher zusammengestellt - beispielsweise von Bernhardus Varenius (vgl. Schwindt/Hammitzsch 1974). Die Autoren kennen Japan jedoch nicht aus eigener Anschauung (vgl. Friese 1990: 36). Trotz der Abschließung, die einer weiteren intensiven Begegnung zwischen Europa und Japan entgegenzustehen scheint, reißen die Kontakte zu keiner Zeit vollständig ab. Neben anderen Mitgliedern der holländischen Handelsniederlassung machen sich besonders zwei deutsche Ärzte - Engelbert Kaempfer (1651-1716) und Philipp Franz von Siebold (1796-1866) - um die Beschreibung und Vermittlung Japans verdient. Trotz widriger Umstände gelingt es Kaempfer während seines zweijährigen Aufenthaltes 1690-92 mit Hilfe eines wissbegierigen japanischen Dieners, sehr viele Informationen über Japan zu kompilieren. ${ }^{5}$ Die vorherigen, meist kurzen Berichte europäischer Japanreisender, vermitteln »eine naturgemäß begrenzte Auswahl von Daten, aber auch von Vermutungen, die stark von den Interessen und dem Bildungsstand des Reisenden geprägt « sind (Haberland 1990: 16f.). Kaempfer schreibt eine erste umfassende Landeskunde, die sowohl auf eigenen Beobachtungen, als auch auf Informationen seiner japanischen Informanten beruht. Auf seinen beiden Reisen nach Edo (heute Tokyo) erforscht und zeichnet er möglichst viele einheimische Pflanzen und kartografiert heimlich die Route. ${ }^{6}$ Kartenwerk, Zeichnungen und Reisebeschreibungen vermitteln ein Japanbild in bislang ungekannter Präzision. Kaempfer widmet sich jedoch nicht nur der Landeskunde und Botanik, sondern beschreibt auch Verfahren der japanischen Medizin und Heilkunde sowie Geschichte, Kultur und Religion Japans. Er widmet sich der japanischen Sprache und sammelt japanische Bilder und Bücher. In seinem ausführlichen Bericht über Japan präsentiert Kaempfer dem Leser ein lebhaftes und ihm aus erster Hand zugängliches Bild von Japan. So gut wie möglich versucht er, sich japanischen Verhaltensweisen und Denkansätzen vorurteilsfrei zu nähern. Im Jahr 1712 veröffentlicht Kaempfer die Amoenitas Exoticae, die auch Abhandlungen $\mathrm{zu}$ japanischen Themen enthalten. Es gelingt ihm jedoch nicht, sein großes Japanwerk zu publizieren. Die englische Übersetzung seines Manuskripts steht posthum ab 1727 zur Verfügung, diese Ausgabe bildet die Grundlage der französischen Übersetzung, die 1729 erscheint (vgl. Kapitza 2001: 7; Delank 1996: 29). Die deutsche Ausgabe erscheint erst 1777/1779 als Geschichte und Beschreibung Japans. Noch im neunzehnten Jahrhundert erfreut sich Kaempfers Werk anhaltender Anerkennung: „Sein Bild von Japan ist mehr als die Wiederholung von Stereotypen aller Reisenden vor ihm« (Haberland 1990: 27).

5 »Den Holländern war alles untersagt, was den Anstrich eines persönlichen Kontaktes oder kulturellen Austausches hatte. Besonders streng verboten war die Einfuhr christlicher Bücher und kultischer Geräte; Gottesdienste, ja sogar schon das Zeigen des Kreuzes war bei strengsten Strafen verboten. Auch das Sammeln und die Ausfuhr von Informationen über Japan waren natürlich nicht erwünscht« (Haberland 1990: 13). Zu Leben und Wirken Kaempfers vgl. auch Haberland 1993.

6 Trotz offiziell eingeschränkten Kontakts zu Japanern ist der Leiter der Handelsniederlassung zunächst verpflichtet, einmal im Jahr nach Edo zu reisen und dem Shogun einen Besuch abzustatten (vgl. Vos 1993: 79f.). 
Als Philipp Franz von Siebold 1823 für sechs Jahre nach Dejima kommt, haben sich die Bestimmungen für die niederländische Handelsniederlassung kaum geändert. Musste Kaempfer aber noch heimlich vorgehen - sein Informant wäre hingerichtet worden, hätten die Behörden von dessen Tätigkeit erfahren - herrscht zu von Siebolds Zeit ein Klima des wechselseitigen wissenschaftlichen Interesses. Die Japaner zeigen sich besonders interessiert an den Errungenschaften der westlichen Medizin. Von Siebold wird gestattet, japanische Patienten in Nagasaki zu behandeln und sein Wissen an japanische Ärzte und Gelehrte zu vermitteln. Seine Forschungen sind vorrangig naturkundlicher Art, sein Interesse erstreckt sich jedoch auch auf zahlreiche weitere wissenschaftliche Gebiete. In der Methodik folgt er Alexander von Humboldt. Seine archivalischen, wissenschaftshistorischen und philologischliterarischen Studien zu Japan sind im Aufbau, in der Intention und selbst in vielen Einzelheiten die Entsprechung zu den verschiedenen Publikationen des Humboldtschen >Amerikanischen Reisewerkes « (Friese 1990: 41).

Wie schon Kaempfer vor ihm verfolgt von Siebold einen universalistischen Ansatz und liefert in seinem mehrbändigen Werk Nippon: Archiv zur Beschreibung von Japan eine sehr umfassende Studie zu zahlreichen Aspekten Japans, beispielsweise zu Geografie, Meteorologie, Flora und Fauna, aber auch zu Kultur und Gesellschaft (vgl. Siebold 1832-1858). Weil sich aber Mitte des neunzehnten Jahrhunderts einzelne Wissenschaften wie die Philologie, die Naturgeschichte oder die Völkerkunde etablieren, gerät der universalistische Ansatz von Siebolds zunächst in Vergessenheit. Erst zu Beginn des zwanzigsten Jahrhunderts beginnt die Auseinandersetzung mit seinem Werk durch die wissenschaftlichen Disziplinen Ethnologie und Japanologie. Als besonderes Verdienst kann von Siebolds Sammlung japanischer volksund naturkundlicher Gegenstände, Bilder und Texte gelten, die er geschlossen dem holländischen Staat übergibt. Zahlreiche Gegenstände aus den unterschiedlichsten Regionen bekommt er als Geschenk oder im Tausch für seine Leistungen als Arzt und Lehrer, weitere kauft er hinzu. Die Verzameling von Siebold ist ab 1837 in Leiden der Öffentlichkeit zugänglich und bildet den Grundstock des späteren Rijksmuseum voor Volkenkunde (vgl. Friese 1990: 41f.). In der Arbeit mit seiner Sammlung überwiegt der völkerkundliche Ansatz, da von Siebold die Wichtigkeit der plastischen Anschaulichkeit fremder Kulturen mittels der gesammelten Gegenstände entdeckt. Zu einer Zeit, in der fremde Kulturen eher in Kuriositätenkabinetten zur Schau gestellt werden, bilden Umfang und Geschlossenheit seiner Sammlung eine Ausnahme. Damit gibt er Anregungen zur Gründung einer ersten systematischen völkerkundlichen Museumspräsentation in Kopenhagen (vgl. ebd.: 42).

Kaum 25 Jahre nach von Siebolds Aufenthalt beginnt mit der gewaltsamen Öffnung Japans durch den amerikanischen Gesandten Commodore Perry eine neue Phase der europäisch-japanischen Beziehungen. ${ }^{7}$ Nachdem Japan 1854 einen ersten Vertrag mit den USA unterzeichnet, der es den Amerikanern erlaubt, bestimmte Häfen anzulaufen und Handel mit Japan zu treiben, folgen kurz darauf ähnliche Vertragsabschlüsse mit zahlreichen europäischen Mächten. Die Zeit der Abschließung ist vorbei. Die Öffnung des Landes wird von innenpolitischen Auseinandersetzungen zwischen Anhängern des Feu-

71853 landet Commodore Matthew C. Perry mit den so genannten $>$ Schwarzen Schiffen in der Bucht von Tokyo und erzwingt die Unterzeichnung des Vertrags von Kanagaw im darauf folgenden Jahr (vgl. Pohl 2002: 59; 94). 
dalsystems und den Unterstützern einer Reformpolitik begleitet. Die Befürworter einer Erneuerung gewinnen schließlich die Oberhand. Die Öffnung wird schon deshalb notwendig, da Japan nicht die Stärke besitzt, den westlichen Nationen mit ihren Dampfschiffen und neuartigen Waffen militärisch standzuhalten. Die einflussreichen Fürsten fürchten eine westliche Kolonisierung nach chinesischem Beispiel. Im Jahr 1868 tritt der letzte Shogun der Tokugawa-Herrschaft zurück, die Feudalfürsten erkennen wieder die Kaiserherrschaft mit Kaiser Mutsuhito an. ${ }^{8}$ Mit der Meiji-Restauration beginnt die Modernisierung Japans. Die Hauptstadt wird von Kyoto in das in Tokyo (östliche Hauptstadt) umbenannte Edo verlegt. Innerhalb kurzer Zeit verändern wirtschaftliche und soziale Reformen das Land. Als 1889 das neue Herrschaftssystem weitgehend gefestigt ist, erlässt der Kaiser eine Verfassung. Japan wandelt sich von einer Feudal- in eine moderne Industriegesellschaft. In dieser Zeit dienen verschiedene europäische Staaten als Vorbilder. Aufgrund der Insellage wird häufig sowohl von englischer als auch von japanischer Seite die Ähnlichkeit zwischen Japan und England postuliert. Zum großen Vorbild wird jedoch Preußen, das anders als England keine Affinitäten zu demokratischen Ideen hat. Wird die neue japanische Armee zunächst von französischen Beratern angeleitet, so werden diese Mitte der 1880er Jahre durch deutsche ersetzt (vgl. Meckel 1990). Das japanische Medizinwesen wird vom deutschen Arzt Erwin Bälz aufgebaut und auch die japanische Verfassung ist an der preußischen orientiert (vgl. Vianden 1990; Luig 1990). Diese wird jedoch nicht einfach übernommen, sondern den japanischen Gegebenheiten angepasst. »Im autoritären, aber modernen Deutschland [sieht] die Meiji-Führung eher ein Modell als in den demokratischen Staaten Europas; circa 60 Prozent aller Spezialisten, die aus Japan zum Studium ins Ausland entsandt [werden], [gehen] nach Deutschland« (Pohl 1997a: 52).

Nicht nur die staatlichen, sondern auch die ökonomischen Strukturen profitieren von westlichen Vorbildern. Importe westlicher Technologie sowie die Hinzuziehung westlicher Berater tragen zum Wachstum Japans bei. Im neunzehnten Jahrhundert kann Japan noch als Entwicklungsland bezeichnet werden, zu Beginn des Ersten Weltkrieges hat es sich jedoch so weit gewandelt, dass es sich von ausländischen Beratern lösen und seinen Kurs eigenständig vorantreiben kann. Die rasante Entwicklung ist möglich, da bereits während der Tokugawa-Zeit (ca. 1600-1868) sowohl Unternehmer als auch die politische Klasse »alle Voraussetzungen geschaffen [haben], die eine >moderne < Entwicklung der Wirtschaft Japans freisetzen« können (Pohl 2002: 62).

In der ersten Phase der Meiji-Zeit steht die militärische und wirtschaftliche Entwicklung im Mittelpunkt, um Japan gegen eine allzu große Einflussnahme der westlichen Mächte zu wappnen. Japan orientiert sich an deren Expansionsstrategien und führt 1894/95 einen Krieg mit China zur Sicherung der Vorherrschaft über Korea, das es 1910 annektiert. 1904/05 gewinnt Japan den Krieg gegen Russland und setzt sich damit erstmalig militärisch gegen eine europäische Macht durch, wodurch es endgültig die allgemeine Anerkennung als Großmacht erreicht (vgl. Nakai 2002: 24). Als Verbündeter Englands besetzt Japan im Ersten Weltkrieg die deutschen Kolonien in China und nimmt auf alliierter Seite an der Versailler Friedenskonferenz teil. Dort kann es sich jedoch nicht mit seinen Forderungen zur Einflussnahme in Chi-

8 Als Regent gibt er sich den Namen Meiji, was als Devise seiner Regentschaft ausgegeben wird. >Meijiく bedeutet Aufklärung. 
na durchsetzen und bekommt lediglich seine kolonialen Ansprüche auf Korea bestätigt. Als Vertreter der einzigen nicht westlichen Nation erfährt die japanische Delegation jedoch keine gleichberechtigte Behandlung. Japan gelingt es nicht, die westlichen Alliierten von der Aufnahme eines Passus zur rassischen Gleichberechtigung in den Versailler Friedensvertrag und später in die Charta des Völkerbundes zu überzeugen (vgl. Pohl 2002: 71).

Die Weltwirtschaftskrise der 1920er Jahre hat auch auf Japan katastrophale Auswirkungen (vgl. ebd.: Kap. 8). Zu Beginn der 1930er Jahre kommt es zu Aufständen von Offizieren, konservative Politiker und Unternehmer werden ermordet. Die Aufstände brechen jedoch schnell zusammen. Die bürgerliche Regierung gerät anlässlich dieser Entwicklungen zunehmend unter den Einfluss radikaler, ultranationalistischer Militärs, »die neben einer Beseitigung der gerade begonnenen Demokratie eine Expansionspolitik nach China und Südostasien« anstreben (ebd.: 72). Das Militär beginnt, autonom zu handeln und errichtet 1932 in China den Marionettenstaat Manchukuo. »Die zivile Führung in Tokyo [kann] nur hilflos zusehen, als es zu gezielten militärischen Aggressionen in China [kommt], die sich zu blutigen Kämpfen ausweiten, « wie beispielsweise dem Massaker von Nanking 1937 (ebd.). Die zunehmende internationale Isolation Japans und des faschistischen Deutschlands lässt die Regierungen 1936 den Anti-Komintern-Pakt zur Absicherung der beiderseitigen Politik gegenüber der Sowjetunion schließen. Dieses Abkommen hat jedoch eher den Charakter einer Zweckpartnerschaft, als dass es Ausdruck von gegenseitigem Interesse ist (vgl. Pohl 1997a: 52). 1940 wird die so genannte >Achse $<$ zwischen Berlin, Rom und Tokyo gegründet, 1941 folgt ein Nichtangriffspakt mit der Sowjetunion. Ende 1941 wird ein General (Tôjô Hideki) zum japanischen Regierungschef. Nun steht einer groß angelegten kriegerischen Expansion Japans im pazifischen Raum scheinbar nichts mehr entgegen (vgl. Pohl 2002: 73f.). Nach dem Angriff auf Pearl Harbor im Dezember 1941 erobert Japan zahlreiche Pazifikstaaten. Ab 1944 wird die japanische Armee von den Alliierten unter Führung der USA zurück gedrängt. Zahlreiche japanische Städte werden durch Brandbomben zerstört. Erst nach dem amerikanischen Einsatz der Atombomben auf Hiroshima und Nagasaki kapituliert Japan im August 1945 bedingungslos. Japan wird zum ersten Mal in seiner Geschichte von einer ausländischen Macht - den USA - besetzt. ${ }^{9}$

Seit der Meiji-Zeit hatte sich Japan vorrangig an Europa orientiert. Durch die amerikanische Besatzung und die für die USA wichtige geostrategische Lage Japans werden zu Beginn des Kalten Krieges und insbesondere während des Korea-Krieges die USA wichtigster westlicher Partner und kulturelles Vorbild Japans. Nach der Unterzeichnung des Friedensvertrages von San Francisco 1951 und der darauf folgenden Unabhängigkeit entwickelt sich die japanische Wirtschaft - erneut an westlichen Vorbildern orientiert - in rasantem Tempo. Während die wirtschaftlichen Beziehungen prosperieren, sind die politischen Beziehungen zwischen Europa und Japan über lange Zeit nur schwach ausgeprägt. Das ändert sich erst in den 1980er Jahren, als der europäische Einigungsprozess sowie Fragen des Welthandels, der Rüstungskontrolle und Friedenssicherung zu einer Annäherung führen (vgl. Rohde 1997: 51). Der wirtschaftliche Erfolg Japans seit dem Ende des Zweiten Weltkrieges führt dazu, dass dem japanischen System lange eine Vorbildfunktion zu-

$9 \mathrm{Zu}$ den Atombombenabwürfen vgl. Teil II, Abschnitt 3.2. und zur Kapitulation vgl. Teil II, Abschnitt 3.3. 
geschrieben wird. Erst nach dem Zusammenbruch der so genannten Bubble Economy zu Beginn der 1990er Jahre wird auch den Europäern bewusst, dass das japanische Wirtschaftssystem Schwachstellen aufweist. ${ }^{10}$ Die oberflächliche Auseinandersetzung mit den wirtschaftlichen Strukturen Japans und die Suche nach dem Geheimnis des japanischen Erfolges verweisen stets auf die tiefe Verständnislücke zwischen Europa und Japan. Japan gilt über weite Strecken als extrem fremd und für Europäer unverständlich. Die Fremdheit weckt jedoch auch Neugier, die sich im Interesse an der japanischen Kultur äußert.

\subsubsection{Europäische Sichtweisen Japans}

Der direkte Kontakt mit Japan hinterlässt seit Jahrhunderten Eindrücke, die sich zu Annahmen, Vorstellungen und Urteilen über Japan und die Japaner verdichten. Die Wahrnehmung Japans lässt sich jedoch nicht vollständig vom Kontext der europäischen Auseinandersetzung mit anderen asiatischen Ländern - insbesondere China - und dem westlichen Konzept des Orients trennen (vgl. Wilkinson 1982: 27). Das daraus resultierende Japanbild tendiert dazu, die notwendigerweise kontingenten Eindrücke zu verallgemeinern und auf das Land oder die Gesellschaft als Ganzes zu übertragen. Sowohl aus der direkten, aber vor allem aus der indirekten, medialen Vermittlung über Reiseberichte, Literatur, Bilder und Erzählungen, verbreiten sich stereotype Sichtund Darstellungsweisen. Dieser Prozess ist sehr langwierig und erstreckt sich unter Umständen über mehrere Generationen. Auch wenn stereotype Darstellungen eine Spur Wahrheit beinhalten sollten, hat sich die gesellschaftliche Realität, die sie zu beschreiben versuchen, vermutlich längst geändert (vgl. Wilkinson 1982: 20). ${ }^{11}$

Die europäische Perzeption Japans beruht auf der oben beschriebenen langen Tradition des Kontakts und hat sich entsprechend der Entwicklungen in den Beziehungen zwischen beiden Weltregionen wiederholt gewandelt. Einige Annahmen über Japan und die Japaner haben sich über Jahrhunderte gehalten, andere sind durch neues Wissen oder differenziertere Darstellungen im Laufe der Zeit modifiziert worden. Dass der Kulturkontakt mit einer positiven Bewertung des fremden Japan beginnt, weckt in Europa ein Interesse, mehr über Japan zu erfahren. Größeres Wissen und zunehmende Erfahrung vermögen das Bild weiter auszudifferenzieren, verhindern jedoch kaum eine Stereotypenbildung. Die Repräsentation Japans ist seit Anbeginn von Stereotypen geformt (vgl. Kreiner/Ölschleger 1996: 9). Es verwundert wenig, dass noch im zwanzigsten Jahrhundert Ideen und Vorstellungen über Japan wiederholt werden, die bereits seit dem sechzehnten Jahrhundert bestehen (vgl. Wilkinson 1982: 17).

Die seit Marco Polo existierenden Vorstellungen von Japan als Paradies scheinen sich in den ersten europäischen Kontakten mit der japanischen

10 Die Bubble Economy, zu Deutsch Luftblasen-Ökonomie, beginnt mit der Aufwertung des Yen gegenüber dem Dollar 1985. Starkes Wachstum am Aktienmarkt, steigende Immobilienpreise und eine großzügige Kreditvergabe heizen die Spekulationswirtschaft stark an. Ende 1989 setzen Maßnahmen der Bank of Japan - wie die Erhöhung der Leitzinsen - der Preisspirale ein Ende. Die Seifenblase platzt und eine tiefe Rezession setzt ein (vgl. Bosse 1997: 35f.).

11 Zur Stereotypenbildung vgl. auch Teil I, Abschnitt 1.2.3. 
Kultur zu bestätigen. Die Japaner werden als den Europäern ebenbürtig, wenn nicht gar überlegen, eingeschätzt (vgl. Cooper 1993; Kreiner 1993: 18). Dies ist allein deshalb erstaunlich, da zu dieser Zeit Völker ohne christlichen Glauben als heidnisch und damit schnell auch als barbarisch und minderwertig bezeichnet werden. Die Japaner bewundert man jedoch wegen ihrer Höflichkeit und Freundlichkeit sowie wegen ihres würdevollen Verhaltens und ihrer Selbst-Disziplin. Erwähnt werden ebenfalls ihre absolute Loyalität und ihr ausgeprägtes Pflichtbewusstsein; sie gelten als scharfsinnig und klug (vgl. Breger 1990: 19). »Sie sollen sich Wissenschaft und Kunstfertigkeit schneller aneignen als Europäer, verabscheuen Lügenhaftigkeit und Diebstahl stärker als alle christlichen und heidnischen Völker« (Kreiner 1993: 19). Beachtung findet die Sauberkeit der Japaner und ihr ansprechendes Äußeres sowie ihre Kleidung und ihr hohes Bildungsniveau. Diese Beobachtungen lassen die Europäer Japan als eine Art zweites Europa am anderen Ende der Welt wahrnehmen. Die Japaner werden als Mitglieder der zivilisierten Welt gesehen und nicht mit anderen nicht-christlichen Völkern Asiens gleichgesetzt.

Wo Europäer Japan als zivilisiertes Land begreifen, vergleichen sie es bereits mit Europa. Die Existenz Japans als Antipode Europas am anderen Ende der Welt lässt ein Bild des Auf-den-Kopf-gestellt-seins entstehen (vg1. Breger 1990: 17f.). Einerseits sind zahlreiche Ähnlichkeiten zu beobachten, andererseits scheint in Japan alles genau gegenteilig zu sein, beinahe »als versuchten sie, bewußt anders zu sein als jedes andere Volk. « ${ }^{12}$ Wiederholt werden etliche Beispiele angeführt: Die Schrift läuft von oben nach unten und von rechts nach links, Bücher werden demzufolge hinten aufgeschlagen. Nicht nur Männer, sondern auch Frauen können schreiben. Anders als in Europa lernen Kinder zuerst schreiben, dann lesen. Man isst rohen statt gekochten oder gebratenen Fisch. Hobel werden gezogen und nicht geschoben, Schlüssel werden anders herum gedreht, obwohl japanische Schlösser den westlichen nachempfunden sind. Auch die Moralvorstellungen sind sehr anders, denn Frauen dürfen ohne das Wissen ihres Mannes ausgehen und öffentliche Badehäuser werden nicht nach Geschlechtern getrennt. Diese beobachtbaren Tatsachen werden von zahlreichen Japankennern in der Zeit vom sechzehnten bis ins zwanzigste Jahrhundert hinein permanent wiederholt und bilden damit die Grundlage für das Klischee der absoluten Andersartigkeit Japans. Meist werden identische Beispiele angeführt, die deshalb in den Kanon des kollektiven Wissens über Japan eingehen. Die Behauptung der grundlegenden Gegensätzlichkeit stellt einen Standard in der europäischen Japanrezeption dar (vgl. Wilkinson 1982: 29ff.). Sie kann als eine Strategie zur »Bewältigung von Andersheit« gesehen werden. Das Andere wird beherrschbar und handhabbar, »indem es als imaginäre Inversion in [das eigene] Bezugssystem rückt« (Pekar 2000: 250).

Die portugiesischen Missionare des so genannten »christlichen Jahrhunderts $\aleph^{13}$ in Japan heben besonders die japanische Sittlichkeit hervor, die sie auf den Konfuzianismus zurückführen. Dabei handelt es sich um eine von Konfuzius begründete und aus China stammende Gesellschaftslehre. Sie beruht auf den »fünf konfuzianischen Kardinaltugenden der gegenseitigen Liebe,

12 So formuliert es der italienische Jesuit und Missionar Alessandro Valignano 1583 (zit. nach Wilkinson 1982: 28).

13 So bezeichnet Pohl 2002: 46ff. die Zeit zwischen dem ersten Kontakt 1543 bis zur Abschließung zu Beginn des 17. Jahrhunderts. 
der Rechtschaffenheit, der Weisheit, der Sittlichkeit und der Aufrichtigkeit« (Meyers Taschenlexikon 1985, Bd. 5: 269; vgl. Pohl 1997b: 55f.; Hervorhebung im Original). Weiterhin definiert der Konfuzianismus die streng hierarchischen Beziehungen zwischen den Generationen und den Geschlechtern sowie zwischen Herrscher und Volk. Um das vierte Jahrhundert nach Christus wird der Konfuzianismus in Japan bekannt und mit einigen Abweichungen von der chinesischen Form als grundlegende Staatslehre übernommen. Als die portugiesischen Missionare entdecken, dass der Konfuzianismus keine originär japanische Philosophie ist, wandelt sich die Bewunderung in eine negative Haltung. Japan wird vorgeworfen, eine Nachahmernation ohne eigene kulturelle Errungenschaften zu sein. ${ }^{14}$ Mit der Entstehung dieses Bildes zeichnet sich erstmalig eine partielle Änderung der europäischen Japanrezeption ab, die jedoch hauptsächlich die katholischen Länder Europas betrifft. Die brutalen Christenverfolgungen zu Beginn des siebzehnten Jahrhunderts wirken sich verstärkend auf den Wahrnehmungswandel aus. Werden die Japaner vorher für ihre Gefühlsbeherrschung, Aufrichtigkeit und Loyalität gelobt, gelten sie nun vor allem im katholischen Europa als gefühllos, roh, rachsüchtig und falsch. In jedem Fall ist ihnen nicht zu trauen (vgl. Breger 1990: 19).

Mit der veränderten Wahrnehmung zeichnet sich ein System in der Japanrezeption $\mathrm{ab}$, das bis heute zu beobachten ist. Japanern zugeschriebene positive Eigenschaften werden in Zeiten von Konflikt und Zwietracht in ihr

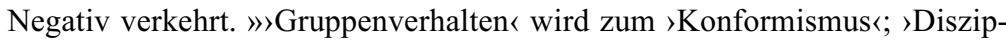
lin $<$ bedeutet $>$ Reglementierung $<$, >Lernbereitschaft $<>$ sklavische Nachahmung«" (Wilkinson 1982: 78). Es handelt sich bei dieser Wandlung des Japanbildes demzufolge nicht um die Aberkennung von den Japanern zuerkannten Eigenschaften, sondern um deren Reinterpretation. Die sich widerstreitenden Erklärungsmodelle der japanischen Mentalität existieren parallel nebeneinander. Sie werden »in die diskursive Strategie integriert, die besagt, dass die Japaner voller Widersprüche [sind]; paradox [sind] jedoch die diskursiven Behauptungen. Diese Strategie macht das beobachtete Subjekt verantwortlich für die Unfähigkeit des Beobachters, es zu verstehen« (Breger 1990: 20; vgl. Wilkinson 1982: 78). Aufgrund des oben erwähnten Klischees der absoluten Gegensätzlichkeit der japanischen Kultur und der den Japanern zugeschriebenen widersprüchlichen Eigenschaften wird die japanische Kultur und Mentalität als eine gedeutet, die nach westlichen Prinzipien unlogisch und deshalb absolut unverständlich ist. Es ist jedoch häufig die europäische Sichtweise, die nicht differenziert genug nach Erklärungsmodellen für gewisse Verhaltensweisen sucht, sondern diese als unverständlich verwirft. Zudem verhindert eurozentrisches Denken in vielen Fällen die Einsicht, dass westliche Ideen und Vorstellungen nur eine Möglichkeit sind. Paradoxe Erklärungsmodelle der japanischen Mentalität sowie die Behauptung, sie wäre nicht zu verstehen, bestimmen die europäische Japanrezeption bis heute. Die Frage nach der Rolle des Christentums prägt die europäische Japanrezeption auch im achtzehnten Jahrhundert. Beispielhaft ist die Kritik an der japanischen Praxis der Selbsttötung, »da der Selbstmord nur aus einer atheistischen Überzeugung heraus praktiziert werden könne, die nach dem Tode keine Bestrafungen mehr annimmt« (Kapitza 2001: 32). Die Kritik richtet sich jedoch auch gegen die holländische Präsenz im eigentlich abge-

14 Dieses Klischee verstärkt sich abermals während der Meiji-Zeit (vgl. Antoni 1993: 9). 
schlossenen Japan: »Durch die Holländer [glaubt] sich ganz Europa kompromittiert, « schließlich scheinen sie sich aus niederen ökonomischen Motiven vor dem Shogun herabzusetzen (ebd.: 30). Damit unterlaufen sie das europäische Überlegenheitsgefühl.

Durch seine europaweite Rezeption prägt Engelbert Kaempfers Werk das europäische Japanverständnis im achtzehnten Jahrhundert nachhaltig. Wegen der sachlichen Berichterstattung wird es oft zitiert und bildet damit den Referenzpunkt zahlreicher historischer und literarischer Werke. Weil Kaempfer Jesuiten und Holländer gleichermaßen kritisiert, wird ihm viel Respekt entgegen gebracht. Moniert wird allerdings seine Haltung zur japanischen $\mathrm{Ab}$ schließungspolitik, die er als durchaus berechtigt beschreibt, da sie die japanischen Traditionen vor westlicher Einflussnahme schützt. Kaempfers Werk dient

»Gelehrten wie Montesquieu und Voltaire als Quelle ihrer Betrachtungen zu Japan, die bemerkenswerterweise diametral zueinander [stehen]: Montesquieu sieht die japanische Bevölkerung versklavt durch das Shogunsystem der Familie Tokugawa, sieht eine orientalische Form der Despotie. Voltaire aber ist überzeugt, daß die gesellschaftliche Ordnung und Gerechtigkeit in Japan geradezu paradiesisch gegen die Zustände in Europa zu nennen sind« (Friese 1990: 37).

Japan wird - aus der europäischen Sichtweise heraus - während der Aufklärung als Vergleichskategorie zu Europa eingeführt. Die Feststellung der Differenz zwischen japanischen und europäischen Verhältnissen eröffnet neue Möglichkeiten der Kritik an den eigenen Zuständen (vgl. Pekar 2000: 240). Nach wie vor ist Japan den Europäern jedoch nur aus Berichten bekannt, erst nach der Öffnung Mitte des neunzehnten Jahrhunderts intensiviert sich der Kontakt.

Trotz der Verbreitung der Berichte über Japan besitzt ein Großteil der Europäer nur geringe Japan-Kenntnisse. Wegen der geografischen Nähe zu China wird Japan oftmals mit China gleich gesetzt, über das durch die europäische Kolonisierung weitaus mehr bekannt ist. Die sich nach 1854 entfaltenden Kontakte zu Japan führen dazu, dass in den deutschen Ländern Bilderbögen und die sich langsam zu Massenmedien entwickelnden illustrierten Wochen- und Monatszeitschriften auch über Japan berichten. Generell besteht ein Interesse an Traditionellem, das im Zuge der europäischen Industrialisierung auch hier im Verschwinden begriffen ist. Deshalb verweisen die bildlichen Darstellungen Japans zunächst auf Trachten und Traditionen. Den Lesern wird das besonders Exotische häufig in Form von Holzschnitten ${ }^{15}$ nahe gebracht; es befriedigt die Neugier nach dem ganz Anderen. Berichte über politische Entwicklungen oder gesellschaftliche Themen werden ebenfalls bildlich illustriert. Häufig werden vorhandene Stereotype über Sauberkeit, Tapferkeit und Anstand der Japaner perpetuiert. »Die deutschen JapanBerichte bleiben jedoch ignorant und unduldsam, wo sie allzu große kulturelle und religiöse Kluften zu überbrücken haben« (Mehl 1994: 37).

Das vermittelte Japanbild ist grundsätzlich sehr positiv. Dieser Eindruck prägt auch 1861 die Reise der ersten preußischen Delegation, die ähnlich den USA und anderen europäischen Mächten vorher, Handelsverträge mit Japan abschließen möchte. Vielleicht »bedingt durch die auch in Deutschland voll-

15 Dabei handelt es sich um Holzschnitte europäischer Provenienz. Sie sind nicht zu verwechseln mit den japanischen Farbholzschnitten ukiyo-e. 
zogene [...] Rezeption des Konfuzianismus« entdecken die Preußen an den Japanern zahlreiche ihnen vertraute Eigenschaften und zum Teil ähnliche Bedingungen wie in Preußen (Krebs 2002: 12f.). Die im Rahmen der Verhandlungen erfolgenden Demütigungen von japanischer Seite werden von den Preußen nicht als solche wahrgenommen, sondern »mit guten Eigenschaften ihres Gastlandes« konnotiert (Martin 2002: 91). ${ }^{16}$ Die Sauberkeit und Ordnung sowie die Tugendhaftigkeit der Japaner scheinen alle stereotypen Vorurteile der Preußen zu bestätigen. Sie finden sogar Ähnlichkeiten im Landschaftsbild der Umgebungen Tokyos und Berlins, vergleichen japanische Teehäuser mit Berliner Ausflugslokalen und erklären alles, was mit ihren preußisch-bürgerlichen Moralvorstellungen nicht in Einklang zu bringen ist, wohlmeinend mit den exotischen Gepflogenheiten Japans (vgl. ebd.). Die vermeintlichen, auch charakterlichen Ähnlichkeiten bewirken eine Rezeption Japans als Preußen Ostasiens. Im Bericht der preußischen Delegation werden dann auch die positiven $»$ Wunschbilder von der exotischen Welt Japans [...] festgeschrieben, gewissermaßen amtlich autorisiert« (ebd.: 78). Sie prägen das deutsche Japanbild noch über lange Zeit.

Die Öffnung Japans und die politische Stabilität nach Anbruch der MeijiZeit (1868-1912) bewirken den Beginn eines regen Austausches zwischen Europa und Japan. Zahlreiche westliche Experten unterstützen die Industrialisierung Japans vor Ort, gleichermaßen reisen japanische Beamte, Gelehrte, Künstler und Studenten nach Europa und Amerika, um sich dort fortzubilden und durch neu hinzugewonnene Erfahrungen und westliches Wissen am Aufbau ihres Landes teilzuhaben. Die regelmäßige japanische Teilnahme an den Weltausstellungen seit 1862, europäische Sammlungen japanischer Kunstwerke und Tourneen japanischer Theatergruppen bieten auch in Europa selbst reichlich Gelegenheit, die fremde Kultur kennen zu lernen (vgl. z.B. Rumpf 1990: 181ff.; Baumuk 1993). Besonders das japanische Kunsthandwerk und die bereits von westlichen Traditionen beeinflussten Holzschnitte lösen in Europa ein reges Interesse an Japanischem, den so genannten Japonismus aus. Der Japonismus konzentriert sich auf Japan vor allem als exotisches Land, das in seiner Andersartigkeit und Ästhetik der europäischen Sehnsucht nach Naturbelassenheit und Fremdheit eine Projektionsfläche bietet. Japan wird als »eine Art Rousseau'sches Utopia des natürlichen Lebens « beschrieben (Krusche 1973: 122). Die Exotik von Landschaft und Architektur ist in der Japanrezeption ebenso wichtig wie die Vorbildlichkeit der japanischen Gesellschaft, die als eine zutiefst menschliche gesehen wird, in der man Rücksicht aufeinander nimmt, seine eigenen Bedürfnisse denen der Gemeinschaft unterordnet und in Harmonie zusammen lebt. Ihr werden Werte zugeordnet, die in Europa vermeintlich mit der guten alten Zeit untergegangen sind. Europäer suchen in Japan die Fremde als »jenseits der Geschichte aufbewahrte Ur-Menschlichkeit, als Kultur romantisch-blauer Blumenhaftigkeit, als ästhetische Verfeinerung, als exotisches Abenteuer, als erotisches Raffinement« (Krusche 1973: 123). Unterstützt wird diese Sehnsucht durch eine Verarbeitung exotischer Japanmotive in der Literatur, so dass Figuren wie

16 Der japanische Minister erscheint beispielsweise nicht selbst, was als diplomatischer Affront zu werten ist. 
beispielsweise Madame Chrysanthème zum Symbol japanischer Exotik werden können. ${ }^{17}$

Neben der Literatur tragen auch illustrierte Zeitschriften zur Vertiefung des Japanbildes bei, wobei in den deutschen Publikationsmedien oftmals eine eher romantische, rückwärts gewandte Perspektive gewählt wird, die in der Berichterstattung traditionellen Themen gegenüber der zeitgenössischen Entwicklung den Vorzug gibt. Zwar wird auch die Modernisierung mit Wohlwollen geschildert, werden Fleiß und Ehrgeiz der Japaner gelobt; besonders die Illustrierten geben aber Einblicke in

»Religion, Fest und Brauchtum, Frauenleben oder Kinderwelt Nippons. Noch handelt es sich nicht um moderne, ungeschminkte Reportagen, vielmehr scheint es, als ob japanische Ästhetik, die Schönheiten japanischer Landschaft, die Harmonie im sozialen Miteinander auch auf die europäischen Beobachter abfärben und ihrem Stil etwas Poetisches, Friedvolles verleihen« (Mehl 1994: 45f.).

Sowohl die Wahl der Themen als auch deren Behandlung ist vermutlich der vorwiegend weiblichen Leserschaft der Illustrierten geschuldet. Stets wird nach »deutschen Denk- und Erfahrungskriterien« beurteilt und man versucht, »für das Fremde vertraute Erklärungsmuster zu finden« (Mehl 1994: 46). Beeinflusst von dieser Grundeinstellung sind diejenigen Europäer, die aus romantischen Motiven nach Japan reisen, oft enttäuscht, denn das Land ihrer Sehnsüchte befindet sich in einem Wandlungsprozess, der es vermeintlich zum Zerrbild Europas macht. An diesem Punkt wird das grundsätzlich positive Japanbild der Romantiker von einer negativen Note getrübt, denn deren Sehnsucht nach Exotik verlangt nach einem Japan, das in der Feudalzeit verharrt und so seinen ursprünglichen Charakter beibehält. Wenn sich schon Europa dem Prozess der Industrialisierung aus wirtschaftlicher Notwendigkeit unterziehen muss, soll - in der romantischen Vorstellung - Japan als eine Art Reservat des Guten und Schönen einen Gegenpol zu Europa bilden. Die industrielle Entwicklung Japans stört das Bild der intakten Gesellschaft, die durch die Degeneriertheit der westlichen Zivilisation verloren zu gehen droht.

Die mit der Meiji-Periode beginnende Industrialisierung wird von den Romantikern als Verwestlichung gesehen, die der japanischen Mentalität nicht entspricht. Kritisiert wird beispielsweise die Aneignung westlicher Kleidung, die als unpassend und dem japanischen Körperbau unangemessen empfunden wird. Die Kritik kann vor dem Hintergrund des Verschwindens der von den Europäern befürworteten japanischen Exotik gesehen werden. Diese Entwicklung wird auch wiederholt in deutschen illustrierten Zeitschriften karikiert (vgl. z.B. Mehl 1994: 39ff.). Die japanische Regierung möchte jedoch nicht unbesehen westliche Sitten übernehmen und damit die eigene Tradition verleugnen. Durch eine gezielte Angleichung an den Westen erhofft sie sich, die japanische Eigenständigkeit zu wahren. Die Adaption westlicher Kleidung, mit der sich sogar das japanische Kaiserpaar der Öffentlichkeit präsentiert, dient als Maßnahme, den Europäern auf Augenhöhe zu begegnen. Ein indigener japanischer Kleidungsstil ließe - nach der offiziellen Auffassung - die Japaner als niedliche exotische Püppchen erscheinen

17 Madame Chrysanthème ist der Titel eines Romans des französischen Schriftstellers Pierre Loti (Paris 1887). Zur Verarbeitung japanischer Motive in der Literatur vgl. z.B. Fleischmann 1999; Meyer 1994; Porra 2000. 
und nicht als gleichberechtigte Verhandlungspartner gelten (vgl. HardachPinke o.J.: 16). Die Übernahme bestimmter westlicher Gebräuche verfolgt ein System und ist mitnichten als unbedachte Nachahmung zu bewerten. In der japanischen Politik und Verwaltung werden Entscheidungen darüber getroffen, welche Technologien und Gebräuche von welchem Land übernommen werden. Andere werden damit gleichermaßen ausgeschlossen. »Der Entscheid zwischen Anpassung oder Widerstand [wird] aufgrund der Fähigkeit, fremde Gedanken auf innere Widersprüche wie auch fehlende Übereinstimmung mit der historischen Realität zu untersuchen, gefällt« (Reinfried 1996: 202). Japan orientiert sich während der Meiji-Zeit also nicht unbesehen an dem Westen, sondern wählt gezielt westliche Elemente aus, die dabei helfen sollen, »aus Japan ein >reiches Land mit einer starken Armee zu machen« Hardach-Pinke o.J.: 15). Gilt in den 1870er Jahren das Motto Zivilisation und Aufklärung, ist ab den 1880er Jahren die Devise Japanischer Geist, westliche Technik dominierend (ebd.: 17). Durch dieses Motto wird einer möglichen japanischen Identitätskrise erfolgreich vorgebeugt, denn die Aneignung westlichen Wissens und westlicher Technologie wird so zu einer Angelegenheit, die das japanische Nationalgefühl nicht in Frage stellt, sondern es noch untermauert. Von europäischer Seite wird diese Sicht jedoch kaum gewürdigt. Es entwickelt sich vielmehr Kritik an der »unreifen Zwitterkultur« (ebd.: 20), die zwar westliche Technologie, nicht aber westliche Ethik und Moral übernimmt.

Die Adaption von Einflüssen anderer Kulturen hat in Japan jedoch Tradition, wie beispielsweise die Übernahme des Konfuzianismus aus China zeigt.

»Das, was wir heute gemeinhin als japanische Kultur erkennen, ist also das Resultat einer Abfolge von fremden Einflüssen unterschiedlichster Herkunft, die in einem geschichtlichen Proze $\beta$ auf der Grundlage autochthoner Denkstrukturen verarbeitet und zu einem neuen Ganzen gefügt [werden]. [...] Insgesamt darf deshalb eine ausgeprägte Rezeptionsbereitschaft von fremden Kulturen als konstituierendes Merkmal der Tradition Japans gelten« (Reinfried 1996: 184f.).

Die für die japanische Kultur so eklatant wichtige Errungenschaft, aus anderen Kulturen ausgewählte Elemente in die eigene in einer Weise zu übernehmen, dass etwas Neues und Eigenes entsteht, wird aus der westlichen Perspektive häufig unterschätzt. Die Verschmelzung diverser Elemente unterschiedlicher Herkunft innerhalb einer Kultur wird nicht als eigenständige kulturelle Leistung akzeptiert. Diese Besonderheit der japanischen Kultur kann vermutlich mit für die westlichen Schwierigkeiten verantwortlich gemacht werden, Japan in seiner kulturellen Komplexität zu begreifen.

Das Nebeneinander von traditionellen japanischen Elementen und moderner Industriekultur gilt oftmals als grundsätzlich nicht miteinander vereinbar. In Europa geht man noch Ende des neunzehnten Jahrhunderts davon aus, dass sich Japan nur mit den westlichen Nationen messen kann, wenn es ganz und gar wie der Westen wird. Ansonsten bestehe die Gefahr eines Zurückfallens in den vormodernen Zustand. Eine Mischung fernöstlicher und westlicher Tradition wird als wachstumshemmend und unharmonisch gesehen (vgl. Hardach-Pinke o.J.: 24f.). Hier wird die Dichotomie in der Bewertung Japans deutlich, die auch heute noch das westliche Japanverständnis prägt. Die japanische Tradition gilt als authentisch und angemessen, die Industrialisierung 
als westlich und damit dem orientalischen Charakter Japans nicht entsprechend. Altes gilt als traditionell japanisch, während Neues als westlich angesehen wird. ${ }^{18}$ Je weiter der Technisierungsprozess fortschreitet, desto wahrscheinlicher wird der Verlust der japanischen Identität, denn eine Verwestlichung muss - nach westlicher Maßgabe - zwangsläufig mit der Abkehr von japanischen Traditionen einhergehen. Diese europäische Sichtweise bescheinigt Japan eine Art Schizophrenie, mit der sich wiederum ein Unverständnis für die japanische Mentalität ausdrückt. Dass diese Sichtweise eine eurozentrische ist, muss nicht besonders hervorgehoben werden. Schaut man für einen Moment nach Europa, lässt sich feststellen, dass hier ganz unproblematisch »alte Kirchen und Kernkraftwerke zu einem harmonischen, historisch gewachsenen Ensemble« zusammengefügt werden (Hardach-Pinke o.J.: 11). Hier wird die Problematik einer Wahrnehmung deutlich, die das Eigene als gegeben hinnimmt und nicht hinterfragt, im Fremden jedoch Inkonsistenzen aufzudecken meint. Das Anlegen verschiedener Maßstäbe offenbart dennoch eine Überheblichkeit des Westens, der in seiner eigenen Entwicklung den einzig richtigen Weg sieht und nicht einmal ansatzweise alternative Strukturen in Betracht zieht. Gleichzeitig scheint in einer solchen Bewertung der japanischen Kultur als Metatext eine Angst vor dem Fremden auf, denn das unverständliche orientalische Moment entzieht sich der Kontrolle durch den Westen.

Japan nimmt sich nach seiner Öffnung nicht nur die westliche Industriekultur zum Vorbild. Es übernimmt auch imperialistisches Großmachtstreben aus Europa und beginnt damit, eine Einflusssphäre im ostasiatischen Raum aufzubauen. Dies dient unter anderem der Sicherung von Absatzmärkten für die eigene industrielle Produktion sowie der Ausweitung des Reisanbaus. Nach dem japanischen Sieg über China 1895 entstehen in Europa erste Bedenken gegen eine mögliche japanische Vorherrschaft im asiatischen Raum, die auch die wirtschaftlichen Interessen der europäischen Mächte tangiert. Die vormalige Überheblichkeit des Westens wandelt sich spätestens nach der russischen Niederlage von Port Arthur 1905 besonders auch in Preußen in die Angst vor der Gelben Gefahr. ${ }^{19}$ Diese polemische Formel trägt dazu bei, »Mißtrauen und Antipathie gegen die Japaner zu verstärken« (Nakai 2002: 25). Japan wird nun zum »Katalysator eines zuvor nur potentiell vorhandenen Hasses, der ohne sein Zutun noch lange hätte unter der Oberfläche schwelen können« (Porra 2000: 192). Man befürchtet, Japan könne die gerade erst erworbene westliche Zivilisation schnell wieder abstreifen und gemeinsam mit den Chinesen einen Krieg gegen den Westen beginnen (vgl. Wilkinson 1982: 57). Die englische Haltung ist zu dieser Zeit eine andere, schließlich hat man bereits 1902 ein Bündnis geschlossen und sieht in Japan gerne das Großbritannien Asiens. Das Wohlwollen hält sich auch nach der russischen Niederlage, man frohlockt, dass das kleine, sich in der Entwicklung befindende Japan das große russische Reich geschlagen hat (vgl. Wilkinson 1982: 61). Generell ist die europäische Japanrezeption um die Jahrhundertwende geprägt durch extreme Gegensätzlichkeiten. Einerseits wird Japan nach wie vor als alter ego Europas gesehen, das sich durch seine Zivilisation und die Modernisierung auf einem ähnlichen Niveau befindet, gleichzeitig erscheint die japani-

18 Selbstverständlich lässt sich diese Annahme nicht aufrecht erhalten, denn zahlreiche zeitgenössische kulturelle Phänomene sind japanischen und nicht westlichen Ursprungs: so z.B. die Manga-Kultur.

19 Über die Entstehung des Schlagworts der Gelben Gefahr vgl. Gollwitzer 1962. 
sche Mentalität jedoch undurchdringlich und rätselhaft, weshalb man nicht vorhersehen kann, wie es sich weiter entwickeln wird. Dadurch stellt es eine »Gefahr für das kollektive [europäische] Selbstbewusstsein« dar (Porra 2000: 205). Die Rede von der Gelben Gefahr lässt aber möglicherweise mehr Rückschlüsse auf die europäische Geisteshaltung $\mathrm{zu}$, als dass sie etwas über die japanische Gesellschaft aussagt (vgl. ebd.).

Die japanische Besetzung der deutschen Kolonie Tsingtau in China kurz nach Beginn des Ersten Weltkrieges wird in Deutschland besonders heftig verdammt, da sich die Deutschen auf zahlreichen Gebieten als Lehrmeister Japans sehen und darin einen Akt des undankbaren Schülers zu erkennen meinen, der vergessen hat, bei wem er in die Lehre gegangen ist. Am japanischen Handeln meint man die »Verschlagenheit des echten Asiaten« zu erkennen (Mathias-Pauer 1984: 131; zit. nach Nakai 2002: 26). Umgekehrt sind die Japaner jedoch auch von Deutschland enttäuscht, das sich nach dem chinesisch-japanischen Krieg den anderen Westmächten anschließt, um gegen eine zu große Einflussnahme Japans in China zu intervenieren und die eigenen ökonomischen Interessen zu wahren. Trotz der problematischen Beziehungen bleibt auf deutscher Seite ein Interesse an Japan als Lieferant exotischer Berichte bestehen. Noch 1935 stellt der japanische Autor Nohara Komakichi einen publizistischen »Japan-Boom« in Deutschland fest. Er lobt insbesondere das deutsche Zeitschriftenwesen, das dem breiten Publikum ein lebendiges Bild von der Entstehung des neuen Japan vermittelt und sich sowohl traditionellen und kulturellen als auch modernen industriellen Aspekten Japans widmet (vgl. Mehl 1994: 49f.).

Die politische Gleichschaltung der deutschen Medien nach 1933 wirkt sich jedoch auch auf die Berichterstattung aus dem Ausland aus. Auslandsreisen werden erheblich erschwert und sind politisch nicht mehr opportun. Man konzentriert sich zunehmend auf deutsche Themen (vgl. Sachsse 1983: 129). Im Dezember 1936 erscheint ein Artikel mit dem Titel »Deutsches in Nippon « in der Illustrierten Die Gartenlaube, der die Parallelen zwischen Japan und Deutschland und den erheblichen deutschen Einfluss auf Japan zum Thema macht (Die Gartenlaube, 2. Dezemberheft 1936, 1184-1186; vgl. Mehl 1994: 50ff.). Dies ist ein glänzendes Beispiel für die deutsche Propaganda, schließlich ist erst Ende November der Anti-Komintern-Pakt mit Japan unterzeichnet worden. Die Freundschaft mit Japan ist mit den rassistischen Überzeugungen des Nazi-Regimes jedoch kaum in Einklang zu bringen, weshalb das japanische Deutschtum propagandistisch ausgeschlachtet wird. Der Artikel ist mit Fotografien illustriert, die beispielsweise Hitler-Bücher in japanischen Buchhandlungen zeigen. In der nationalsozialistischen Berichterstattung über Japan geht es demzufolge nicht mehr darum, die japanische Kultur zu beschreiben, zu verstehen oder zu erklären, sondern Deutschland als überlegen darzustellen, da es auch Kulturen am anderen Ende der Welt zu beeinflussen vermag. Es ist jedoch schwer auszumachen, ob diese Propaganda das deutsche Japanbild nachhaltig beeinflusst. Der 1937 erscheinende Bildband Das ist Japan. Volk und Landschaft (Henle 1937) des deutschen Fotografen Fritz Henle zeugt von dessen »Suche nach den Schönheiten der Welt« im Rahmen der Reisefotografie (Kaufhold 1994: 10). Henle, der 1936 in die USA emigriert, lässt einen deutschen Einfluss auf Japan jedoch unerwähnt.

Vor und während des Zweiten Weltkrieges unterscheidet sich die westliche Wahrnehmung Japans entlang der Grenzen politischer und militärischer Bündnisse. Während die europäischen Achsenmächte Deutschland und Ita- 
lien die militärischen Erfolge der japanischen Armee wohlwollend aufnehmen, wird der japanische Militarismus von alliierter Seite mit Unbehagen beobachtet. Der Beginn der Kriegshandlungen im Pazifik 1941 entzieht einem positiven Japanbild in den alliierten Staaten endgültig den Boden. Als Hauptakteur im Kampf gegen Japan setzen sich insbesondere die USA mit Japan auseinander. Unterschlägt man die besondere, politisch motivierte Sichtweise der Achsenmächte, kann die amerikanische Sicht auf Japan als symptomatisch für die westliche Wahrnehmung während der Kriegsjahre gelten. Japan wird als undurchsichtiger Feind wahrgenommen, der Kriegsmethoden anwendet, die sich dem westlichen Verständnis völlig zu entziehen scheinen. ${ }^{20}$ Das Handeln des feindlichen Japan stellt das US-Militär vor völlig neue Herausforderungen. Um das Unverständnis aufzulösen, wird die amerikanische Kulturanthropologin Ruth Benedict 1944 von den US-Behörden beauftragt, eine ethnologische Studie über Japan anzufertigen, die als Handbuch der Besetzung dienen kann. Aufgrund der Kriegsumstände kann von einer Unvoreingenommenheit gegenüber dem Forschungsgegenstand kaum die Rede sein. Die 1946 publizierte Studie bringt bereits im Titel The Chrysanthemum and the Sword die seit langem perpetuierte sprichwörtliche Gegensätzlichkeit der japanischen Mentalität beispielhaft auf den Punkt (vgl. Benedict 1946). Sie gehört zu den einflussreichsten Abhandlungen über Japan im zwanzigsten Jahrhundert. Die im Titel postulierte Doppeldeutigkeit Japans als einem Land der in der Chrysantheme symbolisierten hochkulturellen Ästhetik und des mit dem Schwert bezeichneten kriegerischen und todesmutigen Weges der Samurai verdeutlicht erneut Faszination und Angst, Anziehung und Abneigung des Westens gegenüber Japan. ${ }^{21}$

In Europa entwickelt sich nur ganz allmählich ein Interesse für Nachkriegsjapan. In deutschen Zeitschriften werden zunächst eher feuilletonistische Themen behandelt. Zunehmend wird der japanische Wirtschaftserfolg, teilweise mit Bewunderung, aber auch mit Vorbehalten, thematisiert (vgl. Mehl 1994: 53ff.). Dabei werden die bereits vorhandenen Stereotype über japanischen Ehrgeiz und Fleiß, das besonders ausgeprägte Gruppenverhalten sowie die Loyalität des Arbeitnehmers gegenüber seiner Firma wiederholt. In den 1980er Jahren gilt Japan einerseits als großes Vorbild, andererseits als wirtschaftlicher Aggressor, was sich in der Formel Japan Inc. ausdrückt. Damit ist die Vorstellung einer rein wirtschaftlich ausgerichteten, zentral gesteuerten Politik verbunden, die Soziales vernachlässigt, rücksichtslos gegen Konkurrenten vorgeht, den eigenen Markt durch Schutzzölle abschirmt und sich hinter undurchsichtigen Verwaltungsvorschriften versteckt, um ausländische Importe zu verhindern (vgl. Wilkinson 1982: 69). In der Angst vor dem wirtschaftlichen Konkurrenten Japan scheint erneut das negative Japanbild auf. Besonders in den USA nimmt die ökonomische Auseinandersetzung die Dimension eines Handelskrieges an, in dem mit ähnlichen Metaphern wie zu Zeiten des Zweiten Weltkrieges operiert wird, was mit dem Begriff des Japan Bashing, dem verbalen Niedermachen des vermeintlichen Feindes, treffend beschrieben ist. ${ }^{22}$ In zahlreichen Publikationen versucht man, das ökonomi-

20 Übersehen wird jedoch, dass auch die deutschen Vorgehensweisen auf europäischen Kriegsschauplätzen neuartige Dimensionen annehmen, die sich kaum mit den Maßstäben bekannter Kriegsführung messen lassen.

21 $\mathrm{Zu}$ Benedicts Studie vgl. Abschnitt 2.3.1.

22 Dt.: auf Japan einschlagen (vgl. Antoni 1993: 9; Aoki 1996: 14). 
sche Geheimnis Japans zu ergründen, sucht nach nationalen Besonderheiten und begründet stets mit dem japanischen Charakter, der für Westler unverständlich ist, weshalb eine Übernahme des Erfolgsrezepts immer an kulturellen Hindernissen scheitern muss.

Das allgemeine Wissen über Japan orientiert sich auch heute noch häufig an standardisierten Vorstellungen. Man weiß vom Pazifikkrieg und den Folgen der Atombombenabwürfe sowie dem japanischen Umgang mit der Vergangenheit aus einer Opferrolle heraus. Die starke Wirtschaftskraft, insbesondere in den Bereichen der Auto- und Konsumgüterindustrie, bildet in der europäischen Japanwahrnehmung einen weiteren Schwerpunkt. Seit den 1990er Jahren wird die Berichterstattung komplexer, man interessiert sich vermehrt für kulturelle Belange. Trotz des verbesserten Informationsflusses im Zeitalter der Globalisierung ist Japan nach wie vor ein Land, über das in Europa sehr viele Klischees und Stereotype verbreitet sind. Auch wenn sich widersprechende Eigenschaften nebeneinander Verwendung finden, beziehungsweise im Wechsel positiv und negativ über Japan geurteilt wird: »Die Begriffe mögen sich ändern, doch die Faszination, oder auch das Unbehagen, angesichts des ganz Anderen, das Japan nach wie vor repräsentiert, sind geblieben« (Antoni 1993: 9).

\subsection{Stereotype Japanbilder}

\subsubsection{Fremd- und Selbstbilder}

Die anhaltende Widerspruchslosigkeit des europäischen Japanbildes legt nahe, dass es sich hier um stereotype Vorstellungen handelt, die in dieser Form nicht der japanischen Gesellschaft entsprechen müssen. Ihren Ursprung haben sie in den frühesten Erzählungen und Begegnungen. Mit zunehmendem Informationsgrad hat eine gewisse Ausdifferenzierung stattgefunden, dennoch kann man nicht von einer maßgeblichen Veränderung der Grundannahmen über Japan sprechen. Zahlreiche Autoren, die seit langer Zeit in den Japanese Studies rezipiert werden, »teilen einen beeindruckenden Grad an Ähnlichkeiten in ihren Darstellungen der moralischen Schlüsseltugenden und -werte der japanischen Kultur und Gesellschaft: Bescheidenheit, Beharrlichkeit, Höflichkeit, Sittsamkeit, Genügsamkeit, Ritterlichkeit, Gerechtigkeit, Tapferkeit, Disziplin, Güte, Aufrichtigkeit, Ehre, Loyalität und Selbstbeherrschung « (Matsumoto 2002: 8f.). Diese Tugenden scheinen alle auf Werten der Samurai - dem Kriegerstand der Feudalzeit - zu gründen. Sie sind im Laufe der Zeit jedoch für die Beschreibung des japanischen Charakters als solchem auch innerhalb Japans selbst übernommen worden und nun Teil eines verallgemeinernden Japanbildes. Einheitlichkeit und Persistenz weisen nach den Erläuterungen im ersten Kapitel auf die stereotypen Qualitäten der europäischen Grundannahmen über die japanische Kultur und Gesellschaft hin. Wie oben bereits erörtert, ändern sich abhängig von den politischen Entwicklungen nicht die grundlegenden Begrifflichkeiten in der Beschreibung Japans und der Japaner, lediglich die Urteile oszillieren wiederholt zwischen positiven und negativen Wertungen. Für jedes japanische Handlungsschema existiert ein entsprechendes europäisches Erklärungsmodell. Scheitern alle anderen Erläuterungen, passt immer die These der prinzipiellen Andersartigkeit der japanischen Mentalität, die für den Westen unlogisch und 
nicht zu durchschauen ist. In der Erklärung einer unüberbrückbaren Differenz wird die Distanz zu Japan als dem Fremden und Anderen gewahrt. Dabei ist es völlig unerheblich, ob der Unterschied positiv oder negativ gewertet wird. Auch wenn wiederholt Parallelen zwischen Europa und Japan aufgezeigt werden, beharrt die europäische Vorstellung auch heute auf einer absoluten Gegensätzlichkeit Japans. Dazu trägt in nicht unerheblichem Maße die Tatsache bei, dass man in Japan selbst, im Zuge einer permanenten Selbstvergewisserung, Diskurse - so genannte Japandiskurse - über die eigene Japanizität führt. Im Rahmen der historischen Entwicklung haben die Japaner die fremde Sicht auf das eigene Land und Volk in ihr Selbstbild übernommen, wenn nicht gar selbst mit konstruiert, um der eurozentrischen Wahrnehmung Eigenes entgegen zu setzen (vgl. Mae 2001: 259). Als Teilhaber am Diskurs zeichnen sie ein Bild davon, wie sie selbst über sich denken und bestimmen damit gleichermaßen, wie sie vom Rest der Welt wahrgenommen werden möchten (vgl. Matsumoto 2002: 20). Eine Differenzierung zwischen Auto- und Heterostereotyp ist deshalb kaum möglich. Selbst- und Fremdbild durchdringen sich gegenseitig und führen zu einer stereotypen Sichtweise auf Japan, die, wenn überhaupt, nur sehr langsam veränderten Vorstellungen weicht.

Die Japandiskurse, die von Japanern wie von Nicht-Japanern geführt, aber vor allem in Japan rezipiert werden, gehen im Kern der Frage nach: Wer sind die Japaner? Mit dieser grundsätzlichen Fragestellung läuft der Diskurs als solcher Gefahr, stereotype Ansichten zu vertreten. Dies ist, neben teilweise sehr unseriösen Publikationen, die auch nationalistische oder chauvinistische Tendenzen aufweisen, einer der Hauptkritikpunkte an den Japandiskursen. Interessant ist die Tatsache, wie bestimmte Sichtweisen auf Japan wiederholt bestätigt werden. Der japanische Kulturanthropologe Aoki Tamotsu beschreibt in seiner Studie über die Japandiskurse der zweiten Hälfte des zwanzigsten Jahrhunderts verschiedene Phasen der japanischen Selbstwahrnehmung, die von einer negativen Rezeption der Japanizität direkt nach Kriegsende, über eine relativistische Haltung bis hin zur positiven Rezeption in den 1980er Jahren reicht (vgl. Aoki 1996). Nach der Hochzeit des japanischen Wirtschaftswachstums und den daraus resultierenden Handelsfriktionen insbesondere mit den USA sowie schließlich im Zuge der Globalisierung hat sich die extrem positive Selbstwahrnehmung wieder relativiert. Dies steht in unmittelbarem Zusammenhang mit einer von ausländischer Seite formulierten fundamentalen Kritik am - als überheblich rezipierten - japanischen Selbstverständnis. Auch die Japandiskurse zeigen je nach politischer Lage unterschiedliche Wertungen der für die japanische Gesellschaft als konstituierend geltenden Merkmale und ähneln darin der bereits beschriebenen westlichen Wahrnehmung.

Nach Aoki markiert die kulturanthropologische Studie The Chrysanthemum and the Sword von Ruth Benedict, die bereits 1948 in Japan erscheint, den Beginn der Japandiskurse nach Ende des Zweiten Weltkrieges. Sie ist die erste holistische kulturanthropologische Studie, die über Japan vorgelegt wird. Die vorhergehende fragmentarische ethnologische Forschung behandelt lediglich regional begrenzte Fragestellungen und versucht nicht, den japanischen Nationalcharakter als Ganzes darzustellen (vgl. z.B. Embree 1939). Benedicts Studie gilt als sehr kontrovers und wird einerseits vor allem wegen des holistischen Ansatzes kritisiert, andererseits jedoch als ein Werk gewürdigt, 
das trotz der widrigen Umstände erstaunlich unvoreingenommen ist und verschiedene kulturelle Aspekte hellsichtig zusammenfasst. ${ }^{23}$

In The Chrysanthemum and the Sword wird die traditionelle japanische Kultur »als einzigartiges System« dargestellt. Es wird eine »leicht verständliche Analyse der Unterschiede zwischen Japan und dem Westen « geliefert, die im Vergleich beständig Japans Andersartigkeit betont (Aoki 1996: 27; Hervorhebung im Original). Die proklamierte Einzigartigkeit und Andersartigkeit des japanischen Inselreiches, dessen geografisch fehlenden Verbindungen $\mathrm{zu}$ anderen ostasiatischen Nationen oftmals auch kulturell gedeutet werden, bestärken das japanische Selbstbild und sind Auslöser für die breite Wirkung von Benedicts Werk in Japan. Die Idee der Einzigartigkeit, die bereits seit Jahrhunderten von westlicher Seite auf Japan projiziert wird, wird in Japan bereitwillig übernommen, denn sie grenzt die japanische Nation sowohl von anderen Nationen im ostasiatischen Raum als auch weltweit ab. Damit wird eine gewisse Überlegenheit konstatiert. Dieses japanische Selbstbild fließt in den westlichen Diskurs mit ein und prägt wiederum die westliche Sichtweise auf Japan bis heute. Die These der japanischen Besonderheit wird beispielsweise auch von Samuel Huntington, der in seiner Abhandlung über den Kampf der Kulturen Japan von anderen ostasiatischen Nationen dezidiert absetzt, übernommen. »Wie ein Bumerang kehrt dieses Bild der beziehungslosen, isolierten japanischen Kultur nun wieder nach Japan zurück. Mit Tatsachen und Fakten, etwa der sehr wohl gegebenen kulturellen Anbindung Japans an den ostasiatischen Raum, haben diese schillernden Bilderwelten nichts mehr zu tun « (Antoni 1999: 145).

Neben der wiederholt erwähnten Gegensätzlichkeit der Japaner bilden zwei zentrale Aspekte in Benedicts Abhandlung die meistrezipierten Thesen und leisten einen Beitrag zur Perpetuierung der stereotypen Wahrnehmung Japans. Zunächst handelt es sich um die Darstellung Japans als Schamkultur, während die westliche als Schuldkultur beschrieben wird. In der Schamkultur ist man »in seinem Handeln, anders als in den von monotheistischen Religionen geprägten Kulturen, nicht einer transzendenten, sinn- und normstiftenden Instanz verpflichtet [...], sondern der gesellschaftlich sanktionierten Verbindlichkeit eines tradierten Verhaltenskodexes« (Griesecke 2001: 103). Anders als in westlichen Kulturen bestimmt der gesellschaftliche Rahmen das Verhalten und nicht ein fixiertes moralisches oder ethisches Verständnis des richtigen Handelns, dem der Einzelne auch unter möglicherweise widrigen Umständen verpflichtet ist.

Die zweite zentrale These ist die der Gruppenorientierung der Japaner, die dem westlichen Individualismus gegenübergestellt wird. Benedict bemerkt zum Prinzip des Gruppenverhaltens, es

»basiere auf dem Vertrauen der Japaner in ein Sozialsystem, welches die Grundlage ihrer gesamten Vorstellungen über menschliche Beziehungen bilde. Dies gelte sowohl für die zwischenmenschlichen Beziehungen als auch für die Beziehungen des einzelnen zum Staat. Auf der Grundlage von familiären Beziehungen formierten sich

23 Kritisiert wird vor allem auch das kriegsbedingte Fehlen von Feldforschung. Griesecke verweist jedoch darauf, dass Benedicts Quellenmaterial umfangreicher ist als gemeinhin angenommen (vgl. Griesecke 2001: 114). Ölschleger 1996 kritisiert die Rückwärtsgewandtheit Benedicts. Aoki 1996: Kap. 2 referiert Würdigungen und Kritiken. 
die gesellschaftlichen und zwischenmenschlichen Beziehungen hierarchisch nach den Privilegien der Generation, des Geschlechts und des Alters. Die Betonung der Hierarchie in den Beziehungen bedeute keine despotische Herrschaft des Machthabers über den Untergeordneten, sondern meine das Übertragen einer pflichtvollen Verantwortung auf den Höherstehenden, dem sich die Untergebenen willig anvertrauen« (Aoki 1996: 38).

Das Prinzip der Gruppenorientierung ist eng mit dem der Schamkultur verknüpft und wird zur Erklärung der japanischen Wirtschaftspraxis ebenso herangezogen wie für die vermeintlich fehlende Emanzipation. Beide Punkte werden vom nachfolgenden Japandiskurs am häufigsten übernommen (vgl. Aoki 1996: 37f.).

Versuche der Dekonstruktion der Allgemeingültigkeit dieser Attribute deuten darauf hin, dass es sich hier um Stereotype handelt. Die Konsistenz des nicht nur westlichen Japanbildes lädt geradezu dazu ein, es auf seine Aktualität hin zu untersuchen. Die »stereotypen Bilder der japanischen Kultur und Gesellschaft sind nicht mehr lediglich Stereotype; sie sind die Japaner« konstatiert der amerikanische Sozialpsychologe David Matsumoto (Matsumoto 2002: 16; Hervorhebung im Original). Er vertritt die These, dass die japanische Gesellschaft einem tief greifenden Umwälzungsprozess unterworfen ist, der nahe legt, die überkommenen Stereotypen aufzugeben und die zeitgenössische japanische Gesellschaft nicht mehr mit der traditionellen gleich zu setzen. Er zieht sozialpsychologische Studien heran, um einige Stereotype beispielhaft zu widerlegen. Damit bestätigt er jedoch die These, Stereotypen beinhalteten immer einen wahren Kern, was wiederum die Probleme der sozialpsychologischen Untersuchungsmethoden verdeutlicht. Wie im ersten Kapitel erörtert, wird die Existenz eines wahren Kerns von Stereotypen unterschiedlich bewertet. Die Annahmen Matsumotos, die er in seinen Studien zu widerlegen sucht, gründen sich auf die perpetuierten stereotypen Vorstellungen der traditionellen japanischen Gesellschaft. Vorrangig bei Fragen der Gruppenorientierung, des Selbstkonzepts und des interpersonellen Bewusstseins lässt sich jedoch kaum nachweisen, dass die entsprechenden Stereotypen zu einem anderen Zeitpunkt zutreffend gewesen wären. Die von ihm formulierte Veränderung markiert lediglich eine Abweichung vom Stereotyp, bestätigt aber nicht retrospektiv dessen Existenz. Trotzdem scheint mir Matsumotos Ansatz geeignet, über die zeitgenössische japanische Gesellschaft in Abweichung zu den tradierten japanischen Stereotypen nachzudenken.

Matsumoto nimmt sich beispielhaft sieben japanische Stereotype vor, die er mittels des ihm vorliegenden sozialpsychologischen und sozialwissenschaftlichen Datenmaterials widerlegt (vgl. Matsumoto 2002: Kap. 2). Er vertritt die These, dass

»eine neue, qualitativ und bedeutungsvoll andere Kultur im Entstehen begriffen ist. Was wir in unserem alltäglichen Leben in Japan beobachten, ist keine Laune und kein Generationsproblem, das die Jugend überwinden wird, sondern es handelt sich um Zeichen realer und drastischer Veränderungen dieser Gesellschaft« (Matsumoto 2002: 36).

Bei den Stereotypen, die Matsumoto widerlegen möchte, handelt es sich zunächst um den japanischen Kollektivismus, die japanische Konzeption des Selbst und das interpersonelle Bewusstsein. Das Selbstkonzept ist das »Zent- 
rum für die Organisation und Überwachung von Verhalten, Wahrnehmungen, Geisteshaltungen, Überzeugungen und individuelle Unterschiede« (Matsumoto 2002: 48). Das interpersonelle Bewusstsein bestimmt den Grad, »in dem Menschen sich über andere in ihrem Leben und in ihrem Umfeld « bewusst sind (ebd.: 54). Gruppenorientierung, Selbstkonzept und interpersonelles Bewusstsein stehen in engem Zusammenhang. Matsumoto führt in seiner Argumentation, die hier nicht en detail referiert werden soll, Belege dafür an, dass die Gruppenorientierung und die mit der Schamkultur in Verbindung stehenden Konzepte heute einen weniger hohen Stellenwert in Japan einnehmen, als im Vorfeld vermutet.

Andere Kritiker stereotyper Japankonzepte weisen beispielsweise darauf hin, dass Selbstkontrolle oder Selbstkonditionierung innerhalb der japanischen Gesellschaft einen gar nicht so erheblichen Kontrast zu europäischen Gesellschaften bilden, wie gemeinhin angenommen.

»Schließlich hat auch die westliche Kultur [...] einen langen Prozeß der Selbstkonditionierung hinter sich, der so erfolgreich war, daß wir ihn kaum mehr an uns selbst bemerken. Der Philosoph und Historiker Norbert Elias hat darauf aufmerksam gemacht, daß der Prozeß der Modernisierung der europäischen Kulturen seit dem Ende des Mittelalters auch begleitet war von einer zunehmenden Unterdrückung der individuellen Triebäußerungen, von dem, was vor allem im französischen Sprachgebrauch mit dem Begriff der Zivilisation bezeichnet wird, nämlich dem Entstehen eines detaillierten Kodex des menschlichen Verhaltens. Elias [...] macht aber auch deutlich, daß mit dem Begriff der Höflichkeit das individuelle Verhalten in Gesellschaft und Gruppe insgesamt angesprochen wird, also die soziale Verantwortung und Rücksichtnahme« (Schlieper 1997: 78; Hervorhebungen im Original).

Diese Argumentation verdeutlicht, dass die Annahmen über die fremde Kultur Japans stärker hervortreten als das Wissen um die eigene Kultur, deren Entwicklung als selbstverständlich gilt und die, möglicherweise nicht ausreichend reflektiert, als Vergleichsperspektive herangezogen wird. Dieses Beispiel zeigt, dass eine Reflexion der Bedingungen der eigenen Gesellschaft zur Bewertung einer fremden unabdingbar ist.

Neben den eher abstrakten Konzepten untersucht Matsumoto noch einige konkretere Vorstellungen über die japanische Gesellschaft. Dazu gehören unter anderen das Bild des vorbildlichen Angestellten (salaryman/sarariiman) und des Ideals der lebenslangen Anstellung. Der Begriff sarariiman wird nach dem Ersten Weltkrieg geprägt und benennt den white-collar (Büro-) Angestellten, der das Gesicht der japanischen Wirtschaft nachhaltig geprägt hat. Im Alltagsgebrauch bezeichnet er heute auch Arbeiter und staatliche Angestellte, selten auch die weiblichen Geschlechts (vgl. Dasgupta 2002: 434). Das Prinzip des sarariiman beruht auf einer Ideologie der Geschlechtertrennung, »die Maskulinität mit Arbeit und Weiblichkeit mit dem Haushalt gleichstellt. Im Gegenzug zur väterlichen Zuwendung von Seiten der Firma wird vom sarariiman erwartet, dass er sich gänzlich der Firma zur Verfügung stellt und die Angelegenheiten des Haushalts seiner Frau überlässt« (ebd.: 434f.). Matsumoto untersucht vor allem die Vorstellung, der japanische Angestellte sei eine Arbeitsbiene, der alle privaten Belange zurückstellt und seine gesamte Zeit und Arbeitsleistung uneingeschränkt dem Arbeitskollektiv, der Firma und damit der japanischen Wirtschaft zur Verfügung stellt (vgl. Matsumoto 2002: 67). Hier zeigt sich, dass insbesondere die jüngeren Ange- 
stellten mit dem japanischen System unzufrieden sind, das beispielsweise eine Anhebung der Gehälter lediglich in Altersprogression und nicht gemessen an der individuellen Leistung vorsieht. Waren früher Arbeitgeber und Arbeitnehmer in einem komplexen System von Verpflichtungen im Rahmen einer lebenslangen Anstellung verbunden, die es oftmals unmöglich machte, beispielsweise bei Unzufriedenheit von der einen oder der anderen Seite den Arbeitsvertrag zu lösen, zeichnet sich auf diesem Gebiet eine Veränderung ab. Firmen befürworten häufiger ein Leistungssystem und Angestellte sind zunehmend bereit, die Arbeitsstelle zu wechseln, wenn die Arbeit nicht ihren Vorstellungen oder Fähigkeiten entspricht (vgl. ebd.: 77). Damit entfernt sich die japanische Arbeitswelt von der stereotypen Uniformität und nähert sich mehr und mehr westlichen Bedingungen an. Am Punkt der lebenslangen Beschäftigung wird ein Unterschied innerhalb der westlichen Sichtweisen deutlich, denn bis vor einigen Jahren war es in Deutschland üblich, ein Leben lang in derselben Firma zu arbeiten, während in den USA seit jeher Arbeitsstellenwechsel selbstverständlich sind. Von daher ist eine unterschiedliche Bewertung dieses Aspektes nahe liegend.

Die veränderte Arbeitswelt, insbesondere die Frage nach der Arbeitszeit, die ein (männlicher) Angestellter in seiner Firma verbringt, steht in unmittelbarem Zusammenhang mit der Institution der Ehe. Widmet der sarariiman nicht mehr seine gesamte Zeit der Firma, wirkt sich dies möglicherweise auf das Verhältnis zu Ehefrau und Kindern aus. So beschäftigt sich Matsumoto auch mit der stereotypen Vorstellung der japanischen Ehe und damit indirekt mit der Stellung der Frau. Die Beziehungen zwischen Männern und Frauen in Japan sind lange Zeit durch die im Konfuzianismus festgeschriebenen Hierarchien benannt. Insbesondere die Tokugawazeit prägt die »drei Gehorsamspflichten der Frau [...]: als Mädchen gegenüber dem Vater, als Ehefrau gegenüber dem Ehemann, als Witwe gegenüber dem ältesten Sohn« (Gössmann 1990: 18). Dies wirkt bis heute nach. Japanische Frauen gelten vom europäischen Standpunkt aus als wenig emanzipiert und nach wie vor ihrem Ehemann untergeordnet. Während westliche Frauen scheinbar die Wahl zwischen Beruf, Familie oder anderen Lebenskonzepten haben, gilt Japan als ein Land mit sehr traditionellen Vorstellungen der Frau als verheirateter Hausfrau und Mutter, die trotz guter Ausbildung auf eine berufliche Karriere verzichtet. In der traditionellen Konstellation genießen Japanerinnen eine gute Ausbildung, viele haben einen Universitätsabschluss. Trotzdem sind sie in der Berufswahl stark benachteiligt, da Firmen damit rechnen, dass Frauen mit der Heirat, spätestens aber mit der Geburt ihres ersten Kindes aus dem Betrieb ausscheiden. Daher sind Firmen oftmals nicht bereit, Frauen eine innerbetriebliche Ausbildung zu ermöglichen. Dies führt zu dem »spezifisch japanischen Paradoxon, daß bislang die jungen Frauen mit den formal höchstbewerteten Bildungsabschlüssen die geringsten Einstellungschancen« haben (Weber 1990: 106). Trotz hoher Qualifikation müssen Frauen oftmals als OL - office ladies - Hilfsdienste leisten, beispielsweise kopieren und den männlichen Angestellten Tee servieren. Sie gelten als Blumen am Arbeitsplatz (shokuba no hana) (vgl. Creighton 1996: 194f.). In dieser Position gehören Frauen nicht der Kernbelegschaft an, Aufstiegsmöglichkeiten bleiben ihnen verwehrt. Diese Ungleichbehandlung im Arbeitsleben führt oftmals dazu, dass gerade hoch qualifizierte Frauen gerne aus dem Beruf ausscheiden und sich für das Hausfrauendasein entscheiden, da sich ihnen hier scheinbar größere Gestaltungsspielräume eröffnen (vgl. Weber 1990: 106). Die Rolle der Hausfrau wird ge- 
sellschaftlich dadurch sanktioniert, dass es kaum Möglichkeiten der Kinderbetreuung für Berufstätige gibt. Weiterhin ist die Altenpflege traditionell familiär geregelt, und es fehlt an finanzierbaren Betreuungsmöglichkeiten für alte Menschen (vgl. Broadbent 2002: 169). Die Familie des ältesten Sohnes kümmert sich üblicherweise um dessen Eltern, somit fällt diese Aufgabe der Schwiegertochter zu. Frauen können demzufolge lediglich in Zeiten berufstätig sein, in denen sie familiär nicht stark gefordert sind. Daraus resultiert eine diskontinuierliche Beschäftigung, die jedoch politisch gewollt ist (vgl. Rosenberger 1996: 13f.). »Frauen spielen eine wichtige Rolle in der Flexibilisierung des japanischen Beschäftigungssystems. [...] Man spekuliert auf den flexiblen Arbeitseinsatz der Frauen, der in Anbetracht einer wirtschaftlich und politisch unüberschaubaren Zukunft besser ins Konzept paßt als die rigide Erwartungshaltung männlicher Berufsanfänger« (Weber 1990: 122f.). Müssen im Zuge wirtschaftlicher Sparmaßnahmen Arbeitsplätze abgebaut werden, können Frauen mit ihren unsicheren, flexiblen und schlecht bezahlten Jobs schnell gekündigt werden. Sie können sich dann wieder der Familie widmen, deren finanzieller Status durch den Arbeitsplatzverlust nicht nachhaltig gefährdet ist, da der Arbeitsplatz des Ehemanns stabiler und erheblich besser bezahlt ist (vgl. Rosenberger 1996: 19).

In der traditionellen Konstellation ist der Ehemann derjenige, der das Geld verdient. Er ist deshalb von häuslichen Pflichten befreit; diese werden vollständig von der Ehefrau übernommen. Das Hausfrauendasein erhält in Japan jedoch eine wesentlich höhere gesellschaftliche Wertschätzung als in europäischen Ländern. »Eine Hausfrau ist normalerweise für alle Aspekte des Haushalts-Managements zuständig, von der finanziellen Haushaltsplanung und dem Bilden von Rücklagen bis hin zum Einkaufen, Putzen, der Urlaubsplanung, Privatunterricht für ihre schulpflichtigen Kinder, Reparaturen im Haus und so weiter « (Buckley 2002a: 202). Die britische Kulturanthropologin Joy Hendry verweist auf die sehr differenzierte traditionelle Rolle japanischer Frauen, die in der Familie unter Umständen eine durchaus entscheidungstragende Rolle innehaben. Dies bleibt jedoch möglicherweise unsichtbar, da der Mann die Familie nach außen hin repräsentiert (vgl. Hendry 2004). Diese Annahme wird von Matsumoto nicht reflektiert, er untersucht Statistiken, die darauf hindeuten, dass in der zeitgenössischen japanischen Gesellschaft die Ehe nicht mehr als einzig mögliche Lebensform gilt, was sich beispielsweise in sinkenden Zahlen von Eheschließungen und steigenden Scheidungsraten ausdrückt. In der stereotypen Vorstellung gilt die Familie als Fundament der japanischen Gesellschaft, eine Abkehr von diesem Modell deutet auf eine grundlegende Veränderung hin. Auch innerhalb der Ehe ändert sich die Rolle der Frau, denn zunehmend wird Gleichberechtigung eingefordert. »Die Form der Ehe, die den Ehemann als Meister und die Ehefrau als ihrem Mann unterwürfig sieht, ist ein Relikt der Vergangenheit« (Matsumoto 2002: 83). Arrangierte Eheschließungen, die auf pragmatischen Gesichtpunkten beruhen, dominierten bis in die 1960er Jahre hinein. Sie sind seither jedoch rückläufig. Heute werden Ehen eher aus emotionaler Zuneigung geschlossen (vgl. Linhart 1990: 62f.).

Stereotype verhindern einen differenzierten Zugang $\mathrm{zu}$ einer fremden Kultur. So problematisch Matsumotos an sozialpsychologischen und sozialwissenschaftlichen Fragestellungen ausgerichtete Dekonstruktion japanischer Stereotype auch sein mag, bietet sie einen Anlass, die japanischen Stereotype 
zu überdenken und das Augenmerk auf die Veränderungen der zeitgenössischen japanischen Gesellschaft zu richten.

\subsubsection{Visuelle Klischees}

Die stereotypen Vorstellungen über Japan und die japanische Mentalität beinhalten auch visuelle Klischees, die nur schwer zu überwinden sind. Die visuellen Vorstellungen über Japan gründen sich ebenfalls auf eine lange Tradition, die bereits mit den Berichten Marco Polos beginnt. Die textlichen Beschreibungen Japans regen die visuelle Phantasie der Europäer an, später kommen Zeichnungen von europäischen Japanreisenden, aber auch japanische Darstellungen hinzu und geben den Phantasiebildern eine konkretere Form. Als die ersten Fotografien in Japan angefertigt werden, sind die visuellen Klischees bereits fest in der Vorstellung verankert, so dass die europäischen Fotografen diese lediglich ins Bild setzen müssen. Bilder von

»Geishas, Samurais, Bogenbrücken, Teehäusern und dem Berg Fuji gehören seit dem 19. Jahrhundert zu den Grundmustern der westlichen Vorstellung von Japan. Häufig kann man sich des Eindrucks nicht erwehren, daß diese Japan-Klischees auch heute noch ein Eigenleben führen, oft jenseits jeglicher Realitätserfahrung mit Japan« (Delank 2000: 255; vgl. auch Iwasaki 1988: 25).

Interessanterweise tragen nicht nur westliche Fotografen zur Perpetuierung dieser Klischees bei. Auch japanische Fotografen nutzen die große Nachfrage nach solchen Fotografien und unterstützen ihre weitere Verbreitung. Der japanische Fotograf Shimooka Renjoo »scheint später Gewissensbisse gehabt $\mathrm{zu}$ haben. In der Erinnerung an seine frühen fotografischen Jahre weist er darauf hin, dass seine Bemühungen, dem touristischen Geschmack für Exotisches gerecht zu werden, zum verzerrten Japanbild in den Vereinigten Staaten und Europa beigetragen haben könnten« (Iwasaki 1988: 25).

Die der japanischen Öffnung folgende Modernisierung führt in den Augen westlicher Japanreisender zur teilweisen Zerstörung der exotischen Landschaft. Fabrikschornsteine und Telegrafenmasten stören die Harmonie von Landschaft und Architektur. Die westliche Nachfrage konzentriert sich bis ins zwanzigste Jahrhundert hinein auf visuelle Darstellungen eines traditionellen Japan. Neben landschaftlichen und architektonischen Sehenswürdigkeiten werden Menschen aller Berufe und Schichten in traditioneller Kleidung fotografiert. So entsteht eine Art Inventar des verschwindenden traditionellen Japan. ${ }^{24}$ Japanische Fotografen eignen sich die Bildvorstellungen der Europäer ebenfalls schnell an und fotografieren Szenen, die sie selbst nicht als abbildungswürdig oder interessant erachten. Bestimmte GenreSzenen werden im Studio mit Laiendarstellern in exotischer Weise inszeniert. Deshalb existieren beispielsweise Fotografien von Harakiri-Szenen oder unechten Samurai. Die Auswahl der fotografischen Motive trägt zur Perpetuierung eines exotischen Japanbildes bei. ${ }^{25}$ Fotografien von Interieurs der neuen Fabriken sucht man in der auf den westlichen Markt ausgerichteten Japanfotogra-

24 Dieses Phänomen findet Parallelen beispielsweise in der US-amerikanischen Indianerfotografie von Edward S. Curtis zur selben Zeit (vgl. Koenig 1998: 350).

25 Präzisere Ausführungen zur frühen fotografischen Darstellung Japans insbesondere in der Reisefotografie folgen in Teil I, Abschnitt 4.2.1. 
fie vergebens, da sie der europäischen Vorstellung von Japan nicht entsprechen (vgl. Delank 2000: 263). Die Suche nach dem ganz Anderen lässt nur das Differente und Exotische reizvoll erscheinen. In der japanischen Fotografie gibt es sehr wohl Ansätze, die Veränderungen im eigenen Land fotografisch zu dokumentieren. So wird beispielsweise die Entwicklung Hokkaidos seit den frühen 1870er Jahren fotografisch begleitet (vgl. Kaneko 2003: 186). Um die Jahrhundertwende entstehen Fotografien der neuen Industrien und des Eisenbahnbaus, auch der chinesisch-japanische und der russischjapanische Krieg werden dokumentiert. Nach dem Ersten Weltkrieg ist die japanische Fotografie stark von der deutschen Avantgarde des Bauhaus und der Neuen Sachlichkeit geprägt, es entstehen stilistisch vergleichbare Dokumente des neuen urbanen Lebens als Zeichen einer sich verändernden Gesellschaft (vgl. ebd.; Minato 1998: 688). Im Zuge der politischen Annäherung zwischen Japan und Deutschland ist die japanische Seite bemüht, den Deutschen das Bild eines modernen Industriestaates zu vermitteln, der gleichwohl fest in seinen Traditionen wurzelt. 1937 erscheint in Deutschland der Bildband Groß-Japan. Dai Nippon, fotografiert von Natori Younosuke (Natori 1942). Die Sichtweise des Bandes unterscheidet sich nachhaltig von der Fritz Henles (vgl. Henle 1937). Dennoch beeinflussen die Fotografien des modernen Japan die europäische Sicht kaum.

Das visuelle Japanbild speist sich jedoch nicht ausschließlich aus den westlichen, vorwiegend romantisierenden Darstellungen Japans. Sowohl Kunsthandwerk als auch japanische Kunstwerke tragen in Europa zur visuellen Vorstellung Japans bei. Im Europa des siebzehnten und achtzehnten Jahrhunderts werden vorwiegend Lackarbeiten und Porzellan importiert. Allerdings handelt es sich oftmals um Waren, die nach Bestellung in Japan angefertigt werden und »demnach ihrerseits von westlichem Geschmack beeinflußt « sind (Impey 1993: 148). Japanische Lack- und Porzellanarbeiten können zu dieser Zeit in Europa noch nicht hergestellt werden, sie werden jedoch mit alternativen Verfahren nachgeahmt. Ab 1720 wird in Meißen die Porzellanproduktion aufgenommen, die Muster sind japanischen und chinesischen Vorbildern entlehnt (vgl. ebd.: 160ff.). Ebenfalls im siebzehnten und achtzehnten Jahrhundert ist man von japanischen Kimonos begeistert, was zu einer regelrechten Modewelle führt. Das Besitzbürgertum, aber auch Studenten beginnen damit, so genannte Japonsche Röcke zu tragen, die die Holländer teilweise preiswert in Indien fertigen lassen (vgl. Kreiner 1993: 19). Es etabliert sich in Europa eine erste visuelle Vorstellung von japanischem Kunsthandwerk, die in die europäische kunsthandwerkliche Produktion einfließt und entsprechend europäisiert wird.

Die Modewelle des Japonismus wird im neunzehnten Jahrhundert vorwiegend durch die Entdeckung japanischer Holzschnitte (ukiyo-e) ausgelöst. Europäische Künstler, Kunstkritiker, Kunsthändler, Sammler und Schriftsteller sorgen ausgehend vom Paris der 1860er Jahre für ihre Verbreitung. Der Japonismus ist als »eine weitere Ausdrucksform des romantischen Eskapismus zu begreifen « und drückt kein wirklich tief greifendes Interesse, »sondern eine in der Tradition der Romantik stehende, eher oberflächliche Begeisterung für japanische Kunst« aus (Budde 1993a: 165). Die Ukiyo-eHolzschnitte des japanischen Meisters Hokusai Katsushika (1760-1849) aus dem fünfzehnbändigen enzyklopädischen Skizzenbuch Hokusai manga, die alle Aspekte des japanischen Lebens darstellen, prägen $»$ mehr als alle anderen japanischen Bücher oder europäischen Reiseberichte das Bild Japans in 
Europa, insbesondere in Bezug auf die visuelle Vorstellung « (Fleischmann 1999: 165; vgl. Budde 1993a: 165). In Japan selbst wird den Farbholzschnitten kein hoher Wert beigemessen, sie gelten als unterhaltsame alltägliche Darstellungen und sind in jeder Buchhandlung erhältlich.

»Mit ukiyo wird die fließende, die vergängliche Welt der heiteren, modischen Vergnügungen bezeichnet, $e$ bedeutet Bild. Diese Darstellungen des städtischen Vergnügungslebens wie Theater, Ringkämpfe, Feste, Prostitution, des Alltagslebens aber auch der japanischen Landschaft [werden] preiswert gehandelt und [können] billig erworben werden« (Budde 1993b: 425; Hervorhebung im Original).

Die Ukiyo-e-Holzschnitte des neunzehnten Jahrhunderts sind bereits von der europäischen Malerei beeinflusst. Japanische Maler und Holzschneider hatten sich im achtzehnten Jahrhundert insbesondere die Techniken der perspektivischen Gestaltung von den Holländern angeeignet (vgl. Shin'ichi 2003: 46). In den neu entdeckten japanischen Holzschnitten findet sich dementsprechend in Europa Vertrautes wieder. In der Rezeption der Holzschnitte bleibt der Schock des ganz Fremdartigen aus. Die Holzschnitte sind »nicht fremd genug, um unverständlich zu sein, doch hinreichend unvertraut, um angenehme Reize auszuüben« (Wilkinson 1982: 38). Die Japanmode beeinflusst nachhaltig die europäische Kunst. Modelle werden in Kimonos gekleidet und Interieurs mit japanischen Requisiten wie Fächern, Wandschirmen und Holzschnitten ausgestattet (vgl. Budde 1993b: 426). ${ }^{26}$

Alte, in Japan wertgeschätzte Kunstwerke unterliegen im Gegensatz zu Ukiyo-e-Holzschnitten besonderen Exportbeschränkungen. Sie befinden sich vorwiegend in Klöstern und in feudalem Privatbesitz und sind in Europa nur wenig bekannt. Oftmals werden sie nur in unzureichenden fotografischen Darstellungen übermittelt. Die Farbholzschnitte repräsentieren insofern nur einen sehr begrenzten Ausschnitt des japanischen Kunstschaffens, werden in Europa jedoch als repräsentativ für die japanische Kunst schlechthin rezipiert. »Die Ukiyo-e-Farbholzschnitte, die ja das eigentliche Wesen der japanischen Malerei verleugnen, können nicht als repräsentativ für die Genremalerei oder gar für die japanische Malerei als Ganzes gesehen werden« (Shin'ichi 2003: 48). Der deutsche Künstler Emil Orlik, der sich auf einer Japanreise in den Jahren 1900/1901 ausführlich mit der japanischen Kunst beschäftigt, beklagt deshalb die seiner Meinung nach völlig fehlerhafte Interpretation japanischer Kunstwerke (vgl. Rumpf 1990: 185f.). Budde verweist jedoch darauf, dass der Erfolg der Ukiyo-e-Holzschnitte auch mit der geschmacklichen Parallelentwicklung des französischen und japanischen Bürgertums in Zusammenhang gebracht werden kann, da in beiden Ländern das Bedürfnis nach einer Demokratisierung der Kunst in Form von Druckgrafik und Fotografie sehr hoch ist (vgl. Budde 1993a: 164).

Das fehlende Wissen um die traditionellen japanischen Kunstformen kann auch im Zusammenhang mit der japanischen Präsentationspraxis von Kunstwerken in Europa gesehen werden. Seit 1862 nimmt Japan an den Weltausstellungen teil, zeigt jedoch meist »dem europäischen Markt zuliebe die Verschmelzungsfähigkeit [seiner] eigenen künstlerischen Traditionen und europäischer Formelemente« (Baumuk 1993: 48). Die Auswahl der Holz-

26 Delank 1996 beschäftigt sich mit dem japanischen Einfluss auf die Kunst im deutschsprachigen Raum. 
schnitte für die Ausstellungen geschieht oftmals nicht aus künstlerischen, sondern aus ethnografischen Gesichtspunkten. 1867 werden beispielsweise Stadtansichten von Tokyo und Darstellungen von Frauen der verschiedenen Bevölkerungsschichten eigens für die Weltausstellung geschaffen (vgl. Budde 1993a: 174). Japanische Ausstellungen, die auf die Präsentation der populären Holzschnitte verzichten, sind für die Europäer eine Enttäuschung, denn sie haben sich an diese Formensprache gewöhnt. Auf der Pariser Weltausstellung im Jahr 1900 zeigt Japan erstmalig Kunstgegenstände der japanischen Tradition vom sechsten bis zum achtzehnten Jahrhundert. Dies löst Ratlosigkeit und Erstaunen aus »vor einer Kunst von erhabener Fremdheit, die eher hilflos europäischen Vergleichsmustern zugeordnet« wird (Baumuk 1993: 48). Zudem zeigt sich das Publikum enttäuscht darüber, dass es nicht mit den gewohnten, »dem europäischen Geschmack schmeichelnden Bijouterien« verwöhnt wird (ebd.). Die visuelle Vorstellung Japans und der japanischen Kunst ist zu dieser Zeit bereits so nachhaltig geprägt, dass die visuellen Klischees fest verankert sind. Es besteht kein Interesse an einer Modifikation der lieb gewonnenen Gewohnheiten. Die Wahrnehmung der wirklich fremden Aspekte der japanischen Kunst setzt eine intensive Auseinandersetzung mit der japanischen Kulturgeschichte voraus. Das europäische Japanbild ist zu diesem Zeitpunkt jedoch so fest gefügt, dass es kaum Änderungen zulässt.

Die visuellen Vorstellungen von Japan haben sich in den letzten 100 Jahren selbstverständlich erweitert. Dennoch kann man davon sprechen, dass sich gewisse visuelle Standards herausgebildet haben. »Die Goldzahn-Oma, die Wachs-Menüattrappen vor den Restaurants, die Reihen tiefgekühlter Thunfische in Tsukiji, dem Tokyoter Fischmarkt, oder die Love-Hotels gehören zum Grundrepertoire des Bildberichts, « schreibt Hijiya-Kirschnereit 1988 (Hijiya-Kirschnereit 1988: 147). Die Shibuya-Kreuzung in Tokyo steht für die technologische Fortschrittlichkeit Japans wie für die drangvolle Enge, die in ganz Tokyo zu jeder Tages- und Nachtzeit zu herrschen scheint. Gruppen von Mädchen in Schuluniformen gehören heute ebenso zum visuellen Klischee von Japan wie blühende Kirschbäume, der Shinkansen-Hochgeschwindigkeitszug, Anzug tragende sowie schlafende Angestellte in der U-Bahn und die postmoderne Architektur zahlreicher seit den 1990er Jahren gebauter Hochhäuser in der Tokyoter Metropolenregion. Diese Bilder tragen dazu bei, die Japaner als wenig individualisierte, gruppenkonforme und fleißige Arbeiter zu zeigen, die Japan zu einem hoch technisierten, aber dennoch den Traditionen verbundenen Land machen. Abbildungen von abenteuerlich gestylten Jugendlichen im Tokyoter Stadtteil Harajuku verweisen auf gesellschaftliche Veränderungen und Elemente von Unangepasstheit, die in der zeitgenössischen japanischen Gesellschaft ebenfalls wie selbstverständlich dazugehören. Ein Verweis auf die ausgeprägten jugendlichen Subkulturen Japans gehört demzufolge gleichermaßen zum Klischee.

Alle oben erwähnten Aspekte sind jedoch auch Teile der japanischen Kultur. Die Zelebrierung der Kirschblüte, die Verehrung des Fuji, die Vorgehensweise bei der Stadtentwicklung, die zu sehr unterschiedlichen Architekturen in unmittelbarer Nachbarschaft führt, sind ebenso wie bestimmte Arten sich zu kleiden und sich zu verhalten prägende Elemente der japanischen Gesellschaft. Was diese Bildelemente zum Klischee werden lässt, sind Absolutheit und geringe Varianz im Auftreten. Erst die unendliche Wiederholung immergleicher Bildmotive lässt sie abgedroschen wirken. In solchen fotografischen Abbildungen wird Japan als das Andere und Differente konstruiert. 
Die Bildproduktion leistet ebenso wie Beschreibungen und Berichte einen Beitrag zur Vorstellung einer fremden Kultur und trägt in der Etablierung visueller Klischees konstant zur Stereotypenbildung bei. Bilder können jedoch neue und andere Aspekte vermitteln und damit zur Veränderung oder Dekonstruktion stereotyper Vorstellungen beitragen. Die zeitgenössische Bildproduktion zum Thema Japan ist breit gefächert, auch japanische Fotografie, japanischer Film und japanische Kunst tragen heute zur Ausdifferenzierung der visuellen Japanklischees bei und ermöglichen neue Sichtweisen. Eine differenzierte Erörterung der europäischen Auseinandersetzung mit Japan mittels der Fotografie folgt in den nächsten Kapiteln.

\section{Zusammenfassung:}

In der Betrachtung Japans aus europäischer Perspektive dient Europa als Bezugsrahmen. Dies führt oftmals dazu, dass mehr kulturelle Differenzen als Ähnlichkeiten wahrgenommen und untersucht werden. Europa kann auf eine lange Tradition des Kontakts mit Japan zurückblicken, das im sechzehnten Jahrhundert erstmalig von Europäern betreten wird. Japan wikt im Grad der Zivilisation Europa ähnlich, weshalb es sehr positiv bewertet wird. Allerdings herrscht ein Bild des Auf-den-Kopf-gestellt-seins vor, da in Japan vieles gegensätzlich scheint. Christenverfolgungen und die darauf folgende 250jährige Abschließung lassen das europäische Japanbild ins Negative umschlagen, ein Phänomen, das entsprechend der politischen Entwicklungen zwischen den Weltgegenden immer wieder zu beobachten ist. Die Wahrnehmung Japans changiert zwischen der Annahme, Japan sei absolut unlogisch und unverständlich und der Vorstellung, Ähnlichkeiten von Charakter und Landschaft ließen sich bis ins Detail finden. Nach der Öffnung Mitte des neunzehnten Jahrhunderts vollzieht Japan eine rasche Modernisierung, die westliche Kritik und Enttäuschung am Verschwinden der japanischen Exotik laut werden lässt. Bewunderung und Kritik halten sich jedoch die Waage. Ehrgeiz und Fleiß werden gelobt, während das Nebeneinander von Tradition und Moderne Missbilligung erfährt. Expansionistische Tendenzen lösen schließlich die Angst vor der Gelben Gefahr aus. Der Militarismus während des Zweiten Weltkrieges stößt auf großes Unverständnis, die wirtschaftliche Entwicklung nach Kriegsende lässt jedoch abermals die europäische Wahrnehmung Japans ins Positive umschlagen.

Unveränderlichkeit und Beharrlichkeit der Vorstellungen über Japan deuten auf vorhandene Stereotypen hin, wobei auch Japan selbst an der Stilisierung und Mystifizierung der eigenen Nation mitarbeitet. Eine Unterscheidung von Auto- und Heterostereotyp ist dementsprechend kaum möglich. Zentrale Themen des japanischen Stereotyps sind die Gruppenorientierung und die Ausrichtung an gesellschaftlichen Normen, die im Gegensatz zum Individualismus der westlichen Gesellschaft gesehen werden. Obwohl nicht erwiesen ist, dass Stereotype einen wahren Kern haben, werden Studien durchgeführt, sie anhand der Entwicklung der zeitgenössischen japanischen Gesellschaft zu widerlegen. Im Zeitalter der Globalisierung kann von einer traditionellen Ausrichtung der japanischen Gesellschaft nicht mehr pauschal gesprochen werden. Die Stereotype manifestieren sich ebenfalls in visuellen Klischees, die durch stetige Wiederholung einen Kanon der visuellen Darstellungen Japans gebildet haben. 


\section{WANN IST FOTOGRAFIE DOKUMENTARISCH?}

»Dokumentarfotografie ist ein Begriff, der sich seit seiner Einführung in den 1930er Jahren jeglicher Definition widersetzt hat « (Newhall 1984b: 1; Hervorhebung im Original). Er benennt ein weites Spektrum sowohl in angewandten als auch in künstlerischen fotografischen Gebrauchsweisen. Weil die unterschiedlichen dokumentarfotografischen Praktiken auf verschiedene Publikationskontexte zielen und deshalb variable Ansätze aufweisen, ist eine allgemein gültige Begriffsdefinition, die alle Gebrauchsweisen mit einschließt, kaum zu erreichen. ${ }^{1}$

Wegen der Schwierigkeiten einer eindeutigen Definition der Dokumentarfotografie werden in diesem Kapitel einige ihrer grundsätzlichen Parameter aus bildwissenschaftlicher Perspektive untersucht. Auf einer allgemeinen Ebene werden ihr Verhältnis zur Welt sowie Fragen nach ihrem Wahrheitsbezug erörtert. Welchen Ansprüchen und Erwartungen begegnet dokumentarische Fotografie, welchen Themen widmet sie sich? Inwieweit beeinflusst die Intention des Fotografierenden die Wirkung des Bildes? Im Hintergrund dieser Fragestellungen bleibt immer der Verweis auf die fotografischen Möglichkeiten der Darstellung des Fremden.

Seit der Erfindung der Fotografie verweigert sich das Dokumentarische als ein dynamischer Prozess einer stilistischen oder inhaltlichen Festlegung. Insbesondere der künstlerische Einsatz fordert die Grenzen des Dokumentarischen wiederholt heraus und versucht, diese zu verschieben, um zu neuen künstlerischen Ausdrucksformen zu gelangen. Der Begriff Dokumentarfotografie gilt nicht »der Bestimmung einer spezifischen Eigenschaft oder Funktion des Mediums Fotografie, sondern einer spezifischen Motivwahl, einer spezifischen Ästhetik und nicht zuletzt einer spezifischen Haltung des Fotografen« (Holschbach 2004: 23f.). Die größte Herausforderung der Dokumentarfotografie liegt in ihrem problematischen Verhältnis zur Realität begründet und dem von ihr ausgehenden Wirklichkeitsversprechen, dessen Einlösung grundsätzlich in Frage steht. Mit der grundlegenden Diskussion wichtiger Begriffe aus dem Feld der Dokumentarfotografie sollen hier einige Parameter und Probleme des Dokumentarischen benannt werden, die auch für das Ver-

1 Eine umfassende historische Darstellung der Entwicklung der Dokumentarfotografie ist z.B. von Newhall 1984a und Frizot 1998a geleistet worden. Auch Ausstellungskataloge zur Dokumentarfotografie versuchen, sich dem Thema theoretisch anzunähern (vgl. z.B. Schneider/Grebe 2004). Der amerikanische Fotograf Arthur Rothstein bemüht sich um eine kurze und prägnante Definition, was ihm jedoch nicht auf befriedigende Weise gelingt (vgl. Rothstein 1986). Zahlreiche Theoretiker setzen sich kritisch mit den Problemen des Dokumentarischen auseinander (vgl. z.B. Solomon-Godeau 2003; Sekula 2000; Rosler 1999). 
ständnis der im zweiten Teil diskutierten fotografischen Arbeiten von Bedeutung sind.

\subsection{Herleitung des Begriffs}

Bis zum Ende des neunzehnten Jahrhunderts gilt jede Fotografie, die nicht eindeutig als inszeniert erkennbar ist, als dokumentarisch. ${ }^{2}$ Eine zusätzliche Qualifizierung der Fotografie als dokumentarisch hätte in den ersten Jahrzehnten nach ihrer Erfindung als Tautologie gegolten (vgl. Werneburg 1996: 76). Denn jedes Foto scheint ein Dokument im vollen Sinne des Wortes ausgestattet mit einer Art natürlicher Beweiskraft, worauf bereits der Begriff Fotografie verweist. ${ }^{3}$ Definiert sind $>$ Dokumente als $» U r k u n d e$, Schriftstück; Beweis. [...] Die eigentliche Bedeutung von lat. documentum ist >das zur Belehrung über eine Sache bzw. zur Erhellung einer Sache Dienliche«" (vgl. Drosdowski 1989: 132). Ob ein Schriftstück aber der Erhellung einer Sache dienlich sein kann, ist eine Frage der Bewertung. Nicht jedes Schriftstück wird als Beweismittel zugelassen und kann als Beweis dienen. Und auch Urkunden unterliegen einem hoch-formalisierten, hoch-konventionalisierten Verfahren, das allein dem Beglaubigen des Schriftstücks, der Urkunde dient. Diese Prozeduren der Beglaubigung scheinen für Fotografien obsolet: Die fotografische Abbildung ist das Resultat eines physikalisch-chemischen Vorgangs, der direkten Einwirkung des Lichts auf die fotografische Emulsion. So scheint offenbar die Welt sich selbst und von allein auf der fotografischen Schicht einzuschreiben, ohne dass der Mensch als unzuverlässiger Mittler zwischen der Welt und ihrem Abbild steht. Dies unterscheidet das fotografische Bild nicht nur vom gemalten, sondern auch vom Schriftstück, das durch Menschen verfasst wurde, wohingegen als Autoren von Fotografien eher die chemisch-physikalischen Ursache-Wirkungs-Zusammenhänge genannt werden müssten; ein Rest dieser Einschätzung der Fotografie findet sich noch in Roland Barthes Buch Die helle Kammer: »Nichts Geschriebenes kann mir diese Gewißheit geben « (Barthes 1985: 96).

Demnach wäre Dokumentarfotografie »so ziemlich alles, « was mit fotografischen Abbildungen in Zusammenhang steht (Solomon-Godeau 2003: 53). Abigail Solomon-Godeau macht deutlich: Mit solch einem Begriff ist nichts gewonnen, kein einziges spezifisches Problem ist angesprochen. Denn der physikalisch-chemische Vorgang bezieht sich genreunabhängig auf jedes mittels fotografischem Verfahren angefertigte Bild. Diese Einschätzung ändert sich erst mit dem Aufkommen von piktoralistischen Tendenzen am Ende des neunzehnten Jahrhunderts (vgl. Starl 2002: 74). Die Piktoralisten - Alfred Stieglitz ist einer ihrer wichtigsten Vertreter - erheben die Fotografie zur Kunstform. Beispielsweise durch die Verwendung von Drucktechniken wie dem Gummi-, Platin- oder Öldruck brechen sie die fotografische Präzision (vgl. Gautrand 1998b: 300). Der Eingriff durch die Hand des Künstlers im Labor soll der Fotografie eine malerische Komponente verleihen, die die ap-

2 Bereits 1840 entsteht die erste fiktive Fotografie von Hippolyte Bayard (vgl. Frizot 1998b: 30).

3 Der Begriff Fotografie (Photographie) leitet sich etymologisch aus den griechischen Wörtern "phôs (phôtós) >Licht< [...] und gráphein >schreiben, aufzeichnen«" ab (vgl. Drosdowski 1989: 528). 
parative Mechanik durchbricht. Die so genannte Kunstfotografie unterscheidet sich grundsätzlich von den detailscharfen Abbildungen des Naturalismus zur selben Zeit. ${ }^{4}$ Anhand der Richtungen des Naturalismus und Piktoralismus erlebt der Widerstreit zwischen einer sachlichen und einer künstlerischen Fotografie einen Höhepunkt. Eine 1915 publizierte Werbeanzeige für ein »malerisches Objektiv« illustriert diesen Konflikt: »Mit dem Fortschritt der Fotografie haben sich zwei unterschiedliche Bereiche herauskristallisiert. Der eine dient der Realisierung von Dokumenten, der andere der Herstellung von Bildern« (Platinum Print 1915: 16; zit. nach: Bunnell 1998: 316). Mit dem Begriff des Dokuments wird hier auf den Bereich der »wissenschaftlichen« Bildproduktion verwiesen, von der eine detailscharfe Abbildung verlangt werde. Dagegen stehe die künstlerische Anfertigung »echter«, das heißt »deutbarer Bilder« (Bunnell 1998: 316).

Dieser strenge Kontrast zwischen Kunst und Dokument in der Fotografie wird im Rahmen der Einführung des Begriffs documentary unterlaufen. Verbürgt ist das erstmalige Auftreten des Begriffs im Jahr 1926, als der britische Filmkritiker John Grierson vom »documentary value« (zit. nach: Starl 2002: 74) eines Films spricht, um ihn »gegen die schlechte Künstlichkeit der Spielfilme insbesondere Hollywoodscher Herkunft« abzugrenzen (Matz 1981: 8). Griersons Einführung des Begriffs Dokumentarfilm zielt explizit nicht darauf, »die Gesamtheit nicht-fiktionaler Filme abzudecken« (Gunning 1995: 112). Das Genre des nicht-fiktionalen Films, wie es bereits seit den Brüdern Lumière existiert, hat sich zu diesem Zeitpunkt bereits stark ausdifferenziert. Neue Montagetechniken, die in Spielfilmen Anwendung finden, wirken sich auch auf die Produktion nicht-fiktionaler Filme aus, die sich dadurch verändern. Grierson sucht im Begriff documentary diese neue Qualität theoretisch zu erfassen. Der Dokumentarfilm, wie Grierson ihn definiert, unterscheidet sich nachhaltig von früheren Produktionen im nicht-fiktionalen Bereich. Signifikant für den Dokumentarfilm ist der schöpferische Umgang mit dem aufgenommenen Material. Der Dokumentarfilm ist ein $»$ nichtfiktionaler Film realer Orte, Personen und Situationen, " (Sloan 1974: 1162) in dem »das filmische Material neu geordnet wird, also durch Schnitt und Zwischentitel in einen diskursiven Zusammenhang gestellt wird « (Gunning 1995: 118). Grierson hebt besonders die ästhetische Praxis im Dokumentarfilm hervor und plädiert für einen kreativen Umgang mit der Realität (vgl. Sloan 1974: 1163). Grierson sucht die Abgrenzung vom Spielfilm: »(1) Authentische Menschen statt Schauspieler, (2) natürlicher Hintergrund statt Dekorationen, (3) authentische Geschehnisse statt ausgedachter Fabeln, (4) eine soziale Referenz der Interpretation der Wirklichkeit« (Lampe 2002: 69). ${ }^{5}$ Warum ästhetische Praktiken in die fotografischen Medien Film und Fotografie eingeführt werden sollten, erklärt Walter Benjamin mit einem Zitat von Brecht in seiner Studie Kleine Geschichte der Photographie:

$»$ Weniger denn je [sagt] eine einfache Wiedergabe der Realität etwas über die Realität aus [...]. Eine Photographie der Kruppwerke oder der A.E.G. ergibt beinahe

$4 \mathrm{Zu}$ den Facetten der künstlerischen Fotografie am Ende des neunzehnten Jahrhunderts vgl. z.B. Hammond 1998; Bunnell 1998; Newhall 1984: Kap. 9, $145 \mathrm{ff}$.

5 Die Besonderheiten der Dokumentarfilmtheorie in Bezug auf künstlerische und nicht-künstlerische Gebrauchsweisen werden in Teil I, Abschnitt 4.1.1. noch präzisiert. 
nichts über diese Institute. Die eigentliche Realität ist in die Funktionale gerutscht. Die Verdinglichung der menschlichen Beziehungen, also etwa die Fabrik, gibt die letzteren nicht mehr heraus. Es ist also tatsächlich etwas aufzubauen, etwas Künstliches, Gestelltes« (Benjamin 1963: 90f.).

Die bloße Ansicht oder fotografische Abbildung des Fabrikgebäudes gibt zum Beispiel keinen Aufschluss darüber, was dort produziert wird. Um die Funktionalität der Fabrik zu beschreiben, reicht eine dokumentierend abbildende Fotografie nicht aus. Zur Erfassung der »menschlichen Zusammenhänge« sei eine »entlarvende oder konstruierende« fotografische Praxis erforderlich, der es gelingen könne, diskursive Verbindungen herzustellen, ohne in ein fiktionales oder, wie Benjamin auch betont, »kunstgewerbliches« Genre abzugleiten (Benjamin 1963: 90).

So ist es naheliegend, dass der zunächst filmtheoretische Begriff $d o c u$ mentary aufgrund der vergleichbaren Zielsetzungen auch auf einen Teilbereich fotografischer Produktionen übertragen wird. In Deutschland wird Griersons Begriff des documentary erst 1947 mit dem Erscheinen des Buches Grierson und der Dokumentarfilm bekannt (Grierson/Forsyth 1947). ${ }^{6}$ Den als dokumentarisch bezeichneten Positionen wird nachgesagt, sie könnten eine authentische Darstellung der Realität leisten. ${ }^{7}$ Dass diese Annahme grundsätzlich in Frage steht, soll im Folgenden ausführlich diskutiert werden.

\subsection{Grundprobleme der Dokumentarfotografie}

Die Dokumentarfotografie ist in sich kein homogenes Genre, das nach bestimmten Grundparametern funktioniert, die benannt werden können und es ermöglichen, eine dokumentarische Fotografie zweifelsfrei von anderen fotografischen Produktionen zu unterscheiden. So kann Dokumentarfotografie sowohl innerhalb angewandter als auch künstlerischer Ansätze betrieben werden. Gemeinsam ist ihnen zunächst lediglich ein direkter Zugriff auf die Welt, den die Dokumentarfotografie jedoch noch mit anderen Herangehensweisen innerhalb der Fotografiegeschichte teilt. ${ }^{8}$ Solomon-Godeau nennt die Kategorie des Dokumentarischen »schwammig" (Solomon-Godeau 2003: 53). Einige Autoren vermeiden diesen Terminus und sprechen lieber von $D o$ kumentarismus. Allerdings bezieht er sich meist auf den angewandten Gebrauch der Dokumentarfotografie. Er verweist auf eine ideologische Grundkonstellation und betont auf diese Weise den vorgeblichen Beweischarakter des Dokumentarischen. Gerade die Frage nach der Beweiskraft ist jedoch eines der Grundprobleme, die es hier zu diskutieren gilt. Ein Beispiel

6 Griersons Buch wird auf Anraten der alliierten Besatzungsmächte in Deutschland publiziert. Damit gehört es zum Kanon derjenigen Veröffentlichungen, die die kulturelle Grundlage einer erfolgreichen Demokratisierung legen sollen. In diesem Kontext steht Griersons Dokumentarfilm als Antithese zum Propagandafilm.

7 Walter Benjamin spricht von der »Authentizität der Photographie« (Benjamin 1963: 92).

8 Beispielsweise mit der »straight photography« (vgl. dazu Teil I, Abschnitt 4.1). 
hierfür bietet eine Aussage von Roy Stryker, der in den 1930er Jahren die Information Division innerhalb der Farm Security Administration (FSA) leitet. ${ }^{9}$

»Der Dokumentarismus ist eine Form der Annäherung an ein Thema, keine fertige Technik; eine Bejahung und keine Verneinung. [...] Die dokumentarische Haltung verneint nicht die gestalterischen Elemente, die ein wesentlicher Maßstab jeder Arbeit bleiben müssen. Sie setzt diesen Elementen nur bestimmte Grenzen und gibt ihnen eine Richtung. So wird Komposition zur Akzentuierung - und Kontur, Schärfe, Filterung, Stimmung, alle jene Bestandteile, die die verschwommene Vorstellung von `Qualität` ausmachen, werden dem Zweck dienstbar gemacht: so beredt wie möglich von den Dingen zu sprechen, die in der Sprache der Bilder gesagt werden sollen« (Stryker 1974: 1180. Übersetzung ins Deutsche nach: Newhall 1984: 252).

In dieser Aussage von Roy Stryker sind viele Parameter angerissen, die innerhalb der Theorie der Dokumentarfotografie eine Rolle spielen: Es geht um Fragen der Haltung, der Gestaltung und Komposition und um Dinge, über die etwas in Bildern ausgesagt werden soll. Was Stryker jedoch als Grundvoraussetzung unausgesprochen lässt, ist die Frage der Relation zwischen fotografischem Bild und der Welt. Es ist fraglich, ob die implizite Behauptung eines ausgezeichneten Bezugs dokumentaristischer Bilder zur Welt aufrechterhalten werden kann. Anders formuliert: Spricht nicht jede Fotografie aufgrund ihrer fotomechanischen Machart von den Dingen in der Sprache der Bilder?

\subsubsection{Das Verhältnis zwischen Bild und Welt}

Eine der wichtigsten Grundannahmen in Bezug auf die Dokumentarfotografie bezieht sich auf ihr indexikalisches Verhältnis zur Welt: Sie gilt, wie Anne Wilkes Tucker zusammenfasst, schlicht als »Tatsachenreport « (Tucker 1984: 53). Zwar ergeben unterschiedliche Sichtweisen verschiedene Darstellungen der Welt, doch diese möglicherweise deutlichen Unterschiede scheinen absolut zweitrangig gegenüber der »ausgesprochene[n] Affinität zur ungestellten Realität« (ebd.: 45). Diese Unabhängigkeit vom individuellen Standpunkt der Urheber ist als der Realismus der Fotografie angesprochen worden. Einige Autoren weisen darauf hin, dass dieser Realismus »als eine objektive (d.h. subjekt-unabhängige) Darstellungsform« verstanden wird (Sachs-Hombach 2006: 222; vgl. auch Böhme 1999: 112; Jäger 2005: 352). Grund hierfür ist der sozusagen automatische Charakter beziehungsweise, mit einem semiotischen Begriff, die Indexikalität der Fotografie. Das von den fotografierten Objekten reflektierte Licht schreibt sich von selbst in die fotografische Emulsion ein.

9 Im Auftrag der FSA, einer von der US-Regierung 1935 eingerichteten Behörde, dokumentieren zahlreiche Fotografen wie Walker Evans, Dorothea Lange, Ben Shahn die zu diesem Zeitpunkt prekäre Situation der Farmer in den USA. Die Information Division der FSA ist Teil der Rooseveltschen Politik des New Deal, um die Staatsausgaben gegenüber der (urbanen) Bevölkerung zu rechtfertigen. Das Dokumentationsprojekt gilt noch heute als eines der umfassendsten und wichtigsten Projekte einer engagierten Dokumentarfotografie. Die gesamten fotografischen Bestände befinden sich in der Library of Congress in Washington DC, auf deren Website http://www.loc.gov/rr/print/catalog.html umfangreiches Material einsehbar ist. Zur Rolle von Roy Stryker vgl. Hurley 1977. 
Das Resultat gilt als Spur dieses naturgesetzlichen, kausalen Vorgangs. ${ }^{10}$ Nach der Zeichentheorie von Charles Sanders Pierce sind diejenigen Ausdrucksweisen indexikalisch,

»in denen der Signifikant mit dem Referenten nicht durch eine soziale Konvention (Symbol) und auch nicht notwendigerweise durch irgendeine Ähnlichkeit (Ikon), sondern durch Kontiguität und einen tatsächlichen Zusammenhang mit der Welt verbunden ist. (Der Blitz ist der Index des Gewitters.) Foto und Film sind, etwas verkürzt gesagt, solche Indizes, Abdrücke, die durch die Kombination von Lichteinwirkung und Chemie auf einer lichtempfindlichen Oberfläche vom Objekt selbst hinterlassen werden« (Metz 2003: 217).

Wird von der indexikalischen Beziehung zwischen Fotografie und Welt ausgegangen, wären Fotografien stets objektive »Abbilder« (Jäger 2005: 351ff.). $»$ Allerdings sind die Bedingungen des genuinen >Index « nur in jenem Augenblick der Aufnahme erfüllt. Alle Entscheidungen, die der Aufnahme vorausgehen und ihr folgen, unterliegen den Funktionszusammenhängen, in denen die fotografische Aufnahme entsteht« (Braun 2002: 119). Dieser Hinweis auf den Augenblick der indexikalischen Beziehung ist ausgesprochen interessant. Zunächst werden mit den Zusammenhängen, in denen eine Fotografie entsteht, wieder Absicht und Individualität der Urheber der jeweiligen Fotografien und deren Milieu ins Spiel gebracht. Viel grundsätzlicher ist aber noch ein bildtheoretisches Problem angesprochen: Eine Fotografie gibt als Spur das zum Zeitpunkt der Ablichtung sich vor dem Objektiv befindende Objekt sichtbar wieder. Nur insofern es dies tut, ist es Bild, fotografisches Abbild. Demgegenüber ist der Rauch als Index des Feuers keine bildliche Wiedergabe des Feuers, der Blitz kein Abbild des Gewitters. Sichtbar werden weder Feuer noch Gewitter, sichtbar sind allein Rauch und Blitz.

In seinem Lexikonbeitrag fasst Peter Braun die semiotische Antwort auf die Frage, wie der fotografische Abdruck zum Bild wird, wie folgt zusammen: Die fotografische Aufnahme »ist eingebunden in die verschiedensten diskursiven Praktiken und folgt ihren Regeln, Normen und Deutungsmustern, d.h. der grundlegende indexikalische Charakter des fotografischen Bildes wird von ikonischen und symbolischen Prozeduren überlagert bzw. dahin überführt« (Braun 2002: 119). Damit ist zunächst gesagt, dass das kausale Anzeichen in ein Zeichen im vollen Sinne des Wortes »überführt« wird. ${ }^{11}$ Zeichen sind Elemente in Diskursen und verweisen in diesen Diskursen auf Gegenstände, von denen die Diskurse handeln. Anzeichen können nicht zu solchen Elementen werden, sie bleiben immer Gegenstand. Zeichen sind Instrumente der diskursiven Praktiken. Nach den verschiedenen semiotischen Theorien sind Bilder nur dann Bilder, wenn sie als verweisende Elemente eines Diskurses gebraucht werden. Es gibt ein breites Spektrum der Erklärungen, wie

10 Während Anzeichen wie Blitz oder Rauch Anzeige eines gleichzeitigen Prozesses sind, ist die Fotografie Anzeige eines vergangenen Ereignisses.

11 Der Unterschied zwischen Anzeichen und Zeichen ist nicht trivial: Wenn auf dem Monitorbild der Überwachungskamera - »dem Nullpunkt der Kamera als visuellem Aufzeichnungsgerät« (Solomon-Godeau 2003: 53) - ein Feuer zu sehen ist, dann brennt es. Wenn hingegen vor dem Fenster Rauch zu sehen ist, zeigt der Rauch - als Index - an, dass es brennen könnte. Es wäre aber auch eine andere Quelle möglich. 
Bilder, zunächst meist flächige materielle Gegenstände, zu Bildern werden; sie reichen von ikonisch-perzeptuellen bis hin zu rein symbolischen, beinahe schon linguistischen Ansätzen. Klaus Sachs-Hombach spricht von Bildern als »wahrnehmungsnahe Zeichen« (vgl. Sachs-Hombach 2006: 73). ${ }^{12}$ Eine Gegenposition dazu nimmt Nelson Goodman ein, der zwischen sprachlichen Zeichen und Bildzeichen allenfalls einen graduellen Unterschied erkennt. ${ }^{13}$ Der zentrale Aspekt des Zeichens besteht in seiner Verweisfunktion. Goodman nennt dies Denotation (vgl. Goodman 1995: 15ff.).

Der Hinweis auf den funktionalen Charakter von Bildern im Allgemeinen und fotografischen Bildern im Besonderen trifft vor allem den Begriff der Ähnlichkeit. Während Pierce das ikonische Zeichen noch mit Hilfe einer Ähnlichkeitsbeziehung definiert, setzt Goodman symbolische und ikonische Zeichen gleich, so dass Ähnlichkeit für die Bezugnahme gerade nicht mehr entscheidend ist (vgl. Wiesing 2005: 26; Goodman 1995: 17). ${ }^{14}$ Goodman erreicht damit zweierlei: Derart gelingt es ihm einerseits, ebenso abstrakte Bilder in seine Theorie der Denotation mit einzubeziehen, wie auch solche gegenständlichen Bilder, die auf fiktive Gegenstände verweisen, beispielsweise auf Einhörner (vgl. Goodman 1995: 31ff.). Andererseits macht er mit dem Hinweis auf den Gebrauchszusammenhang der Denotation deutlich, dass der Bezug eines Bildes auf die Welt keine Eigenschaft des Bildes selbst ist. ${ }^{15}$ Obwohl also für eine semiotische Theorie kein funktionaler Unterschied zwischen einem Bild und jeder anderen Art von Zeichen besteht - alle werden zur Denotation gebraucht -, hält selbst ein strenger sprachanalytischer Ansatz wie der Goodmans Bilder und beispielsweise Schriftzeichen für unterschiedliche Symboltypen. Die Aussage schriftlicher Symbole nennt er »Beschreibung«, die der Bilder »Repräsentation« (vgl. Goodman 1995: 48). Insofern kann der Gebrauch des Begriffs Ikon für Bilder weiterhin beibehalten werden: Ein Ikon ist ein Bildzeichen, das sich nicht auf der funktionalen, aber auf der phänomenalen Ebene von einem Schriftzeichen unterscheidet. ${ }^{16}$

$\mathrm{Zu}$ Beginn des Abschnitts war vom Realismus der Fotografie die Rede. Mit dem Hinweis auf den Zeichencharakter der Fotografie als Bild, als Ikon, ist dieser vermeintlich »objektive« Realismus stark in Frage gestellt. Fotogra-

12 »Semiotische Bildtheorien unterstellen eine enge Verbindung zwischen dem Bildbegriff und dem Zeichenbegriff. Bilder sind danach spezielle Zeichen. An solchen Theorien wird in der Regel kritisiert, dass sie die Eigenarten der Bilder vernachlässigen, weil sie sich zu sehr an sprachwissenschftlichen Modellen orientieren. Zuweilen wird auch generell der Zeichenstatus von Bildern in Frage gestellt. Beides beruht auf Missverständnissen« (vgl. Sachs-Hombach 2006: 77).

13 »Es geht mir um einen Ansatz zu einer allgemeinen Symboltheorie. >Symbol wird hier als sehr allgemeiner und farbloser Ausdruck gebraucht. Er umfaßt Buchstaben, Wörter, Texte, Bilder, Diagramme, Karten, Modelle und mehr« (Goodman 1995: 9; vgl. auch Wiesing 2005: 26).

14 Eine Kritik des Ähnlichkeitsbegriffs leistet Rehkämper 2005: 243f.

15 Hans Jonas kommt einer solchen Eigenschaftstheorie des Bildes schon sehr nah: $»$ An erster Stelle steht die Eigenschaft der Ähnlichkeit. Ein Bild ist ein Ding, das eine unmittelbare oder jederzeit auf Wunsch erkennbare Ähnlichkeit mit einem anderen Ding zeigt.« Im nächsten Satz spricht er allerdings vom »absichtlich hervorgebrachten« Charakter der Bilder. Damit spielt auch er auf eine Gebrauchstheorie an (Jonas 2001: 107).

16 Das Ikon beschreibt Sachs-Hombach als »bildhaftes Zeichen, wenn wir auf das bezeichnete Objekt anhand von Eigenschaften des Zeichens bzw. des Zeichenträgers schließen« (Sachs-Hombach 2006: 42). 
fien scheinen sich weder von anderen Bildtypen, noch von irgendwelchen Zeichen zu unterscheiden: Es bedarf bestimmter Regelkenntnisse und Kompetenzen, das jeweilige Denotationsziel zu erkennen. Andererseits zeichnet eben das fotografische Ikon die indexikalisch genannte Aufnahmesituation aus. Diese Beobachtung führt häufig zu einer beinah paradoxen Charakterisierung des fotografischen Bildes: Obwohl Eigenschaften des physischen Bildträgers keine Rolle für seine Funktion (Denotation) spielen, scheint die Eigenschaft »kausal verursacht« doch ein gewichtige Rolle für die Denotation des Fotos zu spielen: »Der Aspekt der Indexikalität wirkt hier gewissermaßen als Beglaubigung der ikonischen Darstellung« (Sachs-Hombach 2006: 223). Die Aufnahmesituation verbürgt doch offenbar, dass das Abgebildete kein fiktiver Gegenstand sein kann. ${ }^{17}$ Eben daraus $\gg$ ergibt sich der (zumindest während ihrer frühen Entstehungsgeschichte oft erhobene) Objektivitätsanspruch der Fotografie« (Sachs-Hombach 2006: 223). Jedoch wurde oben angeführt, dass das chemisch-physikalische Produkt der Aufnahmesituation erst »überführt« werden muss in die diskursiven Praktiken des Zeichengebrauchs, um selbst ein Zeichen zu sein.

Die Auswirkungen dieser Überführung (kausaler Anzeichen in arbiträre Zeichen) auf den Objektivitätsanspruch des indexikalischen Ikons der Fotografie verdeutlicht der Kunsthistoriker John Tagg am Beispiel vor Gericht als Hauptbeweismittel herangezogener Fotografien. Die Annahme eines subjektunabhängigen Realismus sowie die begriffliche Nähe zum Dokument suggerieren, dass Fotografie in der Lage ist, Dokumente zu erzeugen, die zur Erhellung einer Sache dienlich sind. ${ }^{18} \mathrm{Um}$ zu einem Dokument im Sinne eines Beweises zu werden, muss eine Fotografie gewisse Voraussetzungen erfüllen. John Tagg erläutert diese Parameter anhand von Zitaten aus zwei Werken zur Polizei- und Gerichtsfotografie (vgl. Ehrlich 1967; Pountney 1971): Zunächst müsse der Gegenstand/das Ereignis in einer »neutralen und geradlinigen Weise« gezeigt sein (Ehrlich 1967: 10; zit. nach Tagg 1988: 97). Korrekte Belichtung und Schärfe seien ebenso selbstverständliche Voraussetzungen wie der Verzicht auf Retusche oder das Beschneiden des Formats zur Erzeugung dramatischer Effekte. Ungewöhnliche Kamerastandpunkte seien $\mathrm{zu}$ vermeiden, das Ergebnis solle professionell, aber nicht ästhetisiert aussehen, um vor Gericht Glaubwürdigkeit zu erlangen. Jegliche Ablenkungen vom eigentlich Wichtigen seien zu vermeiden, die Zusammenhänge der Gegebenheiten sinnfällig in einzelnen Bildern oder Bildfolgen darzulegen. Doch all diese fotografischen Voraussetzungen reichen nicht aus. Gleichzeitig müsse der Fotograf unter Eid Zeit und Datum der Aufnahme nennen können und bestätigen, dass er die Abzüge selbstständig hergestellt habe. Fehlende Manipulation sei anhand der Vorlage der Negative nachzuweisen. Hat der Fotograf die Vergrößerungen nicht selbst hergestellt, müsse der Techniker eine beeidete Erklärung abgeben oder gegebenenfalls als Zeuge vor Gericht

17 Die Fotografie eines Einhorns, wenn sie mit analogen Mitteln hergestellt worden ist, zeigt also einen Gegenstand, der im Moment der Aufnahme tatsächlich die Form eines Einhorns besessen hat. Das fotografische Bild kann jedoch sehr wohl fiktiv sein, nämlich wenn es beispielsweise durch Retusche oder digitale Manipulationen verändert worden ist. Auch auf diese Weise kann eine Fotografie auf fiktive Gegenstände verweisen (vgl. dazu Abschnitt 3.2.3.).

18 Der Begriff Erhellung ist im fotografischen Kontext besonders interessant (vgl. den Beitrag von Inka Schube in: Peters 2001). 
erscheinen, um die lückenlose Kette des Besitzes des Filmmaterials zu dokumentieren. Erst dann seien Vergrößerungen und Negative als Beweisstücke vor Gericht zulässig (vgl. Tagg 1988: 97f.). So sehr aus den zitierten Texten hervorgeht, dass es grundsätzlich möglich sei, mit Fotografien etwas zu beweisen, verdeutlicht die aufwändige Prozedur bis zur Zulassung als Beweis, dass eine »objektive« Repräsentation der Welt allein mit fotografischen Mitteln nicht zu erreichen ist. Ohne beeidete Aussage des Fotografen beweist eine Fotografie nichts, sie bleibt Anzeichen, Indiz, Hilfsbeweis (vgl. SachsHombach 2006: 223). Dieser enorm kontextualisierende Apparat wird überdies mit den zunehmenden Möglichkeiten der Manipulation stetig erweitert.

Dies führt zurück zum Fotografierenden, der eng mit dem Abgebildeten verwoben ist. Er hat nicht nur gesehen, was sich im Augenblick der Aufnahme vor der Kamera befunden hat, sondern auch das, was außerhalb des gewählten Ausschnitts der zweidimensionalen Fotografie sichtbar war. Neben den visuellen Parametern, die sich zum Zeitpunkt der Aufnahme im Blickfeld befinden, ist er auch anderen sinnlichen Gegebenheiten ausgesetzt wie beispielsweise Geräuschen oder Gerüchen. Insofern wird er vor Gericht zum Zeugen, der die fotografische Aufnahme in einem räumlichen und zeitlichen Zusammenhang verortet. Als seine beeidete Aussage gilt die von ihm aufgenommene Fotografie.

Anders formuliert: Weil eine Fotografie immer einen zeitlichen, räumlichen und sinnlichen Ausschnitt zeigt, der Gegenstände in bloßer Sichtbarkeit fixiert, kann nicht von einer realitätsgetreuen Wiedergabe der Welt gesprochen werden. Die Aussage der Fotografie als Beweis kann also nicht als ein 〉Es ist so und nicht anders gewesen! muss sagen: >Ich habe die Welt so gesehen,২ oder auch: `So möchte ich die Welt zeigen. $<$ Dies gilt sowohl für die Fotografie allgemein als auch für dokumentarfotografische Abbildungen, auf die im anschließenden Kapitel weiter eingegangen wird. Die Entscheidung darüber, welcher Ausschnitt von Welt im Rahmen der Fotografie festgehalten wird, trifft der Fotograf. Im Bild manifestiert sich immer seine Sichtweise.

Bei der zeichenhaften Verwendung eines fotografischen Dokuments als Verweis bzw. Denotation auf die Welt handelt es sich um eine Gebrauchsweise. Allgemein erfüllen Fotografien keine Beweisfunktion, sie können jedoch mit allen genannten Einschränkungen dazu verwendet werden. Der Zeichengebrauch lässt die Fotografie sozusagen transparent werden: In der beispielhaften Nutzung vor Gericht geht es einzig und allein um das Abgebildete, auf das die Fotografie verweist. Die Machart des Bildes muss mit den vorgegebenen Normen übereinstimmen, dann tritt das Bild als Bild zurück und das Abgebildete erhält die gesamte Aufmerksamkeit.

»Das Zeichen scheint transparent zu werden, so dass das [vorab etablierte] Konzept [der Wahrheit] scheinbar sich selbst präsentiert und das arbiträre Zeichen von einer unberechtigten Gleichheit zwischen Referenz und Referenten, Text und Welt, vereinnahmt wird. Realismus ist eine soziale Praxis der Repräsentation, eine allumfassende Form der diskursiven Produktion, eine Normalität, die eine strikt begrenzte Spanne an Variationen zulässt« (Tagg 1988: 99).

Eine Fotografie kann auch als zugelassener Beweis dementsprechend nur etwas bestätigen, was einem vorab etablierten Konzept von Wahrheit entspricht. Sie ist in ihrem Bezug zur Wirklichkeit nicht nur aufgrund der Be- 
schaffenheit des Mediums, sondern auch aufgrund der Rezeptionsweisen extrem eingeschränkt. Weder Indexikalität noch Ikonizität machen aus einer Fotografie ein Dokument im Sinne eines Beweises, Realismus ist im Prinzip nicht möglich. Zwar legt der kausale Zusammenhang zwischen dem Moment der Aufnahme und dem fotografischen Ergebnis eine dokumentarische Gebrauchsweise nahe, doch die »indexikalische Rekonstruktion des Referenten« der Fotografie ist »irrtumsanfällig, « die Referenz ist unsicher (SachsHombach 2006: 226).

Die Realität, die dokumentarische Fotografie abbildet, existiert unabhängig von ihrer Aufzeichnung. Innerhalb des fotografischen Prozesses wird sie auf bloße Sichtbarkeit reduziert. Andere sinnliche Aspekte wie Materialität der Objekte, Gerüche oder Geräusche finden in der fotografischen Aufnahme keinen Niederschlag. Während aber in der Realität unendliche Wahrnehmungsmöglichkeiten gegeben sind, kann die Fotografie nur eine Sichtweise zeigen. Andererseits gilt diese Einschränkung auf den Sehsinn einigen Autoren, die einen wahrnehmungstheoretischen Ansatz der Bildwissenschaft verfolgen, überhaupt als Ursprung von Bildwahrnehmung. Die Wahrnehmung trifft auf ein Wahrnehmungsobjekt, das irritiert und herausfordert, da es in einigen Aspekten unbestimmt ist (vgl. Huber 2004: 26ff.; Wiesing 2000: 48ff.). ${ }^{19}$ Die Grundidee hierzu stammt von Husserl, dieser spricht von einer »doppelten Gegenständlichkeit« (Husserl 2006: 27f.). Husserl unterscheidet zwischen dem »physischen Bild « (Bildträger) und dem sichtbaren »Bildobjekt $\ll{ }^{20}$ Es komme daher zu Irritationen in der Perzeption der Betrachter, die die Dingwahrnehmung zumeist nicht auslöse. In Anschluss an Husserl könnte man durchaus von einem ästhetischen »Mehr« von Bildern sprechen. Dementsprechend erzeugten sie eine eigene - neue - Bildwirklichkeit (vgl. Böhme 1999: 95). Gernot Böhme formuliert: »Das Foto zeigt die Realität von etwas unter Einschränkung seiner Möglichkeiten [Realität] und Steigerung seiner Wirklichkeit [Foto] « (Böhme 1999: 127). In diesem Sinne spricht er von »gesteigerter Sichtbarkeit« (ebd.). Auch Reinhard Matz schreibt in seinem grundlegenden Artikel zur Dokumentarfotografie, dass Fotografien lediglich »Sichtweisen der Wirklichkeit und niemals diese selbst« liefern (Matz 1981: 9). »Daher ist eine radikale Trennung zwischen der Ordnung der Gegenstände einerseits und der von ihnen gemachten Fotografien andererseits zu vollziehen« (ebd.). Die Unterscheidung zwischen den beiden Welten vertritt ein wahrnehmungstheoretischer oder phänomenologischer Ansatz der Bildtheorie (vgl. z.B. Wiesing 2005). Im Gegensatz zur semiotischen Bildtheorie sieht er die primäre Ebene von Bildern nicht in ihrer Zeichenfunktion. Im phänomenologischen Ansatz besitzt das im Bild sichtbare Objekt eine eigenständige Wirklichkeit. ${ }^{21}$ Es unterliegt keinen physikalischen Gesetzmäßigkeiten

19 Huber und Wiesing beziehen sich auf Edmund Husserl. Eine hier relevante Stelle lautet: »Die Erscheinung des Bildobjekts unterscheidet sich in einem Punkt von der normalen Wahrnehmungserscheinung, [...] der es uns unmöglich macht, sie als normale Wahrnehmung anzusehen: Sie trägt in sich den Charakter der Unwirklichkeit, des Widerstreits mit der aktuellen Gegenwart« (Husserl 2006: 49).

20 Als drittes kommt noch das »Bildsujet« hinzu, was dem Motiv entspricht (vgl. Husserl 2006: 21).

21 Während sich ein Gegenstand in der Welt »nach den Gesetzen der Physik verhält, was wiederum bedeutet, daß er physisch auf den menschlichen Körper einwirken kann, « ist ein Bildobjekt nur sichtbar (Wiesing 2005: 31). 
(beispielsweise kann es nicht altern) und seine »artifizielle Präsenz« besteht in bloßer Sichtbarkeit (Wiesing 2005: 32).

Auch wenn sich die beiden bildtheoretischen Ansätze grundlegend voneinander unterscheiden, erreichen sie in dem Punkt Einigkeit, dass eine realitätsnahe Wiedergabe der Welt in der fotografischen Abbildung prinzipiell nicht möglich ist.

\subsubsection{Fotografie und Wahrheit}

Wenn es keinen »objektiven« Realismus der Fotografie gibt, können Fotografien dann wahr oder authentisch sein? Die grundsätzliche Skepsis gegenüber einem Glauben an die Möglichkeit von Realismus ist auch als die »Krise der Repräsentation« bezeichnet worden. ${ }^{22}$ Der Glaube an die Möglichkeit der Fotografie, Sachverhalte glaubhaft und wahrhaftig darzustellen, existiert jedoch seit ihrer Erfindung. Insbesondere in den alltäglichen Gebrauchsweisen des Schnappschusses oder des Familienbildes tritt das Medium in seiner Bedingtheit in den Hintergrund, die Fotografien scheinen unvermittelt und authentisch, "weil das Wirklichkeitsversprechen der Fotografie $z u$ verlockend erscheint « (Wortmann 2004: 11; Hervorhebung B.L.). Auch Roland Barthes erliegt dieser Verlockung. In alten Fotografien sucht er nach der »Wahrheit des Gesichts « seiner verstorbenen Mutter und entdeckt sie auch (Barthes 1985: 77). In einer Kinderfotografie sieht er »sämtliche mögliche Prädikate [...] vereint, aus denen das Wesen meiner Mutter bestand und die umgekehrt auf den Photos von ihr, auf denen mir etwas fehlte, ausgelassen oder teilweise verändert worden waren« (Barthes 1985: 80). Indem er in einem Bild seiner Mutter nach ihrem Wesen sucht, thematisiert er auch die Frage der Wahrheit des Porträts (vgl. z.B. Gombrich 1977: 10ff.). Hat die Darstellung der wahrnehmbaren und im Moment der fotografischen Abbildung mitunter zufälligen äußerlichen Erscheinung Vorrang vor den nicht auf den ersten Blick erschließbaren Charakterzügen? ${ }^{23}$ Barthes entscheidet sich für letztere Variante, da er alle Fotografien, die seine Mutter in einem Alter zeigen, in dem er sie gekannt hat, nicht als wahrheitsgemäße Darstellungen ihres Wesens akzeptiert. Für Barthes ist der unbekannte Fotograf des Bildes »der Vermittler einer Wahrheit« (Barthes 1985: 80).

Ausgehend von dieser Annahme entwickelt er eine fast mystisch zu nennende Theorie des fotografischen Bildes im Sinne eines »Es-ist-so-gewesen«, als das er die Kausalität zwischen Fotografie und Fotografiertem bezeichnet (Barthes 1985: 87; Hervorhebung im Original). »Die Photographie ist, wörtlich verstanden, eine Emanation des Referenten. Von einem realen Objekt, das einmal da war, sind Strahlen ausgegangen, die mich erreichen, der ich hier bin; die Dauer der Übertragung zählt wenig « (Barthes 1985: 90f.). Es ist nur konsequent, dass Barthes die »Emanation des vergangenen Wirklichen [...] als Magie« bezeichnet (Barthes 1985: 99; Hervorhebung im Original).

22 So der Untertitel eines Buches von Rolf Sachsse 2003. Besondere Aufmerksamkeit hat diese Krise der Repräsentation im ethnografischen Kontext gewonnen (vgl. Teil I, Kapitel 1 und z.B. auch Därmann 2005b).

$23 » I m$ Bereich der Ästhetik werden etwa Kunstwerke als wahr bezeichnet, wenn sie in irgendeinem Sinn eine glaubwürdige Wiedergabe der Wirklichkeit (entweder der faktisch vorhandenen oder einer dahinter liegenden, eigentlichen und wesentlichen Wirklichkeit) sind« (Hügli/Lübcke 1997: 658). 
Denn in seinem Text Die Fotografie als Botschaft schreibt er: »Die fotografische Botschaft ist eine kontinuierliche Botschaft." Als solche sei sie das »perfekte Analogon « des »Wirklichen«, das demnach selbst kontinuierlich ist (Barthes 1990: 13). Nun ist eine Fotografie auf physischer Ebene als materieller Bildträger keineswegs kontinuierlich. Unter dem Mikroskop zeigt sich, diskret abzählbar, das fotografische Korn. Hingegen erscheint ihm das sichtbare Bildobjekt kontinuierlich - ebenso kontinuierlich wie das Wirkliche der Wahrnehmung. Damit will Barthes keineswegs behaupten, das sichtbare Bildobjekt sei durch die fotografische Prozedur kausal verursacht. Auch für ihn gilt die doppelte Gegenständlichkeit Husserls: Die kausale Verursachung betrifft immer den Bildträger und nicht das Bildobjekt (vgl. Wiesing 2005: 64f.). Das Bildobjekt ist auch für ihn allein Resultat der Wahrnehmung (Perzeption), es gibt keine direkte Abbildung der Welt, da diese ja bereits technisch vermittelt ist. Da er trotz dieses Wissens eine direkte Verbindung zwischen Welt und Bildobjekt behaupten möchte - das Foto sei eine »Botschaft ohne Code« - wählt er den Begriff Emanation - als eine Art mystische Kausalität (Barthes 1990: 13; Hervorhebung im Original). Dagegen lässt sich einwenden, dass eine auf Sichtbarkeit beschränkte bildliche Wahrnehmung genauso wenig eine Botschaft sein muss wie etwa eine alltägliche Dingwahrnehmung. Barthes selbst bezweifelt seinen »mystischen « Gedanken: So weist er im selben Artikel darauf hin, dass Botschaften immer kodiert sind, es keine Botschaft ohne sprachähnliche Strukturen geben kann. Er kommt zu dem Schluss, dass womöglich »eine reine Denotation, ein Diesseits der Sprache unmöglich« sei (Barthes 1990: 25; Hervorhebung im Original). Damit widerspricht Barthes sich selbst. Da er jedoch die durch ihn selbst implizit nahegelegte Möglichkeit der Selbstgenügsamkeit und der Selbstständigkeit der bildlichen Wahrnehmung, die wahrnehmungstheoretische Theorie, dass Bilder nicht immer als Zeichen fungieren müssen, nicht akzeptieren möchte, spricht Barthes vom »fotografischen Paradox« (Barthes 1990: 12).

Dieses fotografische Paradox stellt Barthes' Erzählung von der Wahrheit des Mädchenporträts seiner Mutter stark in Frage. Neben dem wahrnehmungstheoretischen Vorschlag, das Paradox zu lösen (Bilder sind nicht notwendig Zeichen, Botschaften) gibt es noch eine andere Möglichkeit der Auflösung. Auf diese verweist Barthes nicht zuletzt selbst: Er beschreibt die Erfahrung mit Fotografien, die noch in keinen Code eingebunden sind, die noch keine feste »Lektüre" gefunden haben, als »traumatisch « (Barthes 1990: 24f.). Man kann auch mit Abschnitt 3.2.1. vorliegender Arbeit sagen: Es handelt sich hierbei um die verstärkte Irritation und Herausforderung des Bildbetrachters, wie sie für die Bildwahrnehmung grundlegend ist. Denn die Bildobjekte sind in der Wahrnehmung auf Sichtbarkeit eingeschränkt. Dem Betrachter gelingt es nicht, das traumatische Bild zu integrieren. Huber macht in diesem Zusammenhang auf das Konzept der »Unbestimmtheitsstellen« des Husserl-Schülers Roman Ingarden aufmerksam (vgl. Huber 2004: 81ff.). Um mit der Einschränkung und widersprüchlichen Wahrnehmung, zum Beispiel der »flachen Tiefe, « (Boehm 2001: 33) zurecht zu kommen, haben die Bildbetrachter die Unbestimmtheitsstellen, die »Leerstellen«, selbst durch Imagination aufzufüllen. Darin bestehe die grundlegende Herausforderung der Bilder. Erst durch die Bewältigung dieser Herausforderung durch Rezipienten kommt eine fotografische Aussage zustande. Mit eben dieser Analyse ließe sich Roland Barthes begegnen: Dass er das Wesen seiner Mutter zu erkennen glaubt, könnte durchaus an seinen »emotional-kognitiven« Leistungen liegen 
(Huber 2004: 84). Was mit dieser Analyse jedoch wiederum betont ist, ist die problematische Beziehung von Bild und Welt: Die Frage nach der Wahrheit bleibt stets eng verknüpft mit dem Weltbezug.

Das ist jedoch nicht weiter überraschend. So steht in einem Philosophielexikon: »Wahrheit: Bestimmung desjenigen, das >wahr >falsch $<$ ist. [...] Im engeren Sinn wird der Begriff als Bestimmung von Urteilen oder Aussagen verwendet« (Hügli/Lübcke 1997: 658). Auf diesen sehr mathematisch-formalen Begriff von Wahrheit scheint auch die Theorie der Unbestimmtheitsstellen zu verweisen. Demnach wäre ein traumatisches Foto im Sinne des Semiotikers Roland Barthes - für den Bilder vergleichbar sind mit Aussagen, insofern sie gelesen werden müssen -, zu vergleichen mit einer mathematischen Formel mit Variablen. Erst wenn die Unbestimmtheitsstellen durch Einsetzung geschlossen werden, kommt eine Gleichung heraus, die wahr oder falsch sein kann. Ein traumatisches Foto ist eines, bei dem es der Imagination nicht gelingt, diese Leerstellen zu füllen.

Diese Betrachtung enthält bezüglich der Frage nach der Wahrheit eine Konsequenz, die zum Beispiel Nelson Goodman explizit zieht: »Statt zu versuchen, die Richtigkeit von Beschreibungen oder Darstellungen unter den Begriff Wahrheit zu subsumieren, sollten wir nach meiner Meinung lieber die Wahrheit zusammen mit ihnen unter den allgemeinen Begriff der Richtigkeit des Passens subsumieren« (Goodman 1990: 161).

Statt um Wahrheit geht es demnach nur noch um etwas, das man in seiner ernüchterndsten Konsequenz als das >Konstruieren< eines jeweils (mithin subjektiv) passenden Bezugs durch die Bildbetrachter fassen kann. ${ }^{24}$ Darin liegt eine Herausforderung für die Dokumentarfotografie:

»In jedem Stadium produzieren Zufallseffekte, bewusste Eingriffe, Entscheidungen und Variationen Bedeutung, unabhängig davon, welche Fertigkeit angewendet wird oder welcher Arbeitsteilung der Prozess unterliegt. Dies ist nicht die Beugung einer vorherigen (wenn auch unwiederbringlichen) Realität, wie Barthes uns Glauben machen möchte, sondern die Produktion einer neuen und spezifischen Realität; die Fotografie, die in bestimmten Transaktionen mit Bedeutung aufgeladen wird und reale Effekte aufweist, kann sich weder auf eine vorfotografische Realität als einer Wahrheit beziehen noch auf eine solche verweisen« (Tagg 1988: 3).

Daran ändert auch die indexikalische Beziehung zwischen Welt und fotografischer Abbildung nichts, da das materielle Produkt des Bildes eine inhaltliche Zuordnung benötigt, die nicht durch eine »Alchemie« erzielt werden kann (Tagg 1988: 3). Die Konstruktion greift unter anderem auf die Kontextualität der Fotografien zurück. So bezieht sich auch Barthes Einschätzung der Wahrheit in der Fotografie immer auf bereits kontextualisierte Fotografien. Er weiß, dass das Mädchen auf dem Foto seine Mutter sein muss. Ebenso weiß er, dass der von Richard Avedon fotografierte William Casby »als Sklave geboren « worden ist, weshalb die Fotografie bezeuge, »daß die Sklaverei Wirklichkeit gewesen ist« (Barthes 1985: 89/45). Ob dokumentarische

24 Goodman schränkt dieses pragmatische Wahrheitsverständnis jedoch dahingehend ein, dass weder Welt in einer fixierten Form auf Darstellung wartend vorliegt, noch »falsche so gut wie richtige Versionen eine Welt erzeugen, auf die sie passen« (Goodman 1990: 161; Anmerkung 20). 
Fotografien allein, ohne ihre kontextuelle Zusatzinformation als wahrhaftig gelten können, ist zu bezweifeln.

Allan Sekula weist darauf hin,

»daß fotografische Bedeutung relativ unbestimmt ist; dasselbe Bild kann in unterschiedlichen Präsentationszusammenhängen eine Vielfalt von Botschaften übermitteln. [...] Die einzig objektive Wahrheit, die uns Fotografien bieten, ist die Behauptung, daß irgend jemand oder irgend etwas [...] irgendwo war und eine Aufnahme gemacht hat. Alles weitere, alles außer diesem Abdruck einer Spur, ist für alles zu haben« (Sekula 2000: 125).

Demnach steht es schlecht um die fotografischen Möglichkeiten, Wahrheit zu vermitteln. Übrig bliebe der Fotografie die Herstellung von Dokumenten als Beweisgegenstände, um sozusagen vor einer Gerichtsbarkeit wahrheitsfähige Aussagen zu machen. Dass auch hier im Sinne von Sekula von Objektivität nicht die Rede sein kann, hat Abschnitt 3.2.1. gezeigt. Die wenigsten Fotografen werden sich allerdings mit einer solchen Art der Fotografie begnügen. Denn es kann nicht ausschließlich darum gehen, wahrheitsfähige fotografische Aussagen über Beweisgegenstände im weitesten Sinne anzufertigen. Es geht also um mehr, als nur die »einfache >Wiedergabe der Realität «, « wie bereits Walter Benjamin in seiner Kleinen Geschichte der Fotografie bemerkt: Das Ziel der »Avantgarde unter den Fachgenossen« der Fotografie sei, Zusammenhänge zu entlarven. Wenn dies nicht möglich sei, müsse etwas »Künstliches, Gestelltes« aufgebaut werden, um Aussagen über die Realität zu machen (Benjamin 1963: 89ff.). Benjamin selbst befällt Skepsis angesichts des hohen Ziels, das er hier formuliert. Die Unbestimmtheitsstellen könnten derart gefüllt werden, dass die Fotografie als Aussage nur Klischees bestätigt. »An dieser Stelle hat die Beschriftung einzusetzen, welche die Photographie als Literarisierung aller Lebensverhältnisse einbegreift und ohne die alle photographische Konstruktion im Ungefähren stecken bleiben muß. [...] Wird die Beschriftung nicht zum wesentlichsten Bestandteil der Aufnahme werden?« (Benjamin 1963: 93).

Anders formuliert: Fotografie muss sich anderen wahrheitsgebenden Verfahren und Kontexten anvertrauen. Dies entspricht der Praxis der angewandten Dokumentarfotografie, so beispielsweise in Wissenschaft oder Journalismus. In diesen Bereichen illustrieren Fotografien häufig Texte mit dem Ziel der wechselseitigen Bestätigung von Text und Bild. Man sollte davon aber nicht zu viel erwarten. Textualisiert liefert die Fotografie nicht mehr Realismus - im Sinne einer objektiven Abbildung - als die Gesellschaft erlaubt, so Bourdieus Analyse. Wenn es darauf ankommt, kann ein Foto, das zur Verifikation eines Textes herangezogen wird, auch zur Falsifikation der verbalen Behauptung führen. Eine fotografische Darstellung der Wirklichkeit werde für realistisch gehalten, weil sie $»$ mit der gesellschaftlichen Definition der objektiven Sicht unserer Welt« übereinstimmt. »Indem sie der Photographie Realismus bescheinigt, bestärkt die Gesellschaft sich selbst in der tautologischen Gewißheit, daß ein Bild der Wirklichkeit, das der Vorstellung entspricht, die man sich von der Objektivität macht, tatsächlich objektiv ist « (Bourdieu 1981: 89). Für das, was Pierre Bourdieu hier anspricht, findet sich auch bei Roland Barthes eine Begrifflichkeit. Barthes nennt dies die »Besänftigung« der Fotografie als Botschaft (Barthes 1990: 25f.). Nach Bourdieu »suchen die Subjekte immer wieder Zuflucht bei Leseschablonen, « womit sie 
das Überraschende ungewöhnlicher Fotografien ausblenden können (Bourdieu 1981: 87).

Die von Barthes angeführten »Formen der Beruhigung« haben vor allem einen Zweck: die Irritationen abzubauen, die Bilder ausüben und die überhaupt - nach Husserls Theorie des Widerstreits - am Anfang jedes Bildbewusstseins stehen. Beruhigung und Besänftigung erfordern, dass es Betrachtern gelingt, dem Bild einen Bezug zuzuschreiben und es so als Repräsentation einer referentiellen Bedeutung aufzufassen. Nach Schließung der Unbestimmtheitsstellen durch die Imagination wird es als eine Art wahre Aussage behandelt. Demnach geht es - egal ob bei ungewöhnlichen oder »normal traumatischen « (Barthes 1990: 25) Bildern - in der von Barthes und explizit von Bourdieu behaupteten gesellschaftlich üblichen Rezeptionsweise von Fotografien darum, sie zu vereinnahmen, ihre beunruhigende Offenheit sozusagen »passend « zu schließen.

Damit ist eine zentrale Fragestellung vorliegender Arbeit erreicht: Wie kann eine Fotografie sich dem Fremden als Fremden widmen, wenn doch in der Rezeptionsweise der Betrachter bereits die schnellstmögliche Schließung von Unbestimmtheitsstellen beziehungsweise die schnellstmögliche Beruhigung von Irritationen angelegt ist? Wie kann Fremdes als Fremdes in einer Fotografie repräsentiert werden, wenn die Rezeption stets auf Vereinnahmung und Besänftigung aus ist?

»Das Problem läßt sich folgendermaßen formulieren: Wenn die Erfahrung der Fremdheit in der Zugänglichkeit des Unzugänglichen besteht, wie könnte dann ein Zugänglichwerden oder Zugänglichmachen, aussehen, das die Unzugänglichkeit des Fremden wahrt? [...] Üblicherweise bedeutet das Zugänglichmachen des Unzugänglichen eine Verringerung der Fremdheit, die sich im Grenzfall völliger Aneignung bis zur Aufhebung der Fremdheit steigert« (Waldenfels 1997: 95f.).

Dementsprechend ist das Fremde vor einer Vereinnahmung durch das mindestens zu schnelle Schließen der Unbestimmtheitsstellen zu bewahren, wenn es in der Fotografie als Fremdes sichtbar werden soll. In diesem Sinne gilt es, Fragen nach den möglichen Annäherungsweisen der Dokumentarfotografie an ihren Gegenstand sowie der inhaltlichen Bedeutung und der Referenzzuschreibung zu erörtern.

\subsubsection{Bedeutung und Sichtbarkeit in der Dokumentarfotografie}

Trotz der problematischen Referenzbeziehung zur Welt und der Schwierigkeiten, die sich in Bezug auf die fotografische Wahrheit konstituieren, existieren dennoch dokumentarfotografische Gebrauchsweisen, die sich mit Welt auseinandersetzen, ohne von vornherein jeglichen Anspruch auf eine sachliche Auseinandersetzung mit dem Gegenstand aufzugeben. Die Thematisierung des Kontextes, in dem Fotografien beispielsweise als Beweise verwendet werden, zeigt, dass über kontextuelle Beziehungen durchaus versucht werden kann, mit fotografischen Mitteln Fremdes sichtbar zu machen.

Die Dokumentarfotografie bewegt sich in ihrer grundsätzlichen Konzeption bereits in einem bestimmten medienspezifischen Kontext, in dem die sehr weit gefächerten Möglichkeiten fotografischer Bilder in gewissen Bereichen eine Einschränkung erfahren. Eine der Grundvoraussetzungen bezieht 
sich auf den Verzicht der Abbildung inszenierter oder gestellter Situationen. Eine Veränderung des Motivs ist innerhalb einer dokumentarfotografischen Praxis nicht zulässig. Dorothea Lange, eine der bekanntesten FSA-Fotografinnen, erklärt ihren Ansatz so: »Hände weg! Was ich photographiere, das belästige ich nicht, ich pfusche nicht hinein und arrangiere nichts« (Dixon 1952; zit. nach Newhall 1984: 247). ${ }^{25}$ Die Realität, auf die sich dokumentarische Fotografie bezieht, ist in diesem Sinne eine, die auch unabhängig von ihrer Aufzeichnung auf diese Weise existiert. Der Verzicht auf Inszenierung vor der dokumentarischen Aufnahme setzt sich in der Absage an Manipulationen in der Dunkelkammer fort. Historisch stehen Manipulationen in $\mathrm{Zu}-$ sammenhang mit labortechnischen Experimenten oder Retuschen, wie sie beispielsweise bei den Piktoralisten üblich sind. Das Aufhellen oder Abdunkeln einzelner Bildpartien gilt hingegen in der Regel nicht als manipulativ, da es der Angleichung der Kontraste dient und mitunter die Sichtbarkeit des Bildobjektes erhöht. ${ }^{26}$ In der Geschichte der Fotografie gilt jedoch mitunter eine Veränderung des Bildausschnitts in der Dunkelkammer als Manipulation. Zahlreiche Fotografen beginnen deshalb damit, ihre Bilder mit dem schwarzen Negativrand zu vergrößern - als Beweis dafür, dass das komplette Bild und nicht nur ein Ausschnitt gezeigt wird (vgl. Becker 1978: 13). Die Auffassungen zu Eingriffen wie Retusche oder nachträgliche Bearbeitung dazu zählt auch ein kreativer Umgang mit Tonalitäten im Bild - sind jedoch sehr unterschiedlich. ${ }^{27}$ In Zeiten digitaler Bilderzeugung und -bearbeitung erstreckt sich der Tatbestand der Manipulation auf einen wesentlich größeren Bereich. Digitale Veränderungen von Bildmotiven - beispielsweise in Form von digitalem Collagieren aus unterschiedlichen Bildern - sind einfach zu bewerkstelligen und im fotografischen Positiv nicht nachweisbar. Mit einer solchen digitalen Manipulation verliert die Fotografie jedoch ihren einzigen und letzten Bezug zur Welt, der ihr - wie eingeschränkt auch immer Glaubwürdigkeit verleihen könnte: den Index. Allein aus diesem Grund können Fotografien, die digitale Eingriffe aufweisen, nicht mehr als dokumentarisch gelten. Der Nachweis einer solchen Manipulation ist jedoch wesentlich schwerer zu führen als bei analogen Fotografien. Aus diesem Grund ist auch das Ethos des Fotografen für die Einordnung als Dokumentarfotografie entscheidend. Im Sinne der Fotografie als Dokument muss er im Zweifelsfall als

25 Dass diese Praxis innerhalb der FSA nicht durchgehend befolgt wird, zeigt ein anderes Beispiel: Arthur Rothstein ist Autor einer sehr umstrittenen Fotografie für die Resettlement Administration (RA: Vorläufer der FSA von 1935-1937), die der RA/FSA den Vorwurf der Manipulation vor allem von Seiten republikanischer Politiker einträgt. Die Abbildung eines ausgeblichenen Tierschädels auf ausgedörrter Erde in South Dakota von 1936 erregt einiges Aufsehen, weil sie sich als inszeniert erweist (vgl. Matz 1981: 9; Hurley 1977: 86ff.).

26 Auf diese Weise erhalten Lichter oder Schatten noch Zeichnung, so dass in sehr hellen oder dunklen Bildpartien keine inhaltlich wichtigen Elemente verborgen bleiben.

27 Dorothea Lange besteht beispielsweise zu Roy Strykers Bestürzung darauf, einen Daumen aus dem Negativ ihres berühmten Bildes der Migrant Mother zu retuschieren, was sie als Verbesserung des Bildes ansieht und nicht als manipulativen Eingriff (vgl. Borhan 2002: 16; Hurley 1974: 142). 
Zeuge seiner fotografischen Aussagen auftreten können und beglaubigen, dass keine Manipulation am Bild stattgefunden hat. ${ }^{28}$

Als visuelles Medium beschäftigt sich die Dokumentarfotografie häufig mit Dingen oder Themen, die nicht allgemein zugänglich sind oder aufgrund ihrer Alltäglichkeit leicht übersehen werden. Sie ziele, schreibt Brigitte Werneburg, " auf das nicht oder wenig Beobachtete, das Marginale, auch und gerade in seiner scheinbar banalsten Form. Damit hat die Dokumentarfotografie teil am modernen Willen zum Wissen « (Werneburg 1996: 74). Dieses Wissen beschreibt Werneburg als ein »neues Wissen« (ebd.), das entweder neue Sachverhalte zugänglich macht oder aber bekannte Tatsachen in neue Erfahrungszusammenhänge stellt und somit ebenfalls neue Erkenntnisse ermöglicht. Das Marginale, mit dem sich die Dokumentarfotografie beschäftigt, ist in vielen Fällen das Soziale. Deshalb wird ihr oft ein »spezifisch humanistischer Blickwinkel« zugeschrieben (Featherstone 1984: vii). ${ }^{29}$ Dies stellt Parallelen zur Theorie des Dokumentarfilms her, der nach Grierson »Informationen über soziale Kontexte vermitteln [soll], um im Sinne demokratischer Partizipation eine Parteinahme der Bürger für eine Expertenmeinung zu ermöglichen« (Hohenberger 1998: 13). In einem ähnlich gelagerten Kontext ist beispielsweise auch die fotografische Arbeit der FSA - prototypisch für die Dokumentarfotografie der 1930er Jahre - zu verstehen, die vor allem der städtischen Bevölkerung die Probleme der Landwirte nahe bringen und ein Verständnis für die Politik des New Deal wecken möchte.

Dokumentarfotografie, die sich für alle ersichtlich mit sozialen Themen beschäftigt, wird als sozialdokumentarisch bezeichnet. Sie stellt einen Teilbereich der Dokumentarfotografie dar. Die sozialdokumentarische Fotografie, die mitunter Zustände als veränderungswürdig zeigt, ist auch als eine »Opferfotografie « kritisiert worden. Nach der scharfen Kritik von Martha Rosler diene sie lediglich dazu, »die Hegemonie einer bestimmten Klasse« zu legitimieren, wobei sich die Fotografie selbst »als unparteiisch und allgemeingültig « ausgebe, indem sie sich auf den »Mythos ihrer Objektivität (Transparenz, Unmittelbarkeit)« berufe (Rosler 1999: 124). Diese Kritik bezieht sich insbesondere auf einen naiven Umgang mit dokumentarischer Fotografie, den Rosler insbesondere in jeder Form von journalistischer Fotografie vertreten sieht (vgl. ebd.).

Mit sozialen oder gesellschaftlich relevanten Themen beschäftigen sich mitunter auch Projekte, die nicht explizit als sozialdokumentarisch bezeichnet werden. Diese Auseinandersetzung muss nicht unbedingt offensichtlich sein. Die Art der Einbeziehung des Sozialen ist stark von der Intention der Dokumentarfotografie abhängig. Dass soziale Themen innerhalb von ethno-

28 Nun ist es natürlich problematisch, jeder einzelnen dokumentarisch anmutenden Fotografie den Manipulationsverzicht nachzuweisen, weshalb grundsätzlich davon auszugehen ist, dass dokumentarische Fotografien, die sich als solche ausgeben, auch so akzeptiert werden können. Dies gilt insbesondere für den angewandten Kontext, denn ein Pressefotograf ist beispielsweise einem journalistischen Ethos verpflichtet, das ihm Aufrichtigkeit in der Darstellung abverlangt. Dass es dennoch immer wieder zur Aufdeckung von Manipulationen journalistischer Fotografien kommt, lässt eine wesentlich höhere Dunkelziffer vermuten.

29 Für manche Kritiker ist der humanistische Blickwinkel so entscheidend, dass sie andere Ansätze nicht mehr dokumentarisch nennen wollen (vgl. SolomonGodeau 2003: 73; Anmerkung 22). 
logischen oder journalistischen Gebrauchsweisen behandelt werden, liegt auf der Hand. Doch auch in der Kunst ist das Soziale - mitunter auf implizite Weise - oft ein wichtiger Bestandteil der Dokumentarfotografie. Abseits von Thema oder Bildsujet kann die in den Bildern aufscheinende Haltung des Fotografen ein soziales Anliegen verkörpern. Beispielsweise verweist der Begriff der dokumentarfotografischen Richtung social landscape darauf, dass sich auch Landschaftsfotografie mit sozialen Aspekten beschäftigen kann. ${ }^{30}$

Die Absage an eine das Motiv überformende Ästhetik sowie die Aufmerksamkeit für soziale Themen und Zusammenhänge kennzeichnen das Interesse an einer inhaltlichen Auseinandersetzung mit dem Gegenstand. Die Auseinandersetzung mit dem Sozialen ist jedoch nicht Bedingung: Den vielfältigen thematischen Möglichkeiten sind keine Grenzen gesetzt, vorausgesetzt, sie verzichten auf Inszenierung und Manipulation. Entscheidend dabei ist aber, dass es keine Bildsujets gibt, die besser oder schlechter für eine dokumentarfotografische Auseinandersetzung geeignet sind. Die Dokumentarfotografie bedarf weder spektakulärer Sujets, noch ist sie gehalten, das, womit sie sich beschäftigt, spektakulär abzubilden. Die Selektion eines fotografierten Bildsujets unterscheidet es bereits von allen nicht fotografierten. Damit erhält das Abgebildete ein Gewicht, das in der Form der Abbildung weiter ausdifferenziert wird. Gleichzeitig ist die Bildästhetik nicht Selbstzweck. Stryker nennt die gestalterischen Elemente $»$ Maßstab jeder Arbeit, « ihnen seien innerhalb der dokumentarischen Fotografie jedoch bestimmte Grenzen gewiesen. Maßgeblich ist ihr Beitrag zur Aussage und zur Wirkung der Fotografie, die über das Ästhetische hinausweisen (Stryker 1974: 1180). Deshalb ist die inhaltliche Auseinandersetzung der Dokumentarfotografie mit einer Absage an das Einzelbild verbunden, da die Darstellung komplexer Zusammenhänge einer Reihe von Bildern bedarf, die zu Serien oder Sequenzen angeordnet werden.

Im klassischen Gebrauch wollen dokumentarische Fotografien also Aussagen machen. Damit sind wir im Feld der Bedeutung. Inhaltliche Bedeutung entsteht im Sinne der semiotischen Bildtheorie immer, wenn ein Bild als Zeichen gebraucht wird, etwa um eine Aussage zu machen. Die inhaltliche Bedeutung wird auch Sinn genannt. Ein Bild wird derart sinnvoll gebraucht, dass es auf ein Referenzobjekt verweist. Man kann also zwischen einer inhaltlichen und einer referentiellen Bedeutung unterscheiden. »Ein Bildobjekt kann nur dann zur bildlichen Bezugnahme verwendet werden, wenn dem Betrachter des Bildobjektes eine Regel bekannt ist, wie sich durch das Aussehen des Bildobjektes ein Bezug zu einem Gegenstand aufbauen läßt. Diese Regel kann als Sinn eines Bildes bezeichnet werden « (Wiesing 2005: 62). Der Sinn bezeichnet dementsprechend, wie etwas angesprochen wird. ${ }^{31}$ Wie oben schon erläutert, ist Sinn keine kategoriale Eigenschaft des Bildes selbst, sondern er wird vielmehr an das Bildobjekt herangetragen: » Er ist weder eine

301966 fand im George Eastman House in Rochester, New York, die Ausstellung Toward a Social Landscape statt. Teilnehmende Fotografen waren: Lee Friedlander, Bruce Davidson, Danny Lyon, Duane Michals und Gary Winogrand. Social Landscaping ist auch weiterhin eine Richtung der künstlerischen Dokumentarfotografie, vertreten beispielsweise durch Lewis Baltz (z.B. Park City, Albuquerque 1980) und John Gossage (The Pond, Millerton 1985).

31 Ein gutes Beispiel für das Wie des Sinns ist der Planet Venus: Morgens wird er als Morgenstern angesprochen, abends als Abendstern. Der Referent ist jedoch immer derselbe Planet. Dieses Beispiel stammt von Gottlob Frege. 
wahrnehmbare Eigenschaft des Bildträgers noch des Bildobjektes« (ebd.). Sinn ist die Art und Weise des referentiellen Gebrauchs des Bildes. ${ }^{32}$

Wie schon in den letzten Abschnitten diskutiert, ist die inhaltliche Bedeutung aber nicht festgelegt, sondern kann - je nach kontextueller Einordnung des Bildes - in vielfältige Richtungen weisen.

»Aber obwohl >Bedeutung theoretisch unbegrenzt ist, ist sie auch historisch und kulturell bestimmt. Vom Moment der Schöpfung an wird die Fotografie etwas $>$ bedeuten`, das die Intention des Fotografen reflektiert. Während diese Bedeutung beim Foto bleibt oder durch historische Recherche rekonstruierbar ist, wird sie eine Schicht $[\ldots]$ unter anderen dem Bild zugewiesenen Bedeutungen bilden « (Edwards 1992: 12).

Elisabeth Edwards weist darauf hin, dass sich in der inhaltlichen Bedeutung sowohl die Intention des Fotografen als auch die Leseweisen des Rezipienten begegnen, die aufgrund unterschiedlicher Imaginationen und kulturellhistorischer Grundvoraussetzungen durchaus verschieden sein können.

Im Feld der Dokumentarfotografie möchte der Fotograf üblicherweise die Betrachter daran teilhaben lassen, was er gesehen, erlebt oder erfahren hat. Als problematisch erweist sich jedoch, dass die Betrachter in der Fotografie möglicherweise lediglich sehen, was sie selbst sehen möchten. Dies muss nicht unbedingt den Intentionen des Fotografen entsprechen, wie das Beispiel der Bildbetrachtung von Roland Barthes gezeigt hat. Der Betrachter eignet sich das Bild an. Der Produzent kann entsprechend auf der Produktionsebene Strategien entwickeln, wie er der Vereinnahmung des Bildes durch den Rezipienten begegnet. Geht es dem Fotografen darum, eine Aussage zu machen, wird er die Fotografie in einer bestimmten Weise konstruieren, damit das Publikum den intendierten Sinn aus der Fotografie herauslesen kann. Es soll bestenfalls eine Auffassung entwickeln, die der intendierten nahe kommt. Man kann verschärft auch sagen: Möchte die Fotografie etwas Konkretes aussagen, muss sie ihre Betrachter dazu bringen, ihre Unbestimmtheitsstellen mit einem Sinn zu füllen, der den Absichten des Fotografierenden entspricht. ${ }^{33}$ Insofern liegt es nahe, dass die Theoretiker der Visual Culture von der Produktion von (inhaltlicher) Bedeutung durch Bilder sprechen (vgl. z.B. Tagg 1988: 3; Hall 2002: 15).

Wie die Rezipienten mit den Unbestimmtheitsstellen der Fotografie umgehen, liegt nicht allein in der Verantwortung der Fotografie selbst. Auch die Gebrauchskontexte bestimmen ihre Bedeutung. Die Auseinandersetzung mit komplexen Themen, die gleichzeitig die Haltung des Fotografen reflektiert, erfordert mehr als ein Einzelbild. Der amerikanische Fotohistoriker Beaumont Newhall schreibt:

"So aufschlußreich und schön ein Dokumentarphoto auch ist, es kann nicht allein aus sich heraus wirken. Bevor das Photo als Dokument akzeptiert werden kann, muss es paradoxerweise erst selbst >dokumentiert<, d.h. einer bestimmten Zeit und einem bestimmten Ort zugeordnet werden. Dies läßt sich erreichen, indem man das

32 Man hat dies auch die Gebrauchstheorie des Zeichens genannt (vgl. Wittgenstein 1984: 416).

33 Solomon-Godeau spricht explizit davon, Kontrolle über die Arbeit gegenüber dem Publikum auszuüben (vgl. Solomon-Godeau 2003: 74). 
Vertraute mit dem Unbekannten zusammenbringt - sei es innerhalb eines Bildes oder in der Gegenüberstellung mehrerer Bilder. Eine Photoserie [...] kann auf diese Weise mehr sein als die Summe ihrer Teile« (Newhall 1984a: 254; vgl auch Newhall 1984b: 5f.).

Auch wenn Newhall hier von der Fotografie als Dokument spricht, treffen seine Äußerungen durchaus auch auf dokumentarische Fotografien zu. Auch sie werden häufig mit dem Aufnahmeort, dem Aufnahmedatum oder mit einer Beschreibung dessen versehen, was die Fotografie zeigen möchte. Insbesondere die Beschriftung von Fotografien kann zu nachhaltigen Veränderungen der Sinnzuschreibung führen, was beispielsweise im Bereich der Propaganda zur Manipulation der Betrachter eingesetzt wird. ${ }^{34}$ Während Propaganda versucht, alternative Bedeutungen zu unterbinden, existieren in der fotografischen Praxis allgemein graduelle Unterschiede in der Lenkung des Betrachters. Diese sind verbunden mit der Gebrauchsweise, denn beispielsweise müssen angewandte Dokumentarfotografien andere Voraussetzungen erfüllen als künstlerische. Erstere erfordern häufig eine leichte Lesbarkeit, während letztere den Betrachtern einen größeren Spielraum der Interpretation einräumen, bei dem womöglich die inhaltliche Bedeutung sogar in den Hintergrund tritt. Die häufig praktizierte textliche Einordnung von Fotografien in größere Zusammenhänge zeigt, dass eine Dokumentarfotografie - trotz ihrer indexikalischen Verbindung zur Realität - als maschinelles Produkt »oft viel weniger intelligibel und viel fremder als Malerei« wirkt (Haus 2000: 91). Neben einer textlich beschreibenden Einordnung kann eine ganze Bildserie ebenfalls zur Kontextualisierung der einzelnen Fotografien beitragen. Indem ein Sachverhalt oder Thema in mehreren fotografischen Bildern behandelt wird, wird durch die verschiedenen Blickwinkel und Darstellungsweisen eine höhere Komplexität erzeugt.

Der Publikationskontext dokumentarischer Fotografie trägt ebenfalls zu ihrer Kontextualisierung bei. Dokumentarfotografie kann beispielsweise in einer Ausstellung, in einem Buch, einer Zeitschrift oder einer Zeitung erscheinen, wodurch in der Regel ein thematischer Kontext hergestellt wird, Bildreihen und -sequenzen von einem oder mehreren Fotografen zu sehen sind und Texte abgedruckt werden. So ist es möglich, dem Publikum einen Rahmen für die Betrachtung vorzugeben und Hinweise auf eine mögliche Sicht- oder Interpretationsweise anzubieten. Auch die Wahl des Titels der ganzen Serie kann Aufschluss über mögliche Bedeutungen geben. Die Kontextualisierung dokumentarischer Fotografien steht in einem engen Zusammenhang mit den vom Fotografen - aber auch der Redaktion oder des Herausgebers - verfolgten Intentionen. ${ }^{35}$ Ihr Einfluss auf die Rezeption ist nachhaltig.

34 Einige Beispiele liefert hier Freund 1976: 173.

$35 »$ Es muß auch betont werden, daß der Einfluß des Veröffentlichungskontextes auf die Bedeutung des Fotos über den offensichtlichen Gegensatz von Galerie und Zeitschrift hinausgeht. Denn in letzterer wirken sich das redaktionelle Umfeld, die Art der Bildunterschrift und des Textes, die Anordnung der Bilder und die Fülle der damit konkurrierenden anderen Bilder (z.B. die möglicherweise auf derselben Seite erscheinenden Anzeigen) auf verschiedenste Art auf die Lektüre und Interpretation der Bilder aus« (Solomon-Godeau 2003: 69). 
Um auch die Auswirkungen des Umfelds auf dokumentarische Fotografien und deren Verständnis durch den Betrachter im Blick zu behalten, scheint es mit Abigail Solomon-Godeau notwendig, »»die Kontrolle über die Arbeit im Hinblick auf ihre Ausstellung, Veröffentlichung oder Distribution zu behalten « (Solomon-Godeau 2003: 74). Es stellt sich jedoch die Frage, ob diese Art des Umgangs die Krise der Repräsentation abzuwenden vermag. Auslöser dieser Krise ist das gewachsene Bewusstsein darüber, dass eine Objektivität der Darstellung nicht erreichbar ist. Die »encodierten und verborgenen Bedeutungen [sind] ans Licht zu bringen, die historischen und formalen Strategien aufzudecken, die die Herstellung, den Sinn, die Rezeption und den Gebrauch einer Arbeit determiniert haben« (Solomon-Godeau 2003: 72). Dies sei Aufgabe von Kritikern und Kunsthistorikern. »Gleichwohl obliegt es dem intelligenten Betrachter, eine fadenscheinige universalistische Lesart zurückzuweisen, die dazu dient, die Fotografie von ihrer ideologischen Arbeit, ihrer (normativen) Verbreitung der Doxa freizusprechen « (Solomon-Godeau 2003: 72; Hervorhebung im Original). Im kritischen Umgang mit den medialen, historischen und formalen Bedingtheiten der Dokumentarfotografie sieht Solomon-Godeau eine Möglichkeit, die Krise der Repräsentation zu meistern. Ihre Auffassung der Dokumentarfotografie bleibt aber mit dem Anspruch verbunden, mit dokumentarischen Fotografien etwas aussagen zu wollen und so den Zweck der Information, Aufklärung und Bildung zu erfüllen. Eine umfassende Kontrolle scheint notwendig, um eine den Intentionen entsprechende Sinnzuschreibung zu erreichen.

Dies widerspricht jedoch der fotografischen Praxis insbesondere in der künstlerischen Dokumentarfotografie. Denn »zur dokumentarischen Haltung gehört [...] der partielle Rückzug des Autors hinter sein/ihr Sujet und damit zugleich die Ermächtigung des Betrachters zu einer eigenständigen Lektüre« (Holschbach 2004: 26f.). Es geht hier aber gar nicht mehr um das »Lesen« von Bildinhalten und die Zuschreibung eines Sinns. Denn diese Ansätze zielen nicht auf die Konstitution einer spezifischen Bedeutung, vielmehr machen sie selbstständige Phänomene im Bild sichtbar und erzeugen eine neue, eigenständige Bildwirklichkeit. Während Solomon-Godeau nach Kontrolle ruft, arbeiten zahlreiche Künstler mit nachhaltiger Offenheit und Sichtbarkeit statt mit Bedeutung. ${ }^{36}$ Sie lassen die Bilder lieber Fragen stellen, statt mit festgelegten pikturalen Aussagen Antworten bereitzustellen. Diese Art des Umgangs scheint besonders geeignet für die Auseinandersetzung mit dem Fremden als Fremdes, denn weder das Fremde noch das Bildobjekt sind real anwesend. Anlässlich des Bildobjektes besteht für den Betrachter die Möglichkeit, sich mit dem Fremden zu konfrontieren. In der Kontextualisierung des einzelnen Bildes wird bei diesen Projekten meist auf Bildunterschriften verzichtet, was zusätzlich die Loslösung von der Referenz verdeutlicht. In der Arbeit mit Bildserien in Ausstellungen oder Künstlerbüchern zeigt sich, dass die Künstler nicht den Kontext im Hinblick auf die zielgerichtete Bedeutungskonstitution kontrollieren möchten, sondern dass das Zusammenspiel der Bilder im Werk selbst begründet ist. Die fotografische Arbeit besteht als Werk innerhalb des Kontextes Buch oder Ausstellung. Diese Praxis der

36 Sie versuchen, die von den Bildern grundlegend ausgehende Irritation wirken zu lassen und nicht durch Einbindung in inhaltliche, womöglich gar »institutionelle« > Gebrauchsweisen für« und daraus resultierendem `Verweis auf` zu beruhigen und zu besänftigen (vgl. Barthes 1990: 26). 
künstlerischen Dokumentarfotografie ermöglicht ein Wahrnehmen der Bildobjekte ohne Konstruktion eines Bezugs. Die damit erreichte Autonomie hat - nach Barthes - »traumatische« Bilder zur Folge, die nicht mehr in ein vorhandenes Bezugssystem eingeordnet werden können. Weil aber das Fremde ebenfalls außerhalb des eigenen Bezugsrahmens angesiedelt ist, könnte sich diese fotografische Haltung als eine erweisen, die es ermöglichen kann, dem Fremden als Fremdem innerhalb der künstlerischen Dokumentarfotografie gerecht zu werden.

\subsubsection{Intention und Wirkung}

Die vorangegangene Diskussion zeigt, dass die Dokumentarfotografie stark von der Herangehensweise und der Haltung der Fotografierenden geprägt ist, die in engem Zusammenhang mit dem Gebrauchskontext zu sehen sind. Zur spezifischen Einordnung muss also immer gefragt werden, mit welcher Intention zu Werk gegangen wird und für welchen Gebrauchskontext die Fotografie gedacht ist.

Bevor überhaupt der Begriff Dokumentarfotografie eingeführt ist, etabliert sich im späten neunzehnten Jahrhundert ein aufklärerisches fotografisches Genre. Wegbereiter dieser Art von Fotografie ist beispielsweise der Polizeireporter und Journalist Jacob A. Riis, mit dem die »retrograde Konstruktion des Dokumentarischen üblicherweise beginnt« (Solomon-Godeau 2003: 60). Er fotografiert in den späten 1880er Jahren in den New Yorker Einwanderervierteln und Slums, um die schlechten Lebensbedingungen anzuprangern und eine Verbesserung der Verhältnisse zu erreichen. ${ }^{37}{ }^{2} \mathrm{Nach}$ diesem Modell des Dokumentarischen wird das Genre im Sinne reformistischer oder verbessernder Intentionen definiert und zwar im Hinblick auf Dinge wie die Adressierung einer Öffentlichkeit, die Rezeption, Verbreitung, und die Idee eines Projekts oder einer Erzählung (im Gegensatz zum Einzelbild)« (ebd.: 60f.). ${ }^{38}$ In diesem Sinne hat sich die Vorstellung einer Aufklärungs-, Informations- und Bildungsabsicht der Dokumentarfotografie bis weit ins zwanzigste Jahrhundert hinein gehalten. Eine solche Auffassung prägt die Fotografie der FSA in den 1930er Jahren ebenso wie bis in die 1960er Jahre hinein die Bildreportagen in Publikumsmagazinen wie beispielsweise der amerikanischen Wochenzeitschrift Life. In einer Zeit allgegenwärtiger fotografischer Sichtbarkeit, in der Handykameras jeden noch so unzugänglichen Winkel der Welt abzulichten scheinen und Internetplattformen wie Youtube und flickr für die Verbreitung des überall aufgenommenen Bildmaterials sorgen, scheint ein solcher Anspruch heute entkräftet. Zum einen bricht anlässlich der Vielzahl dieses alltäglichen Bildmaterials das Ideal weg, wie es Riis in der Geburtsstunde des dokumentarischen Genres vorgelebt hat. Über die

37 Zu Riis und auch Lewis Hine vgl. z.B. Koenig 1998: 354ff.; Newhall 1984a: 138f.; 243f.

38 Die Kritik bescheinigt einem solchen Ansatz, dass er einerseits an das Mitgefühl für die Armen appelliere, aber gleichzeitig die Ängste der Mittelklasse schüre und die Missstände nicht als »systemimmanent« begreife. Aus diesem Grund sei eine solche Fotografie geeignet, vielleicht kurzfristig etwas zu verbessern, eine grundlegende Erneuerung des fehlerhaften politischen oder wirtschaftlichen Systems sei auf diese Weise jedoch nicht zu erreichen (vgl. Rosler 1999: 108; auch Solomon-Godeau 2003: 61ff.). 
»andere Hälfte« der Gesellschaft ist so viel bekannt, dass man mithin gar nicht mehr sagen kann, wo die Trennlinie zwischen hier und dort verläuft. ${ }^{39}$ Das hat sicherlich auch mit gesellschaftlichen Veränderungen zu tun: Die alten Klassengrenzen sind verloren gegangen. Aber es gibt auch fotografische Gründe für die Entkräftung der alten Leitlinien des Genres. Denn einstige, Authentizität verbürgende stilistische Innovationen in der Fotografie stehen »heute als reine Stilmittel zur Verfügung, das heißt, sie werden als solche losgelöst von ihrer ursprünglichen Funktion der Wirklichkeitsdarstellung eingesetzt« (Holschbach 2004: 29). Sie haben mit ihrer Neuheit auch ihre behauptende, mithin anklagende Kraft verloren. Der Eindruck, dass man mit bildlichen Mitteln authentische, die Gesellschaft verändernde Aussagen treffen kann, ist offenbar durch die Krise der Repräsentation widerlegt. Der Gebrauch von Bildern als wahrnehmungsnahe Zeichen scheint - durch die Alltäglichkeit der Bilder - so unsicher geworden zu sein wie die alltägliche Sprache selbst: »In Zukunft wird man vor der Betrachtung eines fotografischen Bildes genauso eine Absprache über die Annäherung daran treffen müssen, wie wir dieses seit der Erfindung des Verfahrens mit der Sprache selbst tun, wenn wir uns einem Text nähern« (Sachsse 2003: 182). Diese Absprachen müssen Fotografen und Publikum gemeinsam treffen. Es ist an den Fotografen, Hinweise zu geben auf die mediale Bedingtheit der Aussagen, die sie mit ihren Bildern treffen. Deshalb wird das alte Ethos des Genres in der angewandten Fotografie nur noch in abgeschwächter Form gelebt. ${ }^{40}$

Im Bereich der künstlerischen Dokumentarfotografie sind die Intentionen und Interessen vielfältig und kaum auf einen Nenner zu bringen. Weil hier die Projekte oft längerfristig angelegt sind und hauptsächlich im eigenen Auftrag entlang der persönlichen Interessen der Fotografierenden entwickelt werden, sind »sie für schnelle, marktkonforme Verwertungszusammenhänge in Presse und Verlagswesen wenig geeignet« (Werneburg 1996: 75). Dies hängt auch damit zusammen, dass sie zum Teil in einer Weise mit Irritation arbeiten, die sie in einem angewandten Zusammenhang wenig geeignet erscheinen lässt. Das ist auch kaum verwunderlich, insofern bildliche Aussagen - im Gegensatz zur angewandten Fotografie - nicht mehr das Ziel sind. Dabei verliert die Dokumentarfotografie hier bei weitem nicht ihren gegenständlichen Charakter. Sie koppelt sich nicht in der radikalen Weise vom Referenten $\mathrm{ab}$, wie dies andere zeitgenössische Fotografien praktizieren (vgl. Teil I, Abschnitt 4.1.2.). Entscheidend für das Ergebnis ist die Haltung des Fotografierenden. Diese ist geprägt durch das Wissen um die medialen Bedingtheiten der Dokumentarfotografie, die ihr Wirklichkeitsversprechen im Sinne einer authentischen Repräsentation der Realität nicht einhalten kann. Die Haltung drückt die Art und Weise aus, wie sich der Fotograf zum gewählten Thema oder Gegenstand selbstreflexiv positioniert. Allgemein be-

391890 publiziert Riis das erste sozialdokumentarische Buch: How the Other Half Lives (vgl. Koenig 1998: 352).

40 Der aus Bangladesch stammende Fotograf G.M.B. Akash kann noch als Vertreter des alten Ethos gesehen werden: Mit einer Dokumentation hat er Missstände islamischer Erziehung in Koranschulen aufdeckt. Die Veröffentlichung der politisch brisanten Fotografien hat ihn gezwungen, sein Heimatland zu verlassen: »Die Kraft der Bilder will er nutzen, um die Verhältnisse zu ändern, um Tabus zu brechen« (Schwabe 2007). 
schreibt Susanne Holschbach die Haltung der künstlerischen Dokumentarfotografie als sich selbst gegenüber

»vorwiegend skeptisch - sie ist sich ihrer Traditionen und der Problematik der Definition bewusst, weiß um die Relativität jeglichen Wirklichkeitsbezugs, um die Begrenztheit subjektiver Perspektiven, um die Medialität von Erfahrungen. Sie weiß um die Effekte unterschiedlicher Präsentationsformen wie der des Buchs oder der Ausstellungswand auf die Rezeption von Bildern, um die bedeutungszuweisende Funktion von Texten und Kontexten; und selbstverständlich auch um die inhärenten Gestaltungsmittel ihres Mediums und die damit verbundenen Manipulationsmöglichkeiten« (Holschbach 2004: 30).

Das alles zusammengefasst kann man vielleicht sagen, dass die sprachliche Funktion der Fotografie und die ihr eigene Bildlichkeit immer häufiger auseinander treten. Ein Ort hierfür kann die künstlerische Dokumentarfotografie sein. In Gebrauchskontexten dient, wie in Abschnitt 3.2.1. dargelegt, die Fotografie als Zeichen, um auf etwas zu verweisen. Dies entspricht auf der Seite der Fotografierenden dem Interesse an einem inhaltlichen Thema, das fotografiert werden soll. Das Auseinandertreten von sprachlicher Funktion und Bildlichkeit kommt dem Unterschied zwischen Interesse und Haltung gleich. Die emotionale Haltung zu einem Thema ist Grundlage des Interesses. Dies auf den Unterschied von Bildlichkeit und Zeichenhaftigkeit übertragen würde bedeuten, dass die Bildlichkeit Grundlage der Zeichenhaftigkeit der Fotografie wäre. Dieses Modell widerspricht semiotischen Erklärungen des Bildes. In semiotischen Bildtheorien gilt der zeichenhafte Verweis, die Abbildung thematischer Gegenstände - von Einzelobjekten, thematisierten Situationen und so weiter - als grundsätzliche Voraussetzung von Bildlichkeit. Für Fotografien scheint dieser Zusammenhang zwischen Bildsujet und Bild noch einmal verschärft: Das sichtbare Bildobjekt wird dazu benutzt, beispielsweise auf den Gegenstand, zu dem eine indexikalische Spur führt, zu verweisen. Bildlichkeit, so die These, entsteht, wenn der Widerstreit der »ikonischen Differenz $«,{ }^{41}$ die Irritation der flachen Tiefe beruhigt und besänftigt wird (vgl. Abschnitt 3.2.2.). Dies kann man auch als Füllen von Unbestimmtheitsstellen fassen, wodurch diesen besonderen physikalischen Objekten ein Referenzobjekt und so ein verweisender Sinn zugeordnet wird. Demgegenüber steht ein Erklärungsansatz, den man mit Lambert Wiesing den wahrnehmungstheoretischen nennen könnte. Hier ist es der Widerstreit selbst, der zur Bildwahrnehmung führt; der Bezug auf Referenzobjekte kommt als sekundäre und »außerbildliche [...] Bedingung eines Bildes« hinzu (Imdahl 1996: 453). Demnach wäre es also selbstverständlich, dass Bilder als Zeichen gebraucht werden können. Sie müssen aber nicht zwingend als Zeichen verwendet werden, um als Bilder zu gelten. Bilder machen etwas sichtbar, können etwas zeigen und präsentieren. Nach Lambert Wiesing entstehen Zeichen »durch Verwendung und nicht durch Anschauung, « weshalb die optische Wahrnehmung eines Bildes noch keinen Zeichengebrauch impliziert (Wiesing 2005: 36). Demnach gilt für Bildobjekte, »was für alle sichtbaren Gegenstände gilt: Sie lassen sich anschauen, ohne daß sie sich aufgrund des Angeschaut-

41 Die ikonische Differenz beschreibt den Gegensatz zwischen der physischen Präsenz des Bildträgers und dem auf ihm nur sichtbaren Bildobjekt (vgl. Boehm 2001: 30). 
Werdens in ein Zeichen verwandeln. [...] Man schaut sich das Bildobjekt an, weil man wissen möchte, wie es aussieht « (Wiesing 2005: 68). ${ }^{42}$

Diese spezifische Bildlichkeit bleibt im semiotischen Ansatz verborgen. Man kann dies auch die besondere Wirkung der eigenständigen Bildwirklichkeit nennen. »Es geht vielmehr um spezifische Wirkungsmächte des Bildes, und in diesem Sinne leisten die Bilder immer mehr, als nur eine vorgängige Realität zu repräsentieren« (Därmann 2005b: 178). Die repräsentierende und die bildliche Ebene treten auseinander. Die künstlerische Dokumentarfotografie möchte diese beiden Ebenen in ein Wechselspiel einbeziehen. Die angewandte Dokumentarfotografie versucht, die Eigendynamik des Bildes in den Hintergrund zu drängen und so das Bildobjekt transparent werden zu lassen. Demgegenüber möchte sich die explizite Kunstfotografie von jeglicher Referenz abkoppeln und nur noch Bild sein. Dabei löst sie sich von den Resten der indexikalischen Spur. Beiden Ansätzen gegenüber sucht die künstlerische Dokumentarfotografie, ein Wechselspiel zwischen Referenzfunktion und eigenständiger Bildwirklichkeit, zwischen Transparenz und Opazität des Bildes zu initiieren. Dieses Wechselspiel ist ihr Versuch zur Bewältigung der Krise der Repräsentation. Ihre Darstellungsabsicht ist nicht mehr die einfache Abbildung eines Themas, sondern die Reflexion auf das Interesse, das jeder Themenfindung vorausgeht. Die künstlerische Dokumentarfotografie setzt sich - unter veränderten Vorzeichen - genau wie die angewandte Dokumentarfotografie mit dem Zwiespalt zwischen Zeichenfunktion und Bildlichkeit auseinander. Sie sucht geradezu die Beunruhigung und permanente Irritation, die in angewandten Kontexten zwecks eindeutiger Aussagen ausgeschaltet werden soll.

Damit verfolgt die künstlerische Dokumentarfotografie eine ganz eigene, selbstreflexive Darstellungsabsicht. Zu diesem Zweck instrumentalisiert sie nicht das Bild als Zeichen, wie es die klassische Dokumentarfotografie tut. Sie nutzt stattdessen den Widerstreit, die Irritation der ikonischen Differenz, die am Anfang jeder Bildwahrnehmung steht. Während die frühe Dokumentarfotografie versucht, bestimmte Sichtweisen auf Themen zu fixieren und zu kanonisieren - was Rosler beispielsweise mit dem Begriff der »Opferfotografie« kritisiert - möchte die künstlerische Dokumentarfotografie gerade bestimmte stereotype oder klischeehafte Betrachtungsweisen erschüttern. Sie versucht dabei nicht, fixierte Sichtweisen durch neue zu ersetzen. Für sie würde dies nur dem Austausch von Ideologien gleichkommen. Ihr geht es gerade nicht darum, bestimmte Positionen, die ein Fotograf gegenüber einem Gegenstand gefunden hat, als Identifikationsangebot an die Bildbetrachter

42 Dieses Anschauen um des Sehens und nicht um der Referenz Willen weist Parallelen zur Auseinandersetzung mit dem Fremden auf. Als Reisender in einer fremden Kultur lassen sich das Land, die Landschaft, die Städte, die Menschen, die Heiligtümer ansehen. Nun ist es möglich, alles Gesehene und Erlebte bewusst in Bezug zum Eigenen zu setzen, zu vergleichen, abzuwägen, zu beurteilen. Diese Form der Aneignung des Fremden kann, wie in Abschnitt 2.2.2. dargelegt, leicht zur Entstehung von Klischees und Vorurteilen beitragen. Dem gegenüber lässt sich die fremde Kultur auch in einer Weise sehen, die sie als Fremdes gelten lässt, ohne die Bezüge zum Bekannten stets in den Vordergrund zu rücken. Hier geht es um den Prozess des Wahrnehmens selbst, dessen primäres Ziel nicht die Aneignung durch Verstehen ist. Solche Fotografien suchen nicht nach einer Sinnzuschreibung durch Referenz, sondern sie erzeugen eine eigenständige Sichtbarkeit. 
weiterzugeben. Denn darin könnten sich unreflektierte Haltungen zum Gegenstand finden, die sie auf diese Weise einfach weitergeben würde. Ihr geht es eher darum, die Bedingtheit einer jeden Position zu einem Thema, die Bedingtheit des Blicks und die denkbaren, darin enthaltenen Haltungen gegenüber dem Thema, herauszuarbeiten. Sie möchte darauf aufmerksam machen, dass bereits jede Position und jedes Klischee eine Antwort ist auf eine Herausforderung, die von einem Gegenstand, von einem Thema, ausgeht.

Hier besteht eine Parallele zur Ausbildung von Interessen an realen Gegenständen der Welt. Bernhard Waldenfels beschreibt sie so: Jedem Blick auf ein Thema in der Welt liege ein Interesse zugrunde. Ein solches Interesse könne als der erste (und entscheidende) Schritt verstanden werden, sich Herausforderungen gegenüber zu positionieren. Ohne Position gebe es kein Interesse - doch wie kommt es zu einer Positionierung? Waldenfels beantwortet dies bezüglich des wissenschaftlichen Interesses so: »Bemerkenswert ist die Tatsache, dass dieser Sichtweise zufolge der Forscher von einer Attraktion ausgeht, die sein `Gegenstand ‘ auf ihn ausübt. Allerdings kann die kulturelle Fremderfahrung auch von einer Repulsion ausgehen oder von einer Mischung von Repulsion und Attraktion« (Waldenfels 1997: 103; Hervorhebung im Original). Der Blick des Forschers antworte auf einen Anreiz oder Anspruch. Der Begriff der Haltung, die die künstlerische Dokumentarfotografie in ihrer Ambivalenz auf eine Herausforderung spürbar machen möchte, bezieht sich auf dieses grundsätzliche Angezogen- oder Abgestoßensein, die die Position gegenüber den eigenen Gegenständen charakterisieren. Die Haltung konstituiert den Gegenstand mit. Dies geschieht, noch bevor dieser einer rationalen und wissenschaftlichen Untersuchung unterworfen wird.

Wie ein Interesse die erste Antwort auf die Herausforderung zur Positionierung gegenüber der Welt ist, ist die Wahrnehmung von Bildlichkeit die erste Antwort auf die Irritation der ikonischen Differenz, die von einem Bildmedium ausgeht. Die bildliche Wahrnehmung eines Bildobjekts - und nicht die irritierender Graustufen - ist die erste Antwort auf diese Herausforderung. Doch so wie ein Interesse eine weitergehende Beschäftigung verlangt, genügt auch die Wahrnehmung eines Bildobjekts nicht, der Irritation des Bildes zufrieden stellend zu begegnen. Die Wahrnehmung eines Bildes als transparentes Zeichen - sozusagen als Aussage - und die damit verbundene Zuschreibung einer Referenz auf ein Bildsujet, beruhigt als weiterführende Antwort auf die pikturale Herausforderung der Irritation. Doch dies kommt eben häufig der schnellstmöglichen Aneignung gleich (vgl. Abschnitt 3.2.2.). Dabei wird die zugrunde liegende, die Konstitution der Sichtweise auf einen Gegenstand mitbestimmende Haltung unreflektiert übernommen. Dagegen wendet sich die künstlerische Dokumentarfotografie. Sie will zwar nach wie vor ein Thema, einen Gegenstand zeigen, doch versucht sie, die Irritation aufrecht zu erhalten. Sie sucht hierfür, das Wechselspiel zwischen semiotischer Funktion eines Bildes und seiner eigenen, spezifischen Bildlichkeit zu nutzen. Ziel ist es, sich des Eindrucks idealer Transparenz des Bildes zu verweigern. Das Bild soll nicht als Aussage, dass ein Gegenstand so oder so ist, verstehbar werden. Vielmehr soll die Frage oder auch die Herausforderung an die Bildbetrachter weitergereicht werden, die die Fotografierenden zur Thematisierung dieser Gegenstände, Situationen oder $\mathrm{Zu}$ stände gebracht hat. In der künstlerischen Dokumentarfotografie wird nicht eine fertige Leseweise bestimmter Phänomene der Welt präsentiert, sondern versucht, die Herausforderung selbst weiterzugeben. Die Betrachter sollen 
sich aufgefordert fühlen, sich einerseits von der Haltung der Fotografierenden zu emanzipieren, um sich so andererseits eine eigene Position gegenüber den Themen zu bilden. Es soll verhindert werden, dass sie eine vorab konfektionierte Meinung und Haltung, eine womöglich stereotype Aneignung, übernehmen.

\section{Zusammenfassung}

Die Wurzeln des Begriffs des Dokumentarischen liegen in der Theorie des Films. Erst 1926 wird versucht, dokumentarische Praktiken begrifflich von inszenierten zu unterscheiden. Die Dokumentarfotografie ist aber, entgegen ihrer Begrifflichkeit, kein homogenes Genre, das sich einfach von anderen unterscheiden ließe. Weil sowohl in der Kunst als auch im angewandten Bereich dokumentarisch gearbeitet wird und die verschiedenen Praktiken unterschiedliche Intentionen und Ziele verfolgen, ist eine Definition kaum möglich. Das Verhältnis zwischen Bild und Welt, das aufgrund einer indexikalischen Verbindung zustande kommt, zeigt sich heute als Argument für die Realitätsnähe der Dokumentarfotografie nicht haltbar. Vielmehr wird entsprechend einer semiotischen Bildtheorie, die Bilder als Zeichen begreift, das Indexikalische in einen zeichenhaften Gebrauchskontext überführt. Das Bild wird funktional verwendet. Dies bezieht sich beispielsweise auf die Nutzung von Dokumentarfotografie als Beweis. Allerdings wird vor Gericht nicht das Foto allein als Beweis akzeptiert, vielmehr muss es in einem sehr aufwändigen Verfahren erst als Dokument bestätigt werden. Auch dies zeugt davon, dass Wahrheit keine intrinsische Bedingung dokumentarischer Fotografie ist. Der semiotischen steht eine wahrnehmungstheoretische Auffassung entgegen. Nach dieser produzieren Bilder eine eigenständige Bildwirklichkeit. Neben dem Weltbezug stellt sich auch hier die Frage nach der Authentizität. Gemäß dem Semiotiker Barthes ist Fotografie durchaus in der Lage, Wahrheit zu vermitteln. In seiner mystisch wirkenden Theorie entsteht ein fotografisches Paradox, weil Fotografien einerseits unkodierte Botschaften vermitteln, es aber Botschaften ohne Code nicht geben kann. Nach Barthes können sich Bildzeichen einer Referenz entziehen, wenn sie zu traumatisch sind, um in das Bezugssystem des Betrachters eingeordnet werden zu können. Goodman, für den Bilder immer Zeichen sind, geht von einem pragmatischen Wahrheitsbegriff aus, so dass wahre Aussagen mittels eines passenden Bezugs konstruiert werden können. Weil aber die Bedeutung des fotografischen Bildes relativ unbestimmt ist, können Bedeutungen auch über eine Kontextualisierung hergestellt werden.

Dokumentarfotografie besteht ohne Inszenierung und Manipulation der Aufnahme und setzt nicht auf eine das Motiv überformende Ästhetik. Sie beschäftigt sich oft mit sozialen Themen und Bereichen, die kaum beachtet werden. Dennoch sind ihr inhaltlich keine Grenzen gesetzt. Insbesondere im angewandten Bereich wird sie meist dazu verwendet, Aussagen zu machen. Die sinnvolle Bezugnahme auf ein Referenzobjekt verleiht ihr Bedeutung. Im künstlerischen Bereich ist die Frage nach der Bedeutung komplexer, weil hier mitunter semiotische Erklärungsansätze nicht ausreichen. Es geht nicht zwingend um das Lesen der Bilder, sondern um das Sichtbarmachen von Phänomenen im Bild, die in einer reinen Sichtbarkeit bestehen.

In ihrer Frühzeit gilt als Ziel der Dokumentarfotografie Aufklärung und Bildung. Davon kann heute keine Rede mehr sein, wobei die Informationsabsicht in der angewandten Dokumentarfotografie nach wie vor besteht. Insbe- 
sondere der künstlerische Ansatz sucht heute nach Wegen, mit Referenz und Bildwirkungen zu experimentieren, um sich anhand eines Interesses und einer Haltung gegenüber der Welt zu positionieren. Im Wissen um ihre mediale Bedingtheit sucht sie danach, die dem Bild innewohnende Irritation nutzbar zu machen und an den Betrachter weiterzugeben. In diesem Sinne scheint sie besonders geeignet für die Auseinandersetzung mit dem Fremden, mit dem man anlässlich von Gegenständen konfrontiert ist, ohne dass es selbst gegenständlich zugänglich wäre. Das Fremde ist kein Gegenstand. 


\section{GebrauchSWEISEN DER DOKUMENTARFOTOGRAFIE}

In ihrer über 150-jährigen Geschichte ist die Fotografie immer wieder zur $\mathrm{Ab}$ bildung des Fremden eingesetzt worden. Bereits in der Vorstellung der neuen Erfindung vor der französischen Académie des Sciences im Jahr 1839 betont Dominique François Arago den Nutzen, den die Daguerreotypie im Einsatz auf Expeditionen und in der Erkundung fremder Länder haben werde (vgl. Arago 1980: 51f.). Diese Gebrauchsweise der Fotografie ist mit ganz unterschiedlichen Intentionen ins Werk gesetzt worden, so dass sowohl verschiedene Wissenschaften oder die Kunst als auch der Unterhaltungs- und Privatsektor davon profitiert haben und noch heute profitieren. Ziel des Einsatzes der Fotografie in der Fremde ist in fast allen Gebrauchsweisen die Überbrückung der Distanz zwischen dem Alltäglichen und dem Fremden, sei es zum Erkenntnisgewinn oder zur Erbauung, zu Erinnerungszwecken oder als Ersatz für Reisen, die nicht gemacht werden können. Es geht um die Darstellung des Fremden. Das Fremde soll möglichst authentisch in den Fotografien gezeigt werden. Die Dokumentarfotografie scheint für die Visualisierung der Erfahrungen mit dem Fremden geradezu prädestiniert.

$\mathrm{Zu}$ unterscheiden sind zunächst die verschiedenen dokumentarfotografischen Gebrauchsweisen, da sie unterschiedlichen Erwartungen und Prämissen unterliegen, die sich entsprechend auf die Resultate auswirken. Von Interesse ist insbesondere die Unterscheidung zwischen künstlerischen und angewandten Gebrauchsweisen. Denn wenn gerade die künstlerische Auseinandersetzung nach Jamme (vgl. Jamme 2002: 200f.) besonders geeignet scheint, um das Fremde unverfälscht zu erfassen, muss sie in ihren Voraussetzungen und Funktionen von den angewandten Praktiken unterschieden werden. Gibt es Möglichkeiten, künstlerische Dokumentarfotografien eindeutig von angewandten abzugrenzen? Wie hat sich die künstlerische Dokumentarfotografie historisch entwickelt? Was ist die Rolle des Fotografen? In diesem Kapitel werden einige grundsätzliche Voraussetzungen des künstlerischen Gebrauchs der Dokumentarfotografie diskutiert. Weil diese Form der Auseinandersetzung mit dem Fremden im zweiten Teil der Arbeit zentral ist, sind hier noch keine konkreten Beispiele der künstlerischen Dokumentarfotografie angeführt.

In der Untersuchung angewandter dokumentarfotografischer Gebrauchsweisen werden solche betrachtet, die sich konkret mit dem Fremden beschäftigen. Dazu gehören die Reisefotografie, die ethnografische sowie die journalistische Fotografie. In einem kurzen historischen Überblick wird jeweils auf deren historische Entwicklungen eingegangen sowie - wenn vorhanden ein Bezug zu Japan gesetzt. Schließlich werden zeitgenössische Beispiele für ihren Gebrauch gegeben. 
Reisefotografie gibt es seit Erfindung des Mediums. Menschen reisen mit der Kamera in fremde Länder und fotografieren dort. Da ihre Intentionen und Ansprüche unterschiedlich sind, lassen sich bald verschiedene Ansätze unterscheiden. Die klassische Reisefotografie existiert jedoch bis heute. Welchen Zweck erfüllt sie und wie verhält sie sich zu Fragen des Dokumentarischen? Lassen sich Fotografien eindeutig dem Genre Reisefotografie zuordnen, wenn sie bestimmte Bedingungen erfüllen?

Als eine wissenschaftliche Nutzungsform hat sich von Anbeginn die ethnografische Fotografie entwickelt. Im Sinne der ethnologischen Wissenschaft wird sie zur Darstellung fremder Völker und Kulturen eingesetzt. Welchen Ansatz wählen Ethnologen in ihrem Gebrauch der Fotografie? Wie werden ethnografische Fotografien verwendet und welche Intention verfolgen sie?

Der Fotojournalismus - im Sinne der modernen Bildreportage - entsteht erst im ersten Drittel des zwanzigsten Jahrhunderts. Mit journalistischen Mitteln werden Fotoreportagen in fremden Ländern produziert und publiziert. Welche Darstellungsformen zeichnet die Bildreportage aus? Wie vermittelt sie die Fremde? Lässt sie sich durch Bildauffassung und Intention von der Reisefotografie unterscheiden?

Unabhängig von der Intention der Fotografie ist für die Herausbildung stilistischer Methoden die technische Entwicklung des Mediums Fotografie ausschlaggebend. Es liegt nahe, dass ein kompliziertes technisches Verfahren mit langen Belichtungszeiten andere bildliche Ergebnisse hervorbringt als eine einfach zu benutzende Technik mit kurzen Belichtungszeiten. Die Handhabung der Technik ist Grundvoraussetzung für die Herangehensweise der Fotografen, was im nachfolgenden Kapitel jedoch nicht mehr explizit erörtert wird. Deshalb möchte ich hier kurz einige Entwicklungen skizzieren, ohne die technischen Parameter allzu umfassend zu erläutern: ${ }^{1}$

Zeitgleich entwickeln Louis Jaques Mandé Daguerre und William Henry Fox Talbot die ersten fotografischen Verfahren, die beide durch extrem lange Belichtungszeiten gekennzeichnet sind. Talbots Kalotypie hat gegenüber der Daguerreotypie den Vorteil, dass es sich um ein Negativ-Positivverfahren handelt und somit eine Vervielfältigung durch Kontaktkopien möglich ist. Während Daguerres Verfahren jedoch über die französische Akademie der Wissenschaften der Öffentlichkeit frei zugänglich gemacht wird, überwacht Talbot seine Patentrechte und verlangt Lizenzgebühren (vgl. Newhall 1984a: 58).

Um 1850 entwickelt Frederick Scott Archer das nasse Kollodiumverfahren, das als Trägermaterial Glasplatten benutzt, die wesentlich besser für Kontaktkopien geeignet sind als die Papiernegative der Kalotypie. Auch die Belichtungszeiten sind nun kürzer, wobei das Stativ nach wie vor unverzichtbar ist. Die Platten müssen jedoch in nassem Zustand verarbeitet werden. Sie werden beschichtet, in nassem Zustand belichtet und sofort entwickelt. Der Fotograf darf sich nie weit von seiner Dunkelkammer entfernen, was für Außenaufnahmen das Mitführen beispielsweise eines Dunkelkammerzelts oder -wagens und sämtlicher Chemikalien notwendig macht. Ähnlich den vorherigen Verfahren muss wegen des großen Aufwands jede Belichtung genau durchdacht und komponiert werden (vgl. z.B. Gautrand 1998a: 158; Newhall 1984a: 61).

1 Die technischen Entwicklungen erläutert ausführlich z.B. Newhall 1984a. 
In den siebziger Jahren des neunzehnten Jahrhunderts wird schließlich die Trockenplatte von Richard Leach Maddox entwickelt. Dieses Verfahren ermöglicht eine fabrikmäßige Herstellung der Platten, so dass der Fotograf sich nun ganz auf die Fotografie selbst konzentrieren kann, ohne am Ort der Aufnahme Laborarbeiten verrichten zu müssen. Zudem sind die Gelatineplatten wesentlich lichtempfindlicher und erlauben nun Belichtungszeiten von Sekundenbruchteilen, was auch die Aufnahme von bewegten Situationen ohne Bewegungsunschärfen ermöglicht. Die Standardisierung der fotografischen Emulsionen stellt weiterhin eine erhebliche Verbesserung des fotografischen Verfahrens dar (vgl. Newhall 1984a: 128ff.). Die Kameras sind jedoch nach wie vor groß und sperrig und die Glasplatten empfindlich, so dass sie beim Transport brechen und wertvolle Negative verloren gehen können.

Gegen Ende des neunzehnten Jahrhunderts eröffnet die Entwicklung von Handkameras neue Einsatzmöglichkeiten der Fotografie. ${ }^{2}$ Die Konstruktion lichtstarker Objektive sowie die Weiterentwicklung der Labortechnik führen dazu, dass nicht mehr ausschließlich Kontaktkopien im Negativformat gemacht, sondern Vergrößerungen angefertigt werden können. Das »Ganzplatten-Format « beträgt 16,5 x 21,6 cm, doch nun werden auch Kameras gebaut, mit denen Glasnegative im Format 4,5 x $6 \mathrm{~cm}$ belichtet werden können (Newhall 1984a: 27). ${ }^{3}$ Im Jahr 1924 erscheint auf dem deutschen Markt die Ermanox, eine Kamera ausgestattet mit einem besonders lichtstarken Objektiv und einem Schlitzverschluss, der Belichtungszeiten von 1/1000 s zulässt. Obwohl es sich hier noch um eine Plattenkamera handelt, erlaubt sie dennoch unauffällige Aufnahmen in Innenräumen, wie sie beispielsweise Erich Salomon berühmt gemacht haben. Ebenfalls 1924 kommt die Leica auf den Markt. Diese erste Kleinbildkamera verwendet Kinofilmmaterial. Sie bietet Fotografen eine bislang ungekannte Mobilität, da ohne Filmwechsel 36 Aufnahmen direkt hintereinander möglich sind.

Mit den unterschiedlichen Kameratypen und Aufnahmeformaten haben Fotografen nun große Wahlmöglichkeiten. Die Großformatfotografie ermöglicht eine hohe Präzision und detailgenaue Abbildung unter Verwendung eines Stativs, während der Fotograf mit der Kleinbildkamera große Flexibilität und Schnelligkeit erlangt. Verschiedene Zwischenformate bilden Schnittmengen zwischen diesen Polen. Bestimmte im neunzehnten und zu Beginn des zwanzigsten Jahrhunderts die Entwicklung der fotografischen Technik die Bildauffassung, benutzen Fotografen heute eine ihrer Arbeitsweise und Bildauffassung entsprechende Technik. Neben der fotografischen Technik sind auch die Druckverfahren wichtig für die Verbreitung und Rezeption von Fotografien. Ohne die Entwicklung des Offsetdrucks um 1910 ist beispielsweise eine mit Fotografien illustrierte Massenpresse undenkbar. ${ }^{4}$ Die technischen Neuerungen sind für die Entwicklung der Bildsprache essenziell, im Folgenden wird dies jedoch nicht erneut thematisiert.

2 Für den Amateurbereich bringt Kodak 1888 die erste Box-Kamera auf den Markt und wirbt mit dem Slogan: "You press the button, we do the rest" (vgl. http://www.kodak.com/US/en/corp/kodakHistory/: 15.07.2008).

3 In der Landschaftsfotografie werden jedoch oft Platten mit Formaten bis zu $70 \mathrm{x}$ $100 \mathrm{~cm}$ eingesetzt (vgl. Heilbrun 1998).

4 Eine ausführliche Erläuterung der Reproduktionsverfahren findet sich z.B. bei Albert/Feyel 1998. 


\subsection{Künstlerische Dokumentarfotografie}

Die Unterscheidung zwischen angewandter und künstlerischer Dokumentarfotografie ist nicht ganz einfach, denn weder der abgebildete Gegenstand noch die Art der Darstellung führen zu einer eindeutigen Zuordnungsmöglichkeit. Der Hinweis, die Kunstfotografie

»sei als zweckfreie nur dem Gesetz ihres Schöpfers unterworfen, [greift] so wenig [...] wie die kunstheiligenden Begriffe aus dem Geist ästhetischer Theorien, die hier das Erhabene ehren und dort das Triviale verteufeln. Wenn Thomas Ruff als Fotograf seinen Anspruch auf Künstlertum mit der Ausbildung und dem Abschluss an einer Kunstakademie rechtfertigt, so macht er ganz lapidar auf den institutionellen Rahmen aufmerksam, in dem etwas zur Kunst wird« (Jocks 2004: 58).

Im vorigen Kapitel sind bereits einige Unterschiede zwischen dem künstlerischen und dem angewandten Feld angesprochen worden, diese werden hier noch weiter ausdifferenziert. Ein entscheidender Faktor ist immer die Gebrauchsweise, die zur Entstehungszeit in enger Beziehung zur Intention des Fotografierenden steht. Fotografien, die im Auftrag eines Reisemagazins entstehen, werden zunächst eindeutig diesem Gebrauchskontext zugeordnet. $\mathrm{Zu}$ einem späteren Zeitpunkt können sie möglicherweise als künstlerische Äußerungen gelten und im Kunstkontext rezipiert werden. Denn der zeitliche Abstand zur Entstehungszeit kann dazu führen, dass Irritationen aufbrechen, die die Bilder Fragen stellen lassen, die früher gar nicht aufgekommen sind. Von daher lassen sich keine Parameter definieren, die langfristig oder gar endgültig über die Zuordnung als künstlerische oder angewandte Dokumentarfotografie entscheiden. Dennoch beeinflusst die ursprünglich intendierte Gebrauchsweise zahlreiche Aspekte der fotografischen Arbeit von der Wahl des Themas über die Art der Darstellung bis hin zur Zusammenstellung der Fotografien und die Form der Publikation. In einer künstlerischen Dokumentarfotografie entscheidet der Fotograf in der Regel eigenständig über diese Parameter und hat somit einen großen Einfluss auf das Ergebnis. Die von Auftraggebern unabhängige Arbeitsweise räumt ihm gleichzeitig große gestalterische Freiräume ein, denn im Gegensatz zur angewandten muss eine künstlerische Dokumentarfotografie nicht leicht verständlich sein oder Sachverhalte eines beigefügten - beispielsweise journalistischen - Textes visuell illustrieren. Sie darf wie im vorigen Kapitel erläutert - mit Irritationen spielen und Fragen stellen.

Die Debatte darum, ob die Fotografie Kunst sei oder nicht, ist so alt wie das Medium selbst. Ihren Ursprung hat sie im ästhetischen Diskurs des achtzehnten Jahrhunderts, der eine Grenze zieht zwischen Technik und Wissenschaft auf der einen und Kunst auf der anderen Seite. Weil die Fotografie als technisches Medium der ersten Seite zugeordnet wird, ist ihr künstlerischer Gebrauch damit zunächst generell ausgeschlossen (vgl. Plumpe 1990: 18). Zudem gilt zur selben Zeit die Mimesis, lange Zeit Ideal jedes künstlerischen Schaffens, nurmehr als Kopie (vgl. ebd.: 24). Die Fotografie, deren exakte Wiedergabe der Welt Arago ausdrücklich anpreist, wird entsprechend als reproduktives Medium gesehen. Sie gilt als technischer Vorgang, dessen 
Handhabung keiner besonderen Fähigkeiten bedarf. ${ }^{5}$ Fotografien werden als mechanische Kopien der sichtbaren Welt gesehen, „während es authentischer Kunst gerade um die Transformation der phänomenalen Wirklichkeit in anschaulich vermittelte und von Zufälligkeiten gereinigte Essentialität zu tun ist « (Plumpe 1990: 32; Hervorhebung B.L.). Nach dieser Argumentation »kann die Photographie Kunstcharakter nur erlangen, wenn ihr Verfahren Individualisierung zuläßt, « wenn der Künstler »den technischen Apparat seiner kreativen Intention zu unterwerfen vermag« (ebd.: 49). Erst wenn die Zufälligkeit der Aufnahme und die Möglichkeit der mechanischen Reproduktion überwunden sind, wird in diesem Sinne die Kamera ein mit dem Pinsel vergleichbares Werkzeug, das der Künstler in einer individuellen Herangehensweise verwenden kann. Nur dann können ihre Erzeugnisse entsprechend als Kunst gelten. Eine obiger These entsprechende individualisierte Anwendung der fotografischen Technik findet zum Ende des neunzehnten Jahrhunderts erstmalig ihren Ausdruck im Piktoralismus. Mit speziellen Drucktechniken wird versucht, die fotografische Präzision zu brechen und der Fotografie eine malerische Note zu verleihen. Nur aufgrund ihrer Ähnlichkeit zur Malerei wird diese Art der Fotografie zunehmend als Kunst akzeptiert (vgl. z.B. Hammond 1998; Bunnell 1998; Newhall 1984a: Kap. 9, 145ff.). Es ist aber gerade nicht die medienspezifische Qualität, an der der Kunststatus festgemacht wird.

Erst im Laufe des ersten Drittels des zwanzigsten Jahrhunderts werden auch fotografische Fotografien als künstlerisch angesehen, wenngleich sie sich durch ihre herausragenden Bildkompositionen klar von damals als sozialdokumentarisch geltenden Positionen - beispielsweise eines Lewis Hine unterscheiden (vgl. z.B. Newhall 1984a: Kap. 9; Koenig 1998). »In direkter Opposition zum Piktoralismus [adaptiert] und [feiert] die straight photography [direkte Fotografie] Qualitäten, die zuvor nur im Bereich der Gebrauchsfotografie verwendet worden [sind] « (Pultz 1998: 477; Hervorhebung im Original). Die direkte Fotografie benutzt die fotografische Präzision als Ausdrucksmittel. Sie betont geradezu das Fotografische und rückt das Mechanische, das Technologische und das Formale in den Vordergrund. Die Motive entstammen meist dem modernen Alltagsleben, das durch eine zunehmende Technisierung geprägt ist (vgl. ebd.). Mit der Kamera lässt sich die »Schönheit im Alltäglichen« entdecken (Newhall 1984a: 178). Die Kamera »kann das Vertraute erfassen, ihm neue Bedeutungen, einen besonderen Sinn verleihen und ihm einen persönlichen Stempel aufprägen« (ebd.). Die direkte Fotografie verleiht ihrem Gegenstand Gewicht und widmet sich nicht ausschließlich von vornherein als wichtig Anerkanntem. Dies ist auch für die Entwicklung der künstlerischen Dokumentarfotografie relevant, denn auch sie verlässt sich nicht auf das Besondere. Unspektakuläres und Alltägliches werden in der künstlerischen Dokumentarfotografie häufig berücksichtigt. Im Vergleich mit der direkten Fotografie, die sich als Einzelbildfotografie um die Ästhetik des Bildgegenstands bemüht, verfolgt die Dokumentarfotografie inhaltlich andere Zielsetzungen. ${ }^{6}$

5 »Der Daguerreotyp verlangt keine Handhabung, die nicht alle ausführen könnten. Er verlangt keine Fähigkeiten im Zeichnen, keine manuelle Geschicklichkeit« (Arago 1980: 53).

6 Parallel zur straight photography entwickeln sich auch in Deutschland verschiedene Strömungen künstlerischer Fotografie. Laszlo Moholy-Nagy vertritt 


\subsubsection{Beschreibung versus Interpretation}

Überlegungen zur Dokumentarfotografie sind auch heute noch im Spannungsfeld zwischen (objektiver) technischer Reproduktion und (subjektiver) künstlerischer Interpretation angesiedelt. Obwohl - wie im vorigen Kapitel gezeigt - der theoretische Diskurs den objektiven Realismus der Fotografie überwunden hat, erweist sich der Glaube an Realitätsbezug und Wahrheitsgehalt dokumentarischer Fotografie auch heute als persistent. ${ }^{7} \mathrm{Um}$ angewandte von künstlerischen Praktiken der Dokumentarfotografie zu unterscheiden, sind Parameter wie objektiv und subjektiv nicht zulässig, weil es Objektivität in der Dokumentarfotografie nicht geben kann und dementsprechend jeder Ansatz mehr oder weniger subjektiv geprägt ist. Um hier eine präzisere Vorstellung der möglichen Unterscheidung von verschiedenen Gebrauchsweisen zu bekommen, ist noch einmal eine Bezugnahme auf die Begriffsbildung in der Filmtheorie sinnvoll.

Als John Grierson 1926 den Begriff documentary einführt, geht es vor allem um die Abgrenzung eines Genres, das keine Schauspieler, sondern »authentische Menschen« einsetzt (Lampe 2002: 69). Als weitere, für das Genre wichtige Punkte sind die folgenden angeführt: "natürlicher Hintergrund statt Dekoration, [...] authentische Geschehnisse statt ausgedachter Fabeln, [...] eine soziale Referenz der Interpretation der Wirklichkeit« (ebd.; vgl. Grierson 1998: 102). Gleichzeitig deckt der Begriff documentary aber gerade nicht den ganzen Bereich des nicht-fiktionalen Films ab, »Reportage-, Magazin- und Belehrungsfilme« werden unterschieden (Grierson 1998: 102). Grierson hofft, dass der Dokumentarfilm »die einfachsten künstlerischen Qualitäten« erreicht (ebd.). Der Dokumentarfilm wird von Grierson nicht nur zum Spielfilm, sondern auch zum (angewandten) Realfilm abgegrenzt und erhält einen künstlerischen Anspruch, den es zu erfüllen gilt. Der Dokumentarfilm hebt sich von anderen nicht-fiktionalen Filmen ab, die Filmtheoretiker Tom Gunning als »Ansichten« bezeichnet (Gunning 1995). »Ansichten beinhalten tendenziell die Aussage, daß das Gefilmte entweder bereits vor der Aufnahme existiert hat (Landschaften, Gebräuche, Arbeitsmethoden) oder auch ohne die Kamera stattgefunden hätte (Sportereignisse, Begräbnisse, Krönungen)« (ebd.: 114; Hervorhebung im Original). Die gefilmten Ereignisse

1927 einen Anspruch der »Fotografie als Kunst«. Er möchte eine »exakte Sprache des Fotografischen « entwickeln. Darunter versteht er unter anderem den Einsatz von Perspektiven (z.B. Vogel- und Froschperspektive), von speziellen (verzerrenden) Linsensystemen, von neuen Kameraarten, von Röntgen- und kameraloser Fotografie und speziellen Farbempfindlichkeiten (vgl. Kemp 1979: 72f.). Im Gegensatz dazu steht Albert Renger-Patzschs Entwurf für einen der Kunst verpflichteten fotografischen Realismus. Auch er möchte die eigenen Mittel der Fotografie einsetzen, beispielsweise um Natur und Pflanzen, Werke von Ingenieuren und Baumeistern oder die Materialität verschiedener Stoffe sichtbar zu machen. Gerade die mechanische und fotografische Abbildungsweise scheint ihm eine eigenständige Kunst der Fotografie zu ermöglichen (vgl. Kemp 1979: 74).

7 In einem Interview sagt der türkische Magnum-Fotograf Ara Güler: »Fotos zeigen die Wahrheit. Deswegen ist Fotografie auch keine Kunst, denn Kunst kann die Welt verfälscht darstellen. Wir Fotografen sind visuelle Historiker« (Jäkel 2007). 
bestehen insofern unabhängig vom Akt der Aufzeichnung. Die »Struktur dieser Filme [dreht] sich immer um die Präsentation von etwas Visuellem [...], um einen Blickfang oder einen besonderen Blickpunkt« (Gunning 1995: 114). Es geht hier häufig um eine Attraktion im Sinne einer »Betonung der Zurschaustellung und [der] Befriedigung der Schaulust« (ebd.). Diese Schaulust bezieht den Betrachter mit ein, denn die Kamera übernimmt den Standpunkt des Beobachters: »Wir erfahren eine Ansicht nicht einfach als die Darstellung eines Ortes, eines Ereignisses oder eines Prozesses, sondern gleichzeitig als Mimesis des Betrachtens selbst« (ebd.; Hervorhebung im Original). Die Kamera versucht, eine gute Sicht auf die Ereignisse zu liefern, so wie die agierenden Personen auch auf die Anwesenheit der Kamera reagieren und sich der Kamera zuwenden, ihr Dinge zeigen oder etwas vorführen. »In einer $A n$ sicht zeigt sich die Welt der Kamera und damit zeigt sie sich dem Zuschauer« (ebd. 115; Hervorhebung im Original). Das Material solcher Ansichten wird in der Filmsequenz seriell angeordnet. Im Schnitt werden die Einstellungen in eine logische Folge gebracht, die Anordnung geschieht nach zeitlichen oder räumlichen Gesichtspunkten (vgl. ebd.: 115f.).

Grierson nennt die Ansichten beschreibend und darstellend, "aber in einem künstlerischen Sinn zeigen sie sich nur selten« (Grierson 1998: 101). Der Dokumentarfilm hingegen dramatisiert. Im Dokumentarfilm nach Grierson »kommen wir von ungeschminkten [...] Beschreibungen von naturgegebenen Stoffen zu bestimmten Zusammenstellungen, Anordnungen und schöpferischen Gestaltungen dieser Stoffe« (ebd.: 102). Während Ansichten die Rolle des Beobachters einnehmen und versuchen, einen guten Blickwinkel auf ein Ereignis zu erhaschen, wird im Dokumentarfilm das - nicht-fiktionale - Material dramaturgisch verdichtet. Es wird nicht beschreibend verwendet, sondern etabliert eine eigene Erzählform. Der Schnitt spielt hierbei eine entscheidende Rolle. Die Interpretation der Realität beginnt allerdings nicht erst bei der Montage, sondern bereits bei den gewählten Einstellungen, beispielsweise dem Einsatz von Nahaufnahmen oder Totalen. Auf diese Weise wird es möglich, die »Bilder in eine Argumentation« einzubetten und sie »als Beweismittel zur Unterstützung oder Verstärkung eines Diskurses« zu verwenden (Gunning 1995: 117). Während die Beschreibung der sichtbaren Welt in Ansichten scheinbar objektiv daher kommt, eröffnet der Dokumentarfilm neue - kreative - Spielräume im Umgang mit nicht-fiktionalem Material. Der Filmemacher kann seine subjektive Haltung gezielt zum Einsatz bringen. Weil aber keine Schauspieler oder künstlich hergestellte Bühnendekorationen eingesetzt werden, gilt der Dokumentarfilm noch als Darstellung von Welt. ${ }^{8}$

Diese Unterscheidung zwischen Ansicht und Dokumentation kann in gewisser Weise auf die Gebrauchsweisen der Dokumentarfotografie übertragen werden. Auch hier ist der Unterschied zwischen angewandter und künstlerischer Praxis in der Differenzierung zwischen Beschreibung und Interpretation zu suchen. Angewandte Dokumentarfotografie kann tendenziell im Sinne einer Ansicht betrachtet werden, während die künstlerischen Gebrauchsweisen Parallelen zum Griersonschen Begriff des Dokumentarfilms aufweisen. Weitere Unterschiede sind in der Intention, der Herange-

8 Grierson bezeichnet den Film Nanook of the North (1922) von Robert Flaherty als einen der ersten Dokumentarfilme. Eine der wohl schärfsten Kritikerinnen des dokumentarischen Genres, Martha Rosler, bezeichnet solche Filme jedoch als »fiktive ethnographische Filme« (Rosler 1999: 145; Anmerkung 12). 
hensweise sowie der Art und Weise zu suchen, wie sich die Fotografie an den Betrachter wendet.

\subsubsection{Verschiedene Ansätze}

Innerhalb des Feldes der künstlerischen Dokumentarfotografie kann kaum von einem homogenen Umgang mit dem Begriff des Dokumentarischen gesprochen werden. Die Vielfältigkeit der künstlerischen Strategien manifestiert sich in verschiedenen Praktiken, die Timm Starl zu differenzieren versucht. Er unterscheidet drei verschiedene künstlerische Ansätze: die archivalische, die konzeptuelle und die dokumentaristische Gebrauchsweise (vgl. Starl 2002: $75 \mathrm{ff}.)^{9}$

Die archivalische Variante ist ein Ansatz, der unter den Gesichtspunkten der Aufzeichnung, Registrierung und Archivierung betrieben wird. Diese Art der Dokumentarfotografie versucht, eine möglichst objektive Sprache $\mathrm{zu}$ sprechen und die Welt so direkt wie möglich abzubilden. Gegenstände und Vorgänge werden »in ihrem Aussehen, Auftreten oder in ihrer Entwicklung möglichst umfassend und genau - manchmal in geradezu enzyklopädischer Vollständigkeit - aufgezeichnet, so dass das gewonnene Material bis zu einem gewissen Grad analytischen Ansprüchen genügt« (ebd.: 75). Als Beispiel für die archivalische Variante führt Starl das Projekt La Mission photographique de la DATAR an. ${ }^{10}$ Dass Fotografie nie objektiv sein kann, ist auch bei archivalischen Projekten grundsätzlich vorausgesetzt. Dennoch wird über die enzyklopädische Herangehensweise versucht, möglichst viele Facetten des Themas fotografisch abzudecken und so zu einer Zusammenschau verschiedener Sichtweisen zu gelangen. Darin liegt die Aussagekraft archivalischer Dokumentarfotografie begründet. Der Charakter archivalischer Projekte ist in der Regel langfristig angelegt und geht mitunter über die individuelle Arbeit eines einzelnen Fotografen hinaus. Diese Gebrauchsweise vertraut - im semiotischen Sinn - weitgehend auf den Verweischarakter des Bildes. Die Bedeutung der Fotografien konstituiert sich aus der Referenz zum Dargestellten. Die Fotografien wollen Aussagen über den dargestellten Gegenstand machen.

Dem konzeptuellen Ansatz wird im Bereich der Kunst die größte Aufmerksamkeit gewidmet. Hier »wird eine Vorgehens- oder Betrachtungsweise gewählt, ohne auf die Funktion des Gegenstands, das Verhalten von Personen oder das jeweilige Erscheinungsbild der Motive Rücksicht zu nehmen « (Starl 2002: 75). Unterschiedliche Objekte und Geschehnisse werden auf eine immer gleiche Weise ins Bild gerückt. Der Aufnahmestil tritt in den Vordergrund, während das Bildmotiv keine primäre Position einnimmt. Es entstehen serielle Einzelbilder, deren Zusammenhalt vor allem durch formale Kriterien

9 Starls Begriffsbildung mag problematisch anmuten, dennoch möchte ich ihr hier aus pragmatischen Gründen folgen.

10 Dabei handelt es sich um eine in der Tradition der Mission Héliographique (1851) und der FSA von der französischen Regierung beauftragte fotografische Bestandsaufnahme der landschaftlichen Gegebenheiten Frankreichs (19841988). Beteiligt sind zahlreiche namhafte Fotografen aus dem In- und Ausland, z.B. Robert Doisneau, Sophie Ristelhuber, Lewis Baltz, Gabriele Basilico. Vgl. z.B. Paysages Photographies. La Mission Photographique de la DATAR. Travaux en Cours 1984/1985, Kat. (Palais de Tokyo, Paris), Paris 1985. 
geprägt ist. Eine vergleichende Betrachtung ist in der Serie angelegt. Die Aussage über den Gegenstand ist eingeschränkt, da die jeweilige Herangehensweise nicht individuell an das Motiv angepasst wird. Solche künstlerischen Projekte bedienen sich zwar der dokumentierenden Funktion des fotografischen Apparats, verwenden aber eher malerische Strategien, so dass das Ergebnis sich tendenziell auf die Vorstellungen des Künstlers und nicht auf die Welt bezieht. Die großformatige Art der Präsentation erinnert an Formate der Malerei und stellt einen hohen ästhetischen Anspruch an das Einzelbild. Die in diesem Ansatz oftmals praktizierte digitale Bearbeitung der Bilder zeugt davon, dass der Indexikalität keine Bedeutung mehr zukommt. Die Bilder koppeln sich vollständig von der Realität ab und vermitteln als Bilder ausschließlich ihre eigene Wirklichkeit (vgl. Sachsse 2003: 178). Dem konzeptuellen Ansatz liegen Ideen der Konzeptkunst zugrunde, auf Entwicklungen innerhalb der Fotografiegeschichte wird kaum zurückgegriffen. Die Künstler der Düsseldorfer Becher-Schule - beispielsweise Andreas Gursky und Thomas Struth - sind Vertreter des von Starl konzeptuell genannten Ansatzes. Es ist jedoch fraglich, ob diese künstlerische Praxis überhaupt noch fotografisch genannt werden kann, da sich ihre Vertreter nicht als Fotografen begreifen und mitunter sogar die Teilnahme an Fotoausstellungen verweigern (vgl. ebd.).

Die dokumentaristische Herangehensweise erlaubt eine dezidiert individuelle Haltung des Fotografierenden. Es werden Erscheinungen »im Hinblick auf ihre Wirkung, die sie auf den oder die BildautorIn ausüben, dargestellt, wobei deren individuelle Erfahrungen und das aktuelle Empfinden maßgebend die Wahl der Motive und die kompositorischen Elemente bestimmen « (Starl 2002: 75). Diese Variante erlaubt eine persönliche Herangehensweise und Auseinandersetzung mit dem gewählten Thema und bietet dem Fotografierenden einen großen Freiraum im Einsatz der gestalterischen Mittel. Fotografische Arbeiten des dokumentaristischen Ansatzes setzen sich intensiv mit ihrem Gegenstand auseinander. In diesem Ansatz besteht die Möglichkeit der Umsetzung von Jammes Vorstellung, dass »nur die Kunst [...] das Fremde so [darstellen] kann, daß es nicht vergewaltigt wird « (Jamme 2002: 191). Nicht die beschreibenden Qualitäten sind nach Jamme wichtig, sondern die individuelle Umsetzung in der künstlerischen Arbeit. Projekte des dokumentaristischen Ansatzes beschäftigen sich insbesondere mit Fragen der Sichtbarkeit fotografischer Bilder. Sie spielen mit den Irritationen der ikonischen Differenz. Gleichzeitig versuchen sie, die Referenz zu transzendieren und auf diese Weise zu einer eigenständigen Bildwirklichkeit zu gelangen. Entscheidend ist nicht der Verweischarakter im semiotischen Sinne, sondern die Sichtbarmachung von Phänomenen im Bild (vgl. hierzu Teil I, Abschnitt 3.2.4.). Somit ist diese dokumentarfotografische Variante am ehesten dazu prädestiniert, einen eigenständigen Beitrag zur Auseinandersetzung mit dem Fremden als Fremden zu leisten. Im Folgenden wird primär auf die Entwicklungen dieser Herangehensweise eingegangen.

\subsubsection{Frühe künstlerische Dokumentarfotografie}

Als die Fotografie mittels Brechung der fotografischen Präzision im Piktoralismus zur Jahrhundertwende zwischen dem neunzehnten und dem zwanzigsten Jahrhundert erstmals als künstlerisches Medium anerkannt wird, dokumentiert der Fotograf Eugène Atget das alte - durch Sanierungsmaßnahmen ver- 
schwindende - Paris. Er arbeitet mit einer technisch längst überholten Plattenkamera und erzeugt Bilder, die eine hoch auflösende Präzision aufweisen. Ein Schild an seiner Ateliertür besagt, dass er »Documents pour Artistes« (Dokumente für Künstler) herstellt (Szarkowski 1985: 29). Er verkauft seine Fotografien nicht nur als Vorlagen an Maler, sondern auch an verschiedene Pariser Stadtarchive, an Architekten, Theater- und Innenausstatter sowie an Kunsthandwerker (vgl. Martinez 1978: 11). Seine Fotografien werden vor allem als Dokumente wahrgenommen, die der Umgestaltung der französischen Hauptstadt geopferte Architekturformen zeigen. Im Sinne der ursprünglichen Bedeutung des Begriffs Dokument erhellen Atgets Bilder Sachverhalte der Pariser Architektur, was insbesondere im Hinblick auf die zukünftigen städtebaulichen Veränderungen bedeutsam ist (vgl. Honnef 1978: 18f.).

Die amerikanische Fotografin Berenice Abbot lernt Atget 1926, kurz vor dessen Tod, kennen und entdeckt in seinen Fotografien Qualitäten, die weit über das von einem Dokument erwartete sachlich Beschreibende hinausgehen. Kurz nach seinem Tod gelangen Atgets Fotografien in Ausstellungen und Zeitschriften an die Öffentlichkeit. In der Folge wird er zum Vorläufer der modernen Fotografie stilisiert (vgl. Szarkowski 1985: 9ff.). Berenice Abbot, die zahlreiche Bilder aus dem Nachlass Atgets erwirbt, richtet das Augenmerk in der Betrachtung von Atgets Werk weg von Fragen der Kategorisierung (Fotografie als Kunst oder nicht) hin zur schöpferischen Leistung Atgets und den neuen Möglichkeiten seines Werks (vgl. ebd.: 15). Die einfache und ehrlich wirkende Ausrichtung von Atgets Fotografien und sein persönlicher Standpunkt werden als künstlerische Leistungen gewertet. In einer Buchbesprechung schreibt der Fotograf Walker Evans im Jahr 1931: »Im allgemeinen ist bezeichnend für ihn eine eher lyrische Auffassung der Straße, deren geübte Beobachtung, ein besonderes Gefühl für Patina, der Blick für das erhellende Detail, dies alles überfangen von einer Poesie, die nicht die $>$ Poesie der Straße $<$ ist oder die >Poesie von Paris $\measuredangle$, sondern die Projektion von Atgets Persönlichkeit« (Evans 2000: 81; dt. Übersetzung nach: Szarkowski 1985: 17). Der nach seinem Tod einsetzenden Rezeption zufolge liegt Atgets Leistung nicht mehr ausschließlich in der akribischen Beschreibung der sichtbaren Welt, sondern in der individualisierten Sichtweise, der »geübten Beobachtung « und der persönlichen Auffassung, die in den Fotografien sichtbar wird. Szarkowski wertet ihn in den achtziger Jahren des zwanzigsten Jahrhunderts als bewussten Künstler, »der in seinen letzten Lebensjahren als er sein Handwerk selbstsicher beherrschte und seine Vorstellung von der Welt einfacher wurde, eindringlicher und reicher an Überraschungen - die olympische Heiterkeit des Entdeckers einer neuen Ordnung im Chaos kannte" (Szarkowsi 1985: 29). Atget gelinge eine Transformation und lyrische Interpretation des Sichtbaren innerhalb seiner Arbeit, weshalb sie als künstlerische gewertet werden könne. Nach seinem Tod erlangt Atgets Werk große öffentliche Aufmerksamkeit und beeinflusst nachhaltig zahlreiche jüngere Fotografen (vgl. ebd.: 15ff.).

Im ersten Drittel des zwanzigsten Jahrhunderts gilt neben Atget auch der deutsche Fotograf August Sander als ein Wegbereiter der dokumentarischen Fotografie. In einem groß angelegten Mappenwerk möchte er in einem reinen fotografischen Stil, der sich auf die Anfänge der Fotografie beruft, die »Menschen des 20. Jahrhunderts« porträtieren. Sander ist fasziniert von der fotografischen Möglichkeit, »Bildnisse zu schaffen, die die Betreffenden unbedingt wahrheitsgetreu und in ihrer ganzen Psychologie wiedergeben« (Brief von 
August Sander an Erich Stenger; zit. nach: Dewitz 2007: 50). Sander thematisiert insbesondere die Darstellungsweise. Die Besonderheit an Sanders Porträtwerk liegt in dem Gesamtkonzept, in dem sich »jedes einzelne Bild als Teil zu einem Mosaik« zusammenfügt und das gerade nicht einzelne Bilder in seriellen Bildabfolgen anhäuft (Dewitz 2007: 59f.). Walker Evans sieht in Sanders Publikation Antlitz der Zeit von 1929 eine »der von Atget prophezeiten Zukünfte der Fotografie« (Evans 2000: 84).

Walker Evans entwickelt sich in den 1930er Jahren selbst zu einem wichtigen Vertreter der künstlerischen Dokumentarfotografie. In seinem Ansatz formuliert er einige Ideen weiter aus, die er bereits bei Atget beobachtet hatte. Mit dem Beginn seiner Arbeit für die Resettlement Administration $(\mathrm{RA})^{11}$ im Jahr 1935 beginnt eine seiner wichtigsten Schaffensperioden. Evans sieht sich selbst als Künstler, der für den »kreativen Akt « lebt (Hurley 1974: 48). Dies führt mitunter zu Problemen, da er bei einer Regierungsbehörde angestellt ist, die eine bestimmte Zielsetzung mit den von ihr beauftragten Fotoprojekten verfolgt. Evans ist seine eigene Arbeitsweise jedoch wichtiger, so dass er 1937 aus der Regierungsbehörde aussteigt, um an frei konzipierten Projekten zu arbeiten (vgl. ebd.: 66).

Evans reflektiert den Dokumentarbegriff in Bezug auf seine Arbeit und plädiert für die Formulierung documentary style, da er den Begriff documentation eher mit der »Polizeifotografie eines Tatorts« in Verbindung bringt (The Estate of Walker Evans 1982: 216). Er befreit

»mit seinem Ansatz die Dokumentarfotografie aus dem Kontext des Instrumentellen, der Erziehung, der Agitation. Evans manifestiert einen Avantgardebegriff für die künstlerische Fotografie, der die Verbindung von künstlerischem Experiment und die Erweiterung fotografischer Ausdrucksmittel mit der Besinnung auf die Grundformen des fotografischen Mediums verbindet. Obwohl dies auch bedeutet, daß inhaltliche Bedeutung ambivalent wird, gibt Evans einen aufklärerischen Anspruch nie auf« (Neumann 1996: 79).

Die Auffassung der Ambivalenz der inhaltlichen Bedeutung scheint zu bestätigen, dass in einer dokumentaristischen Fotografie nach Walker Evans die Zuschreibung von Bedeutung sekundär wird. Evans gelingt es, die vorher diametral entgegen gesetzten Ansprüche der (sozial)dokumentarischen und der künstlerischen Fotografie zusammen zu bringen. Verfolgten frühere (sozial)dokumentarische Projekte - beispielsweise eines Lewis Hine - einen aufklärerischen Anspruch, transformiert Evans das Dokumentarische in einen Stil, den er als Künstler anwenden kann. »Sie sehen, Kunst ist wirklich nutzlos, aber ein Dokument hat Gebrauchswert. Deshalb kann Kunst nie ein Dokument sein, aber sie kann diesen Stil übernehmen « (The Estate of Walker Evans 1982: 216). Evans' documentary style wird als »wohlüberlegt angefertigte visuelle Poesie, getarnt als einfache prosaische Tatsache« beschrieben (Thompson 1982: 12). Mit der Metapher des Lyrischen (vgl. The Estate of Walker Evans 1982: 238) erhält die Dokumentarfotografie einen größeren Spielraum und unterscheidet sich so von anderen dokumentarischen Genres, deren Intention meist die Präsentation von Fakten ist. Die beschreibende Funktion der (angewandten) Dokumentarfotografie wird durch Aspekte der künstlerischen Interpretation des Alltäglichen ergänzt. Evans' Fotografien

11 Vorläufer der Farm Security Administration (FSA). 
ermöglichen eine neue Sichtbarkeit des Bildobjekts und koppeln sich von einer konkreten Zuschreibung von Bedeutung ab. Sie weisen über eine formale Ästhetik hinaus und markieren so eine entscheidende Abgrenzung sowohl zu angewandten Praktiken als auch zu anderen fotografischen Kunstformen. Die Bildästhetik ist nicht Selbstzweck; die Fotografien erreichen eine gesteigerte Sichtbarkeit.

Walker Evans weist mit seinem Ansatz des documentary style über die lange Zeit gültigen Grenzen des Sozialen und Aufklärerischen der Dokumentarfotografie hinaus. Dieser Wandel innerhalb der künstlerischen Gebrauchsweisen der Dokumentarfotografie spiegelt sich auch in der Ausstellung New Documents wider, die John Szarkowski im Museum of Modern Art (MOMA) in New York im Jahr 1967 kuratiert. ${ }^{12}$ In der Ausstellung plädiert er für einen sehr offenen Ansatz der Dokumentarfotografie:

»Eine neue Generation von DokumentarfotografInnen hat den dokumentarischen Ansatz in eine stärker private Richtung umgedeutet. Ihr Ziel ist es nicht, das Leben zu reformieren, sondern es zu kennen. [... Alle diese FotografInnen] teilen die Überzeugung, daß das Alltägliche unserer Aufmerksamkeit bedarf. Gemeinsam ist ihnen auch der Mut, ihren Blick von aller Theorie weitgehend freizuhalten « (John Szarkowski: Wandtext zur Ausstellung, zit. nach Rosler 1999: 126). ${ }^{13}$

Den ausgestellten Fotografen liege nicht daran, die Welt zu verändern. Sie verfolgen vielmehr »persönliche Projekte und versuchen, die Welt über den Akt des Fotografierens und die Fotografien zu verstehen, zu entdecken « (Neumann 1996: 114). Die Vorstellung, Dokumentarfotografie könne die Welt beschreibend darstellen und zur Beseitigung gesellschaftlicher Missstände beitragen, kann hier als überwunden gelten. Die persönliche Sichtweise auf die Welt rückt in den Vordergrund. Diese Herangehensweise trägt der Ansicht Rechnung, dass die Fotografie ohnehin nicht in der Lage ist, Sachverhalte objektiv darzustellen. Sie entbindet von einer beschreibenden Weltsicht und gibt dem Künstler einen großen Spielraum, Phänomene im Bild sichtbar zu machen. Der Künstler kann mit dokumentarischen Mitteln Welt auf eine Weise visualisieren, die nicht für jeden in der Betrachtung der Realität offen wahrnehmbar ist. Wird von der dokumentarischen Fotografie in anderen Bereichen - wie beispielsweise der journalistischen Fotografie nach wie vor eine Beschreibung von Sachverhalten verlangt, die der Betrachter nachvollziehen kann, erlaubt die Entdeckung der Individualität in der künstlerischen Dokumentarfotografie eine Abkehr vom Faktischen. Die Welt fungiert dabei, im Gegensatz zu einer abstrakten oder inszenierten fotografischen Praxis, weiterhin als Vorlage und Ideengeber.

12 Die ausstellenden Künstler sind: Diane Arbus, Lee Friedlander, Gary Winogrand.

13 Rosler kritisiert hier die Beliebigkeit, die die Dokumentarfotografie erhält, wenn sie sich vom Sozialen zurückzieht. Sie bescheinigt den Arbeiten einen »eingeschränkten Horizont« angesichts der weltpolitischen Lage im selben Jahr (vgl. Rosler 1999: 126). 


\subsubsection{Der Fotograf als Autor}

Die Betonung des persönlichen und interpretativen Ansatzes innerhalb der künstlerischen Dokumentarfotografie manifestiert sich in der Vorstellung des Fotografen als Autor. Diese Idee benennt Klaus Honnef bereits Ende der 1970er Jahre mit dem Begriff der Autorenfotografie. In Honnefs Definition weist die Autorenfotografie - eine Analogiebildung zum Autorenfilm - zahlreiche Gemeinsamkeiten zu Timm Starls dokumentaristischem Ansatz der künstlerischen Dokumentarfotografie auf. Honnef beschreibt den Fotografen als Autor, der eine subjektive Sichtweise auf die Welt und damit verbunden eine konkrete Haltung entwickelt und dem in seinen Fotografien Rechnung trägt. Er ist »weder Amateur noch bloßer Profi oder Avantgardekünstler. [...] Der Fotograf als Autor ist Wirklichkeitsfotograf; ganz bestimmte Aspekte der Realität üben eine solche Faszination auf ihn aus, daß er oft seine ganze Lebenstätigkeit ihnen verschreibt« (Kemp 1983: 204). Von Bedeutung ist insbesondere die Abkehr vom Einzelbild, da der Autorenfotograf sich der Ausschnitthaftigkeit seines Mediums bewusst ist und diese gezielt einsetzt, um mit Bildsequenzen eine Inszenierung der Wirklichkeit vorzunehmen (vgl. Honnef 1983: 208). In der Definition wird stets die Subjektivität des Autors hervorgehoben. ${ }^{14}$ Sie wird zur leitenden Motivation der Bildproduktion und erhält damit eine gewisse Radikalität. Der radikal subjektive Ansatz birgt jedoch die Gefahr der Entfremdung vom Bild. Geraten Autor und seine emotionale Befindlichkeit ins Zentrum der Betrachtung, verliert das fotografische Bild selbst an Relevanz. Das Bildobjekt wird zur Präsentationsplattform für die Persönlichkeit des Fotografen (vgl. Rosler 1999: 119). Auch wenn Honnef die in der Ausstellung In Deutschland 1979 gezeigte Dokumentarfotografie als »eine Autorenfotografie reinsten Wassers« (Honnef 1979: 29) beschreibt und Fotografen wie Walker Evans, Dorothea Lange oder Eugène Atget Autorenfotografen nennt, bleibt die Honnefsche Begriffsbildung problematisch. Der Begriff ist eng mit einer Art fotografischem Sonderweg verbunden, weil er versucht, Autorenfotografie von der angewandten Fotografie, der ambitionierten Amateurfotografie, aber auch der künstlerischen Fotografie zu unterscheiden. ${ }^{15}$ Der Begriff der Autorenfotografie ist schwer zu fassen und bleibt hauptsächlich den siebziger und frühen achtziger Jahren des zwanzigsten Jahrhunderts verbunden. Er wird heute kaum noch verwendet.

Das Konzept des Fotografen als Autor mit »unverwechselbare[r] Handschrift« ist hingegen im Fotografiediskurs noch immer relevant. (Weski 2004: 40). Der Fotograf gilt nicht als jemand, der sich »den zu photographierenden Dingen völlig « unterordnet. ${ }^{16}$ Nach Thomas Weski ist das Ziel der künstlerischen Dokumentarfotografie vielmehr, den Gegenstand mit fotografischen

14 »Die ausdrückliche Hervorhebung des Individuellen bereichere die Fotografie [...] um die persönliche Betroffenheit, die der Fotograf in seinen Bildern mitteilt, sowie um die Emotionalität, mit denen er seine Objekte wahrnehme« (vgl. Jocks 2004: 41f.)

15 »Aber man hat meine Begriffsprägung entgegen meinen Intentionen auf die künstlerisch ambitionierten Fotografen übertragen. Wer also ausschließlich graue Raufasertapete fotografiert, gilt als Autorenfotograf« (Honnef 2004: 156).

16 So eine missverständliche und zu Recht kritisierte Aussage des Fotografen Michael Schmidt (vgl. Matz 1981: 6). 
Mitteln zu durchdringen und somit über die »Geste des Zeigens« hinauszuweisen (Weski 2003: 23). Ohne den persönlichen »Zugriff auf das Objekt« diene die Fotografie als »Inventur unter dem Vorwand der Authentizität« (ebd.). Sie bleibe beschreibend, könne aber, aufgrund der Konstruiertheit von Fotografie im allgemeinen, Wahrhaftigkeit nur vortäuschen. Nach Weski kann der Produzent künstlerischer Dokumentarfotografie hingegen im persönlichen Zugriff auf die Realität »auf den ersten Blick Vertrautes [...] mit erweiterter Bedeutung« aufladen und im Bild eine Autonomie erreichen, »die uns aus der Welt der bildenden Kunst bekannt ist« (ebd.). Der Fotografierende erzeuge die Autonomie des fotografischen Kunstwerks nicht aus der beschreibenden Wiedergabe der Realität heraus, sondern aufgrund der persönlichen Auseinandersetzung mit ihr, wodurch er zu einem eigenständigen Blickwinkel gelange.

Ein wichtiger Punkt in der künstlerischen Auseinandersetzung mit der Welt ist laut Weski, dass der Urheber der Fotografie

»nicht einfach unsere Kenntnis von [der Realität] bestätigt, sondern eine Differenz zwischen seiner und unserer Wahrnehmung entsteht. [...] Es geht um eine Darstellung der Wirklichkeit, die über den Gegenstand berichtet, und zugleich um die Formulierung einer Vorstellung von Welt. Mit diesem Verständnis kann man im Rahmen dieses technischen Mediums vom Fotografen als Autor sprechen, der auf der Grundlage von Fakten durch eine minimale Verschiebung der Perspektive eine Erzählung schafft, die ganz dicht am Leben angesiedelt ist« (Weski 2003: 23).

Für Weski ist die Kategorisierung dokumentarischer Fotografie als künstlerisch mit der individuellen Herangehensweise des Fotografen als Autor verbunden. Ziel ist es, die Ebene der Beschreibung zu verlassen und mit der persönlichen Sichtweise den Gegenständen oder Situationen eine eigenständige Wirklichkeit zu verleihen »und sie mit beunruhigender Kraft über sich hinauswachsen zu lassen. Dieses ist eine irritierende Eigenschaft jeder Kunst, denn sie beraubt uns unserer Gewissheit und wirft mehr Fragen auf, als sie beantwortet« (Weski 2003: 23). Weskis Konzeption vom Fotografen als Autor ist auch deshalb so interessant, weil er das Fotografieren als einen Prozess begreift, in dem auf die Welt zugegriffen wird, der Autor aber in den Bildern seine Vorstellung von der Welt mit zum Ausdruck bringt. Die beschreibende Weltsicht, wie sie von der Dokumentarfotografie auch heute oft erwartet wird, wird mittels künstlerischer Autorschaft transformiert. Wenn die Sicht des Künstlers auf die Welt von der der Rezipienten abweicht, entsteht eine Spannung, die das Werk zur Kunst werden lässt. Es geht nicht darum, das zu bestätigen, was bereits bekannt ist, sondern das Bekannte um die individuelle Perspektive des Autors zu erweitern. Im Gegensatz zur angewandten Praxis, in der dokumentarische Fotografie häufig Aussagen trifft, wirft die künstlerische Dokumentarfotografie Fragen auf, die sie nicht unbedingt selbst beantwortet (vgl. Teil I, Abschnitt 3.2.4.). Dadurch entsteht eine Spannung, die künstlerische dokumentarfotografische Gebrauchsweisen von angewandten unterscheidet. In Weskis Konzeption wird deutlich, dass die künstlerische Dokumentarfotografie eine eigene Wirklichkeit schafft, die gerade aus der Differenz zur Realität ihre Besonderheit erhält. 


\subsubsection{Kontextualisierung und Präsentation}

Die Autorschaft des Fotografen endet nicht bei der Herstellung einzelner Fotografien. Weil es problematisch ist, mit einem Einzelbild Zusammenhänge sichtbar zu machen, ist die künstlerische Dokumentarfotografie durchgängig durch ein serielles Arbeitsprinzip gekennzeichnet. Die Haltung des Fotografierenden kann in einer Bildserie auf den Punkt gebracht werden. Durch die intensive Beschäftigung mit einem Thema kann ein serieller Ansatz verschiedene Blickwinkel vereinen und so Sichtweisen verstärken, abmildern oder anderweitig in Beziehung setzen. Vorreiter in der Arbeit mit bildlichen Kontexten ist abermals Walker Evans, der in der ersten Einzelausstellung, die jemals einem Fotografen im Museum of Modern Art in New York gewidmet ist, gezielt mit Bildfolgen arbeitet (vgl. Thompson 1982: 15). Weil er selbst die Hängung der Bilder in der Ausstellung sowie die Kontrolle über die Publikation übernimmt, erweist sich »Evans auch auf diesem Gebiet des künstlerischen Selbstausdrucks als Pionier eines modernen Autorenverständnisses in der Fotografie« (Weski 2003: 24). Auf diese Weise etabliert er als Fotograf die Kontextualisierung seiner Bilder als Teil seiner Arbeit, mit der er seinen Intentionen entsprechend auf bestimmte Wirkungsweisen hin arbeiten kann. Mit seiner Arbeitsweise betont Evans die Wichtigkeit der Präsentation eines Zusammenhalts innerhalb einer Arbeit. Dieser Herangehensweise folgen zahlreiche Künstler, die in Künstlerbüchern Zusammenhänge herstellen und so die Bildfolge als Einheit in der künstlerischen Dokumentarfotografie etablieren.

Eine Bildfolge kann auch ohne textliche Einordnung Bezüge innerhalb einer thematischen Auseinandersetzung sichtbar machen. Der Begriff Bildfolge meint hier zunächst die Abkehr vom Einzelbild in der Arbeit mit Bildkombinationen. Im Rahmen der Bildfolge lässt sich zwischen Bildserie und Sequenz unterscheiden. Während sich die Bildserie umgruppieren lässt und Variationen in der Abfolge der Bilder erlaubt, versucht die Sequenz, eine Art filmische Erzählweise zu etablieren. »Die Offenheit des sequenziellen Ensembles konstituiert jedoch einen entscheidenden Unterschied zum Kino: Es gibt keine lineare Diktatur des Projektors. So ist es leicht, Sequenzen mit Serien zu verwechseln" (Gierstberg 1998: 6). Die Komplexität von Sequenzen zeichnet sich auch dadurch aus, dass nicht einfach einzelne Bilder oder Bildgruppen aus dem Kontext entfernt werden können, um die Arbeit zu repräsentieren. Neben Bildserien und Sequenzen gibt es weiterhin die Möglichkeit, Bilder in Tableaus anzuordnen und so ebenfalls Beziehungen zwischen ihnen herzustellen. Diese Art des Umgangs mit Bildfolgen wird im zweiten Teil der Arbeit thematisiert (vgl. Teil II, Abschnitt 3.6.).

Neben der kontextuellen Einbettung durch Fotografien in eine Bildfolge ist der Einsatz von Text eine für die Wirkung des Werks entscheidende Frage. Zahlreiche Arbeiten der künstlerischen Dokumentarfotografie sind beispielsweise durch den Verzicht auf Bildunterschriften gekennzeichnet. Der fehlende Verweis auf Ort oder Zeitpunkt der Aufnahme zeugt von der Irrelevanz einer referentiellen Bedeutungszuweisung. Das Bild soll als Bild wahrgenommen werden und in seiner Eigenständigkeit eine Wirkung entfalten. Auch in diesem Bereich erweist sich Walker Evans als Pionier, der in seiner Einzelausstellung im MOMA 1938 die einzelnen Fotografien unbeschriftet lässt und lediglich Tafeln mit Bildunterschriften ans Ende der zwei Bildfolgen 
hängt. Auch die Publikation zur Ausstellung, das Buch American Photographs, führt die kurzen Bildtitel lediglich am Ende des jeweiligen Bildteils auf (vgl. Evans 1988; Trachtenberg 1990: Kap. 5). ${ }^{17}$ Die Fotografien selbst sind rechtsseitig abgedruckt, die linke Seite bleibt vakat. So können die Fotografien ohne textliche Zuordnung als Bilder betrachtet werden, was freie Assoziationen erlaubt. In dem Gemeinschaftsprojekt Let Us Now Praise Famous Men, das Evans gemeinsam mit dem Journalisten James Agee im Jahr 1941 publiziert, sind die Fotografien im Bildteil am Beginn des Buches völlig ohne Hinweis auf Entstehungsort oder -zeit und ohne Bildtitel abgedruckt (vgl. Agee/Evans 1941). »Mit dieser Strategie behauptet Evans, dass Fotografien die Autonomie von einer textlichen Einbindung zusteht; sie können und sollen, wie andere Kunstwerke auch ohne Titel zu lesen, zu verstehen sein. Er löst seine Aufnahmen vor allem von der Bindung an einen Ort" (Neumann 1996: 73). Ohne eine Ortsbindung wird die Fotografie von einer direkten Referenz abgekoppelt. Das Bild fungiert nicht primär als verweisendes Zeichen, denn das Bildobjekt erhält im Bild eine übergeordnete Präsenz. Die Frage, wo oder wann der Bildgegenstand real hätte angetroffen werden können oder wer auf dem Bild zu sehen ist, wird nebensächlich. Das Bild wird als Bild wichtig, weil es der Welt eine im Bild gesteigerte Sichtbarkeit verleiht. Dieser Rezeption künstlerischer Dokumentarfotografien verleiht der Fotograf Gary Winogrand Ausdruck, indem er sagt, dass er fotografiere, um zu sehen, »wie die Welt auf Fotografien aussieht. ${ }^{18}$ Das Bild zeigt Welt in einer nur ihm eigenen Weise. Nach Winogrands Auffassung besteht gerade ein wichtiger Unterschied zwischen der real wahrnehmbaren Welt und dem Eindruck, den sie auf dem Foto hinterlässt. Auf der Fotografie wird eine neue, eigenständige Wirklichkeit sichtbar, was Produkte der künstlerischen Dokumentarfotografie so interessant macht. Fehlende Bildunterschriften leisten der Erkenntnis Vorschub, dass im Bild eine neue Bildwirklichkeit erzeugt wird, die nicht auf eine vorfotografische Realität verweist. Insofern kann der Verzicht auf Bildunterschriften, die Ort oder Zeitpunkt der Aufnahme nennen, als eine Methode gesehen werden, die Differenz zwischen Realität und Bildwirklichkeit zu betonen.

Dennoch ist in künstlerischen Positionen häufig eine Textebene vorhanden, beispielsweise in Form des Titels. Sie gibt - ähnlich wie der visuelle Kontext - Hinweise auf eine mögliche Sicht auf die Fotografien. Der Ge-

17 Interessanterweise unterminieren Folgeauflagen der 1938 erschienenen Originalausgabe von American Photographs (beispielsweise die von 1975) diese von Evans getroffene Entscheidung und drucken die Bildtitel jeweils auf der linken Seite neben dem Bild ab. Erst 1988 erscheint eine Neuauflage, die bemüht ist, die Originalauflage so getreu wie möglich nachzuempfinden.

18 »I photograph to see what the world looks like in photographs « aus: http://en.wikipedia.org/wiki/Garry_Winogrand, 17.07.2008. Bei Newhall 1984a: 302 ist dieser viel zitierte Ausspruch Winogrands so zitiert: »Ich photographiere, um nachher zu sehen, wie das Photo aussieht.« Dies ist die direkte Übersetzung aus der englischen Newhall-Ausgabe von 1982: 292. Es scheint sich jedoch um eine fehlerhafte Transkription zu handeln, da es Winogrand im Gegensatz zu anderen Fotografen nicht um das Foto, sondern um die fotografierte Welt auf der Fotografie geht und damit um die Verdeutlichung der Differenz zwischen wahrgenommener und fotografierter Welt. Die Quelle, aus der Newhall zitiert (Image Bd. 15, Nr. 2, 1972: 4) ist mir leider nicht im Original zugänglich. 
samttitel der Arbeit, erläuternde Essays, Künstlerinterviews oder - seltener Bildunterschriften sind Formen textlicher Einordnungen der Fotografien. In der künstlerischen Dokumentarfotografie ist der Text jedoch nicht auf das unmittelbare Verständnis der Bilder ausgerichtet. Er gibt möglicherweise im Titel eine allgemeine Richtung der thematischen Auseinandersetzung vor, verzichtet aber meist darauf, eine bestimmte Betrachtungsweise zu suggerieren. Die Annahme, dass künstlerische Fotografien Fragen stellen (vgl. Weski 2003: 23), verbietet eine konkrete Beantwortung der Fragen im Text. Die daraus entstehende Ambivalenz konfrontiert den Betrachter mit einer nachhaltigen Offenheit.

Der Publikationskontext ist für Lesart und Bedeutungskonstitution in der künstlerischen Dokumentarfotografie ebenfalls relevant. Künstlerische Fotografien werden hauptsächlich in Ausstellungen in Galerien oder Museen gezeigt, sie sind in Katalogpublikationen oder Künstlermonografien abgebildet. Im Kunstkontext sind jedoch auch andere fotografische Gebrauchsweisen präsent, weshalb ein Auftritt an der Museumswand noch nicht eindeutig auf das spezifische Genre der künstlerischen Dokumentarfotografie schließen lässt. Im Museum gezeigte Bilder werden jedoch gemeinhin als Kunstproduktionen rezipiert. Die künstlerische Dokumentarfotografie gerät - insbesondere wenn sie auf erklärende textliche Information verzichtet - zuweilen unter Legitimationsdruck, da sie sich in ihrer nachhaltigen Offenheit einer Referenz verweigert. Ist das Publikum gewohnt, in Fotografien Aussagen zu finden, die es mit Hilfe von Bildunterschriften sinnstiftend konstruieren kann, wird es zuweilen von künstlerischer Dokumentarfotografie enttäuscht (vgl. Buchloh 1995: 195). Ohne Text geben sich Betrachter oft unsicher über die Bedeutung des Abgebildeten. Deshalb wird im Ausstellungskontext meist eine Einordnung und Erklärung durch Texte von Kuratoren oder Museumspädagogen vorgenommen. Gleiches gilt für die Publikation künstlerischer Arbeiten in ihr fremden Medien wie beispielsweise Publikumsmagazinen. Der Publikationskontext weist der künstlerischen Dokumentarfotografie jedoch keine spezifische Funktion zu, wodurch sie sich von anderen dokumentarischen Formen, die meist einen recht konkreten Informations- oder Unterhaltungsauftrag haben, unterscheidet.

Eine besondere Form der Publikation ist das monografische Künstlerbuch, das sich als festgelegte Präsentationsform für eine sequenziell konzipierte künstlerische Dokumentarfotografie anbietet. Im Unterschied zum Ausstellungskatalog ist das Künstlerbuch eine autonome künstlerische Form. Von der Bildauswahl über die Festlegung von Reihenfolge und Bildformaten, die Verwendung von Text bis hin zum Layout entwickelt der Künstler das Buch häufig in Eigenregie, möglicherweise unterstützt von einem Grafiker oder Kurator. Die wichtigen Entscheidungen liegen jedoch beim Künstler selbst. Obwohl das Künstlerbuch häufig als Begleitpublikation zu einer Einzelausstellung erscheint, wird oftmals auf einen kuratorischen Text und damit auf die Einordnung in einen kunsthistorischen Kontext verzichtet. Die Arbeit steht für sich, das Publikum soll sich ganz auf die Fotografien konzentrieren können. Die Betrachtung der Bilder hat in der Regel oberste Priorität. Das Künstlerbuch spiegelt die Produktionsbedingungen einer künstlerischen Dokumentarfotografie wider. Sie entsteht in der Regel im eigenen Auftrag des Künstlers. Insofern ist es idealer Weise dazu geeignet, die Intention des Künstlers zu präsentieren, der das Werk als geschlossene Einheit innerhalb der Buchdeckel präsentiert. 
Die hier vorgestellte dokumentaristische Herangehensweise innerhalb der künstlerischen Dokumentarfotografie zeichnet sich durch die Nutzung von Irritation und dem Wechselspiel mit Referenz und Wirkung von Bildern aus, wie bereits Teil I, Abschnitt 3.2.4. darlegt. Aufgrund ihrer Affinität zum Künstlerbuch und ihrer Möglichkeiten in Bezug auf den Umgang mit dem Fremden werden im zweiten Teil dieser Arbeit zahlreiche praktische Beispiele gegeben. Deshalb wird an dieser Stelle auf ein konkretes Beispiel verzichtet.

\subsection{Angewandte Dokumentarfotografie}

Die Auseinandersetzung mit der Geschichte und den Grundlagen der künstlerischen Praxis der Dokumentarfotografie hat bereits einige Unterschiede zwischen angewandten und künstlerischen Praktiken offen gelegt. Diese gilt es insofern weiter auszudifferenzieren, als auch innerhalb des angewandten Bereiches verschiedene Voraussetzungen für die unterschiedlichen dokumentarfotografischen Gebrauchsweisen existieren. Die Verwertungszusammenhänge markieren das Terrain, in dem sich der jeweilige Ansatz bewegt. Weil Reise-, ethnografische und journalistische Fotografie unterschiedliche Ideen verfolgen, werden sie hier im Einzelnen in Bezug auf das Fremde vorgestellt. Dies hilft dabei, die angewandten Praktiken weitergehend von den künstlerischen zu unterscheiden. So sollen die jeweils spezifischen Errungenschaften in der Auseinandersetzung mit dem Fremden präziser erfasst werden. Es ist jedoch nicht immer einfach, klare Trennlinien zwischen den Genres zu ziehen. Zu einer Zeit, in der fotojournalistische Projekte heute in Magazinen und morgen im Museum gezeigt werden, in der ethnografische Dokumente im wissenschaftlichen aber auch im journalistischen oder künstlerischen Kontext publiziert werden und künstlerische Arbeiten im Museum ebenso wie in Publikumszeitschriften zu finden sind, sind die Übergänge fließend. In diesem Sinne ist es notwendig, die Interessen und Intentionen im Entstehungsprozess der Fotografien ebenso zu reflektieren wie ihren Publikationskontext.

\subsubsection{Reisefotografie}

Die Bedeutung der Reise innerhalb der bürgerlichen Gesellschaft nimmt seit dem achtzehnten Jahrhundert zu. Reisen wird immer beliebter, wobei Erfindungen des neunzehnten Jahrhunderts wie die der Eisenbahn und des Dampfschiffs das Reisen erschwinglicher und sicherer machen und damit zu seiner Popularität beitragen (vgl. Asmus 1983: 8). Die Erfindung der Fotografie leistet ihren Beitrag zur Veränderung der Reisedarstellungen. Bereits zwischen 1840 und 1844 erscheint in Paris eine Serie von 114 Reiseansichten unter dem Titel Excursions Daguerriennes. Daguerreotypien der Architektur aus Ländern rund um das Mittelmeer sowie aus Amerika werden nachgezeichnet und im Aquatinta-Verfahren gedruckt, was auf das große Interesse an Ansichten aus der Fremde verweist (vgl. Newhall 1984a: 27; Adam 1979: 117).

»Die unverzügliche Anwendung der Fotografie auf die Darstellung des Reisens wird durch die Tatsache erklärt, dass sich im Reisen einerseits eine dreihundertjährige Kultur und Wissenschaft des Raums und der Mobilität [kristallisiert], als sie auch andererseits der Ausdruck ihrer eigenen Zeit [ist] - der Epoche der kapitalistischen 
Globalisierung, der Konstruktion einer neuen Mittelklasse-Identität und der dramatischen Beschleunigung der Fortbewegung und Kommunikation. Fotografie [ist] ein repräsentationales Werkzeug, das im Dienst dieser Prozesse verbessert wird « (Osborne 2000: 9).

Als Reisefotografie gilt zunächst alles, was Fremdes abbildet, seien es archäologische Ausgrabungen, Architekturen, Landschaften oder fremde Völker. Der Gebrauch der Reisefotografie differenziert sich ab 1880 zunehmend aus (vgl. Heilbrun 1998: 149). Forschungsreisende - beispielsweise Archäologen oder Ethnologen - setzen die Fotografie im Dienst der Wissenschaft ein. Professionelle Fotografen produzieren exotische Ansichten ferner Länder zunächst zum Verkauf, später zur Publikation in Büchern, Zeitschriften und Reiseführern. Touristische Reisende fotografieren auf ihren Reisen zur Erinnerung. Der ethnografischen Fotografie ist der Abschnitt 4.2.2. gewidmet. Die touristische Fotografie als amateurhafte Variante wird hier nicht berücksichtigt.

\section{Reisefotografie als authentische Darstellung ferner Welten}

Die im neunzehnten Jahrhundert angenommene Authentizität der Fotografie sorgt dafür, dass das neue Medium unverzüglich andere bildliche Darstellungen des Fremden ablöst. Wird die Fremde vorher gezeichnet, um sie zu dokumentieren und ihr Präsenz zu verleihen, wird dies nun zur Aufgabe der Fotografie. ${ }^{19}$ Für die frühen Betrachter garantiert ihre indexikalische Beziehung zum aufgenommenen Gegenstand, dass sich die Ferne in der fotografischen Abbildung materialisiert (vgl. Teil I, Abschnitt 3.2.1.). In Form der Daguerreotypie oder später des fotografischen Abzugs lässt sich die Ferne nicht nur anschauen, sondern auch besitzen. Die Reisefotografie erfüllt im neunzehnten Jahrhundert - neben Information und Bildung - einerseits den Zweck, die Sehnsucht nach der Ferne zu wecken und die Menschen zum Reisen zu motivieren. Andererseits vermag sie die Erinnerungen an die Reise zu materialisieren. Die Fotografie ist eine solide Substanz, die verspricht, »den Träger der Papierwährung der Fotografie mit der Goldmünze der touristischen 〉Erfahrung« und dem Entzücken des Reisenden« zu belohnen (Osborne 2000: 11). Diese Erfahrung kann für diejenigen eine virtuelle bleiben, die aus finanziellen, zeitlichen, gesundheitlichen oder anderen Gründen die Anstrengungen einer Reise nicht auf sich nehmen können (vgl. z.B. Theye 1989a: 27f.). Eine Serie von Fotografien eines fernen Landes kann zur »armchair travel« werden, zur Reise im eigenen Sessel (Asmus 1983: 12). Wenn die Möglichkeit besteht, die Orte der Sehnsüchte selbst zu bereisen, wird die touristische Erfahrung zur Realität. Dabei sind Erwartungen und reale Erfahrungen nicht immer in Einklang zu bringen. Wenn der Reiz des Fremden in der Begegnung mit ihm verschwindet, kommt es zu Enttäuschungen (vgl. ebd.: 9). Sie werden möglicherweise durch die vorab bekannten Fotografien herbeigeführt, denn was in den Bildern spektakulär und exotisch wirkt, erscheint in der Realität mitunter banal oder ist in der dargestellten Form bereits im neunzehnten Jahrhundert so nicht mehr anzutreffen.

19 Seit Jahrhunderten existieren auch literarische Darstellungsformen des Fremden wie beispielsweise Erfahrungsberichte und Belletristik. Hier interessiert jedoch nur die Entwicklung der bildlichen Darstellung. 
Der Grund hierfür ist in den Bildwelten der Reisefotografien zu suchen. Die Fotografien spiegeln meist die Erwartungshaltung der Europäer gegenüber den fernen Ländern wider. »Die Publikumswirksamkeit der Reisefotografie [gründet] sich zunächst auf die visuelle Präsentation derjenigen Orte und Regionen, die trotz >aufbrausenden Weltenverkehrs` vielen Europäern auch weiterhin verschlossen« bleiben (Theye 1989a: 27). Besonders die Länder des fernen Ostens gelten als exotisch. Die Erwartungen an das Exotische werden in den Fotografien bedient, denn die Fotografen wollen den Reisenden, aber auch den ortsansässigen europäischen Kolonialbeamten, Kaufleuten und Wissenschaftlern, ihre Bilder verkaufen. Diese werden einzeln oder in hochwertigen Alben zusammengestellt ins ferne Europa geschickt. Gewünscht ist die Befriedigung der Sehnsucht nach dem Exotischen und Besonderen, was dazu führt, dass die vom kolonialen Alltag, der Zerstörung und Wandlung der ursprünglichen Strukturen geprägten Verhältnisse nicht fotografiert werden. »Bevorzugtes Objekt in der Asienphotographie des neunzehnten Jahrhunderts [ist] [...] immer dasjenige, das die Abwertung einer anderen Kultur und die Einordnung in ein, für westliche Augen zurückliegendes Zeitalter« zulässt. ${ }^{20}$

\section{Frühe japanische Reisefotografie}

Die frühen Japan-Fotografien zeugen von einer vergangenen Epoche, die den neuen Entwicklungen wenig Raum gibt. Sie werden vor allem durch westliche Fotografen angefertigt, die sich in den Vertragshäfen niederlassen und dort Fotostudios gründen. Eine herausragende Stellung nimmt dabei die Hafenstadt Yokohama ein, in der sowohl westliche als auch japanische Fotografen Fotostudios eröffnen, weshalb die Reisefotografie der zweiten Hälfte des neunzehnten Jahrhunderts oft mit Yokohama-Fotografie bezeichnet wird (vgl. z.B. Delank 2000: 255). ${ }^{21} \gg$ Die kommerzielle Fotografie in Japan [ist] das Resultat eines einmaligen kulturübergreifenden Austauschs, was sie von anderer Reise- und Expeditionsfotografie des neunzehnten Jahrhunderts unterscheidet« (Banta 1988: 12).

Der britische Kriegsberichterstatter Felice Beato, der unter anderem den Krimkrieg (1853-1856) und den Zweiten Opiumkrieg in China (1856-1860) dokumentiert hat, reist im Sommer 1863 nach Japan (vgl. Siegert 1991: 11). Dort eröffnet er gemeinsam mit Charles Wirgman - Maler und Korrespondent der Illustrated London News - in Yokohama ein Atelier und wird zu einem der ersten und wichtigsten Yokohama-Fotografen. 1877 verkauft er das Atelier mitsamt allen Negativen an den österreichischen Baron Raimund von Stillfried-Rathenicz, dessen eigenes Studio durch einen Brand fast vollständig vernichtet worden ist (vgl. ebd.: 15f.). Der Verkauf von Studio mit Nega-

20 So verkörpern Maharadschas beispielsweise einerseits das Paradiesische der indischen Kultur, andererseits stehen sie für die Versinnbildlichung des Mittelalters und damit für die Rückständigkeit der indischen Zustände (Theye 1983: 71). Wie im zweiten Kapitel dargelegt, unterscheidet sich die westliche Wahrnehmung Japans aufgrund der eher partnerschaftlichen (nicht kolonial geprägten) Beziehungen von der anderer asiatischer Länder, weshalb diese Aussage nicht unbedingt auf alle Japanfotografie des neunzehnten Jahrhunderts zutrifft (vgl. auch Teil I, Abschnitt 2.2.2.).

21 Das erste Fotoatelier eines japanischen Berufsfotografen wird 1862 von Ueno Hikoma jedoch in Nagasaki eröffnet. Dort lehrt seit 1857 der holländische Sanitätsoffizier Pompe van Meerdevoort neben Medizin auch Fotografie (vgl. Bennett 1991: 24; Ishii/Iizawa 2003: 312). 
tiven, die ohne Autorenangabe weiterhin genutzt werden können, ist eine übliche Praxis. Stillfried-Rathenicz verkauft das Studio 1885 an seinen und Beatos besten Schüler Kimbei Kusakabe und die Negative an die Firma A. Farsari \& Co (vgl. Bennett 1991: 25). ${ }^{22}$ So werden auch Beatos Aufnahmen, noch lange Zeit nachdem er Japan verlassen hat, von Touristen gekauft.

Die Yokohama-Fotografie konzentriert sich im Wesentlichen auf zwei Motivgruppen, wie sie auch in einem von Beato 1868 veröffentlichten zweibändigen Kompendium vertreten sind. ${ }^{23}$ Im ersten Band mit dem Titel View of Japan finden sich Aufnahmen von Landschaften, Dörfern und Städten, im zweiten Teil, betitelt Native Types, versammelt er Porträts von japanischen Berufsgruppen und Typen. Beato ist »der erste Photograph in Japan, der auch die für Ausländer noch unbekannten Landesteile« dokumentiert (Siegert 1991: 11). Er begleitet Reisegesellschaften und richtet seinen Blick nicht ausschließlich auf touristische Attraktionen wie zahlreiche Fotografen nach ihm. $^{24}$

In die Motivgruppe Blick auf Japan, wie sie auch zum Repertoire anderer Reisefotografen zählt, lassen sich Fotografien berühmter Landschaften und kultureller Denkmäler wie beispielsweise dem großen Buddha von Kamakura oder dem Fuji als berühmtesten Berg Japans, aber auch Prozessionen und Festivals einordnen (vgl. Tucker 2003: 7). Die Außenaufnahmen sind dokumentarisch und gelten als $»$ mehr oder weniger authentische Darstellungen des damaligen japanischen Lebens« (Winkel 1991: 29). Die Dokumentarfotografien versuchen, ohne allzu offensichtliche Inszenierung auszukommen und die sichtbaren Verhältnisse unter Ausklammerung der modernen Entwicklungen aufzuzeichnen. Die Landschaftsfotografien greifen häufig Themen aus der traditionellen japanischen Kunst auf.

»Die offensichtlichste Verbindung ist die Gemeinsamkeit der dargestellten Orte, die in Fotografien meist dieselben >berühmten reizvollen Orte sind, wie sie in ukiyo-e Landschaftsdrucken bereits standardisiert worden sind. [...] Man findet eine weitere Ähnlichkeit der Komposition, denn die Fotografien übernehmen dieselbe Technik von nahen Elementen vor einem weiter entfernten landschaftlichen Hintergrund. Diese nahen Objekte, meist ein Baum oder Blumen, [dienen] als eine Art Rahmung für das Bild als Ganzes, beispielsweise in zahlreichen Fotografien des Fuji« (Iwasaki 1988: 29).

Die zweite Gruppe der professionellen Fotografien zeigt im Studio inszenierte Genre-Szenen, die einen Einblick in die traditionelle japanische Kultur geben sollen (vgl. Theye 1989a: 27). Sie sind ausschließlich für Ausländer bestimmt. Diese Fotografien werden von japanischen Historikern unter dem Sammelbegriff »customs and costumes« zusammengefasst (Tucker 2003: 7; vgl. Kinoshita 2003: 16f.).

22 Beatos Atelier besteht unter wechselnden Besitzern bis 1912 (vgl. Delank 1996: 41).

23 Photographic Views of Japan with Historical and Descriptive Notes, Compiled from Authentic Sources, and Personal Observations During a Residency of Several Years (vgl. Philipp 1991: 7).

24 Beatos Landschaftsaufnahmen sind ausführlich dokumentiert in: Philipp/Siegert/Wick 1991. 
»Diese Bilder zeigen Aspekte Japans, die den Westlern am exotischsten [erscheinen]. Sie [sind] oftmals inszeniert, um den Käufern das zu geben, was sie zu sehen [erwarten]: Schauspieler [posieren] als Samurai und Prostituierte oder Händlerinnen [verkleiden] sich als Geisha, häufig bekleidet mit einer bunten Mischung an Kostümen. Diese Bilder [sind] nicht nur gestellt, sondern inkorrekt. Die Klasse der Samurai [wird] zum Beispiel im Zuge der Meiji-Restauration 1868 abgeschafft und die Samurai [werden] gezwungen, ihren kennzeichnenden Dutt abzuschneiden. Deshalb [tragen] die >Samurai< in späteren Fotografien Perücken und Schwerter, die ein echter Samurai niemals benutzt haben würde« (Tucker 2003: 7).

Im Gegensatz zu späteren Yokohama-Fotografen kann Beato noch auf authentische Vertreter einiger Berufsstände zurückgreifen. Bei dieser Dokumentation verfolgt er »eine enzyklopädische Idee, wie sie einem bürgerlichen Erkenntnisinteresse seiner Zeit entspricht« (Philipp 1991: 8). Er arrangiert Personen und Accessoires sorgfältig im Studio und richtet sein Augenmerk insbesondere auf die Fremdheit japanischer Gewohnheiten. Deshalb ist er auf die Mitwirkung seiner Modelle angewiesen. Es entwickelt sich »ein Dialog, an dem beide Seiten beteiligt sind. [...] Felice Beato geht es um Einsicht in die fremde japanische Kultur. Seine kommerziellen Interessen widersprechen diesem Bemühen keineswegs« (ebd.).

Während sich Beato »hinsichtlich der Kleiderordnung in den Konventionen seines Gastlandes bewegt, « stellen andere Fotografen mitunter auch die körperlichen Reize ihrer weiblichen Modelle in den Vordergrund (ebd.: 9). Eine Unterart der customs and costumes Fotografie zeigt Japanerinnen oftmals kaum verhüllt beim Baden oder bei der Toilette, in traditioneller Kleidung oder als Geisha. ${ }^{25}$ Bereits frühe westliche Reisende nehmen teilweise mit großer Neugier, teilweise mit Abscheu die ungenierte japanische Badekultur wahr. ${ }^{26}$ Mit den Fotografien der partiell nackten Frauen kann ein Voyeurismus - verbrämt durch das Interesse an der fremden Kultur - ausgelebt werden. Dabei entsprechen solche Inszenierungen eher den westlichen Bedürfnissen als den kulturellen Traditionen Japans. Sie »dokumentieren die in der Fantasie westlicher Künstler aufregend fremde, sexuell geschmeidige, fernöstliche Frau« (Handy 1988: 55).

Die inszenierten Fotografien etablieren eine stereotype Sichtweise der japanischen Exotik, die sich teilweise bis heute gehalten hat (vgl. Domenig 1997: 49; Teil I, Abschnitt 2.3.2.). Die in Japan betriebene Reisefotografie des neunzehnten Jahrhunderts zeichnet sich jedoch durch »Elemente der Idealisierung « aus, da die Wertschätzung Japans und der Japaner gegenüber negativen Rezeptionsweisen überwiegt (Krase 1995a: 49).

\section{Reisefotografie als Exportschlager}

Reisefotografien Japans werden nicht nur von im Lande ansässigen Ausländern angefertigt. Innerhalb kürzester Zeit etablieren sich auch japanische Fotografen, die sich dieser Art der Fotografie annehmen. Sie entwickelt sich

25 Z.B. inszeniert Stillfried-Rathenicz Frauen oftmals mit entblößten Brüsten (vg1. Philipp 1991: 9; ein Bildbeispiel findet sich auf der Website des Musée Nièpce: http://www.museeniepce.com/catalogues/im.php?id=8\&img=344, 17.07.2008).

26 Heinrich Schliemann beschreibt z.B. mit neugierigem Interesse die gleichzeitige Nutzung der Badehäuser durch beide Geschlechter und deren mangelnden Sichtschutz zur Straße (Schliemann 1984: 68). 
zu einem großen Exportschlager, der seine Hochkonjunktur in der letzten Dekade des neunzehnten Jahrhunderts erreicht (vgl. Winkel 1991: 29). Die Bilder werden sowohl von in Japan lebenden Ausländern als auch von Reisenden gesammelt. Sie verweisen auf eine vergangene Epoche, da die Fotografen dieser Zeit »die Notwendigkeit verspüren, angesichts der internen und externen Transformationen die untergehenden Traditionen einzufangen. Damit verstärken sie den geheimnisvollen orientalischen Nimbus im Westen, wo die Fotografien ferner Länder und Völker zu einer sehr populären Handelsware geworden sind « (Banta 1988: 13). Kaum ein Reisender der zweiten Hälfte des neunzehnten Jahrhunderts kann ein solches unverfälschtes Japan angetroffen haben. Das exotisch Fremde ist im japanischen Alltag dieser Zeit kaum in der Form zu finden, wie es die Fotografien glaubhaft machen wollen. In Europa oder Amerika erwartet man jedoch keine Ansichten von neu gebauten Straßen und Fabriken, die den Fortschritt und die sich wandelnde Situation zeigen. Mit solchen Veränderungen sind die Menschen bereits in ihrer Heimat konfrontiert. In der Bildbetrachtung möchten sie die Sehnsucht nach paradiesischen Orten abseits einer beschleunigten westlichen Gesellschaft ausleben (vgl. Iwasaki 1988: 26). Dieses romantische Motiv prägt die Reisefotografie bis heute.

Die professionellen Reisefotografien des neunzehnten Jahrhunderts werden als Einzelbilder oder in fertigen Alben verkauft. Teilweise stellen sich die Reisenden selbst eine Bildauswahl zusammen. Alben beinhalten in der Regel eine Auswahl aus den verschiedenen Motivwelten, sowohl dokumentarische Aufnahmen von Landschaften, Sehenswürdigkeiten oder Festen, als auch inszenierte Studioaufnahmen, die Sitten und Gebräuche stilisiert darstellen. Die Bildzusammenstellungen deuten auf die bis heute noch gültige inhaltliche Aufgabe der Reisefotografie hin. Sie soll ein möglichst umfassendes Bild der fremden Kultur vermitteln, wobei der Schwerpunkt auf der Abbildung des Besonderen beziehungsweise des Anderen liegt. Man möchte sich über die Gegebenheiten und die Schönheit der Natur informieren und sich an Baudenkmälern und architektonischen Besonderheiten erfreuen. Des Weiteren interessiert man sich für kunsthandwerkliche Artefakte und die Tätigkeiten, die mit ihrer Produktion verbunden sind. Schließlich sind die Menschen von Interesse, ihre Art sich zu kleiden oder zu frisieren und wie sie ihre kulturellen Traditionen leben. Ob Kleidung oder traditionelle Verrichtungen tatsächlich den Alltag der Menschen bestimmen oder ob dies nur noch zu ausgewählten Gelegenheiten geschieht, ist lediglich von nachrangigem Interesse. Ausgeklammert werden meist Aspekte der fremden Kultur, die auch in der Region des Zielpublikums anzutreffen sind.

Ende des neunzehnten Jahrhunderts breitet sich zunehmend die Amateurfotografie aus. Das selbst aufgenommene Bild verdrängt die professionell hergestellten Reisebilder (diese leben später in Form der Postkarte wieder auf). Der »fotografische Berichterstatter über das exotische Leben in fernen Ländern [wird] ein Opfer des Massentourismus« (Honnef 1979: 23).

\section{Beispiele einer zeitgenössischen Reisefotografie}

Die professionelle Reisefotografie ist nicht nur in ihrer historischen Form dem Exotischen und Besonderen verpflichtet. Heute wird sie in Reiseführern, 


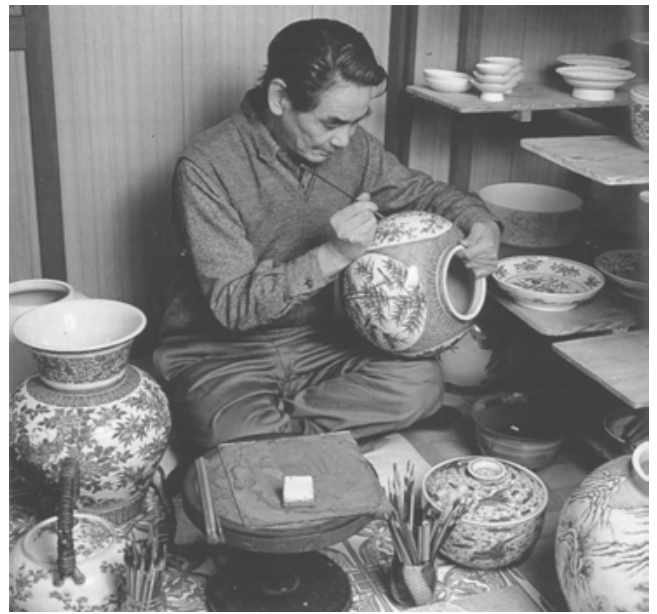

"Die japanische Keramik ist ein Handwerk mit langer Tradition" (Karl Baedecker GmbH 1993: 72; Orig. in Farbe).

Reisezeitschriften, ${ }^{27}$ Bildbänden und in Form von Postkarten publiziert. Nimmt man sich beispielsweise einen beliebigen Reiseführer oder Bildband über Japan heraus, kann man feststellen, dass ein Großteil der publizierten Fotografien einem traditionellen Japanbild verhaftet ist. Die meisten Bilder zeigen historische Sehenswürdigkeiten oder eine besonders herausragende Natur, die oftmals ohne großes Vorwissen als typisch japanisch oder weniger differenziert als typisch asiatisch erkannt werden können. Besonderer Wert wird auch auf die Darstellung von Menschen in traditionellen Gewändern und in der Ausübung traditioneller Tätigkeiten gelegt. Relativ unspezifische Stadt- oder Landschaftsansichten, die nicht ohne zusätzliche Information eindeutig Japan zugeordnet werden können, sowie von Menschen, die alltäglichen Verrichtungen nachgehen und sich in unspezifischer Kleidung in einem unspezifischen Umfeld bewegen, sind selten. Die Auswertung eines Baedecker-Reiseführers von 1993 ergibt ein Verhältnis von 100 Fotos, die einer spezifisch japanischen Tradition zugeordnet werden können (vgl. z.B. Karl Baedecker GmbH 1993: 72), zu 32 Fotografien, die technologische Errungenschaften, relativ unspezifische Stadt- oder Naturansichten beziehungsweise Menschen im Alltag zeigen. Noch extremer fällt die Bildauswahl eines großformatigen Bild- und Textbandes über Japan von 1984 aus (vgl. Binder 1984). Hier stehen 145 als traditionell einzustufende Fotografien 22 Bildern eines modernen Japan gegenüber. Ohne daraus allgemeingültige Schlussfolgerungen ziehen zu wollen, zeigt diese Stichprobe jedoch, dass die Reisefotografie in den vorliegenden Publikationen der dem Zielpublikum zugeschriebenen Erwartungshaltung entspricht. Exotischem wird gegenüber der Alltagskultur Vorrang eingeräumt. Aus der Bildauswahl ließe sich der Schluss ziehen, dass Japan nach wie vor ein stark traditionell geprägtes Land ist, das zum großen Teil über eine historische Bausubstanz verfügt. Diese stereotypische Dar-

27 Reisezeitschriften sind beispielsweise Geo, National Geographic oder Merian, wobei sich Reisefotografie insbesondere in den Spezialausgaben findet, die einem bestimmten Land oder Ort gewidmet sind. 
stellungsweise ist ein Kriterium, das zunächst die Reisefotografie auszeichnet. Inwieweit auch andere fotografische Formen zu einer solchen Darstellungsweise neigen, bleibt zu untersuchen.

Neben der Auswahl aus typischen Bildsujets ist auch die Bildkomposition hervorzuheben. Sowohl in der historischen als auch in der zeitgenössischen Reisefotografie ist eine Vorliebe für das klassisch durchkomponierte und ausgewogene Bild festzustellen. Der Bildinhalt wird in der Regel ins Zentrum gerückt, es wird nicht mit der Perspektive experimentiert. Die Bildsprache ermöglicht eine ruhige und kontemplative Bildbetrachtung, Überraschungen sowohl im Bildsujet als auch in der Bildauffassung bleiben aus. Die Bilder strahlen eine zuversichtliche Ruhe und Schönheit aus und irritieren nicht. Das Exotische wird domestiziert, indem es in eine vertraute Bildsprache übersetzt wird. Der Betrachter gewinnt das Gefühl, das Fremde in seiner Fremdheit erfassen und verstehen zu können, ohne sich einer Irritation durch das Fremde ausgesetzt zu sehen.

Bei der Reisefotografie handelt es sich in der Regel um eine Einzelbildfotografie. Trotz der Zusammenstellung von Bildgruppen in Alben oder gedruckten Publikationen steht das einzelne Bild für sich. Es ist mit einer Bildunterschrift versehen, das eine Zuordnung des Ortes oder der abgebildeten Handlung ermöglicht. Das einzelne Bild kann aus der Bildgruppe entfernt werden und verliert damit nicht seine Aussagekraft. Als ästhetisches Artefakt werden besonders bedeutsame Fotografien - sei es, dass sie besonders wichtige Sehenswürdigkeiten abbilden oder aber durch ihre Gestaltung hervorstechen - als Plakat oder Postkarte einzeln gewürdigt. Der bildliche Zusammenhang spielt für das Verständnis der einzelnen Fotografie kaum eine Rolle. Viel entscheidender ist der Text, der eine genaue lokale und historische $\mathrm{Zu}$ ordnung vornimmt und durch seine Faktizität Glaubwürdigkeit verleiht. Unabhängig von der Bildunterschrift kann weiterer Text die Wirkung des Abgebildeten vertiefen, indem er Hintergrundinformationen und Erläuterungen dessen liefert, was nicht auf dem Bild zu sehen ist oder in seiner Bedeutung nicht entschlüsselt werden kann. Er kann Dinge, die die Fotografie nicht zeigt, in ihr scheinbar sichtbar machen. Der Text dient auch der Konkretisierung der Erwartung an die Bilder. Er ist geradezu prädestiniert dafür, Erwartungen zu wecken, die der Betrachter im Bild bestätigt finden kann. Das Bild wird zeichenhaft als Verweis auf das Dargestellte verwendet und erfüllt damit rein illustrative Zwecke.

Die Reisefotografie zeichnet sich durch ihren dokumentierenden Anspruch aus. Sie versucht, den für sie interessanten - und damit meist exotischen - Teil der Welt in ihrem Sinne objektiv abzubilden. Dabei kann der Bildausschnitt so gewählt werden, dass unliebsame Bildgegenstände eliminiert werden. Die Existenz einer Schnellstraße neben einem Tempel lässt sich durch die Wahl des Bildausschnitts ausklammern, was zu einer romantisierenden Darstellungsweise der fremden Kultur führt. Dies schmälert jedoch nicht die Rezeption der Fotografie als dokumentierend, denn sie ist auf jeden Fall in der Fremde hergestellt worden und mit dem Fremden über eine indexikalische Spur verbunden. Im üblichen Publikationskontext von Reiseführern und Bildbänden wird eine spezifische Sichtweise auf das fremde Land konstruiert, die das Alltägliche und Gewöhnliche sowie das Soziale tendenziell ausklammert. Die Reisefotografie kann über die kulturell bedeutungsvollen Aspekte einer fremden Kultur informieren, eine umfassende und hintergründige Erhellung der Zustände sind von ihr nicht zu erwarten. Ihre 
Funktion besteht darin, das Fremde und Exotische hervorzuheben und mit ihren Aussagen darüber Sehnsüchte zu wecken. Die Reisefotografie konstruiert das Fremde als Anderes, weshalb sie zur Darstellung des Fremden als Fremdes wenig geeignet ist.

\subsubsection{Ethnografische Fotografie}

Besonders in der frühen Phase gleicht die ethnografische Fotografie noch stark der Reisefotografie. ${ }^{28}$ Beide sind auf der Suche nach dem unberührten Anderen, das sich nicht durch den Kontakt zu Kolonisten und westlichen Reisenden verändert. Im neunzehnten Jahrhundert sind sie beseelt vom Wunsch, die unbekannten Welten in ihrer Ursprünglichkeit zu belassen und zu erforschen, um die Sehnsucht nach dem Exotischen zu befriedigen. Während die Reisefotografie jedoch am Bild interessiert ist, fungiert die ethnografische Fotografie als Beleg innerhalb einer wissenschaftlichen Praxis und bedarf deshalb nicht primär ästhetischer Qualitäten.

Die ethnografische Fotografie hat sehr unterschiedliche Ansätze zur Darstellung fremder Kulturen entwickelt und spielt heute nur noch eine untergeordnete Rolle. Film und Video haben die Standbildfotografie weitgehend verdrängt, so dass diese eher im historischen Kontext und zur Aufarbeitung der Ethnologiegeschichte herangezogen wird. Die frühe ethnografische Fotografie beschäftigt sich hauptsächlich mit schriftlosen Kulturen in den kolonisierten Ländern. Dies ist vermutlich der Grund, warum ich keine ethnografischen Japanfotografien aus dieser Zeit habe finden können. In diesem Abschnitt werden deshalb die allgemeine Entwicklung der ethnografischen Fotografie und ihre Strategien im Umgang mit dem Fremden skizziert. Zum Abschluss wird ein Beispiel für eine zeitgenössische ethnografische Fotografie in Japan gegeben.

\section{Frühe ethnografische Fotografie}

Die Erfindung der Fotografie und der Beginn ethnologischer Forschungen erfolgen ungefähr im selben Zeitraum (vgl. z.B. Banta/Hinsley 1986b: 39; Krech 1984: 6). Deshalb ist die Fotografie insbesondere in der Ethnologie des neunzehnten Jahrhunderts von großer Bedeutung. Die Ethnologie und die physische Anthropologie sind zu diesem Zeitpunkt beschreibende Wissenschaften, die sich darum bemühen, Fakten zu recherchieren und aufzuzeichnen, um sie anschließend im Sinne der Evolutionstheorie zu interpretieren (vgl. Morphy/ Banks 1997: 6). Sie profitieren stark vom Imperialismus und Kolonialismus

28 Unter dem Begriff der ethnografischen Fotografie sollen hier verschiedene fotografische Strömungen betrachtet werden, die der Ethnologie und der Anthropologie zuarbeiten. Im englischen Sprachraum bezeichnet der Begriff der Anthropologie teilweise das Forschungsgebiet, das in Deutschland Ethnologie heißt. Im Deutschen wird zwischen Ethnologie und Anthropologie unterschieden. Die physische Anthropologie dient einer biometrischen Vermessung der Ethnien, während die Ethnologie sich den kulturellen Belangen fremder Gesellschaften widmet. Hier werden Ethnologie und Anthropologie synonym verwendet, da in der englischsprachigen Literatur die im Deutschen übliche begriffliche Unterscheidung nur selten getroffen wird. Ist jedoch die Anthropologie im deutschen Sinn gemeint, wird dies durch die Verwendung des Begriffs physische Anthropologie verdeutlicht. 
des neunzehnten Jahrhunderts, da sie die bestehenden Machtstrukturen für sich nutzen können. Die kolonisierten Völker haben keine Möglichkeiten, ihrer enzyklopädischen Kategorisierung durch die europäische Fotografie etwas entgegen zu setzen.

Die physischen Anthropologen, die oftmals von Haus aus Mediziner sind, suchen den Zugang zu fremden Völkern über deren Körper. ${ }^{29}$ Diese zu vermessen und zu untersuchen ist ihnen ein wichtiges Anliegen, bei dem die dokumentierenden Möglichkeiten der Fotografie nützlich sind. Um die Fotografien im Nachhinein miteinander vergleichen zu können, müssen die Aufnahmebedingungen übereinstimmen. Die Körperhaltung der Fotografierten ist vorgeschrieben, sie müssen zudem möglichst unbekleidet sein, um eine Messung der Größen am Bild zu gewährleisten. Zu diesem Zweck wird teilweise mit gerasterten Hintergründen oder Messlatten gearbeitet. ${ }^{30}$ Mit so genannten Typenaufnahmen wird versucht, einen möglichst typischen Vertreter einer Ethnie zu fotografieren, der gleichsam alle wichtigen Eigenschaften eines Volkes oder Stammes vereint und somit den Idealtypus verkörpert. Weiterhin wird auch nach Extremtypen gesucht, die in größtmöglichem Maß vom Idealtypus abweichen (zum Typenbild vgl. Krech 1984; Theye 1989b: 94f.). Die Schwierigkeiten der Versuche einer enzyklopädischen Dokumentation fremder Völker bestehen mitunter darin, dass die fotografierten Personen häufig nicht gerade stehen, was einer Vergleichbarkeit entgegen wirkt. Die der Fotografie eigene perspektivische Verzeichnung stellt ein weiteres Problem dar. Sie verhindert die präzise Ermittlung der Körpermaße. Dieser - den Menschen erniedrigenden - Art der Fotografie wird zum Ende des neunzehnten Jahrhunderts nur noch illustrative Bedeutung beigemessen (vgl. Theye 1989b: 93f.). Die anthropometrischen und typologischen Aufnahmen ähneln häufig denen von europäischen Gefängnisinsassen zur gleichen Zeit (vgl. Tagg 1988: 60ff.) Daran offenbart sich das Interesse einer vergleichenden Wissenschaft, die dokumentierende Qualität der Fotografie zu nutzen, um enzyklopädisches Wissen anzuhäufen und durch körperliche Merkmale Rückschlüsse auf Entwicklungsstand oder Charaktereigenschaften zu ziehen. Die Darstellung des Fremden in der Fotografie der physischen Anthropologie konzentriert sich ausschließlich auf das standardisierte Menschenbild. Weder soziales oder geografisches Umfeld, Sitten und Gebräuche noch materielle Güter sind von Interesse.

Die physische Anthropologie macht nur einen Teilbereich der ethnografischen Fotografie des neunzehnten Jahrhunderts aus. Fritsch schlägt zur Ergänzung der wichtigeren anthropometischen Fotografien die Herstellung ethnografischer Aufnahmen vor. Darunter versteht er $» j$ jedes Bild, welches sich auf den Menschen selbst und seine Umgebung bezieht, soweit er sich dieselbe durch seine Thätigkeit gestaltet hat « (Fritsch 1875: 612; zit. nach Schindlbeck 1989: 18). Zahlreiche Ethnologen nutzen die Kamera zur Aufzeichnung ihrer Beobachtungen. Dabei vertreten sie meist einen sehr naiven Standpunkt bezüglich der dokumentarischen Qualitäten der Fotografie. »Während sie

29 Aktives Mitglied der Berliner Gesellschaft für Anthropologie, Ethnologie und Urgeschichte ist beispielsweise der Arzt Rudolf Virchow (vgl. Schindlbeck 1989; vgl. auch Wiener 1990: 115).

30 Im 19. Jahrhundert werden Fachbücher und Nachschlagewerke publiziert, die wichtige Aspekte der anthropometrischen Fotografie zusammenfassen. Oft erwähnt wird in diesem Zusammenhang Fritsch 1875 (vgl. Wiener 1990: 119). 
[annehmen], dass die Fotografie eine objektive Aufzeichnungspraxis [ist], [machen] sie Bilder, die den von ihnen unterstützten theoretischen Annahmen grundsätzlich [widersprechen] und [enthüllen] eine weit komplexere Welt als es ihr evolutionäres Grundgerüst« erlaubt (Morphy/Banks 1997: 7f.). Weil das Lesen und Verstehen von Fotografien stark von den Prämissen der Betrachtung abhängt, lassen sich nicht nur historische ethnografische Fotografien heute anders lesen als im Kontext ihrer Entstehung. Die Ethnologen des neunzehnten Jahrhunderts nutzen die Kamera vielfach dazu, die »untergehenden, sterbenden, verschwindenden Völker und/oder ihre Kulturen« aufzuzeichnen (Poignant 1992: 42; Hervorhebung im Original). Sie sind mit dem Problem konfrontiert, dass die beobachteten Kulturen sich durch den Kontakt mit den Europäern bereits rapide verändern. Sie wollen das Ursprüngliche, ganz Andere entdecken und sind enttäuscht, wenn sie Völker vorfinden, die »bereits von der Zivilisation `beleckt«« sind (Theye 1989b: 110).

\section{Themengebiete der frühen ethnografischen Fotografie}

Im neunzehnten Jahrhundert lassen sich verschiedene Gruppen von ethnografischen Fotografien differenzieren, die zusammen ein recht komplexes Bild fremder Kulturen zeichnen. Fritsch schlägt die Darstellung von Personen in ihrer bevorzugten Körperhaltung und ihrer eigenen Kleidung vor, um Kleidung, Schmuck und Waffen sowie ihre Art des Tragens zu dokumentieren (vgl. Fritsch 1875: 613; zit. nach Schindlbeck 1989: 18). Häufig finden solche Aufnahmen auch im Studio statt, da der Fotograf die Situation dort besser kontrollieren kann. Dies gilt insbesondere für die frühe Phase der Fotografie mit ihren langen Belichtungszeiten. Die daraus resultierenden Fotografien repräsentieren jedoch die kolonialen Machtverhältnisse, in denen sich die fotografierte Person als ethnografisches Objekt den Bedingungen des Studios und damit des weißen Fotografen unterzuordnen hat (vgl. Wiener 1990: 126136: Kontrollierte Wildheit im Studio). Dadurch sind solche Porträts oft nicht allzu weit von anthropometrischen Aufnahmen entfernt.

Fritsch vermerkt weiterhin die Notwendigkeit, »Waffen und Geräte sowie ihre Anwendung, Wohnungen, Bauten, [...] Handwerk und Kunst« zu fotografieren (Schindlbeck 1989: 18; nach Fritsch 1875: 613). Die Dokumentation der materiellen Kultur verweist auf früheste wissenschaftliche Bestrebungen, zahlreiche Alltags- und Kultgegenstände fremder Völker zu sammeln oder diese den Sammlungen in "graphischer Übertragung« zuzuführen (Wiener 1990: 151). Aus der heutigen Sicht ist die isolierte Darstellung einzelner Objekte jedoch problematisch, da die konkrete Verwendung des Abbildungsgegenstandes in zahlreichen Fällen nicht erkennbar ist (ebd.: 153). Die Fotografie dient hier der Inventarisierung von Objekten und hilft bei der Einrichtung völkerkundlicher Museen in Europa. Die fotografische Inventur ist elementar, denn die gesammelten Gegenstände müssen genau katalogisiert werden. Die Fotografien der materiellen Kultur fremder Völker dienen einem ähnlichen Zweck wie die der physischen Anthropologie: Sie sollen beim Vergleichen und Archivieren helfen. Dementsprechend werden die Fotografien hauptsächlich zu illustrativen Zwecken verwendet. Sie werden Texten beigefügt, die die beobachteten Völker beschreiben und Forschungsergebnisse präsentieren. Sie visualisieren die Beobachtungen der Ethnologen. Bildunterschriften nehmen eine präzise Zuordnung vor.

Als weiteres Themenfeld lassen sich »Scenen des privaten und des öffentlichen Lebens« anführen (Fritsch 1875: 613; zit. nach Schindlbeck 1989: 
18). Erst handliche Kameras mit kurzen Verschlusszeiten ermöglichen das Festhalten von Momenten oder Bewegungsabläufen im Bild. Dies wirkt sich auch auf die Bildauffassung der ethnografischen Fotografie aus. »Immer häufiger [werden] asymmetrische Bildaufteilungen bevorzugt « (Wiener 1990: 159; Hervorhebung im Original). Die Fotografie wird spontaner und löst sich langsam von den starren Inszenierungen.

Eine weitere Kategorie stellen Landschaftsaufnahmen dar, die in einer länderkundlichen Tradition gemacht werden. Sie zeigen zum einen weitgehend unberührte Naturlandschaften, »mit alles überwucherndem Pflanzenwuchs, Urwalddickicht, aber auch leere Einöden, karge Wüsten und steinige Felslandschaften« (Theye 1989b: 99). Zum anderen zeigen sie Kulturlandschaften, in denen die Interaktion der Völker mit der sie umgebenden Landschaft deutlich wird. Nach Fritsch sollten »Landungsplätze, Häfen, Schiffe und Boote [sowie die] Feldbebauung« Sujets ethnografischer Aufnahmen sein (Schindlbeck 1989: 18; nach Fritsch 1875: 613).

»Beide Gebiete [Natur- und Kulturlandschaften] sind in den Landschaftsfotografien nicht immer streng voneinander zu unterscheiden, denn überall dort, wo Menschen leben - und diese Gegenden [stehen] im Blickpunkt der Forscher und Fotografen üben sie Einfluß auf die sie umgebende Natur aus, so daß es dort eigentlich keine unveränderte ursprüngliche Natur mehr geben kann« Theye 1989b: 99).

Die ethnografischen Motivwelten überschneiden sich teilweise mit denen der Reisefotografie, so dass für das neunzehnte Jahrhundert eine Abgrenzung der beiden Felder kaum möglich ist. Für Ethnologen ist die Auswertung der Fotografien schwierig, wenn professionelle Fotografen - auf deren Unterstützung sie in der Regel angewiesen sind - Gegenstände falsch zuordnen oder Menschen mit Kleidung oder Kultgegenständen anderer Stämme fotografieren. Während professionelle Fotografen solche Fälschungen teils aus Unwissenheit, teils aus bildnerischen Gründen produzieren, legen Ethnologen Wert auf eine präzise Zuordnung von Ethnien und materiellen Gütern. Die Aussage über das Abgebildete hat für sie mehr Relevanz als die bildnerische Qualität.

\section{Neue ethnografische Ansätze und Visual Anthropology}

In der ersten Hälfte des zwanzigsten Jahrhunderts verändern sich zahlreiche Parameter, die auch zu einer anderen fotografischen Produktion führen. Mit dem Ende der Hochzeit des Kolonialismus verschiebt sich der Fokus der Ethnologie. Die Enzyklopädisierung der materiellen Kultur verliert an Wichtigkeit, das Interesse der Forscher zielt nun auf ein umfassendes Verständnis der Sitten und Gebräuche und des Verhaltens fremder Völker. Mit Malinowskis teilnehmender Beobachtung bricht eine neue Ära in der Ethnologie an (vgl. Teil I, Abschnitt 1.2.1.). Das Vertrauen in die Objektivität der Beobachtung einerseits und in die des Mediums andererseits ist ausschlaggebend für die im Rahmen der Feldforschung entstehenden Bilder. Stereotype bildliche Darstellungen bezeugen die Voreingenommenheit der Fotografierenden und porträtieren die beobachteten Menschen als exotische kulturelle Artefakte (vgl. Banta/Curtis 1986a).

Um das Problem der Voreingenommenheit zu umgehen, entwickeln Margaret Mead und Gregory Bateson einen neuen Ansatz des ethnografischen Einsatzes der Dokumentarfotografie. Während ihres mehrjährigen Forschungsaufenthalts in Bali in den 1930er Jahren schaffen sie ein riesiges 
Konvolut von ethnografischen Fotografien, von denen lediglich ein Bruchteil publiziert ist (vgl. Sullivan 1999: 1f.). Die Fotografien werden als »Notizen, Zeichen und Schatten « bezeichnet (ebd.: 1). »Notizen insofern, als die Anthropologin die Fotografien als Gedächtnisstütze oder als Aufzeichnung für das, was er oder sie sieht, nutzt« (ebd.). Die Fotografien als Notizen werden zu Dokumenten. Sie dienen dem Fotografierenden - im Sinne der Definition des Dokuments - als Belege des Beobachteten. Sie sind »Zeichen, wenn die Fotografien Teil des Versuchs der Anthropologin werden, anderen zu erhellen, was er oder sie gesehen hat« (ebd.). In diesem Gebrauch werden die Fotografien zur Belehrung über eine Sache genutzt und verweisen auf ihr Referenzobjekt. Dies zeichnet sie ebenfalls als Dokumente aus, die hier als Illustrationen eines Sachverhalts gesehen werden können. Schließlich sind sie »Schatten, da die Fotografien ihre Form zu großen Teilen aus der Welt beziehen, in die der Anthropologe einen Blick geworfen hat« (ebd.). Der Begriff des Schattens verweist wiederum auf die indexikalische Beziehung der Fotografie zur Welt. Nach Sullivans Interpretation sind Meads und Batesons Fotografien Dokumente im lexikalischen Sinn, die einen direkten Bezug zum Abgebildeten herstellen.

Mead und Bateson fotografieren, um Sachverhalte aufzuzeichnen und ihr Beobachtungsvermögen im Feld zu unterstützen. »Bateson [nutzt] die Medien Fotografie und Film als Mittel der Untersuchung, um durch den Prozess möglicherweise ein Verständnis für die balinesische Kultur zu entwickeln, während Mead sie in einem eher positivistischen Sinn als Instrument der Aufzeichnung von Daten für nachfolgende Analysen [nutzt] (Morphy/Banks 1997: 11). Beide Herangehensweisen dienen der Analyse des Wahrgenommenen, wobei in der Betrachtung der Fotografien Aspekte aufscheinen können, die in der direkten Beobachtung übersehen worden sind. Deshalb eignet sich die Fotografie besonders gut, »um Notizen über menschliches Verhalten zu machen « (Margaret Mead in einem unveröffentlichten Brief an Franz Boas vom 19.5.1941; zit. nach Sullivan 1999: 3). In ihrem Projektantrag hatte Mead argumentiert, dass das Verständnis für die fremde Kultur erst nach und nach vertieft wird. Wenn nun von Anfang an fotografische Notizen gemacht werden, lassen sich diese Bilder zu einem späteren Zeitpunkt mit dem hinzu gewonnenen Wissen erneut analysieren, was zu einem verbesserten Verständnis der beobachteten Völker führen kann (vgl. Sullivan 1999: 3f.). Besonders für nonverbale Kommunikation, für die in der Ethnologie keine Methodik der Beobachtung und Aufzeichnung existiert, kann die Kamera genutzt werden (vgl. ebd.: 16). In diesem Sinne kann die ethnografische Fotografie etwas leisten, was einem Text nur schwerlich gelingt. Sie dient nach Mead und Bateson nicht mehr nur als Illustration des ethnografischen Textes, sondern ist in der Lage, eigenständig Sachverhalte zu erläutern. Mead vertraut dabei auch auf die große Anzahl der Bilder, die einem voreingenommenen Blick entgegensteht. Für sie ist ein Einsatz visueller Medien auch durch aufgestellte und automatisch ausgelöste Kameras möglich, was zu einer Bildproduktion ohne die gezielte Entscheidung des Ethnologen für einen bestimmten Ausschnitt und einen bestimmten Moment des Auslösens führt. Sie sieht die fotografische Dokumentation als eine Möglichkeit, weit mehr Material zu sammeln, als es der beobachtenden Wissenschaftlerin in der begrenzten Zeit der Feldforschung möglich ist.

Margaret Mead plädiert noch in den 1970er Jahren für den Einsatz von Fotografie und Film in der ethnologischen Feldforschung. Nur visuelle Me- 
dien hätten die Möglichkeit, die Textbasiertheit der Ethnologie zu durchbrechen und beispielsweise Tänze und Verhaltensformen für die Nachwelt zu konservieren. Während Film und Video in der Visual Anthropology auch heute noch eingesetzt werden, hat die Verwendung von ethnografischer Fotografie nach dem Zweiten Weltkrieg immer weiter abgenommen. Der Grund ist möglicherweise darin zu suchen, dass der monografische Text des Ethnologen als die direkte Vermittlung der teilnehmenden Beobachtung gilt.

»Der Anthropologe hat mit seiner eigenen Person die Funktion der Glasplatte oder des Filmstreifens übernommen. Dies ermöglicht ihm - vorbereitet, um Botschaften in negativer Form zu empfangen und aufzunehmen, während eines Moments der Aussetzung [Exposition] >im Feld « nach entsprechender Entwicklung - die Aufzeichnungen in einem >positiven Stadium in der ethnografischen Monografie zu präsentieren« (Pinney 1992: 82).

Der Fotografie haftet zunehmend der Ruf der Voreingenommenheit und der Konstruktion ihres Gegenstands an, weshalb die textliche Form als die neutralere gilt. Im ethnografischen Text lässt sich das Problem einer voreingenommenen Sichtweise formulieren, was mit Fotografie nur schwer möglich ist. Zudem scheint es zunehmend schwierig, eine Bildsprache der ethnografischen Fotografie zu entwickeln, die sich deutlich von einer touristischen oder professionellen Reisefotografie unterscheidet. Der Einsatz der Kamera verdeutlicht die Machtverhältnisse, da der Ethnologe als Fotograf agiert, während die beobachteten Menschen passiv bleiben. Die Kamera schafft somit eine Distanz zwischen Forschern und beobachteten Individuen. In der ethnologischen Feldforschung, die auf Beobachtungen und den daraus resultierenden Aufzeichnungen beruht, werden die beobachteten Menschen auch als Informanten und Gesprächspartner mit einbezogen und können somit aktiv zur Feldforschung beitragen, wodurch sich die Distanz zwischen Forschern und Erforschten minimiert. Die ethnografische Dokumentarfotografie wird jedoch auch durch den Einsatz von Video verdrängt. Das Bewegtbild scheint die Beobachtung wesentlich besser zu unterstützen als die Standbildfotografie. Ein erfolgreicher Einsatz der Kamera kann generell nur durch ein Verhältnis von Verantwortung und Vertrautheit zwischen Ethnologen und erforschten Gemeinschaften garantiert werden (vgl. Banta/Hinsley 1986c: 119).

Die bereits im ersten Kapitel angesprochene Krise des ethnografischen Textes hat gleichermaßen auch die ethnografische Fotografie ergriffen. Ethnologen wie Christoph Jamme oder Elizabeth Edwards argumentieren, dass die Kunst, respektive die künstlerische Fotografie, im Rahmen der ethnologischen Forschung wesentlich mehr zur Erhellung fremder Kulturen beitragen können als die eigentliche ethnografische Fotografie (vgl. Teil I, Abschnitt 1.3.2.; Morphy/Banks 1997: 26; Edwards 1997). Ohne einen Text können ethnografische Fotografien kaum zur schlüssigen Erläuterung komplexer $\mathrm{Zu}$ sammenhänge im ethnologischen Sinn beitragen. Dies ist unabhängig davon, ob es sich bei den Fotografien - wie in den meisten Fällen - um Einzelbilder oder aber um Serien und Sequenzen handelt, wie sie in Meads und Batesons Ansatz verwendet werden.

Prinzipiell gibt es keine festen Kriterien, die eine Fotografie als ethnografisch kennzeichnen. »Jede Fotografie kann von ethnografischem Interesse sein, kann ethnografische Tragweite oder Bedeutung zu einer bestimmten Zeit oder aus einem spezifischen Grund heraus haben« (Pink 2001: 51). Eth- 
nologen können heute vergangene Kulturen mit Hilfe von Reisefotografien des neunzehnten Jahrhunderts erforschen. Und auch touristische, journalistische oder andere Fotografien sagen etwas über fremde Kulturen aus (vgl. Edwards 1992). Die Bedeutung von Fotografien ist willkürlich und subjektiv und wechselt mit dem Betrachter, dem Kontext und der Zeit (vgl. Pink 2001: Kap. Photography in Ethnographic Research: 49-76).

\section{Beispiel einer zeitgenössischen ethnografischen Fotografie}
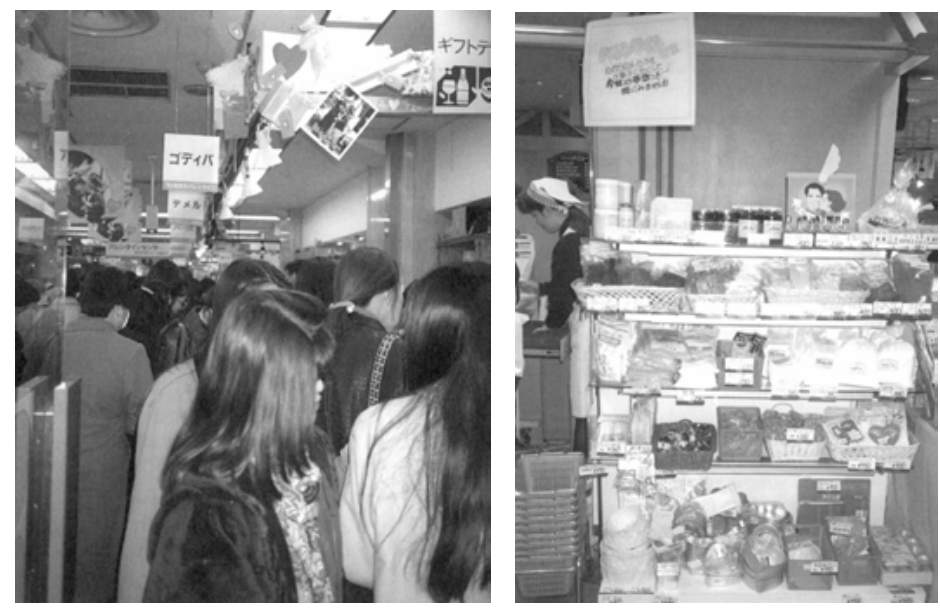

"4.18. Crowd of women buying Valentine's Day chocolates".

»4.19. Baking supplies for Valentine's Day treat«s (Rupp 2003: 146/147).

Um die Ambivalenz des ethnografischen Bildmaterials zu verdeutlichen, sei hier beispielhaft eine Publikation über die Geschenkkultur in Japan herausgegriffen, die im Gegensatz zu manch anderer ethnografischen Monografie Fotografien zur Verdeutlichung der Beobachtungen einsetzt (vgl. Rupp 2003). Bei 24 der 34 Abbildungen handelt es sich um schwarzweiß gedruckte Fotografien. ${ }^{31}$ Sie sind jeweils mit einer Bildunterschrift versehen, laufen im Text mit und sind den entsprechenden Kapiteln zugeordnet. Sie sind von der Autorin fotografiert. Verschiedentlich wird versucht, einen Teilaspekt des Themas in einer Bildfolge zu bearbeiten, ansonsten handelt es sich um Einzelbilder. Die Fotografien zeugen von keiner besonderen gestalterischen Intention, sie wirken beiläufig fotografiert, wobei sich der Gegenstand, der durch die Bildunterschrift benannt wird, meist in der Bildmitte befindet und eindeutig zu erkennen ist (vgl. ebd.: Abb. 4.19; 147). Gelegentlich wird noch einmal in der Bildunterschrift auf etwas Beachtenswertes hingewiesen, wobei dessen Bedeutung nur aus dem Text erschlossen werden kann. Nur wenige von den abgebildeten Fotografien stechen unter gestalterischen Gesichtspunkten hervor. Eine einzelne Fotografie erschließt sich weder als Bild noch mit Hilfe der Bildunterschrift (vgl. ebd.: 112). Es ist stark angeschnitten und kein Gesicht der abgebildeten Personen ist erkennbar. Eine weitere Fotogra-

31 Bei den anderen Abbildungen handelt es sich um Zeichnungen, auf die ich hier nicht weiter eingehen werde. 
fie fällt auf durch den gewählten Bildausschnitt und durch die Tatsache, dass kein Gesicht der abgebildeten Personen der Kamera zugewandt ist (vgl. ebd.: Abb. 4.18; 146). In beiden Fällen scheint die Aufnahmesituation keinen anderen Blickwinkel zugelassen zu haben. Die Fotos sind der Ethnologin trotzdem wichtig und in Verbindung mit dem Text offenbar ausreichend aussagekräftig. Ohne den ethnografischen Kontext könnte es sich bei den meisten Bildern um touristische Aufnahmen handeln. Mit wenigen Ausnahmen lassen sich die Fotografien auch ohne Bildunterschrift einem japanischen (oder asiatischen) Kontext zuordnen, weil in den meisten Bildern japanische Schriftzeichen zu sehen sind. Das spezifisch Japanische wird im Sinne der ethnografischen Aussage unterstrichen. Die Bildauffassung zeugt von keiner eigenständigen Bildsprache oder Bildtradition, die die Fotografien eindeutig als ethnografisch kennzeichnen. Die Fotografien werden illustrativ gebraucht, sie werden durch den Text erläutert; ihre Referenz zum Dargestellten ist entscheidend.

Die Bildauffassung der ethnografischen Fotografie ist nicht primär auf das gute Bild im ästhetischen Sinne gerichtet. Ein gutes Foto ist eines, das die Beobachtungen des Ethnologen und seine textlichen Ausführungen unterstützt. Die Fotografie soll - wie der Ethnologe selbst - eine neutrale Beobachterposition einnehmen. Die ethnografische Fotografie dient als Informationsquelle, die ihre Bedeutung aus dem Kontext bezieht. Dies geschieht unabhängig davon, ob Einzelbilder oder Bildfolgen eingesetzt werden. Es lässt sich keine pauschale Aussage über den Umgang mit Klischees in ethnografischen Fotografien machen. Anhand der untersuchten Publikation wird deutlich, dass partiell Differentes ins Bild gerückt wird. ${ }^{32}$ Andererseits ist die Autorin bemüht, Aspekte der ethnologischen Untersuchung in ihrer alltäglichen gesellschaftlichen Verankerung zu fotografieren, was zu Bildern führt, die mit klischeehaften Bildvorstellungen brechen. Insgesamt weist die ethnografische Fotografie keine mediale Eigenständigkeit auf, was sie für eine rein bildnerische Praxis der Auseinandersetzung mit dem Fremden als Fremden ausschließt.

\subsubsection{Journalistische Fotografie}

»Die Aufgabe der ersten Photoreporter bestand darin, einzelne Aufnahmen zu machen, um eine Geschichte zu illustrieren. Erst von dem Augenblick an, wo das Bild selbst zur Geschichte wird, die in einer Folge von Photos über ein Ereignis berichtet, während der danebenstehende Text oft nur aus Bildunterschrift besteht, beginnt der Photojournalismus « (Freund 1976: 122). Gisèle Freund, selbst Fotojournalistin, greift hier eine Reihe wichtiger Merkmale des Fotojournalismus auf. Entscheidend sind die Erzählkraft der Bilder, das Prinzip der Serialität und die Relation zum Text. Freund grenzt die Fotoreportage direkt von einer Pressefotografie ab, die in der einzelnen Fotografie aktuelle und tagespolitisch relevante Ereignisse ins Bild setzen muss und somit eher illustrativen Zwecken dient. Solche Pressefotografien sind meist dem »Sensationellen, Oberflächlichen oder Banalen « verpflichtet (Goldsmith 1985: 13). Sie zeigen ein Ereignis oder dessen direkte Auswirkungen. Sie werden über Bildagenturen verbreitet und direkt am nächsten Tag in Tageszeitungen veröffentlicht. Auch wenn sie zu einem späteren Zeitpunkt in Form

32 So z.B. die Abbildungen der Karpfen-Fahnen (vgl. Rupp 2003: Abb. 4.13, 4.14; 136f.). 
von Bildfolgen an anderer Stelle publiziert werden oder im musealen Kontext erscheinen, ${ }^{33}$ handelt es sich um eine ereignisbasierte Einzelbildfotografie. An dieser Stelle soll jedoch eine journalistische Fotografie näher betrachtet werden, die an Hintergrundinformationen interessiert ist und Bildfolgen produziert. Die klassische Fotoreportage, auch Foto-Essay genannt, wird in Publikumszeitschriften veröffentlicht, die sich mit einem breiten Themenspektrum befassen.

Die Trennung zwischen professioneller Reisefotografie und Fotojournalismus kann nicht allein über das Publikationsmedium vorgenommen werden. Denn auch in Publikumszeitschriften erscheinen Reisereportagen und in Reisemagazinen werden fotografische Beiträge zu spezifischen Themen publiziert. Entscheidend ist die inhaltliche Auseinandersetzung mit dem Fremden. Geht es darum, dem Leser/Betrachter ein fremdes Land im Allgemeinen, also Sehenswürdigkeiten, Klima, Menschen und Kultur nahe zu bringen, möchte ich von einer Reisefotografie sprechen. Handelt es sich um einen Bildbeitrag, der sich intensiv mit einem ausschnitthaften - primär zeitgenössischen - Aspekt der fremden Kultur beschäftigt, möchte ich ihn als Fotojournalismus einordnen.

Die Fotoreportage unterscheidet sich von der tagesaktuellen Pressefotografie insbesondere dadurch, dass sie nicht in einem einzelnen Bild ein Ereignis dokumentieren muss, sondern in mehreren Bildern Zusammenhänge herstellen kann. Ziel der Fotoreportage ist die »Einordnung begrifflich zusammenhängender Einzelbilder unter eine gemeinsame Idee [...] zu einem einheitlichen Ganzen« (Raphael 1933: 26; zit. nach: Pohl 1983b: 98). Es entstehen Bildstrecken, die eine neue Erzählform entwickeln und so den textlichen Journalismus erweitern. Die Fotografie muss nicht mehr ausschließlich einen Text illustrieren. Sie emanzipiert sich gewissermaßen vom geschriebenen Wort, auch wenn sie nicht ganz ohne Text in Form von Bildunterschriften auskommt. Diese Form der Bildreportage wird so heute kaum noch in Publikumszeitschriften publiziert. Sie ist eher in monografischen Bildbänden zu finden (vgl. z.B. Salgado 1993; Peress 1994).

\section{Objektivität und Authentizität im Fotojournalismus}

Nachdem bereits seit dem Ende des neunzehnten Jahrhunderts die Möglichkeit besteht, Text und Bild gleichzeitig zu drucken, gewinnt die Fotografie in der illustrierten Presse zunehmend an Bedeutung. ${ }^{34}$ Die moderne Fotoreportage entwickelt sich jedoch erst - bedingt durch das Zusammenspiel neuer Kameratechnik, wirtschaftlicher Interessen der massenhaft verbreiteten illustrierten Zeitschriften und der Bedürfnisse des Publikums - hauptsächlich im Deutschland der 1920er Jahre (vgl. Freund 1976: 122). Ihr wird eine absolute Authentizität zugeschrieben, weil von ihr als journalistischer Form grundsätzliche Objektivität verlangt wird. Der Journalist hat die Aufgabe, wahrheitsgetreu und neutral zu berichten. Der Fotojournalist hat Fotografien zu liefern, die diesem Berufsethos entsprechen. Die journalistische Fotografie gilt als Verkörperung des Dokumentarischen schlechthin. Ihre Objektivität

33 Beispielsweise im Rahmen der World Press Photo Ausstellungen, die weltweit gezeigt werden.

34 Für einen Überblick über die technischen Entwicklungen der Druckverfahren vgl. z.B. Albert/Feyel 1998; Newhall 1984a: 257ff.; Steinorth 1992. 
und Authentizität werden nur selten hinterfragt. »Das Bild selbst [wird] zur Nachricht« (Stahr 2004: 49f.).

Von großer Bedeutung ist deshalb der explizit formulierte »Verzicht auf inszenierte oder gestellte Bilder« (Theye 1989a: 32; vgl. Pohl 1983b: 98; Gidal 1993: 15). Darin unterscheidet sich die Fotoreportage von ihren Vorläufern und garantiert - so weit möglich - die Authentizität des Dargestellten. ${ }^{35}$ Der Verzicht ist jedoch nicht absolut, denn der Fotoreporter hat eine klar definierte Aufgabe. Er muss eine Situation sinnvoll in Bilder fassen und dabei Fotografien schaffen, die etwas aussagen. Aufgrund der Gegebenheiten vor Ort ist dies aber nicht immer möglich. Bestimmte Inszenierungen bilden jedoch keinen Verstoß gegen das Objektivitätsgebot der journalistischen Ethik. ${ }^{36}$ Dies verdeutlicht die Dehnbarkeit des Begriffs des Authentischen in der journalistischen Fotografie. Die Realität kann ohnehin nur die vom Fotografen wahrgenommene sein. »Wirklichkeit ist immer eine persönliche, individuell empfundene Realität« (Eskildsen 1985: 15). Die Wirklichkeit gibt es nicht, von daher kann sie auch nicht fotografisch abgebildet werden (vgl. Teil I, Abschnitt 3.2.1.). Inszenierungen oder konstruierte Bilder sind jedoch verpönt, obwohl sie Sachverhalte möglicherweise besser erläutern könnten als authentische Fotografien.

»Das aktuelle, nachträglich gestellte Photo ist trotzdem niemals ganz und gar ein Werk der Phantasie. Zwischen ihm und der von ihm illustrierten Wirklichkeit bestehen komplexe Beziehungen. Als Rekonstruktion von Begebenheiten, die tatsächlich stattgefunden haben, ist sein Inhalt allemal der des Ereignisses; als Erfindung neuer Begebenheiten seit dem Ereignis behält es zumindest dessen Akteure bei. Die Details, die es der Wirklichkeit entlehnt, rekonstruiert es in aller Regel mit peinlicher Genauigkeit, erst in der Strukturierung dieses Materials entfernt es sich von ihr« (Boltanski 1981: 147).

Entscheidend für die Fotoreportage ist eben nicht nur der Moment der Aufnahme, sondern - möglicherweise von großer Tragweite - die weitere Bearbeitung des Bildmaterials. Freund, die als Fotografin nicht die einzige ist, deren Fotografien durch unterschiedliche Bildunterschriften mit gegensätzlichen Bedeutungen publiziert werden, bezeichnet die Objektivität des Fotos als Illusion. »Die Kommentare, die man ihm mitgibt, können seine Bedeutung völlig verändern« (Freund 1976: 173).

\section{Wechselwirkungen zwischen Fotografie und Kontext}

Ein die Wirkung der Fotoreportage beeinflussender Faktor ist das Layout. Im Layout werden Fotografien beschnitten und von der Größe her gewichtet. Auch die gestalterische Anwendung von Typografie - das betrifft beispielsweise Schriftfarbe und -größe und die Art, wie sie mit den Bildern kombiniert ist - ist Teil des Layouts und wirkt sich auf die Rezeption der Fotografien

35 Dass diese prinzipiell nicht erreicht werden kann, erläutert Teil I, Abschnitt 3.2.2.

36 Vgl. beispielsweise die berühmte Fotografie von Joe Rosenthal (U.S. Marines raise the American flag atop Mount Suribachi during World War II, Iwo Jima, Volcano Islands, 1945), die, um der Situation des ersten Siegs auf japanischem Territorium größere Bedeutung zu verleihen, angeblich nachträglich gestellt worden ist (vgl. Landsberg o.J.). 
aus. ${ }^{37}$ Thematisch zusammenhängende Seiten mit voneinander abhängigen Abbildungen gibt es bereits seit Beginn des zwanzigsten Jahrhunderts, »im günstigsten Fall handelt es sich dabei um Sequenzen, die von einem Fotografen in räumlicher und zeitlicher Einheit aufgenommen« werden (Saure 1992: 22). Der innovative Charakter der neuartigen Fotoreportagen der zwanziger Jahre entsteht durch »Reihungen, Überschneidungen und Überblendungen« des Bildmaterials (ebd.). Das Bild wird gleichrangig mit dem Text behandelt und erhält durch das Layout weiteres Gewicht. Foto-Essays verwenden zum Teil nur noch Bildunterschriften und verzichten auf weitere erläuternde Texte, denn die Fotografien sprechen für sich; ein zentraler Text scheint überflüssig. Die Fotoreportage ersetzt den Text. Im Layout bekommt die Fotoreportage einen Anfang und ein Ende. »Um ein zentrales symbolisches Photo, welches bereits alle Elemente der Geschichte enthält, sind eine Reihe von Bildern gruppiert, die die Geschichte in Details erzählen« (Freund 1976: 131). Text erscheint in der Überschrift und in den Bildunterschriften, die die Bedeutung des Bildmaterials festlegen. Im Sinne eines journalistischen Textes hat die Bildreportage einen klaren Informationsauftrag. Die Aufarbeitung des Bildmaterials bis hin zur Publikation entscheidet über ihre Aussage. Diese Arbeit wird nicht vom Fotografen selbst übernommen. Der Fotograf gibt mit den Negativen die Kontrolle über seine Bilder aus der Hand. Er entscheidet nicht einmal darüber, welche Bilder verwendet werden. Bildredakteure und Layouter legen durch Bildauswahl, Layout und Text die Richtung der Fotoreportage fest und entscheiden über die endgültige Erscheinungsform (vgl. Eskildsen 1985: 10ff.; 15). Unter Umständen werden Ausschnitte aus den Fotos gewählt oder kleinere Retuschen vorgenommen (vgl. Boltanski 1981: 139).

Nicht nur Bildunterschriften und Layout sind für die Bildwirkung entscheidend. Der Publikationskontext setzt sich aus weiteren Faktoren zusammen:

»Die Pressefotografie ist eine Botschaft. [...] Und der Übermittlungskanal ist die Zeitung selbst oder genauer, ein Komplex nebeneinander bestehender Botschaften, in dessen Zentrum die Fotografie steht und dessen Umfelder aus dem Text, dem Titel, der Bildbeschriftung, dem Layout und auf abstraktere, aber nicht weniger sinformierendeく Weise, durch den Namen der Zeitung gebildet werden« (Barthes 1990: 11).

Barthes bringt das Zusammenspiel der verschiedenen Faktoren zur Bedeutungskonstitution der journalistischen Fotografie auf den Punkt. Werbung unterbricht die Bildstrecken durch ihre eigene Bildsprache. Diese Aspekte bilden den Wirkung und Rezeption prägenden Kontext der journalistischen Fotografie.

Die Gestaltung der Fotoreportage richtet sich nach Vorwissen und Informationsgrad der Leser.

$»$ Es ist wahrscheinlich, daß eine gute Pressefotografie [...] das beim Leser vorausgesetzte Wissen mit einkalkuliert, indem Abzüge ausgewählt werden, die eine möglichst große Menge derartiger Informationen enthalten [...]; fotografiert man das

37 Vgl. dazu z.B. Tucker 1984: 41: »But while facts were acknowledged as the basic component of documentation, the information conveyed by photographic facts could be sharply altered, even totally transformed, by the sequence and manner of its presentation« (Tucker 1984: 41). 
zerstörte Agadir, so bringt man besser einige Zeichen der >Arabität` an, obwohl die >Arabität $<$ mit dem Desaster selbst nichts zu tun hat; denn die dem Wissen entsprungene Konnotation ist immer eine beruhigende Kraft« (Barthes 1990: 24).

Die journalistische Fotografie baut auf Wiedererkennbarkeit. Sie soll sich ähnlich einem Text erschließen und keine Fragen aufwerfen, sondern Antworten geben. Dazu bedarf es einer »hohe[n] Erzählqualität der verwendeten Fotografien, [...] die Fotos [müssen] die aufgenommene Situation möglichst klar verdeutlichen« (Theye 1989a: 32). Sie müssen Elemente enthalten, die der Leser/Betrachter leicht entschlüsseln kann, um die Zusammenhänge in der intendierten Form zu verstehen. ${ }^{38}$ Die Fotoreportage im Sinne eines Tatsachenberichts sollte im Idealfall nicht künstlerischer Ausdruck oder Selbstverwirklichung des Fotografen sein, sondern von neutraler beobachtender Position Sachverhalte darstellen. Das bedeutet jedoch auch, dass in den Fotografien die Machtverhältnisse respektiert werden und keine Kritik geübt wird. Den Fotoreportern fällt es stets leichter, »Verständnis für ihre Motive aufzubringen, als sie zu kritisieren. Kritische Fotografien wirken, insbesondere wenn es um Menschen geht, stets subjektiver« (Ritchin 1998: 602). So wird die Kritik eher dem schreibenden Journalisten überlassen, der »keine körperliche Nähe zum thematisierten Gegenstand benötigt« (ebd.: 602f.).

\section{Die Entwicklung des Fotojournalismus}

In den frühen Fotoreportagen der zwanziger und dreißiger Jahre des zwanzigsten Jahrhunderts wird in der Schilderung eines Ereignisses häufig die Person des Fotografen als die des Erlebenden mit einbezogen. Durch seine Präsenz am Ort des Geschehens bürgt er mit seiner Person für die Authentizität der Aufnahmesituation (vgl. Theye 1989a: 32). Der Fotograf ist dabei, er beobachtet nicht von einem entfernt liegenden Punkt her, sondern er ist Teil des Geschehens. Daraus ergeben sich Fotografien, die mit Anschnitten und dynamischen Perspektiven arbeiten. Die lebhafte Bildsprache macht sich nicht nur die journalistische Fotografie der zwanziger Jahre zu Eigen. Die Errungenschaften des neuen Sehens ${ }^{39}$ werden in der Fotoreportage einem großen Publikum zugänglich gemacht. Es sind aber nicht nur die Perspektiven, die die Authentizität verbürgen, sondern auch der veränderte Umgang mit der Bildschärfe. Bewegungsunschärfen und eine geringe Tiefenschärfe werden Teil der Bildaussage. »Nicht mehr die Schärfe eines Bildes macht seinen Wert aus, sondern sein Gegenstand und die Gefühle, welche es erweckt« (Freund 1976: 126). Auch heute unterliegt die journalistische Bildauffassung stark den ästhetischen Strömungen ihrer Zeit. Es wechseln sich Perioden, in denen sich »das formal ästhetische Foto im Großformat« durchsetzt ab mit Phasen, die einen seriellen Charakter der Fotografien berücksichtigt wissen wollen und auf ihre erzählerischen Qualitäten setzen (Eskildsen 1985: 13). Zudem ist der Umgang mit Fotografien je nach Medium unterschiedlich. Das Publikumsmagazin Stern verfolgt beispielsweise eine andere Bildsprache als das Wirtschaftsmagazin Brandeins. Es ist dementsprechend nicht möglich,

38 »Magazine photographs must be readable at a glance« (Tucker 1984: 46).

39 Unter dem Neuen Sehen versteht man eine in den 1920er Jahren entwickelte neue Fotoästhetik, die unter anderem mit Perspektiven - beispielsweise der Vogelperspektive - spielt (vgl. z.B.: Gräff 1929; Hausmann/Gräff 1979; Frizot 1998c). 
eine allgemeingültige Aussage über die journalistische Bildauffassung zu machen.

Die illustrierte Presse entwickelt sich in den 1920er Jahren parallel zum Kino. Sie ist Ausdruck einer neuen Schnelllebigkeit und Unruhe, in der "nicht der Wunsch nach Wissen, sondern die Schaulust« bedient wird (Dewitz/Lebeck 2001: 112). Der Fotoessay wird um 1930 herum zu einer »Art filmischer Kurzgeschichte mit statischen Bildern« (ebd.). Als Thema der Fotoreportage entwickelt sich bereits in den zwanziger Jahren ein vielseitiges Spektrum des Besonderen sowie des Alltäglichen, »nicht die Wichtigkeit eines Stoffes [entscheidet] über die Auswahl und Annahme von Bildern, sondern allein der Reiz des Bildes« (ebd.). So ist es nicht verwunderlich, dass in diese Zeit auch der Beginn der Paparazzi-Fotografie fällt. ${ }^{40}$ Die menschliche Komponente adressiert den Einzelnen in der Masse und bietet dem Leser/Betrachter Möglichkeiten der Identifikation beziehungsweise der Anteilnahme am Geschehen (vgl. Boltanski 1981: 141f.). Die unmittelbare Wirkung der Fotografie kann den Leser vergessen lassen, dass es sich bei der Bildreportage um eine fiktive Wirklichkeit handelt, die erst in der Auswahl der Bilder und ihrer Zusammenstellung im Layout entsteht. »Der Leser, der sich über die Seiten einer Illustrierten beugt, [ist] von ihr durch nichts getrennt. Er kann sich mit Leichtigkeit mit den Personen identifizieren, die er vor sich sieht« (Freund 1976: 131).

» $\mathrm{Zu}$ den für die Leser interressantesten Themenbereichen [zählt] der Reisejournalismus mit seinen Berichten von fernen Ländern und exotischen Kulturen. Gerade hier [ist] das absolut Unbekannte, das heißt, das noch nicht selbst Erlebte [...] gefragt« (Saure 1992: 29). Werden in der Frühzeit der Pressefotografie solche Beiträge mit Bildmaterial unterschiedlichster Quellen illustriert, zeichnet sich die Fotoreportage aus fremden Ländern dadurch aus, dass sie aus einer Hand vor Ort produziert ist, der Fotograf oftmals auch den Text schreibt und im Zuge umfangreicher Recherchen seine eigenen Eindrücke fotografisch ins Bild rückt. Es entstehen Reportagen, die bestimmte gesellschaftliche Verhältnisse im Detail schildern und nicht allgemein über das Land berichten. ${ }^{41}$ Die differenzierte Betrachtung lässt die fremden Kulturen nicht mehr nur als exotischen Unterhaltungsstoff erscheinen. Die Reiseberichte der zwanziger Jahre stehen meist »in enger Relation zu wissenschaftlichen - ethnologischen und geografischen - Expeditionen, die eine größere Authentizität und Seriosität suggerieren sollten; selten kommt ein prononciertes touristisches Interesse zum Vorschein« (Saure 1992: 30). Dies steht in engem Zusammenhang mit den Produktionsbedingungen der Reisereportagen. In deren Anfangszeiten agieren die Fotografen oftmals im eigenen Auftrag und verkaufen ihre Fotografien an möglichst viele Zeitschriften und Bildagenturen. Solche Berichte stammen häufig von »Gelegenheitsjournalisten, die sich in einer fernen Weltgegend [aufhalten], ein oder zweimal eine Veröffentlichung [schaffen] und danach nie wieder [auftauchen] « (Stahr 2004: 70; Hervorhebung im Original). Die Publikationen helfen mitunter dabei, die Reisen von Abenteurern oder Hobbyethnologen zu finanzieren. $\mathrm{Ab}$

40 Dewitz/Lebeck 2001: 111 bezeichnen den Aufmacher Der Photograph als Journalist. Eine Lanze für den Illustrationsfotografen aus dem Jahr 1919 in der Berliner Illustrierten Zeitung als erste Paparazzi-Geschichte.

41 Wie beispielsweise die Reportage über Arbeiterviertel in Bombay von Harald Lechenperg von 1932 (vgl. Pohl 1983b: 121ff.). 
Mitte der zwanziger Jahre beginnen Illustrierte damit, selbst Fotografen in ferne Länder zu entsenden und »Vorschüsse für die Herstellung von Fotoreportagen über ihre Auslandsreisen zu bezahlen« (ebd.: 71). Dies bleibt jedoch eher die Ausnahme.

Bereits in den späten zwanziger Jahren erweist sich die unabhängige Position des Fotoreporters, "von dem eine Informations- und bestenfalls Erkenntnisvermittlung erwartet wird,« als Illusion (Eskildsen 1985: 14). Als Auftragnehmer einer Redaktion kollidieren seine persönlichen Erfahrungen und Vorstellungen mitunter mit denen des Auftraggebers werbefinanzierter Medien (ebd.). Von der Euphorie der freien Entfaltung und der objektiven Darstellung der Wirklichkeit, wie sie bei den frühen Bildjournalisten anzutreffen ist, kann demnach kaum mehr die Rede sein. Heute bemühen sich Fotojournalisten vielfach um Präsentationsmöglichkeiten ihrer Fotoreportagen außerhalb von Zeitschriften, beispielsweise in Ausstellungen oder Fotobüchern (vgl. Ritchin 1998: 607f.). Die Fotografen der Agentur Magnum entwickeln zum Beispiel ihre Themen in Eigenregie und versuchen, sie teilweise vorab durch den Rechteverkauf an verschiedene Zeitschriften oder durch das Akquirieren anderer Geldquellen zu finanzieren. ${ }^{42}$ So sichern sich Bildreporter größere Freiheiten, denn sie müssen nicht die Haltung einer Redaktion in ihren Bildern vertreten und können daher unabhängig agieren.

Das Arbeitsfeld des Fotojournalismus hat sich stark verändert, so dass die Bedingungen heute kaum mit denen aus den Anfangsjahren vergleichbar sind. Boomt in den zwanziger und Anfang der dreißiger Jahre die illustrierte Presse vor allem in Deutschland, verlagert sie sich ab 1933 in andere europäische Länder und in die USA. In der Nachkriegszeit erlebt sie auch in Europa erneut einen Höhepunkt. Es entwickeln sich neue Bild- und Gestaltungsideen. Als Künstler bekannte Fotografen publizieren auch Bildstrecken in Illustrierten. ${ }^{43}$ In der zweiten Hälfte der vierziger Jahre schöpfen zahlreiche Illustrierte das »neue innovative Potential der essayistischen Bildgestaltung mit Fotografie« aus (Dewitz/Lebeck 2001: 230). In den fünfziger Jahren bilden sich »die Unterschiede zwischen Fotoreportage und Fotoessay [...] stilgeschichtlich weiter aus« (ebd.: 250). Magazine wie Life räumen den Bildstrecken viel Platz ein, so dass bildnerisch interessante Perspektiven, Anschnitte und Kontraste in großzügigem Layout präsentiert werden können. Damit lässt sich zunächst noch der Konkurrenz Fernsehen trotzen. Doch Anfang der siebziger Jahre gelingt dies nicht mehr: Als 1972 die Zeitschrift Life ihr Erscheinen einstellt, wird vom Ende der Epoche des Fotojournalismus gesprochen (vgl. Freund 1976: 161). Fotoreportagen, die lediglich mit Bildunterschriften auskommen, sind in den verbliebenen Zeitschriften und Magazinen rar geworden. Es existieren jedoch weiterhin serielle Bildformen, die dem fotojournalistischen Ethos verpflichtet sind. Der finanzielle und personelle Aufwand fotojournalistischer Auftragsproduktionen ist jedoch deutlich niedriger als zu den Hochzeiten des Bildjournalismus in der Mitte des zwanzigsten Jahrhunderts.

42 Der Fotograf Sebastiao Salgado geht beispielsweise so vor (vgl. Howe 2001).

43 So z.B. Walker Evans, der bereits 1938 eine Ausstellung im Museum of Modern Art in New York hatte: Chicago in Fortune (02/1947) sowie Faulkner's Mississippi in Vogue (10/1948) (vgl. Dewitz/Lebeck 2001: 230). 


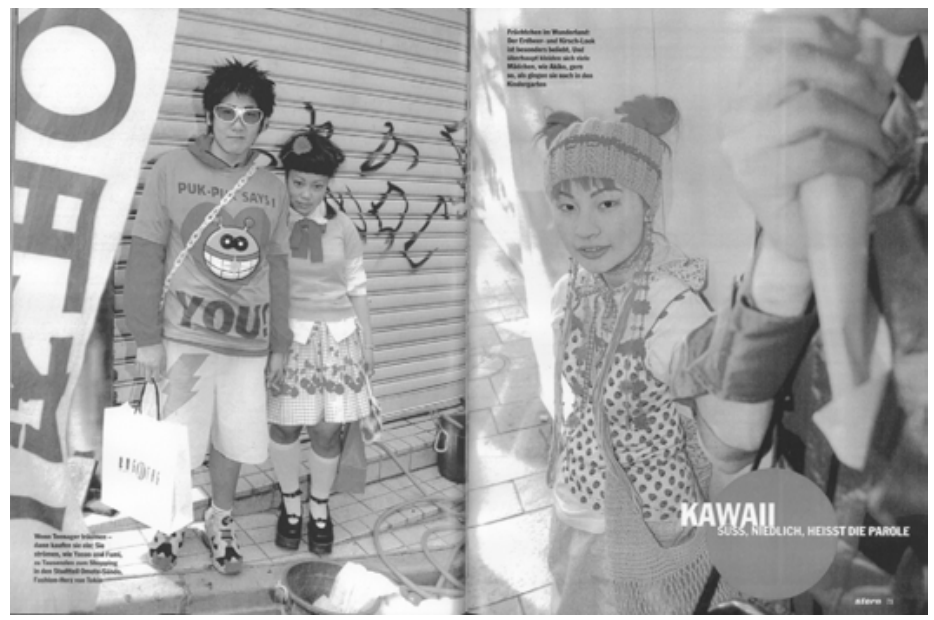

Doppelseite aus Jacobi/Siemens 1999: 70/71 (Orig. in Farbe).

\section{Beispiel einer zeitgenössischen Fotoreportage}

Als Beispiel für eine Bildreportage in zeitgenössischer Aufmachung sei hier ein Beitrag aus dem Publikumsmagazin Stern von 1999 vorgestellt (vgl. Jacobi/Siemens 1999). Die Reportage - mit Fotografien von Tom Jacobi und einem Text von Jochen Siemens - besteht aus 18 Fotografien in unterschiedlichen Formaten, die inklusive zweiseitigem Text und zwei ganzseitigen Anzeigen insgesamt zwölf Doppelseiten einnimmt. Die Reportage behandelt einen Bereich der Tokyoter Jugendkultur. Die Fotografien zeigen japanische Jugendliche in farbenfrohen bis schrillen Kostümen. Die Bildunterschriften erläutern die Kostümierungen und geben zum Teil Ausschnitte aus Interviews wieder. Die abgebildeten Personen befinden sich meist in der Bildmitte, wobei in der Distanz zum Gegenstand variiert wird und so weitere Personen teils angeschnitten mit ins Format gebracht werden (vgl. ebd.: 70f.). Lediglich zwei Fotos zeigen einen eng begrenzten Ausschnitt, ohne das Gesicht der abgebildeten Person einzubeziehen. Nur auf wenigen Abbildungen ist etwas vom Umfeld, das im Text als ein Stadtteil Tokyos identifiziert wird, zu sehen. Die Reportage konzentriert sich in den Bildern ausschließlich auf die Kostümierungen. Der Text beschreibt Details aus dem Leben der Jugendlichen und deren sozialem Umfeld. Die Bildsprache ist dokumentierend, sie ist ganz dem abgebildeten Gegenstand verpflichtet. Sie verstärkt durch Farbgebung und die teilweise eingesetzten Anschnitte oder Blickwinkel, das Schräge der Outfits, die beispielsweise mit Elementen der Manga- und Science-FictionKultur oder auch eines Samurai- oder Nazi-Kults durchsetzt sind. Durch Schärfe und zentrale Position der Bildgegenstände wird jedoch verdeutlicht, dass es sich um eine konventionelle Bildsprache handelt, die dem Publikum vertraut ist. Der Betrachter wird durch die Fremdheit des Motivs herausgefordert und nicht durch eine experimentelle Bildsprache. Die Jugendlichen werden direkt in ihrem Umfeld porträtiert und nicht offensichtlich für die Fotos inszeniert. Sie handeln konform zu ihrer Selbstdarstellung, die bereits in den Kostümen zum Ausdruck kommt. Innerhalb der Bildstrecke entsteht Dynamik, weil mit Abständen zum Motiv und Kamerawinkeln variiert wird. 
Dennoch liegt der Schwerpunkt eher auf dem Motiv und nicht auf dem Bild als Bild. ${ }^{44}$

Bilder und Text der Reportage ergänzen sich, denn weder kann ein Text die Aufmachung der Jugendlichen so präzise beschreiben wie die Fotografien, noch können die Fotos Auskunft über die soziokulturellen Hintergründe geben. Dazu wäre eine weit komplexere fotografische Recherche über ein breites Spektrum der japanischen Jugendkultur notwendig. Die Bilder haben somit eine illustrative Funktion. Die Fotoreportage erfüllt ihre Aufgabe im Rahmen der Publikumszeitschrift Stern, denn sie liefert spezifische Informationen über eine Menschengruppe in der japanischen Kultur. Es sind visuell interessante und fremdartige Motive ausgewählt, die in einer leicht verständlichen Bildsprache vermittelt werden. Der Leser/Betrachter kann sich an der farbenfrohen fremden Welt erfreuen und fühlt sich informiert. Die Verbindung aus Bildern, Bildunterschriften und Text vermittelt Japan als ein Land, das zwischen Tradition und Fortschritt oszilliert und damit sehr eigenwillige Subkulturen erzeugt. Es wird ein positives Gefühl von Fremdheit und Andersartigkeit vermittelt.

Die journalistische Fotografie wendet sich primär humanistischen Aspekten des Lebens zu, sie interessiert sich für soziale Themen. Unabhängig davon, ob sie Hintergrundinformationen zu tagespolitischen Ereignissen oder eine eher feuilletonistische Weltsicht vermittelt, erfüllt sie einen Informationsauftrag. Wichtig ist, dass die Fotografien nicht irritieren und Fragen stellen, sondern Antworten geben. Deshalb müssen Inhalt und Form kohärent sein und an das Wissen, das beim Betrachter vorausgesetzt wird, anknüpfen. So gelingt es einer journalistischen Fotografie zwar, mitunter spektakuläre Sichtweisen zu liefern, sie bleibt aber dennoch verständlich und gut lesbar. Sie liefert möglicherweise differente Perspektiven auf das Fremde, muss aber immer am Wissenstand der Betrachter anknüpfen, weshalb sie sich selten vollständig von klischeehaften Darstellungen lösen kann. Schließlich beeinflusst auch die Abhängigkeit von Text und Layout ihre Aussagekraft. So werden journalistische Fotografien mitunter zu reinen Illustrationen, die kaum Aussagen unabhängig von den ihnen hinzugefügten textlichen Informationen treffen können. Hier sind jedoch die redaktionellen Vorgaben entscheidend, die sich auf die Bildsprache nachhaltig auswirken. Die Verlagerung der Reportagefotografie von Magazinen hin zu Buchpublikationen und Ausstellungspräsentationen sowie die spezifische Form des Fotoessays verweisen jedoch auf deren Ambitionen, sich von den Instruktionen der Bildredaktionen zu lösen. So entstehen fließende Grenzen zwischen journalistischer Fotografie und künstlerischer Dokumentarfotografie.

\section{Zusammenfassung:}

Erst im zwanzigsten Jahrhundert erhalten fotografische Projekte, die sich mit fotografischen Methoden der Welt nähern, also Schärfe und Realitätsnähe fotografischer Verfahren nutzen, eine Anerkennung als Kunst. Eine solche Fotografie geht interpretierend mit nicht-inszeniertem Material um. Damit befindet sie sich im Gegensatz zu angewandten Methoden, die primär auf die

44 Die Abbildungen unterscheiden sich kaum von denen in zahlreichen japanischen Jugendmagazinen. In Zeitschriften wie z.B. Keza werden Jugendliche im Tokyoter Stadtteil Harajuku porträtiert. Diese Fotografien werden im Magazin als Modestrecke präsentiert. 
beschreibenden Qualitäten der Fotografie setzen. Für die künstlerische Dokumentarfotografie ist die Figur des Autors zentral, der einen eigenständigen Zugang zur Welt entwickelt und Fotografien in bildnerischen Zusammenhängen präsentiert, die eine Differenz zur wahrnehmbaren Realität aufbauen. Indem der Autor die Fotografien Fragen stellen lässt, spielt er mit den Irritationen einer ohnehin lückenhaften Wahrnehmung. Auf diese Weise etabliert er eine nachhaltige Offenheit, die zur Wirkung der Fotografien beiträgt.

Die Reisefotografie ist historisch eine der ersten Nutzungsformen der Fotografie überhaupt. Sie versucht, über die Fremde zu informieren, wobei sie sich primär der Darstellung des Exotischen verpflichtet fühlt und Sehnsüchte weckt. Damit leistet sie stereotypen Vorstellungen der Fremde Vorschub. Die ethnografische Fotografie wird vorwiegend zur visuellen Unterstützung in der ethnologischen Forschung eingesetzt. Sie dient vorrangig der Illustration von wissenschaftlichen Ergebnissen der Feldforschung, kann aber auch als Erweiterung der Beobachtungsfähigkeiten des Forschers im Feld eingesetzt werden. Sie ist eher illustrativ zu nennen, entwickelt kaum eine eigenständige Bildauffassung und findet abseits der ethnologischen Monografie wenig Beachtung. Die journalistische Fotografie ist in besonderem Maße einer authentischen Abbildung verpflichtet, da dies Gebot ihres journalistischen Ethos ist. Auch sie kann jedoch nur eine spezifische bildliche Realität erzeugen. Sie ist stark abhängig von Text, Layout und Publikationskontext, versucht jedoch, in Bildfolgen Hintergründe zu erhellen. Ihre Vielschichtigkeit verdankt sie den unterschiedlichen Produktionsbedingungen im redaktionellen Auftrag oder als unabhängig konzipierte. In ihren Anfängen ist sie Vertreterin eines Neuen Sehens, bleibt in ihrer Bildauffassung jedoch den jeweiligen Konventionen ihrer Zeit verbunden.

In der Auseinandersetzung mit den verschiedenen dokumentarfotografischen Richtungen hat sich gezeigt, dass angewandte Positionen allgemein eher zur Illustration von Aussagen über das Fremde verwendet werden und nicht an einer grundlegenden Thematisierung des Fremden als Fremdes interessiert sind. Die künstlerische Dokumentarfotografie öffnet demgegenüber Freiräume, sich in einer offenen, fragenden Art und Weise dem Fremden zu nähern. Dies hat zur Folge, dass sie das Fremde nicht unbedingt in einer Andersartigkeit fixiert, sondern es als Fremdes bestehen lässt. Aus diesem Grund konzentriert sich der zweite Teil vorliegender Studie ausschließlich auf Projekte der künstlerischen Dokumentarfotografie, die sich mit Japan beschäftigen. 


\section{TEIL II:}

Fotografische PRAXIS:

EUROPÄISCHE JAPANFOTOGRAFIE 



\section{JAPAN NACH 1945 \\ DOKUMENTARFOTOGRAFISCHE SICHTWEISEN}

AUF NACHKRIEGSJAPAN

Die fotografische Fremdsicht auf Japan im neunzehnten Jahrhundert zeigt, dass zahlreiche Europäer sich insbesondere für die exotisch anmutenden Ansichten Japans interessieren. Fremdartige Kleidung, Architektur oder Traditionen üben einen besonderen Reiz aus, was sich auch in der bildnerischen Umsetzung, insbesondere der Reisefotografie, manifestiert. Wie in Teil I, Abschnitt 2.3.2. dargelegt, unterliegen die visuellen Vorstellungen seit dem Zweiten Weltkrieg den veränderten Bedingungen des durch die amerikanische Besatzung ausgelösten gesellschaftlichen Wandels. Die westliche Aufmerksamkeit richtet sich in zahlreichen Publikationen nach wie vor auf solche Aspekte der japanischen Kultur, die anders sind. In der ständigen Wiederholung einer spezifischen Sichtweise, die Japan als das Andere konstruiert, etablieren sich zahlreiche visuelle Klischees, die sich bis heute auf die westliche Japanrezeption auswirken. Die Dokumentarfotografie, die sich aufgrund ihres spezifischen Umgangs mit der Welt als herausragendes Medium zur Darstellung fremder Kulturen etabliert hat, leistet in der Vermittlung Japans einen wichtigen Beitrag. Das gilt mitunter in Bezug auf die Perpetuierung visueller Klischees, aber sie hat auch Teil an einer Darstellung, die über eine stereotype Wahrnehmung hinausweist.

Wie in Teil I, Kapitel 3 erörtert, werden dokumentarische Fotografien mitunter als authentisch oder wahr rezipiert. Weil auch Dokumentarfotografie aufgrund ihrer medialen Konzeption nicht als authentisch gelten kann, ist es zu einer Krise der Repräsentation gekommen. Die fotografischen Ausdrucksmöglichkeiten stehen immer im Verhältnis zu den Vorstellungen und Ansätzen des Fotografierenden, der intendierten Gebrauchsweise der Fotografien sowie ihrer Zeitgenossenschaft. So wie sich die fotografierte Kultur im Lauf der Zeit verändert, so verändern sich auch die Vorstellungen darüber, wie Fotografie sich ihrem Gegenstand nähert und welche visuellen Parameter eingesetzt werden können. Zudem werden ältere Japanfotografien den Fotografen, die ein neues Japanprojekt konzipieren, bekannt sein. Insofern steht die fotografische Auseinandersetzung mit Japan in engem Zusammenhang mit der in Teil I, Kapitel 2 geschilderten allgemeinen Japanrezeption. Die ständige Wiederholung bestimmter Sichtweisen führt auch in der kritischen Auseinandersetzung mit der Ausschnitthaftigkeit fotografischer Bildwelten dazu, dass sie mitunter als einzig zutreffende Beschreibungen wahrgenommen werden.

Auf diese Weise entstehen Klischees, die auf zutreffenden Grundvoraussetzungen beruhen mögen, in ihrer Betonung des Differenten in der fremden Kultur aber nur eine Sichtweise auf das fremde Land darstellen. Wenn es 
aber auch Darstellungen gibt, die einen Blickwinkel jenseits der Klischees etablieren, scheint es interessant, ihre spezifische Sichtweise genauer zu analysieren. Denn während klischeehafte Darstellungen kaum neue Informationen liefern können, eröffnen Positionen, die das Fremde als Fremdes zeigen, neue Möglichkeiten der Erkenntnis. Von daher interessieren hier solche Bildwelten, die neue oder andere Sichtweisen in der Japandarstellung aufweisen. Das sich seit dem Ende des Zweiten Weltkrieges verändernde Interesse an Japan manifestiert sich einerseits in der Wahl der Themen, andererseits in der fotografischen Umsetzung. Ob es den Fotografierenden dabei gelingt, über Jahrhunderte hinweg tradierte Vorstellungen und Annahmen über die japanische Gesellschaft in Frage zu stellen oder sogar zu modifizieren, ist eine wichtige Fragestellung der vorliegenden Betrachtung.

Rein beschreibende Darstellungen fremder Kulturen, wie sie beispielsweise in ethnologischen Untersuchungen vorkommen, sind mit dem Problem konfrontiert, dass sie Authentizität einfordern, die wegen der Grundvoraussetzungen der Feldforschung nicht leistbar ist. Der individualisierte künstlerische Zugang wird als mögliche Alternative gesehen, eine subjektive Schilderung der fremde Kultur zu erreichen, die das Fremde nicht als Anderes konstruiert, sondern Fremdheit als Erfahrung zulässt (vgl. Jamme 2002: 200f.). Weil in der künstlerischen Auseinandersetzung Erfahrungen transformiert werden können und die Neutralität des Beobachtenden keine Grundvoraussetzung ist, kann die Kunst zu neuen Einblicken in die fremde Kultur verhelfen. Schließlich verdeutlicht nach Jamme die Kunst, »daß in jeder interkulturellen Verständigung eine interpretative Problematik liegt« (ebd.). In diesem Teil der Arbeit liegt der Schwerpunkt der Betrachtung deshalb auf der künstlerisch-fotografischen Auseinandersetzung mit der japanischen Kultur.

Der zeitgenössischen künstlerischen Dokumentarfotografie kommt in dieser Arbeit eine besondere Aufmerksamkeit zu, weil sie Aussagen über die heutige Japanrezeption machen kann. Als Fundament der Betrachtung von Arbeiten aus den 1990er Jahren dient an dieser Stelle ein kursorischer Überblick über drei ausgewählte dokumentarfotografische Positionen, die aus der Zeit zwischen dem Kriegsende und den 1980er Jahren stammen. An den Positionen der international renommierten Fotografen Werner Bischof (Bischof 1955), William Klein (Klein 1965) und Ed van der Elsken (Elsken 1988) lassen sich die Veränderungen in der Entwicklung des westlichen Japanbildes exemplarisch darstellen. Gleichzeitig zeigen sie Tendenzen im künstlerischen Umgang mit Japan auf, wie sie auch in zeitgenössischen Positionen - in abgewandelter Form - anzutreffen sind. Die Auswahl bezieht sich auf Fotografen, die zwischen einem journalistischen und einem künstlerischen dokumentarfotografischen Ansatz einzuordnen sind. Ihre Japanprojekte sind in monografischer Buchform erschienen. Dieser Form der Aufbereitung kommt - wie in Teil I, Abschnitt 4.1.5. dargelegt - eine besondere Bedeutung zu. Die Buchform ermöglicht es dem Fotografierenden, die Wirkung der einzelnen Fotografien innerhalb der Arbeit in einen Zusammenhang zu bringen. Er entscheidet über die Bildauswahl, die Anordnung im Layout sowie die Einbeziehung von Texten. In Bildfolgen kann er einen visuellen Kontext herausarbeiten und auf diese Weise sein inhaltliches Anliegen in mehreren Fotografien formulieren. Gezeigt wird das Werk, so wie der Fotograf es zusammengestellt hat und nicht die durch eine Redaktion getroffene Auswahl gelungener Einzelbilder, die möglicherweise nur einen kleinen Ausschnitt der Arbeit präsentieren. Das Künstlerbuch ist deshalb ein Medium, das die Intentionen des 
Fotografen treffend wiederzugeben vermag. Aus diesem Grund liegt der Schwerpunkt der Betrachtung auf fotografischen Japanprojekten, die in monografischen Künstlerbüchern erschienen sind. Auch andere Publikationsformen leisten ihren Beitrag zum westlichen Japanbild, doch in monografischen Künstlerbüchern erschienene Arbeiten zeugen von abgeschlossenen Projekten, deren Intention es ist, eine spezifische Sichtweise auf Japan zu zeigen. Sowohl in der Betrachtung der drei zwischen 1955 und 1988 erschienenen monografischen Bücher als auch in den seit den 1990er Jahren entwickelten Positionen interessieren grundsätzliche Fragen der Themenwahl, der Bildauffassung und des vermittelten Japanbildes.

Nach Arthur C. Danto ist

»Bildverstehen $[\ldots]$ ein Interpretieren, das aus solchen Schlußfolgerungen besteht, die eine Person allein aufgrund ihrer Wahrnehmungskompetenz ziehen kann. Da es jedoch kein Thema in der Philosophie gibt, das durch begriffliche Konflikte so vernebelt worden ist wie das Problem, auf welche Art und Weise wir etwas wahrnehmen, ist es schwierig, hier weiter zu kommen« (Danto 2001: 142; Hervorhebung im Original).

Aufgrund dieser Problematik ist es notwendig, sich den Fotografien mittels ausführlichen Beschreibungen zu nähern. Nur so ist ein Verstehen auf der Grundlage des im Bild Dargestellten und der Art der Darstellung möglich.

\subsection{Werner Bischof: Japan}

Der Schweizer Fotograf Werner Bischof (1916-1954) reist 1951 und 1952 im Auftrag verschiedener Zeitschriften mehrfach nach Japan. ${ }^{1}$ Seine Japanfotografien entstehen nicht als freie Arbeiten, sondern im Zusammenhang mit den Publikationen der Auftraggeber, weshalb sie sich in einen Kontext von journalistischer oder von Reisefotografie einordnen lassen. Bischofs Arbeitsweise ist jedoch nachhaltig durch die Ausbildung bei Hans Finsler geprägt, einem wichtigen Vertreter der Neuen Sachlichkeit. Nach Aussage seines Lehrers versucht Bischof immer wieder, »durch die Gesetzmässigkeit des Bildaufbaus das Geschehen aus der Willkür des Zufalls herauszulösen zu einer allgemeingültigen Aussage« (Zitat Finsler in: Göltz 1991: 46). Sein Kollege René Burri bescheinigt ihm die Fähigkeit, »das klare, gereinigte, vom Unnötigen befreite Bild « zu erzeugen (Zitat Burri, ebd.: 55). Bischof bemüht sich darum, mit der einzelnen Fotografie eine Aussage zu treffen, die er in den Kontext der Bildfolge einbindet. Seine Arbeit weist jedoch über eine rein beschreibende fotografische Praxis hinaus.

Das Buch Japan erscheint kurz nach Bischofs Tod im Jahr 1955. Insofern ist nicht klar, wie eng Bischof an der Zusammenstellung der Bilder, dem Layout und der Auswahl des begleitenden Textes beteiligt ist, also ob es sich um seine persönliche Bildzusammenstellung oder eine redaktionelle Auswahl handelt. Der Titel weist darauf hin, dass hier Japan als Ganzes gezeigt wird und nicht nur ein kleiner Ausschnitt. Mit diesem Ansatz zeigt Bischofs Werk ein Interesse an der Vermittlung grundlegender kultureller Traditionen des

1 Biografische Anmerkungen zu Bischof vgl. Bischof 1990; zum Japanaufenthalt vgl. Phillips 2004: 47. 
bereisten Landes. Die Aufteilung in drei Kapitel - Was nicht verlorenging, Japan heute und Wird Japans alte Theaterkunst noch lange bestehen? - bestätigt diese Annahme, denn auf diese Weise wird Traditionelles mit zeitgenössischen Entwicklungen zusammengeführt. ${ }^{2}$

Dem Bildteil vorangestellt ist eine subjektive Annäherung an Japan durch den Journalisten Robert Guillain, der sich für die Natur und das traditionelle Japan begeistert, Modernisierung und Urbanisierung aber kritisch bewertet. ${ }^{3}$ Er verweist darauf, dass das stereotype Japan nicht existiert, denn er kann weder »kleine trippelnde Japanerinnen, kleine Puppen, Frauen mit Perücken und ganz gezierten Gehaben, « noch »Männer mit einem gefrorenen Lächeln« oder »Häuser aus Papier« entdecken (Guillain 1955: X). ${ }^{4}$ Er legt dar, dass die traditionelle Folklore in Europa mit der Industrialisierung weitgehend verschwunden sei, während die Japaner in der Modernisierung das Traditionelle bewahrt haben. Vertritt er zunächst scheinbar ein positives Japanbild, gerät er bald in die Falle der Stereotypisierung. Mit der Bestätigung der japanischen Dichotomie eines Nebeneinanders von Fernost und West versucht er, »Konflikte, deren Schauplatz die japanische Seele ist « zu erklären: »Die [von den Konflikten] Betroffenen passen sich indessen nicht schlecht an, begabt, wie sie sind, mit einer außerordentlichen Geschicklichkeit, unaufhörlich von einer Seite ihres Wesens zur anderen hinüberzuwechseln, und glücklicherweise wenig geneigt zur kartesianischen Logik« (ebd.: XVI). ${ }^{5}$ Er kritisiert japanisches Verhalten in einem modernen Setting wie der U-Bahn und reiht stereotype Allgemeinplätze aneinander, die das moderne Japan in keinem positiven Licht erscheinen lassen. Nach seiner Auffassung existiert ein äußeres verwestlichtes - und ein inneres - traditionelles - Japan, das er als »japanisches Japan« beschreibt und nach dem er sich sehnt (ebd.). Da er jedoch den japanischen Charakter nur für wenig wandlungsfähig hält, scheint ihm der Bestand japanischer Tradition gesichert. »Sie sind bei der Unbequemlichkeit und Leere ihrer Behausungen ohne Möbel und ohne Heizung geblieben [...] und zwar nicht nur, weil das Leben in amerikanischem Stil zu kostspielig ist für sie, sondern weil ihnen die Einfachheit im Blut liegt und weil der vornehme Japaner den Luxus und das Geld verachtet« (ebd.: XXIX). Die Naivität seiner Aussagen verwundert aus heutiger Sicht, da Guillain nur nebenbei die Anstrengungen des Wiederaufbaus eines völlig zerstörten Landes würdigt und auch in diesem Zusammenhang Bischofs Fotografien, die Armut explizit zeigen, unerwähnt lässt. Schließlich fotografiert Bischof ein amerikanisch besetztes Land, denn erst 1952 erhält Japan seine Unabhängigkeit zurück.

2 In der englischen Ausgabe weichen die Kapitelbezeichnungen von den deutschen ab: Old Japan, Japan Today und The Traditional Japanese Theatre (vgl. Bischof 1955, englischsprachige Ausgabe).

3 »Die Hauptstadt ist ein gigantisches, chaotisches Dorf. Das traditionelle Japan scheint verschwunden infolge der planlosen Invasion der modernen Technik« (Guillain 1955: X).

4 »An alledem ist nichts Wahres!« (Guillain 1955: X). Aus seinen Ausführungen erhält der Leser den Eindruck, dass Guillain selbst in Japan gewesen ist und nicht nur über Bischofs Bilder schreibt.

5 Diese Aussage verweist auf die westliche Annahme, Japaner hätten zwei unterschiedliche Persönlichkeiten, zwischen denen sie umschalten können: eine traditionell japanische und eine westliche, die ihrem Charakter eigentlich fremd ist. Damit greift er erneut die These der japanischen Schizophrenie auf (vgl. auch Teil I, Abschnitt 2.2.2.). 
Guillain lobt die Fotografien Werner Bischofs, weil er in ihnen Spuren des traditionellen Japan entdeckt, die noch überall zu finden seien. Guillains rückwärts gewandte Sichtweise kann jedoch nicht ungebrochen auf die Fotografien übertragen werden.

Jedem der drei Kapitel des Bildteils sind kurze nummerierte Textabschnitte vorangestellt, die die einzelnen Fotografien erklären. Ob diese Texte von Bischof selbst stammen, ist nicht bekannt, ihr Duktus verweist jedoch auf Ereignisse, die eng mit dem Zeitpunkt des Fotografierens verknüpft sind. Die teils schwarz-weißen, teils farbigen Fotografien sind hoch- und querformatig und meist im Anschnitt abgedruckt. ${ }^{6}$ Querformate erstrecken sich teilweise über den Falz, füllen jedoch die Doppelseiten nie ganz aus. Hochformate werden paarweise auf Doppelseiten nebeneinander angeordnet. Es gibt keine Vakat-Seiten. Werden Querformate auf Einzelseiten gestellt oder Hochformate beschnitten, entstehen weiße Ränder. ${ }^{7}$ Die Qualität des Drucks ist sehr hochwertig. Die schwarzweißen Fotografien sind auf mattes, die farbigen auf seidenglänzendes Papier gedruckt. In den Schwarzweißfotografien entsteht eine umfangreiche Tonalität, die Farbaufnahmen wirken brillant und klar. Die Ausstattung des Bandes entspricht dem bildnerischen Anspruch des Fotografen.

Der Bildteil des ersten Kapitels Was nicht verlorenging besteht aus 40 Fotografien. Das erste Kapitel zeichnet sich durch eine ruhige, fast meditative Bildsprache aus. Die Motive von Tempeln, Gärten, Mönchen, Teezeremonie, Ikebana-Stunde oder japanischer Braut sind klassisch gestaltet. In der Bildfolge widmen sich oft mehrere Fotografien einem ähnlichen Bildsujet. Mehrere Bilder zeigen beispielsweise Priester in zeremoniellen Gewändern oder Kinder bei einem Tempelbesuch. Zuweilen werden auf Doppelseiten $\mathrm{Zu}$ sammenhänge evoziert, wie das Beispiel der linksseitig angeordneten Fotografie eines Ikebana-Künstlers, das mit einem Foto von Frauen, die ein Geschehen beobachten, kombiniert ist (vgl. Bischof 1955: 25/26). In einer gut durchkomponierten Bildsprache gelingt es Bischof, die Ästhetik seiner Bildmotive aufzugreifen und in die Fotografien zu transponieren.

Der zweite Teil, Japan heute, besteht aus 49 Bildern. Das Kapitel beginnt mit einer Bildfolge, die den Besuch des Kaiserpaars in Hiroshima zeigt. Diese sechs Fotografien ${ }^{8}$ bilden ein geradezu journalistisches Ensemble, das man sich gut im Zusammenhang mit einem Bericht über die Situation zehn Jahre nach Kriegsende in einer Publikumszeitschrift vorstellen kann. Neben dem Kaiserpaar und dem damit verbundenen Zeremoniell werden wartende Kinder mit japanischen Flaggen sowie die Gedenkstätte am Atombombendom und die verheilten Hautverletzungen eines Atombombenopfers gezeigt.

Es folgen Fotografien, die sich im Zusammenhang mit dem urbanen Raum, mit der amerikanischen Besatzung sowie der Armut der Bevölkerung beschäftigen. Bilder von amerikanischen Soldaten und Prostituierten sind ebenso vertreten wie die von Literaten oder Besuchern einer Ausstellung mit Bildern von Matisse und Picasso. Bischof zeigt das Leben der einfachen Leute

6 Das Buch ist ein Hochformat, 28,5 x $23 \mathrm{~cm}$. Eine Paginierung gibt es nur im Textteil (vgl. Bischof 1955).

7 Hochformate werden z.T. so beschnitten, dass sich das Seitenverhältnis ändert (vgl. ebd.).

8 Später folgt noch eine siebente: Bild Nr. 88 (vgl. ebd.). Ein Beispiel für Bischofs Kaiserbild findet sich in Abschnitt 1.4. 
ebenso wie Handwerker und den Mittelstand. Bischofs Kritik an den Zuständen hat eine völlig andere Grundlage als die Guillains. Während Guillain die kurze Periode der Modernisierung und japanische Charakterschwächen für die Unzulänglichkeiten der Zustände verantwortlich macht, zeigt Bischof die Situation der Ärmsten in mitfühlender Haltung. Er verweist auf eine Rückständigkeit, die vielleicht mit der Frühzeit der europäischen Industrialisierung vergleichbar ist und vermutlich mit dem verlorenen Krieg zu tun hat. ${ }^{9} \mathrm{Im} \mathrm{Zu}$ sammenhang mit den Bildtexten lassen sich diese Bilder als eine Kritik an der japanischen Regierungspolitik lesen, was auf Bischofs Ansatz der engagierten Dokumentarfotografie verweist. Parallel zum urbanen Alltag fotografiert Bischof auch das Leben auf dem Land. Dieses ist traditionell geprägt, was sich an den Anbaumethoden, der Kleidung und den Interieurs der Bauernhäuser ablesen lässt. Die Fotografien aus ländlichen Gebieten knüpfen an die Darstellungen des ersten Kapitels an. Während dort jedoch im Schwerpunkt ein spirituelles Leben gezeigt wird, ist hier ein ländlicher Alltag dargestellt. Als weiterer Aspekt werden in diesem Kapitel sportliche Betätigungen abgebildet. Dabei stellen Lockerungsübungen auf einem Provinzbahnhof und ein Volleyballspiel ein modernes Japan dar (vgl. ebd.: 86/87), während mit einem Sumô-Ringer wiederum eine Verbindung zur Tradition hergestellt wird (vgl. Abschnitt 1.4.).

Auch wenn einige Fotografien aus dem Abschnitt Japan heute stark an ein traditionelles Japan erinnern, macht Bischof mit der Einteilung deutlich, dass auch im Nachkriegsjapan japanische Traditionen fortleben. Diese findet man nicht ausschließlich in der Wahrnehmung der spirituell-religiös konnotierten Wurzeln der japanischen Kultur, sondern auch im Leben auf dem Land oder der modernen Großstadt. Gerade das großstädtische Leben ist jedoch auch von westlichen Einflüssen geprägt, was sich beispielsweise in der Art sich zu kleiden oder englischsprachigen Hinweisen im Straßenverkehr ausdrückt. Während die englischen Kapitelüberschriften schematisch alt und neu unterscheiden, wirken die der deutschsprachigen Ausgabe etwas differenzierter. Das, »was nicht verlorenging, « stellt eine Verbindung zur Vergangenheit her, ist aber eben nicht nur das alte Japan. Der Vergangenheitsbezug des ersten Kapitels, den die englische Ausgabe herstellt, wird in der deutschsprachigen Ausgabe relativiert (vgl. Bischof 1955).

Auch die Bilder des zweiten Kapitels sind sorgfältig komponiert, Bischof geht jedoch teilweise näher an die Menschen heran als im ersten Teil. Trotzdem blicken die fotografierten Personen nur in Ausnahmefällen direkt in die Kamera. Der Fotograf bleibt auf Distanz, er ist von außen kommender Beobachter, der aufzeichnet, aber nicht am Geschehen teilnimmt.

Das letzte Kapitel widmet sich dem traditionellen japanischen Theater in seinen verschiedenen Formen von Puppentheater, Nô und Kabuki. Auch hier sind die Kapitelüberschriften der deutschen und englischsprachigen Ausgaben nicht identisch. Während in der englischen Ausgabe die Überschrift The Traditional Japanese Theatre lautet, heißt es in der deutschsprachigen Version: Wird Japans alte Theaterkunst noch lange bestehen? (vgl. ebd.). Während die englische Überschrift die Tradition in der Kapitelüberschrift erwähnt und somit an Vergangenes anknüpft, richtet sich die Frage der deutschen Ausgabe eindeutig in die Zukunft: Aufgrund der großen Veränderungen in

9 Die Fotografien Nr. 71 und 72 zeigen z.B. die schwierigen Arbeitsbedingungen in veralteten Industriebetrieben (vgl. Bischof 1955). 
der japanischen Gesellschaft scheint es zu Beginn der 1950er Jahre nicht sicher, ob sich alte japanische Traditionen werden behaupten können. Während die spirituellen Traditionen sich bereits resistent gegenüber Veränderungen gezeigt haben, ist das Theater nach Bischofs Ermessen offensichtlich nicht in dem gleichen Maße gesellschaftlich gefestigt. Die zwanzig Fotografien dieses Kapitels zeigen traditionelle Bunraku-Puppen, Schauspieler in Kostümen und Musikinstrumente. Der Fotograf blickt auch hinter die Kulissen und beobachtet die Vorbereitungen vor dem Auftritt. Bischofs Theaterfotografien zeigen unterschiedliche Nuancen der Beobachtung. Der thematische Zusammenhalt der Fotografien in diesem Kapitel verweist auf eine mögliche Nutzung als Bildstrecke eingebettet in einen Bericht über das japanische Theater.

Bischofs Japanfotografien verbinden Aspekte des traditionellen Japan mit den aktuellen gesellschaftlichen Umbrüchen, die in der Zeit der amerikanischen Besatzung ihren Anfang nehmen. In einen Rahmen aus traditionellen Themen des religiösen Lebens einerseits und der Theaterkunst andererseits fügt Bischof Beobachtungen über die japanische Gesellschaft ein. Seine Fotografien des - aus damaliger Sicht - heutigen Japan zeigen die vielschichtigen Facetten der japanischen Gegenwart, die auf traditionelle Wurzeln zurückgreifen kann, sich aber gleichzeitig in einer Phase der Veränderung befindet. Sie ist einerseits gezeichnet von Krieg und Besatzung, andererseits präsentiert sie sich als fortschrittlich. Die Dichotomie von Tradition und Moderne, die westliche Beobachter in Japan seit der Öffnung des Landes im neunzehnten Jahrhundert beobachten, versucht Bischof im zentralen Kapitel aufzulösen, indem er verschiedene Bereiche miteinander verbindet. In seinem Buch befriedigt er einerseits das westliche Interesse an fernöstlicher Exotik, andererseits erweitert er diesen Blickwinkel um gesellschaftspolitische Aspekte, die auch in westlichen Nachkriegsgesellschaften in ähnlicher Form anzutreffen sind.

Der den Fotografien beigefügte Text von Robert Guillan betont ein Interesse am japanischen Japan, das Bischof zwar bedient, aber in seiner Darstellung des zeitgenössischen Japan bricht. Hier scheint Kritik an den Verhältnissen durch, da er sich auch der Armut, Kriegsinvaliden und veralteter Technologie widmet. Insgesamt ist Bischofs Interesse an traditionellen Aspekten der japanischen Gesellschaft jedoch nicht zu leugnen. Bischof betont insbesondere im ersten Kapitel die Ruhe und Klarheit japanischer Bauten und Gartenkunst. Damit stellt er ausgewogene und friedliche Aspekte der japanischen Kultur heraus. Die Ereignisse des Krieges liegen zu dieser Zeit noch in der jüngsten Vergangenheit, so dass anti-japanische Kriegspropaganda sicher vielen ehemaligen Kriegsgegnern noch eindrücklich in Erinnerung ist. Bischof betont dementsprechend die humanistischen Seiten. Umso erstaunlicher ist es, dass der beigefügte Einführungstext von Robert Guillain sich so negativ gegenüber dem zeitgenössischen Japan äußert, da sich diese negative Haltung in Bischofs Fotografien nicht findet.

Bischofs ruhige und klare Bildsprache erinnert an Magazinfotografie auf höchstem Niveau. Die Fotografien sind durchgängig hervorragend komponiert und erfüllen als Einzelbilder einen hohen ästhetischen Anspruch. Leichte Unschärfen ergeben sich aus den Lichtverhältnissen der Innenräume, da der Fotograf keine zusätzlichen Lichtquellen einsetzt. In den Bildkompositionen ist der Bildgegenstand stets genau zu erkennen, Fragen an das Abgebildete werden in den vorangestellten Bildtexten beantwortet. Das Buch als Ganzes verfolgt keine stringent erzählende Strategie, innerhalb der einzelnen 
Kapitel bildet sich jedoch stets eine Einheit. Zusammenstellungen von Bildern zu einzelnen Themen funktionieren auch gut als Bildstrecken. Die Ansprüche an einen Überblick über ein fremdes Land werden erfüllt. Tradition und Gesellschaft werden reflektiert, ohne allzu viele - beispielsweise historische - Details zu erwähnen. Die Bildunterschriften vermitteln ansatzweise ergänzende Informationen über die Situation im Nachkriegsjapan, die aus den Bildern nicht herausgelesen werden können. Bildauswahl und -kombinationen erfüllen ästhetische Kriterien und ergeben einen umfassenden Einblick. Der einführende Text versucht, die fremde Kultur ansatzweise zu erklären. Er bezieht sich weniger auf die Fotografien als auf die Vorstellungen des Autors, die sich nicht unbedingt mit denen des Fotografen decken. Mit distanziert beobachtendem Blick erfasst Bischof viele Facetten, die aus europäischer Sicht fremd anmuten. Dennoch betont er nicht die Fremdheit oder beutet exotische Ansichten aus. Vielmehr zeugt sein Blick von dem Interesse an einem Land, das sich in einer Phase des Um- und Aufbruchs befindet.

Unabhängig davon, ob sich Werner Bischof dem spirituellen Leben der Japaner, den traumatischen Erinnerungen an den Krieg oder dem harten Alltag auf dem Land widmet, arbeitet er mit einer Strategie der Ästhetisierung. Die Bilder konzentrieren sich in einer klaren und prägnanten Bildsprache auf das meist ins Zentrum gerückte Sujet und sind ästhetisch sehr ansprechend. Durch Bischofs umfassende Beherrschung des fotografischen Mediums wird das Buch - in einem ganz traditionellen Sinn - sehr fotografisch. In seiner Darstellung verzichtet Bischof beispielsweise auf Bilder von wichtigen japanischen Sehenswürdigkeiten, wodurch sich seine Sichtweise von einer traditionellen Reisefotografie unterscheidet. In der Distanziertheit seines Blicks bleibt Bischof stets der außenstehende Betrachter, der Situationen präzise zu beobachten und ins Bild zu setzen vermag. Bischofs Erfahrungen beruhen geradezu auf der eingehaltenen Distanz. Auf diese Weise kann er auch hierarchische Gegebenheiten der japanischen Gesellschaft oder die Amerikanisierung der japanischen Städte während der amerikanischen Besatzung aufzeigen.

Bischofs reale Distanz zum aufgenommenen Gegenstand vermittelt aber auch eine gefühlte Distanz. Die japanische Gesellschaft erscheint als von der westlichen sehr weit entfernt. Die Fotografien verweisen auf ein dort, das in großem Abstand zu einem hier existiert. Dies heißt jedoch nicht, dass er mit seinen Bildern eine Exotisierung des Fremden betreibt. Vielmehr repräsentieren seine Fotografien einen neugierigen Blick auf ein vermeintlich Anderes, das sie in seiner ganzen Vielfältigkeit zu beleuchten suchen. Die Strategie der Ästhetisierung ist ein Faktor, der die Distanz zum Abgebildeten weiter unterstreicht und die Differenz zum Eigenen deutlich in den Vordergrund treten lässt. Damit werden mitunter auch klischeehafte Vorstellungen über das fremde Land bestätigt, wobei Bischof durchaus einen eigenständigen Standpunkt bezieht. Die Konzentration auf das einzelne Bild, das zwar in einen Kontext eingebettet wird, aber dennoch für sich sprechen muss, trägt weiterhin dazu bei. Zeitgemäß ist Bischofs Wunsch, einen überblicksartigen Eindruck über das Land zu erzielen, da in den 1950er Jahren Japan in Europa eine eher nebensächliche Rolle spielt. Mit seiner an eine journalistische Bildauffassung angelehnten Bildsprache nähert sich Werner Bischof dem Japanthema eher beschreibend, etabliert aber dennoch einen persönlichen Blickwinkel. 


\subsection{William Klein: Tokio}

Der in Paris lebende amerikanische Fotograf William Klein $(* 1928)$ reist auf Einladung eines japanischen Verlegers 1961 nach Tokyo. ${ }^{10}$ Klein, der seit 1948 als Künstler in Paris lebt, kann an der Ecole de Paris einige Erfolge als abstrakter Maler vorweisen, bevor er zu fotografieren beginnt (vgl. Jouffroy 1982: 57). Sein Interesse gilt von Anfang an einer künstlerischen Fotografie.

Sein Buch mit dem Titel Tokio erscheint im Jahr 1965. Klein widmet sich im Gegensatz zu Werner Bischof und Ed van der Elsken ausschließlich der japanischen Hauptstadt. Das Buch Tokio stellt einen wichtigen Beitrag zur dokumentarfotografischen Auseinandersetzung mit Japan aus westlicher Sicht dar und übt zudem einen erheblichen Einfluss auf Kleins japanische Kollegen aus (vgl. Holborn 1986: 76; Phillips 2004: 51). Im Vorwort erteilt Richard Friedenthal zunächst japanischen Stereotypen eine Absage. Er verweist darauf, dass »das rätselhafte [japanische] Lächeln, das vielleicht nur eine Maske ist, « dem Reich der Legende angehört (Friedenthal 1965: o.S.). Friedenthal beschreibt Tokyo als moderne Stadt, die den stereotypen Japanvorstellungen in keiner Weise entspricht. Der Text bezieht sich im Schwerpunkt auf die Fotografien und entwickelt entlang Kleins Bildsprache eine Idee von der rastlosen und modernen Metropole, in der das Traditionelle zunehmend verdrängt wird. Autor und Fotograf interessieren sich gerade für das Moderne, weshalb auf Traditionelles insgesamt kaum eingegangen wird. Zehn Jahre nach Bischofs Japanarbeit zeigt sich hier bereits ein großer Unterschied, weil die moderne Entwicklung Japans in dieser Publikation nicht kritisch, sondern fasziniert und wohlwollend betrachtet wird. Friedenthal verweist auf die immer kürzer werdenden Reisezeiten und bezeichnet Japan als »Nachbarn«, zu dessen besserem Verständnis das Buch einen Beitrag leisten könne (vgl. ebd.).

Dem Vorwort angeschlossen ist ein Text von William Klein. Aus der subjektiven Sicht des Fotografen heraus kommentiert er vorab die Bilder. Der Text beschreibt jedoch nicht einzelne Fotografien, vielmehr werden kontextuelle Informationen auch für Doppelseiten oder Bildstrecken geliefert. Die Zuordnung geschieht über eine sporadische rechtsseitige Paginierung im Bildteil. Die Texte sind unterschiedlich lang. Neben umfangreichen Beschreibungen oder literarischen Zitaten gibt es auch kurze Bildtitel, weshalb die Texte nicht zu allen Bildern gleichwertige Informationen liefern. Die assoziative Art der textlichen Informationen legt nahe, dass diese nicht konkret zu den Bildern gelesen werden müssen. Der Betrachter soll eher die Bilder anschauen und seinen eigenen Assoziationen freien Lauf lassen, um dann zeitversetzt seine Vorstellungen mit den Berichten des Fotografen anzureichern.

Der Bildteil ist in drei Kapitel unterteilt, die die Überschriften Ritus, Album und Ikebana tragen. Jedes Kapitel beginnt mit einer weißen linken Seite, auf der die Kapitelnummer sowie die Kapitelüberschrift auf Deutsch und auf Japanisch gesetzt sind. Die grobkörnigen schwarzweißen Fotografien zeichnen sich durch hohe Schwärzen und wenig Mitteltöne aus. Der Fotograf verwendet keine zusätzlichen Lichtquellen, so dass insbesondere bei Innenaufnahmen große Schwarzflächen entstehen. Das matte Papier verstärkt die Bild-

10 Für biografische Anmerkungen vgl. Klein 1989: 174. 
schwärzen zusätzlich und nimmt ihnen ihre Differenzierung. Die Fotografien sind in der Regel im Anschnitt gedruckt. Querformate erstrecken sich meist ohne Bildrand über die gesamte Doppelseite. Nur wenn mehrere Bilder auf einer Doppelseite abgedruckt sind, entsteht in geringem Ausmaß ein weißer Rand. Sowohl in der Bildästhetik als auch in der Anordnung im Layout verweigert sich Klein einer Herangehensweise, die gut durchkomponierte und ausgewogen belichtete Fotografien in einer ästhetisch ansprechenden Form präsentiert. Die Fotografien erhalten damit eine Unmittelbarkeit, die Distanzen aufhebt. Damit unterscheidet sich Kleins Ansatz grundsätzlich von Bischofs.

Klein widmet sich fast ausschließlich der Menschendarstellung. Er geht sehr nah an die fotografierten Personen heran. ${ }^{11}$ Der Bildraum wird oftmals durch eine hohe Tiefenschärfe extrem verdichtet, weshalb die meisten Bilder sehr komplex sind und zahlreiche Anhaltspunkte der Betrachtung liefern. Daraus - und durch das oft randlose Layout - entsteht ein atemloses Bild, das dem Betrachter keine Ruhe gönnt, beispielsweise in Form von Vakat-Seiten. Jeder Akt des Umblätterns liefert neue komplexe Bildinformationen, die sich nicht auf den ersten Blick erschließen. Das große Buchformat bietet bei Format füllendem Abdruck querformatiger Fotografien nicht genug Abstand, um das Bild als Ganzes zu erfassen. ${ }^{12}$ Die Kombination von Bildaufbau und Buchformat erfordert das sukzessive Abfahren der Bilder mit den Augen, um sich deren Inhalt zu erschließen. Entsprechend wird im Vorwort darauf verwiesen, dass es sich bei Kleins Fotografien um »Schlagzeilen« handelt. »Man verstehe sie als Hinweise auf mehr, auf den 〉Text<, womit nicht unser kleines Vorwort oder die Bilderklärungen gemeint sein sollen. Man lasse die Bilder in sich einsinken und denke über sie nach. Sie haben viel zu erzählen« (Friedenthal 1965: o.S.). Als schlagzeilenhaft kann der erste Eindruck gewertet werden, der durch eine Lektüre der Fotografien vertieft werden muss. Die weiterführende Beschäftigung mit dem einzelnen Bild kann einen genaueren Aufschluss über das Abgebildete geben.

Das Ritus-Kapitel behandelt Rituale, die mit der japanischen Tradition in Verbindung gebracht werden können, auch wenn es sich teilweise um zeitgenössisch abgeänderte Formen der Rituale handelt. ${ }^{13}$ Die Fotografien des Kapitels zeigen sportliche Rituale, solche aus dem zeitgenössischen Avantgarde-Theater, Friseur- und Badehaussituationen, künstlerische Aktionen, Demonstrationen, aber auch das Parlament, die Börse, Cocktailparties oder Familienfeste. Diese Liste beansprucht keine Vollständigkeit und gibt lediglich einen ausschnitthaften Einblick. Ohne in der Bildsprache auf die bekannten Vorbilder zu rekurrieren, etabliert Klein eine sehr eigenwillige Sichtweise auf die moderne japanische Gesellschaft. Die Wahl der Themen verweist noch auf westliche Vorstellungen des traditionellen Japan und damit auch auf bildnerische Vorläufer, die Bildsprache negiert hingegen die foto-

11 Der deutsche Reportagefotograf Robert Lebeck, der Klein 1961 in Tokyo begegnet, berichtet von seiner Faszination, Klein beim Arbeiten zuzusehen: »Fasziniert von seiner Vorgehensweise und davon, wie nah er heranging, wodurch er bei den Fotografierten Reaktionen hervorrief, konnte ich zeitweilig gar nicht mehr fotografieren. Sein Nahherangehen war in Japan insofern kein Problem, als die Menschen gutmütig sind. Sie lieben es, fotografiert zu werden« (Lebeck 2006: 177).

12 Hochformat, 35 x $26 \mathrm{~cm}, 184$ Seiten, s/w.

13 Beispielsweise handelt es sich um die japanische Vorliebe für Baseball (yakyu) (vgl. Klein 1965: 26/27). 
grafische Tradition der westlichen Japanfotografie. Ausgehend von den gewählten Themen mag man sich an die fotografischen Abbildungen von Sumô-Ringern, Friseuren oder Badenden erinnern, die bereits im neunzehnten Jahrhundert den fotografischen Kanon der westlichen Sicht auf Japan geprägt haben. Durch die Abbildung großer Menschenmengen in zahlreichen Fotografien zeigt Klein auch die große urbane Dichte. In der Bildsprache deutet Kleins Arbeit kaum auf visuelle Vorläufer, die Auswahl der Themen greift jedoch auf tradierte Japanvorstellungen zurück.

Die Kapitelüberschrift Album weckt Assoziationen zu den touristischen Japan-Alben, die im neunzehnten Jahrhundert für westliche Touristen hergestellt werden. Klein imitiert zwar die traditionellen Alben nicht, trotzdem ergeben sich einige thematische Parallelen zu diesem Genre. Hingegen ist Kleins Bildsprache zum Zeitpunkt der Entstehung der Japanbilder noch immer radikal neu. ${ }^{14}$ Die Radikalität der Bildsprache aus dem ersten Kapitel wird fortgesetzt. In diesem Kapitel werden vorwiegend Paare, Familien, Kinder, Arbeiter und Passanten gezeigt. Es sind hauptsächlich Gruppenporträts und Straßenszenen, die dieses Kapitel dominieren. Klein fotografiert aber auch das Kaiserpaar (vgl. Abschnitt 1.4.) und den Präsidenten der Elektrofirma Tôshiba.

Die Überschrift des dritten Kapitels Ikebana. Die Kunst des Blumenarrangements wirkt in der Verbindung mit den Fotografien recht unverständlich, weil Klein weder Blumen noch Naturdarstellungen zeigt. Das kürzeste Kapitel des Buches beginnt mit dem Porträt eines Bildhauers zwischen seinen Arbeiten. Klein führt auf diese Weise in eine Welt des Ornaments ein, die im weiteren Verlauf des Kapitels zugespitzt wird. Schornsteine, Baukräne und Industrieanlagen verschmelzen in der Zweidimensionalität der Fotografien zu grafischen Formen. In einigen Bildern werden noch Menschen gezeigt, sie verbinden sich jedoch zunehmend mit den Ornamenten des urbanen Raums und werden aus einigen Bildern ganz eliminiert. In den Straßenszenen dominieren Typografie und Filmplakate. Telegrafendrähte, Bahnschienen und Leuchtreklamen werden zu grafischen Elementen abstrahiert. In wesentlich stärkerem Ausmaß als in den vorhergehenden Kapiteln entsteht in den Bildern eine Schichtung, die hier zur Oberfläche wird, wo sie vorher den Bildraum zum Betrachter hin öffnet. Der Mensch steht nicht mehr im Mittelpunkt der Darstellung. Bilder von grafischer Strenge wechseln sich ab mit solchen, die ein großes Durcheinander der Formen zeigen. In den Bildtexten wird die Abstraktion als »Ikebana« bezeichnet. ${ }^{15}$ Klein greift westliche Vorstellungen der japanischen Ästhetik auf, um sie sofort zu brechen. Nicht die klare, abstrakte Form dominiert die Fotografien, sondern - mit wenigen Ausnahmen ${ }^{16}$ - ein komplexes Chaos aus Elementen des Urbanen. Hieraus ergeben sich zwei mögliche Lesarten: Erstens, gestalten die Japaner ihre Umwelt wie Ikebana oder zweitens, macht der Fotograf Ikebana aus dem, was er in Japan

14 Zehn Jahre zuvor hatte er bereits in ähnlich radikalem Stil seine Heimatstadt New York porträtiert und war damals weitgehend auf Ablehnung gestoßen, weshalb das Buch zunächst in Frankreich publiziert wurde (vgl. Klein 1956).

15 Beispielsweise: »176-177. Architektur Ikebana in Tokios Innenstadt.« Oder »182-183. Neon-Nacht Ikebana« (Klein 1965: o.S.).

16 S. 164/165 zeigt moderne und klassische Hausfassaden; diese Doppelseite ist eine der wenigen, die kein Bild im Anschnitt zeigt und die Ruhe der Bilder mit dem weißen Rand zusätzlich betont. 
vorfindet. In diesem Sinne wäre er ein Ikebana-Künstler, der die vorgefundene gebaute Welt auf japanische Weise zu einem japanischen Objekt formt.

Kleins Japanbild unterscheidet sich nachhaltig von dem Werner Bischofs. Während sich Bischof zehn Jahre zuvor nur vorsichtig der japanischen Moderne nähert, interessiert sich Klein gerade für das Moderne, das insbesondere im Urbanen sichtbar wird. Er reflektiert dies anhand von Themen, die sich an das westliche Japanbild anlehnen. Allerdings formuliert seine Sichtweise einen Bruch mit der herkömmlichen westlichen Japandarstellung. Klein erprobt eine Form der künstlerischen Dokumentarfotografie, die er nicht spezifisch im Hinblick auf Tokyo entwickelt. Er ist der Tradition des Dokumentarischen verpflichtet, findet jedoch eine eigenständige Form, die sich radikal von einer reisefotografischen oder journalistischen Herangehensweise unterscheidet. Er arbeitet zwar partiell mit Bildfolgen, diese funktionieren jedoch kaum in einer journalistischen Weise. Kleins Fotografien möchten nicht informieren, sie möchten Erlebtes, Erlebbares sichtbar machen. Klein taucht ganz in die moderne Urbanität Tokyos ein. Seine Bilder sind teilweise schwer zugänglich und sehr komplex, sie irritieren. Dieser Sachverhalt zeugt eindeutig von seinen künstlerischen Intentionen. Die Bilder stellen Fragen und geben sie an den Betrachter weiter. Die Bildästhetik ist sehr eigen, der Fotograf arbeitet mit Unschärfen, radikalen Anschnitten und reduzierter Tonalität. Es geht ihm nicht um gut komponierte Einzelbilder. Der individualisierte Ansatz zeigt eine spezifische Weltsicht, erhebt aber keinen Anspruch auf Vollständigkeit. Anders als Bischof tritt Klein nicht als externer Beobachter auf. Durch die Nähe zum Fotografierten scheint er unmittelbar am Geschehen teilzuhaben. Die Bildtexte verweisen auf Kleins gute Kenntnisse der fotografierten Situationen und seine Bekanntschaft mit einigen der abgebildeten Personen. Die Arbeit entwickelt ihre Kraft aus der Zusammenstellung der Bilder im Buch. Das Werk liefert insgesamt ein atemloses, dicht gedrängtes Porträt der pulsierenden Metropole, die japanische Züge enthält, aber deren Rhythmus nicht mehr traditionell genannt werden kann.

William Klein hebt in seiner Japandarstellung die Distanz zum Gegenstand auf. Entsteht noch in Bischofs Bildern der Eindruck eines respektvollen Umgangs mit Japan, weil der Fotograf mittels Distanzierung bemüht ist, die Intimsphäre der fremden Kultur zu wahren, entwickelt Klein einen eher respektlosen Ansatz. Indem er möglichst nah herangeht, saugt er mit dem Weitwinkelobjektiv seiner Kamera alles ein. Bildwürdig ist das, was die Kamera nah genug an sich heranlässt. Schauspielern, protestierenden Studenten oder Familien beim Sonntagsausflug nähert er sich ebenso wie dem Kaiserpaar. Kleins Fotografien kennen keinen Unterschied zwischen sozialen Klassen oder in der japanischen Gesellschaft bestehenden Hierarchien. Durchbricht Klein in seiner bildnerischen Strategie den ästhetisierenden und auf Allgemeingültigkeit bedachten Ansatz seines Vorläufers Bischof, interessiert er sich dennoch für traditionelle Japanthemen, die er in einem neuen Blickwinkel zeigt. Es entsteht der Eindruck, dass er das traditionelle Japanbild durchaus zur Kenntnis nimmt und zahlreiche Aspekte auf individuelle und subjektive Art aufgreift. Möchte er nicht ganz Japan zeigen, versucht er sich dennoch an einem - gezielt subjektiv angelegten - Bild der pulsierenden Metropole Tokyo.

Kleins Darstellung profitiert davon, dass er sich selbst mitten in die Menge begibt und überall ganz vorne dabei ist. Er nimmt am Leben der Metropole teil, um es abbilden zu können. Wichtig ist, dass die Fotografien tat- 
sächlich eine Nähe zu Japan transportieren. Er stellt Tokyo gerade nicht als einen weit entfernten Ort dar, sondern versucht vielmehr, die Parallelen des alltäglichen Lebens zu anderen Metropolen in den 1960er Jahren aufzuzeigen. Die Strategie ist also das Gegenteil einer Exotisierung, weil sie eher auf das Aufzeigen von Ähnlichkeiten bedacht ist, ohne jedoch japanische Eigenheiten nivellieren zu wollen. Das Tokyo-Buch kann in seiner Eigenständigkeit als Werk bestehen.

Die Bildästhetik spielt wie bei Bischof eine wichtige Rolle, ist jedoch sehr anders gelagert. Das grobkörnige Schwarzweiß von Kleins Aufnahmen stellt das Gegenteil der differenzierten Belichtung und ausgefeilten Bildaufteilung bei Bischof dar. Während bei Bischof das bildwichtige Zentrum der Fotografien immer auszumachen ist, helle und dunkle Partien gut durchgezeichnet sind, weiß der Betrachter der Klein'schen Fotografien nicht, welches Objekt denn nun das wichtigste im Bild ist. Lichter und Schatten formen häufig weiße oder schwarze Flächen und betonen so eine fast rohe Unmittelbarkeit. William Kleins künstlerische Annäherung an das Thema Japan ebnet den Weg zu einem veränderten, weil weniger distanzierten und subjektiveren fotografischen Umgang mit der fremden Kultur.

\subsection{Ed van der Elsken: Die Entdeckung Japans}

Der niederländische Fotograf Ed van der Elsken (1925-1990) reist von 1959 bis 1988 fünfzehn Mal nach Japan. Als Autodidakt fotografiert er sowohl im eigenen Auftrag als auch für Zeitschriften. Insbesondere seine Buchpublikationen zeugen von den »Stärken seiner künstlerisch-gestalterischen Kreativität und Intention « (Kaufhold 2000: 25). 1988 veröffentlicht er eine Zusammenstellung der in Japan entstandenen Fotografien unter dem Titel $D e$ Ontdekking van Japan in Buchform (vgl. Elsken 1988). ${ }^{17}$ Der Titel legt nahe, dass hier eine Abhandlung über das Land als Ganzes vorliegt. Van der Elsken konzentriert sich jedoch in der Tradition der Straßenfotografie hauptsächlich auf den urbanen Raum. Dem Buch ist ein umfangreicher Einleger mit dem Titel Ratatouille Japonica beigegeben, der Texte, Zeitungsausrisse, Fotosequenzen und Grafiken enthält. Es handelt sich offenbar um eine tagebuchähnliche Kommentierung van der Elskens Japanreisen. ${ }^{18}$ Das Buch selbst enthält keine umfangreiche textliche Einführung. Dem Band ist lediglich eine Textseite vorangestellt, die über seine Japanbesuche kurz Auskunft gibt. Der Bildband besteht aus zwei Teilen. Die frühen Fotografien von 1959/1960 werden von denen der 1980er Jahre getrennt. Die Zäsur wird durch eine Doppelseite mit Text und Erinnerungsbildern markiert. Hier berichtet van der Elsken von seinen Erfahrungen mit Japan und mit japanischen Kollegen. Er schreibt auch, dass er viele Orte besucht habe, aber Tokyo letztendlich am spannendsten fand, weshalb er sich auf seinen Reisen vermehrt dort aufgehalten habe. ${ }^{19}$

17 Biografische Angaben in: Elsken 2000: 178; auch: Kaufhold 2000.

18 Da hier nur ein Überblick des Buches geliefert werden soll, wird auf den Einleger nicht eingegangen.

19 »Ik ben op vrij veel plekken geweest in Japan. Op het platteland, in een aantal steden en dorpen. Een paar maanden in Osaka, een paar maanden in Kyoto. 
Der Betrachter erhält zunächst keine textlichen Informationen zu den Bildern, am Ende des Bandes sind jedoch Miniaturen der Fotografien mit subjektiv erzählenden Bildtexten abgedruckt. Eine Zuordnung ist über die Paginierung möglich. Die Texte sind unterschiedlich lang und liefern teilweise Hintergrundinformationen, die nicht aus den Bildern hervorgehen. Die grobkörnigen Schwarzweißfotografien sind oftmals sehr dunkel, der hochwertige Bilderdruck auf glänzendem Papier lässt jedoch auch in dunklen Bereichen die Zeichnung noch erkennen. In dem großformatigen quadratischen Band sind die Fotografien immer im Anschnitt gesetzt. ${ }^{20}$ In der Regel sind auf einer Doppelseite mehr als zwei Bilder abgedruckt, wodurch ähnlich wie bei Klein eine hohe Bilddichte erzeugt wird. Die Leerräume sind im ersten Teil durchgängig schwarz, was die Düsternis der Bilder noch vertieft. Im zweiten Teil wird vorwiegend mit weißen Rändern gearbeitet. Stoßen Bilder aneinander, werden sie mit einer feinen schwarzen Linie voneinander abgesetzt.

Der erste Teil des Bildbandes zeugt von van der Elskens großer Faszination für die japanische Kultur. Einer Tradition der Straßenfotografie verpflichtet widmet er sich ausgiebig den städtischen Ausgehvierteln, wo er beispielsweise auf Yakuza und Prostituierte trifft. Er verweist jedoch auch auf die japanische Bildtradition des Holzschnittes mit Bildern aus einer Ausstellung, fotografiert Garküchen, Puppenspieler, Tempelbesucher, im Theater das Geschehen auf der Bühne und im Zuschauerraum, Sportereignisse wie Sumô (vgl. Abschnitt 1.4.) und Jûdô, bettelnde Kriegsinvaliden, Geishas, sich auf der Straße zum Gruß verbeugende Menschen, Demonstranten und die berühmten U-Bahn-Stopfer. Japan wird als ein modernes Land mit Tradition gezeigt, manche Fotografien thematisieren eine Situation des Umbruchs. So sind die Schaufensterpuppen hinter dem bettelnden Kriegsinvaliden eindeutig westlicher Provenienz (vgl. Elsken 1988: 43); Geishas in Kyoto werden offensichtlich auch von japanischen Touristen als fotografierenswerte Exotinnen betrachtet (vgl. ebd.: 48f.). Obwohl van der Elsken oft sehr nah am Geschehen ist und sich die Fotografierten teilweise der Präsenz des Fotografen bewusst sind, beobachtet er aus einer distanzierten Haltung heraus. Die Fotografien fokussieren meist einen zentralen Bildgegenstand, während sich der Hintergrund mehr oder weniger stark in der Unschärfe verliert.

Der zweite Teil ist mehr noch als der erste dem Menschenbild verpflichtet. Van der Elsken ist noch immer ein Straßenfotograf und fotografiert Typen, auf die er trifft. Porträts von Punks, Poppern, Rockern, absurd kostümierten Jugendlichen oder Barfrauen - um nur einige zu nennen - wechseln sich mit Straßenszenen ab. Die Porträtierten wissen meist um die Präsenz der Kamera. Er scheint den Menschen wesentlich näher als im ersten Teil, bleibt aber trotzdem ein distanzierter Beobachter, jemand, der nicht dazu gehört. Nicht nur die Porträts von Randgruppen wie Obdachlosen und unangepassten Jugendlichen deuten auf sein Interesse für das Soziale oder Politische hin. Er fotografiert auch Demonstrationen ultranationaler Gruppen oder Jugendliche, die Nazi-Outfits tragen. In einigen wenigen Bildern werden traditionelle Themen aufgegriffen, wobei diese kaum in einer herkömmlichen Form umgesetzt werden. Die Fotografie eines Teichs mit japanischen Karpfen wird im Bildtext mit der Symbolik des japanischen Chauvinismus in Verbindung ge-

Maar het werd meer en meer Tokyo. In Tokyo heb je alles en het leven is er dramatischer, tragischer, spannender dan elders in Japan« (Elsken 1988: 63). 
bracht (vgl. ebd.: 136/137). Das Bild des Vaters, der sein Kind zu den Kirschblüten empor hebt, verweist auf die Bedeutung der Kirschblüte für die Japaner, macht aber deutlich, dass van der Elsken an dieser traditionell japanischen Motivwelt nicht weiter interessiert ist (vgl. ebd.). Teilweise greift er erneut Motive aus dem ersten Bildteil auf, wie beispielsweise die Jungen in Schuluniform, die fotografierte Geisha oder die sich zum Gruß oder Dank Verbeugenden.

Die Bildsprache van der Elskens ist nicht so radikal wie die Kleins, sondern eher zurückhaltend. Er ist ein Beobachter, der sich auf einen Bildgegenstand konzentriert und aus der Situation heraus fotografiert. Gelegentliche Unschärfen sind der Situation geschuldet, auch er verwendet keine zusätzlichen Lichtquellen. In der Ausarbeitung seiner Bilder lässt er den Himmel oder den Bildhintergrund oftmals dunkel zulaufen, manchmal sind Nachbelichtung und Abwedeln im Vergrößerungsprozess deutlich zu erkennen. Dieser gestalterische Eingriff ist eher ungewöhnlich für eine dokumentierende Straßenfotografie, macht aber deutlich, dass van der Elsken tatsächlich den Schwerpunkt auf den für ihn entscheidenden Bildgegenstand gelegt sehen möchte und damit Vordergrund und Hintergrund voneinander trennt. Dies reduziert die Komplexität der Bilder, weil Informationen aus dem Bildhintergrund gezielt ausgeblendet werden. Van der Elskens Herangehensweise ist künstlerisch zu nennen. Das Buch vermittelt jedoch keinen konzeptionell geschlossenen Eindruck, was sicher auch an dem langen Zeitraum liegt, über den van der Elsken wiederholt nach Japan reist. Seiner subjektiven Straßenfotografie, die sich nicht für herausragende Ereignisse, sondern für alltägliche Situationen interessiert, bleibt er über Jahre hinweg treu. Als Straßenfotograf beobachtet und dokumentiert van der Elsken genau und entwirft ein kaleidoskopisches Bild. Anders als der Titel vermuten lässt, versucht er nicht, möglichst viele Facetten Japans abzudecken. Aus diesem Grund und wegen der teilweise unvermittelt und roh wirkenden Bildsprache handelt es sich eindeutig um eine künstlerische Dokumentarfotografie. Thematische Schwerpunkte der Arbeit, wie die Sequenzen von Obdachlosen oder Jugendlichen, sind auch als Magazinfotografie vorstellbar, vielen Bildern fehlt jedoch eine in der journalistischen Fotografie üblichen Zuspitzung. In der Zusammenstellung des Gesamtwerks werden einzelne Aspekte kontextualisiert, was dazu führt, dass ein eindrückliches und vielschichtiges Bild der japanischen Gesellschaft entsteht. Die Gedrängtheit der Fotografien im Layout deutet weiter darauf hin, dass gerade in der Vielzahl der Bilder und Themen ein dem Fotografen wichtiger Gesamteindruck entsteht.

Indem Ed van der Elsken Randgruppen mit Sympathie und Ausdauer abbildet, zeigt er ein Bewusstsein für Probleme in der japanischen Gesellschaft, deren politische Relevanz evident ist. Dabei vermeidet er jedoch eine dezidiert anklagende Haltung. »Seine ungezwungene Begeisterung und sein Sendungsbewußtsein ließen ihn an Orten fotografieren, die sogar Japaner eher zu meiden pflegten « (Yokoe 2000: 159).

Ed van der Elskens Ansatz liegt in Bezug auf die Distanziertheit zum Gegenstand zwischen den beiden zuvor betrachteten Positionen. Einerseits verbindet er in seinen Fotografien die 1950er mit den 1980er Jahren, da er über einen langen Zeitraum hinweg wiederholt in Japan fotografiert. Andererseits steht auch seine Art und Weise, sich mit Japan zu befassen, zwischen den anderen beiden Positionen. Weder bleibt er gezielt auf Distanz zur fremden Kultur, noch stürzt er sich mitten hinein ins japanische Leben. Als Flaneur 
auf den japanischen - vorrangig jedoch Tokyoter - Straßen beobachtet er die japanische Kultur aus der Fußgängerperspektive. Seine Zugehörigkeit ist ambivalent. Er sieht und fotografiert das, was auch andere Fußgänger sehen können, aber er hält eine Distanz, um seiner subjektiven Herangehensweise einen kritischen Abstand zu verleihen. Van der Elskens Fotografien zeigen die japanischen Straßen als contact zone (vgl. Teil I, Abschnitt 1.2.1.). denn was er sieht und ins Bild rückt, lässt ihn nicht unbeeinflusst. Traditionelle Themen behandelt er ebenso wie neuere Entwicklungen der japanischen Gesellschaft, deren Veränderung im Lauf der Jahre sich in van der Elskens Fotografien abzeichnet.

Die Alltäglichkeit der beobachteten Phänomene schlägt sich auch in der Bildauffassung nieder, denn Elsken zeigt die Dinge nicht als exotisch oder außergewöhnlich, sondern nähert sich ihnen auf sachliche, unspezifische und damit unspektakuläre Weise. Er erzeugt ein einfühlsames Porträt der japanischen Gesellschaft, das auch die Schattenseiten integriert. Betonen seine frühen Fotografien noch kulturell Differentes, nivellieren sich die Unterschiede zunehmend, da sich van der Elsken hauptsächlich für den japanischen Alltag interessiert. Er wird zum Zeugen der Veränderungen der japanischen Gesellschaft, die sich zunehmend von traditionellen Elementen löst und immer mehr Aspekte einer globalisierten Welt in sich aufnimmt. Japanische Eigenheiten bleiben jedoch im Blickfeld des Fotografen. Er behandelt sie ebenso unspektakulär wie die neuen Dimensionen der Jugendkultur.

\subsection{Vergleich: Bildnerischer Umgang mit traditionellen Themen}

In den drei vorgestellten Positionen zu Nachkriegsjapan zeichnen sich unterschiedliche Herangehensweisen im Umgang mit dem Thema Japandarstellung ab. Dies ist deshalb interessant, weil sich im Laufe der Zeit die fotografischen Annäherungsweisen an dieses Thema ebenso verändern wie die fotografierte Gesellschaft selbst. In Teil I, Abschnitt 2.3.2. wird dargelegt, dass sich die visuellen Vorstellungen von Japan in Europa über Jahrhunderte hinweg herausbilden und noch heute die westliche Japanrezeption beeinflussen. Die hier kursorisch vorgestellten zwischen 1951 und 1988 fotografierten Arbeiten zeugen von spezifischen - auch zeitlich bedingten - Sichtweisen auf Japan. Sie beeinflussen aufgrund ihres Bekanntheitsgrades auch zeitgenössische Künstler, die sich mit Japan auseinandersetzen. Insofern ist es interessant, die konkrete Beschäftigung mit spezifisch japanischen Themen zu betrachten. Eine vergleichende Analyse kann über die sich verändernde Annäherung an Japan Aufschluss geben.

Während Bischof noch ein recht traditionelles Japanbild zeigt, verhandelt Klein teilweise traditionelle Themen in neuer Bildsprache. Van der Elsken zeigt in den frühen Fotografien ein traditionelles Japan, geht in den späteren Bildern jedoch dazu über, klassische Japanthemen nur in geringem Umfang zu streifen. Die unterschiedlichen Herangehensweisen sollen mittels eines Bildvergleichs zu Sumô und Darstellungen des Kaisers genauer erläutert werden. Sumô wird in allen drei Publikationen thematisiert, van der Elsken behandelt es sogar zwei Mal. Kaiserfotografien sind nur bei Bischof und Klein zu finden. Bei van der Elsken spielt die japanische Monarchie keine Rolle. Als traditionelle Sportart, die noch heute im großen Maßstab betrieben 


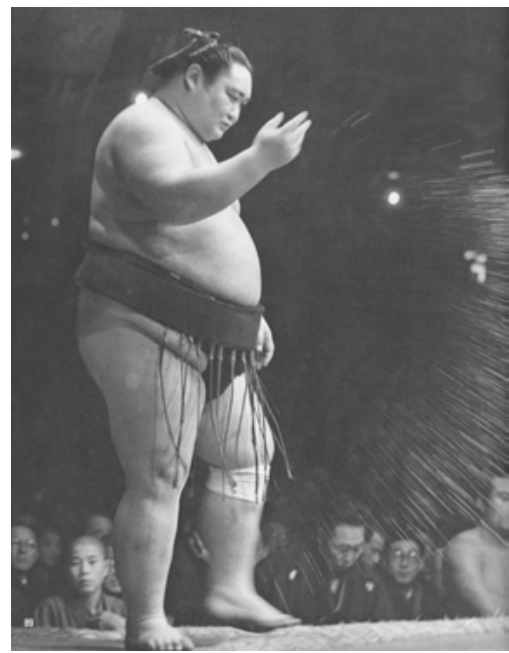

Werner Bischof: Sumô-Ringer (Bischof 1955: 89)

wird, ist Sumô ein fester Bestandteil der japanischen Gesellschaft. Hier begegnet die japanische Tradition einem zeitgenössischen Interesse für Sportveranstaltungen. Ähnlich wie Geishas oder buddhistische Mönche fehlen Sumô-Ringer in kaum einer westlichen Publikumspublikation über Japan (vgl. z.B. Geo Special 2006: 7; Merian 1992: 20f.; Merian 1972: 25). Gleichzeitig ist Sumô heute internationalisiert: Einerseits wird es heute auch in Deutschland im Fernsehen übertragen, andererseits nehmen immer mehr nicht-japanische Ringer auch an großen Wettkämpfen teil.

Bischof beendet das zweite Kapitel, Japan heute, mit dem Bild eines Sumô-Ringers (Bischof 1955: 89). Die hochformatige schwarzweiße Ganzkörperaufnahme füllt eine linke Seite vollständig aus. Der Ringer hebt sich im Profil eindrücklich vor dem schwarzen Hintergrund ab und nimmt - mit Abstand zum Rand - die linke Bildhälfte ein. Er ist nicht angeschnitten. Charakteristische Haartracht, Bekleidung und Leibesfülle sind eindrücklich zu sehen. Die Fotografie ist ungefähr aus der Höhe der Knie des Ringers gemacht, der offenbar auf einer Bühne steht. Das Publikum verliert sich in der Unschärfe und reicht von den Füßen bis zu den Knien des Ringers. Der Ringer befindet sich in einer Bewegung, die durch die leichte Unschärfe des rechten Arms gekennzeichnet ist, da der Protagonist nach dem Bildtext Salz zur rituellen Reinigung des Ringes vor dem Kampf ausstreut. Das Salz bildet ausgehend von der Hand des Ringers in den Linien der Bewegungsunschärfe einen Halbkreis auf der rechten Bildhälfte. Das sehr harmonisch komponierte Bild baut eine große Spannung auf. Es scheint die gespannte Atmosphäre vor Beginn des Kampfes zu visualisieren. Die Kraft des Ringers verbindet sich mit einem meditativen Moment der Ruhe und Konzentration.

William Kleins Sumô-Fotografie steht relativ am Anfang des ersten, mit Ritus überschriebenen Kapitels (Klein 1965: 22/23). Es ist querformatig und füllt eine gesamte Doppelseite. Die Distanz, die Bischof in seiner Fotografie zum Ringer hält, ist bei Klein aufgelöst. Aufgrund des starken Anschnitts fällt zunächst eine Figur am unteren Bildrand in der linken Hälfte ins Auge. Der mit einem Kimono bekleidete Mann hält in der rechten Hand einen Stab 


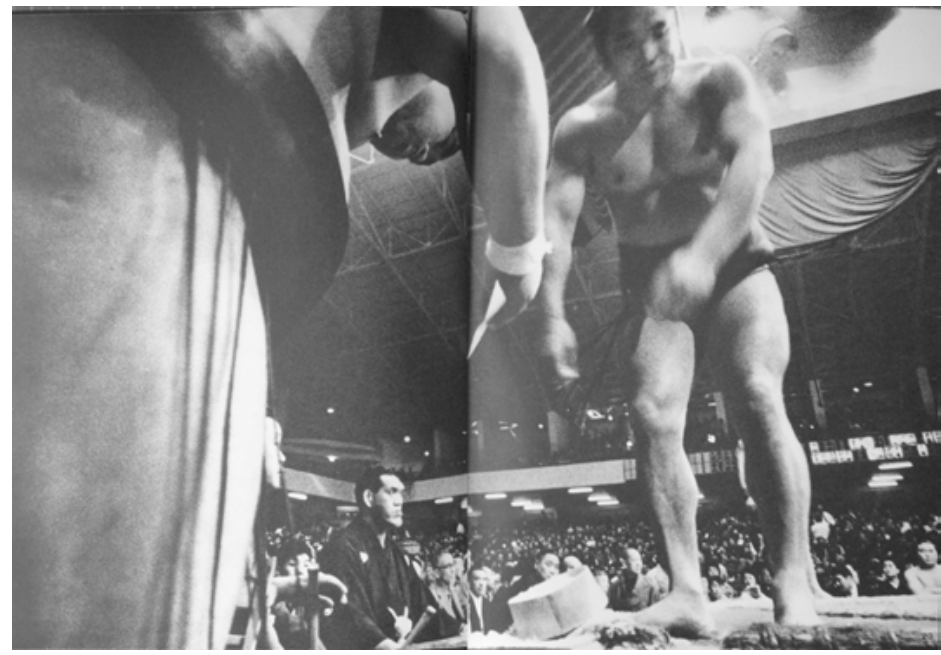

William Klein: Sumô-Ringer (Klein 1965: 22/23).

und scheint an der Bühne vorbei zu blicken. Das Halbprofil zeigt ein markantes Kinn und aufgeworfenen Lippen, die Augen sind leer; seine Erscheinung wirkt sehr martialisch. Links neben diesem Mann schiebt sich eine weitere Hand mit einem Stab in das Blickfeld, über die hinweg ein Junge direkt in die Kamera blickt. Die Zuschauer rechts neben und hinter dem ersten Mann sind weniger gut zu erkennen. Aufgrund der Untersicht ist der große Hallenbau mit gefüllten Rängen gut zu erkennen, was auf die Popularität des Sumô hindeutet. Der Fotograf steht unmittelbar hinter einem fülligen Ringer der sich gerade vor dem Gegner verbeugt. Der Ringer ist sehr stark angeschnitten. Am linken Bildrand sind unscharf Oberschenkel mit langen Fransen der Bekleidung und Gesäß zu sehen, am oberen Bildrand vor und über die Bildmitte hinausragend bilden Brustwarze, Gesicht und Hand einen Bogen, wobei der Fokus auf das Gesicht gelegt ist. Auf der rechten Bildhälfte befindet sich ein zweiter Ringer, der ebenfalls in der Bewegung einer Verbeugung festgehalten ist. Aufgrund der Unschärfe ist das Gesicht des zweiten Ringers, der wesentlich schlanker und muskulöser als der erste erscheint, kaum zu erkennen. Zudem befindet sich über ihm eine Lichtquelle, die eine Gegenlichtsituation erzeugt. Vor den Füßen des zweiten Ringers wirkt die Bühne sehr unordentlich, ein topfartiger runder Gegenstand steht leicht schräg auf nicht zu identifizierendem Gewirr. Die Fotografie wirkt sehr direkt und wenig stilisiert. Der Fotograf beschreibt die Ringer selbst als »harmlos und zahm und nur im Kampf miteinander gefährlich« (Klein 1965: o.S.). Der Eindruck von Rohheit und Gewalt entsteht eher durch den Blick auf den martialisch wirkenden Zuschauer und nicht durch die Kämpfer selbst. Sumô wird hier weniger als Tradition gezeigt, sondern als Sportveranstaltung, die zahlreiche Menschen anzieht. Sumô ist gesellschaftliches Ereignis. Die Fotografie verweist damit auf etwas, das dem Betrachter in der Komplexität seiner kulturellen Bedeutung verschlossen und entsprechend fremd bleibt.

Van der Elsken widmet sich sowohl 1959 als auch 1988 dem Thema Sumô. Die erste Doppelseite zeigt zwei Fotografien aus einem Trainingscamp (Elsken 1988: 38/39). Beide Fotografien sind sehr dunkel gehalten. Auf der linken se- 

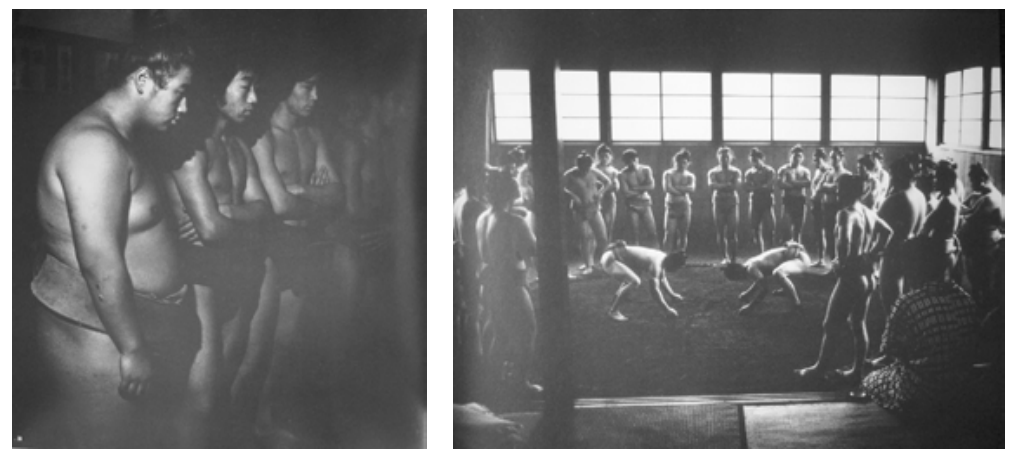

Ed van der Elsken: Sumô-Ringer (Elsken 1988: 38/39).

hen wir drei junge Ringer, die in einem Halbkreis stehend ein Geschehen zu betrachten scheinen. Der linke Ringer ist im Profil in seiner Fülle sehr gut zu erkennen, die anderen sind schlanker und verlieren sich im Dunkel. Hinter ihnen an der Wand befinden sich Tafeln mit japanischen Schriftzeichen, die aufgrund der Dunkelheit ebenfalls kaum zu erkennen sind. Die zweite Fotografie zeigt einen größeren Ausschnitt vermutlich desselben Raumes, in den nur durch über Kopfhöhe befindliche Papierfenster Licht fällt. Die jungen Männer bilden einen offenen Kreis um ein Ringerpaar in Hockstellung. Der Ring scheint aus Lehmboden zu bestehen. Die Zuschauer - man erkennt am rechten Bildrand eine Frau - sitzen auf Tatami-Matten. Das Dunkel der Fotografien, die Männerkörper sowie der Raum deuten auf einen archaischen Ritus hin. Die Fotografien zeigen ein sehr traditionelles Bild.

Ein ganz anderer Eindruck entsteht bei den Aufnahmen von 1988 (Elsken 1988: 134/135). Auf einer Doppelseite sehen wir drei querformatige Fotografien, die eine Gruppe von fünf Männern mit traditioneller Ringer-Haartracht, bekleidet mit Kimono und Geta ${ }^{21}$ zeigen. Die Männer befinden sich auf den großen Fotografien in einem Fast-Food-Restaurant. Im linken Foto stehen drei Männer auf der rechten Bildhälfte als Gruppe der Kamera zugewandt, das Gegenlicht belässt sie schematisch im Halbdunkel. Weiter hinten sind auf der linken Bildhälfte die anderen beiden mit dem Rücken zur Kamera zu sehen, sie scheinen gerade am Tresen zu bestellen. In der Bildmitte der rechten Fotografie steht eine Figur isoliert, halb von hinten gesehen, wartend in einer Schlange, ein anderer Ringer wird gerade bedient. Im Halbdunkel kann man sowohl die anderen Ringer als auch weitere Personen wahrnehmen. Das dritte, kleinere Foto zeigt die Gruppe von hinten auf der Straße mit ihren Einkäufen in der Hand. In den Bildtexten bemerkt der Fotograf, dass diese Bilder in der Provinz gemacht zu sein scheinen, jedoch aus Tokyo stammen. Die Ringer befinden sich hier außerhalb der Situation des Wettkampfes, in der man sie automatisch verortet. In ihrer bunt gemusterten traditionellen Kleidung fehlt ihnen eine Anmutung von Stärke oder gar Gewalt. Das Nebeneinander von traditioneller Kleidung und Fast-Food-Restaurant wirkt zunächst etwas befremdlich. Der Fotograf setzt die Situation jedoch so lapidar ins Bild, dass das Verhalten der Ringer eine selbstverständliche Alltäglichkeit bekommt. Auf diese Weise gelingt van der Elsken eine Darstellung japani-

21 Geta: traditionelle japanische Holzsandalen. 


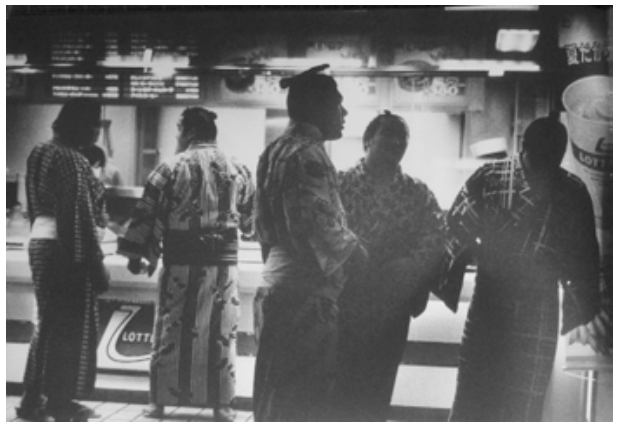

Ed van der Elsken: Sumô-Ringer (Elsken 1988: 134/135).

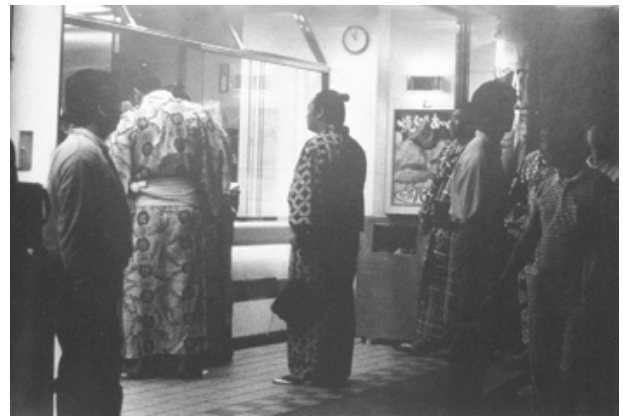

Ed van der Elsken: Sumô-Ringer (Elsken 1988: 134/135).

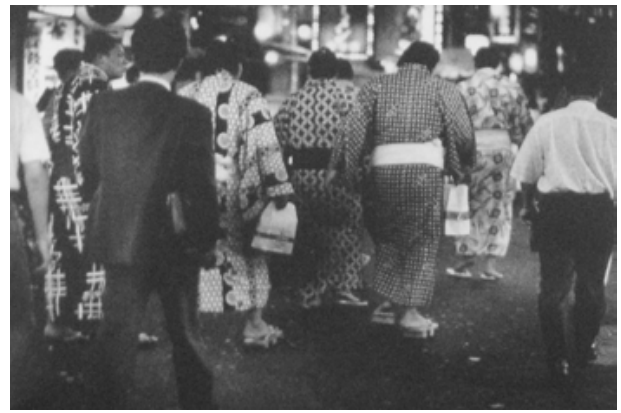

Ed van der Elsken: Sumô-Ringer (Elsken 1988: 134/135).

scher Eigenheiten ohne die - für das europäische Auge existierende - Exotik der Situation voyeuristisch auszubeuten.

Der Vergleich des Umgangs mit dem traditionell japanischen Thema Sumô verweist auf eine sich verändernde Haltung in der bildmäßigen Umsetzung. Existiert in den 1950er Jahren noch ein Bedarf an einer beschreibenden Darstellung, die Körperkult, das Rituelle und die fremdartige Ästhetik eindrücklich ins Bild rückt, verweisen die späteren Sichtweisen auf die Popularität dieser traditionellen Sportart, ohne jedoch eine Ästhetisierung oder Exotisierung zu betreiben. Die Fotografen nehmen die Existenz des Sumô nach wie vor zur Kenntnis und räumen ihm einen Platz in ihren Japanarbeiten ein. Innerhalb der fotografischen Erzählung erhält Sumô jedoch keine hervorstechende Bedeutung mehr. Es ist ein Aspekt unter vielen, die sich in den japa- 


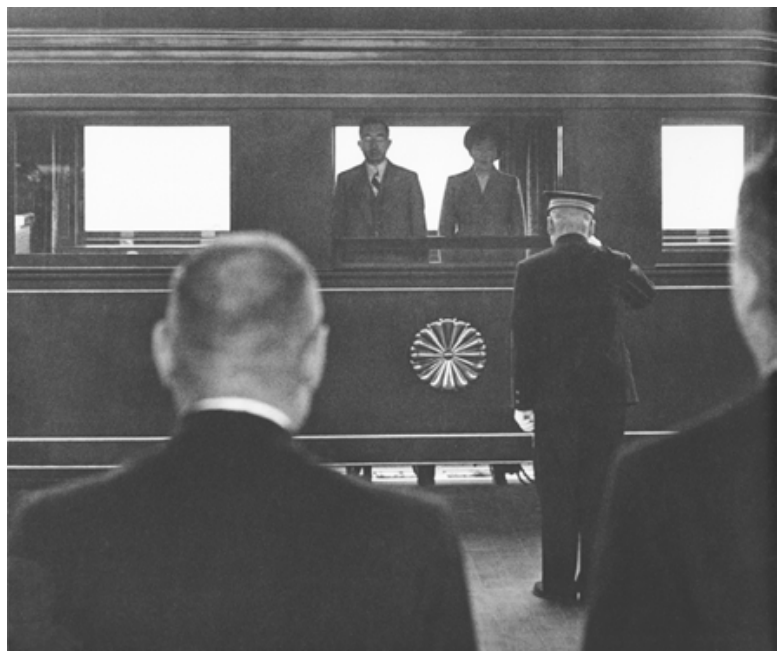

Werner Bischof: Kaiserpaar (Bischof 1955: 42).

nischen Alltag einfügen. Bischofs Fotografie hebt vergleichbar mit van der Elskens frühen Aufnahmen noch die Körperlichkeit des Ringers und Accessoires wie Kleidung und Frisur hervor. Rituelle und traditionelle Aspekte des Sports werden betont. In Kleins Fotografie ist Sumô ein Sport, der Arenen füllt, das traditionelle Element tritt in den Hintergrund und wird von dem Ereignischarakter der Veranstaltung verdrängt. Das spezifisch Japanische wird nicht betont. In van der Elskens späteren Fotografien gehören die Ringer ebenso wie Fast-Food zum japanischen Alltag. Ähnlich wie bei Klein erfahren sie keine Exotisierung.

Ein weiteres Thema gibt Aufschluss über die sich verändernde Japandarstellung. Sowohl in Werner Bischofs als auch in William Kleins Publikation werden Bilder des damaligen japanischen Kaisers Hirohito mit seiner Frau, Kaiserin Nagako, gezeigt. Van der Elsken fotografiert das Kaiserpaar nicht. Als Vorbemerkung ist zu erwähnen, dass sich der Tenno vor dem Ende des Krieges fast nie in der Öffentlichkeit zeigt und nur wenige autorisierte Fotografien verbreitet sind. Erst mit Aberkennung seiner Göttlichkeit im Zuge der japanischen Kapitulation 1945 beginnt er damit, öffentlich aufzutreten (vgl. Dower 1999: Kap. 9-11).

Werner Bischof begleitet einen Kaiserbesuch in Hiroshima in mehreren Fotografien, hier soll Abbildung 42, das das Kaiserpaar in der Frontalansicht zeigt, betrachtet werden. Das Querformat erstreckt sich in der Breite über eine Einzelseite, oben und unten ist der Umraum weiß. Es zeigt das in der Bildmitte aus dem Fenster eines Eisenbahnwagens sehende Kaiserpaar. Unterhalb des Waggonfensters befindet sich das kaiserliche Insignium der goldenen Chrysantheme. Nebeneinander stehend schauen die beiden mit ernster Miene aus dem Waggon heraus auf das Geschehen am Bahnsteig. Die rückwärtigen Fenster des Wagens bestehen aus Milchglas, vor dem sich das Paar sehr gut abhebt. Durch das Gegenlicht verbleibt es jedoch im Halbdunkel. Im Vordergrund des Bildes ist die Situation auf dem Bahnsteig zu sehen. Unscharf sind die Silhouetten zweier Männer in Anzügen von hinten zu erkennen, wobei der rechte stark angeschnitten ist. Aus der Kameraperspektive etwas weiter hinten, unmittelbar vor dem Fenster des Waggons, nimmt ein Bahnangestellter 


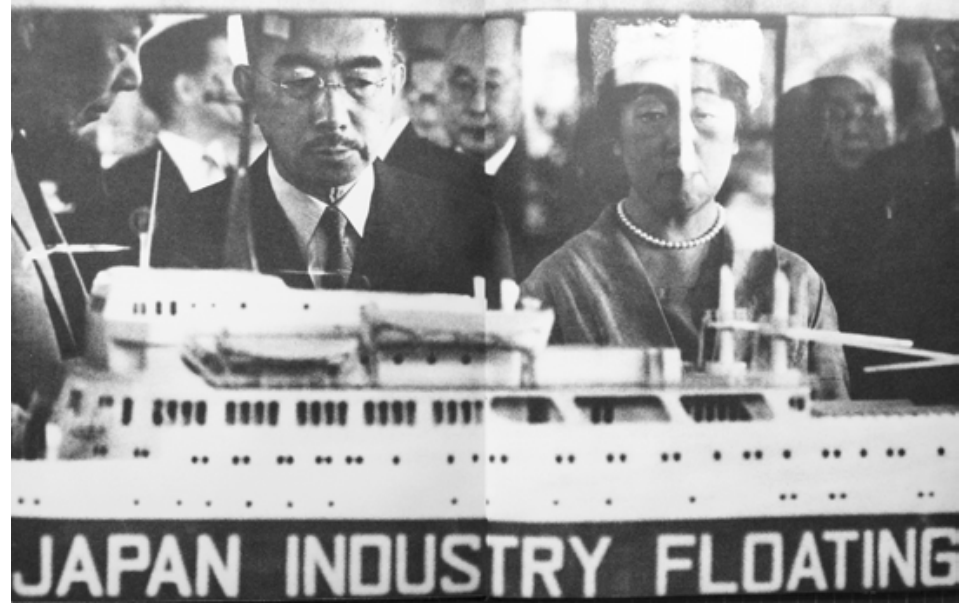

William Klein: Kaiserpaar (Klein 1965: 90/91).

eine demütige Haltung ein. Er hebt die weiß behandschuhte Hand zum Gruß an die Schirmmütze. Die Bildkomposition zeichnet sich durch eine räumliche Dreieckskonstellation aus, die eine Bewegung links vom Vordergrund über den Mittelgrund des Grüßenden hin zum Kaiserpaar führt. Die Staffelung lässt eine deutliche Distanz zwischen Betrachter und Kaiserpaar entstehen und setzt so die hierarchische Distanz ins Bild. Das Kaiserpaar ist das Zentrum, alle Aktivität geschieht ihm zu Ehren. Die Fotografie bringt in großer Klarheit einen ehrfurchtsvollen Respekt vor dem japanischen Staatsoberhaupt zum Ausdruck.

William Klein kommt in seiner Fotografie des kaiserlichen Paares zehn Jahre später zu einer ganz anderen Darstellung. Das einzige Bild des Tenno und seiner Frau ist das dritte Bild des zweiten Kapitels Album (Klein 1965: 90/91). Das große Querformat erstreckt sich über die gesamte Doppelseite. Das Kaiserpaar befindet sich recht Format füllend in der Bildmitte und schaut in Richtung des Fotografen auf ein Schiffsmodell in einer Glasvitrine, die eine Barriere zwischen Fotograf und Kaiserpaar bildet. Der Kaiser trägt einen Anzug mit Krawatte, die Kaiserin ein Kostüm, einen kleinen hellen Hut mit angedeutetem Schleier und eine Perlenkette. Am unteren Bildrand ist als Beschriftung des ausgestellten Schiffsmodells in Versalien der Schriftzug »Japan Industry Floating « zu lesen. Kleins Bildtext benennt als Anlass den kaiserlichen Besuch einer Industriemesse. Im Hintergrund verlieren sich in der Unschärfe zahlreiche Personen, die zum Teil in Richtung des kaiserlichen Paares blicken. Anders als auf Bischofs Fotografie scheint den Protagonisten vom Publikum jedoch nicht allzu viel Aufmerksamkeit entgegen gebracht zu werden. Obwohl er durch die Vitrine vom Kaiserpaar getrennt ist, rückt der Fotograf sehr nah heran, so dass der Gesichtsausdruck des Kaisers gut zu erkennen ist. Das Gesicht der Kaiserin ist durch eine Spiegelung im Glas der Vitrine teilweise verdeckt, ihr Gesicht ist durch die Reflexion senkrecht in zwei Hälften unterteilt, die Nase verschwindet. Ihr Gesichtsausdruck wirkt dadurch fast stumpf und wenig vorteilhaft, was despektierlich erscheint. Die Bildkomposition verdeutlicht, dass Klein dem japanischen Staatsoberhaupt keinen besonderen Respekt entgegen bringt, das Kaiserpaar wird ähnlich dis- 
tanzlos abgebildet wie andere Menschen, denen Klein auf der Straße begegnet. Die Bildkomposition deutet in keiner Weise an, dass es sich hier um das vormals göttliche japanische Staatsoberhaupt handelt. Kleins Fotografie wirkt im Gegensatz zu Bischofs wie ein zufälliger Schnappschuss. Der kaiserliche Besuch einer Industriemesse strahlt eine gewisse Alltäglichkeit aus, es ist keine Spur von ehrfürchtiger Distanz zu erkennen.

Der Bildvergleich scheint insofern interessant, als die Bildkomposition eine sich verändernde Haltung gegenüber einer traditionellen japanischen Institution zum Ausdruck bringt. Der ehrfurchtsvolle Abstand in Bischofs Fotografie findet sich in Kleins Bild nicht. ${ }^{22}$ Einerseits deutet dies auf die unterschiedliche Wahrnehmung und Arbeitsweise der Fotografen hin, andererseits verweist der Unterschied auch auf einen veränderten Umgang mit japanischen Traditionen. Klein zeigt das Kaiserpaar aus ähnlicher Nähe wie andere Protagonisten seiner Fotografien, macht also keinen Unterschied zwischen Volk und Kaiser. Damit widersetzt er sich einer stereotypisierenden Sichtweise der japanischen Gesellschaft, die als streng hierarchisch strukturiert gilt, und eröffnet dem westlichen Betrachter neue Wege der Interpretation. Van der Elsken misst der Thematik des japanischen Kaiserhauses keine Bedeutung bei. Die Institution der Monarchie ist weit entfernt von seinem Interesse für die Alltäglichkeit der Straße.

Die fotografischen Ansätze von Werner Bischof, William Klein und Ed van der Elsken reflektieren sowohl die der jeweiligen Zeit entsprechende Herangehensweise an die fremde Kultur als auch die individuell unterschiedlichen Motivationen und Ideen der subjektiven Annäherung an Japan. In der gemeinsamen Betrachtung der drei Arbeiten wird der sich verändernde Umgang mit traditionellen japanischen Themen deutlich. Insbesondere in Bischofs Arbeit, aber auch in den frühen Fotografien van der Elskens zeichnet sich noch ein großes Interesse für ein traditionelles Japan und die Besonderheiten der japanischen Kultur ab. Kleins Arbeit bricht zwar mit der Art des Umgangs, bewegt sich aber dennoch entlang traditionell japanischer Themen. Klein fügt dem jedoch zusätzliche Aspekte hinzu, was eng mit der gesellschaftlichen Entwicklung in der Tokyoter Metropolenregion zusammenhängt. Van der Elskens Langzeitbeobachtung vermag die entwicklungsbedingten Veränderungen des urbanen Japan am ehesten zu reflektieren. Der Fotograf setzt sich - mit Phasen der Unterbrechung - wiederholt mit Japan auseinander, was es ihm ermöglicht, gesellschaftliche und bauliche Veränderungen wahrzunehmen und dies in seine Fotografie einzubeziehen. Dementsprechend verändert sich auch der Fokus seiner Fotografien weg von traditionell Japanischem hin zur Darstellung einer globalisierten urbanen Kultur mit japanischen Elementen.

Mit den unterschiedlichen Zugängen der Fotografen zur fremden Kultur Japans ändert sich auch der Umgang mit Klischees. Zeigt Bischofs Fotografie Japan eher noch als das Andere, nimmt die Differenzierung in den anderen Positionen zu. Klein und van der Elsken widmen sich zunehmend der Darstellung des Alltäglichen, was auf die japanische Normalität verweist, in der sich auch eigenkulturelle Aspekte der Fotografen widerspiegeln. Insbesondere die zurückgenommene Straßenfotografie van der Elskens zeigt, dass ihm

22 Da beide Fotografen aus Republiken ohne Monarchie (Schweiz und USA) kommen, kann eine eigenkulturelle Prägung als Grund für die unterschiedliche Haltung wohl ausgeschlossen werden. 
eine vielschichtige Darstellung des Normalen wichtiger ist, als das Differente der japanischen Kultur hervorzuheben. So zeigt bereits sein Ansatz Möglichkeiten auf, fotografisch das Fremde in seiner Fremdheit zu belassen und somit eine Darstellung zu erreichen, die Klischees hinter sich lässt. Kleins Arbeit markiert in Bezug auf die Darstellung von Japanklischees eine ambivalente Position. Auch er wendet sich ab von den bekannten Stereotypen, seine Themenwahl deutet jedoch an, dass einige japanspezifische Kategorien nach wie vor in seinem Denken verankert sind, weshalb er diese Kategorien wiederholt durchbricht und ihnen Neues hinzufügt. Die sich verändernde Rezeption Japans in der westlichen Fotografie, beispielhaft an den drei Positionen Bischofs, Kleins und van der Elskens vorgeführt, bilden somit eine Ausgangsbasis für die Betrachtung der zeitgenössischen dokumentarfotografischen Annäherungen an Japan.

\section{Zusammenfassung:}

Die historischen dokumentarfotografischen Positionen von den 1950er bis in die 1980er Jahre hinein verdeutlichen, wie sich der Umgang europäischer Fotografen mit der Darstellung Japans verändern. Die klischeehafte Darstellung Japans wird in der künstlerischen Auseinandersetzung im Laufe der Zeit zurückgedrängt. Individuelle und subjektive Erfahrungen des Fremden eröffnen eine differenzierte Sicht auf das Fremde. Während Werner Bischof noch einer umfassenden Japandarstellung verpflichtet ist und eine Distanz zum Gegenstand bewahrt, hebt William Klein die Distanz zum Gegenstand auf. Er nähert sich auf fast respektlose Art der Tokyoter Gesellschaft, greift dabei aber häufig traditionell behandelte Themenkomplexe auf. Diese zeigt er in bildnerisch neuer Art und Weise. Ed van der Elsken bleibt in seiner Langzeitbeobachtung Japans interessierter Straßenfotograf, der auf zurückhaltende Art das Geschehen beobachtet und damit die Veränderungen in der japanischen Gesellschaft dokumentiert. Unaufdringlich aber bestimmt schwenkt seine Wahrnehmung von Aspekten der Differenz auf Elemente einer Kultur, die viele Parallelen zur westlichen Welt aufweist, aber dennoch ihr japanisches Gesicht behält. Alle drei Fotografen verfolgen unterschiedliche Strategien. Bischof arbeitet mit einer Strategie der Ästhetisierung, Klein mit einer der Aufhebung von Distanz, während in van der Elskens Strategie das Alltägliche betont wird. Alle drei Strategien zeugen von den vielfältigen Möglichkeiten der Annäherungen an das Fremde in der künstlerischen Dokumentarfotografie. 


\section{ZEITGENÖSSISCHE}

\section{DOKUMENTARFOTOGRAFISCHE SICHTWEISEN}

AUF JAPAN

Die zeitgenössische fotografische Auseinandersetzung mit Japan steht zunehmend im Spannungsfeld zwischen der langjährigen Tradition europäischer Japanfotografie und der wachsenden Aufmerksamkeit für japanische Fotografie. Neben der europäischen fotografischen Auseinandersetzung mit Japan hat auch die Rezeption der japanischen Nachkriegsfotografie das Japanbild zeitgenössischer Fotografen nachhaltig geprägt. Der markanteste Unterschied zwischen westlichen und japanischen Sichtweisen auf Japan, ist in der Wahl der Themen zu suchen. Japanische Fotografen widmen sich beispielsweise Themen des Alltags oder der eigenen Identität. Sie können die Vertrautheit ihres Publikums mit den kulturellen Gegebenheiten voraussetzen und mit ihren visuellen Untersuchungen in andere Bereiche vordringen als es dem ausländischen Betrachter möglich ist. Dies führt mitunter zu Verständnisproblemen bei europäischen Betrachtern japanischer Fotografie, da ihnen die Bedeutungen kultureller Grundparameter nicht immer bekannt sind. Der europäische Blick auf Japan trifft bei einem europäischen Publikum hingegen auf eine gleichwertige Ausgangsbasis, da die betrachtete Kultur als fremd erkannt wird. Europäische Fotografen thematisieren auf verschiedenen Reflexionsebenen den Blick von außen, setzen sich in Japan mit einer ihnen fremden Kultur auseinander und vermitteln diesen Prozess vorrangig einem westlichen Publikum.

In Japan selbst besteht ein nachhaltiges Interesse an fotografischen Außendarstellungen des Landes, weil die Sichtweisen auf das Eigene und das Fremde unterschiedlich sind. Die Außensicht auf Japan nimmt allgemein in der japanischen Selbstbestimmung eine wichtige Stellung ein. So genannte Japandiskurse versuchen eine Positionierung Japans und gehen der Frage nach: Wer sind die Japaner? (vgl. Teil I, Abschnitt 2.3.1.). Der Prozess der Selbstvergewisserung ist mitunter der Tatsache geschuldet, dass Japan als Inselnation lange Zeit nur wenig Außenkontakte hatte, woraus die Idee der Einzigartigkeit der japanischen Kultur entspringt. Die Intensivierung der Außenbeziehungen seit der Mitte des neunzehnten Jahrhunderts sowie der verlorene Zweite Weltkrieg haben eine eingehende Befragung der eigenen kulturellen Identität ausgelöst. »Während der gesamten Nachkriegszeit [hat] der Blick von >außen großen Einfluß auf die Selbsteinschätzung der Japaner ausgeübt. Die Kreuzungspunkte der inneren und äußeren Sichtweisen, die sich um die Möglichkeiten der Japaner und der japanischen Kultur drehten, haben eine unübersehbar wichtige Bedeutung « (Aoki 1996: 60). Der Fremdblick auf Japan hilft bei der Bestimmung der eigenen Position, weshalb nach wie vor ein Interesse daran besteht, zu erfahren, wie Japan von außen gesehen wird. Ge- 
rade weil der Außenblick in Japan als wichtig erachtet wird, besitzen fotografische Japandarstellungen westlicher oder europäischer Fotografen in Japan einen hohen Stellenwert. Das lässt sich unter anderem an Ausstellungen ablesen, die zu diesem Thema in Japan gezeigt werden. ${ }^{1}$

Das japanische Interesse an Außendarstellungen des eigenen Landes trifft auf die Faszination westlicher Fotografen, die der modernen Industrienation mit ihren differenten kulturellen Wurzeln noch immer sehr aufgeschlossen begegnen. Der daraus resultierenden Anziehungskraft ist es zu verdanken, dass unzählige Fotografien in Ausstellungen, Katalogen und Buchpublikationen Eindrücke von Japan vermitteln oder Geschichten über Japan erzählen und somit ihren Beitrag zum westlichen Japanbild leisten. Aus dieser großen Anzahl gilt es, einige künstlerische Positionen auszuwählen, um sie hier umfassend zu betrachten. Der Fokus liegt auf der künstlerischen Dokumentarfotografie, da sie nach der Grundüberlegung einen individuellen und persönlichen Umgang mit dem Fremden pflegen und möglicherweise Japan in einer Weise zeigen kann, die über die etablierten Klischees hinausweist. ${ }^{2}$

Als Auswahlkriterium für die Untersuchung künstlerischer Dokumentarfotografie steht das monografische Künstlerbuch im Zentrum. Wie in Teil I, Abschnitt 4.1.5. erläutert, kann es als eine Form gesehen werden, die in Umfang und Gestaltung das künstlerische Werk optimal präsentiert. Denn von der Bildauswahl über die Arbeit mit Texten bis hin zur Gestaltung des Layouts ist der Künstler maßgeblich an allen wichtigen Entscheidungen beteiligt. Das monografische Künstlerbuch reduziert das fotografische Projekt nicht auf eine redaktionelle Auswahl, sondern entspricht dem künstlerischen Anspruch des Fotografierenden. Zudem beinhaltet ein Künstlerbuch in der Regel ausschließlich eine Arbeit, die in einem konzeptuellen und inhaltlichen $\mathrm{Zu}$ sammenhang entstanden ist. Liegt ein auf Japan bezogenes Künstlerbuch vor, kann davon ausgegangen werden, dass der Künstler dies als ein thematisch orientiertes Projekt konzipiert und realisiert hat. Das Projekt wird im Buch für die Rezipienten als Einheit zusammengefasst. Im Gegensatz dazu stehen Bücher, die Japanfotografien neben anderen Bildern zeigen. Eine solche Buchkonzeption lässt darauf schließen, dass die Japanfotografien eingebettet in einen größeren inhaltlichen Rahmen entstanden sind, so dass der konzeptionelle Ausgangspunkt nicht in einer Auseinandersetzung mit der japanischen Kultur oder anderen Japan spezifischen Themen zu verorten ist (vgl. z.B. Waplington 1997). In der Auswahl geht es vor allem um solche Arbeiten, die Japan als Fremdes erfassen, indem sie Aspekte der japanischen Kultur sichtbar machen und auf diese Weise zu einer Erweiterung des europäischen Japanbilds beitragen. Die thematische Vielfalt innerhalb des Buches ist ein weiteres Element der Auswahl. Da ein umfassender Einblick in die fremde Kultur Japans nur über ein vielfältiges Themenspektrum zu erreichen ist, scheiden monothematisch angelegte Publikationen für die Betrachtung aus.

1 Für die Zeit meines Aufenthaltes in Tokyo vom 1. April bis zum 30. Juni 2006 sind mehrere Ausstellungsprojekte erwähnenswert: Hellen van Meene: Tokyo Girls (Meene 2006); Wim und Donata Wenders: Journey to Onomichi (Wenders 2006); Two Mountains: Balthasar Burkhards Fotografien japanischer Berge und Naoya Hatakeyamas Bilder der Schweizer Alpen, ausgestellt im Tokyo Art Museum, April bis Juli 2006.

2 Deshalb werden Bildbände, die nicht eindeutig einem künstlerischen Kontext zuzuordnen sind, nicht weiter berücksichtigt (vgl. z.B. Grames 1979; Langford 1991; Turner 1995). 
Das bezieht sich auf Künstlerbücher, die sich ausschließlich mit einem bestimmten Phänomen der japanischen Kultur beschäftigen ebenso wie auf solche, die ausschließlich Tokyo beziehungsweise das urbane Japan thematisieren (vgl. z.B. Lüscher 1996; Hils 1999; Benge 2006). »Für Europäer bedeutet Japan oft Tokyo, « was einer großen Einschränkung in der Japanbetrachtung gleichkommt (Bauret 2000: 6).

Bevor jedoch in den nächsten Kapiteln exemplarisch die monografischen Künstlerbücher von Paul Graham und Elisabeth Neudörfl vorgestellt werden, soll hier ein Einblick in verschiedene Strategien und Herangehensweisen im Umgang der westlichen künstlerischen Dokumentarfotografie mit dem Thema Japan gegeben werden.

\subsection{Japan und die Düsseldorfer Becher-Schule}

\subsubsection{Die erste Generation}

Der dokumentarfotografische Blick auf Japan wird häufig mit den weit verbreiteten Bildern von Thomas Struth (*1954) assoziiert, der einer der prominentesten Vertreter der so genannten Düsseldorfer Becher-Schule ist. Er gehört zu den Fotografen, die 1976 als erste bei Bernd Becher das Studium aufnehmen. Seine Fotografie Shibuya Crossing hat wohl mit zum Weltruhm dieser Tokyoter Straßenkreuzung beigetragen (vgl. Struth 2002: 55).

Thomas Struth fotografiert in den 1980er und 1990er Jahren wiederholt in Japan Bilder für verschiedene Werkgruppen. So finden sich in seinem Werk Straßen (vgl. Herzogenrath 1992a: 63), Familienbilder (vgl. Struth 2002: 63; 115), und Museumsfotografien (vgl. ebd.: 40f.) aus Japan. Dennoch möchte er nicht Japan oder spezifische Aspekte Japans dokumentieren. Seine Japanfotografien suchen die Vergleichbarkeit mit denen aus anderen Städten und Ländern, »das Abzubildende [interessiert ihn] mehr als die Abbildung " (Herzogenrath 1992b: 16). Struths Interesse gilt beispielsweise den Strukturen des Urbanen, die er in seinen »Unbewusste Orte « betitelten Straßenfotografien meist in einer mittigen Zentralperspektive ins Bild rückt. Die Parallele in der Perspektive verdeutlicht, dass nicht auf die Spezifik des jeweiligen Ortes eingegangen wird. Erst durch die immer gleiche Darstellung erhalten die Orte eine vergleichbare Allgemeingültigkeit. Struth möchte keine Geschichten über die Orte selbst erzählen oder das ihnen Besondere angemessen ins Bild setzen. In der Zusammenschau der Motive aus verschiedenen Ländern entsteht eine allgemein gehaltene Erzählung über das Urbane. Der serielle Charakter seiner Arbeit ergibt sich aus der Kombination von Einzelbildern, jede einzelne Fotografie kann als repräsentativ für die Serie als Ganzes gelten.

Daran lässt sich ablesen, dass Struth in seiner Arbeit kein dokumentarisches Interesse im Sinne der in Teil I, Abschnitt 4.1.2. erläuterten dokumentaristischen Variante der Dokumentarfotografie verfolgt. Die Einschätzung von Struths Fotografien als dokumentarisch »resultiert möglicherweise daraus, daß seine Photos in den Anfangsjahren bisweilen in Ausstellungen zu sehen waren, die Dokumentarphotographie zeigten« (Pfab 2001: 91f.). Struth geht es nach Aussagen seines ehemaligen Assistenten Rupert Pfab »nicht um das Festhalten von Zuständen in bestimmten Momenten, sondern um ein allgemeingültiges Thematisieren architektonischer Realitäten und der Atmosphäre des Gewöhnlichen, Alltäglichen, die unserem Bewußtsein weitgehend ver- 
borgen bleiben, kurz: um >unbewußte Orte« (ebd.). Struth ist eher an strukturellen Aspekten der Themen Straße oder Familie interessiert und nicht daran, sich intensiv mit der japanischen Kultur auseinanderzusetzen. Japanisches interessiert lediglich im Kontext der Vergleichbarkeit. Aus diesem Grund gibt es auch keine Publikation, die seine Japanbilder zusammenfasst. Eine solche war - nach Pfab - auch nie intendiert.

Neben Thomas Struth haben als Becher-Schüler der ersten Generation auch Andreas Gursky (*1955) (vgl. z.B. Felix 1994: 105; 69) und Candida Höfer (*1944) (vgl. Höfer 2001) in Japan fotografiert. Ähnlich wie Struth lassen sie sich nicht gezielt auf die japanische Kultur ein. Auch sie verfolgen Abbildungsstrategien im Sinne eines konzeptuellen Ansatzes der Dokumentarfotografie (vgl. Teil I, Abschnitt 4.1.2.). In ihren Arbeiten zählt eher die bildnerisch-ästhetische Annäherung an den Gegenstand als ein inhaltliches Interesse. Beispielhaft fotografiert Gursky einzelne Motive wie die Tokyoter Börse. Seit den frühen 1990er Jahren bearbeitet er seine Fotografien digital, so dass sie ohnehin nicht mehr zum Bereich der Dokumentarfotografie gerechnet werden können. Candida Höfer fotografiert für ihren Zyklus »Die Bürger von Calais« auch die in Japan aufgestellte Bronzeplastik von Rodin (vgl. Höfer 2001). Die Intention dieser Arbeit bezieht sich aber allein auf die Skulptur in ihrem Umfeld.

Die erste Generation der Becher-Schule verfolgt fotografische Strategien, die zwar dokumentarisch anmuten, aber letztlich in ihrem konzeptuellen Anspruch vor allem das Pikturale im einzelnen Bild betonen und sich nicht mit fotografischen Mitteln der intensiven Untersuchung einer fremden Kultur widmen. Sie sind nicht in den Bereich des dokumentaristischen Ansatzes in der künstlerischen Dokumentarfotografie zu rechnen. Serielle Prinzipien und das Hervorheben von Einzelbildern verdeutlichen, dass diese Werke im Bereich der Konzeptkunst anzusiedeln sind (vgl. Teil I, Abschnitt 4.1.2.). Ausgehend von der Annahme, dass eine individuelle Auseinandersetzung notwendig ist, um das Fremde als Fremdes zu erfassen, kann ein auf Vergleichbarkeit angelegter konzeptueller Ansatz - unabhängig von der Qualität - diese Vorgabe kaum erfüllen. Deshalb finden die Arbeiten der ersten Generation der Becher-Schule hier keine weitere Berücksichtigung.

\subsubsection{Heiner Schilling}

Heiner Schilling (*1969) gehört zu einer späteren Generation der BecherSchule, er studiert von 1993 bis 1998 in der Klasse von Bernd Becher an der Düsseldorfer Kunstakademie. Er ist der einzige Becher-Schüler, der ein monografisches Buch mit Japanfotografien veröffentlicht. ${ }^{4}$ Weil sein Ansatz sich zunächst von dem auf Vergleichbarkeit und Serialität angelegten Ansatz anderer Becher-Schüler unterscheidet, soll seine Arbeit hier etwas genauer betrachtet werden. Das Buch The Entropic Forest erscheint anlässlich seiner Ausstellung im Yokohama Museum of Art im Mai 2000. Neben dem Bildteil enthält das Buch einen etwa ebenso umfangreichen Textteil mit literarischen Miniaturen von Hiroo Yamagata. Diese erzählen von einem zukünftigen To-

3 Auskunft von Rupert Pfab in einem persönlichen Gespräch in Düsseldorf am 30.5.2007.

4 Es handelt sich dabei um die Ergebnisse eines einjährigen Japanaufenthalts 1998/99 (vgl. Schilling 2000). 
kyo. Mitunter ergeben sich Korrespondenzen zwischen einzelnen Bildern und Texten, wobei sich nicht erschließt, ob die Texte auf die Bilder reagieren oder umgekehrt (vgl. z.B. Yamagata 2000: 44f.; Schilling 2000: 26).

Schillings Fotografien zeigen hauptsächlich die urbane Dichte der Metropole Tokyo, setzen aber keinen erkennbaren inhaltlichen Schwerpunkt im Sinne einer Auseinandersetzung mit der japanischen Kultur. Thematisch fotografiert er hauptsächlich die neusten Architekturen und die verdichtete Urbanität Tokyos sowie die städtische Peripherie. Die vorrangig menschenleeren Fotografien von Außen- und Innenräumen beziehen nur gelegentlich Personen als Nutzer der gebauten Welt mit ein. Schilling beobachtet aus der Distanz heraus und nimmt keinen Kontakt zu den abgebildeten Menschen auf. Seine Fotografien zeigen - im Sinne der titelgebenden Entropie ${ }^{5}$ - einen Zustand des Stillstands; einen Moment der Ruhe im veränderlichen System der Metropole Tokyo, was durch die Statik der Großformatfotografie unterstrichen wird. Im Unterschied zu anderen Fotografen der Becher-Schule benutzt Schilling die Großformatkamera jedoch in einem hohen Tempo und fotografiert wesentlich mehr Motive als in diesem Format gemeinhin üblich. Sein Ansatz entspricht nicht der seriellen Herangehensweise anderer BecherSchüler, weil er unterschiedliche Motive und individuelle Kameraeinstellungen sucht. Ob seine Arbeit jedoch als künstlerische Dokumentarfotografie im Sinne einer dokumentaristischen Herangehensweise gelten kann, bleibt zunächst fraglich, denn mindestens eine Fotografie lässt eine digitale Bearbeitung vermuten, so dass Manipulationen auch bei anderen Bildern nicht ausgeschlossen werden können (vgl. Schilling 2000: 26). ${ }^{6}$

\section{The Entropic Forest}

Das Buch The Entropic Forest umfasst eine Auswahl von 39 Fotografien und die sowohl auf Japanisch als auch auf Englisch abgedruckten Texte von Hiroo Yamagata. Schilling ist im Impressum nur als Autor der Fotografien genannt, was darauf schließen lässt, dass es sich um einen Ausstellungskatalog und nicht explizit um ein Künstlerbuch handelt, für das Schilling die Gesamtkonzeption entwickelt hat. Text- und Bildteil des Buches sind in zwei Einzelbände getrennt, die in einer durchsichtigen, mit dem Titel bedruckten Plastikhülle zusammengefasst sind. Die Zweiteilung verweist auf die Mög-

5 »Entropie [griech.], Zustandsgröße thermodynamischer Systeme und Maß für die Irreversibilität der in ihnen ablaufenden Prozesse. In einem abgeschlossenen System (ohne Energiezu- oder abfuhr) kann die Gesamt-Entropie nie abnehmen, bei reversiblen Prozessen (Idealfall) bleibt sie konstant. In der unbelebten Welt herrscht die natürliche Tendenz, sich auf einen Zustand immer größerer Unordnung (z.B. gleichmäßige Durchmischung zweier Gase) hinzubewegen. Diese im 2. Hauptsatz der Wärmelehre (sog. Entropiesatz) formulierte Gesetzmäßigkeit besagt, dass in einem abgeschlossenen System die Wahrscheinlichkeit für einen Zustand umso größer ist, je größer seine Unordnung ist. Die Entropie ist ein Maß für diese Unordnung « (Meyers Taschenlexikon 1990). In der physikalischen Welt heißt die gleichmäßige Verteilung von Teilchen Unordnung, weil sie nicht mathematisch geordnet sind. Ich danke Christoph Löhr für diesen Hinweis.

6 Der Künstler hat sich der Autorin gegenüber nicht zu seiner Arbeit geäußert, so dass konkrete Fragen der digitalen Bearbeitung oder des Zusammenwirkens zwischen Bildern und Texten ungeklärt bleiben müssen. 
lichkeiten einer japanischen und westlichen Nutzung. ${ }^{7}$ Die ideale Lesart stellt das mittige Aufschlagen dar. Es gibt die Ansicht auf beide Einzelbände frei, wobei der rechte Band die Fotografien beinhaltet und der linke den Text. ${ }^{8}$

Die zwölf atmosphärischen Textminiaturen sind ein wichtiger Bestandteil des Buches, sie sind in einem zukünftigen Tokyo der Mitte des 21. Jahrhunderts angesiedelt. Es handelt sich um kleine verdichtete Geschichten, die urbane Situationen oder in ihnen stattfindende Handlungen beschreiben. Inhaltlich geht es zum Beispiel um Hochhausarchitekturen, Fernsehen, Verkehr, Überwachung oder Cybersex, um nur einige Themenbereiche zu nennen. Die Stimmung der Geschichten korrespondiert mit der Atmosphäre der Fotografien.

Die meist querformatigen Farbfotografien sind in variablen Größen abgedruckt. Alle Bilder sind mit weißem Rand auf die Buchseite gesetzt. Im Verhältnis zum Aufnahmeformat sind Buchformat und Abbildungsgröße sehr klein gewählt, wodurch die Präzision der Großformatfotografien an Qualität verliert. Alle Bilder weisen ein die Buchseite großflächig nutzendes Format auf und sind fast gleich groß, dennoch variieren die Formate sowohl im Seitenverhältnis als auch in der absoluten Größe im Millimeterbereich. ${ }^{9}$ Daraus lässt sich schließen, dass der Fotograf den Ausschnitt frei wählt und sehr präzise festlegt, ohne sich an das originale Aufnahmeformat oder ein grafisches Raster zu halten. Ist eine solche Praxis im Umgang mit Fotografien allgemein nicht ungewöhnlich, irritiert dennoch die Tatsache, dass sich die Bildformate innerhalb eines Buches einem konsequent angewendeten grafischen Raster entziehen. Schillings Umgang mit den Formaten zeigt, dass er das einzelne Bild in den Vordergrund stellt. Dennoch sind die meisten Fotografien auf Doppelseiten als Bildpaare angeordnet, seltener stehen Einzelbilder allein. Auf insgesamt drei ausklappbaren Seiten sind Fotografien in einem breiten Panoramaformat abgedruckt. Es gibt keine Bildunterschriften, die Auskunft über das Fotografierte geben.

Um genaueren Aufschluss über Schillings Intentionen zu erhalten sowie sein Verhältnis zur Dokumentarfotografie auszuloten, sollen nun einige Fotografien genauer analysiert werden. Daraus lassen sich Rückschlüsse auf seinen fotografischen Ansatz sowie sein Interesse an der Auseinandersetzung mit Japan ziehen.

Die Reihenfolge der Fotografien lässt sich nicht sequentiell lesen, sie basiert auf doppelseitigen Anordnungen, die in der Abfolge keine thematische Dramaturgie entwickeln, sondern eher formale Zusammenhänge aufweisen. Die Doppelseiten sind meist aus ästhetischen Erwägungen heraus zusammengestellt. Die erste und die letzte Fotografie bilden eine Klammer, beide sind vom selben Standpunkt aus aufgenommen und zeigen einen Ausschnitt

7 Japanische Bücher werden aus westlicher Perspektive gesehen von hinten nach vorne gelesen.

8 Die einzelnen Bände im Format 19 x $16,8 \mathrm{~cm}$ sind als rot bedruckte Broschur gebunden. Umlaufend ist in rot noch einmal der Titel aufgedruckt, in kleinerer Typografie in weiß sind auf den Einzelbänden jeweils Titel und Autorenname gesetzt.

9 Die Formate variieren bei den Querformaten in etwa zwischen 16,5 $\mathrm{cm}$ und 15,5 $\mathrm{cm}$ in der Breite und 11,9 cm bis $14,8 \mathrm{~cm}$ in der Höhe (ausgenommen die extremen Querformate der ausklappbaren Seiten). Die Hochformate weisen alle eine Höhe von 14,8 cm auf, in der Breite liegen sie ungefähr zwischen 9,1 cm und $12,2 \mathrm{~cm}$. 


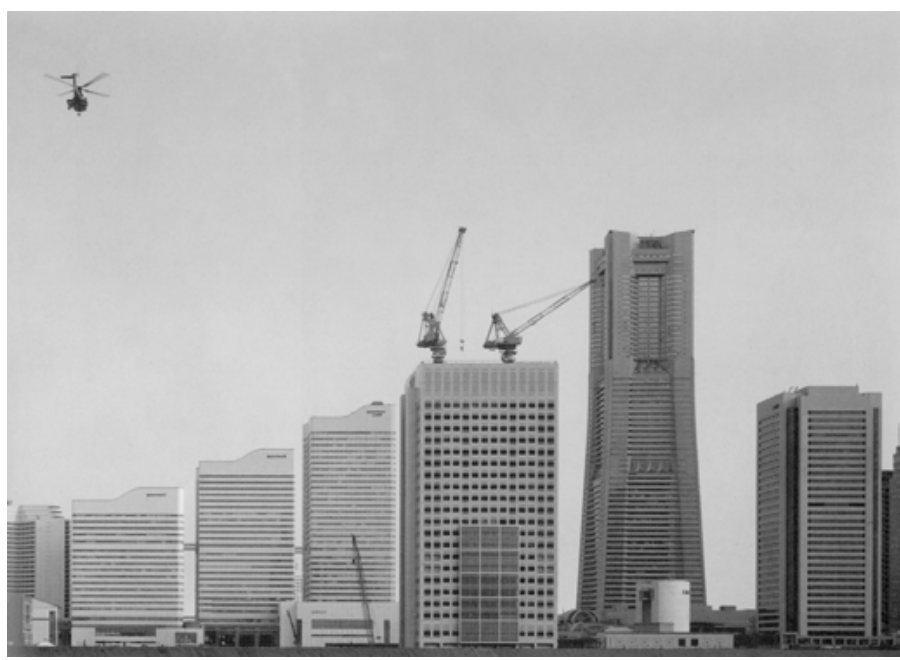

Abb.: Schilling 2000: 5 (Orig in Farbe).

der Skyline eines in den 1990er Jahren neu gebauten Komplexes in Yokohama. ${ }^{10}$ Wird in der ersten Fotografie noch gebaut, zeigt das letzte Bild den $\mathrm{Zu}$ stand nach Abschluss der Bauarbeiten (Schilling 2000: 5; 51). Zusammen entwickeln die Fotografien einen zeitlichen Bogen.

Die Fotografie auf Seite fünf zeigt, aus einiger Distanz aufgenommen, eine Skyline bestehend aus sieben Hochhäusern. Die Gebäude ragen nur wenig über die vertikale Bildmitte hinaus und geben dem blauen Himmel Raum, der in Bodennähe eine leicht rötliche Färbung annimmt, was auf den Zeitraum der Dämmerung hinweist. Die Fotografie wird an der unteren Bildkante durch einen grünen Streifen abgeschlossen, möglicherweise handelt es sich um einen deichähnlichen Wall. ${ }^{11}$ In der linken oberen Ecke der Fotografie fliegt ein Helikopter über die Szenerie. Das signifikanteste Gebäude ist ein hoher, massiv wirkender Turm auf der rechten Seite der Fotografie, der sich nach oben hin verjüngt. Der Landmark Tower in Yokohama ist als höchstes Gebäude Japans bekannt, er befindet sich auf dem 1896 konstruierten ehemaligen Werftgelände Yokohamas (vgl. Watanabe 2001: 199f.). Er wurde 1993 in einer Phase gebaut, als

»neureiche japanische Städte einer Wahrzeichen-Mentalität verfielen und im Glauben, ein bürgerliches Bewusstsein zu stimulieren, Architekten zur Errichtung idiosynkratischer Gebäude engagierten. Diese Gebäude wurden ausnahmslos zum >Stadtgespräch «, aber sie zerstörten die traditionellen Stadtbilder und oftmals auch den guten Geschmack. Ein Beispiel hierfür ist der Landmark Tower« (Coaldrake 1996: 254).

10 Der Stadtteil, in dem sich dieser Gebäudekomplex befindet heißt Minato Mirai 21, wobei minato im Japanischen Hafen, mirai Zukunft bedeutet.

11 So etwas ist nicht ungewöhnlich, denn in der Bucht von Tokyo wird viel Land durch Aufschüttung gewonnen. 


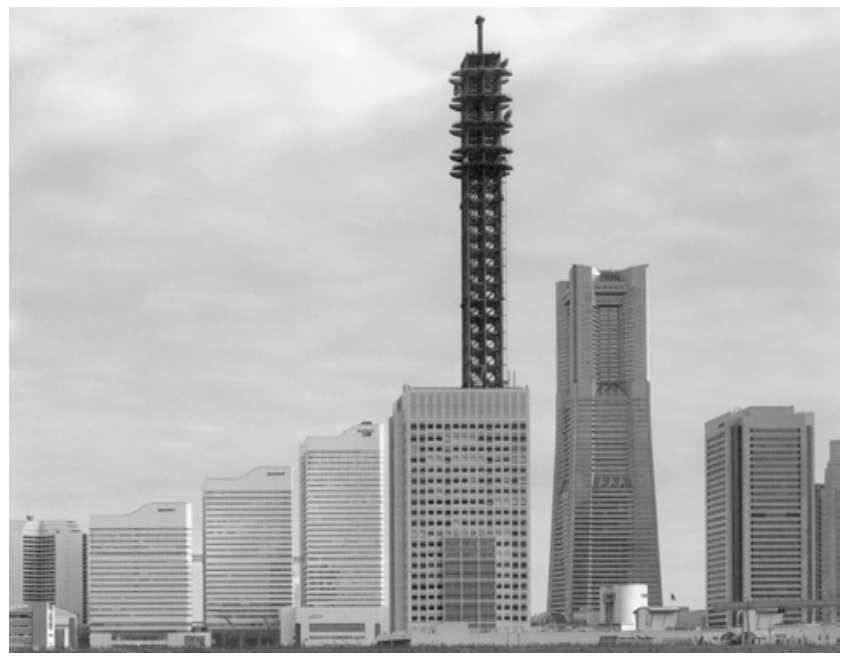

Abb.: Schilling 2000: 51 (Orig in Farbe).

Als modische Architektur treibt die vom amerikanischen Architekten Hugh Stubbins gebaute Struktur Yokohamas Image »als irgendwie schick und ein bisschen exotisch oder sogar fremdländisch« voran (Coaldrake 1996: 255). Der Urbanist Coaldrake kritisiert nicht grundsätzlich den Wunsch nach einem solchen Symbol, verweist aber auf die dahinter stehende politische Propaganda, die kritisch zu hinterfragen sei.

Schilling fotografiert dieses Wahrzeichen als ein Element unter anderen, es ist nicht das wichtigste Gebäude auf der Fotografie. Die Distanz des Turms zu den anderen Gebäuden lässt ihn aber deutlich hervortreten. Von links führt eine Reihe in der Höhe gestaffelter Hochhäuser auf den Turm hin. ${ }^{12}$ Links neben dem Landmark Tower steht etwas weiter im Vordergrund ein rechteckiges Gebäude, auf dessen Dach zwei große rote Kräne unabgeschlossene Bautätigkeiten signalisieren. Auf dem Boden, etwas links von dem Gebäude, befindet sich ein weiterer Kran. Die Anwesenheit der Kräne sowie ihre rote Farbe verschaffen dem architektonisch eher unspektakulären Bau eine erhöhte Aufmerksamkeit. Die klare Bildaufteilung und Farbigkeit verleihen Schillings Fotografie eine distanzierte und nüchterne Wirkung.

Die Fotografie auf Seite 51 zeigt die fast identische Skyline, doch inzwischen sind die Bauarbeiten abgeschlossen und vom Dach des Hochhauses links neben dem Landmark Tower erhebt sich, die gesamte Vertikale des Bildraums ausnutzend, ein gewaltiger Sendeturm mit auf verschiedenen Plattformen angebrachten Parabolantennen. Die Sendeanlage ist höher als das sie tragende Hochhaus, durch ihre dunkle Farbe hebt sie sich deutlich von den Hochhäusern ab, was ihre Präsenz noch zusätzlich unterstreicht. Oberhalb des schmalen Grünstreifens sind rechts im Bild niedrige Gebäude neu hinzugekommen. Ein Bretterzaun lässt weitere Bautätigkeiten vermuten. Der Himmel ist in dieser Fotografie leicht bewölkt, die Gebäude werden aber von rechts durch die Sonne beleuchtet, was ihre Kanten erstrahlen lässt. Die Fo-

12 Die drei ähnlichen, aber unterschiedlich hohen und breiten Hochhäuser wurden 1997 als Queens Square Yokohama gebaut (vgl. Watanabe 2001: 216). 
tografie strahlt eine ähnliche Klarheit aus wie die erste. Schilling fotografiert die Architektur mit einer erhabenen Anmutung, die nichts von einem urbanen Alltag spüren lässt. Die Gebäude erscheinen als frei stehendes Ensemble ohne Anschluss an die Stadt.

Zwischen beiden Aufnahmen liegt ein undefinierter zeitlicher Abstand, ihr Einsatz als Anfangs- und Schlussbild verweist auf das Verstreichen von Zeit. Dieser Prozess signalisiert Veränderung, die meist mit der Erwartung eines Fortschritts einhergeht. Das Verhältnis zwischen beiden Bildern bleibt dennoch merkwürdig statisch. Auch wenn der neu gebaute Sendemast eine gravierende Veränderung der Silhouette darstellt, erscheinen die Fotografien eingefroren, als ob sie nichts miteinander zu tun hätten. Sie bleiben als Einzelbilder isoliert und lassen das Verstreichen von Zeit nicht spürbar werden. Schilling demonstriert hier seine Faszination an der neuen japanischen Architektur, die Formen annimmt, wie man sie in Europa eher selten findet. Sie ist wesentlich radikaler und rücksichtsloser und meist kaum durch Bauordnungen eingeschränkt.

Mit Ausnahme des großen Interesses an neuer Architektur lassen sich in The Entropic Forest kaum Themenschwerpunkte herausarbeiten. Heiner Schillings Vorgehensweise legt eher ästhetische als inhaltliche Maßstäbe zugrunde. Sein Interesse gilt vorrangig bildnerischen Elementen und der japanischen Architektur. Ein sich wiederholendes Stilmittel ist die Sicht von oben. Zahlreiche Bilder sind von einem erhöhten Standpunkt aus gemacht. Diese Sicht betont ein Moment der Nicht-Zugehörigkeit des Fotografen, denn sie schafft eine deutlich wahrnehmbare Distanz zwischen Fotografierendem und Aufnahmegegenstand. Damit unterstreicht Schilling seine Position als externer Beobachter in einem fremden Land.

Die Fotografien auf der Doppelseite acht und neun dienen als Beispiele für Schillings Ansatz der Bildkonzeption. Die Fotografie auf Seite acht zeigt eine fast quadratische Aufsicht auf einen Innenhof. Das Zentrum der Fotografie, das gleichzeitig fast die gesamte Bildfläche einnimmt, bildet eine kreisrunde grüne Rasenfläche, die von hellgrauen, abweisend wirkenden Wänden umschlossen ist. Kleine quadratische Fenster durchbrechen die Wände zum Innenhof hin, geben aber aufgrund der starken, fast senkrechten Aufsicht der Aufnahmeperspektive keinen Blick ins Innere frei. In der rechten oberen Bildecke durchbricht ein offenes Tor die Wand. Von dort ausgehend formt ein geteertes Rechteck eine Diagonale, die sich in das grüne Rund hinein in Richtung Bildmitte erstreckt. Auf dem ordentlich eingefassten Teerstreifen sind zahlreiche Fahrräder abgestellt und deuten auf einen menschlichen Gebrauch. Der Hof beherbergt weiterhin eine kubisch anmutende Versorgungseinrichtung, deren Rohre auf die Hauswand zulaufen und dort im Rasen verschwinden. Die Fotografie zeigt einen etwas schmuddeligen ungepflegten Innenhof. Farbgebung und Komposition betonen jedoch die grafische Ausgewogenheit von Kreisform und Rechtecken im Bild selbst, was durch das fast quadratische Bildformat noch unterstrichen wird. Die Gestaltung der Fotografie unterläuft den Bildgegenstand, weil sie die formalästhetischen Aspekte in den Vordergrund rückt. Gleichzeitig kann dies auch als Statement des Fotografen gelesen werden, der selbst in eher abweisenden Situationen eine Ästhetik zu entdecken vermag. Ob dies eher eine Aussage über den Gestaltungswillen des Fotografen oder aber über die japanische Kultur ist, bleibt dahingestellt. 


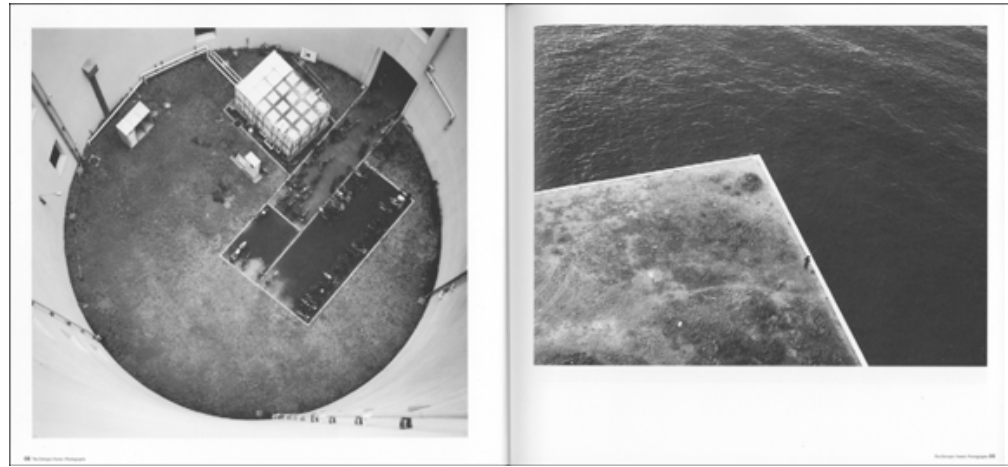

Doppelseite aus: Schilling 2000: 8/9. (Orig in Farbe).

Die Kombination mit dem Bild auf Seite neun weist auf eine Strategie der Ästhetisierung hin, denn die hier abgedruckte Fotografie unterstützt die formalästhetische Gestaltung des vorangegangenen Bildes. Das Querformat ist abermals in starker Aufsicht aufgenommen. Ausgehend von der linken unteren Bildecke ragt ein rechtwinkliger Vorsprung in eine ruhige dunkelblaue Wasserfläche hinein. Die künstlich angelegte Landzunge ist mit winterlich gelb-braunem Gras bedeckt. Auf der rechten Seite ist eine sehr kleine angelnde Figur zu erkennen. Die leicht schräg ins Bild gerückte Landzunge ist so aufgenommen, dass beide Seiten in etwa die gleiche Länge aufweisen, was ihr eine quadratische Anmutung gibt. Beide Fotografien auf der Doppelseite vereint somit der Blick von oben gepaart mit den streng geometrischen Formen von Kreis, Rechteck und Quadrat. Der Bildaufbau zeigt Schillings perfektionierten Umgang mit Spannung erzeugenden Diagonalen. Auch die Farben harmonieren sehr gut miteinander. Zudem zeigt die erste Fotografie einen von einem hellen Quadrat begrenzten eher dunklen Kreis, während in der zweiten Fotografie ein helles Quadrat in eine dunkle Fläche hinein ragt. Daraus wird deutlich, dass die Anordnung der beiden Fotografien auf einer Doppelseite so gewählt ist, um die Bildwirkung der einzelnen Fotografie zu verstärken. Die Reduktion des Bildobjekts auf formale Aspekte führt zu einer Klarheit in den Fotografien, die möglicherweise auch auf japanische Gestaltungsrichtlinien anspielt. Schilling tritt als Urheber der ästhetischen Komposition jedoch deutlich hervor.

Heiner Schilling fotografiert hauptsächlich menschenleere urbane Szenerien, gelegentlich kommen jedoch Personen mit ins Bild. Man kann sie aber kaum als Protagonisten der Fotografien bezeichnen, vielmehr erscheinen sie als Nutzer einer gebauten Welt, die sich kaum von architektonischen Details unterscheiden. Sie erlangen keine Präsenz als eigenständige Personen. Dies spiegelt sich auch in Yamagatas kurzem Einführungstext wider, der $»$ Durch den entropischen Wald. Hin zu einer Welt, in der Menschen nurmehr unbedeutende Details sind « überschrieben ist (Yamagata 2000: 35). Als Beispiel soll hier das Bild auf Seite 49 betrachtet werden. Die als Einzelbild rechtsseitig abgedruckte Fotografie im Querformat zeigt eine kaum einzuordnende Situation. Parallel zur unteren Bildkante verläuft im Vordergrund des Bildes eine halbhohe Betonmauer, vor der rechts ein Mann steht, dem Betrachter den Rücken zugekehrt. Er schaut auf einen Gegenstand, der vor ihm auf der Mauer steht. Da er diesen aber durch seine Person und zusätzlich durch sei- 


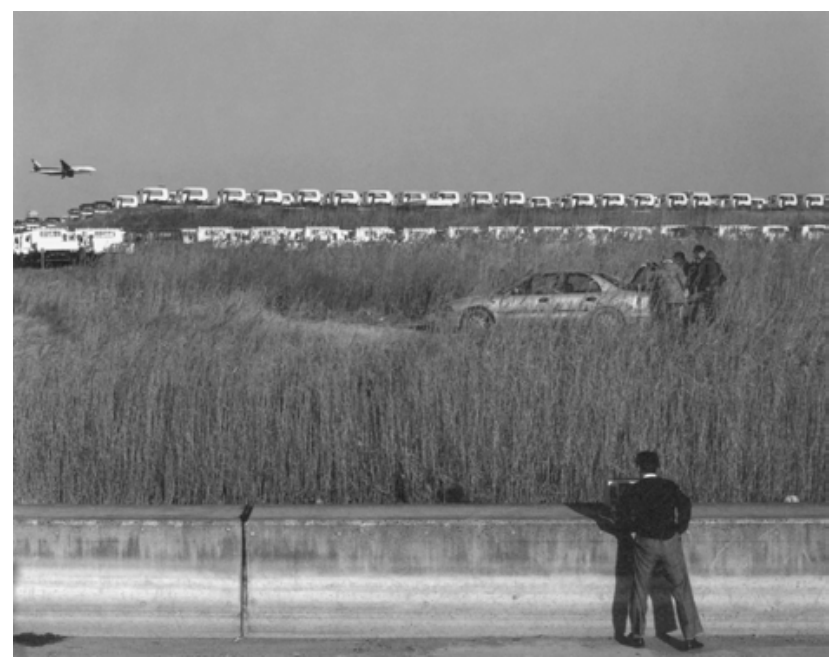

Abb.: Schilling 2000: 49 (Orig in Farbe).

nen Schattenwurf verdeckt, sieht man nicht, worum es sich handelt. Es könnte ein tragbarer Computer, ein Fernseher oder ein Koffer sein, dies bleibt aber reine Spekulation. Der Mann trägt eine graue Anzughose und einen schwarzen Pullover über dem weißen Hemd; mit den Händen in den Hosentaschen zieht er die Hose stark nach oben. Hinter der Mauer befindet sich ein mit schilfähnlichem hohen Gras bedecktes, leicht ansteigendes Feld. Das Gras ist winterlich braun. Dort steht in der vertikalen Bildmitte rechts ein silberner PKW mit geöffneter Heckklappe, um dessen Kofferraum mehrere Personen in dunkler Kleidung versammelt sind. Sie sind zu weit vom Kamerastandpunkt entfernt und teilweise vom hohen Gras verdeckt, dass man ihre Handlungen nicht erkennt. Weiter hinten im oberen Bereich des Hügels stehen in vielen Reihen weiße Kleinlaster, was auf den Werksparkplatz eines Autoherstellers hindeutet. Das obere Bilddrittel gibt den Blick auf den blauen Himmel frei. An der linken Bildkante fliegt ein großes Flugzeug sehr dicht über den Lastwagen in das Bild hinein. Die geringe Flughöhe suggeriert eine Nähe zum Flughafen. Die Fotografie gibt zahlreiche Rätsel auf, denn die Situation bleibt völlig unklar. Die Aktivität um den geöffneten Kofferraum des Privatwagens lässt illegale Handlungen möglich erscheinen, dem scheint aber die Präsenz der Person im Vordergrund zu widersprechen.

Schilling lässt die skurrile Situation für sich stehen. Die Anwesenheit der Personen im Bild ist unerlässlich, da ihre Präsenz der Fotografie ihre Rätselhaftigkeit verleiht. Die Fotografie gibt keinen Aufschluss über die Personen und ihre Handlungen. So bleiben sie abstrakt, ein Element neben Flugzeug und Kleinlastern. Schilling agiert als heimlicher Beobachter, der aus der Entfernung zuschaut und eine große Distanz hält. An einer Kontaktaufnahme mit den Menschen zeigt er sich nicht interessiert. Da auch der Kontext im Buch keine weitere Erklärung dieser Fotografie liefert, wird abermals deutlich, dass Heiner Schilling sich vorrangig am Visuellen orientiert. Die ästhetische Qualität des einzelnen Bildes steht für sich, es findet kaum eine Kontextualisierung über die anderen Bilder statt. So bleiben sowohl die Handlungen der abgebildeten Personen als auch ihre Präsenz vor Ort nebensächlich. Die 


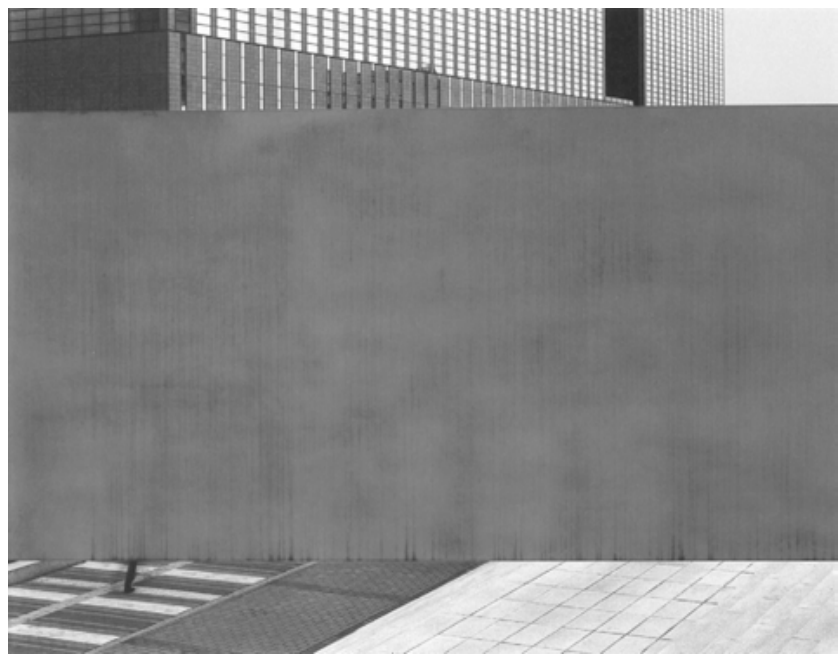

Abb.: Schilling 2000: 26 (Orig in Farbe).

Bildästhetik und die Atmosphäre des Merkwürdigen, Unheimlichen stehen im Mittelpunkt.

Die Atmosphäre in den bislang betrachteten Fotografien von Heiner Schilling verweist auf eine Stilisierung der Welt im Bild. Die Fotografien wirken zum Teil sehr künstlich. Sie zeigen wenig von einem gelebten Alltag der Gegenwart. Diese Atmosphäre steht in direktem Zusammenhang mit den Texten von Hiroo Yamagata, die einen flüchtigen Einblick in eine mögliche Zukunft des urbanen Tokyo bieten. Der Eindruck von Zukünftigem in Form von baulich realisierter Science-Fiction sticht in einigen Fotografien besonders deutlich hervor, zudem entstehen direkte Parallelen zwischen Bild und Text.

Die Fotografie auf Seite 26 gibt Rätsel auf. Das Querformat wird durch eine horizontal verlaufende Farbfläche in drei Abschnitte geteilt. Wie eine Wand zieht sich ein roter Streifen über die gesamte Breite des Bildes und bedeckt mehr als die Hälfte der Bildfläche. Ober- und unterhalb sind Fragmente des städtischen Raums zu sehen. Oben zeigt sich eine nach rechts fluchtende graue, mit Fenstern durchsetzte Hochhausfassade, unterhalb des roten Bandes ist ein Gehweg zu sehen, der aus verschiedenen Arten von Pflastersteinen besteht. Das dunkelrote Band ist durchsetzt von Farbverläufen, die sich wie Rost- oder Regenspuren vertikal durch die Fläche ziehen. Irritierend ist ein einzelnes Bein auf der linken Seite. Es sieht so aus, als ob die Person mit Ausnahme des ruhenden Beines aufgrund einer längeren Belichtungszeit in der Bewegung zum Verschwinden gebracht worden ist. ${ }^{13}$ Diese Fotografie irritiert auch deshalb, weil nicht klar ist, ob sie mit analogen fotografischen Mitteln erzeugt oder digital collagiert ist. Die sich sowohl auf den Vordergrund des roten Bandes als auch auf den Hintergrund erstreckende Bildschärfe scheint mit klassischen fototechnischen Mitteln kaum zu erreichen. Die Möglichkeit einer digitalen Collage bekräftigt den Eindruck, dass Schilling

13 Dieser Effekt erinnert an Otto Steinerts berühmtes Foto Einfußgänger von 1950, ein wichtiges Bild der subjektiven Fotografie (vgl. Frizot 1998a: 675). 
seine Bilder gezielt von ihrer Referenz abkoppelt. Ob nun tatsächlich digitale Mittel zum Einsatz kommen, ist nachrangig.

Die Fotografie steht in engem Zusammenhang mit Yamagatas Text Watching (vgl. Yamagata 2000: 45). Der Text beginnt mit der Zeile: »Ein rotes Band bedeckte den ganzen Bildschirm« (ebd.). Die Geschichte handelt von der - in einer möglichen Zukunft - neu entdeckten Option, einer flächendeckenden Beobachtung durch die Manipulation von Überwachungssystemen zu entgehen. Einer verfolgten Person gelingt es, seine Verfolger durch einen plötzlich das Bild störenden roten Streifen abzuschütteln. Das Bild auf Seite 26 wirkt wie eine unmittelbare Illustration dieses Textes. Es besteht aber auch die Möglichkeit, dass die Fotografie Yamagata zu seinem Text inspiriert hat. Dieser enge Zusammenhang zwischen Text und Bild stellt Fragen zur Autonomie von Schillings Fotoarbeit. Kann sie illustrativ genannt werden, geht es um die Erzeugung einer spezifischen Atmosphäre oder um die Dokumentation des urbanen Tokyo?

Die inhaltlichen Parallelen zu den fiktiven Texten von Yamagata rücken Schillings Fotografien in die Nähe von Fiktion, unabhängig davon, ob tatsächlich digitale Manipulationen vorgenommen werden. Seine Fotografien wirken zunächst dokumentarisch, doch die betonte Ästhetik und die Fokussierung auf das einzelne Bild verweisen eher auf Vorbilder aus der BecherSchule als auf eine fotografische Tradition nach Walker Evans. Auch wenn Schilling kein serielles Prinzip wie Thomas Struth verfolgt, entsteht der Eindruck, dass er Japan benutzt, um zu seinen Bildern zu gelangen. Mittels einer ästhetisierenden Bildsprache setzt er verschiedene Orte unterschiedslos ins Bild. Sowohl vollgestellte Innenhöfe als auch allerneuste Architekturen werden innerhalb ästhetischer Parameter erfasst. Die Fotografien zeugen von seiner Faszination für die spezifische Urbanität Tokyos sowie für die futuristisch anmutenden Architekturen auf den neu gewonnenen Landflächen in der Bucht von Tokyo. Heiner Schilling zeigt in seinen Fotografien einen Moment des Stillstandes und präsentiert die japanische Metropolenregion losgelöst von Ansichten atemloser Geschäftigkeit. In statisch wirkenden Bildern konzentriert sich Schilling auf strukturelle Elemente, die er ästhetisch ansprechend ins Bild setzt. Sein Interesse orientiert sich vorrangig an den Oberflächen des Sichtbaren. Der präzise Blick erfasst die sichtbare Welt, ohne vordergründig stereotyp Japanisches ins Bild zu rücken. Dennoch lassen sich die meisten der abgebildeten Orte und Architekturen problemlos mit der Vorstellung einer futuristischen Anmutung japanischer Großstädte und ihrer Andersartigkeit in Einklang bringen.

Schilling bleibt in all seinen Bildern ein außen stehender Betrachter. Stets behält er eine Distanz zum Gegenstand bei und versucht nicht, mit ihm in Berührung zu kommen. Die oftmals höher gelegene Aufnahmeposition unterstreicht die Situation der Fremdheit zusätzlich. Befinden sich in den meist menschenleeren Fotografien doch einmal Personen im Bild, sind sie eher von hinten oder aus großer Distanz aufgenommen, weshalb keine Wechselbeziehung zwischen ihnen und dem Fotografen entsteht. Die fotografische Perspektive betont die Fremdheit zwischen Fotograf und Abgebildetem.

Eine konkrete Verortung der Bilder mittels Bildunterschriften findet nicht statt, was davon zeugt, dass die referentielle Bedeutung nicht im Vordergrund steht. Die fiktiven Texte von Hiroo Yamagata, schaffen zudem einen Kontext, der einer atmosphärisch fiktiven Bildbetrachtung den Weg weist. Zwar sind Text- und Bildteil durch die Aufteilung auf zwei Einzelbän- 
de räumlich voneinander getrennt, dennoch lassen sich direkte Bezüge zwischen Bildern und Texten herstellen.

The Entropic Forest lässt die Faszination für das Abgebildete deutlich erkennen und gleichzeitig das künstlerische Interesse an der Gestaltung des Bildes. Für Schilling ist das Bild als Bild wichtig, aber in einer Weise, die sich vollständig von Bezügen zur realen Welt abkoppelt. Seine Annäherung an Japan kann als Strategie der Stilisierung und Fiktionalisierung beschrieben werden. Im kurzen Vorwort zu den Fotografien gibt er auf die Frage, warum er überhaupt nach Japan gefahren sei, die Antwort: »Hier bin ich also, um zu sehen, wie es ist und was es ist « (Schilling 2000: 4). Es geht um das Sehen dessen, was auf dem Bild ist und wie es aussieht. Es wird deutlich, dass es Schilling nicht um kulturelle Aspekte Japans geht. Vielmehr findet er in Japan auf visueller Ebene genau das, was er sucht, nämlich die Oberflächen, die er sich für seine Bilder wünscht. Weil es dort so aussieht, ist Japan der $\mathrm{Zu}$ sammenhang, in dem er seine Bilder finden kann. In diesem Sinne sind Japan oder die japanische Kultur nicht mehr wichtig. Es zählt ausschließlich die Visualität dessen, was die Welt an Sichtbarkeit zur Verfügung stellt. Diese lässt sich in eine gesteigerte Sichtbarkeit im Bild transformieren.

Die Konzentration auf das Einzelbild, die Betonung des Ästhetischen, der direkte Bezug zu fiktiven Texten sowie die Möglichkeit digitaler Manipulation zeugen von einem dezidiert künstlerischen Ansatz. In diesem Sinne versucht The Entropic Forest gar nicht erst, kulturelle Dimensionen Japans zu erschließen. Das Fremde als Fremdes ist eine Kategorie, die hier keine Relevanz besitzt. Die Konzeption von Schillings Arbeit verweist auf eine fotografische Auseinandersetzung, die trotz aller formaler Unterschiede mit dem anderer Becher-Schüler vergleichbar ist. Als solche ist sie in die Kategorie der konzeptuellen Dokumentarfotografie einzuordnen (vgl. Teil I, Abschnitt 4.1.2.).

\subsection{European Eyes on Japan}

Ein herausragendes Beispiel für das große Interesse an einem Außenblick auf Japan ist das 1999 initiierte Projekt European Eyes on Japan. Im Rahmen dieses noch andauernden Projekts werden europäische Fotografen jeweils für einen Zeitraum von ein bis zwei Monaten eingeladen, um eine Arbeit in einer der 47 japanischen Präfekturen zu fotografieren. ${ }^{14}$ Ziel ist es, fotografische Darstellungen aller Präfekturen zu produzieren und damit ein umfassendes Bild Japans zu zeigen. Als Gesamtkonzept entspricht das Projekt einem archivalischen Ansatz der künstlerischen Dokumentarfotografie (vgl. Teil I, Abschnitt 4.1.2.). Die im Rahmen des Projekts entstandenen Fotografien werden in Japan und in europäischen Ländern ausgestellt sowie in einer inzwischen zehn Bände umfassenden Publikationsreihe veröffentlicht. ${ }^{15}$ Die Bände 1-7 beinhalten Fotografien von 23 Präfekturen.

14 Teilweise fotografieren die ausgewählten Fotografen auch in mehreren Präfekturen oder mehrere Fotografen fotografieren in derselben Präfektur.

15 Die Bücher sind allerdings in Europa kaum im Buchhandel erhältlich oder in Bibliotheken präsent. Die Ausstellungen sind vor allem in Japan, in Europa unter anderem in Frankreich und Belgien gezeigt worden. Obwohl auch deutsche Fotografen beteiligt sind, gab es bislang keine Ausstellung in Deutschland. In- 
Das langfristig angelegte Projekt European Eyes on Japan schickt europäische Fotografen auch in weit abgelegene Regionen, die selten in fotografischen Arbeiten über Japan präsent sind. Weil sich sehr viele verschiedene Fotografen mit den ihnen jeweils eigenen Interessen und Ansätzen bislang in der Japanfotografie unterrepräsentierten Gebieten widmen, entsteht in der Gesamtschau ein sehr vielschichtiges und komplexes Bild Japans. Gezielt werden die regionalen Unterschiede innerhalb Japans berücksichtigt, denn für Europäer repräsentiert die Metropole Tokyo oftmals das gesamte Land, was jedoch einer sehr verkürzten Sichtweise entspricht (vgl. Bauret 2000: 6). Gleichzeitig ist aber keine objektivierende Darstellung Japans beabsichtigt, denn den eingeladenen Fotografen ist es freigestellt, mit welchen Intentionen und thematischen Schwerpunkten sie in Japan fotografieren. Die einzelnen Beiträge sind dementsprechend unterschiedlich. Aufgrund der Gesamtkonzeption des Projekts steht es jedoch nicht im Mittelpunkt meiner Betrachtungen künstlerischer Dokumentarfotografie Japans.

»Das Projekt geht einher mit der Schaffung von Kunstwerken im Auftrag, die in diesem Sinne eine besondere Rolle im Gesamtwerk der Künstler einnehmen: Die Arbeiten werden in einem festgelegten Zeitraum entwickelt, die Bedingungen werden von einer den Auftrag vergebenden Institution festgelegt und die Publikation (das Buch, die Ausstellung) der Resultate weicht möglicherweise von den Intentionen des Fotografierenden für seine/ihre Arbeit ab« (Frisinghelli 2003: 103).

Die in European Eyes on Japan vertretenen Künstler arbeiten für nur wenige Wochen innerhalb eines festgelegten Gebiets. Die im Katalog abgebildeten Fotografien stellen eine kuratorische Auswahl dar, auch sind in einem Katalog die Arbeiten von drei bis sechs Fotografen zusammengefasst. Damit soll keine Wertung über die Qualität der Arbeiten abgegeben werden, die insgesamt sehr hoch ist. Die Voraussetzungen unterscheiden die im Rahmen von European Eyes on Japan entstehenden fotografischen Projekte jedoch nachhaltig von solchen, die aus eigener Initiative heraus entwickelt, realisiert und deren Resultate im Sinne des Künstlers in einem Künstlerbuch präsentiert werden.

In den bis zum Jahr 2007 erschienenen sieben Bänden des Projekts European Eyes on Japan sind 31 Künstlerinnen und Künstler vertreten, die in 23 Präfekturen fotografiert haben. Um einen kleinen Einblick in die unterschiedlichen Arbeitsansätze und Strategien der Annäherung an Japan zu geben, sollen hier exemplarisch drei Künstler vorgestellt werden. Aus dem vielfältigen Spektrum der 31 Ansätze werden solche Arbeiten vorgestellt, die unterschiedliche Strategien im Umgang mit Japan verfolgen und somit eine große Bandbreite der Möglichkeiten zum fotografischen Umgang mit dem Fremden aufzeigen.

\subsubsection{Naomi Tereza Salmon}

Die in Weimar lebende israelische Künstlerin Naomi Tereza Salmon (*1965) ist eine der ersten Künstlerinnen, die im Rahmen von European Eyes on Japan im September 1999 nach Japan reist. Sie hat den Auftrag, in Toyko und 
seinen Vororten zu fotografieren. Das Projekt Japan Tomography ${ }^{16}$ zeugt von einer sehr individuellen Herangehensweise an das Thema. Salmon fotografiert nicht die Straßen der Stadt, die Menschen, Häuser oder Werbeplakate, sondern sie sammelt Dinge. Sie sucht kleine Objekte, wie man sie in sehr unterschiedlichen Läden in der japanischen Hauptstadt - und vermutlich auch landesweit - kaufen kann, die sie erst zu Hause in Weimar unter Studiobedingungen auf weißem Hintergrund fotografiert. Damit setzt sie ihre bereits erprobte Arbeitsweise fort, denn in den fünf Jahren zuvor hat sie sich verschiedenen Themenbereichen auf diese Weise genähert (Salmon 2000: 70). Ihre ganze Aufmerksamkeit gilt den Objekten, die die vielschichtigen Beobachtungen, die sie in Tokyo macht, wiedergeben können. Ihre Suche nach den Dingen steht unter der Fragestellung: »Wie Kultur einfangen?« (ebd.). Sie sucht zeitgemäße, gebräuchliche Objekte, die sie meist in ihrer Originalverpackung belässt (vgl. ebd.: 71). Im ersten Band von European Eyes on Japan sind Fotografien von 95 Objekten abgedruckt, deren Bildunterschriften jeweils das Objekt selbst sowie den Ort des Einkaufs dokumentieren. In den Fotografien bringt Salmon die Objekte auf ein einheitliches Maß, was einen Grad der Abstraktion einführt. Einige Dinge sind recht leicht zu identifizieren, während andere wegen fehlender Sprachkenntnisse sowie kultureller Fremdheit rätselhaft bleiben. Die Bildunterschriften benennen die Objekte, deren Funktion sich Europäern jedoch nicht immer erschließt. Die textliche Erklärung vermag, die anlässlich der Gegenstände empfundene Fremdheit zu reduzieren.

Salmon sucht die Gegenstände in sehr unterschiedlichen Geschäften aus, so dass sie in ihrer Auswahl zahlreiche Bereiche der Kultur streift. Neben Küchenzubehör, kulinarischen Spezialitäten, die abgepackt im Supermarkt erhältlich sind, finden sich Lifestyle- und Büroartikel ebenso wie Kinderspielzeug, traditionelles Schuhwerk, Kosmetikprodukte oder Souvenirs. Auf diese Weise verschafft Salmon den Betrachtern einen umfangreichen Einblick in die japanische Warenwelt. Die Künstlerin vermittelt aber nicht nur über die ausgewählten Produkte einen Einblick in die japanische Kultur, sondern auch über die Verpackungen, die in Japan einen großen Stellenwert einnehmen. Salmons Arbeit ist sehr konzeptuell, die Fotografin wählt eine Bildsprache, die die Objekte in den Vordergrund treten lässt und im Sinne einer Sachfotografie sehr objektiv wirkt. Durch die Nivellierung der Größenunterschiede und das Herauslösen der Objekte aus ihrem Kontext erhalten sie eine eigenwillige Präsenz. Die Fotografie tritt hingegen in den Hintergrund. Das fotografische Bild wird transparent und gibt den Blick auf das Objekt und dessen Verpackung frei.

Abbildung zwei zeigt die Verpackung von Räucherstäbchen, was sich dem westlichen Betrachter ohne Blick auf die Bildunterschrift jedoch kaum erschließt (vgl. Salmon 2000: 72). Die Grafik der Verpackung verweist auf japanische Holzschnitte aus dem achtzehnten und neunzehnten Jahrhundert. Dies weckt Assoziationen zum traditionellen Japan. Die Abbildung zeigt eine Verkaufssituation von Räucherstäbchen, wie sie auch heute noch anzutreffen

16 ») Tomography< is a medical term (as in >computer tomography<, or C.T.). Tomography shows a transparent with several smaller images of the photographed (or scanned) body part in all its layers or >slices`, >Tomo $<$ also happens to have a meaning in Japanese: it stands for >together, things surrounding someone« (Salmon 2000: 71). 

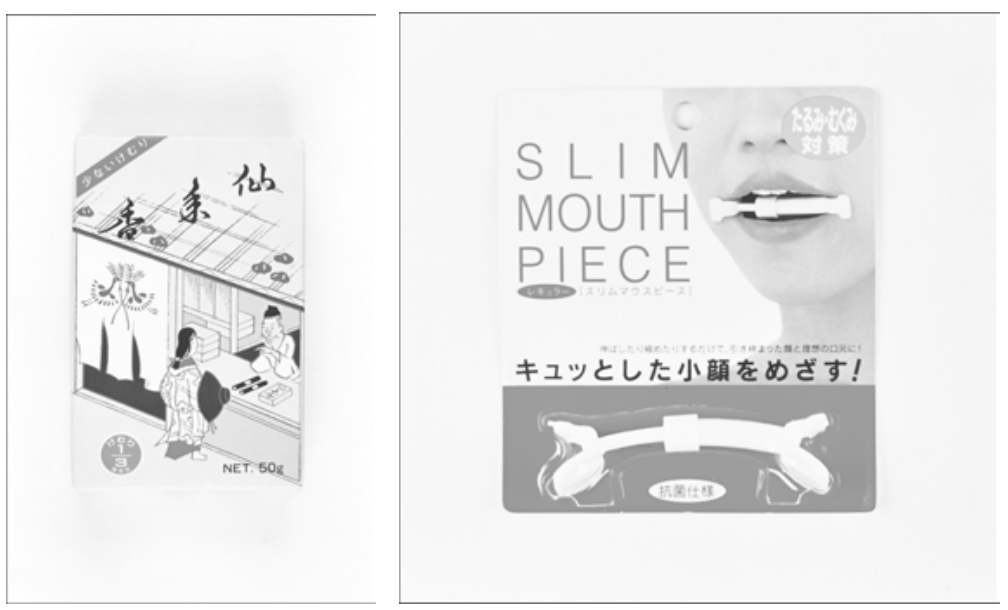

"2. Box with incense sticks found in a supermarket, Kita-Aoyama». »14. 'Slim Mouth Piecer device for stretching slim mouth, found in a lifestyle department store, Shibuya (Salmon 2000: 72; 74; Orig. in Farbe).

ist. Ohne Kenntnis darüber, dass Räucherstäbchen traditionell an Tempeln und Schreinen verkauft werden, erschließt sich dem westlichen Betrachter die Bedeutung des Abgebildeten jedoch nicht. Die Oberfläche des Bildes bleibt deshalb undurchdringlich und fremd.

Abbildung vierzehn zeigt einen merkwürdig anmutenden Gegenstand, der der Weitung eines schmalen Mundes dienen soll (ebd.: 74). Die Fotografie auf der Verpackung des in Plastik eingeschweißten Produkts zeigt dessen Anwendung. Allein die Existenz eines solchen Objekts lässt den westlichen Betrachter schmunzeln. Gleichzeitig entsteht ein Gefühl von Fremdheit, denn aus westlicher Sicht erscheint der Nutzen des Produkts mindestens fragwürdig. Es scheint die Annahme zu bestätigen, dass Japaner anders sind und merkwürdige Vorstellungen von Schönheit pflegen. Die Ernsthaftigkeit, mit der der Gebrauch auf dem Verpackungsbild demonstriert wird, verweist auf ein kulturelles Phänomen, dessen Schönheitsideal offensichtlich schmale Münder als hässlich empfindet. Die englische Beschriftung demonstriert, dass Lifestyleprodukte mit einer Internationalisierung verbunden sind, was offenbar den Verkauf fördern soll. Möglicherweise ist es aber auch aus Amerika importiert. Weil Salmon dieses Produkt auswählt, es aber gleichermaßen fotografisch isoliert, bleibt die Fotografie insgesamt vage. Möglich wäre beispielsweise, dass das Objekt auch in Japan eher als Scherzartikel verkauft wird, was sich dem Betrachter aber nicht erschließt. Die vielen Spekulationen anlässlich dieser Fotografie und des dort abgebildeten Gegenstands verdeutlichen, dass trotz der Sachlichkeit der Aufnahme zahlreiche Unbestimmtheiten bleiben. Hier wird deutlich, dass sich jenseits des Abgebildeten eine Wirkung entfaltet, die Aspekte kultureller Fremdheit anklingen lässt. Es offenbart sich die Problematik der einzelnen Fotografie, Zusammenhänge herzustellen. Das fotografische Herauslösen eines Produkts aus dem Zusammenhang verweist auch auf die begrenzten Möglichkeiten des fotografischen Bildes.

Abbildung 53 zeigt einen Schlüsselanhänger mit der Plastik-Imitation eines japanischen Nationalgerichts: Tempura. Es gibt zahlreiche Möglichkeiten, 


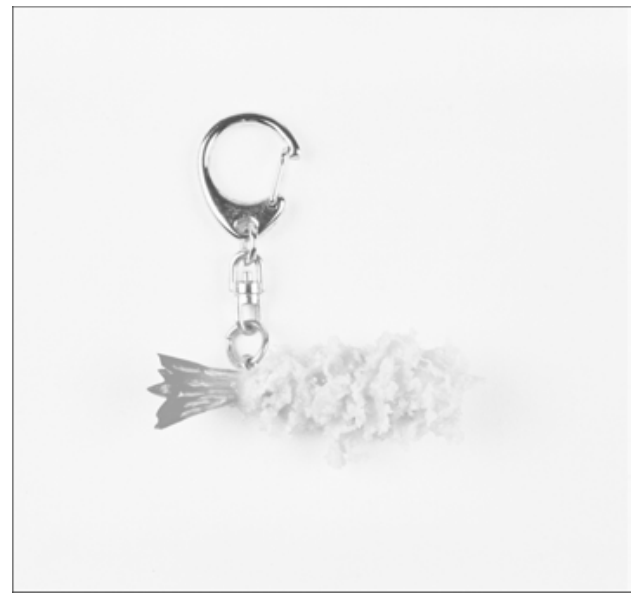

»53: Key-ring with plastic imitation of tempura, found in a store for plastic food imitation, Kappabashi« (Salmon 2000: 80; Orig. in Farbe).

dieses Objekt zu sehen: Zunächst ist es ein schlichtes Souvenir. Dann kann es dazu herangezogen werden, die japanische Praxis der Anfertigung von Plastikreproduktionen von Lebensmitteln sinnfällig zu zeigen, die in der Regel in Restaurants die Spezialitäten anpreisen. Als Verweis auf die Ernährung betont es den Stellenwert der Essenszubereitung in der japanischen Kultur. Fisch ist ein wichtiges Nahrungsmittel, was im Garnelenschwanz repräsentiert ist. Der Fundort Kappabashi - das weiß derjenige, der über genaueres Wissen von Tokyo verfügt - verweist schließlich auf einen Tokyoter Stadtteil, in dem fast ausschließlich Geschäfte angesiedelt sind, die Küchen- und Restaurantzubehör verkaufen. Je nach Vorwissen eröffnet das Objekt im Betrachter eine Reihe von Assoziationsmöglichkeiten zur japanischen Kultur. In der Interpretation geht es jedoch stets um das Objekt selbst, nicht aber um das Bild.

In Salmons Arbeit erweist sich die Auswahl der Objekte als entscheidend für die Wirkung. Der sachliche Aufnahmestil lässt die Fotografie hinter das dargestellte Objekt treten. In dieser Art des Umgangs wird die komplexe und nicht unproblematische Beziehung zwischen der Fotografie als Bild und der Fotografie als Zeichen deutlich. Geht es in der Betrachtung der Fotografien ausschließlich um die dargestellten Objekte oder geht es gerade um die Möglichkeit der Fotografie, eine Wirkung zu erzeugen, die über das Dargestellte hinausweist, beispielsweise indem etwas aus dem angestammten Kontext entfernt und in einen neuen Zusammenhang gestellt wird? Salmons Arbeit dokumentiert zwar die Objekte selbst, gleichzeitig werden die Fotografien aber auch zur Begegnung mit Fremdheit. Denn weder in der Betrachtung der Fotografien noch unter Hinzuziehen der Bildunterschriften kann die Arbeit vollständig verstanden werden. Salmon spielt gleichermaßen mit der deutlich erkennbaren Referenz einerseits und den sich entfaltenden Wirkungen andererseits, die als Herausforderung für den Betrachter bestehen bleiben. Salmons Ansatz ist konzeptuell, die Ambivalenz zwischen Referenz und Wirkung zeugt jedoch von einer dokumentaristischen Herangehensweise. Als fotografische Arbeit über Tokyo stellt sie eine innovative Möglichkeit im Umgang mit dem Fremden dar. Gleichzeitig offenbart Salmons Arbeit die 
Offenheit von European Eyes on Japan. Salmon überträgt ihre erprobte konzeptuelle Herangehensweise auf das Japanprojekt und setzt somit ihre bewährte künstlerische Praxis fort. Dies stellt eine mögliche Strategie zum Umgang mit dem Fremden dar.

\subsubsection{Hans van der Meer}

Alle bei European Eyes on Japan eingeladenen Fotografen sind letztlich mit einem ähnlichen Problem konfrontiert: Für kurze Zeit sind sie Gast in einem Land, mit dem sie sich unter Umständen noch nie zuvor beschäftigt haben. Hier suchen sie nach Möglichkeiten, den stereotypen Ansichten, die auch in den Broschüren für Touristen verbreitet werden, etwas Eigenständiges entgegen zu setzen. Auch der niederländische Fotograf Hans van der Meer (*1955) schreibt: »Ich suchte nach einer Art von Wahrheit in Fotografien, der Wahrheit hinter den stereotypen Fotografien von Angestellten und von der Jugendkultur oder den Touristen-Broschüren der Präfektur Okayama« (The EUJapan Fest Japan Committee 2002: 57).

Van der Meer reist im Juni/Juli 2001 in die Präfektur Okayama, ${ }^{17}$ sein Projekt ist in insgesamt 23 Fotografien in Band vier der Publikationsreihe abgedruckt. Für seine Arbeit orientiert er sich an den lokalen Gegebenheiten der eher ländlichen/kleinstädtischen Region. Einige Tage nach seiner Ankunft gelingt es ihm, einen Weg zu finden, Menschen in ihrer Umgebung zu fotografieren (vgl. ebd.). In verschiedenen Orten der Präfektur fotografiert er aus einiger Distanz jeweils eine einzelne Person, die er ins Bildzentrum rückt. Die fotografierte Figur ist immer der einzige Mensch auf der Fotografie. Dadurch, dass van der Meer einen weit entfernten Kamerastandpunkt wählt, ist die Person meist nicht sehr gut zu erkennen. Kleidung und Ort verweisen aber auf den Beruf oder die Motivation, sich an diesem Ort aufzuhalten. Einen guten Eindruck bekommt der Betrachter von der Umgebung, der van der Meer stets viel Raum gibt. Die Fotografien sind aus unterschiedlichen Entfernungen gemacht, manchmal auch von einem erhöhten Kamerastandpunkt aus. So erhält der Betrachter einen abwechslungsreichen und umfassenden Eindruck der regionalen Gegebenheiten. Durch die räumliche Weite seiner Fotografien widersetzt sich Hans van der Meer der Annahme, Japan biete seinen Bewohnern nur wenig Raum.

Van der Meer gibt seinem Projekt - anders als Salmon - keinen Titel. Die hochformatigen Fotografien sind jeweils mit einer Orts- und Datumsangabe (Monat und Jahr) versehen. Weitere Informationen ergeben sich aus den Fotografien selbst. Die Fotografie aus Ushimado vom Juni 2001 zeigt eine Situation auf dem Land (ebd.: 35). Den Vordergrund ganz ausfüllend erstreckt sich ein üppig grün bewachsenes Feld bis hinein in die im Hintergrund liegenden Hügel. In der Bildmitte steht eine verhüllte und mit breitkrempigem Strohhut bekleidete Person, die in den Armen eine Art Kürbis hält. Ob es sich um einen Mann oder eine Frau handelt, ist nicht zu erkennen. Links stehen einige Hütten und Schuppen an einer sich am Feldrand entlang schlängelnden schmalen Straße, die von Strommasten gesäumt ist. Die rechts und links im Hintergrund an das dicht bewachsene Feld angrenzenden Flächen scheinen brach zu liegen. Die Hügel im Hintergrund sind von Büschen

17 Die Präfektur Okayama liegt im Südwesten der Hauptinsel Honshu nördlich der Insel Shikoku. 

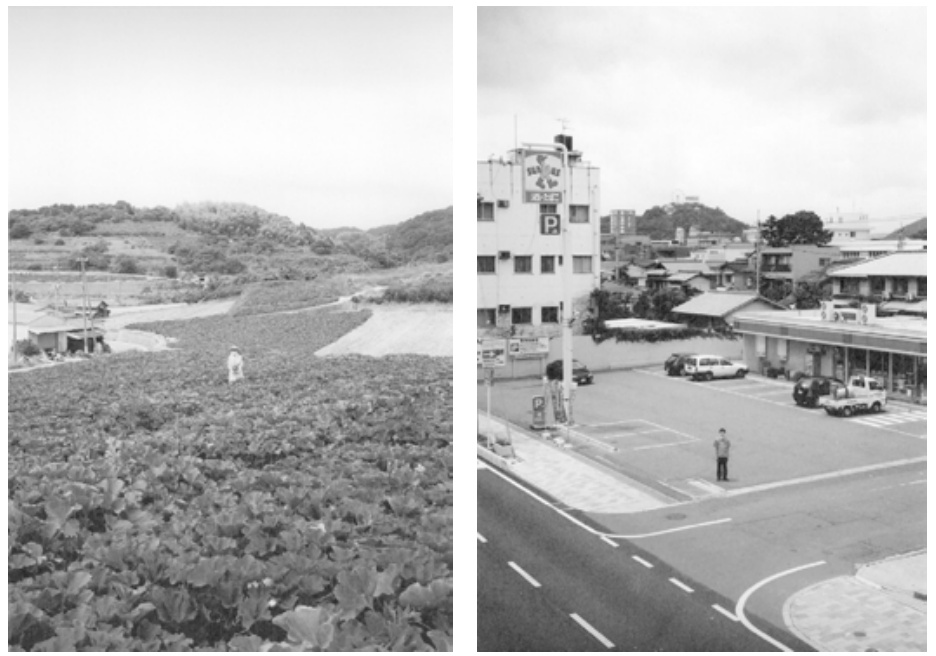

Abb.: Hans van der Meer: »Ushimado, June 2001 «; »Okayama City, July 2001" (The EU-Japan Fest Japan Committee 2002: 35; 43; Orig. in Farbe).

und Gras bewachsen. Dem Betrachter eröffnet sich hier eine ländliche Idylle, die auf kleinteiligen Ackerbau im Familienbetrieb deutet. Aufgrund der weiten Entfernung lässt sich wenig zur Person in der Bildmitte sagen; die Landschaft wirkt hingegen aufgrund des saftig grünen Feldes fruchtbar. Van der Meer erzählt in dieser Fotografie mehr über das Land und seine Nutzung als über dessen Bewohner.

Seite 43 zeigt eine Fotografie aus Okayama City vom Juli 2001. Aus leichter Obersicht fotografiert van der Meer einen auf dem Parkplatz eines kleinen Verbrauchermarktes (convenience store) stehenden Mann. Die Farbigkeit seiner Kleidung lässt ihn als Angestellten des Marktes erkennen, denn grün und rot wiederholen sich sowohl am Vordach des eingeschossigen Gebäudes als auch auf dem Parkplatzzeichen mit dem Logo der Markt-Kette. Der Mann hat eine militärische Haltung angenommen. ${ }^{18}$ Der Parkplatz befindet sich an einer kleinen Straßenkreuzung mit schmalen Straßen. Links hinter dem Parkplatz steht ein mehrstöckiges gesichtsloses Wohnhaus. Rechts von diesem eröffnet sich der Blick über eine wechselnd mit kleineren Wohnhäusern - teils im japanischen Stil - und Appartement-Gebäuden bebaute Fläche hin zu einem grün bewachsenen Hügel, an dessen Spitze ein kleines Riesenrad erkennbar ist. Die lockere Bebauung und der Hügel im Hintergrund deuten auf eine kleinstädtische Situation. Die gesamte Szenerie vermittelt eine ruhige und wenig verdichtete Atmosphäre. Der Blick von oben zeigt die gemischte Bebauungssituation, in der traditionell japanische Wohnhäuser und höhere Appartement-Gebäude in direkter Nachbarschaft stehen. In den umliegenden Hügeln wird für Möglichkeiten der Freizeitgestaltung gesorgt, worauf der kleine Vergnügungspark hinweist. Van der Meer gelingt es mit seiner Fotografie, viele Details einer japanischen Kleinstadt ins Bild zu setzen. In der eingehenden Betrachtung lassen sich Klimaanlagen und Werbe-

18 Van der Meer bemerkt: „Some of them stood to attention without being asked to do so« (The EU-Japan Fest Japan Committee 2002: 57). 


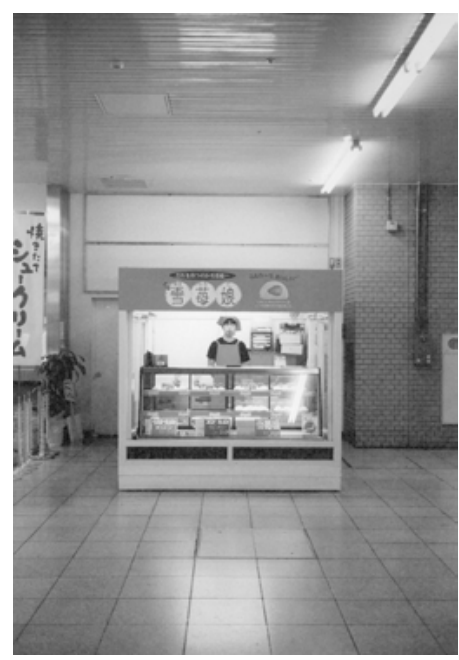

Abb.: Hans van der Meer: "Okayama City, July 2001" (The EU-Japan Fest Japan Committee 2002: 51; Orig. in Farbe).

schilder, Telegrafenmasten und Ziegeldächer eingehend studieren. Ohne scheinbar vordergründig das Augenmerk auf etwas Bestimmtes zu richten, eröffnet van der Meer durch seinen Blickwinkel ein breites Panorama, das sich der Betrachter selbstständig erschließen kann.

Als letzte Fotografie von Hans van der Meer soll hier die einzige Innenaufnahme betrachtet werden. Das Bild auf Seite 51 stammt ebenfalls aus Okayama City vom Juli 2001. Hier geht van der Meer wesentlich näher an die Person heran, was auch das Umfeld stärker eingrenzt. Eine Verkäuferin in rosafarbener Schürze und Kopftuch steht in einem mobilen Stand, der sich vermutlich in einer Bahnhofshalle befindet. Sie ist durch das im Stand befindliche Licht hell beleuchtet. In der Glasvitrine vor ihr sind japanische SüBigkeiten ausgelegt. Vermutlich handelt es sich um eine regionale Erdbeerspezialität, denn auf dem ebenfalls rosafarbenen Schild über dem Stand sind neben japanischen Zeichen auch stilisierte Erdbeeren zu sehen. Hinter der Verkäuferin finden sich einige Verpackungsmaterialien. Das Umfeld um den Stand wirkt klar und aufgeräumt. Der geflieste Fußboden ist sehr sauber, nichts liegt herum. Am linken Bildrand sind einige Pfosten sehr ordentlich aufgereiht, die als Absperrung verwendet werden können. Dort steht auch eine Grünpflanze. Im Anschnitt ist eine gelbe hochformatige Fahne mit japanischer Beschriftung zu sehen. Die Bahnhofshalle ist mit Neonröhren erleuchtet. Am rechten Bildrand verläuft eine beigefarbene Backsteinwand, an der einige Stromleitungen mit Schaltereinrichtungen sichtbar entlang laufen.

Obwohl das Umfeld hier aufgrund der Innenraumsituation reduziert ist, vermittelt die Fotografie dennoch einen umfassenden Einblick in die Situation. Wer schon einmal in Japan mit der Bahn durch das Land gereist ist, wird sich an viele solcher Stände erinnern. Denn zur japanischen Kultur gehört es dazu, Familie und Kollegen von Reisen regionale Spezialitäten mitzubringen.

Mit seinem Projekt verfolgt Hans van der Meer einen Ansatz, der sehr unterschiedliche Situationen in ein serielles Format bringt. Die inszenierte Figur in der Bildmitte schafft eine Konstanz, die sich durch alle Fotografien 
der Serie zieht. Die Umgebungen, in denen die Personen angetroffen werden, vermitteln sehr vielfältige Eindrücke der Region. Es gelingt van der Meer, die Kleinstadt mit seinen Vororten und den umliegenden Dörfern ins Bild zu setzen und zwischen unterschiedlichen Orten der Präfektur eine visuelle Verbindung herzustellen. Das Konzept entwickelt er aus seinen ersten Eindrücken heraus. Insofern geht er auf die lokalen Gegebenheiten ein und gelangt dennoch zu einer stringenten Umsetzung innerhalb seines Projekts. Die konzeptuelle Herangehensweise erinnert an die Arbeit von Thomas Struth. Weil sie aber nicht primär auf Vergleichbarkeit angelegt ist, sondern vielmehr als Hilfsmittel dient, die Vielfältigkeit der Region in Bilder zu fassen, ist sie etwas anders gelagert als Struths Ansatz. Van der Meers Bilder bieten Einblicke in die Präfektur Okayama und wenden sich ab von Japan-Klischees. Sie erklären nichts und bemühen sich nicht, Fremdheit auflösen. Die lokalen Gegebenheiten werden sichtbar gemacht. In der Kürze der Zeit seines Aufenthaltes vertraut der Fotograf vorrangig seinen visuellen Wahrnehmungen. Scheinbar kann der Betrachter an van der Meers Einblicken als Fremder in der japanischen Provinz teilhaben.

\subsubsection{Margherita Spiluttini}

Im Herbst 2002 reist die österreichische Fotografin Margherita Spiluttini (*1947) für drei Wochen in die auf der japanischen Südinsel Kyushu gelegene Präfektur Oita. Die Gefahr, in stereotypen Japanbildern zu verharren, sieht sie als Motivation, sich »vollends in die Hände des Unbekannten zu begeben« (The EU-Japan Fest Japan Committee 2003: 101). Spiluttini reist vor allem mit dem Auto durch die Präfektur und fotografiert hauptsächlich Landschaften, in denen der menschliche Eingriff sichtbar ist sowie Dörfer, Kleinstädte und die allgegenwärtigen Zeichen der Religiosität, die sie sehr faszinieren (vgl. ebd.). Ihrer Arbeit liegt kein konkret greifbares Konzept zugrunde, vielmehr lässt sie sich von der rein visuellen Erforschung der Gegend treiben. Insofern finden sich neben Landschaftsaufnahmen beispielsweise auch Innenansichten aus Tempeln oder traditionellen Geschäften. Fast ausnahmslos sind die Fotografien menschenleer, nur selten sind Personen mit abgebildet.

Auch Margherita Spiluttini gibt wie Hans van der Meer ihrem Projekt keinen eigenen Titel. Ohne Bildunterschriften erhält der Betrachter lediglich die Information, dass die Fotografien im Oktober und November 2002 in der Präfektur Oita gemacht worden sind. Insgesamt 25 Fotografien sind im fünften Band der Publikationsreihe abgedruckt.

Die Fotografie auf Seite 75 zeigt eine Baustellensituation. Ein terrassierter Hang wird mit Hilfe eines quadratischen Betongitters abgestützt. Das helle Raster fasst die schwarze Erde ein, um Schutz vor Erdrutschen zu bieten. Fotografiert ist die Szenerie mit Arbeitern in Baggern und Baufahrzeugen von der gegenüber liegenden Straßenseite aus. Angeschnitten im Vordergrund liegt ein frisch angelegter Gehsteig, die Straße nimmt das untere Drittel der querformatigen Fotografie ein. Oberhalb der terrassierten Erde befindet sich dichter, grüner Wald. Schwarze Telegrafendrähte laufen in der oberen Bildhälfte quer durch das Bild. Am Fuß des Hangs verrichten behelmte und uniformierte Arbeiter nicht eindeutig zuzuordnende Tätigkeiten. Rechts im Bild leiten Pfeile den Verkehr um. Spiluttini zeigt eine alltägliche Baustellensituation. Lediglich die Art der Befestigung des Hangs wirkt sehr massiv. 


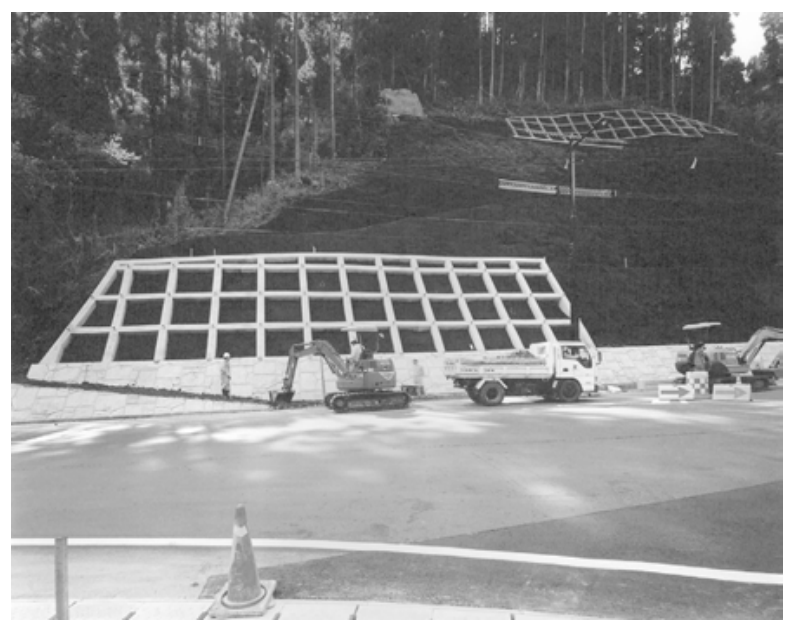

Abb.: Margherita Spiluttini (The EU-Japan Fest Japan Committee 2003: 75; Orig. in Farbe).

Allerdings sind solche Hang- und Uferbefestigungen aus den Bildern des japanischen Fotografen Toshio Shibata bekannt (vgl. z.B. Shibata 1999).

Die Szene zeigt einen Einblick in die Landschaftsgestaltung zur Verhinderung von Erdrutschen. Ist in dieser Fotografie noch Erdreich zu sehen, zeigt die Fotografie auf Seite 85 eine bereits beendete Baumaßnahme. In der Bildmitte erhebt sich wie ein Felsen die betonierte Abbruchkante eines Hügels, der in der Mitte mit einem der ersten Fotografie vergleichbaren Betongitter abgestützt ist. Die Fotografie zeigt eine herbstliche Mittelgebirgslandschaft mit dicht bewachsenen Hängen. Im Vordergrund verläuft ein Trampelpfad entlang eines kaum sichtbaren Flussbettes, braunes Gras und gelb blühende Gewächse säumen den Pfad. Am rechten Bildrand überquert eine rote Stahl-

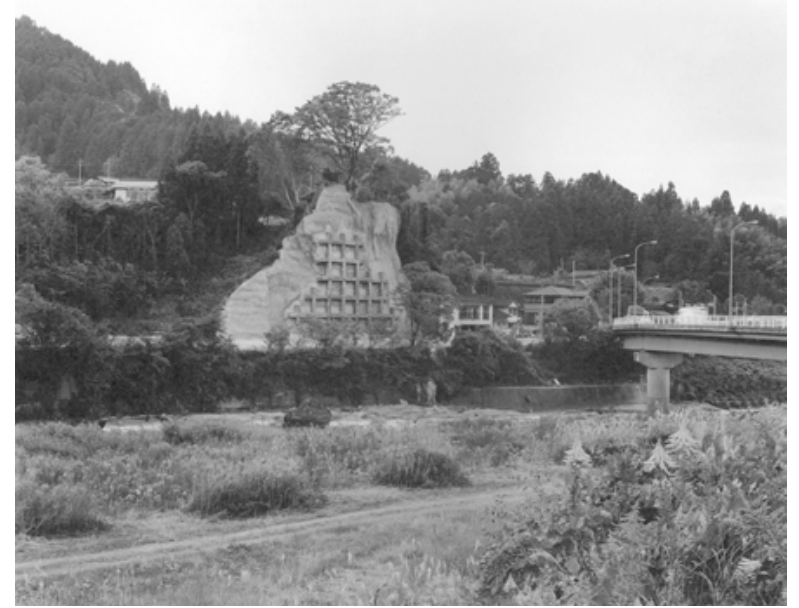

Abb.: Margherita Spiluttini (The EU-Japan Fest Japan Committee 2003: 85; Orig. in Farbe). 


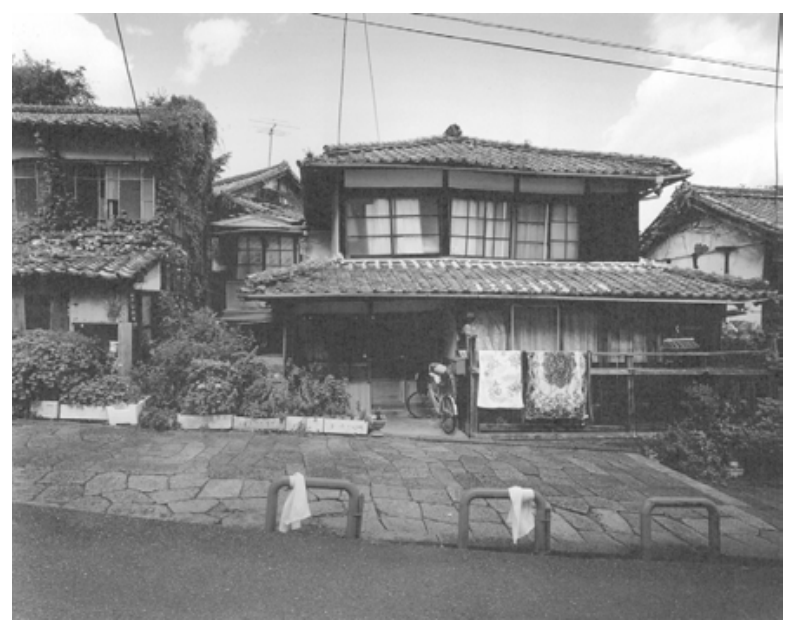

Abb.: Margherita Spiluttini (The EU-Japan Fest Japan Committee 2003: 80; Orig. in Farbe).

brücke den Fluss, links von ihr - jenseits des Flusses - sind einige moderne Wohnhäuser zu erkennen. Die Landschaft wird von dem zentralen Betonfelsen dominiert; Spiluttini bettet ihn jedoch in die Landschaft ein. Es entsteht ein zurückhaltender Eindruck, der etwas zeigen möchte, ohne vordergründig zu bewerten. Die Schutzmaßnahme gehört zur Landschaft ebenso wie Brücken, Straßen und menschliche Behausungen.

Die letzte hier vorgestellte Fotografie von Margherita Spiluttini zeigt ein traditionelles japanisches Wohnhaus (vgl. (The EU-Japan Fest Japan Committee 2003: 80). Von einer leicht nach rechts abfallenden Straße aus fotografiert Spiluttini eine Häuserreihe. Leicht rechts aus dem Zentrum gerückt befindet sich ein Haus mit Erdgeschoss und erstem Stock. Die oberen Fenster muten etwas schief an. Ein mit Ziegeln bedecktes Vordach überdacht das Erdgeschoss. Der erste Stock springt etwas zurück und ist abermals von einem grauen Ziegeldach bedeckt sowie mittig mit einem Abschlussstein versehen. Die Fenster im ersten Stock stehen nicht parallel nebeneinander, sondern neigen sich in gegensätzlichen Winkeln. Die einzelnen Scheiben der Fensterkassetten bestehen zum großen Teil aus mattiertem Glas, von innen sind die hellen Vorhänge zugezogen. Auch im Erdgeschoss sind alle Vorhänge - hier in verschiedenen Farben - geschlossen. Vor der Eingangstür parkt ein Fahrrad, über das Geländer rechts daneben sind Handtücher zum Trocknen aufgehängt. Links neben der Eingangstür stehen Blumenkästen, die üppig grün bewachsen sind. Sie reichen bis zum Nachbargrundstück, wo ein vergleichbares Haus von Grünpflanzen bewachsen ist. Vor den Häusern befindet sich ein mit Steinplatten belegter Gehweg, von der geteerten Straße wird er durch drei niedrige rote torförmige Metallbügel abgegrenzt. An zwei der drei Bügel sind weiße Tücher befestigt.

Spiluttini dokumentiert in dieser Fotografie die traditionelle japanische Wohnbebauung. Holz, Ziegel und mattiertes Glas sind die vorrangig verwendeten Werkstoffe. Schiefe, verzogene Fenster lassen sie nicht sonderlich komfortabel erscheinen, die zugezogenen Vorhänge deuten darauf hin, dass das Innere in ein schummriges Dämmerlicht getaucht sein muss. Lediglich 
die geteerte Straße im Vordergrund sowie die den Himmel durchziehenden Stromleitungen oder die auf einem im Hintergrund liegenden Haus befestigte Fernsehantenne verweisen auf die Gegenwart. Auch wenn es sich hier um ein pittoreskes traditionelles Japanmotiv handelt, entsteht dennoch nicht der Eindruck eines touristischen Blicks. Entscheidend für die Wirkung der Fotografie ist das Einbeziehen der Bügel, die die traditionelle Anmutung leicht brechen und dadurch ebenso einen Bezug zur Gegenwart setzen wie die Farbigkeit der Fotografie selbst. Spiluttini zeigt hier traditionell Japanisches, ohne es als das fremde Andere zu verkitschen. In ihrer Darstellung erhalten die traditionell japanischen Häuser etwas sehr Alltägliches.

Spiluttini erkundet die sichtbare Welt der Präfektur Oita, ohne ein offensichtliches Konzept zu verfolgen. In einer zurückhaltenden Art lässt sie sich auf das für die Bewohner Alltägliche ein, das sich deutlich von unserem unterscheidet. Sie setzt es in einer Form ins Bild, dass es dem westlichen Betrachter etwas über das ländliche Leben in der Region zeigt, ohne es jedoch zu exotisieren.

In der Präfektur Oita wurde im Jahr 2003 ein ergänzendes Projekt entwickelt, in dem Fotografen der Präfektur ihre Heimat porträtierten. Die Ergebnisse des japanischen Blicks auf die Präfektur sind unter dem Titel Oita Today parallel zur European Eyes on Japan-Ausstellung gezeigt worden und weisen interessante Unterschiede des Blickwinkels auf. ${ }^{19}$ Die parallele Präsentation von Fremd- und Selbstsicht verdeutlicht noch einmal die große Bedeutung, die einem Projekt wie European Eyes on Japan in Japan beigemessen wird.

Die ausgewählten Beispiele zeigen unterschiedliche Umgangsweisen mit der Situation innerhalb des Projekts European Eyes on Japan. Gleichzeitig zeugen sie auch von den auf ein Minimum reduzierten Intentionen der Fotografen, die innerhalb einer sehr kurzen Zeitspanne kaum die Möglichkeit haben, groß angelegte oder konzeptionell umfangreiche Projekte zu realisieren.

\subsection{Verschiedene Strategien der Annäherung an Japan}

Jede sich mit Japan beschäftigende fotografische Arbeit, die im Bereich der künstlerischen Dokumentarfotografie angesiedelt ist, leistet auf ihre Weise einen Beitrag zum westlichen Japanbild. Das geschieht unabhängig davon, ob sie visuelle Klischees reproduziert, sich einem bestimmten Thema widmet oder ganz allgemein gehalten ist. Selbst innerhalb eines Ansatzes wie dem von Thomas Struth, dessen primäres Ziel nicht in der Vorstellung der japanischen Kultur liegt, können Fotografien dazu verwendet werden, Aussagen über Japan zu machen. Neben konkreten, in Bildern vermittelten Informationen kann

19 Die sehr unterschiedlichen Resultate lassen sich einerseits auf die von ihrer Herkunft geprägten Blickwinkel zurückführen, andererseits aber auch auf die Auswahl der beteiligten Fotografen. Während die europäischen Fotografen in Zusammenarbeit mit der Leiterin der Kulturhauptstadt Europas 2003 (Graz), Christine Frisinghelli, aufgrund ihrer überregionalen Bedeutung ausgewählt wurden, haben die die Präfektur Oita repräsentierenden japanischen Künstler eher lokale Bedeutung (vgl. The EU-Japan Fest Japan Committee 2003; Oita Today, Kat. 2004). 
in der Japanfotografie aber gerade auch die Auseinandersetzung mit dem Fremden als Fremdes interessant sein, die nicht versucht, das Gesehene einzuordnen und zu verstehen, sondern in seiner Fremdheit bestehen zu lassen. Interessant sind insofern auch die Strategien, mit denen die Fotografierenden sich mit der Fremdheit auseinandersetzen, der sie in Japan begegnen. Versuchen sie, das Fremde zu verstehen und ihr Verständnis zu vermitteln? Oder geben sie ihre Irritation an den Betrachter weiter, indem sie von einer Einordnung des Wahrgenommenen absehen?

Entscheidend ist unter anderem die Intention des Fotografierenden. Sie wirkt sich auf die gewählte Strategie aus, um die Intention optimal umzusetzen. Die drei innerhalb von European Eyes on Japan vorgestellten Arbeiten zeigen drei sehr unterschiedliche Arten des Umgangs mit der Situation, auf Einladung innerhalb eines kurzen Zeitraums eine Arbeit in Japan zu fotografieren. Sie stellen verschiedene Möglichkeiten im Umgang mit einer Projekteinladung dar. Einigkeit herrscht unter den Fotografen darüber, dass Japanisches gezeigt werden soll, woran sich vielleicht Eigenheiten der japanischen Kultur erkennen lassen. Dies entspricht der Intention der Fotografierenden. Im Bewusstsein um die Gefahr der stereotypen Darstellung sucht jeder nach einer eigenen Haltung und entsprechend nach einem individuellen Ansatz.

Naomi Salmon überträgt ein in ihrem Werk erprobtes Konzept auf ihre Arbeit in Tokyo. Indem sie alltägliche Objekte in einer sachlichen Technik fotografiert, zeigt sie einen kleinen Ausschnitt aus der japanischen Warenkultur. Gleichzeitig thematisiert ihre Arbeit das Problem der Unterscheidung zwischen der Ebene des Bildsujets und der des Bildobjekts. Die scheinbar transparenten, als Zeichen verwendeten Fotografien werden opak, weil sie sich einer vollständigen Aneignung entziehen. Fremdheit bleibt als Aspekt der Arbeit bestehen. Indem sie die Ausschnitthaftigkeit der Fotografie besonders deutlich hervortreten lässt, zeigt ihre Konzeption eine ungewöhnliche Lösung in der Auseinandersetzung mit der japanischen Metropole.

Hans van der Meer entwickelt sein fotografisches Konzept in Reaktion auf die von ihm vorgefundenen Gegebenheiten in der Präfektur Okayama. Einerseits geht er auf den Ort und die Menschen ein, andererseits schützt ihn der konzeptionelle Ansatz davor, ins Beliebige abzugleiten. Die Konzeption schafft eine Klammer, um die verschiedenen Orte innerhalb der Präfektur miteinander zu verbinden. Dies hilft ihm dabei, eine stereotype Sichtweise auf Japan zu überwinden, ohne mit den Bildern etwas erklären zu wollen.

Margherita Spiluttini überlässt sich ganz der Erkundung des Sichtbaren in der Präfektur Oita, da sie dies für die beste Möglichkeit hält, dem Fremden zu begegnen. Ohne einen offensichtlichen konzeptionellen Rahmen entwickelt sie eine zurückhaltende beobachtende Bildsprache. Weil sie japanische Landschaften und Traditionelles meist mit Objekten der industrialisierten Gegenwart verbindet, vermag auch sie mit ihrer Darstellung romantisierende Klischees zurückzuweisen. Der Betrachter bekommt einen Eindruck der Region, wobei die Fotografien auf Werturteile verzichten.

Alle drei Künstler entwickeln innerhalb kurzer Zeit eine Haltung gegenüber dem Japanthema, die ihnen bei der Umsetzung ihrer Arbeit hilft. Dabei nutzen sie - wie dargelegt - verschiedene Strategien. Im Unterschied zu umfangreicheren Projekten, die langfristig konzipiert und mit einem längeren Japanaufenthalt verbunden sind, sind die Intentionen der Teilnehmer von $\mathrm{Eu}$ ropean Eyes on Japan sehr zurückhaltend: Etwas von der Region zu zeigen und weitgehend Klischees zu vermeiden. 
Zeitgenössische Fotografen entwickeln ihren Umgang mit Japan aus dem Wissen um vorangegangene Positionen der Japandarstellung heraus. In der Konzeption ihrer Arbeiten versuchen sie mitunter, sich von vorangegangenen Positionen abzugrenzen. Dennoch können gelungene Strategien auch übernommen und im Sinne der eigenen Arbeit abgewandelt werden. So sind zuweilen Parallelen zwischen zeitgenössischen Annäherungsweisen und Strategien ihrer Vorläufer zu beobachten.

Eine fotografische Arbeit in Japan anzufertigen, heißt noch nicht, dass ein Interesse an der Auseinandersetzung mit oder Darstellung der japanischen Kultur besteht. Auch Aspekte der Fremdheit müssen nicht thematisiert sein. Wie beispielsweise der Ansatz von Heiner Schilling zeigt, können japanische Bildsujets auch verwendet werden, um eine eigenständige Bildlichkeit zu erzeugen. Schillings Japanfotografie kann zwar auch Informationen über Japan liefern, dies scheint aber nicht ihr primäres Ziel. An Schillings Arbeit lässt sich weder ein spezifisches, auf die japanische Kultur oder Gesellschaft bezogenes Interesse ablesen noch eine Thematisierung des Fremden. Dennoch findet er genau dort solche Motive, die er für die Ästhetik seiner Arbeit nutzbar machen kann. Er konzentriert sich vorrangig auf die Erzeugung ästhetischer Einzelbilder, ohne an serielle Prinzipien der Becher-Schule anzuknüpfen. Einen inhaltlichen oder thematischen Schwerpunkt setzt er einerseits auf die neusten Architekturen oder die neu hinzu gewonnen Landflächen in der Bucht von Tokyo, auf Zentrum und Peripherie. Andererseits sind insgesamt sehr verschiedenartige Fotografien in die Arbeit eingebunden, die scheinbar wenige Verbindungen zu anderen Bildern innerhalb der Arbeit aufweisen. ${ }^{20}$ Präzision und Ästhetik der Arbeit stechen sofort hervor, so dass auch von einer Strategie der Ästhetisierung gesprochen werden kann. Schilling betreibt jedoch gleichzeitig eine Fiktionalisierung, die die Arbeit vom Referenten abkoppelt. Verstärkt wird diese Abkopplung auch durch die große Distanz, die Schilling gegenüber seinen Motiven einnimmt.

Durch die Strategie der Fiktionalisierung unterscheidet sich Schillings Arbeit nachhaltig von anderen Arbeiten, die ebenfalls mit einer Ästhetisierung arbeiten, wie beispielsweise die Werner Bischofs. Im Gegensatz zu Schilling ist Bischof stark daran interessiert, Japan und die japanische Kultur der frühen 1950er Jahre ins Bild zu setzen. Seine Japandarstellung schließt verschiedene Schichten von ländlicher und urbaner Bevölkerung, Traditionen und neusten Trends ein und überträgt diese inhaltliche Beschäftigung mit Japan in ästhetisch ansprechende Bilder. Ein vergleichbares Interesse an einer Auseinandersetzung mit dem fremden Land findet sich bei Schilling nicht. Bischofs Sichtweise ist ausgewiesen durch eine Distanziertheit, womit er der fremden Kultur großen Respekt entgegenbringt. Fremdheit wird nicht in einer selbstreflexiven Form thematisiert, vielmehr liegt der Fokus auf der Beschreibung, die auf eine Weise eingesetzt wird, etwas über das Fremde zu erzählen. Bischof bleibt dementsprechend dem traditionellen fotografischen Ethos verbunden.

Bereits zehn Jahre nach Bischof hebt William Klein in seiner Japanfotografie - wie in Teil II, Abschnitt 1.2. gezeigt - die Distanz zum Gegenstand auf. Er löst sich aus der Rolle des diskreten Beobachters heraus, um mög-

20 So zum Beispiel die nah gehaltene farbintensive Aufnahme eines Treppengeländers, die auf einer Doppelseite mit dem Bild eines dunkelgrünen Bambushains kombiniert wird (vgl. Schilling 2000: 44f.). 
lichst intensiv an dem teilzuhaben, was er abbildet. Dabei vermittelt er dem Betrachter die Atmosphäre des Geschehens. Auch wenn die Bedeutung der Ereignisse möglicherweise aufgrund von grundlegenden kulturellen Unterschieden dem westlichen Betrachter nicht immer verständlich ist, überträgt sich in Kleins Fotografien ein atmosphärisches Miterleben. Klein taucht in die fremde Kultur ein und versucht nicht, alles, was er sieht zu verstehen oder zu erklären. Er arbeitet mit der Irritation des Betrachters, der anlässlich der Fotografien selbst mit dem Fremden konfrontiert ist. Die Nähe zum Gegenstand verstärkt das Fremdheitsgefühl noch. Diese Strategie ist besonders im historischen Kontext bemerkenswert, denn Klein ist einer der ersten westlichen Fotografen, der die respektvolle Distanz zum fremden Japan durchbricht und so zu einer bislang nicht gekannten Sichtweise auf Japan gelangt. Für Klein ist Dokumentarfotografie nicht mehr sachlich verbrämte Distanz, sondern das Sichtbarmachen von Ereignissen und Beobachtungen, die er selbst hautnah erlebt. Dieses subjektive Erleben in Fotografien zu einer gesteigerten Sichtbarkeit zu verdichten, ist für Klein eher Maßstab der künstlerischen Dokumentarfotografie als das sachlich anmutende Einhalten einer Distanz zur fremden Kultur. Elemente von Kleins Strategie der aufgehobenen Distanz finden sich beispielsweise im in den 1990er Jahren fotografierten Japanprojekt Empty Heaven des englischen Fotografen Paul Graham, das im nächsten Kapitel ausführlich betrachtet wird.

Der in Teil II, Abschnitt 1.3. vorgestellte Fotograf Ed van der Elsken ist in seiner Arbeit ganz der Straßenfotografie verpflichtet. Er bewegt sich zwar im Geschehen, ist aber dennoch nicht Teil davon. Als Flaneur wandert er durch japanische Straßen und beobachtet das Leben dort. Er ist sich seiner Rolle als außenstehender Fremder bewusst, aber durch seine über Jahrzehnte währende empathische Beobachtung ist er näher am Geschehen als beispielsweise Werner Bischof. Ed van der Elsken interessiert sich besonders für den japanischen Alltag. Fremdheit nimmt er als gegeben; er versucht sie nicht zu erklären, sondern ihr in seiner Zurückhaltung Raum zu geben. Während er sich in seinen frühen Fotografien aus den fünfziger und sechziger Jahren des zwanzigsten Jahrhunderts noch mehr den japanischen Besonderheiten widmet, sucht er in späteren Jahren mehr und mehr nach dem Alltäglichen, das sich zunehmend dem Leben anderer Metropolen ähnelt, ohne jedoch ganz das Japanische zu verlieren. Van der Elsken verfolgt eine Strategie der Suche nach dem Alltäglichen. Er ist sich der aus seiner Fremdheit resultierenden Nicht-Zugehörigkeit durchaus bewusst und entwickelt aus dieser Position heraus seine Beobachtungen. Parallelen finden sich in abgewandelter Form in zeitgenössischen Ansätzen wieder, so zum Beispiel in der Arbeit Future World der deutschen Fotografin Elisabeth Neudörfl, die durch eine thematische Konzentration den Ansatz der beobachtenden Straßenfotografie weiterentwickelt. Ihre Arbeit wird im vierten Kapitel des Teils II ausführlich vorgestellt.

\section{Zusammenfassung}

Auch wenn Fotografen der Becher-Schule, wie beispielsweise Thomas Struth, häufig als Dokumentarfotografen bezeichnet werden, zeigt sich, dass ihre Intentionen sehr anders gelagert sind als die derjenigen Fotografen, die eine dokumentaristische Herangehensweise wählen. Denn ihr thematisches Interesse ist primär an der Bildlichkeit selbst ausgerichtet und nicht an einer Auseinandersetzung mit der fremden Kultur. Heiner Schillings Arbeit macht deutlich, dass Japan hier als adäquater Lieferant für die Bildideen des Künst- 
lers angesehen wird, aber die Erkundung Japans als Dargestelltes Fremdes für die Intentionen nicht von Belang ist.

Arbeiten, die auf Einladung im Rahmen von European Eyes on Japan entstehen, werden innerhalb kürzester Zeit realisiert und werden in redaktionell betreuten Katalogen publiziert. Da die Produktionsbedingungen andere sind als die von selbstständig konzipierten umfangreichen Projekten, sind die Intentionen der Künstler meist darauf reduziert, etwas von der Region zu zeigen und möglichst über stereotype Bildwelten hinauszuweisen. Zur Erlangung dieses Ziels entwickeln die Fotografen eigenständige Strategien, die über ihren Umgang mit dem Fremden Auskunft geben und interessante Ergebnisse liefern, die durchaus in der Lage sind, den Betrachter mit Elementen von Fremdheit zu konfrontieren.

Die in diesem und dem vorherigen Kapitel vorgestellten dokumentarfotografischen Positionen geben Aufschluss über die verschiedenen Intentionen und Strategien der Japanbetrachtung. Projekte, die eine Strategie der Ästhetisierung verfolgen, neigen tendenziell dazu, Japan als differentes Anderes wahrzunehmen. Sie interessieren sich hauptsächlich für Motive, die die Andersartigkeit Japans und der japanischen Kultur betonen. Weil solche Darstellungen mitunter zur Klischeebildung beitragen können, sind sie für die Frage nach der Überwindung von Klischees nicht weiter relevant. Von Interesse sind hier vielmehr solche Arbeiten, die versuchen, das Fremde als Fremdes zu fassen und einen Beitrag zu einem erweiterten Japanbild zu leisten.

Vor dem Hintergrund der bislang betrachteten Positionen werden in den folgenden Kapiteln die Japanarbeiten des englischen Fotografen Paul Graham und der deutschen Fotografin Elisabeth Neudörfl auf ihre Strategien der Japanbetrachtung hin befragt. Beide Arbeiten liegen in Form eines Künstlerbuchs vor, das das jeweilige Projekt vollständig präsentiert. Beide Künstler zeichnen verantwortlich für Bildauswahl und Gestaltung der Publikation. So kann davon ausgegangen werden, dass sich Intention und Haltung der Künstler aus den Publikationen herauslesen lässt. Mit welchen Vorstellungen wenden sich Graham und Neudörfl Japan zu, welche Haltung entwickeln sie gegenüber ihrem Gegenstand und welche Strategien wenden sie an, um ihre Intentionen an die Betrachter zu vermitteln? Die beiden Künstlerbücher werden als Fallbeispiele herangezogen, um die Möglichkeiten einer künstlerischen Dokumentarfotografie in der Darstellung des Fremden konkreter zu befragen. Bezugnehmend auf die Untersuchungen aus den ersten beiden Kapiteln von Teil I ist die Erörterung des fotografischen Umgangs mit Klischees und Stereotypen von Bedeutung. Vor dem Hintergrund der betrachteten Positionen seit den fünfziger Jahren des zwanzigsten Jahrhunderts interessieren Unterschiede in den zeitgenössischen Repräsentationen Japans zu denen vergangener Zeiten. Wie binden zeitgenössische Fotografen traditionelle Japanthemen ein? Werden diese noch berücksichtigt oder sind sie für heutige Japandarstellungen irrelevant? Kann es gelingen, neue Sichtweisen zu etablieren und damit zu einem vertiefenden Verständnis für die japanische Kultur zu gelangen? Finden die Künstler einen individuellen Zugang zum Fremden, die dem Fremden gerecht wird, »es nicht vergewaltigt«? (Jamme 2002: 200). 



\section{Paul Graham: empty Heaven}

Bevor er in Japan fotografiert, erprobt der englische Fotograf Paul Graham den fotografischen Umgang mit dem Fremden bereits in verschiedenen europäischen Ländern. ${ }^{1}$ Die Konzeption von New Europe schärft seinen Blick gegenüber dem gesellschaftlichen Umgang mit historischen Ereignissen in Europa (vgl. Graham 1995b: o.S.; Graham 1993). In Japan wendet er seine Aufmerksamkeit einem gesellschaftlichen Bereich zu, der ihm als Fremdem besonders auffällt, der fotografisch aber schwierig zu erfassen scheint. Es geht ihm um die Frage, "wie sich Geschichte und Macht verkleiden und maskieren - und wie dies in das Gefüge des bewußten und unbewußten Japans eingeflossen ist « (Graham 1995b: o.S.). Gemessen daran, dass sich die Fotografie gemeinhin am Sichtbaren orientiert, scheint sich dieses Thema der fotografischen Darstellung zu entziehen. Graham ist jedoch der Meinung, man könne $»$ Fotografien dazu benutzen, das Unsichtbare sichtbar zu machen, eine Bildsprache jenseits der Bildoberfläche zu schaffen « (ebd.). Zur Umsetzung eines solchen Vorhabens bedarf es einer symbolhaften Bildsprache.

Bereits beim ersten Durchblättern wird deutlich, dass Grahams Bilder auf verschiedenen Ebenen gelesen werden können. Da ist zunächst das Bild selbst, das als ästhetische Komposition Inhalte abbildet. Diese Inhalte können auf einer ikonischen oder symbolischen Ebene gelesen werden. Bedeutung entsteht weiterhin in der Anordnung verschiedener Bilder zu Bildpaaren, Sequenzen und Tableaus. Schließlich wirken die Fotografien, weil sie mit Irritationen arbeiten, die trotz referentieller Lesart nicht beruhigt werden können. Graham arbeitet auf sehr vielschichtige Weise mit der Wirkung seiner Bilder. Im Interview erwähnt Graham sein Interesse an einer Kunst, die mit einer impliziten Bildsprache operiert, »die an der Oberfläche eine schlichte Aussage macht, unter der sich aber ein Code von Symbolen, Metaphern und Anspielungen verbirgt. « So entsteht »eine andere Ikonografie, « die Inhalte auf indirekte Weise anspricht (ebd.). Einen Hinweis auf eine solche Lesart bietet das im Anschluss an den Bildteil auf einer ansonsten weißen Doppelseite eingefügte Zitat der britischen Anthropologin Joy Hendry. Es bezieht sich auf die japanische Kultur, lässt sich aber auch als Verständnishilfe der Fotografien lesen: »Der Westen ist vorrangig mit dem >Auspacken〈, dem Enthüllen des Wesens der Dinge beschäftigt. Wir sollten vielmehr die Methode des

1 Paul Graham wurde 1956 in Harlow in England geboren. Seine wichtigsten - in Monografien publizierten - Arbeiten umfassen neben Empty Heaven (Graham 1995): A1. The Great North Road (Graham 1983); Beyond Caring (Graham 1986); Troubled Land (Graham 1987); In Umbra Res (Graham 1990); New Europe (Graham 1993); End of an Age (Graham 1999); American Night (Graham 2003); A Shimmer of Possibility (Graham 2007). 
Verbergens beachten...« (Joy Hendry, zit. nach Graham 1995a: o.S.). ${ }^{2}$ Dies lässt sich auch auf Grahams Vorgehensweise übertragen. Die Fotografien machen Oberflächen sichtbar. Durch den Einsatz des Blitzlichtes, die Nähe zum Abgebildeten und die daraus resultierende Flächigkeit der Bilder wird der betrachtende Blick gleichsam zurückgeworfen. "Seine Fotografien übertragen auch in ihrer betonten Nähe zum Aufnahmegegenstand die Empfindung von Unvertrautheit und Fremdheit, von Anonymität und Leere« (Krase 1995b: 52). Die Fotografien lassen sich - mit wenigen Ausnahmen - auf einen Blick erfassen, sie scheinen jedoch etwas zu verbergen. Das NichtAbgebildete klingt an und hinterlässt durch seine Abwesenheit eine Leerstelle. Diese kann im Zusammenspiel der Bilder und der daraus entstehenden Meta-Ebene nur teilweise angefüllt werden. Demzufolge ermöglicht die Art des Verbergens Rückschlüsse auf das Verborgene.

Thematisch interessiert sich Paul Graham nicht für eine allgemeine Darstellung des fremden Landes Japan, sondern für einen spezifischen Aspekt der zeitgenössischen japanischen Gesellschaft. Dieses Anliegen zeugt von seinem künstlerischen Ansatz, denn er möchte verborgen liegende Strukturen mittels einer dokumentarischen Fotografie sichtbar machen.

Anders als die im ersten Kapitel von Teil II betrachteten Positionen führt Grahams Projekt Japan nicht explizit im Titel. Erst die Unterzeile erläutert, dass es sich um Fotografien aus Japan handelt. Der Titel Empty Heaven - leerer Himmel - ist sehr poetisch gewählt. ${ }^{3}$ Im englischen Sprachgebrauch existieren mehrere Wörter für das deutsche Wort Himmel. Graham wählt an Stelle des eher naturwissenschaftlichen Begriffs $s k y^{4}$ das religiös konnotierte Wort heaven ${ }^{5}$ und eröffnet damit einen breiten Assoziationsraum. Den Begriff vom leeren Himmel muss der Betrachter mit eigenen Assoziationen anfüllen. Graham liefert in der Arbeit selbst keine konkreten Anhaltspunkte. Nach der Wahl des Titels befragt, gibt Graham an, dieser sei inspiriert von einem japanischen Sprichwort, "»Higaisha Ishikii<, das >der Himmel ist leer - oder $>$ Gott schaut nicht hin $<$ bedeutet, $«{ }^{6}$ mit dem man in fatalistischer Weise Ungerechtigkeiten kommentiert. Im buddhistischen Glauben, der in Japan weit verbreitet ist, stellt die Leere ein zentrales Element dar. Die transzendente absolute Wahrheit des Buddhismus, »die im Gegensatz zur vermeintlichen Fülle des illusionären Diesseits [steht, wird] als leer bezeichnet. [...] Leere ist

2 Das Zitat stammt, leicht abgewandelt, aus dem Buch Wrapping Culture (Hendry 1993: 5). Hendry bezieht sich auf die von ihr beschriebene japanische Kunst des Verpackens. Als konkrete Beispiele dienen ihr beispielsweise Geschenk- und Warenverpackungen. Sie dehnt ihre Beschreibungen jedoch auf gesellschaftliche Hierarchien sowie Architektur und Stadtplanung aus.

3 Interessanterweise bedeutet das Zeichen ku/sora (空) im Japanischen sowohl Himmel als auch Leere.

4 »the space we look up to from the earth, where we see the sun, moon and stars « (Hornby 1986: 806).

$5 \gg 1$ home of God and the saints [...] 2 God, Providence [Vorsehung] [...] 3 place, state of supreme happiness [...] 4 the firmament« (Hornby 1986: 398).

6 >Higaisha Ishikii< heißt wörtlich etwas wie >Opferbewusstsein ২. »A silly example would be if you were a good and faithful friend to your neighbours and looked after them lovingly in their many final years, and then finally they died but left all their money to the cat hospital - then you would utter this phrase« (Korrespondenz zwischen Graham und der Autorin, April 2006). 
das Ziel der meditativen Versenkung« (Reese o.J.). ${ }^{7}$ Neben den Anklängen an den Buddhismus kann der Titel jedoch auch in Zusammenhang mit dem Ende des Zweiten Weltkrieges in Japan gelesen werden, da dieses historische Thema als zentraler Aspekt von Grahams Arbeit wiederholt anklingt. ${ }^{8}$ Die zahlreichen Interpretationsmöglichkeiten verdeutlichen die Ambivalenz des Titels, der sich nicht festlegt, aber gleichwohl in engem Zusammenhang mit Japans Kultur und Geschichte gelesen werden kann.

\subsection{Das Buch}

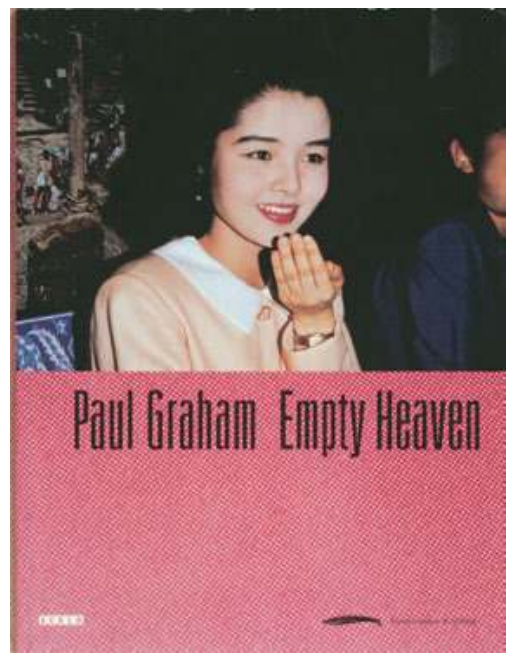

Buchtitel (Graham 1995a).

Das Buch Empty Heaven, erscheint 1995 im Scalo Verlag als Ausstellungskatalog zur gleichnamigen Ausstellung, die im Kunstmuseum Wolfsburg vom 19. August bis zum 12. November 1995 gezeigt wird (Graham 1995a). ${ }^{9}$ Es bildet den Ausgangspunkt der vorliegenden Betrachtung, da es - anders als der Besuch einer Ausstellung - einem für alle nachvollziehbaren Ablauf innerhalb des festgelegten Layouts folgt. Das Buch ist ein reines Bilderbuch.

7 Ein auf alte Zen-buddhistische Traditionen zurückgehendes Meditationsstück (honkyoku) trägt den Titel Kokû (leerer Himmel). Ihm wohnt ein besonders meditativer Gehalt inne. Es »soll bereits im 13. Jh. von einem Zen-Meister namens Kyochiku nach einem Traum geschaffen worden sein« (Brandwein 2000).

8 So bleiben z.B. die Bomber aus, die während der letzten Kriegsphase täglich über Japan hinweg ziehen, auch die atomaren Wolken haben sich aufgelöst. Im übertragenen Sinne könnte auch das Ausbleiben der »aufgehenden Sonne«, des japanischen Nationalsymbols, angesprochen sein und damit die Überwindung des Ultranationalismus.

9 Hardcover mit schwarzem Papierbezug und zweifarbig bedrucktem Buchrücken im Format $24 \mathrm{~cm} \times 32 \mathrm{~cm}$, weißes Vorsatzpapier; 88 Seiten ohne Paginierung, insgesamt 55 Farbfotografien vollformatig im Hoch- und Querformat auf gestrichenem Kunstdruckpapier. Der hochglänzende Schutzumschlag ist vorderseitig mit zwei, rückseitig mit einer Fotografie bedruckt. 
Es beinhaltet weder einen erklärenden Text, noch eine Einführung von kuratorischer oder verlegerischer Seite. Als einzigen Text neben Titel, Bildtiteln und Impressum enthält Empty Heaven das oben erwähnte Zitat. Die in sich geschlossene Form des Buches mit dem Verzicht auf beschreibende Texte und direkt am Bild vermerkte Bildtitel, lässt die Arbeit des Künstlers in den Vordergrund treten. Insofern kann das Buch als Künstlerbuch gelten. Graham selbst wird im Impressum als erster Verantwortlicher für das Buchkonzept genannt. Der beigefügte Einleger kann als Erweiterung des Künstlerbuches in Richtung Ausstellungskatalog gesehen werden (Graham 1995b). ${ }^{10}$ Das hier abgedruckte Interview mit der Kuratorin Uta Grosenick gibt Einblick in Grahams Motivation der fotografischen Auseinandersetzung mit Japan und erläutert teilweise seine bildnerische Herangehensweise an das Thema. Ergänzt wird dies mit bio- und bibliografischen Informationen zu Paul Graham und seinem Werk.

Graham nutzt die Linearität der Buchform, die es ihm ermöglicht, formale Zusammenhänge durch Bildkombinationen auf Doppelseiten oder durch hintereinander folgende Bilder herzustellen. Mit Vakatseiten oder Typografie werden Zäsuren eingefügt, die Bildstrecken voneinander abgrenzen. Graham verzichtet auf eine unterschiedliche Gewichtung der Bilder mit Hilfe variabler Bildformate. Er verwendet lediglich zwei Bildgrößen, die sich aus dem Hochformat der Einzelseite und dem Querformat der Doppelseite ergeben. Hochformatige Bilder können auf Doppelseiten direkt miteinander kombiniert werden. Bei den sich über die ganze Doppelseite erstreckenden Querformaten werden durch formale oder inhaltliche Übereinstimmungen und Kontraste Verbindungslinien zwischen den einzelnen Fotografien hergestellt. Mit diesem Ansatz können Aussagen vertieft, aber auch in Frage gestellt werden. Damit beginnt Graham bereits in der Einganssequenz und etabliert so seine Vorgehensweise.

\subsection{Die Eingangssequenz}

Das Buch beginnt unmittelbar mit der ersten Fotografie, weder Schmutztitel noch Titelei sind vorangestellt. Der Titel schließt die erste Sequenz von fünf aufeinander folgenden Fotografien ab und bildet eine Zäsur zwischen Auftakt und weiterem Verlauf des Buches.

Das vollformatig rechtsseitig angeordnete Hochformat der ersten Fotografie zeigt das Brustbild einer schwarz gekleideten jungen Frau, die sich in einem Wohnzimmer zu befinden scheint (Abb. 1). Ihre rot geschminkten Lippen markieren den Bildmittelpunkt. Fast berührt sie mit dem Zeigefinger der linken Hand ihre Nasenspitze. Die Geste wirkt einerseits natürlich, doch weil das Blitzlicht, dessen Einsatz durch die harten Schlagschatten deutlich zu erkennen ist, die Bewegung einfriert, wird sie artifiziell. Dennoch wirkt das Porträt nicht inszeniert. Der Fotograf reißt die Geste aus dem Zusammenhang des Bewegungsablaufes. Im Einzelbild wird sie geschichtslos, die Motivation der Gestik erschließt sich nicht. Die unvollendete Bewegung lässt einen Eindruck von Unvollständigkeit entstehen. Undurchschaubar lächelnd schaut die

10 Zwölfseitiger Einleger, zweisprachig (Englisch und Deutsch) ohne Paginierung, gedruckt auf rosafarbenem mattem Papier im Format A4 $(21 \mathrm{~cm} \times 29,7 \mathrm{~cm})$, geheftet. 


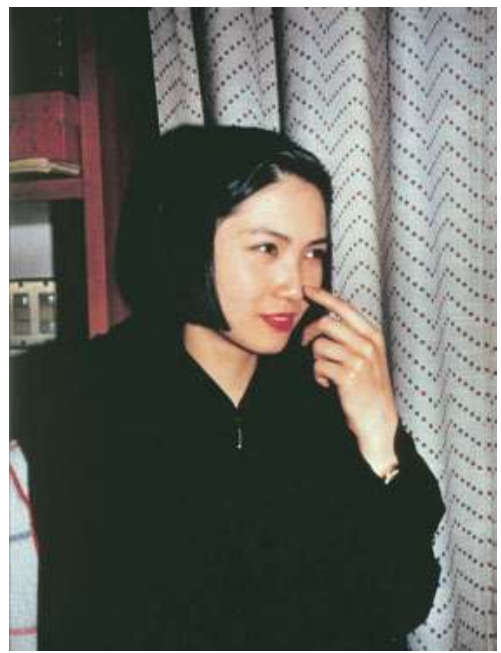

»1. Naoko, Tokyo 1989«; wie alle Bilder in diesem Kapitel aus Graham 1995a: o.S.

junge Frau rechts aus dem Bild hinaus. Das Frauenporträt zeigt eine junge Japanerin, aber es porträtiert sie nicht in dem Sinne, dass es etwas über ihre Persönlichkeit aussagt. Lediglich Haarschnitt, Kleidung und Make-up geben einige Hinweise auf die Person selbst. Das Zimmer, in dem sie sich befindet, zeigt nichts Spezifisches. Die Fotografie deutet auf eine Person in einer globalisierten Welt, die nach unspezifischen Kriterien gekleidet ist und wohnt. Da der Fotograf kein individualisierendes oder psychologisierendes Porträt herstellt, rücken Gestik und Distanziertheit in den Vordergrund. Diese Aspekte sind auch bei weiteren im Buch befindlichen Frauenporträts zu beobachten. ${ }^{11}$

Der Blick der jungen Frau führt rechts aus dem Bild hinaus und lädt zum Umblättern ein. Auf der nächsten Doppelseite ist die vollformatige Fotografie des Motorblocks eines fabrikneuen Autos abgedruckt (Abb. 2). Das Kabelgewirr vermittelt ein geordnetes Chaos, das dem Laien jedoch unverständlich bleibt, da ihm eine Bezeichnung der einzelnen Teile und ihrer Funktion nicht möglich ist. Diejenigen, die sich mit Automotoren auskennen, sind in der Lage, jedes einzelne Teil zu benennen und wissen um dessen Funktion. Das Vorwissen beeinflusst die Bildbetrachtung nachhaltig. Aufgrund der Bildgröße fällt es schwer, die Fotografie als Ganzes wahrzunehmen. Erst mit vergrößertem Betrachtungsabstand entsteht ein vollständiger Bildeindruck, der die Ästhetik des Abgebildeten hervortreten lässt. Dominierend ist die schwarze Farbe der Kabel und Rohre, die sich von aluminium- und messingfarbenen Teilen des Motors abhebt und vereinzelt von farbigen Kabelisolierungen durchbrochen wird. Die Fotografie versucht nicht, die Funktion des Motors zu vermitteln. Die Schönheit und Technizität, die sich in der Fotografie offenbart, verbirgt gleichzeitig das Funktionale dahinter. Kraft und Leistung des Motors erschließen sich nicht aus der visuellen Anschauung. Um jene zu messen, bedarf es anderer Parameter.

11 Insgesamt gibt es zehn solcher Frauenporträts in Empty Heaven, damit bilden sie den umfangreichsten Motivkomplex innerhalb der Arbeit. 


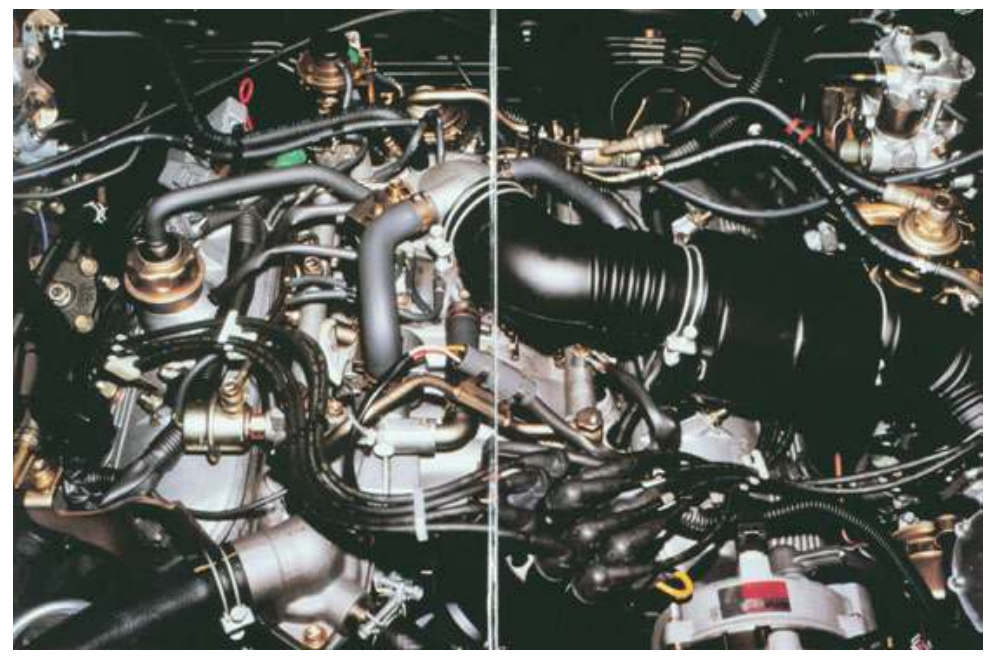

»2. Toyota Engine \#1 (Century), Tokyo 1995«.

Die Fotografie des Motorblocks lässt sich symbolisch lesen. Auf einem kleinen Schild an der rechten unteren Bildkante entdeckt man den Namen Toyota, auf einem Kabel am linken Bildrand ist der Ortsname Yokohama zu lesen: Die japanische Autoproduktion wird zum Thema. Die Unverständlichkeit der technischen Prozesse in einem Automotor weicht der Kenntnisnahme der wirtschaftlichen Gegebenheiten, die Japan als innovationsfreudig ausweisen. Aufgrund ihrer Größe und Wettbewerbsfähigkeit kommt der Autoproduktion innerhalb der japanischen Wirtschaft eine tragende Rolle zu. Der Autohersteller Toyota ist besonders hervorzuheben, denn er zeigt sich seit den 1950er Jahren federführend in der Entwicklung von innovativen Organisationsformen und Produktionstechniken. ${ }^{12}$ Der Toyotismus ermöglicht erhebliche Effizienzsteigerungen zur Profitmaximierung durch Automatisierung und Flexibilisierung der Arbeitsabläufe. ${ }^{13}$ Das bei Toyota entwickelte System hat die Strukturen der industriellen Produktion weltweit nachhaltig verändert. Die Fotografie des Toyota-Motors symbolisiert das Potenzial der japanischen Wirtschaftskraft. Die ökonomische Stärke der Autoindustrie steht in engem

12 Das nach Toyota benannte System des Toyotismus tritt die Nachfolge des Fordismus an und verweist damit auf veränderte globale Zustände, in denen nicht zwingend westliche (US-amerikanische) Firmen an der Spitze stehen. Der Fordismus hatte - ausgehend von Innovationen beim amerikanischen Autobauer Ford - die Industrieproduktion nach dem Ende des Ersten Weltkrieges revolutioniert (vgl. z.B. Koller 2001).

13 Dies geschieht auch mit Hilfe des Einsatzes neuer Technologien. Dem einzelnen Arbeiter wird mehr Verantwortung übertragen, Hierarchien werden verflacht und Produktionsgänge ausgelagert. Ein Maximum an Flexibilität, Produktivität und Schnelligkeit gewährleistet eine effiziente Anpassung der Produktion an die Nachfrage. Aufgrund der Notwendigkeit einer engen $\mathrm{Zu}-$ sammenarbeit mit Zulieferbetrieben und der Kollision mit gewerkschaftlichen Interessen lässt sich das Toyota-System jedoch nicht ohne Abstriche auf andere Länder übertragen (vgl. Gorz 2000: 44ff.; Noble 2002: 36ff.; Low 2002: 241f.; Koller 2001). 


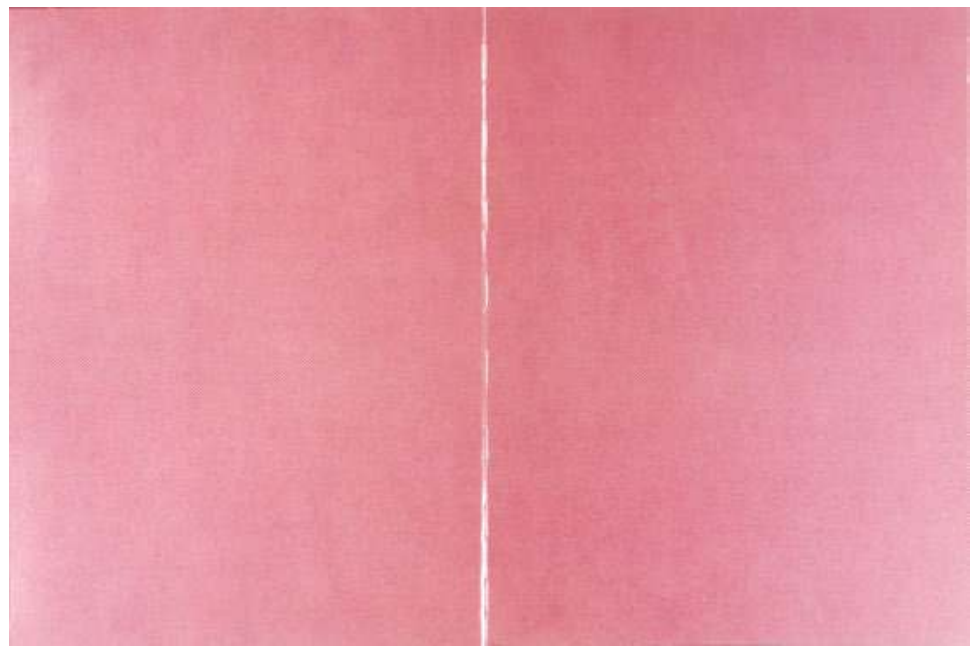

»3. Printed Pink \#1, Tokyo 1992«.

Zusammenhang mit Fragen von Macht und Machtverteilung. Diese Lesart lässt sich problemlos auf die anderen Motorfotografien übertragen, die auf der ästhetischen Ebene alle »sehr verführerisch« wirken, wie Uta Grosenick es formuliert (vgl. Graham 1995b: o.S.). ${ }^{14}$

Die Fülle der Motorabbildung weicht einer gewissen Leere auf der Fotografie der folgenden Doppelseite (Abb. 3). Obwohl sich die Farbe Magenta sehr in den Vordergrund drängt, bietet die gleichmäßige Anordnung der gedruckten Rasterpunkte dem Auge wenig Halt. Im oberen und unteren Drittel verschwimmt das Druckraster leicht in der Unschärfe. Dies deutet trotz der gleichförmigen Farbigkeit eine Tiefe an, da die Filmebene der Kamera nicht parallel zum ausgebreiteten Papier liegt. Die Farbfläche bleibt aber Oberfläche und vermittelt eine extreme Künstlichkeit. Die Farbe Rosa nimmt - in unterschiedlichen Sättigungsgraden - einen hohen Stellenwert in Grahams Arbeit ein. Der Einleger ist auf rosafarbenem Papier gedruckt, der Titel ist in rosa abgesetzt. Die Farbe taucht im Verlauf des Buches wiederholt auf. Rosa wirkt lieblich, süß, kitschig. Mädchenhaftes und Erotisches wird nicht nur in Japan in rosa dargestellt. ${ }^{15}$ Rosa ist in der japanischen Kultur aber insbesondere als Farbe der Kirschblüten (sakura) von besonderer Bedeutung. Alljährlich wird die Kirschblüte als Symbol des Frühlings gefeiert. Hanami - das Ansehen der Kirschblüten - wird mit Picknicks und Familienausflügen be-

14 Da die insgesamt sechs Fotografien von Motorblöcken innerhalb der Arbeit alle in ähnlicher Funktion eingesetzt werden, wird dieser Motivkomplex nicht noch einmal gesondert analysiert.

15 Shôjo-Manga, die speziell für pubertierende Mädchen gezeichnet werden, bedienen sich extensiv der Farbe Rosa und anderer kitschiger Elemente (vgl. z.B. Schneider o.J.; Koithahn 2000). Billig produzierte Softpornos werden pink films genannt, Kaffeehäuser, in denen von Hostessen erotische Dienste angeboten werden, heißen pink salon (vgl. Buckley 2002c: 391f.). 


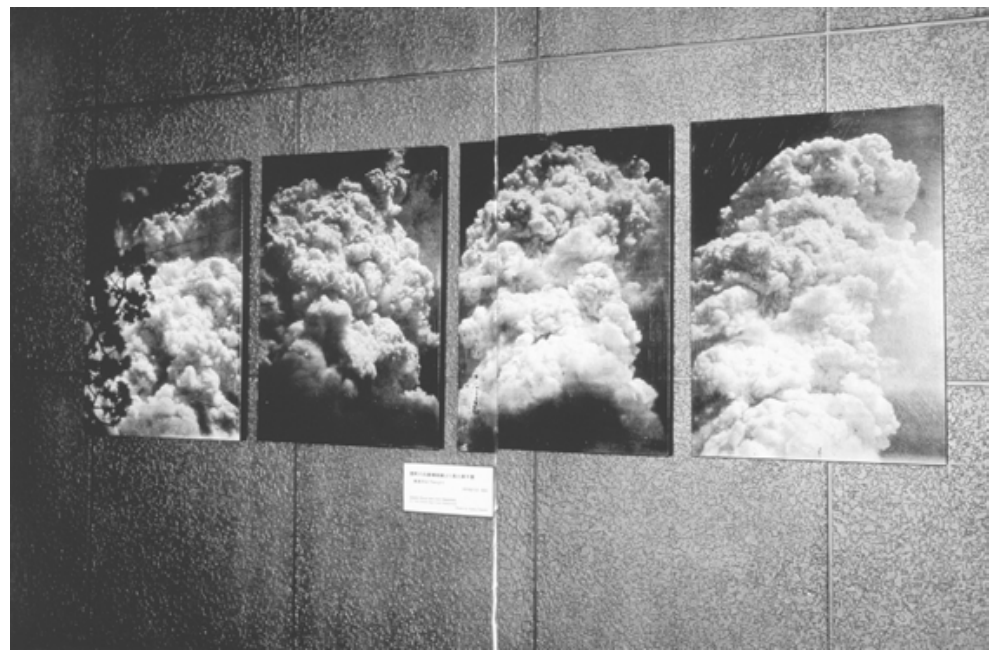

»4. Atomic Cloud Photograph, Hiroshima 1989«(Orig. in Farbe).

gangen. ${ }^{16}$ Die Kirschblüte ist »Metapher für die vergängliche Natur des menschlichen Lebens. Es heißt, die fallende Kirschblüte stellt sowohl die flüchtige Schönheit als auch die Blutstropfen des Samurai dar, dessen Leben, ebenso wie die Schönheit, ephemer erblüht« (Kobayashi 2002: 63). Die Gleichstellung von Schönheit und Kriegstod mittels einer symbolischen Farbgebung mutet von europäischer Warte sehr fremd an. Die Farbe Rosa nimmt dem Soldaten und damit dem Krieg das Martialisch-Gewalttätige, sie verharmlost und romantisiert. Als Symbol für Süße und Niedlichkeit jedoch funktioniert Rosa kulturübergreifend. Graham spielt in seiner Arbeit mit der Doppeldeutigkeit der Symbolik. Für den westlichen Betrachter, dem der Zusammenhang zwischen der Farbe Rosa und dem Kriegstod unbekannt ist, bildet rosa als Symbol für Süße einen harten Kontrast zu Fotografien historischer Ereignisse. Mit dem Wissen um die erweiterte japanische Bedeutung kommt eine weitere Verständnisebene hinzu und verstärkt die Bedeutung der verwendeten Bildkombinationen (vgl. Abschnitt 3.3.).

Die querformatige Fotografie der nächsten Doppelseite zeigt eine Museumsinstallation von vier nebeneinander hängenden schwarz-weißen Fotografien, die - nach der unter den Bildern befindlichen Hinweistafel - die atomare Wolke von Hiroshima aus einem Blickwinkel 2,7 km südöstlich des Hypozentrums zeigen (Abb. 4). Die amerikanischen Atombombenabwürfe im August 1945 mit ihren verheerenden Folgen für die Einwohner der Städte Hiroshima und Nagasaki sind so bekannt, dass die Städtenamen metonymisch für die Zerstörungskraft der Atombombe stehen. Der Einsatz der Atombomben in einem bereits so gut wie gewonnenen Krieg trägt bis heute dazu bei, dass sich Japan eher als Opfer der Kriegshandlungen sieht und die eigene Rolle in ei-

16 Auch in den Künsten ist die Kirschblüte ein beliebtes Thema. Zur Bedeutung der Farbe Rosa in der japanischen Kunst vgl. Fuse 2006: 54-63. Die Farbe Rosa in der zeitgenössischen Kunst allgemein wird in Nemitz 2006 thematisiert. 


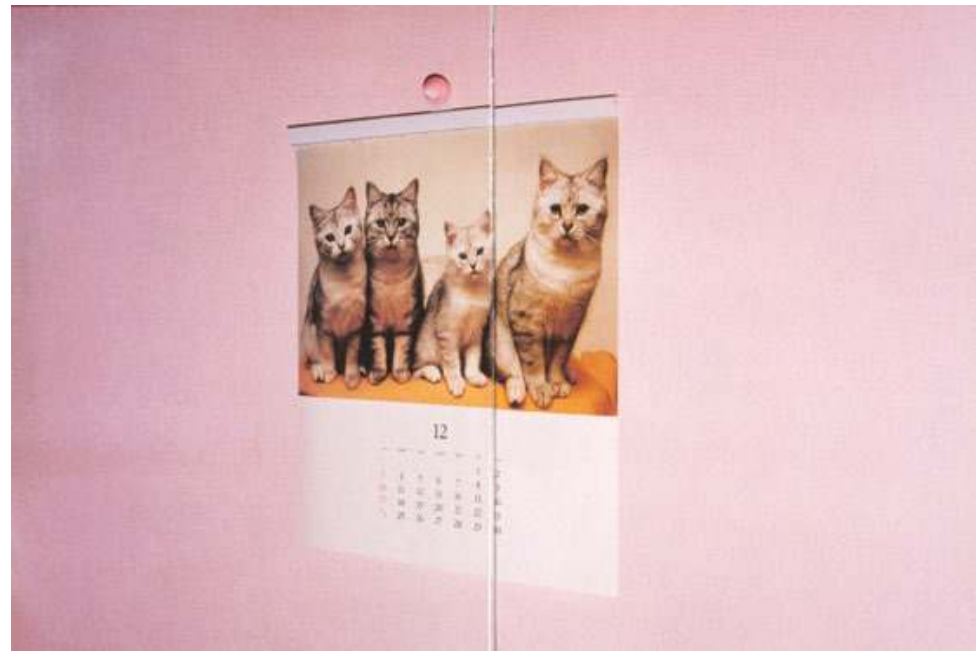

»5. Cat Calendar, Tokyo 1989«.

nem brutal geführten Angriffskrieg verharmlost. ${ }^{17}$ Die Atombomben können als Symbole für das Vergessen eigener Kriegshandlungen und die Verdrängung der japanischen Schuld gesehen werden. Dies spiegelt sich auch in Grahams Fotografie wider. Die gezeigten Wolkenfotografien sind ästhetisch sehr ansprechend, das Wissen um die historische Realität der Atombombenexplosionen setzt jedoch eine Kette von negativen Assoziationen frei. Die Diskrepanz zwischen der Bildästhetik der ausgestellten Fotografien und dem Wissen um die mehrdeutige Rolle der Atombombenabwürfe verdeutlicht die Zwiespältigkeit dieser Symbolik. Die ausgestellten Fotografien scheinen die Realität zu verharmlosen. Obwohl es sich bei Grahams Aufnahme um eine Farbfotografie handelt, wirkt sie aufgrund der Ausstellungsinstallation auf grauer Wand schwarz-weiß. Die aus der Unfarbigkeit des Motivs in Kombination mit dem Einsatz eines Blitzlichtes entstehende Härte tritt besonders im Kontrast zur Farbigkeit des vorangegangenen Bildes hervor. Mit dem Wissen um die Symbolkraft der Farbe Rosa in der japanischen Kultur, die Kriegerisches verharmlost, entsteht in der Kombination der beiden Fotografien eine erweiterte Bedeutung, die zwar im einzelnen Bild angelegt ist, sich in der $\mathrm{Ab}$ folge der beiden Bilder jedoch verstärkt.

In der folgenden, abermals querformatigen, Fotografie wird die Farbe Rosa erneut aufgegriffen (Abb. 5). Auf einer pastellig rosafarbenen Tapete hängt in der Bildmitte ein großer Fotokalender. Das Bild des Monats Dezember zeigt vier Katzen, die mit leicht geneigten Köpfen dem Betrachter direkt

17 Die Rolle dieser verheerenden Kriegshandlung in der Beendigung des Zweiten Weltkrieges in Ostasien ist umstritten. Während die amerikanische Seite lange Zeit darauf beharrte, mit dem Einsatz der Atombomben den Krieg maßgeblich verkürzt und damit Leben amerikanischer Soldaten gerettet zu haben, gilt diese Begründung heute als hinfällig. Von großer Bedeutung war wohl das politische Motiv der USA, gegenüber der Sowjetunion Stärke zu demonstrieren. »Japans Versäumnis, den auch ohne die Atombomben bereits verlorenen Krieg zu beenden, machte es möglich, dass die Katastrophe über Hiroshima und Nagasaki hereinbrach« (vgl. Coulmas 2005b: 14f./19). 
in die Augen schauen. Das Kalenderbild der Katzen ist so fotografiert, dass es an das Kindchen-Schema des Menschen appelliert, der »alles, was klein ist und einen im Vergleich zum Körper großen runden Kopf hat, niedlich findet« (Gelfert 2000: 31). Niedlicher Kitsch, um den es sich hier eindeutig handelt, beschwört »Geborgenheit und emotionale Integration. Psychologisch [bewirkt er] etwas, das man Regression nennen könnte, denn [er bietet] dem Rezipienten die Möglichkeit, vor den Anforderungen der Realität auszuweichen und sich in eine schönere, einfachere, weniger entfremdete, kurz, in eine kindliche Welt zurückfallen zu lassen« (ebd.: 65). Die Komposition aus Katzenkalender, rosafarbener Tapete und Snoopy-Clip, der den Kalender an der Wand befestigt, hebt den Kitsch der Katzenaufnahme besonders hervor. Die Fotografie von Graham ist dabei jedoch ganz sachlich, sie verweist auf Kitschiges, ohne selbst kitschig zu sein. Dies steht in unmittelbarem Zusammenhang mit der Art und Weise, wie der Künstler seine Fotografien kombiniert. Die Härte des vorherigen Fotos kontrastiert auf das Größtmögliche mit der rosafarbenen Pastelligkeit dieses Bildes. Die Tatsache, dass die Zahl der Katzen auf die Zahl der vorangegangenen Explosionswolken rekurriert und beide Fotografien eine Bild-im-Bild-Thematik aufweisen, lässt sie deutlich als Bildpaar hervortreten. Gleichzeitig kann der Verweis auf den Kitsch als Möglichkeit gesehen werden, sich der von der Atombombe hervorgebrachten harten Realität zu entziehen und in die Welt eines »Scheinparadieses « zu flüchten (ebd.: 66). Somit manifestiert sich in der Deutung der Fotografie der Museumsinstallation von Hiroshima die Kritik am japanischen Umgang mit der Vergangenheit. Im Interview mit Grosenick äußert sich Graham äußerst kritisch über die japanische Art des gefahrlosen Zugangs zur Geschichte über ein »Opferbewusstsein«: »Aber wir müssen schon ein paar Fragen mehr stellen, wir müssen es vorantreiben, das Trauma der Vergangenheit, die psychologischen Schatten müssen über diesen Punkt hinaus reichen« (Graham 1995b: o.S.). Dies formuliert er auch als Kritik an japanischen Fotografen, die sich der Vergangenheit fast ausschließlich über Hiroshima und Nagasaki nähern.

Die Bild-im-Bild-Thematik der vierten und fünften Fotografie berührt einen weiteren Aspekt. Sowohl die Atomwolkenfotografien als auch das Katzenfoto erfüllen eine ästhetische Bildfunktion, auch wenn sie inhaltlich sehr konträr sind. Die Katzenfotografie ist dazu bestimmt, dem Betrachter die Emotion von Geborgenheit zu vermitteln, was ihr ohne weitere Kontextualisierung gelingt. Die Wolkenfotografien ästhetisieren hingegen ein historisches Ereignis, obwohl sie in der Museumsinstallation eher als Mahnung denn als Wertschätzung der durch die Bombe entfesselten Kräfte eingesetzt sein dürften. Die historischen Fotografien bedürfen der Einordnung in einen Rezeptionskontext, sie können als ästhetische Produktion ihrer Aufgabe kaum gerecht werden. Dies wirft Fragen an die Fotografie auf, insbesondere an die in den von Graham abfotografierten Fotografien eingesetzte Form der Dokumentarfotografie. Nicht die visuelle Oberfläche bestimmt die Lesart, sondern der inhaltliche Bezug. Während bei der Katzenfotografie Oberfläche und Inhalt weitgehend identisch sind, liegt bei den historischen Fotografien ein eklatanter Bruch zwischen Oberfläche und Inhalt vor. Die Thematisierung dieser Frage innerhalb einer fotografischen Arbeit lässt Rückschlüsse auf Grahams eigenen Umgang mit Fotografie zu. Hinter und zwischen den visuellen Oberflächen sind Aussagen verborgen, die es zu erforschen gilt. Skepsis gegenüber der sichtbaren Oberfläche ist ein wichtiger Teil in Paul Grahams 
Empty Heaven. Sie wird geradezu Bestandteil der Arbeit. Das Hinterfragen der abgebildeten Oberfläche kann bei der Erschließung dieser Arbeit wertvolle Unterstützung leisten. Damit wird die Aussage von Graham, man könne mittels Fotografie Unsichtbares sichtbar machen, etwas verständlicher.

Mit der fünften Fotografie endet die Eingangssequenz des Buches, es folgt eine weiße Doppelseite mit in Schwarz und Rosa abgesetzter Typografie. Die beschriebene Sequenz bildet eine Art Establishing Shot und leitet den weiteren Verlauf des Buches ein. Es werden verschiedene Motive eingeführt, die sich im Verlauf des Buches wiederholen. Graham bringt sehr unterschiedliche Motivwelten zusammen. Ist es auf den ersten Blick schwierig, die teilweise sehr heterogenen Bildmotive als Einheit zu begreifen, zeigt eine erste Analyse, dass die an der Oberfläche zu beobachtenden Brüche thematische Zusammenhänge offenbaren. Die Bildsprache unterstreicht den Zusammenhalt durch formale Ähnlichkeiten, so dass sich die Fotografien trotz motivischer Heterogenität von Anfang an als Einheit begreifen lassen. Als bildnerisches Mittel wird neben der gesuchten räumlichen Nähe zum Gegenstand auch das Blitzlicht verwendet, dessen Einsatz der Farbigkeit ihre eindringliche Intensität verleiht. Der Blitzlichteinsatz lässt die Gegenstände gegenüber dem Hintergrund durch ihre Schlagschatten hervortreten, was sich insbesondere in den Frauenporträts bemerkbar macht. Die Figur wird deutlich vom Hintergrund abgesetzt. Im Gegensatz dazu wird aber bei vielen Motiven die Flächigkeit der Oberfläche betont, was auf subtile Weise Bezüge zur traditionellen japanischen Kunst herstellt, die vor der Begegnung mit westlicher Kunst ohne räumliche Perspektive auskommt. Graham selbst sagt, er verwende das Blitzlicht, um eine Verbindung zum atomaren Blitz herzustellen, dessen "versengendes und blendendes Licht alles bis zum Punkt des Verbrennens überdeutlich zeigt« (Korrespondenz zwischen Künstler und Autorin, April 2006).

Bereits die Eingangssequenz verdeutlicht Grahams symbolische Bildsprache: Die Bildsujets verweisen auf Dinge, die jenseits des Abgebildeten liegen; Außerdem werden die einzelnen Fotografien in einen Gesamtkontext eingebettet. So zeigt sich bereits früh im Buch, dass Grahams dokumentarfotografischer Ansatz auf den Zusammenhang des Werkkomplexes vertraut. Die einzelne Fotografie erklärt sich oftmals nicht selbst, die Aussage entsteht im Zusammenspiel der Bilder miteinander und der Wechselwirkungen, die sich zwischen ihnen entfalten.

Im Folgenden werden nun einzelne Motivgruppen beispielhaft vorgestellt. Auf diese Weise können Zusammenhänge in der Arbeit erfasst sowie Ziele analysiert und bewertet werden. Eine einzelne Analyse aller 55 im Buch abgebildeten Fotografien ist nicht sinnvoll, da sich Motive und Formen der Bildkombination wiederholen. Die Tatsache, dass sie sich wiederholen, ist demnach für den Gesamtkontext wichtig.

\subsection{Angeeignete Bildwelten}

Bereits in der Anfangssequenz verwendet Graham abfotografiertes Bildmaterial. Graham räumt vorgefundenen Bildern einen hohen Stellenwert innerhalb seiner Arbeit ein. Er bestimmt über Ausschnitt, Größenverhältnis und Einbeziehung von Rahmen und Kontext. Er nutzt historische Fotografien, Gemälde und Motive aus der Populärkultur. Im Akt der Reproduktion eignet sich Gra- 


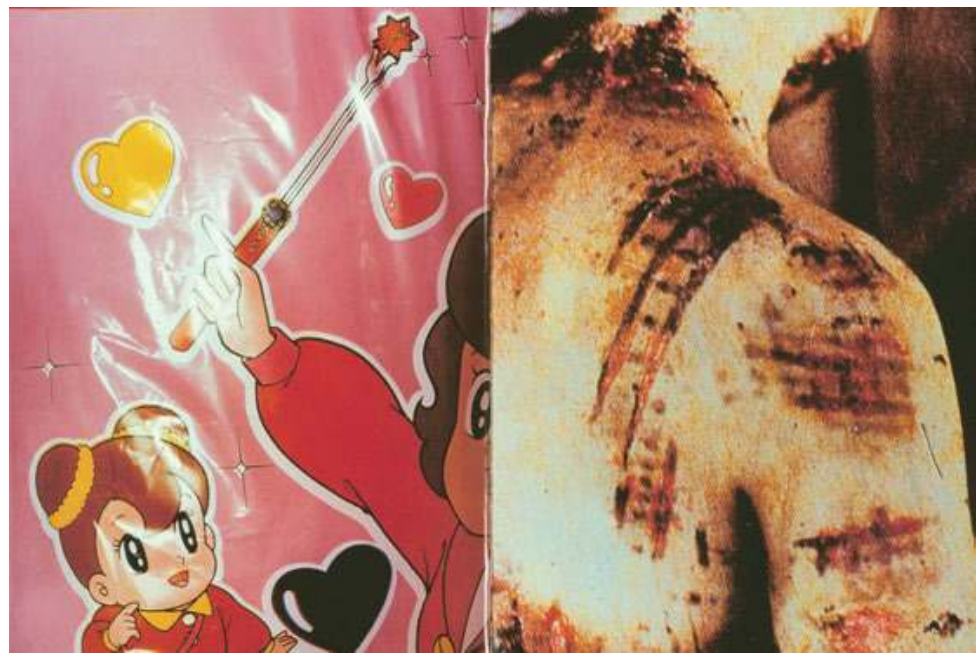

Doppelseite: »7. Candy Wrapper, Tokyo 1990«; »8. Kimono Pattern Flash Burn Photograph, Hiroshima 1990«.

ham japanische Bildwelten an, die ihm als Fremdem zunächst nicht zur Verfügung stehen. Weil er Material aus ganz unterschiedlichen Bereichen nutzt, steht ihm auf diese Weise ein breites Spektrum visueller Möglichkeiten zur Verfügung. Mittels Reproduktionen kann er in die Historie zurückblicken und Geschichtliches in gegenwärtige Zusammenhänge überführen. Indem er den Blickwinkel der vorgefundenen Bildwelten adaptiert, die Bilder aber gleichzeitig in neue Zusammenhänge einbettet, verschiebt er die Bedeutung des Ausgangsmaterials. Über die Herkunft des verwendeten Bildmaterials gibt Graham keine Auskunft. Im Bildtitel ist lediglich die Stadt vermerkt, in der er seine Aufnahmen gemacht hat. Die abfotografierten Bilder verwendet Graham - vergleichbar mit der Bildkombination in der Eingangssequenz meist paarweise mit anderen Motiven.

Die Doppelseite mit den Fotografien sieben und acht ist ein herausragendes Beispiel für Grahams Umgang mit vorgefundenem Bildmaterial. Das linksseitig angeordnete Hochformat zeigt den Ausschnitt eines knallig rosafarbenen »Süßigkeiten-Einwickelpapiers« (Abb. 7). Ein stark vom rechten Bildrand angeschnittenes, dem Betrachter zugewandtes Manga-Mädchen hält in seiner rechten Hand einen Zauberstab. ${ }^{18}$ Von seinem Gesicht ist gerade ein Auge zu sehen. Die den Zauberstab haltende Hand befindet sich fast in der Bildmitte. Der ausgestreckte Arm des Mädchens bildet eine Diagonale in Richtung der linken oberen Bildecke, der Zeigefinger weist auf ein dort befindliches gelbes Herz. Der Zauberstab formt eine gegenläufige Diagonale hin zur rechten oberen Bildecke. Ein kleineres, ebenfalls rot gekleidetes Manga-Mädchen schaut dem ersten von der linken unteren Bildkante auf den ausgestreckten Arm. Bunte Herzen und stilisierte Sterne ergänzen das Motiv.

18 Manga ist die japanische Bezeichnung für Comic (vgl. Buckley 2002b: 295ff.). Es handelt sich hier um den japanischen Manga-Charakter Sari-chun, eine Zauberin, die in den 1970er Jahren Protagonistin einer populären ZeichentrickFernsehsendung war (vgl. Gespräch mit Yoshihara 2006). 
Die Reflexion des Blitzlichtes auf dem glänzenden Papier macht Falten und Knicke sichtbar und lässt die den Zauberstab haltende Hand sehr hell erscheinen. Dadurch wird der Punkt, an dem die Diagonalen des Bildes zusammentreffen, noch stärker betont.

Das niedliche Manga-Motiv bildet einen harten Kontrast zur Fotografie auf der rechten Buchseite. Hier fotografiert Graham den engen Ausschnitt einer gedruckten historischen Farbfotografie, die - wie der Bildtitel besagt Brandwunden in Form eines Kimonomusters auf der Schulter einer Person zeigt (Abb. 8). ${ }^{19}$ Das Druckraster ist deutlich zu erkennen. Trotzdem stört es die unmittelbare Präsenz der Verletzung kaum. ${ }^{20}$

Die Farbigkeit der offenen Wunden korrespondiert auf erschreckende Weise mit der des Süßigkeiten-Papiers. Die anatomischen Parallelen von Arm und Schulter bilden eine weitere formale Übereinstimmung zwischen den beiden Fotografien. Dies verdeutlicht explizit ihren inhaltlichen Kontrast. Die Harmlosigkeit des Papiers überträgt sich nicht auf die historische Fotografie, sondern verstärkt deren Wirkung. In der Format füllenden Anordnung der beiden Bilder nebeneinander auf einer Doppelseite verletzt Graham eine Konvention, die eine solche Bildkombination undenkbar erscheinen lässt. Gerade deshalb verfehlt sie ihre Wirkung nicht. Das Süßliche verstärkt den Schmerz und überdeckt ihn nicht, wie die von den Japanern eingenommene Opferrolle ihre Kriegsschuld vielleicht an der Oberfläche vergessen macht, sie aber nicht zum Verschwinden bringen kann. Graham formuliert, er wolle in der Konfrontation von süßlichen Motiven mit historischen Realitäten »die Verbindung zwischen dieser vorsätzlichen Traumwelt und den Schatten der Vergangenheit aufspüren. Jede schmerzhafte Nachwirkung scheint verkleidet worden, erträglich gemacht worden zu sein, die Seele wurde mit Zucker überzogen, um sie vor der Bitterkeit der Erinnerungen zu schützen« (Graham

19 Es handelt sich um einen engen Ausschnitt der historischen Fotografie, wie eine Abbildung aus der Arbeit Aerospace Folktales des Künstlers Allan Sekula von 1973 verdeutlicht. Sekula bildet Doppelseiten aus dem Band »The Effects of Nuclear Weapons« ab. Auf einer Doppelseite findet sich die historische Fotografie, die hier deutlich erkennbar eine Frau in einem Raum zeigt, die Schulter und Rücken entblößt, um ihre Verletzungen zu zeigen. Die Bildunterschrift lautet: »The patient's skin is burned in a pattern corresponding to the dark portions of a kimono worn at the time of the explosion « (Breitwieser 2003: 130). Der Vergleich zwischen den Reproduktionen der historischen Fotografie bei Sekula und Graham lässt die Wirkung durch die Wahl des Ausschnitts bei Graham noch deutlicher hervortreten. Bei Sekula überwiegt die Sachlichkeit, die sich aus der Schwarzweißfotografie, der Distanz zur unmittelbaren Verletzung aufgrund des größeren Ausschnitts sowie der Reproduktion aus einem Fachbuch ergibt. Das Wissen um den Ausschnitt und das Erlebnis der Farbe verdeutlicht, dass Graham die Unmittelbarkeit der Verletzung mittels Ausschnitt und Farbigkeit betont und in der Bildkombination noch verstärkt.

Graham zitiert hier jedoch nicht Sekulas Arbeit, sondern verwendet eine Fotografie, die seiner Aussage nach eine Ikone ist und in Japan allgemein bekannt (Korrespondenz zwischen der Autorin und dem Künstler, April 2006). In den Gesprächen mit japanischen Fotografie-Experten wird jedoch deutlich, dass die vermeintliche Ikone mitunter nicht als solche erkannt und nicht mit den Atombombenabwürfen in Beziehung gesetzt wird. Das wird beispielsweise im Gespräch mit Yoshihara 2006 deutlich.

20 Die Bedeutung von Oberflächen für Grahams Arbeit wird hier mit den Themen Haut und Druckraster erneut deutlich. 


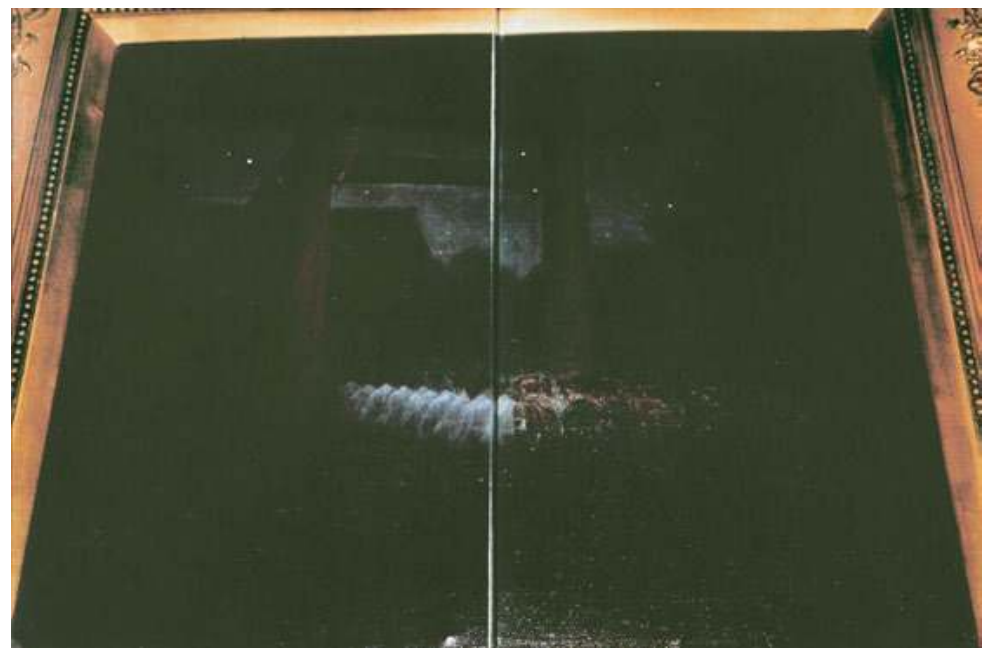

»10. State Shinto Procession Painting, Tokyo 1990«.

1995b: o.S.). Graham stellt eine solche Verbindung mittels inhaltlicher Kontrastierung und formaler Übereinstimmungen beider Fotografien her. Der Zauberstab in der Hand des Manga-Mädchens kann als Wunsch gelesen werden, den Schmerz auf märchenhafte Weise zum Verschwinden zu bringen. Doch die Präsenz des verwundeten Körpers lässt auf die Unmöglichkeit einer solchen Lösung schließen.

Graham möchte mit den Paarungen »einen Zusammenhang herstellen, wo oberflächlich gesehen gar keiner zu sein scheint [...]. Die Gegenüberstellungen schaffen schockierende, unübersehbare Verbindungen, nicht nur zur Verhüllung von alten Erinnerungen, sondern zum Maskieren und Demaskieren von Macht« (ebd.). Die schockierende Wirkung ist in oben analysierter Bildkombination nicht zu übersehen.

Indem Graham ein die bunte Gegenwart repräsentierendes Bild mit einer Fotografie der harten Realität der Vergangenheit konfrontiert, löst er zahlreiche Assoziationen im Betrachter aus. Seine eigenen im Interview formulierten konkreten Assoziationen sind nicht immer direkt nachvollziehbar, aber in der paarweisen Anordnung eröffnet Graham ein Assoziationsfeld, das die Betrachter mit ihren eigenen Kenntnissen und Erfahrungen füllen können. Graham weist in eine Richtung, indem er mit seinen Bildern Reibungsflächen erzeugt. Die Bedeutung müssen sich die Betrachter selbst erschließen.

Ein abfotografiertes Ölgemälde bildet den Auftakt zur dritten Sequenz im Buch. In einer querformatigen doppelseitigen Fotografie reproduziert Graham das Gemälde einer »Staatlichen Shintô Prozession« nicht frontal, vielmehr fotografiert er es von unten und schneidet dabei die untere Kante des Bildes ab (Abb. 10). Die Kamera befindet sich nicht parallel zur Bildebene, so dass an den Seiten das nach oben aufeinander zulaufende Holz des verzierten und mit Gold belegten Bilderrahmens im Anschnitt sichtbar wird. Die Kante des Bilderrahmens bildet den oberen Abschluss der Fotografie. Das Ölgemälde stellt eine nächtliche Szenerie mit klarem Himmel und funkelnden Sternen dar, es ist insgesamt sehr dunkel. Schemenhaft überragt das große Tor (torii) einer daran erkennbaren shintôistischen Schreinanlage die Bildmitte; 
links im Hintergrund ist im Dunkel ein Gebäude zu erahnen. ${ }^{21}$ Insbesondere die Bildränder des Ölgemäldes versinken im Schwarz. Die Struktur der Leinwand wird an der unteren Bildkante durch die Reflexion des Blitzlichtes sichtbar. Vorrangig ist auf der Fotografie die Bildmitte des Gemäldes zu erkennen. Hier ist die Rückseite einer Prozession von Menschen zu sehen, die durch das Tor hindurch in den Schrein einzieht. Vorweg gehen weiß gekleidete Personen gefolgt von uniformierten Soldaten. Man kann die ehrfurchtsvoll geneigten Köpfe der Soldaten erkennen. Die nach oben aufeinander zulaufenden Bilderrahmenkanten scheinen diese Bewegung in der Fotografie noch zu unterstreichen.

Auch ohne weitere Informationen über das Gemälde lässt es sich als zentralperspektivisches Ölgemälde im westlichen Stil einordnen. Dies verweist auf den Yôga-Stil in der japanischen Malerei, der sich im späten neunzehnten und frühen zwanzigsten Jahrhundert damit beschäftigt, »einheimische Bildthemen in die Idiomatik westlicher Salonmalerei« zu übersetzen (Croissant 1993: 534). ${ }^{22}$ Auf eine solche Richtung weist das von Graham abfotografierte Gemälde hin, es handelt sich vermutlich um eine Form von Historienmalerei. Hier ist die Verbindung von shintôistischer Religion und japanischem Militarismus wichtig. Der durch Großmachtsphantasie und Ideologie in den 1920er und 1930er Jahren entstandene japanische Ultranationalismus prägt diese Verbindung nachhaltig. Sie trägt Mitverantwortung an der japanischen Kriegsschuld. Die Düsterkeit des gemalten Bildes überträgt sich auch auf Grahams Fotografie und verheißt damit nichts Gutes. Das Wissen um die Tatsache, dass es sich bei dem auf dem Gemälde abgebildeten Schrein um den Yasukuni-Schrein handelt, verbindet den historischen Inhalt des Gemäldes mit der Gegenwart. Besuche hoher politischer Repräsentanten Japans im Yasukuni-Schrein sind Auslöser eines tiefen Zerwürfnisses mit den asiatischen Nachbarn Korea und China. Sie zeugen von einer mangelnden Sensibilität der japanischen Regierung im Umgang mit den Gefühlen der ehemaligen Kriegsgegner sowie der fehlenden Einsicht in die eigene Rolle als kriegerischer Aggressor, die den Nachbarländern viel Leid zugefügt hat. Der Yasukuni-Schrein ist ein Symbol für die in Japan fehlende Aufarbeitung der Vergangenheit, worauf Graham mittels seiner Fotografie verweist.

21 Den abgebildeten Schrein identifiziert Enari 2006 im Gespräch als den Tokyoter Yasukuni-Schrein, in dem aller japanischer Kriegstoter gedacht wird, unter anderem auch einiger verurteilter Kriegsverbrecher des Zweiten Weltkrieges. Er ist seit jeher Symbol des japanischen Nationalismus und Mitlitarismus.

22 Diese Art der Malerei etabliert sich in Japan nach Beginn der MeijiRestauration ab 1868, als ein »Rezeptionsproze $\beta$ westlicher Kultur und Kunst von beispielloser Intensität« beginnt (Croissant 1993: 533). Die so genannte Yôga-Malerei möchte in Japan »nicht nur die Sehgewohnheiten verändern, sondern auch Genres und Bildthemen der Malerei Europas übernehmen« (ebd.). Im Gegensatz zur traditionellen japanischen Malerei wird die Yôga-Malerei nicht einhellig anerkannt; bereits 1883 stellt der Staat die Förderung westlicher Malerei wieder ein, da Nationalisten zunehmend zur Wahrung der eigenen Traditionen aufrufen (vgl. Atsushi 1993: 179). Japanische Künstler mit Interesse an westlicher Malerei müssen sich nun vorrangig in Europa ausbilden lassen. Nach Japan zurückgekehrt, gelingt es einigen von ihnen, die Yôga-Malerei erneut ins Gespräch zu bringen, indem sie sich vermehrt japanischen Themen widmen. 


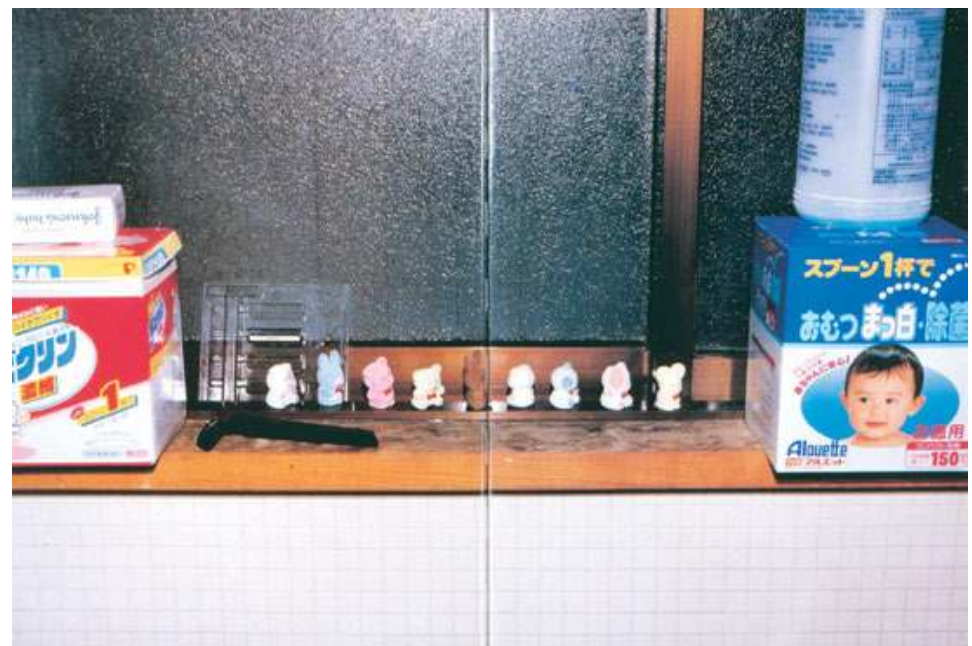

»11. Toy Animal Procession, Tokyo 1990«.

Die Kombination von Querformaten funktioniert im Buch anders als in einer Ausstellungssituation, denn die Buchform ermöglicht nur eine zeitlich versetzte Betrachtung der miteinander in Beziehung gesetzten Fotografien. Trotzdem sind die Bildpaare insgesamt gut auszumachen. ${ }^{23}$ Die Abbildung des Gemäldes der Shintô-Prozession ist mit der nachfolgenden querformatigen Fotografie paarweise kombiniert. Die formalen Parallelen zwischen beiden Fotografien erschließen sich nicht unbedingt auf den ersten Blick, werden aber aus den Bildtiteln ersichtlich: die zweite Fotografie zeigt eine »Spielzeugtier-Prozession« (Abb. 11). Auf einem hölzernen Fensterbrett über einer weiß gekachelten Wand - vermutlich in einem Badezimmer - formiert sich eine Prozession aus kleinen unterschiedlich pastellfarbigen Spielzeugtieren. Die neun Tierchen stehen nicht mit den Gesichtern zum Betrachter, vielmehr schauen sie alle nach rechts und scheinen einem pastellgelben Bärchen mit roter Fliege zu folgen. Lediglich das vierte Tier von rechts steht entgegen der Marschrichtung. Die Prozession wird auf beiden Seiten eingerahmt von Pappschachteln, die Produkte für die Babypflege enthalten. Die rechte Schachtel zeigt die Fotografie eines dunkelhaarigen Babys, das in Richtung der Prozession blickt. Vor den Spielzeugtierchen liegt auf der linken Bildseite ein einfacher Rasierer, dessen mit einer letzten Wechselklinge bestückte Klarsicht-Plastikverpackung auf der linken Seite an das aufgeraute Glas des Fensters gelehnt ist.

Graham rückt dieses kleine, eher unauffällige Ensemble ins Zentrum der Betrachtung. In der Kombination der beiden Prozessions-Fotografien wird die skurrile Parallele der Bildmotive betont. Das kitschig süßliche Ensemble ist Bestandteil einer alltäglichen Szene und bringt den Betrachter zum Schmunzeln. Es verleiht der gemalten Prozession Gewicht und betont die historische Distanz zwischen Vergangenheit und Gegenwart. Die harmlose Spielzeugtier-Prozession verankert die Militärprozession eindeutig in der

23 Über die Anordnungen der Bilder im Layout vgl. Abschnitt 3.1. und Abschnitt 3.6. 


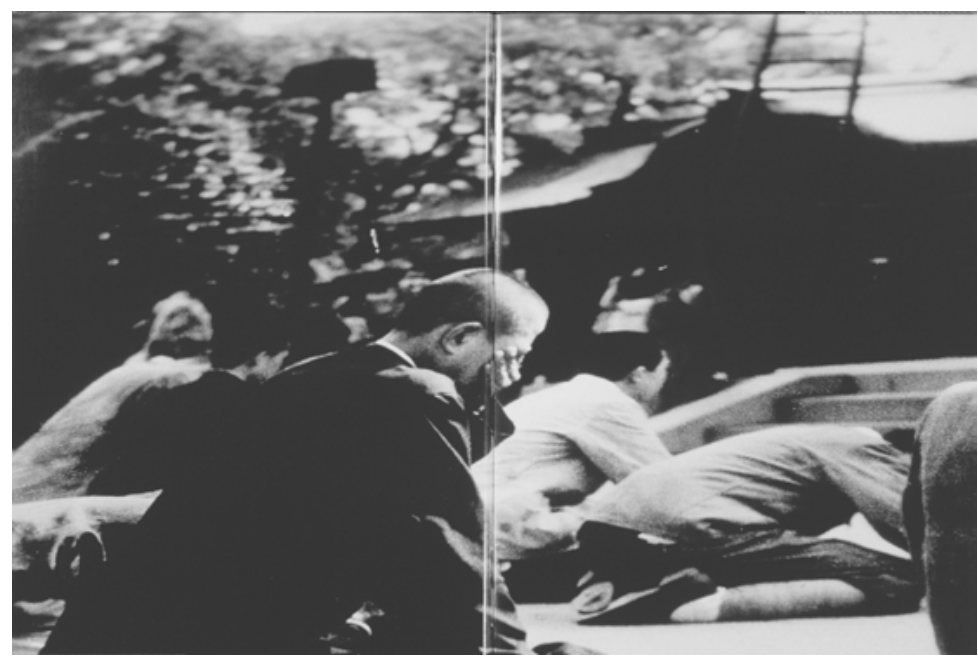

"29. Surrender Photograph, Tokyo 1990«(Orig. in Farbe).

Vergangenheit. Dennoch verbindet das Element der Prozession die beiden Perioden miteinander. Die Bildkombination verstärkt die bereits im ersten Bild angelegte Relation zwischen Gegenwart und Vergangenheit, zwischen Kitsch und historischer Realität.

Im folgenden Beispiel wird historisches Bildmaterial ohne formale oder inhaltliche Parallelen mit einer weiteren Fotografie kombiniert. Die von Graham angeeignete Fotografie zeigt den Moment der japanischen Kapitulation am Ende des Zweiten Weltkrieges (Abb. 29). Graham fotografiert vermutlich einen Ausschnitt aus der historischen Fotografie, denn die gesamte querformatige Bildfläche wird von der schwarz-weißen Fotografie eingenommen, Bildbegrenzung oder Installationsanordnung liegen außerhalb des gewählten Ausschnitts. Das historische Bild wirkt leicht verzerrt. Körnung und Kratzer der historischen Fotografie sind in Grahams Bild jedoch gut zu erkennen. Das Zentrum von Grahams Fotografie bildet eine im Profil zum Betrachter kniende Person, die in einem Ausdruck von Bestürzung die Hand vor das Gesicht schlägt. Die kurz geschorenen Haare der dunkel gekleideten Figur lassen darauf schließen, dass es sich um einen Mann handelt. Die Perspektive von schräg links hinten und die vor das Gesicht gehaltene Hand ermöglichen jedoch keine genaue Identifikation. Im Hintergrund links neben dem Mann sowie rechts von ihm - und damit vor ihm kniend - befinden sich weitere Personen, die zum Teil in tief verneigter Position ausharren. Die Richtung der Verneigung ist rechts. Es ist aus Grahams fotografiertem Ausschnitt nicht ersichtlich, was dort, wohin sie sich verneigen, passiert. Rechts im Bildhintergrund ist eine Hütte zu erahnen, die auf der linken Seite von Bäumen begrenzt wird. Vor der Hütte kann man einige wenige Stufen erkennen. Aufschluss über das religiös anmutende Geschehen gibt der Begriff Kapitulation im Bildtitel. So weiß der informierte Betrachter, dass die historische Fotografie am 15. August 1945 aufgenommen worden ist. ${ }^{24}$ In Berichten über

24 Der Tag der bedingungslosen Kapitulation Japans markiert das Ende des Zweiten Weltkrieges. Obwohl zahlreiche japanische Städte durch Flächenbombar- 
die Aufnahme der Kapitulation in der Bevölkerung wird stets von starken emotionalen Reaktionen gesprochen, denn die meisten Japaner hatten im festen Glauben an den Kaiser Entbehrungen und menschliche Verluste getragen. Nun fühlen sie sich leer, betrogen und absolut erschöpft (vgl. z.B. Dower 1999: 33ff.; Nagai 1962: 118f.). Die Emotion der Hauptfigur auf Grahams Fotografie deckt sich mit diesen Berichten. Die tiefe emotionale Erschütterung der abgebildeten Situation ist von heutiger westlicher Sicht aus kaum nachvollziehbar, würde man doch eher Erleichterung über das Ende des Krieges und vor allem das Ende der Bombardements vermuten. ${ }^{25}$ Graham setzt die historische Fotografie in dem von ihm etablierten Kontext ein, um den Einfluss des Kaisers und der Regierung auf die japanische Bevölkerung zu verdeutlichen. Auch ohne genaue Kenntnisse über die Kapitulation wird die Emotionalität innerhalb der abgebildeten Szene deutlich.

Die Kapitulations-Fotografie bildet ein Paar mit der Abbildung einer knallig rosafarben bedruckten Fläche, die dem in der Eingangssequenz beschriebenen Bild ähnelt. ${ }^{26}$ Das Bild wirkt sehr flächig, nur mit einem vergröBerten Betrachtungsabstand ist ein leichter Farbverlauf zu erkennen. Zwischen den beiden Fotografien scheint zunächst weder ein formaler noch ein inhaltlicher Bezug zu bestehen, denn die pinkfarbene Flächigkeit kontrastiert sich stark mit der historischen Schwarz-Weiß-Fotografie. Hier kommt die japanische Deutung der Farbe Rosa erneut zum Zug, denn sie verkörpert auch die Sterblichkeit des Kriegers (vgl. Abschnitt 3.2.). Insofern schafft die rosafarbene Fläche doch eine Verbindung zur japanischen Kriegsschuld und damit auch zur Kapitulationssituation. Graham arbeitet in diesem Bildpaar mit einer großen bildnerischen Differenz. Auf der metaphorischen Ebene verweist er auf die Unmöglichkeit, die im historischen Bild zutage getretenen streng hierarchischen und religiös anmutenden Machtkonstellationen mit einer rosafarbenen Schicht zu bedecken. Das bedruckte Papier zeigt erneut Elemente der Oberfläche und der Verpackung auf, hinter denen etwas verborgen werden kann und auch verborgen wird. Die Art der Verpackung verweist jedoch symbolisch auf das Verborgene selbst und auf dessen Bedeutung. Die Verbindungslinie zwischen den beiden Fotografien bleibt in diesem Bildpaar

dements stark zerstört, Hiroshima und Nagasaki durch die Atombombenabwürfe weitgehend vernichtet waren und die Japaner bereits seit Jahren hungerten, hatte die Devise stets geheißen, dass bis zum bitteren Ende gekämpft werde. Die meisten Japaner traf deshalb der Vorgang am 15. August 1945 völlig unvorbereitet. Die Bevölkerung wurde im ganzen Land dazu aufgefordert, sich vor den Radioapparaten zu versammeln, um mittags der Bekanntgabe der bedingungslosen Kapitulation durch Tenno Hirohito beizuwohnen. Seine Stimme war niemals zuvor im Radio zu hören gewesen und seine Sprache war so abgehoben, dass noch eine Weile Verwirrung in der Bevölkerung herrschte, ob der Inhalt tatsächlich richtig verstanden worden und dies nicht doch amerikanische Propaganda sei. Tatsächlich waren der Kapitulationserklärung einige Intrigen vorausgegangen, denn in der Nacht zum 15. August hatten fanatische Generäle versucht, die Schallplatte mit der aufgezeichneten Ansprache des Kaisers zu stehlen und ihn umzubringen, um so die Kapitulation zu verhindern (vgl. Pohl 2002: 74).

25 Dies gilt besonders, weil die Zerstörungskraft der neuen von den USA nur wenige Tage zuvor eingesetzten Waffen bekannt war und weitere Einsätze befürchtet werden mussten.

26 »30. Printed Pink \#2, Tokyo 1992«. Aufgrund der Schwierigkeit, in der Reproduktion Details zu erkennen, wird diese Fotografie hier nicht gezeigt. 


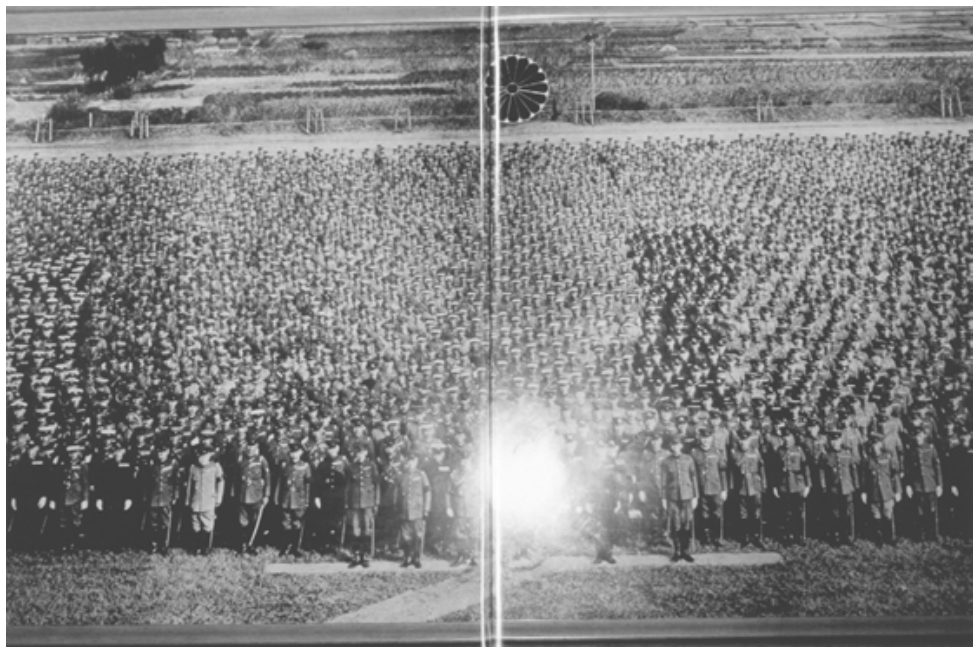

"48. Hirohito and Imperial Army Photograph, Tokyo 1990« (Orig. in Farbe).

eher vage. Diese Feststellung soll jedoch nicht als Werturteil über mehr oder weniger gelungene Bildkombinationen gelesen werden. Vielmehr wird deutlich, dass Graham über ein breites Spektrum an Möglichkeiten im Umgang mit seinen Fotografien verfügt. Die mit den Fotografien und ihrer Anordnung eröffneten Betrachtungsmöglichkeiten geben dem Publikum Raum für eigene Assoziationen.

Als letztes Beispiel für Grahams Umgang mit angeeignetem Bildmaterial soll hier abermals eine abfotografierte Schwarzweißfotografie betrachtet werden (Abb. 48). Aus den bislang besprochenen Fotografien sticht diese Aufnahme durch einen deutlich erkennbaren bildnerischen Eingriff hervor. Graham fotografiert die historische Fotografie so, dass am oberen und unteren Bildrand der schlichte Holzrahmen angeschnitten ist, während sich die Vorlage am rechten und linken Bildrand außerhalb des gewählten Ausschnitts fortsetzt. Abgebildet ist die historische Fotografie einer großen Ansammlung uniformierter Soldaten - der kaiserlichen Armee -, die in Reih und Glied aufgestellt für das Foto posiert. Das ursprüngliche Bild ist von einem erhöhten Standpunkt aus aufgenommen, so dass die Gesichter größtenteils unverdeckt sind. Die Fotografie ist sehr hoch aufgelöst. Trotz der abgebildeten Menschenmenge, die vermutlich einige hundert Personen umfasst, sind die Gesichter in den ersten Reihen deutlich erkennbar. Die Soldaten sind auf einer Wiese aufgestellt, im Hintergrund erstreckt sich parallel zur Kamera ein Weg, der von frisch gepflanzten Bäumen gesäumt ist. Dahinter sind Wiesen und Felder zu erkennen. Graham fotografiert mit parallel ausgerichteter Kamera. Im unteren Bilddrittel, nur wenig rechts aus der Bildmitte herausgerückt, löscht die Reflexion des Blitzlichtes die dort befindlichen Personen aus. Eine weiße runde Leerstelle entsteht. Unterhalb dieser Leerstelle deutet ein Podest an, dass dort der Kaiser als Hauptfigur steht. Graham blitzt Kaiser Hirohito jedoch aus seiner Fotografie heraus. Analog zur Positionierung des Kaisers befindet sich im oberen Bilddrittel das kaiserliche Insignium der sechzehnblättrigen Chrysantheme. Es bildet eine schwarze Kreisform mit 
kleinem weißen Rand und markiert eine Parallele zur hellen Reflexion des Blitzes.

Die mit einem Blitz erfolgende Auslöschung des Kaisers aus der historischen Fotografie verweist indirekt auf den gleißenden Blitz der Atombombe und die Auslöschung zahlreicher Menschenleben. Graham nimmt hier einen entscheidenden künstlerischen Eingriff vor, denn dem gewöhnlichen Museumsbesucher präsentiert sich ein sehr anderes Bild. ${ }^{27}$ In den bisher analysierten Fotografien vorgefundenen Bildmaterials beschränkt sich Grahams Interpretation der Vorlagen hauptsächlich auf die - durchaus schwerwiegende - Wahl des Ausschnitts. Hier geht er einen Schritt weiter, indem seine Fotografie noch entscheidender vom Original abweicht, als wenn er nur einen Ausschnitt genommen hätte. Graham nutzt diese Form, um die fragwürdige Rolle des Kaisers während des Krieges zu thematisieren. ${ }^{28}$ Erneut offenbart sich Grahams Interesse an Fragen der Macht, das sich auch in der formalen Umsetzung im Umgang mit vorgefundenem Bildmaterial manifestiert.

Graham stellt der abfotografierten historischen Fotografie wiederum eine süßliche Szenerie zur Seite (Abb. 49). Die barock anmutende Zuckerdose aus Porzellan mit prächtiger Goldkante nimmt eine zentrale Position in der Bildmitte ein. ${ }^{29}$ Oben auf dem weißen Zucker sind einige bunte Zuckerkörner verteilt. Die Farbigkeit dieser wenigen Zuckerkristalle scheint den Zucker noch süßer machen zu wollen. Thematisiert wird abermals die klebrig süße Schicht, die zur Verdrängung der Vergangenheit verwendet wird. Die bunten Zuckerkristalle bleiben Oberfläche. Da der Zucker ohnehin süß ist, erfüllen die farbigen Kristalle lediglich eine ästhetische Funktion, sie ergeben keinen tieferen Sinn. Auf der metaphorischen Ebene lässt sich hier ein Zusammenhang zum Bild des Kaisers herstellen. Die oberflächliche Ausblendung der Person Hirohitos in Grahams Fotografie ändert so wenig an seiner Verantwortung für die in seinem Namen begangenen Taten der Armee wie die hinzugefügten farbigen Kristalle an der grundsätzlichen Funktion des Zuckers.

27 Hier möchte ich der Auffassung von Andrew Wilson widersprechen, der meint: »The photograph of Hirohito is photographed as any of us would see it in a museum« (Wilson 1996: 41). Gerade die Tatsache, dass Graham die ausgestellte Fotografie anschneidet und mit der Reflexion des Blitzlichtes den Kaiser auslöscht, macht den künstlerischen Eingriff deutlich. Die Annahme, die Betrachtungserfahrung der historischen und der Fotografie Grahams sei identisch, ist unzutreffend.

28 Die mangelnde japanische Aufarbeitung der Kriegsschuld wird zum Teil darauf zurückgeführt, dass die US-amerikanischen Besatzer kein Interesse an einer Diskussion über die Verstrickungen des Kaisers zeigten. Statt ihn abzusetzen oder vor einem Kriegsgericht anzuklagen, setzten die Amerikaner lediglich durch, dass er seiner Göttlichkeit abschwor. Alle - sowohl von amerikanischer als auch von japanischer Seite unternommenen - Versuche, die kaiserliche Rolle während des Krieges genauer zu recherchieren, wurden von Seiten des Leiters der Besatzung, General MacArthur, verhindert. Er war der Meinung, dass nur eine starke Führungsfigur ihm eine reibungslose Einführung der Demokratie in Japan ermöglichen würde. Die Mitarbeit Hirohitos an der Transformation der den Amerikanern so fremden und fanatisch erscheinenden japanischen Gesellschaft schien ihm unabdingbar (vgl. Dower 1999: 287ff.).

29 Das westlich anmutende Porzellan verweist auch auf die Wechselbeziehungen zwischen Japan und dem Westen. Das westliche Design verschweigt, dass die europäische Porzellanproduktion u.a. die japanische zum Vorbild hatte. Es handelt sich hier sozusagen um einen Reimport einer originär japanischen Form. 


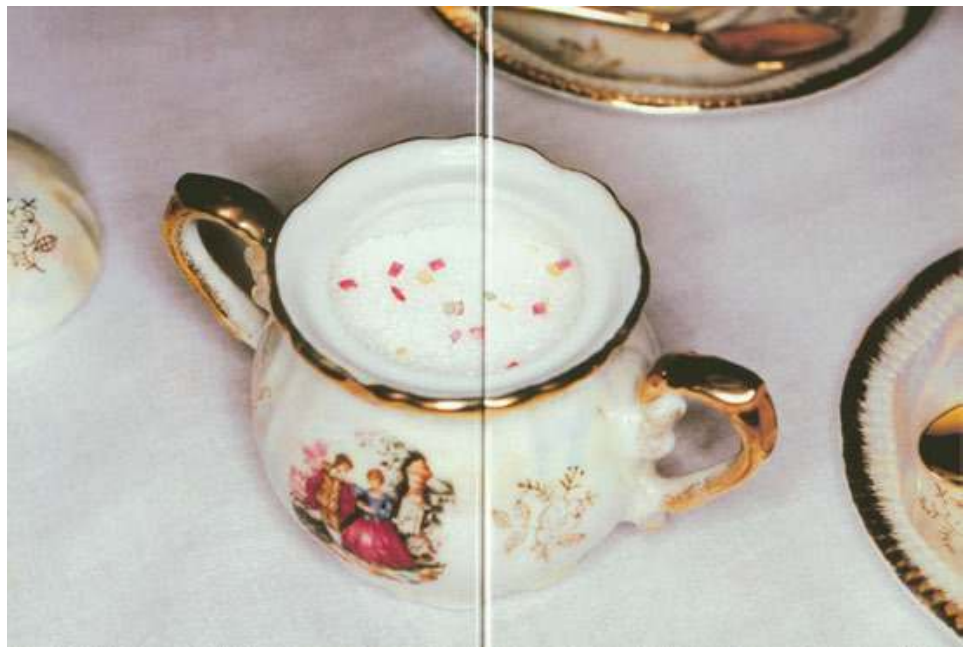

»49. Rainbow Sugar, Tokyo 1995«.

Die oberflächliche Weise der Entlastung Hirohitos nach dem Krieg in Form einer Absage an seine Göttlichkeit war eine Handlung ohne tiefgreifende Folgen. Diese Art der Vergangenheitsbewältigung kommt einer ästhetischen Korrektur an der Oberfläche gleich, die an den historischen Realitäten von Schuld und Verantwortung nichts ändern kann. Erneut konstruiert Graham in der vorliegenden Bildpaarung inhaltliche Zusammenhänge, die nicht ohne eine tiefer gehende Analyse zu erfassen sind. Der Einsatz von angeeignetem Bildmaterial ermöglicht es Graham, einen direkten Bezug zur Geschichte und somit eine Verbindung zwischen japanischer Gegenwart und Vergangenheit herzustellen. Er wählt sein Bildmaterial sehr präzise aus, um eine eindrückliche emotionale Wirkung zu erzeugen. Die paarweise Anordnung mit inhaltlich stark kontrastierendem Bildmaterial, das mehr oder weniger formale Übereinstimmungen aufweist, unterstützt die Wirkung.

\subsection{Künstliche Natur}

Die Natur besitzt einen besonderen Stellenwert in der japanischen Kultur. »Viele Japaner hängen der verbreiteten Vorstellung an, der japanische Blick auf die Natur sei grundverschieden vom europäischen. Das Streben, die Natur zu unterwerfen, wird als Eckstein der westlichen Zivilisation dargestellt, wohingegen die Japaner, anstatt gegen die Natur zu kämpfen, sich ihrer Macht beugen, seit undenklichen Zeiten in Harmonie mit ihr leben « (Coulmas 2005a: 197). Diese Annahme verweist hauptsächlich auf eine ideologische Konstruktion, denn auch in Japan sind Probleme wie Bodenversiegelung oder Umweltverschmutzung bekannt. Die »Würdigung der Natur« ist jedoch »zentrales Glaubenselement« (ebd.: 112). Graham, der vorrangig in Innenräumen fotografiert, berührt dieses Thema trotzdem in Empty Heaven, indem er Verweise auf die Natur in eine extreme Künstlichkeit einbettet. Ein Motivkomplex, der insgesamt drei Fotografien umfasst, beschäftigt sich mit Kirschbäumen, die als nationales Symbol gelten können (Abb. 17; 32; 36). 

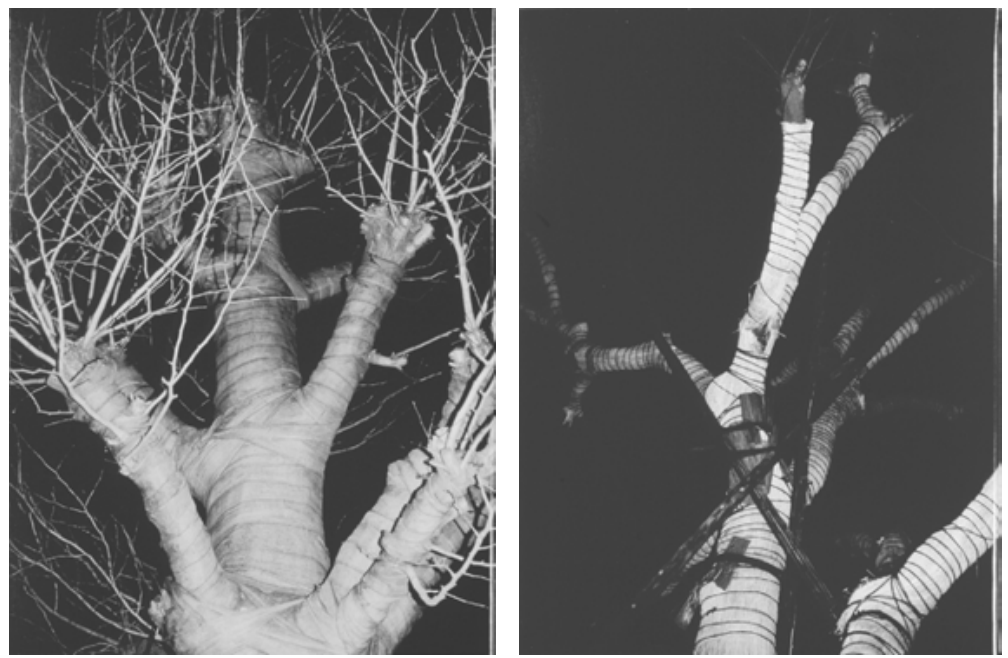

»17. Wrapped Cherry Tree \#1, Financial District, Tokyo 1995«; »36.

Wrapped Cherry Tree \#3, Financial District, Tokyo 1995«(Orig. in Farbe).

Die Abbildung blühender Kirschbäume gehört zum Standardrepertoire zahlreicher Japanreisender, Graham zeigt dieses klassische Thema jedoch auf sehr individuelle Weise. ${ }^{30}$ Die drei hochformatigen Fotografien zeigen »umhüllte Kirschbäume«, die sich - von unten angeblitzt - vor dem schwarzen Nachthimmel abheben. Die Bäume sind im Winter fotografiert und tragen keine Blätter. Ihre Stämme und dicken Äste sind mit Binden aus Sackleinen oder Bast umwickelt, in Abbildung 36 wird die Umwicklung noch durch Draht verstärkt, ein grober Holzverhau stützt die schweren Äste zusätzlich. Aus den Umwicklungen ragen lediglich kleine dünne Äste hervor. ${ }^{31}$

Die Bäume scheinen mit Bandagen verbunden, was eine Verletzung andeutet. Die Bandagierungen, die vermutlich dazu angebracht sind, um vor Beschädigungen zu schützen, lassen die Bäume in Grahams Fotografien zu Schwerverletzten werden, die einer langfristigen Rekonvaleszenz bedürfen. Trotz ihrer Stabilität wirken die Bäume fragil und hilfsbedürftig. Dies tritt besonders in der ersten der drei Fotografien zutage, denn hier wirkt die angeblitzte Bandagierung fast weiß und erscheint wie ein frisch angelegter Mullverband. Der menschliche Eingriff wird auf schmerzliche Weise erfahrbar. In Grahams Fotografien fehlt den Kirschbäumen das Schöne und Erhabene, das üblicherweise zu ihrer Darstellung gehört. Verkörpern die Kirschblüten und damit indirekt auch die Kirschbäume für Japaner Reinheit und Einfachheit, setzt Graham dem die Künstlichkeit des menschlichen Eingriffs in die Natur entgegen. Die vermeintliche Natürlichkeit des Kirschbaumes weicht einer kulturellen Bedingtheit. Die Bäume werden in den Fotografien $\mathrm{zu}$ archaischen Formen. Ihre Umhüllung verweist auf jenseits des Sichtbaren Liegendes. Die Natur in Form des Kirschbaumes scheint ganz und gar in eine

30 Vgl. z.B. die Fotografien von Robert van der Hilst in: The EU-Japan Fest Japan Committee 2000b: 38-41.

31 In Japan dienen solche Umwicklungen dazu, kranke oder schwache Bäume während des Winters vor der Kälte zu schützen. 


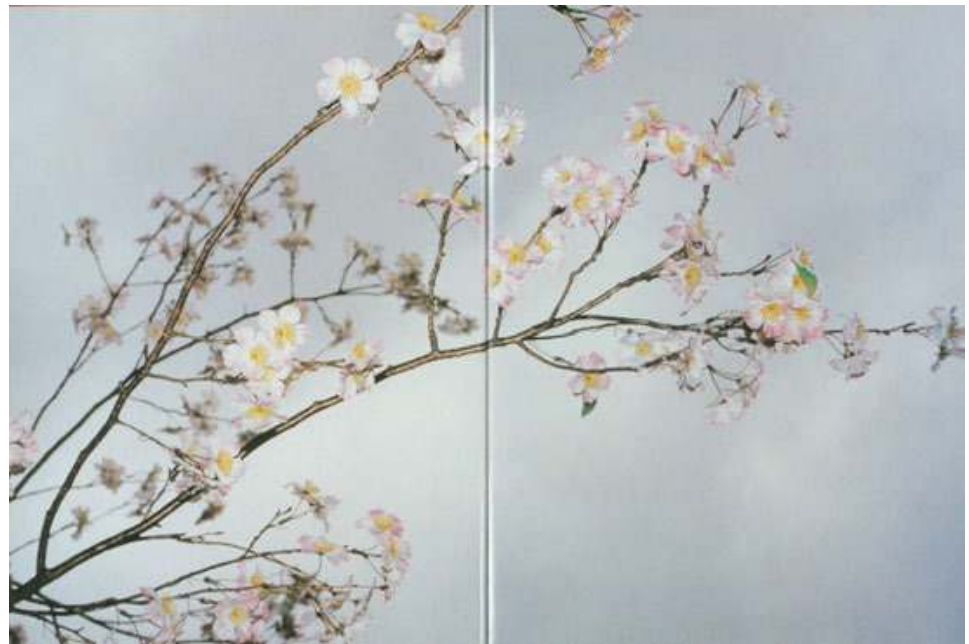

»21. Artificial Cherry Blossom, Tokyo 1991«.

künstliche und gestaltete Welt überzugehen. »Charakteristisch für das Verhältnis von Mensch und Natur in Japan ist [...] die Betonung [...] des gleitenden Übergangs von Kultur und Natur. Die zum Teil höchst artifizielle Formgebung der Natur [...] wird deshalb nicht als widersprüchlich empfunden« (Coulmas 2005a: 278). Der menschliche Eingriff in die Natur spiegelt sich in Grahams Kirschbaumfotografien wider. Im Gegensatz zur japanischen Gartenkultur, die auf die Erhabenheit der unberührten Natur verweist, fehlt hier jeglicher Ausdruck von herkömmlicher Schönheit. Es ist Nacht und Winter und die durch Perspektive und Blitzlicht erzeugte Direktheit der Abbildung verweigert sich der Bewunderung einer Natur, die höchst artifiziell ist. In der Wiederholung betont Graham die Bedeutung der auf die Natur ausgeweiteten menschlichen Einflusssphäre. Dies passt abermals zu Grahams Anspruch, Visualisierungen zum Thema Macht und deren Maskierung zu finden. Zusätzlich erscheint in der Umhüllung erneut das Motiv der Verpackung. ${ }^{32}$ Interessant ist auch der Ort der fotografischen Aufnahmen, denn sie sind alle im Financial District in Tokyo gemacht, was abermals auf Aspekte der Macht verweist. Auf einer sehr abstrakten Ebene laufen in diesen Fotografien verschiedene Assoziationslinien zusammen.

Das Kirschbaum-Thema greift Graham erneut an anderer Stelle mit einer querformatigen einzeln stehenden Fotografie auf (Abb. 21). Die Fotografie zeigt künstliche Kirschblüten, die mit Draht an echten Zweigen befestigt sind. Sie verweist damit auf ein Erlebnis, das dem Betrachter in den Fotografien der Kirschbäume vorenthalten wird. Die Blüten treten wegen des Blitzes sehr plastisch in Erscheinung, sie sind tagsüber außen vor einem grau bewölkten Himmel fotografiert. Es findet eine Verkehrung von Natur und Künstlichkeit statt. Wirken die fotografierten echten Kirschbäume der Natur

32 Der Fotograf Enari Tsuneo weist darauf hin, dass Japan auf dem Weg zum wirtschaftlichen Erfolg sehr viel Natur zerstört hat, weshalb Graham mit den bandagierten Kirschbäumen die Verletzlichkeit der natürlichen Ressourcen Japans ausdrücke (vgl. Enari 2006). 
sehr weit entrückt, entsteht hier auf den ersten Blick ein eher natürlicher Eindruck, der lediglich durch den Einsatz des Aufhellblitzes gebrochen wird. Erst beim näheren Hinschauen entdeckt man die Drähte, mit denen die Plastikblüten befestigt sind. Trotzdem ist die Fotografie weit davon entfernt, kitschig zu sein. Die Ambivalenz zwischen Natur und Künstlichkeit wird direkt betont. Die Kirschblüte verliert in der Plastikform die ihr innewohnende ephemere Zartheit. Nicht Vergänglichkeit, sondern Dauerhaftigkeit und Robustheit stehen im Vordergrund. Auf diese Weise kann nicht einmal das Wetter, das in diesem Bild tendenziell nach Regen aussieht, den Kirschblüten etwas anhaben. Die Härte, die die Bilder der umhüllten Kirschbäume auszeichnet, setzt sich in der Fotografie der artifiziellen Kirschblüten fort. Während jedoch die echten Kirschbäume krank und verletzt wirken, demonstriert die Fotografie der künstlichen Kirschblüten Stabilität. So entsteht eine Diskrepanz zwischen den Abbildungen selbst und den weiterführenden Assoziationen der Betrachter.

Graham spielt in den Naturmotiven mit der Ambivalenz zwischen Natur und Künstlichkeit, den Gegensätzen von Sichtbarkeit und Unsichtbarkeit. ${ }^{33}$ Jegliche Form von Natur unterliegt in Grahams Bildern dem gestaltenden Eingriff durch den Menschen, der damit seinen Machtbereich ausdehnt. Nimmt der Betrachter manche Fotografien an der Oberfläche zunächst wie kleine alltägliche Absurditäten wahr, wie man sie fast überall finden mag, entstehen auf einer symbolischen Ebene starke Verbindungen. Durch den stilistischen Einsatz der Wiederholung von Motiven und die stringente Bildauffassung sowie eine vielschichtige Symbolik erzielt Graham die eindringliche Wirkung seiner Fotografien.

\subsection{Menschenbilder}

\subsubsection{Frauenporträts}

Eine wichtige Motivgruppe in Empty Heaven sind die Frauenporträts. Das Buch beginnt mit einem solchen Porträt, ein weiteres folgt unmittelbar nach der Titelei. Mit insgesamt zehn Fotografien bilden sie den umfangreichsten Motivkomplex innerhalb des Werkes. Es handelt sich um in halbnaher oder naher Einstellungsgröße aufgenommene Hochformate, die die Person ins Zentrum rücken. ${ }^{34}$ Die Aufnahmeperspektive bezieht stets den Raum mit ein. Kleidung und Haltung erlauben Rückschlüsse auf die Person. In allen Frauenporträts ist die Gestik signifikant. Die Fotografie friert die an sich flüchtige

33 Die Verwobenheit von Natur und Künstlichkeit ist in zwei weiteren Fotografien thematisiert: »9. Artificial Roses in Bell Jar, Tokyo 1995« erzeugt eine starke Emotionalität durch eine Bildauffassung, die Assoziationen zu Trauer und Vergänglichkeit erzeugt, obwohl die Methode der Trocknung den Rosen eine lange Haltbarkeit verleiht. »54. Roots in Bottle, Tokyo 1992« zeigt eine Grünpflanze, deren dichtes Wurzelwerk in einem Glas mit Wasser kaum Halt findet. Hier drängen sich abermals Fragen nach dem menschlichen Eingriff in die Natur und die Interdependenz von Natur und Künstlichkeit auf. Es offenbart sich der Widerstand der Natur gegen ihre Konservierung.

34 Die Bildunterschriften geben meist den Vornamen der Porträtierten, Ort und Jahreszahl an. 


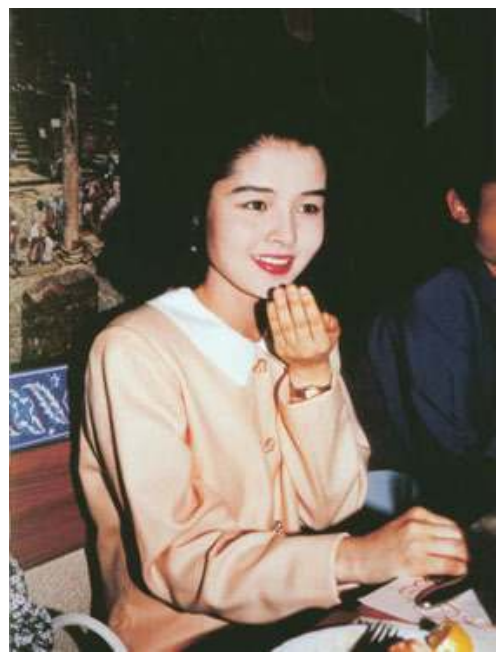

»6. Girl with White Face, Tokyo 1992«.

Geste der Handbewegung ein, macht sie sichtbar und damit sprechend. Die "prominente Rolle, die der Hand neben dem Gesicht und dessen Sprechwerkzeugen zukommt, « wird betont (Pompe 2003: 14). Weil aber die Gesten der Hand historisch und kulturell kodiert sind, sind ihre Bedeutungen in Grahams Fotografien für den westlichen Betrachter nicht leicht zu entschlüsseln (vgl. Blessing 2004: 38). Die Hände der Protagonistinnen verdecken mitunter Teile des Gesichts, was die Lesbarkeit zusätzlich erschwert. Weil Graham genau diese Fotografien aussucht, die andere Fotografen wohlmöglich als misslungen aussortieren würden, bestimmt die Gestik die Wirkung der Bilder. Sie erhält teilweise einen höheren Stellenwert als das Gesicht selbst.

Die zweite Sequenz des Buches beginnt mit dem Porträt eines »Mädchen[s] mit weißem Gesicht « (Abb. 6). ${ }^{35}$ Die Fotografie ist rechtsseitig angeordnet, die linke Seite bleibt weiß. Im Gegensatz zu den anderen Frauenporträts wird ihr Name nicht genannt. ${ }^{36}$ Der Bildtitel bestätigt eine Tatsache, die sofort ins Auge fällt, denn das Gesicht wirkt gepudert und wesentlich heller als Hals oder Hände. Dieser Effekt wird sowohl durch den Einsatz des Blitzlichtes als auch durch den knallig rosafarbenen Lippenstift, das schwarze Haar sowie die dunklen Augen und Augenbrauen der Protagonistin unterstrichen. Ähnlich wie im ersten Porträt der Eingangssequenz ist die junge Frau mitten in einer Bewegung eingefroren. Sie führt ihre linke Hand in einer Geste zum Mund, die andeutet, dass sie ihn bedecken möchte. Sie lächelt und lauscht offenbar gebannt einer ihr gegenüber sitzenden Person, die nicht mit abgebildet ist. Ihre leuchtenden dunklen Augen, die am Betrachter vorbei rechts aus dem Bild hinausschauen, verweisen auf einen hohen Grad an Aufmerksamkeit.

35 Dieses Bild ist auch als Ausschnitt auf dem Schutzumschlag des Buches abgedruckt.

36 Die Porträtierte hat lange Zeit als Sprecherin des staatlichen Fernsehsenders NHK in der Region Osaka gearbeitet und ist in der Kansai-Region recht bekannt, wie mir die Kuratorin Ikeda Yuko im Gespräch mitteilte (vgl. Ikeda 2006). 
Die schulterlangen Haare der Protagonistin sind lockig frisiert. Sie trägt eine teuer aussehende apricotfarbene Kostümjacke mit Perlenknöpfen und eine kleine goldene Uhr. Außer dem durch das dichte Haar hervorblitzenden Ohrring ist kein Schmuck zu erkennen. Sie wirkt sehr feminin, gleichzeitig aber naiv und mädchenhaft, was durch die Gestik noch unterstrichen wird. Sie sitzt in einem Restaurant, das westliche Speisen serviert. Die Mahlzeit ist beendet, worauf in der rechten unteren Bildecke Geschirr und Besteck hinweisen. Links hinter ihr hängt eine Fotografie an der Wand, die Touristen in einer antiken Ausgrabungsstätte zeigt, weshalb es sich vermutlich um ein europäisches Restaurant handelt. Am rechten Bildrand ist eine links neben der Protagonistin sitzende Person so angeschnitten, dass ihr Gesicht außerhalb der Fotografie liegt. Der Blick des Betrachters wird automatisch auf das weiße Gesicht der Porträtierten gelenkt.

Graham fotografiert die junge Frau sehr distanziert. Trotz dem während der Aufnahme bestehenden geringen Abstand zwischen Fotograf und Protagonistin erschließt sich kaum etwas von der Persönlichkeit der Porträtierten, was über Kleidung und Styling hinausgeht. Ihre sorgfältige Aufmachung zeugt davon, dass ihr Äußerlichkeiten sehr wichtig sind. Der Kleidungsstil lässt sie wohlhabend erscheinen. Sie wirkt mädchenhaft niedlich, aber unnahbar und auf gewisse Weise stereotyp japanisch, obwohl das Umfeld ein europäisiertes ist. Das wahrgenommene Klischee lässt sich mit der japanischen Tradition in Verbindung bringen, in der weiß geschminkte Gesichter bereits seit dem Mittelalter allein schon deshalb als schön und edel gelten, weil sie Personen von der unter freiem Himmel arbeitenden Landbevölkerung abgrenzen (vgl. Coulmas 2005a: 212). Während andere Schönheitsideale wie das Schwärzen der Zähne oder das Abrasieren der Augenbrauen bei verheirateten Frauen nicht bis heute fortbestehen, deutet das weiß geschminkte Gesicht der Porträtierten darauf hin, dass sich Feinheit noch immer durch einen hellen Teint ausdrückt. Die Kombination von weißem Gesicht und roten Lippen, wie sie auch im Make-up der Geisha bis heute Anwendung findet, gilt als glückverheißend. ${ }^{37}$ Die Porträtierte sieht nicht annähernd wie eine Geisha aus, ihre Gestik verweist aber auf die japanische Etikette. »Die charakteristische Geste der den Mund beim Lachen oder auch beim Sprechen bedeckenden Hand « ist »unter Japanerinnen aller Schichten weit verbreitet« (ebd.: 213). Mit dieser Geste wird einerseits etwas verborgen, andererseits spricht sie für sich selbst und wirkt deshalb enthüllend.

Ein weiteres exemplarisches Frauenporträt ist das Porträt von Rie (Abb. 16). Die rechtsseitig angeordnete Fotografie ist auf der Doppelseite einem weiteren Frauenporträt zur Seite gestellt. Die junge Frau ist in einer halbnahen Einstellung fotografiert. Sie sitzt auf dem Fußboden eines traditionell japanischen Raumes. Sie ist dem Betrachter frontal zugewandt, den sie jedoch nicht anschaut. Ihre linke Hand verdeckt - mit angewinkeltem kleinen Finger - die rechte Wange in einer Bewegung, als wäre sie gerade im Begriff, sich die kurzen schwarzen Haare hinter das Ohr zu streichen. Der Daumen der Hand weist auf die Nasenspitze, so dass Mund und ein Teil der Nase ebenfalls verdeckt sind. Die Bedeutung der Geste bleibt unklar. Sie schaut gedankenverloren rechts am Betrachter vorbei aus dem Bild hinaus. Abermals verdeutlichen die Schlagschatten den Einsatz des Blitzlichtes, das die Gestik in

37 Sie findet sich beispielsweise in Geschenkbanderolen und der japanischen Flagge (vgl. Coulmas 2005a: 213). 


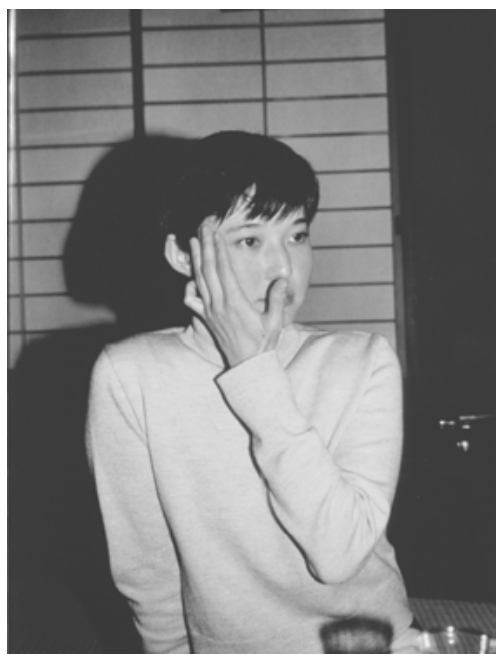

»16. Rie, Tokyo 1995« (Orig. in Farbe).

der Bewegung einfriert. Das Bild ist wie die anderen Porträts nicht inszeniert, wirkt aber weniger artifiziell als das Porträt des Mädchens mit dem weißen Gesicht. Dies steht vermutlich in Zusammenhang mit der fotografierten Person, die sehr entspannt und deshalb natürlich wirkt. Sie trägt einen unspektakulären hellgrauen Rollkragenpullover und ist kaum geschminkt. Der Raum ist klar strukturiert. Rie sitzt auf Tatami-Matten, im Hintergrund ist eine mit Papier bezogene Schiebetür (shoji) zu erkennen. Die Klarheit der Komposition unterstreicht die ruhige Ausstrahlung der fotografierten Person. Die Porträtierte wirkt weniger manieriert und distanziert als die vorher beschriebene Frau mit weißem Gesicht. Obwohl das Porträt in einem japanischen Umfeld aufgenommen ist, scheint es weniger klischeehaft. Graham fertigt hier abermals kein psychologisches Porträt an. Ries Art sich zu kleiden und zu geben ist jedoch sehr anders als die der Frau im vorangegangenen Beispiel, was auch auf die unterschiedlichen Charaktere hinweist.

Die hier exemplarisch vorgestellten Frauenporträts machen deutlich, dass Graham mit formaler Stringenz arbeitet. Alle Frauenporträts zeigen junge Frauen in einem ähnlichen Größenverhältnis, alle verharren in einer nicht inszenierten, aber durch das Blitzlicht eingefrorenen Geste. Sie schauen nicht direkt zum Betrachter und entziehen sich somit dessen Blick. Dies trägt dazu bei, dass sie unnahbar, distanziert und rätselhaft wirken. Andererseits deuten die Ähnlichkeiten der Bildauffassung die unterschiedlichen Charaktere und Persönlichkeiten der einzelnen fotografierten Personen an. Feine Nuancierungen weisen darauf hin, dass die gefühlte Distanz zu den Frauen nicht auf jeder Fotografie die gleiche ist. Im direkten Vergleich entwickeln sich Abstufungen. So bekommt jede fotografierte Frau etwas Eigenes, das sie von den anderen unterscheidet. In der fotografischen Betonung von Manierismen und Distanz erhalten sie fast eine persönliche Note, die - wenn auch nur sehr verhalten - auf ihre Individualität hindeutet.

Graham betont, dass ihm die Intensität der Porträts sehr wichtig ist. Gleichzeitig möchte er eine Verbindung hergestellt sehen zwischen dem Verhalten der Frauen und der »Verhüllung der Psyche« (Graham 1995b: o.S). 
Graham sieht die Frauenporträts als ein Mittel, die Abschottung von Gefühlen mit dem fehlenden historischen Bewusstsein in Verbindung zu bringen. $\mathrm{Ob}$ der aufmerksame Beobachter eine solche Verbindung herzustellen vermag, ohne auf Grahams Aussagen zurückzugreifen, ist fraglich. Die Verschleierung von Befindlichkeiten wird dennoch in den Frauenporträts offensichtlich, so dass Grahams Intention durchaus nachvollziehbar ist. Die Qualität der Porträts wird in Grahams individuellem Ansatz und seinem Vermögen, eine Ambivalenz zwischen Sichtbarem und Unsichtbarem zu erzeugen, offenbar. Trotz vergleichbarer Porträtauffassung besitzt jedes einzelne Porträt etwas Eigenständiges.

Die Porträts sind teilweise in Privaträumen, aber auch in Restaurants fotografiert. Namensnennung und Bildauffassung deuten darauf hin, dass Graham mit den meisten Frauen bekannt ist und sie darauf vorbereitet sind, sich von ihm fotografieren zu lassen. Es entsteht ein Austausch zwischen Fotograf und Modell. Graham bleibt als Fotograf nicht anonymer Beobachter. Er nimmt Kontakt auf und lässt Situationen entstehen, in denen er seine Bildideen umsetzen kann. Die in den Porträts transportierte Distanz ist eine bewusst herbeigeführte, die nichts über Grahams persönliche Interaktion mit den Protagonistinnen aussagt.

\subsubsection{Bürokraten}

Für die Männerporträts wählt Graham eine bildnerische Form, die einen Vergleich der Fotografien ermöglicht. Die stilisierte Bildauffassung tritt stark hervor, da Graham den Personen so nahe kommt, dass nur noch ein Ausschnitt des Gesichts im Profil zu sehen ist - von Höhe der Augenbrauen bis hin zur Mitte des Kinns. Der Hintergrund ist schwarz. Somit werden Unterschiede der Kleidung oder der Umgebung eliminiert. Das fotografierte Gesicht wird zur Oberfläche, die Person als solche ist nicht mehr auszumachen. Die zunächst einzige offensichtliche Variante in den hochformatigen Fotografien besteht in der unterschiedlichen Ausrichtung der Profile nach links und rechts. Die Entscheidung für die jeweilige Blickrichtung steht in enger Verbindung mit dem Layout des Buches (vgl. Abschnitt 3.6.). Im Gegensatz zu den Frauen werden die Männer in den Bildtiteln nicht mehr mit Namen benannt, sie werden mit »Mann«, einer Nummer und dem Ort der Aufnahme - dem Tokyoter Stadtteil Kasumigaseki - bezeichnet. Der Ort der Aufnahme spielt für Graham eine bedeutende Rolle, denn es ist der Stadtteil, »in dem alle Bürokraten arbeiten « (Graham 1995b: o.S.). Aspekte der Macht stehen in enger Verbindung mit den Menschen, die die Macht ausüben oder aber denen, die die Machthaber unterstützen, indem sie ihre Dienste zur Verfügung stellen. Die Bürokraten gehören zur letzten Gruppe. Graham gibt an, dass in Japan die Bürokraten gemeinsam mit den Geschäftsleuten und den Politikern bestimmen was läuft. Aber: »Sie wurden nicht gewählt und sind eigentlich auch nicht repräsentativ« (ebd.). Die porträtierten Männer verkörpern Macht. Als Einzelperson ist ihre Teilhabe an der Macht vermutlich gering, als Teil des Apparats trägt jedoch jeder einzelne Bürokrat zur Aufrechterhaltung der Machtdistribution bei. Dass es sich bei den fotografierten Herren um Bürokraten handelt, erschließt sich jedoch nicht aus den Fotografien. Doch auch ohne dieses spezifische Wissen können sie aufgrund der standardisierten Bildauffassung als Vertreter der breiten Masse der Angestellten - der so ge- 

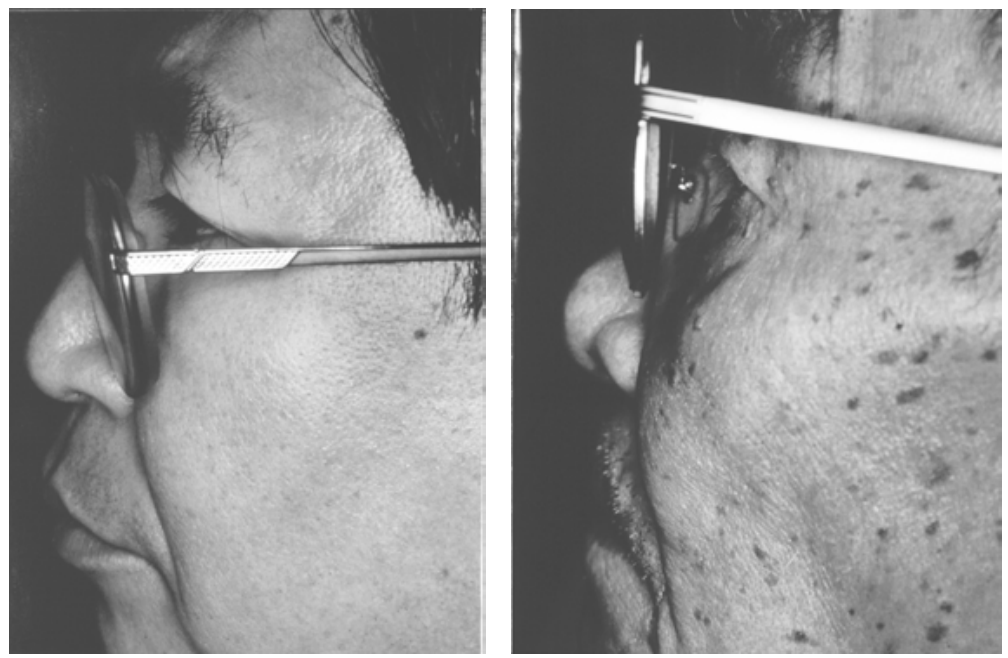

»22. Man \#1, Kasumigaseki, Tokyo 1995«; »28. Man \#2, Kasumigaseki, Tokyo 1995« (Orig. in Farbe).

nannten >salary men $($ (sarariiman) - gelten, denen das Stereotyp einen bienenhaften Fleiß, aber kaum Individualität zumisst (vgl. Teil I, Abschnitt 2.3.1.).

Oberflächlich gesehen scheint es kaum Unterschiede zwischen den einzelnen Porträts zu geben. »Mann \#1 « beispielsweise trägt eine recht große Brille mit Metallbügel (Abb. 22). Die Nase ist klein, die Falten moderat, sein Alter ist schwer einzuschätzen. Seine linke Gesichtshälfte ist leicht von oben fotografiert, so dass sein linkes Auge oberhalb des Brillenbügels zu sehen ist. Er hat dichte Wimpern und struppige Augenbrauen, aus denen einige längere Haare wild herausragen. Er hat schwarze Haare und ist glatt rasiert, seine Haut ist ebenmäßig. Links unter der spärlichen Kotelette hat er einen Leberfleck. Das Porträt ist extrem unspezifisch. Graham geht nah heran, ohne ein Interesse an der Person selbst zu offenbaren. Der Fotografierte ist entindividualisiert und damit komplett austauschbar. Graham äußert im Interview, dass er die Männer porträtieren möchte, »ihr Profil, ihre Augen berühren, so etwas wie die Tore zu ihrer Seele« (Graham 1995b: o.S.). Diese Aussage mutet recht skurril an und ist schwer nachvollziehbar, denn es scheint unmöglich, dem Porträtierten - außer räumlich - nur annähernd nah zu kommen oder ihn als Person überhaupt zu erfahren. Die Augen direkt zu sehen ist bei Brillenträgern jedoch ausschließlich aus dieser Aufnahmeposition möglich. Statt der Person nahe zu kommen, entsteht trotz der räumlichen Nähe, die der Fotograf zum Motiv hält, eher das Gefühl einer extremen Distanz.

Die Aufnahme von »Mann \#2« ist auf den ersten Blick der von »Mann $\# 1$ « sehr ähnlich (Abb. 28). Auch er ist ein Brillenträger mit kleiner Nase, Graham fotografiert ebenfalls seine linke Gesichtshälfte. Durch die leichte Untersicht liegt das linke Auge hier unter dem metallenen Bügel der großen Brille. Es ist weniger vom Auge sichtbar als bei Mann \#1. Im Vergleich fallen Details ins Auge: Die Rasur von Mann \#2 liegt länger zurück und im Bartwuchs zeigen sich zwischen den schwarzen einige weiße Stoppeln. Seine Haut wirkt schlaffer und weist zahlreiche Pigmentflecken auf. Er ist wesentlich älter als Mann \#1. Seine Augenbrauen sind ebenfalls buschig, jedoch in 
der Fotografie anders angeschnitten und deshalb nicht so deutlich sichtbar, wie auch von seinen Haaren nichts zu sehen ist. Auch Mann \#2 ist nicht als Individuum fotografiert. Dennoch treten plötzlich Unterschiede viel stärker hervor als zunächst angenommen. Wo auf den ersten Blick scheinbar alle Männer ähnlich oder sogar gleich aussehen, offenbaren sich beim zweiten Hinschauen zahlreiche Unterschiede. Je mehr Porträts man intensiv anschaut, desto größer wird das Spektrum der beobachtbaren Differenzen.

Der Umgang Grahams mit dem Genre Porträt verdeutlicht, dass er andere Mittel als eine individualisierende Abbildung von Personen für die Arbeit Empty Heaven einsetzt. Den anderen Fotografien ähnlich entfalten auch die Porträts ihre Wirkung auf einer symbolischen Ebene. Grahams Bildauffassung weicht stark von herkömmlichen Ideen der Menschendarstellung ab, die sich eher am Individuum orientieren als dass sie das Porträt für andere Zwecke benutzen. Er legt den Schwerpunkt auf eine standardisierte Unnahbarkeit und scheint damit das Stereotyp der fehlenden Individualität und Unterscheidbarkeit der Japaner zu unterstreichen. In der näheren Betrachtung offenbart sich jedoch, dass auf diese Weise Unterschiede besonders deutlich hervortreten und somit der Aspekt der Austauschbarkeit hinterfragt wird.

\subsection{Sequenzen und Tableaus}

Wie in den vorigen Abschnitten angesprochen, arbeitet Graham mit Bildpaarungen, Sequenzen und Tableaus, um die inhaltliche Aussage seiner Fotografien zu unterstützen. Da er jedoch lediglich zwei verschiedene Bildformate verwendet, ist die Anordnung der Fotografien im Layout sehr eingeschränkt. Nur die paarweise Nebeneinanderstellung hochformatiger Fotografien ist so auf einer Doppelseite möglich. Querformatige Bildpaare erstrecken sich zwangsläufig über zwei Doppelseiten. Noch problematischer als eine Abgrenzung von Paarungen und Sequenzen ist im Buch der Umgang mit Tableaus. Ein Tableau ermöglicht die gleichzeitige Betrachtung mehrerer neben- oder untereinander gestellter Fotografien. Eine solche Konstellation scheint unter den gewählten layouttechnischen Voraussetzungen unmöglich. In einer Anordnung hintereinander gelingt es Graham dennoch, im Layout einen Eindruck von Zusammengehörigkeit innerhalb einzelner Bildstrecken zu erreichen. Damit unterstützt er eine Lesart, die Bildfolgen als Tableau wahrnehmbar machen. Dies ist zwar nicht mit einer Ausstellungspräsentation vergleichbar, visualisiert aber deren Idee. Sequenzen und Tableaus sind nur sporadisch durch Vakatseiten voneinander abgegrenzt, wodurch eine hohe Bilddichte erzeugt wird. Die Anordnung im Layout ermöglicht dennoch eine schlüssige Lesart.

Beispielhaft soll hier eine Reihung von elf Fotografien auf neun Doppelseiten vorgestellt werden, die durch Vakatseiten abgegrenzt ist. Sie beginnt mit der Fotografie Nummer 38, dem rechtsseitig angeordneten Porträt einer jungen Frau (Abb. 38). Die linke Hälfte der Doppelseite ist weiß. Yuka schaut rechts aus dem Bild hinaus und gibt so die Richtung zum Umblättern vor. Die folgende Doppelseite zeigt eine eindeutig als solche erkennbare Paarung der historischen Fotografie einer Atombombenexplosion mit der Fotografie eines mit einem Barcode markierten Einwickelpapiers (Abb. 39; 40). 

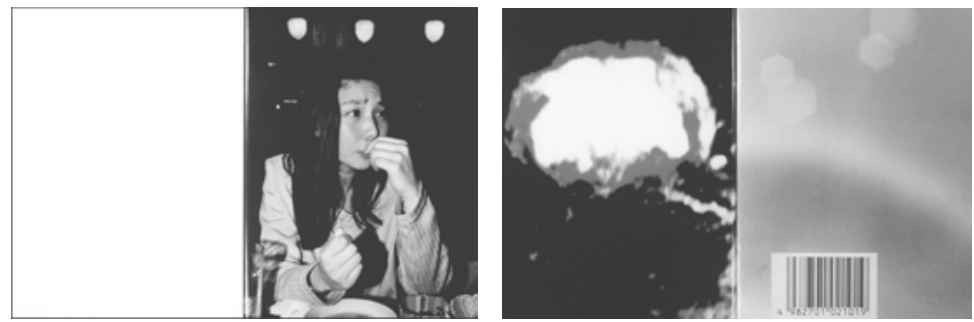

»38. Yuka, Tokyo 1992«; »39. Atomic Fireball Explosion, Nagasaki 1992«; »40. Wrapping Paper with Printed Colourful Explosion, Tokyo 1990« (Orig. in Farbe).
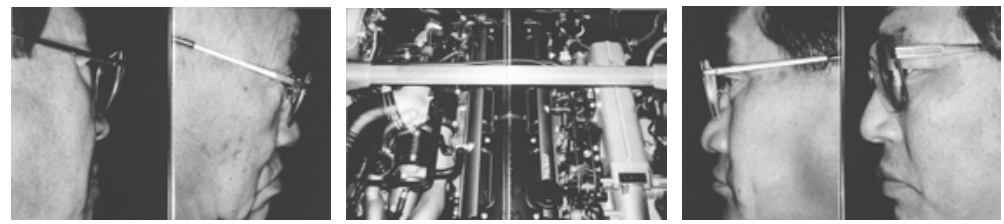

»41. Man \#5, Kasumigaseki, Tokyo 1995«; »42. Man \#6, Kasumigaseki, Tokyo 1995«; »43. Toyota Engine \#3 (Aristo), Tokyo 1995«; »44. Man \#7, Kasumigaseki, Tokyo 1995«; »45. Man \#8, Kasumigaseki, Tokyo« (Orig. in Farbe).
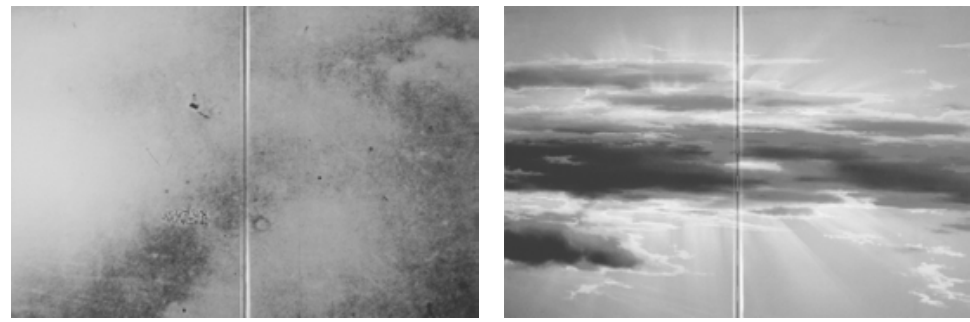

»46. Atomic Cloud Photographic Backdrop, Hiroshima 1990«; »47. Rising Sun Painted Backdrop, Tokyo 1990« (Orig. in Farbe).
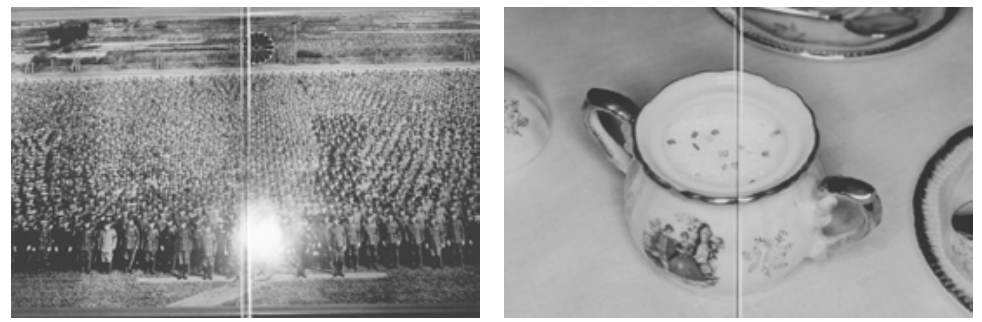

»48. Hirohito and Imperial Army Photograph, Tokyo 1990«; »49. Rainbow Sugar, Tokyo 1995« (Orig. in Farbe).

Auf der nächsten Doppelseite folgen zwei Porträts von Bürokraten (Abb. 41; 42). Beide fotografierte Personen schauen nach rechts. Diese Anordnung scheint ungewöhnlich, wird in Layouts doch oftmals versucht, eine formale 
Verbindung zwischen doppelseitig präsentierten Fotografien herzustellen. Die beiden Personen treten jedoch nicht miteinander in Beziehung. Es folgt die querformatige Abbildung eines Motorblocks auf der nächsten Doppelseite (Abb. 43). Die Fotografie wirkt sehr symmetrisch. Das obere Bilddrittel ist durch eine über die gesamte Horizontale verlaufende metallene Stange vom restlichen Bild abgetrennt, die eine Verbindungslinie zwischen den Brillengestellen der Porträtierten schafft. Die vertikale Mitte markiert ein breiter schwarzer Bereich, auf dem die Typenbezeichnung des Motors abgesetzt ist. Ähnlich den anderen Motorenabbildungen strahlt die Fotografie Ruhe und Kraft zugleich aus. Blättert man abermals um, sind nun zwei Bürokratenporträts zu sehen, die beide nach links schauen (Abb. 44; 45). Hier wird offensichtlich, dass es sich bei der Anordnung der vier Porträts flankierend zur Fotografie des Motorblocks eindeutig um ein Tableau handelt. Der Motorblock wird von den Personenabbildungen eingerahmt, die immer in Richtung des Motorblocks schauen. Auch ohne die Möglichkeit, diese fünf Bilder gemeinsam zu betrachten, wird die Intention des Fotografen deutlich. Es folgt die Abbildung einer flächigen historischen Schwarzweißfotografie im Querformat, die von der Fotografie einer ebenfalls flächigen apricotfarbenen Sonnenaufgangsstimmung gefolgt wird (Abb. 46; 47). Die formalen Parallelen beider Bilder lassen auf eine paarweise Anordnung schließen, ebenso wie die Kombination der folgenden Abbildungen, die aus dem oben analysierten Bildpaar der Fotografie des kaiserlichen Heeres und des RegenbogenZuckers besteht (Abb. 48; 49).

Es folgt auf der nächsten Doppelseite eine Vakatseite links, rechts steht ein Frauenporträt. Die Vakatseite trennt die vorangegangen Fotografien von der folgenden Sequenz ab, demzufolge gehört das rechtsseitige Frauenporträt bereits zur nächsten Sequenz. An diesem Beispiel lässt sich deutlich nachvollziehen, dass sich sowohl aus der Abfolge der Bilder als auch aus der inneren Logik der Arbeit heraus die Anordnung von Einzelbildern, Bildpaaren und Tableaus aus dem Layout erschließt.

\subsection{Bewertung}

Paul Grahams Annäherung an Japan folgt - wie aus den Fotografien ersichtlich wird - einer thematischen Konzeption. Diese Herangehensweise ist nicht $\mathrm{zu}$ verwechseln mit dem konzeptuellen Ansatz der Dokumentarfotografie, wie er in Teil I, Abschnitt 4.1.2. erläutert wird, vielmehr handelt es sich um einen konzeptionellen Ansatz innerhalb der dokumentaristischen Variante der Dokumentarfotografie.

Das konzeptionelle Vorgehen ermöglicht eine intellektuelle Herangehensweise, die erarbeitetes Wissen mit der visuellen Wahrnehmung verbindet. Die Entwicklung einer Konzeption beinhaltet in der Regel eine umfassende Recherche des zu bearbeitenden Themas. Sie dient einerseits dazu, das Thema einzugrenzen und inhaltliche Parameter der Auseinandersetzung festzulegen. Andererseits werden hier auch Aspekte der visuellen Umsetzung fixiert. Dies geschieht mitunter, ohne zu wissen, was den Fotografen vor Ort erwartet. Ein solches Vorgehen ermöglicht eine starke Konzentration, weil sich der Fotograf nicht ausschließlich von den Oberflächen der sichtbaren Welt leiten lässt. Denn der Blick des Fotografierenden wird durch die vorab entwickelte Konzeption gelenkt, die dennoch eine individualisierte Annäherung an den 
Gegenstand zulässt. Gleichzeitig wird durch die Konzeption eine Ablenkung durch ansprechende visuelle Oberflächen vermieden, die möglicherweise zu ästhetisch interessanten Bildern führt, aber vom Thema entfernt. Der Vorteil gegenüber einer Fotografie, die sich ausschließlich mit dem Sichtbaren konfrontiert, liegt in der thematischen Konzentration und der Möglichkeit, die Wahrnehmung auf Elemente fokussieren zu können, die vielleicht nicht auf den ersten Blick offensichtlich sind, aber dennoch für die thematische Auseinandersetzung wichtige Facetten liefern. Das durch eine intensive Recherche gewonnene Wissen hilft dabei, die Wahrnehmung in die entsprechende Richtung zu erweitern.

Ein konzeptionelles Vorgehen verweist gewissermaßen auf einen Prozess der Konstruktion, denn hier wird von vornherein unterstrichen, dass eine objektive Darstellung des Fremden unerreichbar ist. Das bedeutet jedoch nicht zwangsläufig, dass das Fremde zum Anderen gemacht wird. Vielmehr eröffnet die Absage an die Möglichkeit, überhaupt eine authentische Darstellung mit fotografischen Mitteln erzielen zu können, einen großen Freiraum. Künstler, die einen solchen dokumentarfotografischen Ansatz verfolgen, wissen, dass Dokumentarfotografie kein Garant für Objektivität und Authentizität ist. Sie kennen die medialen Bedingtheiten genau. Deshalb können sie sich konsequent ihrem Thema widmen, wie beispielsweise Graham es in Empty Heaven tut.

Eine konzeptionelle Vorgehensweise lässt sich deutlich an Paul Grahams Arbeit ablesen, denn in der Konzentration des Blicks und insbesondere in der Auslassung von Überblicksaufnahmen wird deutlich, dass der Fotograf in seiner Auseinandersetzung mit Japan nach Motiven sucht, die sich von denen anderer Japanarbeiten unterscheiden. Ausschlaggebend ist dabei ein inhaltliches Interesse, das im gesellschaftspolitischen Bereich angesiedelt ist. Anders als andere Fotografen, die sich in Japan dem visuell Besonderen anhand des Stadtbilds oder der Landschaft widmen, begibt sich Graham auf die Suche nach Dingen, die wenig offensichtlich sind. Er muss eine Bildsprache entwickeln, die einen Zugang jenseits der visuellen Oberflächen ermöglicht. Allein deshalb wird eine konzeptionelle Herangehensweise notwendig, die auf intellektueller Ebene nach bildnerischen Lösungswegen sucht. Dies geschieht beispielsweise durch die Aneignung vorgefundenen Bildmaterials. Sowohl die Auswahl der unterschiedlichen Motive als auch deren Anordnung im Buch verweisen auf konstruktive Elemente innerhalb der Arbeit. Um seine Motive zu finden, sucht Graham gezielt Orte auf, die ihm für seine Konzeption Material liefern können. Dazu gehört beispielsweise der Besuch des Tokyoter Stadtteils Kasumigaseki, in dem Regierungsbeamte ihren Dienst tun. Die Männer fotografiert er auf eine Weise, die deutlich auf eine vorab ersonnene Konzeption hinweist und einen konventionellen Porträtbegriff negiert. Das historische Bildmaterial, wie zum Beispiel Bilder der kaiserlichen Armee oder der Kapitulation, ist im japanischen Alltag nicht präsent. Um an solche Bilder zu gelangen, müssen gezielt bestimmte Museen und Ausstellungen besucht werden. ${ }^{38}$ Sowohl die Auswahl der Motive als auch die bildmäßige Umsetzung verweisen auf Grahams konzeptionelle Herangehensweise.

Paul Graham beobachtet in Empty Heaven seine Motive teilweise aus extremer Nahsicht. Das verleiht Formen und Strukturen sowie deren oberflächli-

38 Der japanische Fotokünstler Oshima Naruki erzählt, dass man solche Fotografien in Japan nur selten zu sehen bekäme (vgl. Oshima 2006). 
cher Beschaffenheit eine sie besonders betonende Präsenz. Gleichzeitig verdeutlicht diese Sichtweise die Unmöglichkeit, mit der Kamera Einblicke jenseits der Oberfläche zu erhaschen. Die Kamera kann nur sichtbar machen, was zu sehen ist. Doch Graham verengt den Bereich der Sichtbarkeit auf einen schmalen Spalt. Er reduziert, verdichtet, spart aus und erreicht so eine Konzentration, die wiederum einen Raum eröffnet, der hinter der Oberfläche verborgen liegt, der gesteigerte Sichtbarkeit bietet. In diesem Raum liegt die Qualität seiner Arbeit verborgen, denn hier wird deutlich, dass seine Fotografie mehr zu zeigen vermag, als die Oberfläche hergibt. ${ }^{39}$

Graham orientiert sich an der sichtbaren Welt. Er rückt Dinge ins Bild, die auch anderen Japanreisenden auffallen könnten. Er inszeniert nicht, er dokumentiert. Mittels Dokumentarfotografie erfasst Graham jedoch nicht die großen Zusammenhänge im einzelnen Bild; er arbeitet nicht an der fotografischen Umsetzung von Schönheit oder Besonderheit der japanischen Kultur. Er lenkt vielmehr die Aufmerksamkeit auf einen Bereich, der für ihn als Außenstehenden durchaus wahrnehmbar, aber dennoch nicht direkt für jeden zugänglich ist. Die Beziehung zwischen japanischer Gegenwart und Vergangenheit, die auf einer von Graham beobachteten mangelnden Auseinandersetzung der Japaner mit ihrer eigenen Geschichte beruht, ist für diejenigen, die Japan nur kurz besuchen, sicher kaum erkennbar. Für Graham hat diese Auseinandersetzung jedoch eine Notwendigkeit, die er in Fotografien umzusetzen sucht. Dafür entwickelt er eine eindringliche Bildsprache, die sich zunächst hauptsächlich entlang der Oberflächen bewegt. Wie die genaue Untersuchung der Fotografien jedoch zeigt, entwickeln Grahams Bilder eine inhaltliche Tiefe, die aufgrund von Hintergrundwissen und mit Hilfe von Bildkombinationen entsteht. Der Bildgegenstand ist immer ins Zentrum gerückt und deutlich zu erkennen. Die Fotografien sind sehr ästhetisch, wobei die inhaltliche Ausrichtung erkennbar bleibt, weil die Wiederholung von Motiven und die sequenzielle Anordnung immer auf die Gesamtheit des Buches verweist. Die Bedeutung der Fotografien erschließt sich zunächst nicht umfassend. Auf den ersten Blick erscheinen sie oft rätselhaft. Ihr symbolischer Gehalt, der die inhaltlichen Aussagen vertieft, tritt deutlich hervor. Indem seine Fotografien Fragen aufwerfen, regt Graham das Publikum dazu an, sich - auch jenseits der inhaltlichen Bedeutung - der gesteigerten Sichtbarkeit und Wirkung der Bilder zu stellen. Grahams Arbeit zeigt beispielhaft, wie in einer künstlerischen Praxis Irritationen und Leerstellen gewinnbringend eingesetzt werden können. Die symbolisch-ikonografischen Lesarten reichen trotz umfangreichen Kontextwissens nicht aus, um Grahams Arbeit bis ins letzte Detail zugänglich zu machen. Es bleiben Irritationen, die nicht besänftigt werden können. Der Betrachter wird anlässlich der von Graham fotografierten Gegenstände mit unzugänglicher, unerklärlicher Fremdheit als nicht auflösbarer Fremdheit - konfrontiert.

Dies erreicht Graham auch mit der Zusammenstellung der Bilder, die er miteinander kommunizieren lässt. Die Fotografien ergänzen sich und erweitern im Zusammenspiel ihr Spektrum. Die Zusammenstellung der Fotografien zu Paaren und Sequenzen lässt Wechselwirkungen zwischen Bildern entstehen, die auf den ersten Blick keine oder nur formale Gemeinsamkeiten

39 Bereits in New Europe bedient sich Graham einer ausschnitthaften Sichtweise, die er in Empty Heaven jedoch deutlich zuspitzt. Seine Vorgehensweise ist speziell auf das Japanthema zugeschnitten. 
aufweisen. Dieser Umgang mit der Dokumentarfotografie ist eindeutig künstlerisch. Im Sinne der im ersten Teil entwickelten Annäherungen an das Dokumentarische vertraut Graham auf die Wirkung der Bilder, ohne sie direkt mit textlichen Informationen zu versehen. Die Abkopplung von Bild und Text ermöglicht eine konzentrierte Bildbetrachtung. Das Bild erhält als Bild eine eigenständige Sichtbarkeit. An das Ende des Buches gestellte Bildtitel und das im Beileger abgedruckte Interview können bei Interesse als Zusatzinformation gelesen werden. Die Sachlichkeit der knapp beschreibenden Bildtitel, die auch Aufnahmeort und Jahreszahl nennen, zeugen von einem traditionell dokumentarischen Anspruch, der jedoch durch die künstlerische Herangehensweise transzendiert wird.

Grahams Auswahl der Motive und die Weise, sie ins Bild zu setzen, zeugen von der Subjektivität des Künstlers, der einen eigenen Blick auf Japan etabliert. Graham konstruiert mit Auswahl und Anordnung der Fotografien gezielt ein Japanbild, obwohl er auf die wahrnehmbare Realität zugreift und sie nicht inszeniert. Die Einengung des Blicks sowie der thematische Fokus weisen auf die Ausschnitthaftigkeit des künstlerischen Ansatzes hin. Graham weiß um die Unmöglichkeit, mittels Fotografie allgemeingültige Aussagen zu machen. In seiner Arbeitsweise bestätigt Graham die Konstruiertheit, die der Fotografie generell zu Eigen ist. Er bemüht sich nicht um ein objektiviertes Erscheinungsbild, das vorgibt, eine für alle sichtbare Realität abzubilden. Trotzdem entsteht nicht der Eindruck, dass der Künstler selbst in den Vordergrund tritt, um seiner subjektiven Weltsicht Ausdruck zu verleihen. Die Fotografien überzeugen durch ihre Sachlichkeit. Diese ermöglicht dem Betrachter, Grahams Beobachtungen als gültige Aussagen über Japan anzunehmen. Graham formuliert mit Empty Heaven keine subjektive Einzelmeinung, sondern bezieht glaubhaft Position zu einem Aspekt der zeitgenössischen japanischen Gesellschaft. So verbindet er die direkte Weltsicht der Dokumentarfotografie mit den bildnerischen Freiheiten des Künstlers.

Bei der Betrachtung der ausgewählten Motive fällt auf, dass Graham Themen berührt, die mit klassischen japanischen Stereotypen in Verbindung gebracht werden können. Vertreten sind unter anderem hübsche, undurchdringlich lächelnde Asiatinnen, Motorblöcke, die auf die starke japanische Autoindustrie verweisen und Hiroshima, das große japanische Trauma. Die Abbildung von rosafarbenem Kitsch lässt sich mit japanischer Anime- und Manga-Kultur in Verbindung bringen. Bürokraten sind in einer identischen Bildauffassung fotografiert, so dass zunächst Ähnlichkeit und Austauschbarkeit ins Blickfeld rücken. Irritierend ist dabei jedoch, dass sich Grahams Fotografien nachhaltig von den üblichen stereotypen Japandarstellungen unterscheiden. Sie verweisen auf Stereotype, ohne selbst stereotyp zu sein. Die in den Motiven abgebildeten Themen aktivieren im Betrachter vorhandenes Wissen über Japan. ${ }^{40}$ Die Art der Darstellung wirft jedoch Fragen auf. Bei eingehender Auseinandersetzung mit der Arbeit muss auch ein voreingenommener Betrachter feststellen, dass Grahams Fotografien dabei helfen, Stereotype zu hinterfragen.

40 Dabei gehe ich immer von Betrachtern aus, die selbst noch nie in Japan gewesen sind. Bei denjenigen, die über vielschichtige Kenntnisse der japanischen Gesellschaft verfügen, ist die Wahrnehmung von Grahams Fotografien vermutlich stark durch die eigenen Erfahrungen geprägt. 
Bestes Beispiel hierfür ist Grahams Umgang mit den Bürokratenporträts. Sie sind steif und übermäßig formalisiert aufgenommen, womit sie auf die angenommene Gleichförmigkeit japanischer Geschäftsmänner verweisen. Graham betont mit seiner Bildauffassung, dass es sich um eine rein männliche Gesellschaft handelt, bei der die einzelnen Protagonisten austauschbar sind. Japanische Angestellte (sarariiman) werden nicht aufgrund ihrer individuellen Fähigkeiten eingestellt, sondern um die ihnen zugeteilten Aufgaben effizient zu erledigen. Individualität oder Kreativität scheinen hier nicht gefragt. In Grahams Fokussierung der Oberflächen der Gesichter dreht sich diese Annahme jedoch um. Plötzlich treten individuelle Unterschiede wie Bartwuchs, Haaransatz, Pigmentierung der Haut und gewählte Brillenform sehr deutlich hervor. Diese Beobachtung lässt Zweifel an der These aufkommen, dass alle japanischen Geschäftsmänner gleich aussehen. Die visuelle Anmutung lässt sich dann auch auf weitere Aspekte der Persönlichkeit übertragen. Auf subtile Weise werden hier Zweifel am Klischee gesät. Diese Beobachtung ist auch in anderen Motivkomplexen zu finden.

Verweisen die gewählten Motivgruppen in ihrer Thematik, aber nicht in ihrer Umsetzung auf japanische Stereotype, wird gleichzeitig deutlich, dass Grahams Japandarstellung auf zahlreiche japanische Motivwelten verzichtet. Indem Graham vornehmlich in Innenräumen fotografiert, klammert er im Westen bildnerisch bekannte Bereiche der japanischen Gesellschaft aus. Großstädte sind in ihrer modernen Urbanität ebenso wenig präsent wie Landschaften. Personen sind immer einzeln, nie in der Gruppe fotografiert. Grahams Bildauffassung lässt über den konkreten Japanbezug nachdenken, denn nur wenige Fotografien repräsentieren ausschließlich in Japan auffindbare Situationen. Graham zeigt Motivwelten einer globalisierten Welt, wie sie an zahlreichen Orten anzutreffen sind. Dennoch gelingt es ihm, spezifisch Japanisches hervorzuheben und damit einem japanischen Publikum Identifikationsmöglichkeiten zu bieten. ${ }^{41}$ Die fotografierten Personen, die die durchschnittlichen Europäer nicht von Chinesen oder anderen Asiaten unterscheiden können, sind ebenso außerhalb Japans anzutreffen wie Motorblöcke oder kitschige Gegenstände. Den Innenaufnahmen vergleichbar sind auch Grahams Außenaufnahmen reduziert. Draußen fotografiert er meist nachts und setzt dort die Nähe zum Objekt sowie das Blitzlicht in der gleichen Funktion ein wie innen. Unabhängig davon, ob der Blitzlichteinsatz durch die entstehende Flächigkeit auf die traditionelle japanische Kunst oder den atomaren Blitz verweist: Die inhaltliche Auseinandersetzung mit Japan wird durch dieses formale Mittel unterstrichen. Die Verbindung von historischem Bildmaterial und japanischer Symbolik mit eher unspezifischen Fotografien stellt unmittelbare Bezüge zu Japan her und erzeugt die thematische Präsenz. Indem er darauf verzichtet, signifikante Sehenswürdigkeiten oder Landmarken zu fotografieren, entzieht Graham die Arbeit einer Neugierde, die auf das Exotische und Differente gerichtet ist. Die Alltäglichkeit der Motive suggeriert Parallelen zu bekannten Umgebungen und lässt Japan weniger fremd erscheinen. Gleichzeitig wirkt in Grahams Fotografien eine gewisse Anonymität und Fremdheit mit, was die Lücke zwischen dem Eigenen und dem Fremden betont. Graham zeigt das Fremde als Fremdes. Seine Fotografien geben keine Antworten, sondern werfen selbst Fragen auf. Sie beschreiben nicht ein

41 Das bestätigen zahlreiche japanische Gesprächpartner (vgl. z.B. Kikuta 2006; Teil II, Abschnitt 5.1.). 
fremdes Land, sondern reagieren auf die beobachtete Fremdartigkeit. Damit transportieren sie gleichsam ein Stück der Fremderfahrung, die auch den Betrachter auffordert, auf die Fotografien zu reagieren.

Wie im ersten Kapitel des ersten Teils dargelegt, ist die Begegnung mit dem Fremden stets geprägt durch das Wechselspiel zwischen Fremdem und Eigenem. Das Eigene dient als Vergleichsmaßstab, der Blick ist oft geleitet durch vorher angeeignetes Wissen und frühere Erfahrungen. Die Distanz zwischen Beobachter und Beobachtetem ermöglicht ein genaues Hinsehen und erweist sich oft als hilfreich. Denn von den Beobachteten als banal und uninteressant beurteilte Situationen können möglicherweise gerade das Interesse des Beobachters wecken. Was für die Ethnologie sehr gut funktioniert, lässt sich auch auf die Fotografie übertragen. Der Fotograf kann die ihm fremde Welt mit geschärftem Bewusstsein wahrnehmen. Diese Außenseiterposition ermöglicht es Graham, sein Augenmerk auf sensible gesellschaftliche Bereiche wie die Verdrängung der Vergangenheit zu richten. Im Interview mit Uta Grosenick erfährt der Leser, dass dies ein Thema ist, mit dem sich japanische Fotografen nicht beschäftigen. Von daher scheint es auch überflüssig zu fragen, ob Graham seine Außenseiterrolle störe. Graham wehrt diese Frage zu Recht ab (vgl. Graham 1995b: o.S.). Seine Arbeit spricht für sich.

In Grahams Bildern wird sichtbar, dass er weder ausschließlich etwas ihm ganz Fremdes beobachtet, noch alles permanent mit dem Eigenen vergleicht. Er tritt als Ausländer und unbeteiligter Beobachter hervor, dem das Verhältnis der japanischen Gesellschaft zur Vergangenheit auffällt. Die Bilder visualisieren die eher abstrakte Beobachtung des »Maskieren[s] und Demaskieren[s] von Macht« (ebd.). Sie werten nicht, sondern versuchen, gesellschaftliche und historische Mechanismen offen zu legen, die zur beobachteten Situation geführt haben. Die Fotografien helfen dabei, die Situation besser zu verstehen. Sie nehmen keine moralisch überlegene Position ein, sie unterstützen eine Begegnung mit der japanischen Kultur auf Augenhöhe. Im besten Sinne operieren sie in einer contact zone und zeugen von einer intensiven Auseinandersetzung des Fotografen mit der japanischen Kultur. Eurozentrismus lässt sich in den Fotografien nicht nachweisen, aber im positiven Sinne ein genaues Hinschauen, Abwägen, Differenzieren und ein Agieren vor dem Hintergrund des Eigenen. Die Bilder eignen sich das Fremde nicht an. Sie fixieren nicht, sondern geben die Fremdheitserfahrung gewissermaßen an den Betrachter weiter, der selbst Wege entwickeln muss, wie er damit umgeht.

Graham zeigt in seinen Fotografien nichts Exotisches. Sie sind eher unspektakulär. Weder wird durch ihre Fremdheit eine Sehnsucht nach fernöstlicher Exotik befriedigt, noch wird der Betrachter durch zu viel Fremdheit überfordert. Indem sie auf Bekanntes rekurrieren, bieten die Bilder Anknüpfungspunkte. Beispielsweise werden Klischees aufgerufen, dann aber kritisch befragt. Das Thema wird mittels Bildauffassung und Bildkombinationen zuspitzt. So entsteht eine Komplexität, die die Kategorien des Fremden und des Eigenen durchdringt, sie miteinander verwebt und Unterschiede nivelliert. Die entstehenden Verbindungslinien verweisen auf eine Sichtweise, die sich dem Fremden nicht aus einer staunenden Distanz heraus nähert, sondern es als Teil einer gemeinsamen Geschichte und Entwicklung zeigt. Dass auch Unterschiede zwischen Japan und Europa zum Tragen kommen, rechtfertigt den Ansatz.

Indem er eine große Nähe zu seinen Motiven etabliert, knüpft Graham auch an Traditionen der Japanfotografie, beispielsweise William Kleins, an. Auch Klein kommt seinen Motiven sehr nah, auch er setzt sich mit bekannten 
Japanthemen auseinander. Während Klein jedoch versucht, eine große Komplexität in seinen Bildern zu erzeugen, reduziert Graham seinen Blickwinkel und etabliert damit eine neue Sicht. Seine Fotografie widersetzt sich nachgerade einer weitwinkligen Dokumentarfotografie, die innerhalb eines Bildes Zusammenhänge aufzuzeigen sucht. Grahams Fotografie sucht in den Leerstellen und Lücken zwischen den Bildern nach Zusammenhängen, die sich dem Betrachter nicht auf den ersten Blick offenbaren.

Eine fotografische Darstellung hat gegenüber einer schriftlichen den entscheidenden Vorteil, dass sie nicht argumentieren muss. Sie muss weder alle Aspekte eines Themas erschöpfend untersuchen, noch muss sie ein Fazit und damit eine Wertung präsentieren. So zeugt auch Grahams Arbeit von einer Ambivalenz, die der Betrachter mit seinem Wissen, seinen Erwartungen und seinen Erfahrungen ergänzen muss. Das Ergebnis ist nicht festgelegt, denn es unterscheidet sich von Betrachter zu Betrachter. Der Fotograf behandelt das Thema in seinem Sinne umfassend, die visuellen Impulse lassen jedoch unterschiedliche Interpretationen zu. Grahams Arbeit ist geprägt von Offenheit. Das führt dazu, dass die Fotografien nicht fixieren. Sie zeigen Japan nicht als klischeehaftes Anderes, sondern eröffnen Möglichkeiten zu einer Wahrnehmung Japans als Fremdem, das nicht ausschließlich ganz anders ist. Damit zeigt Graham, dass die Grenzen zwischen Fremdem und Eigenem fließend sind und Fremdheit nicht ausschließlich im Differenten und Anderen besteht. Indem Graham mit seiner Bildauffassung unterschiedliche Sichtweisen ermöglicht, Fragen offen lässt und nichts erschöpfend erklärt, kann der Betrachter auch nach mehrmaligem Anschauen immer wieder Neues entdecken und zu unterschiedlichen Reaktionen oder Schlussfolgerungen geleitet werden. Diese Art des Umgangs macht Grahams Fotografie so interessant.

\section{Zusammenfassung}

Paul Graham verkürzt den Abstand zu den fotografierten Gegenständen auf ein Minimum und untersucht im Spannungsfeld zwischen Detailaufnahmen und Porträts Aspekte der japanischen Gesellschaft. Mittels vorgefundenen Bildmaterials entwirft er Verbindungslinien zwischen der traumatischen japanischen Vergangenheit und der Gegenwart. Dabei thematisiert er anhand der Darstellung von Oberflächen das, was sich dahinter verbirgt. In kritischer Haltung verweist er auf die unzulängliche Aufarbeitung der japanischen Kriegsschuld. Graham konzentriert sich auf die Abbildung von Elementen, die eindeutig mit klischeehaften Vorstellungen Japans in Verbindung gebracht werden können. Gleichzeitig befragt er diese Annahmen, womit er eine spannende Sichtweise auf Japan etabliert. Er nutzt die Irritation nachhaltiger Offenheit, um die Betrachter mit einer Fremdheitserfahrung zu konfrontieren, die nicht das Fremde als Anderes fixiert, sondern mit seinen Fotografien zu eigenständigen Erfahrungen mit dem Fremden einlädt. 


\section{Elisabeth Neudörfl: Future World}

Die deutsche Fotografin Elisabeth Neudörfl reist 1998 mit einem Stipendium des Deutschen Akademischen Austausch Dienstes (DAAD) für vier Monate nach Japan, um dort ein Projekt über Fragen der Sicherheit zu fotografieren. Während eines kürzeren Aufenthaltes im darauf folgenden Jahr arbeitet sie weiter an dem Thema. Erste Kontakte nach Japan knüpft sie bereits 1993 auf einer Reise, wo sie das Künstlerbuch o.T. (Japan-Buch), ein 26 Fotografien umfassendes Unikat fotografiert. ${ }^{1}$ In einer konzeptionellen Vorgehensweise behandelt Elisabeth Neudörfl in ihren fotografischen Arbeiten gesellschaftliche, politische und historische Themen. Auch mit Fragen des Urbanen setzt sie sich wiederholt auseinander.

Ausgehend von diesen Grundvoraussetzungen beschäftigt sich Neudörfl in Japan vor allem mit der urbanen Situation in Tokyo, einer der dichtest besiedelten Regionen der Erde. In ihrem Projektantrag beschreibt sie ihr Anliegen, ein »Fotoprojekt über das Sicherheitsbedürfnis in Japan« zu fotografieren (vgl. Neudörfl 1997). Die Idee zu dem Thema entwickelt Neudörfl aus Beobachtungen anlässlich ihres ersten Japanbesuchs und ihrer daraus folgenden intensiven Beschäftigung mit Japan. »Der Mangel an Raum, die Dichte der Besiedlung fordern, im Kontext des hohen technologischen Standards, ein dichtes Regelwerk und ein ausgeprägtes Kontrollsystem des gesellschaftlichen Miteinander, « schreibt die Kuratorin Inka Schube 2002 anlässlich Neudörfls Ausstellung im Sprengel Museum Hannover (Schube 2002: o.S.). Die Auseinandersetzung mit Fragen der Sicherheit, die das individuelle und gesellschaftliche Handeln prägen, bildet die Leitlinie in Neudörfls Beschäftigung mit Japan. Das japanische Sicherheitsbedürfnis kann in enger Verbindung zu den geografischen Umständen Japans gelesen werden. Naturkatastrophen haben Japan in seiner Geschichte wiederholt heimgesucht, Erdbeben, Flutwellen und Taifune stellen eine permanente Bedrohung dar. Das große KantôErdbeben vernichtet 1923 einen Großteil der Metropole Tokyo. ${ }^{2}$ Die Bilder des Erdbebens von Kobe, die im Januar 1995 um die Welt gehen, sind allgemein bekannt. ${ }^{3}$ Wenn das Dasein durch äußere Faktoren stetigen Unsicherheiten unterworfen ist, ist der Wunsch nach Sicherheit in kontrollierbaren

1 Elisabeth Neudörfl wurde 1968 in Darmstadt geboren. Ihre wichtigsten fotografischen Arbeiten neben Future World (Neudörfl 2002) sind: Burn Warehouse Burn (Neudörfl 1993a), o.T. (Japan-Buch) (Neudörfl 1993b), venceremos (Neudörfl 1994), der Stadt (Neudörfl 2007), Plan (Lockemann/Neudörfl 1999), Super Pussy Bangkok (Neudörfl 2006).

2 Kantô ist die Bezeichnung für das Gebiet rund um die Bucht von Tokyo. Es umfasst insgesamt sieben Präfekturen.

3 Dazu hat u.a. der japanische Fotograf Miyamoto Ryuji beigetragen, der in Kobe direkt nach dem Erdbeben fotografiert hat. Seine Bilder sind z.B. 2002 auf der Documenta 11 in Kassel gezeigt worden. 
Bereichen durchaus nachvollziehbar. Das Thema Sicherheitsbedürfnis und Kontrolle wird in Neudörfls Arbeit nicht explizit als inhaltlicher Schwerpunkt erwähnt und erschließt sich aufgrund des gewählten Ansatzes nicht unbedingt auf den ersten Blick. Dennoch kann das Thema als eine Leitlinie der Fotografin angesehen werden, das in vielfältiger Abwandlung wiederholt aufscheint und einen möglichen Interpretationsrahmen setzt.

Der Titel Future World weist nicht gezielt in diese Richtung, obwohl Kontrolle und Überwachung und damit verbunden Fragen der Sicherheit in Zukunftsentwürfen häufig eine zentrale Position einnehmen. Was aber verbindet den Begriff Zukunftswelt mit Japan? Dass Japan in technologischer und wirtschaftlicher Hinsicht an der Weltspitze operiert, ist eine hinlänglich bekannte Tatsache. Wichtige technologische Neuerungen werden in Japan entwickelt und erreichen andere Weltgegenden erst einige Zeit später, so dass Japan bereits heute mit Technologien ausgestattet ist, die anderswo erst morgen ankommen. So könnte man meinen, unsere eigene - technologische Zukunft schon heute in Japan erspähen zu können. Das Image Japans als $Z u$ kunftswelt steht aber nicht nur in enger Verbindung mit technischen Innovationen. Die starke Verdichtung des urbanen Raums, der durch extravagante Architekturen sein futuristisch anmutendes Aussehen erhält, trägt weiter zur Wahrnehmung Japans als Zukunftswelt bei (vgl. z.B. Tajima/Powell 1997). Zahlreiche fotografische Ansichten Tokyos vermitteln das Bild einer gebauten Utopie, wie man sie auch in Science-Fiction-Produktionen antreffen könnte. Das Science-Fiction Genre vermittelt meist utopische Entwürfe, die sehr weit von unserer Gegenwart entfernt scheinen. Hier ist die Zukunft das fremde Andere, das durch die zeitliche Distanz immer eine Differenz zur Gegenwart markiert.

Es existieren jedoch auch Science-Fiction-Entwürfe, in denen die $\mathrm{Zu}$ kunft alltäglich daherkommt. Zukünftiges ist hier gekennzeichnet durch technische Neuerungen, die den menschlichen Alltag zwar prägen, ihn jedoch nicht völlig verändern. ${ }^{4}$ In letztere Kategorie fügt sich auch Neudörfls Arbeit ein. Elisabeth Neudörfls Future World verweigert sich spektakulären Ansichten. Japan wird gerade nicht als das fremde Andere gezeigt, das mit der uns Europäern bekannten Welt wenig Übereinstimmung aufweist. Der in Future World etablierte Blick auf Japan transportiert ein Moment der Alltäglichkeit und oszilliert damit zwischen Vertrautheit und Fremdheit. Die Zukunft in der Future World scheint als eine Abwandlung des Vertrauten auf.

Bereits der Titel deutet darauf hin, dass Neudörfl nicht die Erzeugung eines allgemeinen Japanbildes anstrebt. In der Auswahl der Motive betont sie vorwiegend Aspekte zeitgenössischer Urbanität. In einer zurückgenommenen Schwarzweißfotografie im Kleinbild-Format behält die Fotografin meist eine Distanz zum Abgebildeten. Sie beobachtet von Ferne und erzeugt dabei Fotografien, die sich nach und nach erschließen. Der die Fotografien betrachtende Blick wandert durch das Bild und entdeckt immer wieder Neues. Das Abgebildete und dessen Bedeutung erschließen sich oft nicht auf den ersten Blick. Im Gegensatz zu Paul Graham, in dessen Bildern das Abgebildete sofort erfassbar ist, wobei sich Bedeutungen erst aus dem Zusammenhang heraus entwickeln, liefert Neudörfl einen indeterminierten, aber dennoch sehr

4 Ein solcher Zukunftsentwurf findet sich z.B. im Roman Hard-BoiledWonderland und das Ende der Welt des japanischen Schriftstellers Murakami Haruki aus dem Jahr 1992 (Murakami 1995). 
direkten Blick. In ihrer Komplexität vermitteln Neudörfls Fotografien eine Freude am Sehen und Entdecken und ermöglichen eine ganz andere Erfahrung als Grahams Bilder. Während sich Graham fotografisch vorrangig mit Oberflächen beschäftigt, untersucht Neudörfl die Strukturen des Raums.

\subsection{Das Buch}

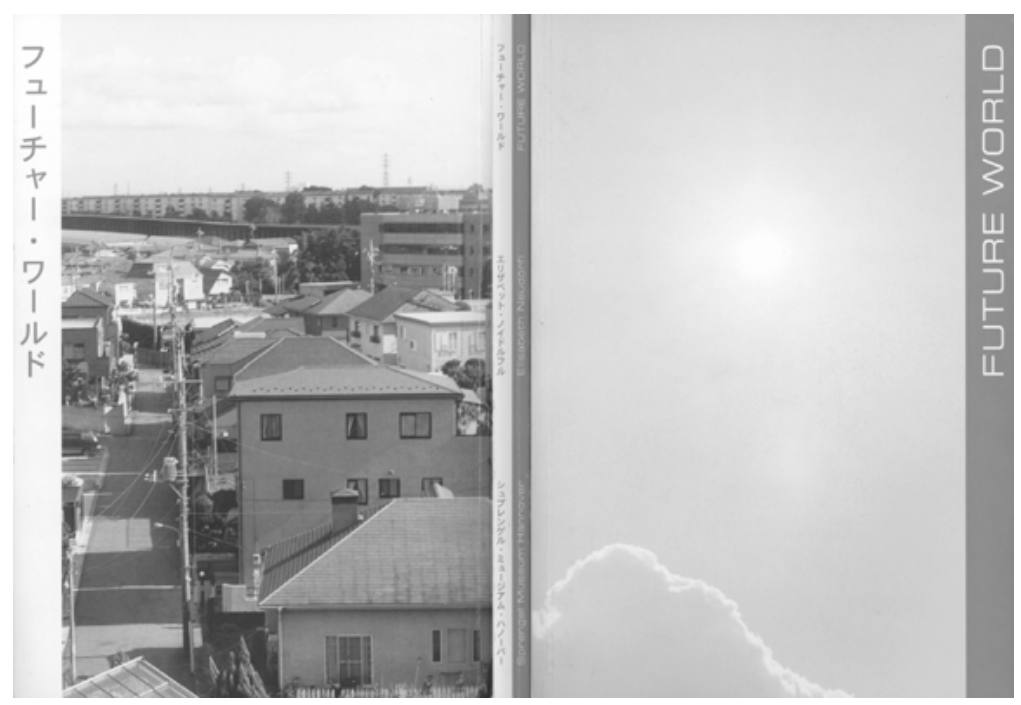

Buchtitel: asiatisch-westlich (Neudörfl 2002; Orig. in Farbe).

Das Buch Future World erscheint parallel zur gleichnamigen Ausstellung, die im Sprengel Museum Hannover vom 3. Juli bis zum 22. September 2002 gezeigt wird (Neudörfl 2002). ${ }^{5}$ Das Buch ist so konzipiert, dass es sowohl auf westliche als auch auf asiatische (japanische) Weise rezipiert werden kann. Es hat keine Vorder- und Rückseite, denn die Rückseite aus westlicher Sicht ist die Vorderseite aus japanischer. Der westliche Titel zeigt die erste Fotografie des Buches Format füllend im Anschnitt. Auf der rechten Seite erstreckt sich ein metallisch blaugrüner Balken über die gesamte Höhe des Bandes. Dort ist der Titel typografisch in weiß - um 90 Grad gestürzt - abgesetzt. Analog zum westlichen ist der japanische Titel gestaltet. Auch hier findet die erste Fotografie des japanischen Einstiegs als Titelbild Verwendung. Ein weißer Balken verläuft auf der linken Seite über die Höhe des Formats. Typografisch ist der Titel hier in der japanischen Silbenumschrift Katakana in metallischem blaugrün abgesetzt. ${ }^{6}$ Der Buchrücken ist ebenfalls zweige-

5 Zweifarbige Broschur mit aufklappbarem Umschlag im Format 16,5cm x 24cm; 144 Seiten ohne Paginierung, insgesamt 80 hochformatige Schwarzweißfotografien auf mattem Kunstdruckpapier. Der Band ist auf der Vorder- und der Rückseite mit jeweils einer Fotografie bedruckt.

6 Die Silbenschrift Katakana wird im Japanischen dazu verwendet, Lehnwörter aus fremden Sprachen in ihrer Aussprache zu japanisieren. Dies ist eine gängige Praxis der Aneignung fremder Begriffe ins Japanische und wird heute im Um- 
teilt und verweist auf westliche und japanische Lesart. Entsprechend ist das Impressum in den aufklappbaren Umschlag der Broschur gedruckt, vorderseitig auf Deutsch, rückseitig auf Japanisch. Die Handhabung des Buches verweist auf eine gleichbehandelte Nutzung durch westliche und japanische Leser. Um Missverständnisse zu vermeiden, soll hier grundsätzlich, wenn nicht anders erwähnt, von der westlichen Reihenfolge ausgegangen werden. ${ }^{7}$

Neudörfl fotografiert ausschließlich im Hochformat, die Fotografien sind in zwei verschiedenen Größen gedruckt. Unterschieden werden ganzseitig im Anschnitt stehende Porträts von anderen Aufnahmen, die unter anderem urbane Situationen, Landschaften oder Menschengruppen zeigen und umlaufend mit einem weißen Rand versehen sind. ${ }^{8}$ Meist sind die Fotografien auf Einzelseiten mit nebenstehender Vakatseite gesetzt. Im vorderen Buchteil stehen die Bilder rechtsseitig, im hinteren linksseitig, was wiederum mit der westlichen und der japanischen Konvention der Buchbetrachtung zusammenhängt. Die Aufmerksamkeit westlicher Betrachter richtet sich beim Umblättern zuerst auf die rechte Seite, die der japanischen auf die linke. Ab Bild 34 von westlicher Seite aus gesehen ist die Betrachtungsweise den japanischen Lesegewohnheiten angepasst; das heißt, die Fotografien stehen dann im Schwerpunkt linksseitig. Im ganzen Buch sind auf insgesamt sieben Doppelseiten jeweils zwei Fotografien nebeneinander gestellt. Ansonsten folgen die Fotografien hintereinander und können in einem Fluss betrachtet werden. Anders als bei Empty Heaven sind Sequenzen und Gruppen nicht scharf voneinander abgetrennt. Lediglich die Einzelporträts - achtzehn von insgesamt 80 Fotografien - bilden auch aufgrund ihres abweichenden Formats eine Zäsur und strukturieren den Ablauf der Bilder. Sie sind über das gesamte Buch verteilt. Im Gegensatz zu den übrigen Fotografien zeichnen sich die Porträts durch eine extreme Nahsicht aus: Die Gesichter sind Format füllend ins Bild gesetzt. Es werden aber keine direkten Bezüge zwischen Porträts und Außenaufnahmen hergestellt.

Das im Inneren der Umschlagsklappen verborgene Impressum ist der einzige Text im gesamten Buch, auch der Titel erscheint nur außen auf dem Umschlag. Future World beginnt direkt mit der ersten Fotografie. Das Fehlen eines Textes, der dem Betrachter den Zugang zu den Fotografien erklären oder erleichtern könnte, macht deutlich, dass dieser Ausstellungskatalog als Künstlerbuch konzipiert ist. Elisabeth Neudörfl ist im Impressum sowohl bei der Ausstellungs- als auch bei der Buchkonzeption an erster Stelle genannt. Da die Künstlerin vollständig auf Bildtitel verzichtet, müssen sich die Betrachter das Buch eigenständig intuitiv erschließen. ${ }^{9}$ Die Verweigerung jeglicher textlicher Hilfestellung, in welche Richtung die Bilder anzuschauen und $\mathrm{zu}$ interpretieren sind, deutet eine Radikalität an, die voll auf die Aussagekraft

gangssprachlichen auch auf Ausdrücke angewendet, für die die japanische Sprache eigene Worte kennt. `Fyuhchah Warudo benutzt die englischen Wörter und übersetzt nicht in japanische Begriffe. Um eine Übersetzung zu umgehen, hat sich Neudörfl für einen englischen Titel entschieden.

7 Für die Beschreibungen nummeriere ich die Fotografien ausgehend vom westlichen Einstieg durch. Das ist eine pragmatische Lösung, denn Neudörfl selbst sieht keine Nummerierung vor. Eine Paginierung fehlt.

8 Letztere sind im Format $12,5 \mathrm{~cm}$ x $18 \mathrm{~cm}$ mittig auf der Seite mit weißem Rand gedruckt.

9 In der Ausstellung lag ein Blatt aus, das mit einem kurzen erläuternden Text der Kuratorin Inka Schube die Betrachter an Neudörfls Fotografien heranführte. 
der Fotografien und das Assoziationsvermögen der Betrachter vertraut. Die Fotografien stehen für sich. Damit die Betrachter ihre eigenen Assoziationen und Ideen entwickeln können, bedarf es einer intensiven Beschäftigung mit den Fotografien. Die vom Titel angedeutete Richtung bleibt vage. Der Titel hat nicht die Aufgabe, auf eine bestimmte Sichtweise hinzuweisen und ist nicht als Interpretationshilfe zu verstehen. Das Wissen um den Titel Future World soll nach Neudörfls Aussage nicht die Betrachtungsweise lenken (Korrespondenz zwischen Künstlerin und Autorin: Februar 2002). Die Wahl eines Titels, der keine eindeutige Aussage transportiert, verweist gleichermaßen auf die nachhaltige Offenheit der Fotografien selbst.

Es ist innerhalb dieser Arbeit nicht sinnvoll, die insgesamt 80 Fotografien jeweils einzeln $\mathrm{zu}$ analysieren, weshalb wichtige Themenkomplexe herausgegriffen und anhand einiger Bilder exemplarisch vorgestellt werden. Neudörfl handelt die unterschiedlichen Themen nicht en bloc ab, vielmehr verteilt sie sie innerhalb des Buches. Die Themenkomplexe bestehen zum Teil aus mehr als zehn Fotografien, die in Gruppen von zwei oder mehr Bildern angeordnet sind. Die Themenbereiche durchdringen sich und sind mitunter nicht klar zu trennen, was Future World sehr abwechslungsreich macht.

Ähnlich wie in Paul Grahams Arbeit Empty Heaven bietet es sich an, die ersten Fotografien des Buches Future World als Einheit zu begreifen. Die Bilder werden durch die ihnen folgenden Porträts zu einer kurzen Sequenz zusammengefasst. Da Neudörfls Buch sowohl von vorne, als auch von hinten - in westlicher und japanischer Manier - begonnen werden kann, werden hier beide Einstiege in das Buch betrachtet.

\subsection{Die Eingangssequenzen}

\subsubsection{Der westliche Einstieg}

Das Buch beginnt mit einer Fotografie des Himmels (Abb. 1). Die recht gleichmäßige hellgraue Fläche wird im vertikalen oberen Drittel durch einen zentralen hellen Fleck - die verschleierte Sonne - durchbrochen. In die linke untere Bildecke schiebt sich eine ebenfalls hellgraue Wolke, deren fransige Kante hell erleuchtet ist. Dieser Blick nach oben setzt eine positive Grundstimmung. Die Sonne ist präsent, auch wenn es ihr nicht gelingt, durch den Dunstschleier hindurch zu dringen. Das zentrale Symbol des Landes der aufgehenden Sonne wird hier ins Bild gesetzt. Die Sonne ist auch ein gängiges Symbol in der japanischen Populärkultur und allseits präsent. Ein Bezug zu Japan ist hergestellt, dem Bild lässt sich zunächst jedoch keine spezifische Bedeutung zuordnen, es bleibt ambivalent. ${ }^{10}$

Auch in der zweiten Fotografie nimmt die Sonne eine bedeutende Position ein (Abb. 2). Ein wenig weiter nach rechts unten gewandert, leuchtet sie nun durch Zweige und Laub eines Baumes hindurch. Der Baum verstellt den direkten Blick. Die Blätter im Vordergrund bleiben unscharf, erst weiter oben gewinnen sie an Bildschärfe. Das dichte Blattwerk gibt nur Fragmente des Himmels frei. Future World beginnt mit dem Blick nach oben und setzt zu-

10 Auch wenn Neudörfl keine spezifischen Hinweise auf Hiroshima oder Nagasaki liefert, verleitet der Blick in den japanischen Himmel mitunter dennoch dazu, Assoziationen zu den atomaren Wolken anklingen zu lassen. 


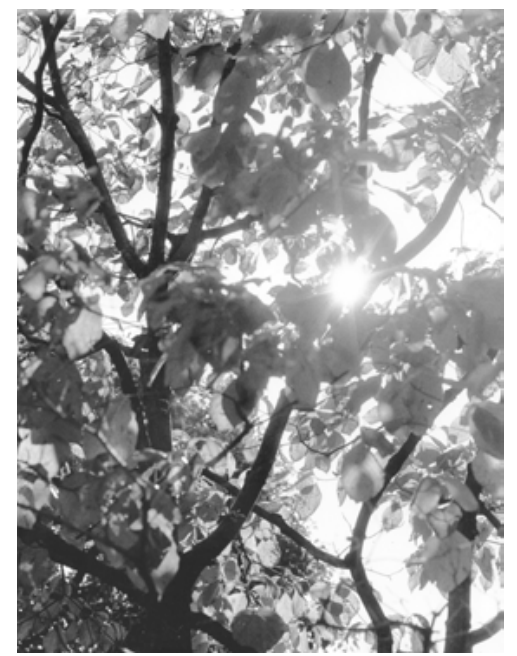

Abb. 1 und 2; wie alle Bilder in diesem Kapitel aus Neudörfl 2002: o.S.

nächst die Natur als Thema. Wie in Teil II, Abschnitt 3.4. bei der Analyse von Grahams Arbeit dargestellt, ist die Naturverbundenheit der Japaner ein wichtiges kulturelles Element. Die Fotografien sind jedoch sehr offen angelegt und transportieren nichts konkret Japanspezifisches.

In die Naturdarstellungen dringt in der dritten Fotografie die Zivilisation ein (Abb. 3). Abermals richtet sich der Blick der Fotografin nach oben, die Fotografie zeigt Zweige mit jungen Blättern, die vom Balkon eines Hauses ins Bild ragen. Allerdings handelt es sich hier nicht um eine Manifestation der Natur, denn die Zweige sind aus Plastik, was aber nicht unbedingt sofort auffällt. Im urbanen Umfeld ist für Natur nur wenig Raum, weshalb auf die Naturverbundenheit mittels einer Simulation verwiesen wird. Den Hintergrund bildet eine Hausfassade, deren Struktur aufgrund fehlender Tiefenschärfe - der geringe Schärfebereich wird von den Blättern in der Bildmitte eingenommen - und des nach oben gerichteten Blicks nicht deutlich erkennbar ist. Im oberen Bilddrittel heben sich die Blätter farblich kaum vom hellgrauen Himmel ab. Es handelt sich um eine Szenerie in einem Wohnviertel, wobei die Zweige mehr Raum einzunehmen scheinen, als ihnen auf einem Balkon zusteht. Sie ragen aus dem Balkonumfeld heraus und sind sehr präsent, was sie als der Architektur überlegen erscheinen lässt. Aufgrund ihrer Materialstruktur sind sie jedenfalls robust genug, um den alltäglichen Widrigkeiten des Stadtlebens zu trotzen.

Die vierte Fotografie öffnet den Blick und zeigt einen größeren Landschaftsausschnitt, der von einer Terrasse oder einem Balkon aus fotografiert ist (Abb. 4). Das Bild ist in der vertikalen Bildmitte geteilt. Die obere Hälfte nimmt ein ansteigender Berghang ein, dessen Baumbewuchs an zahlreichen Stellen durchbrochen ist. Die Höhe des Berges ist aufgrund des gewählten Bildausschnitts nicht zu erkennen. Kahle Baumstämme und Graswuchs verweisen auf eine beschädigte Natur, lediglich in größerer Höhe ist der Baumbestand durchgängig. Aufgrund der fehlenden Tiefenschärfe ist die Landschaft jedoch nicht detailliert zu erkennen. Die Bildschärfe liegt auf der unteren Bildhälfte, die von einem in Plastikfolie eingeschlagenen Balkongitter einge- 

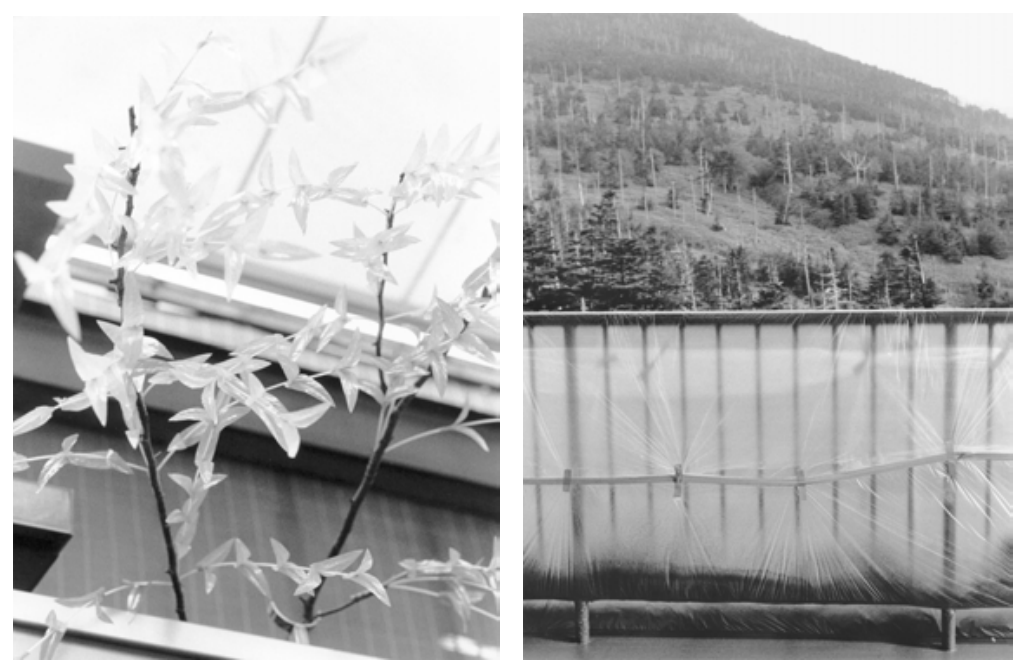

Abb. 3 und 4.

nommen wird. Das scharf abgebildete, sorgfältig eingepackte Gitter rückt den zivilisatorischen Eingriff in den Vordergrund und gesteht der Natur nur eine Rolle als Kulisse zu. ${ }^{11}$ Hier ließe sich über die Bedingungen der Aufnahme spekulieren, aber die Umstände ihres Entstehens sind nebensächlich. Neudörfls Fotografien wollen das Abgebildete nicht erklären. Die Rahmenbedingungen der Aufnahmesituation oder des gezeigten Gegenstands sind nicht entscheidend für die Entstehung des Bildes. Die Autorin stellt das Bild selbst ins Zentrum, das als Bild seine Wirkung entfaltet.

Die folgende Naturaufnahme zeigt einen Bambushain, womit erstmals auf ein Moment der Fremdheit in Form einer exotischen Vegetation verwiesen wird (Abb. 5). ${ }^{12}$ Die eingesetzte Tiefenschärfe belässt die vorderen Stämme unscharf und bildet erst die weiter hinten stehenden scharf ab. Die Bäume sind oben angeschnitten, so dass ihre Kronen kaum zu sehen sind. Die geraden Bambusstämme betonen die Vertikalen im Bild, sie in regelmäßigen Abständen unterteilende helle Ringe sorgen für eine horizontale Gliederung. Zwischen den kahlen dünnen Stämmen werden eine Lichtung und dichtere Bewaldung im Hintergrund sichtbar. Der Boden zwischen den Bambusstäm-

11 Im Gespräch erläutert die japanische Kuratorin Matsumoto ihre Sichtweise auf das Bild: »Seit den 1950er und 60er Jahren pflanzen wir in Japan vorsätzlich Zedern auf den Bergen, weil Zedern sehr einfach zu pflanzen sind und schnell wachsen, weshalb sie Material für viele Dinge liefern. Deshalb sind fast alle japanischen Berge von Zedern bedeckt. [...] Hier haben wir ein typisches Beispiel des Zedern-Berges. Und hier [in der unteren Bildhälfte] entsteht eine Spannung durch das Klebeband, das so sorgfältig verklebt wurde. Deshalb sehe ich hier eine sehr japanische Art des Umgangs mit geordneten Objekten, die unter Spannung gehalten werden. [Im unteren Teil] hat man die Mikro-Ebene, [im oberen Teil] die Makro-Ebene. Aber es ist dieselbe Haltung in beiden Teilen« (Matsumoto 2006).

12 Kikuta 2006 und Kasahara 2006 bezeichnen im Gespräch beide diese Fotogafie als eine der wenigen in Neudörfls Arbeit, die traditionell japanische Elemente aufweisen. 

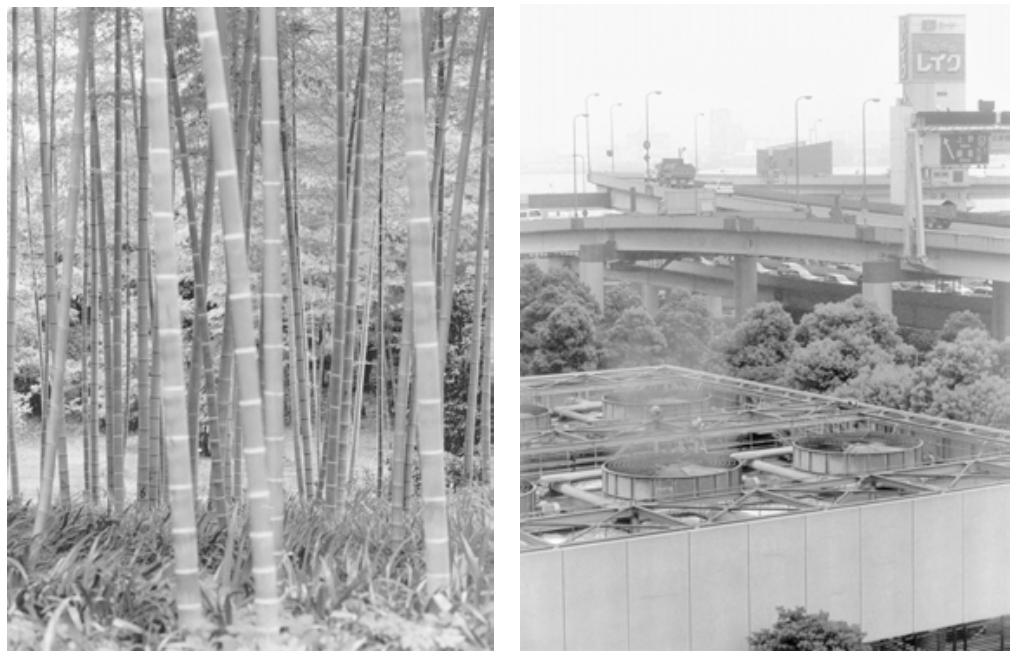

Abb. 5 und 6.

men ist mit niedrigem Gras bewachsen. Einige der scharf abgebildeten Stämme sind mit der Nummer 6 gekennzeichnet. Auf diese Weise wird ein menschlicher Eingriff angedeutet. Die Vegetation mag fremd erscheinen, doch in der hier dargestellten Form ist sie domestiziert, verwaltet und damit unter Kontrolle. Die Fotografie entwickelt eine Sogwirkung, denn die Staffelung des Raums durch die Stämme sowie der gewählte Schärfeverlauf verleihen ihr große Tiefe. ${ }^{13}$

Die nun folgende Fotografie markiert einen Bruch, denn hier steht erstmals nicht mehr die Natur im Mittelpunkt (Abb. 6). Das Bild zeigt eine urbane Situation mit auf verschiedenen Ebenen verlaufenden Straßen. Die untere Bildhälfte wird von der Aufsicht auf eine technische Anlage dominiert, die mit den auf ihrem Dach befindlichen mächtigen Ventilatoren vermutlich einen Tunnel entlüftet. Die Anlage ist von Bäumen umgeben. Die obere Bildhälfte zeigt auf verschiedenen Ebenen gestaffelte Straßen. Die oberste verliert sich im Dunst, der die hinter einer Bucht gelegene Skyline nur vage erahnen lässt. Die oberen Ebenen der Straßen verstellen die Sicht auf die tiefer gelegenen, auf denen dennoch ein hohes Verkehrsaufkommen zu beobachten ist. Ein Wegweiser am rechten Bildrand bezeichnet Stadtteile von Tokyo. Die aufgeständerten Autobahnen sind ein Markenzeichen japanischer Urbanität. In Tokyo werden die ersten fünf dieser Autobahnen anlässlich der Olympischen Sommerspiele 1964 vollendet, um eine moderne Infrastruktur für das internationale Ereignis bereitzustellen und die weit verstreut liegenden Sportstätten miteinander zu verbinden (vgl. Tajima 1996: 16). In anderen Städten

13 Die Bildaufteilung lässt Ähnlichkeiten zu traditionellen japanischen Holzschnitten anklingen: Bäume oder Zweige im Vordergrund verstellen den Blick auf eine sich öffnende Landschaft im Hintergrund, die dennoch gut zu erkennen ist. So z.B. bei Ando Hiroshige, Pflaumengarten von Kameido, Farbholzschnitt aus der Serie 100 Ansichten von Edo, 1858, Oban-Format, 36,8 x 24,4 cm (vgl. Delank 1996: Farbtafel I). 
sind ähnliche Autobahnen gebaut worden. ${ }^{14}$ Die Position der Stadtfotografie an dieser Stelle illustriert die Strategie der Künstlerin, keine formal oder inhaltlich streng abgeschlossenen Sequenzen innerhalb des Buches zu verwenden. Die Stadtansicht bricht mit der Ausrichtung auf Naturdarstellungen in den vorangegangenen Fotografien und greift anderen vor, die die vertikale Staffelung des Urbanen thematisieren (vgl. Abschnitt 4.3.). Somit entsteht in der Betrachtung eine Art Wellenbewegung. Themen werden angeschnitten, um an späterer Stelle erneut - teilweise ausführlicher - verhandelt zu werden.

Die Anordnung der Bilder in der Eingangssequenz führt den Betrachter vorsichtig an den urbanen Raum heran. Im Gegensatz zu späteren Fotografien ist die Komplexität der ersten Bilder reduziert, sie sind recht schnell erfassbar. Erst die sechste Fotografie zeigt eine vielschichtigere Situation, die zur Erfassung der Details eingehender betrachtet werden muss. Die ersten fünf Fotografien des Buches Future World haben alle einen Bezug zur Natur. Zusätzlich eint sie ein verstellter Blick. Neudörfl richtet die Kamera auf die Welt, jedoch ist der Ausschnitt begrenzt und wird zusätzlich durch den Schärfeverlauf eingeengt. In der ersten Fotografie ist die Sonne aufgrund des Dunstschleiers nicht sichtbar, so wie sie durch Zweige und Laub in der nächsten ebenfalls nur angedeutet zu sehen ist. Das künstliche Blattwerk der dritten Fotografie ist scharf fokussiert und verdeckt den Blick auf das Haus, das durch die mangelnde Tiefenschärfe noch weiter in den Hintergrund gedrängt wird. Das verhüllte Balkongitter verstellt den Blick auf die Landschaft, so wie in der fünften Fotografie die vorderen Bambusstämme einen klaren Blick auf die scharf fokussierten hinteren Bäume verhindern. Die Fotografin erzeugt auf diese Weise eine Distanz zum Gegenstand. Deutlich zeigt sich Neudörfls Ansatz, nicht einen Gegenstand ins Zentrum des Interesses zu rücken, sondern das gesamte Bildfeld auszunutzen und damit bedeutungsoffene Bilder zu schaffen. Neudörfls Fotografie transportiert eine beiläufige Beobachtung und beharrt nicht auf der Feststellung so sei es wirklich gewesen. Somit erschließt sich die Bedeutung des Abgebildeten nicht ohne weiteres und bleibt häufig ambivalent. Eine symbolische Lesart scheint jedoch nicht intendiert. Elisabeth Neudörfls Fotografien stehen nicht stellvertretend für etwas anderes. Sie bleiben als Bilder ganz bei sich.

Neudörfls subtile Strategie offenbart sich bereits in der ersten Sequenz. Die Fotografien verweisen auf etwas nicht explizit Benanntes. Sie erklären nichts. Die Bilder stehen zunächst einzeln für sich, inhaltliche und formale Bezüge bleiben vage. In der Abfolge entstehen keine deutlich erkennbaren Sequenzen oder Bildpaare. Dennoch formulieren die ersten Fotografien des Buches über das Naturthema eine lockere inhaltliche Verbindung. Obwohl sich die Fotografien einzeln betrachten lassen, was die Konzentration auf das Einzelbild fördert, fügen sie sich in den Zusammenhang des Buches ein. Die Abfolge der Bilder im Buch bildet eine sehr offene Struktur.

$14 »$ The expressway system [...] dominates the central area of Tokyo [...]. Similar systems have been built in Osaka and Nagoya since the 1970s, with rather similar results« (Sorensen 2002: 192f.). 

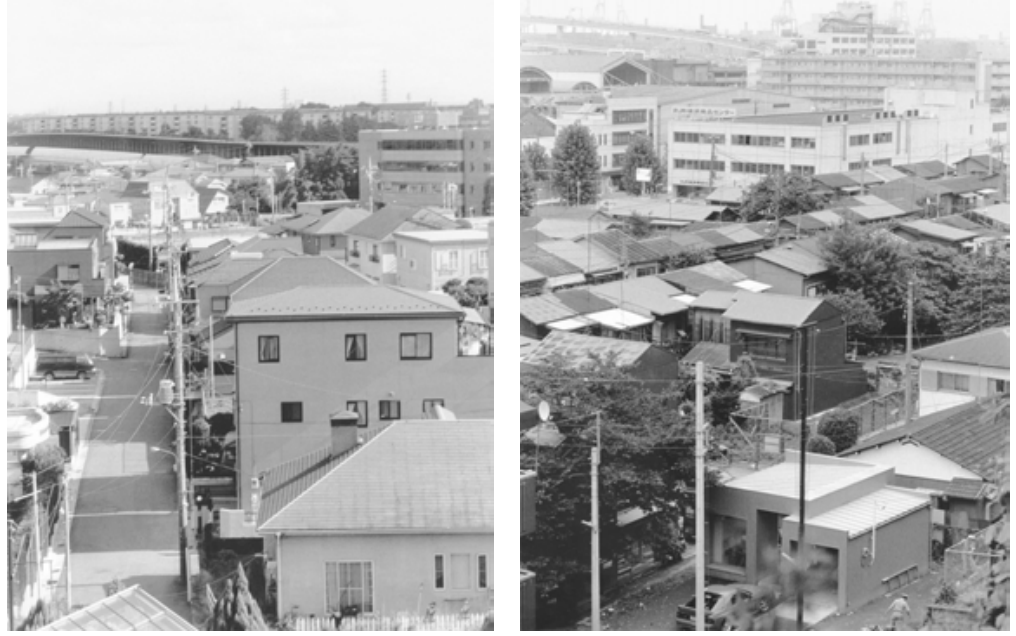

Abb. 80 und 79 .

\subsubsection{Der japanische Einstieg}

Der japanische Einstieg vermittelt im Vergleich zum westlichen einen anderen Eindruck. Die japanische Version beginnt direkt mit dem Urbanen. Landschaft oder Natur sind in der ersten Bildfolge der japanischen Version nicht zu finden. Bis zum ersten Porträt stehen fünf Fotografien hintereinander und bilden vergleichbar mit dem westlichen Einstieg einen losen Zusammenhalt. Das wie die folgenden vier Fotografien linksseitig auf der Doppelseite abgedruckte erste Bild (Abb. 80) zeigt den aus erhöhter Perspektive aufgenommenen Blick auf ein Wohnviertel. Zwei- bis dreistöckige einzeln stehende Wohnhäuser staffeln sich, ausgehend von der rechten unteren Bildecke, entlang einer Straße in die Tiefe des Raums. Die schmale Straße, die auf der linken Bildhälfte geradewegs ins Bild hineinführt, wird von Telegrafenmasten gesäumt. Rechts hinten steht ein etwas höheres Bürogebäude. Das Wohnviertel wird im oberen Bilddrittel durch ein Band mit etwa vierstöckigen Siedlungsbauten abgeschlossen, das durch eine Art Spundwand vom vorderen Wohnviertel abgegrenzt ist. Die Fotografie vermittelt die banale Alltäglichkeit eines ruhigen städtischen Wohnbereichs mit aufgelockerter Bebauung. In den Fenstern hängen Gardinen, kein Mensch ist auf der Straße zu sehen. Das Urbane erhält einen sehr beiläufigen Charakter.

Die folgende Fotografie zeigt abermals einen Blick von oben auf ein städtisches Viertel (Abb. 79). Dieses ist jedoch viel heterogener als das erste. Wohnhäuser stehen dicht gedrängt an einer - selbst nicht sichtbaren schmalen Straße und bilden eine leicht ansteigende Diagonale quer durch die Bildmitte. Im Vordergrund deutet eine geräumige Garage, neben der zwei uniformierte Figuren das Grundstück aufräumen, auf eine aufgelockerte Bebauung, während die kleinteilige Wohnarchitektur der Bildmitte im Hintergrund an großflächigere Büro- und Apartment- sowie an Lagergebäude angrenzt. Eine große Straße führt im entfernten Bildhintergrund, vermutlich als Brückenauffahrt, am linken Bildrand aus dem Bild hinaus. Im Hintergrund 


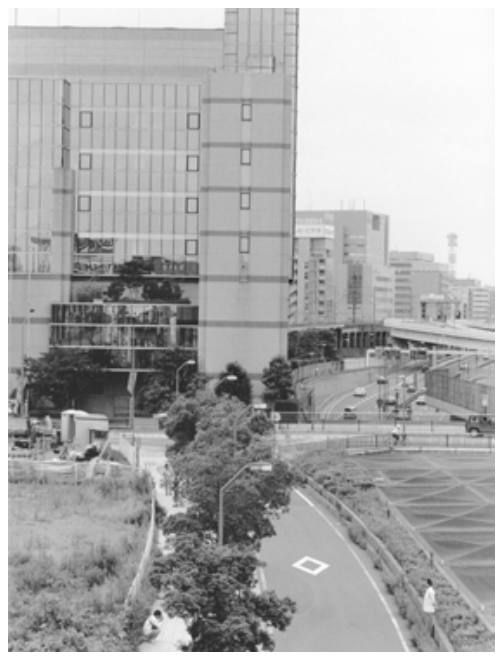

Abb. 78 .

zeichnen sich von Dunst eingehüllt die Krananlagen eines Hafengebiets ab. Wohnstraßen befinden sich in unmittelbarer Nachbarschaft zu Kleinindustrie und Hafenanlagen. ${ }^{15}$ Wirkt das erste Bild in seiner Dichte noch verhältnismäßig aufgelockert, zeigt sich hier die Verdichtung des urbanen Raums mit unterschiedlichen Nutzungsformen. Neudörfl verschafft dem Betrachter im Wortsinn einen Überblick.

Auch das nächste Bild ist von einem erhöhten Standpunkt aus aufgenommen. Eine schmale Straße führt in einem leichten Bogen von unten rechts in das Bild hinein (Abb. 78). Die Straßenbäume verdecken den linken Bürgersteig. Rechts von der Straße ist eine tiefer liegende Fahrstraße mit einem Gitter abgedeckt, links befindet sich eine von Pflanzen überwucherte Brachfläche. Dahinter deuten Bauutensilien auf eine mögliche Veränderung dieses Zustands hin. Blickfang des Bildes ist ein etwa fünfzehnstöckiges Bürogebäude in der linken Bildhälfte, an das sich im Hintergrund weitere Gebäudekomplexe anschließen, gesäumt von einer weiter unten entlang führenden Straße. Im unteren Bilddrittel steht rechts eine Person vor der Leitplanke der schmalen Straße. Links auf dem Bürgersteig ist eine weitere Person zu erkennen, die aus der Hocke heraus erstere fotografiert. Neudörfls Bild zeigt eine urbane Grenzsituation. Der Übergang zwischen dichter Bebauung und Brache erscheint sehr abrupt, die Brachfläche wirkt etwas befremdlich in der dicht bebauten Umgebung. Insbesondere irritieren aber die beiden Personen, die sich an einem urbanen Un-Ort in touristischer Manier fotografieren. Neudörfl lässt die Situation bewusst offen und zeigt uns nicht die Kulisse der tou-

15 Diese urbane Anordnung verweist auf die Probleme der japanischen Stadtplanungspolitik des zwanzigsten Jahrhunderts, die Sorensen detailliert beschreibt. Die enge Nachbarschaft von Wohngebieten und Industriezonen führt er auf die wenig detaillierte Trennung der unterschiedlichen Nutzungsformen in ausgewiesenen Planungsgebieten zurück. Da die japanische Stadtplanung meist wenig reguliert betrieben wird, sind die Trennlinien zwischen den verschiedenen Nutzungen relativ weich. Eine strikte Trennung von Industrie- und Wohngebieten findet kaum statt (vgl. Sorensen 2002: 220ff.). 

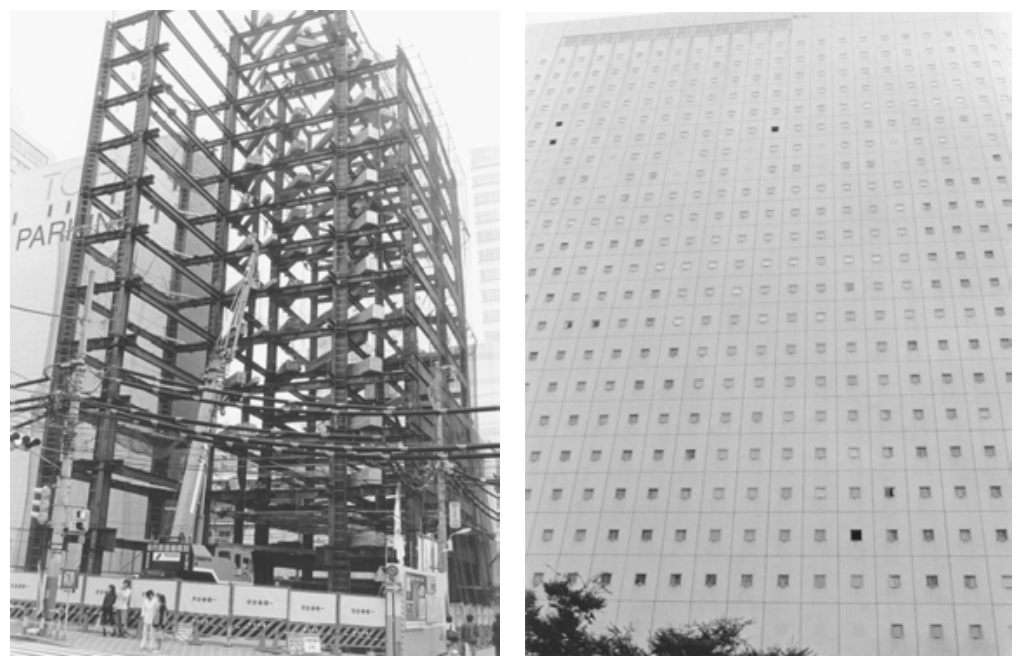

Abb. 77 und 76.

ristischen Fotografie. Die sich fotografierenden Touristen bilden aber nur einen Aspekt in Neudörfls Abbildung. Ein weiterer Schwerpunkt liegt in der Darstellung eines auf verschiedenen Ebenen gestaffelten urbanen Raums, der in der Brachfläche ein Veränderungspotenzial aufweist. Auch diese Fotografie verdeutlicht Neudörfls Umgang mit dem Bild. Die Fotografie hat keinen zentralen Bildgegenstand, der das Thema bestimmt. Das Bild schneidet verschiedene Themen an, ohne eine bestimmte Lesart vorzugeben. Die Betrachter können sich die Fotografie allmählich erschließen und inhaltlich mit eigenen Assoziationen anfüllen.

Die vierte Fotografie ist vom Straßenniveau aus nach oben fotografiert (Abb. 77). Die zentrale Bildmitte wird durch das Stahlskelett eines ungefähr zwölfgeschossigen Rohbaus ausgefüllt. Die stabil wirkende Konstruktion fügt sich in das im Anschnitt sichtbare benachbarte urbane Umfeld ein. Das Baugrundstück ist schmal, die Gebäude stehen offenbar dicht gedrängt nebeneinander. Die dunklen Stahlträger heben sich deutlich von den hellen Gebäuden der Umgebung ab. Die Vertikale wird durch die sich nach oben verjüngenden Linien betont. Der unfertige Zustand des Gebäudes verweist auf das urbane Veränderungspotenzial einer sich wandelnden Stadt. Das Schließen von Lücken bewirkt eine zunehmende urbane Verdichtung, was aber im Bild nicht explizit ausformuliert wird. So wie das ästhetische Erscheinungsbild des fertigen Gebäudes nicht aus seiner Struktur ablesbar ist und zahlreiche vorstellbare Möglichkeiten offen lässt, verhält es sich auch mit der Offenheit in Neudörfls Fotografien. Interpretationsansätze sind durch den Kontext gegeben, es handelt sich aber nur um ein Grundgerüst, das vielschichtigen Sichtweisen Raum gibt.

Die fünfte und damit letzte Fotografie dieser Bildfolge zeigt einen massiven Plattenbau, der das Bildformat fast vollständig ausfüllt (Abb. 76). Oben ist ein kleines Stück Himmel zu sehen, nach rechts und links setzt sich das Gebäude außerhalb des Bildraums fort. Es ist durch rechteckige einzelne Platten gegliedert, in die jeweils mittig ein Fenster eingelassen ist. Obwohl einige Platten keine Fenster haben, zeichnet sich dort dennoch der Ort des 
Fensters dunkel ab. In fast allen Fenstern sind die Gardinen zugezogen. Lediglich vier Fenster der 23 sichtbaren Geschosse stehen offen und bilden schwarze Unterbrechungen in der massiven Fassade, die abweisend und schmutzig wirkt. Das sich nach oben verjüngende Gebäude verblasst im Dunst. An der linken unteren Bildkante ragt dunkles Gestrüpp ins Bild, das die düstere Atmosphäre dieses architektonisch belanglosen Kolosses nicht zu durchbrechen vermag. Massivität und Eintönigkeit des Gebäudes lassen an eine Big-Brother-Welt denken, in der jegliche Individualität unterbunden und der Einzelne einer absoluten Kontrolle unterworfen ist. An dieser Stelle zeigt Neudörfl die negativen Seiten der Future World.

Insbesondere die letzte Fotografie verdeutlicht den großen atmosphärischen Unterschied zwischen dem westlichen und dem japanischen Einstieg in das Buch Future World. Im Gegensatz zum japanischen Einstieg wirkt der westliche sehr sanft. Der Betrachter wird langsam und vorsichtig an das vielschichtig Urbane herangeführt. Der japanische Einstieg ist durch Fotografien einer zunehmend verdichteten Urbanität gekennzeichnet. Die ersten Fotografien auf beiden Seiten vermitteln eine positive Grundstimmung. Während diese Stimmung im westlichen Einstieg zunächst kaum gebrochen wird, werden die Fotografien auf der japanischen Seite zunehmend härter. Weiterhin unterscheiden sich beide Anfänge durch ihre Komplexität. Die Fotografien des westlichen Einstiegs sind verhältnismäßig reduziert und schnell zu erfassen. Der japanische Beginn vermittelt von Anfang an eine hohe Informationsdichte in den Bildern. Um alle Details zu erfassen, muss sich der Betrachter die Fotografien nach und nach erschließen.

Die Strategie, westliche und japanische Betrachter auf unterschiedliche Art in das Buch einzuführen, verweist auf verschiedene Ebenen von Fremdheit. Während japanische Betrachter mit einem Außenblick auf ihr eigenes Land und so mit vermeintlich Vertrautem konfrontiert werden, präsentiert sich westlichen Betrachtern das Bild einer zunächst als fremd angenommenen Welt. Sie werden langsam an die Materie herangeführt, während den japanischen Betrachtern ein wesentlich direkterer Einstieg geboten wird. Nach dem Einstieg vermischen sich die Bereiche, da Neudörfl nicht mit klar abgegrenzten Kategorien des Fremden und des Eigenen operiert. Schließlich besteht die Möglichkeit, dass japanischen Betrachtern der Außenblick Fremdes in der eigenen Kultur zu offenbaren vermag, während westlichen Betrachtern Parallelen zu ihnen bekannten Welten eröffnet werden können. Damit arbeitet Neudörfl entlang der Annahme, dass Fremdes und Eigenes relationale und damit miteinander verbundene - Kategorien sind, die einer starken individuellen Prägung unterliegen. In den Fotografien herrscht auf beiden Seiten eine Ambivalenz vor, die es unmöglich macht, das Thema des Buches konkret zu erfassen und die Fotografien eindeutig zuzuordnen. In den Einstiegen eröffnet sich keine klare Perspektive hinsichtlich der Betrachtung des Buches. Die Offenheit der Fotografien verlangt dem Betrachter eine eigenständige Sichtweise ab. Den Bildern gegenüber kann er eine eigenständige Haltung einnehmen, denn von der Fotografin wird keine Positionierung vorgegeben. Neudörfl entwickelt kein eindeutiges Narrativ, das eine Richtung vorgibt, schafft aber dennoch eine Konzentration, die zum Weiterblättern einlädt. 


\subsection{Verdichtete Stadt}

Wie bereits in der japanischen Eingangssequenz gesehen, stellt das Urbane einen wichtigen Themenkomplex innerhalb der Arbeit Future World dar. Besonders interessant sind dabei solche Fotografien, die die starke vertikale Verdichtung des Stadtraums thematisieren und den Blick auf die zahlreichen vorhandenen Ebenen lenken. Neudörfl fotografiert verstärkt Architekturen der Infrastruktur und konzentriert sich damit auf eine Einteilung des Raums abseits von Gebäudestrukturen. In diesem Zusammenhang ist das Konzept des wrapping in der japanischen Kultur interessant, das die britische Anthropologin Joy Hendry in ihrem Buch Wrapping Culture entwickelt (vgl. Hendry 1993; auch Teil II, Abschnitt 3.1.). ${ }^{16}$ Wrapping ist Hülle oder Verpackung. Dieses Phänomen wird verschiedentlich in Zusammenhang mit der japanischen Geschenkkultur erörtert, die der Art der Verpackung eine große Bedeutung beimisst (vgl. Rupp 2003). Hendry dehnt das Konzept des wrapping jedoch auf weitere Bereiche der japanischen Kultur und Gesellschaft aus. In ihrem Sinne kann es als eine Form der Schichtung gelesen werden. ${ }^{17}$ Dieses Modell wendet sie auch auf den Raum an, der ebenfalls verpackt werden kann (vgl. Hendry 1993: Kap. 5). Architektur ist demnach eine strukturierende Umhüllung des Raums. Sie ordnet ihn und bestimmt die Größenverhältnisse, die wiederum die individuelle Erfahrung des (urbanen) Raums prägen. Architekten $»$ kreieren und ordnen den leeren Inhalt des Raums. [...] Diese Ordnung des Raums ist die Zielsetzung des Bauens und nicht das physische Objekt selbst« (Hillier/Hanson 1984: 1).

Wenn für den Architekten die Ordnung des Raums Auftrag und Ziel in der Planung eines Gebäudes ist, so kann für die Stadtplanung die Raumordnung durch Verkehrswege als Zielsetzung gelten. Das Verkehrswegenetz wird dem urbanen Wachstum entsprechend angepasst. Große Magistralen, Alleen und Boulevards stellen Infrastrukturen für den Durchgangsverkehr zur Verfügung und helfen dabei, Stadtviertel miteinander zu verbinden, grenzen sie aber auch voneinander ab. Kleine nachbarschaftliche Straßen markieren Wohnviertel, beruhigen den Verkehr und schaffen so ein möglichst geräuscharmes Wohnumfeld. Fernverkehrsstraßen ermöglichen einen zügigen Anund Abreiseverkehr innerhalb des Stadtgebiets. Früher durften sich die Straßen

»mehr oder weniger selbständig ihren Weg bahnen, vorausgesetzt, daß sie so wenig Platz wie möglich einnahmen. [...] Das umfassende Netz öffentlicher Durchgangsstraßen, die die verschiedenen Viertel miteinander verbinden und Zugang schaffen, entstand erst in jüngerer Zeit; es wurde dem Stadtplan ohne Rücksicht auf die bestehenden Maße von Parzellen und Gittern aufgesetzt. Das Ergebnis ist eine Schichtenfolge von schier unglaublicher Komplexität, bei der Starrheit von flexibler Ordnung abgelöst wurde« (Tajima/Powell 1997: 46).

16 Die Bezeichnung Hendrys als Anthropologin übernehme ich dem Titel eines ihrer Bücher, in dem sie ihre eigene Feldforschung reflektiert: An Anthropologist in Japan (Hendry 1999).

17 Hendry sieht beispielsweise in der japanischen Sprache und ihren diversifizierten Höflichkeitsformen ein Modell des wrapping ebenso wie in der japanischen Kleidung und japanischen Formen sozialer Interaktion. 
Parallel zum Straßennetz, das primär durch den Individualverkehr genutzt wird, existiert in den meisten urbanen Ballungsgebieten Japans ein Schienennetz, das den Transport von großen Menschenmengen ermöglicht; zum Beispiel von Berufspendlern. In japanischen Metropolen sind Straßen- und Schienennetz häufig auf mehreren Ebenen angelegt, um das hohe Verkehrsaufkommen auf engem Raum zu bewältigen. Mehrstöckige Autobahnen, ebenerdige und unterirdische Straßensysteme sowie Monorails, Hochund U-Bahnen prägen das Stadtbild nachhaltig. Die oberirdisch geschachtelten Verkehrswege sind nicht zu übersehen, so dass Fotografien des Tokyoter Stadtgebiets ohne sie kaum denkbar sind. ${ }^{18}$

Auf zahlreichen von Neudörfls Fotografien nehmen auf mehreren Ebenen verlaufende oberirdische Verkehrswege großen Raum innerhalb des Bildes ein. Die horizontalen Wege dienen der Staffelung des vertikalen Raums. In der Darstellung der verschiedenen Ebenen nutzt Neudörfl das Hochformat optimal aus. Mit der Schichtung des Urbanen verweist sie auf die extreme Verdichtung in der so genannten Tokaido Megalopolis. ${ }^{19}$ Die durch das Verkehrswegenetz erzeugte Verdichtung des urbanen Raums strukturiert und segmentiert auch den Bildraum in den Fotografien dieses Themenkomplexes. Die gestaffelten Verkehrswege sind präsent, ohne sich aufzudrängen. Neudörfl beobachtet auf zurückhaltende Art und Weise. Sie kritisiert oder kommentiert nicht. Die Wertung des Gesehenen überlässt sie dem Betrachter. ${ }^{20}$

Bereits das letzte Bild des westlichen Einstiegs gehört dem Themenkomplex der verdichteten Stadt an (vgl. Abschnitt 4.2.1.) Die auf zwei Doppelseiten hintereinander folgenden Fotografien vierzehn und fünfzehn setzen dieses Thema fort. Das rechtsseitig angeordnete Bild (Abb. 14) ist von einem ebenerdigen Standpunkt aus fotografiert. Auf der schmalen Straße im Vordergrund - einem Fußgängern vorbehaltenen Weg - geht eine Frau mit dem Rücken zum Betrachter rechts aus dem Bild hinaus. Ein niedriger Zaun trennt die schräg ins Bild laufende Straße von der dahinter verlaufenden Fahrstraße. Eine Hochbahn, die im oberen Drittel von links kommend durch das Bild führt, überdacht die von einem Zebrastreifen markierte Autostraße. Starke

18 »The expressway system so dominates the central area of Tokyo that it is impossible not to notice it« (Sorensen 2002: 192f.).

19 Dieser Begriff verweist auf die wichtige Überlandstraße Tokaido, die bereits während der Tokugawa-Zeit (1603-1867) ausgebaut wurde und das vormalige Edo (heute Tokyo) mit der damaligen Hauptstadt Kyoto verband. TokaidoMegalopolis bezeichnet den gewaltigen Industriegürtel, der sich von Tokyo ausgehend in westlicher Richtung bis nach Fukuoka im Norden der Insel Kyushu erstreckt. In diesem Gebiet ist nicht nur ein Großteil der japanischen Produktionskapazitäten gebündelt, hier ist auch die Mehrheit der japanischen Bevölkerung zu Hause: »Here live some two-thirds of the population, on only 23 per cent of the country's land. Here also, where some 85 per cent of the GDP is produced, are concentrated the bulk of the country's fixed assets, the main research and development labs, international communications facilities and global financial centres « (Sorensen 2002: 1).

20 Dass sehr unterschiedliche Sichtweisen eines solchen Umgangs mit dem Stadtraum möglich sind, verdeutlicht Sorensen 2002: 192f. Er beschreibt, dass mit dem Bau der aufgeständerten Autobahnen die Verbindungen zum historischen Tokyo gekappt wurden, was aus nostalgischen Gründen an verschiedenen Stellen kritisiert worden ist. In diesem Sinne wäre auch eine historisierende Perspektive möglich, die die urbane Verkehrsinfrastruktur negativ wertend darstellt. 

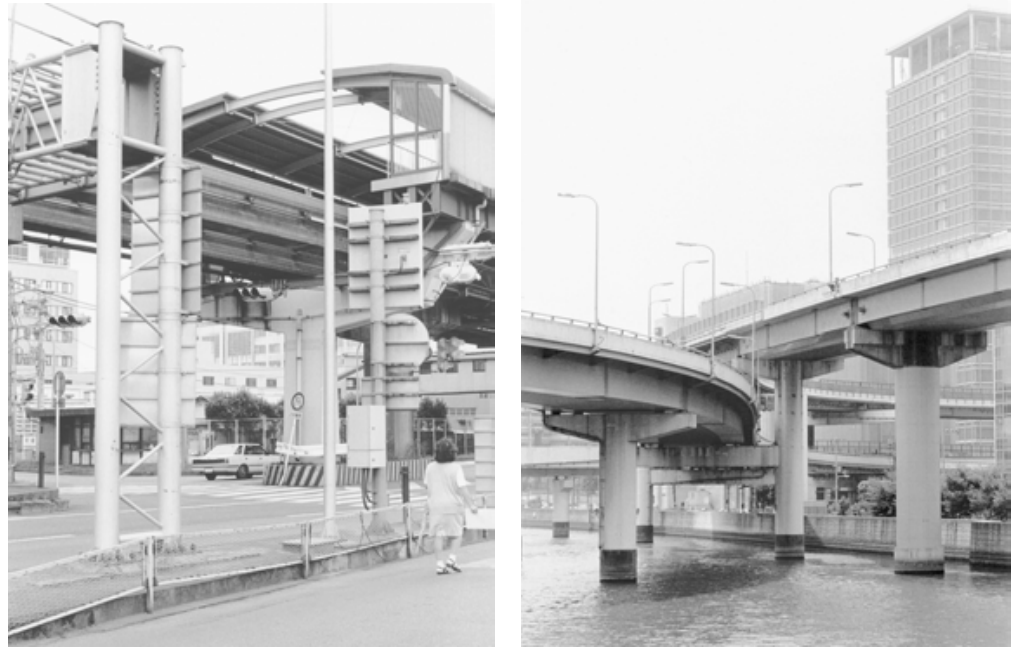

Abb. 14 und 15 .

Stahlträger verankern die Bahnkonstruktion zwischen den Fahrbahnen im Boden. Im Hintergrund der Fotografie, hinter Straße und Hochbahn, sind an der Straße flache, weiter hinten halbhohe Bürogebäude zu erkennen. Die Zwischenräume lassen nur wenig vom Himmel erahnen. Verkehrsampeln, die in Japan horizontal angeordnet sind, Verkehrsschilder und Stromleitungen sind nur einige der sichtbaren Details. Auch diese Fotografie ist - wie die meisten Stadtansichten Neudörfls - sehr komplex. Trotz der abgebildeten Verdichtung wirkt das Bild auf der unteren Ebene weit, da weder Fußweg noch Straße im Moment der Aufnahme intensiv genutzt werden. Neudörfls Fotografie zeigt die Ausnutzung des städtischen Raums auf mehreren Ebenen, wodurch er sehr strukturiert wirkt. Bilden die Ebenen von Straße und Bahn Horizontalen, werden diese durch die Vertikalen der Tragekonstruktionen durchbrochen. Die Fotografie selbst konzentriert sich auf die Darstellung der ausgeprägten Fragmentierung des Raums, weshalb die konkreten Elemente der Abbildung an Wichtigkeit verlieren.

Auch die folgende Fotografie thematisiert die verschiedenen Ebenen japanischer Urbanität (Abb. 15). Über einen von Beton eingefassten Kanal spannen sich sowohl von links als auch von rechts kommend aufgeständerte Autobahnen. Die rechts mittig ins Bild stoßende Straße überdacht die von links in einer Kurve kommende. An den Rändern der Autobahnen ragen Straßenlaternen signifikant in den diesigen Himmel. Der Blickwinkel von unten betont die T-Pfeiler der Stützkonstruktion. Die Fotografin hält eine Distanz zu den Hochstraßen und steht selbst nicht in ihrem Schatten. Der Kanal im Vordergrund suggeriert eine Weite, die nur von den Pfeilern durchbrochen wird. Den rechten Bildrand schließt ein Hochhaus im Anschnitt ab. Im unteren Bereich sind im Hintergrund die verschiedenen Straßenebenen und einige Häuser zu erkennen. Am Ufer des Kanals wachsen teilweise Büsche. Die im Wasser stehenden Pfeiler machen deutlich, dass Straßenverbindun- 

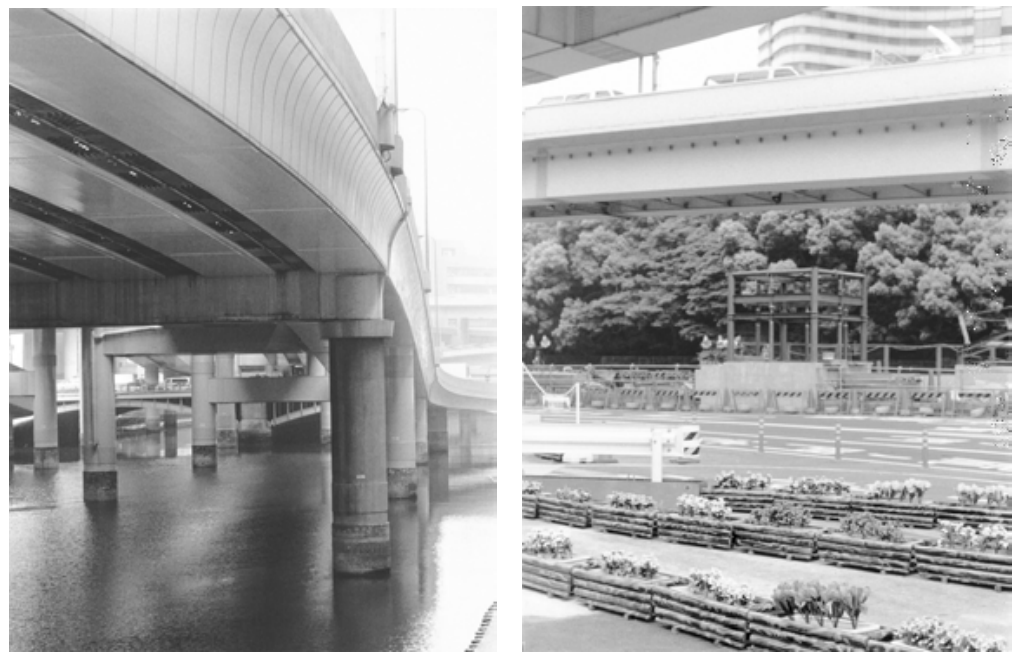

Abb. 55 und 60.

gen eine höhere Priorität als Wasserwegen eingeräumt wird. ${ }^{21}$ Die Überbauung der Flüsse und Kanäle mit Autobahnen »verhalf zu außerordentlichen Einsparungen, die beim Kauf von teurem innerstädtischem Land angefallen wären, aber transformierte unglücklicherweise einen der möglichen großen urbanen Vorzüge Tokyos in unangenehm feuchte, schattige und laute Wasser-Fragmente« (Sorensen 2002: 193). Auf Neudörfls Fotografie ist von den Nachteilen dieser Art der Verwendung des Raums jedoch nichts zu merken. Die Fotografie zeigt ein modernes urbanes Nutzungskonzept, das, indem es den urbanen Raum auf verschiedenen Ebenen strukturiert, keinen Platz verschenkt, sondern sinnfällig von ihm Gebrauch macht. Der Blick von unten verhindert die Sicht auf die Autos, so dass nichts die Klarheit der Abbildung stört. Die verschiedenen Ebenen der Autobahnen wirken in Neudörfls Fotografie ganz natürlich. Sie zeigt, dass sich die Hochstraßen in einer Metropole wie Tokyo in das Stadtbild eingliedern und ihm eine in die Zukunft ausgerichtete und fortschrittliche Anmutung verleihen.

Einen etwas anderen Eindruck der Überbauung der Wasserwege zeigt Neudörfl in einer Fotografie weiter hinten im Buch (Abb. 55). Hier läuft die hochgestellte Autobahn sehr massiv von links kommend ins Bild hinein und füllt einen großen Teil des Bildraums aus. Deutlich überschattet sie das Wasser. Die Pfeiler, die hier außen angeordnet sind, wirken ebenfalls sehr robust. ${ }^{22}$ Die zwei Abbildungen mit ihren unterschiedlichen Blickwinkeln verdeutlichen das breite Spektrum von Neudörfls Arbeit. Lichte und kritische Aspekte sind gleichermaßen integriert, ohne dass die Fotografin eine dezidierte Position bezieht. Neudörfls behutsame Strategie zeugt jedoch nicht von

21 Bereits während der Meiji-Ära verlieren die Wasserwege an Bedeutung. »Der Transport über die Wasserwege ging immer mehr zurück, je weiter sich die Eisenbahnlinie erstreckte« (Shimada 1994: 165).

22 Die Kuratorin Ikeda Yuko zieht mittels dieser Fotografie einen Vergleich zur Fotografie des Bauhaus und des Konstruktivismus (vgl. Ikeda 2006). 
einer fehlenden Haltung ihrem Gegenstand gegenüber, sondern von einer präzisen Beobachtung, die verschiedenen Sichtweisen Gültigkeit einräumt.

Als letzte Fotografie aus diesem Themengebiet soll Abbildung 60 betrachtet werden. Die Fotografie ist aus der Fußgängerperspektive aufgenommen. Das untere Bilddrittel wird bestimmt durch drei Reihen von Plastikblumenkästen, die aussehen, als ob sie aus Rundhölzern zusammengebaut sind. In den Kästen befinden sich Plastikwannen mit verschiedenen Blumen. Ob es sich dabei um echte oder um Kunstblumen handelt, ist nicht klar zu erkennen. Das Arrangement, das sich am Rand einer mit Pollern abgetrennten Straße befindet, ist sehr liebevoll gestaltet. Die hinterste Blumenreihe bildet die Fortsetzung einer links aus dem Bild führenden Leitplanke. Auf der anderen Straßenseite stehen zahlreiche Gitter, die mit Steinen beschwert sind. Eine kubische Stahlkonstruktion auf einem Betonsockel ist dort nicht genau zu identifizieren. Den Bildhintergrund bilden Bäume. Über diese Szenerie führt eine Hochstraße quer durch das Bild, deren Stützkonstruktion außerhalb des Bildausschnitts liegt. Die seitliche Begrenzung der Straße gibt die Sicht auf die Dächer von Kleinbussen und anderen Fahrzeugen frei, oberhalb ist ein kleines Stück Himmel, rechts ein Hochhausfragment zu sehen. Die Staffelung des Raums wird hier auf verschiedenen Ebenen betont. Die Reihen der Blumenkästen mit Straße und Absperrgittern vermitteln eine räumliche Tiefe, die Hochstraße bildet eine obere Begrenzung und vermindert damit den Eindruck von Raumhöhe. Die Anordnung der Blumenkästen im Stadtraum unterhalb einer Hochstraße wirkt äußerst befremdlich. Dieses kleine - vermutlich künstliche - Biotop scheint von der oben entlang führenden Straße geradezu überdacht und damit beschützt zu werden.

Jede einzelne der vorgestellten Fotografien birgt in ihrer Komplexität ein großes Potenzial an Entdeckungsmöglichkeiten, das hier unmöglich erschöpfend behandelt werden kann. Neudörfls Blick auf das urbane Japan zeigt einen fragmentierten, geschichteten Stadtraum, der von mächtigen Verkehrswegen beherrscht wird. Nicht die Gebäudearchitektur steht bei Neudörfls Stadtentwurf im Mittelpunkt, sondern die Verkehrsinfrastruktur. Die Aufmerksamkeit für Strukturen bildet eine Parallele zu den Naturbildern des westlichen Einstiegs. Verkehrswege und das Geflecht urbaner Lebensadern können mit den Verzweigungen der Äste und Blätter der zu Anfang gezeigten Bäume verglichen werden und bieten somit weitere Interpretationslinien an.

Die Fotografin vermeidet das Spektakuläre und präsentiert mit distanziertem Blick einen wesentlichen Aspekt japanischer Urbanität. Neudörfl visualisiert mittels der Abbildung von Schichtungen des urbanen Raums Hendrys Idee des wrapping of space in der japanischen Kultur. Die Fotografien transportieren gleichzeitig große räumliche Tiefe und Höhe, die Neudörfl durch Einbeziehung vorhandener architektonischer Strukturen betont. Dies erscheint als signifikantes Merkmal japanischer Raumaufteilung in großstädtischen Ballungsgebieten. ${ }^{23}$ Die Hochstraßen gliedern den Raum und sind im Wortsinn abgehobene Strukturen, die einen ganz anderen Zugang zur Stadt ermöglichen, als er vom Erdboden aus möglich ist.

23 Hendry zitiert den ungarischen Architekten Botand Bognar mit den Worten: $»$ The Japanese have always been able to give an illusion of depth to spacial compositions, regardless of their actual, usually small or shallow, dimensions" (Bognar 1985: 60; zit. nach Hendry 1993: 100f.). 
$»$ Diese >Achterbahn für Autos, die die Höhen und Tiefen der Stadtlandschaft durchmißt, schlängelt sich zwischen Bürogebäuden hindurch, taucht in unterirdische Tunnel ein und rauscht über niedrige Dächer hinweg. Dem ohnehin hügeligen Tokio wird durch dieses weltweit einzigartige Verkehrssystem eine zusätzliche dynamische Dimension verliehen, da es die Unterschiede der verschiedenen Wohngebiete, Geschäftsviertel und Industriezonen deutlich sichtbar macht« (Tajima 1996: 16).

Auf den Hochstraßen befindet man sich nicht in der Stadt selbst, sondern auf einer Ebene darüber, die eher zu Beobachtung als zu direkter Teilhabe am Geschehen einlädt. So lässt sich auch Neudörfls Position in der Beobachtung dieser Strukturen im besten Sinne als abgehoben beschreiben, auch wenn sie ihre Fotografien in der Regel aus der Fußgängerperspektive heraus macht. Die verschiedenen Anmutungen, die sie den Verkehrswegen in ihren Fotografien verleiht, deuten auf einen distanzierten Fremdblick, der ohne im einzelnen Bild eine konkrete Haltung zu transportieren, den Betrachtern einen Überblick über die angetroffene Situation verschafft. Diese haben nun die Aufgabe, selbst eine eigene Haltung dem Gegenstand gegenüber zu entwickeln. Neudörfls Blick auf das urbane Japan konzentriert sich auf die Zwischenbereiche der Architektur und damit auf die Gliederung des Raums am Beispiel der Verkehrsinfrastrukturen. Diese zeigt Neudörfl eingebettet in eine allägliche Nutzung. Ihre Fotografien weisen auf Differentes hin, ohne es in einer Ausschließlichkeit als Anderes zu präsentieren.

Anthropologin Hendry schreibt dem wrapping auch eine Schutzfunktion zu. In Neudörfls Fotografien der gestaffelten urbanen Situationen lässt sich ebenfalls beobachten, dass die hochgestellten Verkehrswege die darunter liegenden Bereiche zu überdachen vermögen und Schutz - beispielsweise vor der Witterung - bieten können (vgl. z.B. Abb. 60; Neudörfl 2002). Sie sorgen auch für eine strikte Trennung des Durchgangsverkehrs vom lokalen und schützen somit Fußgänger und Radfahrer vor allzu großer Nähe zu schwerem Verkehr. Damit bieten sie ein gewisses Maß an Sicherheit. Das gut ausgebaute System von Bahnen des öffentlichen Nahverkehrs sichert den Transport zum und vom Arbeitsplatz und vermindert somit den Individualverkehr, was wiederum dem Schutz der Umwelt zugute kommt. ${ }^{24}$ Der hier angedeutete Aspekt von Schutz und Sicherheit ist nur einer unter vielen, weshalb der folgende Abschnitt diesen Themenkomplex genauer untersucht.

\subsection{Sicherheit}

Das Thema Sicherheit prägt als anthropologische Konstante das menschliche Dasein. In unserer hoch entwickelten Zivilisation beschränkt es sich nicht nur auf Aspekte der Ökonomie oder der Unversehrtheit von Leib und Leben, sondern es erstreckt sich auf zahlreiche Bereiche des alläglichen Lebens hinein in gesellschaftliche und soziale Zusammenhänge. Sicherheit impliziert Aspekte von Kontrolle, denn mittels Kontrolle kann es gelingen, Unsicherheiten zu minimieren. Die Bedrohung durch Terrorismus in Verbindung mit avan-

24 »72 Prozent des Stadtverkehrs [wird] von den elektrischen Bahnen bewältigt; der Energieverbrauch der Bürger von Tokio [ist] darum weit geringer als - zum Beispiel - jener der Einwohner von Los Angeles, von der Luftverschmutzung nicht zu reden« (Harpprecht 1992: 46). 


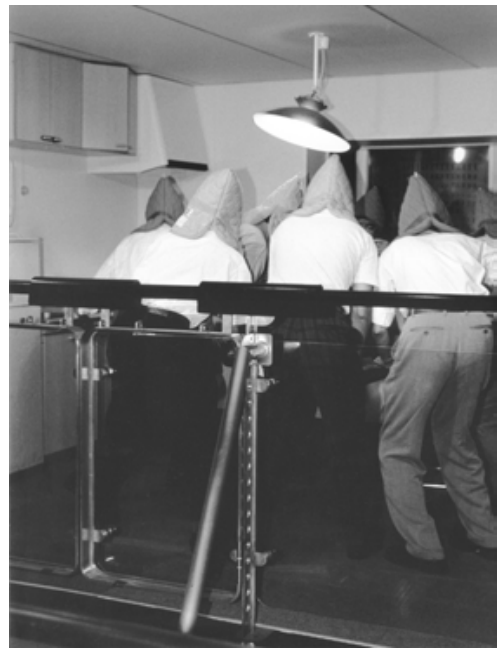

Abb. 29.

cierten Möglichkeiten technischer Überwachung und Kontrolle hat dem Thema Sicherheit im globalen Zusammenhang in den letzten Jahren zunehmend Aufmerksamkeit verschafft. Sicherheit hat jedoch keine universale Gültigkeit. Es muss immer gefragt werden: Sicherheit für wen? Ist diese Frage in gesellschaftlichen Zusammenhängen relevant, existieren andere Situationen, die sich generell einer menschlichen Kontrollierbarkeit entziehen und damit große Unsicherheitsfaktoren darstellen. Dazu gehören beispielsweise Naturereignisse wie Erdbeben, Taifune oder Flutwellen. Die Bedrohung durch Naturkatastrophen ist in Japan stets präsent, so dass ein besonderes Bedürfnis nach Sicherheit innerhalb der japanischen Gesellschaft durchaus nahe zu liegen scheint. Ein solches beobachtet Elisabeth Neudörfl in Japan. »Dieses enorm große Bedürfnis nach Sicherheit hat mich interessiert. Es zieht sich wie ein roter Faden durch meine Ausstellung« (Eggers 2002: 80). Bereits in ihrem Konzeptentwurf für das Projekt formuliert sie sehr unterschiedliche Aspekte des japanischen Sicherheitsbedürfnisses, das von der Gruppenzugehörigkeit über die hierarchische Gliederung der Gesellschaft bis hin zu technischen Sicherheitsmaßnahmen reicht (vgl. Neudörfl 1997: 1f.) Interessant an Neudörfls Arbeit ist die breite Streuung des Themas Sicherheit. Neudörfls Beobachtungen erstrecken sich auf sehr unterschiedliche gesellschaftliche Ebenen, wodurch gleichzeitig der japanspezifische Charakter dieses Themas herausgearbeitet wird. Durch den zurückhaltenden Ansatz drängt sich das Thema nicht auf, sondern wird beinahe nebensächlich mitverhandelt.

Zahlreiche Fotografien in Future World, die sich mitunter auch in andere Kategorien einordnen lassen, thematisieren implizit oder explizit Fragen der Sicherheit. Sicherheit steht in enger Relation zu Unsicherheit und eine solche nutzt Neudörfl häufig auf der Bedeutungsebene der Fotografien, wie an Abbildung 29 zu beobachten ist. Die hier gezeigte Situation ist zunächst schwer einzuordnen. Hinter einer halbhohen Glasscheibe stehen im Zentrum des Bildes sechs Männer in einer Gruppe beisammen, fast alle wenden dem Betrachter den Rücken zu. Die Männer sind sehr ähnlich gekleidet und tragen 

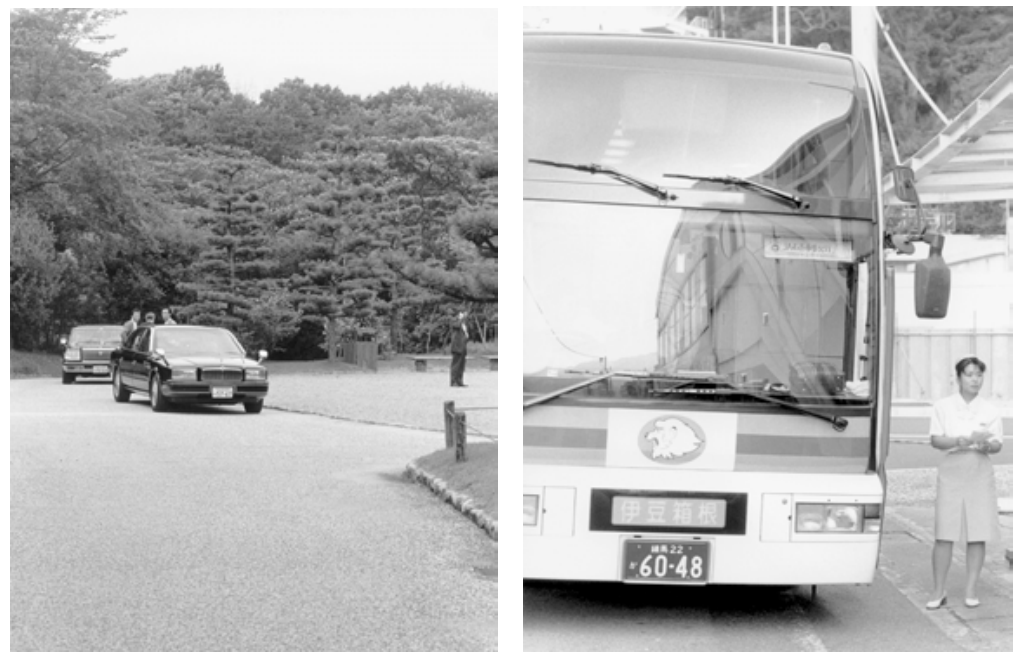

Abb. 35 und 36.

als Kopfbedeckung seltsame wattierte Hauben. Sie stehen unsicher, als ob der Boden schwankt, worauf auch die pendelnde Küchenlampe hinweist. Das Bild vermittelt einen eigenartigen Eindruck, denn Verhalten und Kleidung der Männer sind schwer einzuordnen. Da die Protagonisten dem Betrachter den Rücken zuwenden, bleibt ihr Handeln ungewiss, man kann lediglich darüber spekulieren, was sie gerade tun. Daraus entsteht in der Fotografie eine Irritation, mit der die Fotografin gezielt arbeitet. Die Fotografie steht allein, weder die vorherigen noch die nachfolgenden Bilder geben eine genauere Erklärung über das Geschehen. Mit dem Wissen, dass die Fotografie in einem Erdbebensimulationszentrum aufgenommen ist, lässt sich das Thema zuordnen, die Unsicherheit über das wirkliche Geschehen bleibt jedoch bestehen. Neudörfl verbindet in dieser Fotografie Sicherheitsaspekte der japanischen Gesellschaft mit einer Unsicherheit auf der Bedeutungsebene. Erneut wird deutlich, dass Neudörfls Fotografien die abgebildeten Situationen nicht erklären wollen. Leerstellen und Unsicherheiten entziehen auch die Bedeutung der Fotografien einer vollständigen Kontrollierbarkeit. Dennoch entfalten Neudörfls Bilder eine eindrucksvolle Wirkung, die sich gerade auch aus ihrer Offenheit ergibt. Die Betrachter werden mit Fragen konfrontiert, auf die die Bilder keine Antwort geben. Dies fordert dem Betrachter eine hohe Eigenleistung $\mathrm{ab}$.

Einen anderen Aspekt des Themas Sicherheit zeigt die linksseitig abgedruckte Abbildung 35. Auf einer breiten Kiesauffahrt stehen in einiger Entfernung etwa in der Bildmitte zwei schwarze Luxuslimousinen hintereinander. Zwischen den beiden Autos stehen drei Männer in Anzügen, zwei schauen direkt in die Kamera, der dritte ist nur von hinten zu sehen. Den Bildhintergrund bildet ein Wald. Rechts neben den Autos befindet sich ein leicht erhöhter Platz mit einfachen Picknickbänken, dort steht ein vierter Mann und telefoniert, den Rücken der Gruppe zugewandt. Die Distanz, die die Fotografin zu den Männern hält, deutet darauf hin, dass das Fotografieren nicht bemerkt werden soll. Das Bild löst eine unmittelbare Assoziation zur japani- 
schen Mafia aus, der Yakuza. ${ }^{25}$ Nicht erst seit die Zugehörigkeit zu YakuzaOrganisationen strafbar ist, tarnen sich deren Mitglieder oft als Geschäftsmänner. ${ }^{26}$ Obwohl die abgebildete Situation sehr unspezifisch ist und die Gesichter aufgrund der großen Distanz kaum zu identifizieren sind, meint man, eine solche Situation aus zahlreichen Filmen zu kennen und stuft die Männer automatisch als gefährlich ein. Neudörfl setzt den Bezug zu bekannten Bildwelten gezielt ein. Sie benötigt nur eine einzelne Fotografie, um eine ganze Kette von Assoziationen auszulösen und verweist damit auf die hinlänglich bekannten Praktiken der Yakuza und die Gefährdung der öffentlichen Ordnung, die von ihren Gruppen ausgeht. Die Distanz der Fotografin zu den als gefährlich eingestuften Männern dient als Sicherheitsabstand und trägt somit weiterhin zur Wirkung der Fotografie bei. Die Fotografin und die Betrachter können einen Anblick aus der Ferne erhaschen, befinden sich aber in einem respektvollen Abstand und somit in Sicherheit. Auch wenn die Fotografie eine scheinbar bekannte Szene zeigt, bedient sie dennoch nicht das Klischee der gefährlichen Unterweltbosse. Neudörfl verzichtet darauf, Insignien der Yakuza wie Waffen oder Tätowierungen zu fotografieren und verankert die Szene in einer alltäglichen Normalität. Die Interpretation der fotografierten Szene findet demnach nicht in der Fotografie selbst, sondern im Kopf der Betrachter statt.

Die Fotografie auf der folgenden Doppelseite thematisiert das japanische Sicherheitsbedürfnis eher implizit (Abb. 36). Die links angeschnittene Front eines modernen Reisebusses nimmt den größten Teil des Bildraums ein. Da die großen Frontscheiben des Busses einen Zweckbau spiegeln, ist nicht erkennbar, ob sich bereits Passagiere an Bord befinden. Rechts oben auf der Innenseite der Scheibe ist ein Zielschild befestigt. Mittig unter der Windschutzscheibe ist ein Löwenkopf-Logo angebracht, vermutlich ist es das Signet des Reiseveranstalters. Rechts neben dem Bus steht eine Frau frontal zum Betrachter, die aufgrund ihrer uniformähnlichen Kleidung und ihrer Körperhaltung als Reiseleiterin erkennbar ist. Sie trägt eine weiße Bluse mit einer Schleife am Kragen, einen hellen Kostümrock, schlichte weiße Damenschuhe sowie eine Kappe auf dem Hinterkopf. In den Händen hält sie ein Blatt Papier. Ihr Blick ist am Betrachter vorbei rechts aus dem Bild hinaus auf ein Geschehen gerichtet, das außerhalb der Bildbegrenzung stattfindet. Die Person der Reiseleiterin vermittelt eine große Sicherheit. Sie kümmert sich um die Reisenden und wacht über die Details der Reise. Sie weiß, wie viele Personen mitreisen und sorgt dafür, dass alle Reisenden sicher am Zielort angelangen. Sie verkörpert das Bedürfnis vieler Japaner, lieber aufgehoben in einer Gruppe statt als Individualtouristen die Welt zu erkunden. Neudörfl zeigt in dieser Situation gerade nicht die Reisegruppe, die der Reiseleitung folgt, sondern sie zeigt die Person, die das Bedürfnis nach Sicherheit verkörpert und mit einer angespannten Erwartungshaltung ihre ganze Aufmerksamkeit auf

25 Die Yakuza sind seit Jahrhunderten die Protagonisten des organisierten Verbrechens in Japan. Neben traditionellen Aktivitäten wie Drogen- und Menschenhandel, Prostitution, illegalem Glücksspiel und Schutzgelderpressung nehmen Yakuza-Organisationen heute auch Einfluss auf Finanzmärkte und sind in politische Korruption verwickelt (vgl. Timmerberg 1992; Herbert 2002: insbesondere $110 \mathrm{ff}$.; 142ff.).

26 Die Gesetzgebung wurde 1992 erlassen (vgl. Timmerberg 1992; Herbert 2002: 171ff.). 

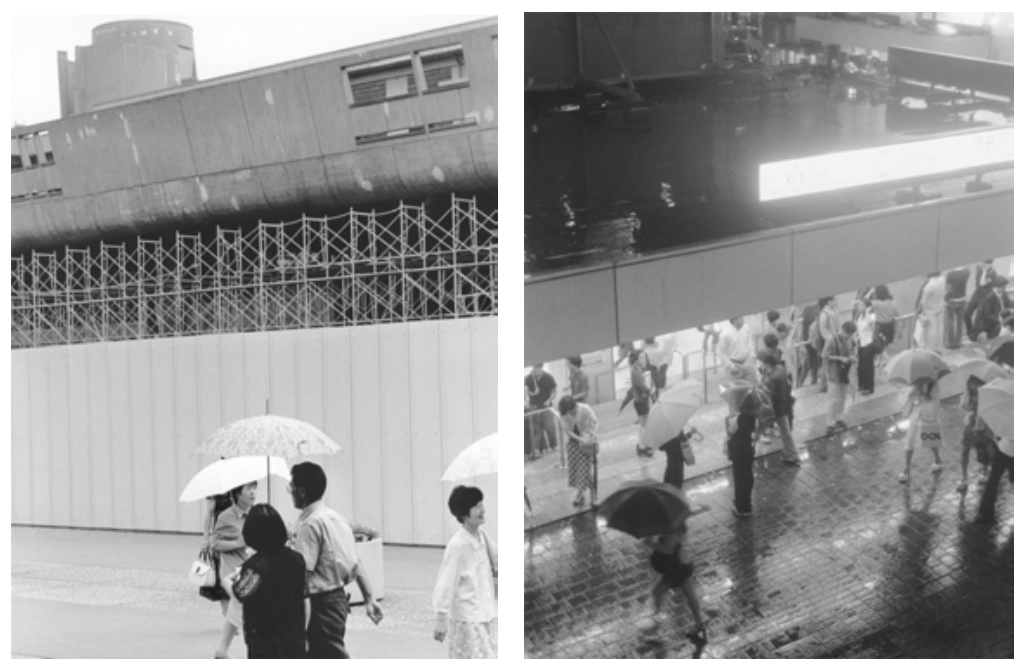

Abb. 67 und 72 .

die bevorstehende Aufgabe konzentriert. ${ }^{27}$ Auch in dieser Fotografie zeigt Neudörfl einen Aspekt der japanischen Gesellschaft, ohne eine konkrete Wertung im Bild selbst zu verankern.

Schutz vor der Witterung ist in einem Land, das zu verschiedenen Jahreszeiten extreme Wetterlagen kennt, ein sinnvolles Anliegen. Fotografie 67 zeigt Passanten, die sich mit aufgespannten Schirmen vor Hitze und Sonneneinstrahlung schützen. Die wenigen Fußgänger, die einen breiten Fußweg im Vordergrund des Bildes nutzen, nehmen lediglich einen kleinen Teil der Fotografie ein. Im Hintergrund erhebt sich ein teils eingerüsteter und von einem gleichmäßigen Zaun umgebener massiver Betonbau, der die Anmutung eines Schiffes hat. So lässt sich ein zentraler Gegenstand in der Fotografie nicht ausmachen, doch scheint die Massivität des Betonbaus den Elementen auf ähnliche Art zu trotzen wie die hellen Sonnenschirme der Menschen. Die vollständig versiegelte Fläche, die keinen Platz für Schatten spendende Bäume bietet, verstärkt die Anmutung eines künstlich verschärften klimatischen Problems in urbanen Ballungsgebieten. Implizit verweist dies auf negative Seiten einer Future World, die trotz hoher Technisierung natürliche Gegebenheiten nicht vollständig kontrollieren kann. Damit knüpft diese Fotografie an weitere an, in denen Schirme ein bildprägendes Element darstellen (vgl. Abb. 71-73). Insbesondere die nachts bei Regen aufgenommenen Fotografien 71 und 72 lassen Assoziationen an das Science-Fiction Genre anklingen. Wer Filme wie beispielsweise Blade Runner kennt, dem drängen sich Assoziationen zu diesem Film geradezu auf. ${ }^{28} \mathrm{Ob}$ diese Assoziation intendiert ist, erschließt sich nicht. Weil die Autorin nicht zielgerichtet auf Aussagen hin arbeitet, kann das Vorwissen die Lesart der Fotografien nachhaltig beeinflussen. Weil die Bilder so offen sind, scheinen solche Assoziationen eine Möglichkeit, ein Verständnis für die Arbeit zu entwickeln. Die verschiedentlich eingestreuten

27 Zum Thema des japanischen Gruppenverhaltens vgl. Abschnitt 4.6.1.

28 Vgl. Blade Runner: ein Film von Ridley Scott, 1982. Dieser Film spielt groBenteils nachts, wobei es häufig stark regnet. 
Verweise an bekannte Bild- oder Filmwelten lassen jedoch die Vermutung $\mathrm{zu}$, dass sie durchaus beabsichtigt sind und gezielt den Interpretationsraum von Neudörfls Fotografien erweitern.

An Elisabeth Neudörfls Umgang mit dem Thema Sicherheit wird abermals ihr fotografischer Ansatz deutlich, der auf eine eindeutige oder plakative bildmäßige Umsetzung verzichtet. Nicht allgemeingültige, für Sicherheit stehende Symbole werden ins Bild gesetzt, sondern die Durchdringung des Alltags durch sicherheitsrelevante Elemente. Dies kommt der Abkehr von klischeehaften Darstellungsmethoden gleich.

\subsection{Freizeit}

Eine Erweiterung des Themas Sicherheit bildet der Bereich der Freizeitaktivitäten. Aufgrund der Abhängigkeit vom Wetter lassen sich Sportarten wie Skifahren oder Surfen in der Regel nur saisonal betreiben. Interessierte Sportler müssen meist Reisen auf sich nehmen, um in Gebiete zu gelangen, wo sie ihrer Sportart nachgehen können. In einer Gesellschaft, die stark auf Effizienz setzt und der arbeitenden Bevölkerung nur wenige Urlaubstage im Jahr einräumt, ist es vermutlich schwierig, solchen Hobbys nachzugehen. Daher wird in Japan versucht, die witterungsbedingten Beschränkungen außer Kraft zu setzen und die Sicherheit zu bieten, jederzeit jede Sportart ausüben zu können. Dies zeugt auch von einer Konsumhaltung, die das Freizeitverhalten prägt. Elisabeth Neudörfl untersucht dieses Thema an verschiedenen Orten. Sie besucht eine Grasskipiste ebenso wie eine rund ums Jahr geöffnete Skihalle und eine Meeresstrandschwimmhalle. Erst der technologische Fortschritt ermöglicht die Errichtung solch großer Hallen, aber Neudörfl konzentriert sich nicht vordergründig auf technische oder die Natur simulierende Details. Auch hier arbeitet sie mit Totalen und bildet die Menschen als Nutzer der künstlichen Anlagen ab. Die technologischen Aspekte der Freizeiteinrichtungen bilden den Hintergrund. Auf diese Weise stellt Neudörfl eine Verbindung zwischen Hochtechnologie und ihrem Gebrauch durch die Menschen her.

Auf einer Doppelseite sind die Fotografien einer Skihalle und einer Strandsituation miteinander kombiniert. Die leicht unscharfe Fotografie der Skihalle ist aus der Sportlerperspektive gemacht (Abb. 37). Der Betrachter schaut hinter anderen Skifahrern hinterher, die den Hügel hinunterfahren. Bildprägend ist im oberen Bildteil die Hallenkonstruktion, die sich über die gesamte Breite des Bildes spannt. Im vertikalen Zentrum der Fotografie stehen Säulen, die zwei Pisten voneinander abgrenzen. An ihnen haben sich organisch anmutende Ablagerungen aus Schnee festgesetzt. Links im Hintergrund ist eine Liftanlage zu erkennen. Die Künstlichkeit der Situation ist in der Fotografie sehr präsent, dennoch entwickelt Neudörfl eine komplexe Situation im Bildraum, die zahlreiche Aspekte des Themas integriert. Weder ist Kritik an der künstlichen Welt Skihalle formuliert, noch lässt sich eine Affirmation des technischen Fortschritts ablesen.

Im Vordergrund der Strandfotografie laufen zwei Kinder mit großen aufblasbaren Schwimmringen vom Betrachter weg in Richtung Wasser (Abb. 38). Der Schattenwurf deutet auf eine starke Sonneneinstrahlung und damit auf herrliches Strandwetter. Der Strand ist insgesamt sehr voll, Familien tummeln sich sowohl auf dem Sand als auch im seichten Wasser. In der verti- 

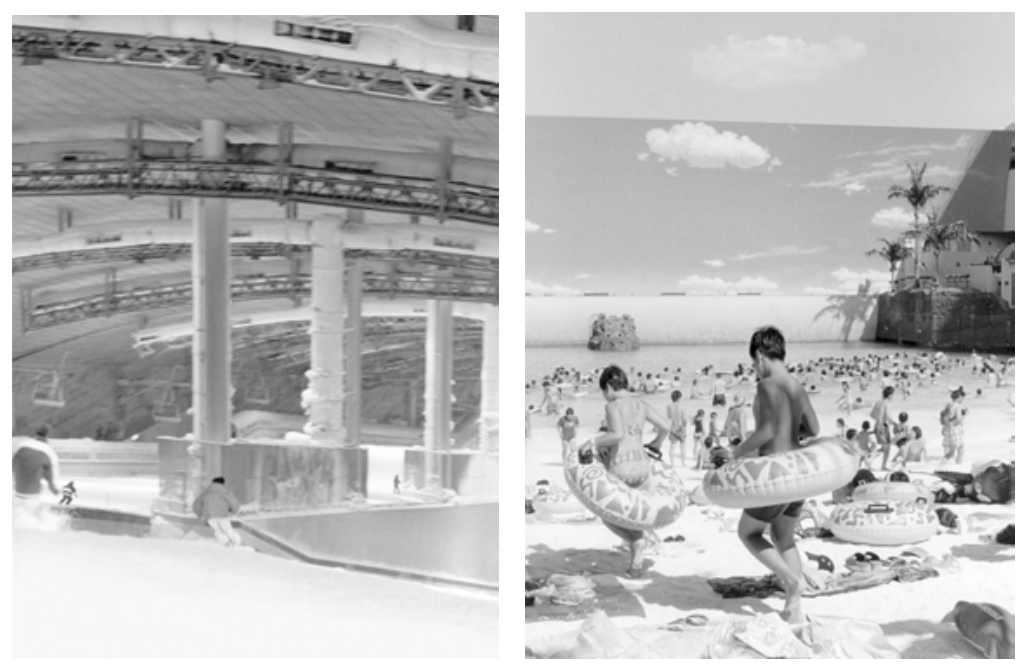

Abb. 37 und 38 .

kalen Bildmitte ist im Hintergrund eine Wellblechwand zu sehen, oberhalb befindet sich ein gemalter Himmel, der abrupt endet und den Blick auf den echten freigibt. Eine einzige weiße Wolke des echten Himmels ist der gemalten direkt darunter in der Form sehr ähnlich. Eine Badeinsel aus Stein und Palmen auf hohem Betonsockel versucht, Südseeatmosphäre zu suggerieren. Die Strandsituation des Freizeitbades ist simuliert. In der Simulation verliert das Meer an Gefahrenpotenzial, denn die Badenden können sich dem Vergnügen unbehelligt von gefährlichen Wellen, Tieren oder Strömungen hingeben. ${ }^{29}$ Bei schlechtem Wetter lässt sich das Dach schließen, so dass ein von Temperaturen unabhängiges Strandvergnügen möglich ist. Neudörfl thematisiert die Konstruierheit der Szenerie auf sehr feinsinnige Weise. Statt gezielt die Künstlichkeit der Einrichtung zu fokussieren, setzt sie auf das Beobachtungsvermögen der Betrachter, diese selbst zu entdecken.

Nur in der folgenden Fotografie ist dies nicht mehr möglich, denn eine dynamische Unschärfe bestimmt das Bild (Abb. 39). Die künstlichen Details geraten deshalb aus dem Blickfeld. Mittig surft ein Mann auf Brandungswellen. Rechts hinter ihm befindet sich eine hohe Insel mit einer Palme; im Hintergrund ist Himmel mit kleinen weißen Wolken zu sehen. Die leichte Unschärfe unterstreicht die Dynamik des Surfers. Was nach einem tropisch anmutenden Vergnügen aussieht, ist ein künstlich erzeugtes Wellenbad, wie der aufmerksame Betrachter aus den vorangegangenen Fotografien weiß. Diese Fotografie perfektioniert die Simulation im Bild, da sie deren Elemente mittels Unschärfe ausblendet. Dies dient jedoch nicht der Legitimation der künstlichen Welt oder der Täuschung der Betrachter, denn es leitet zur Fotografie auf der nächsten Doppelseite über (Abb. 40). Dort steht, abermals mittig, ein Surfer auf seinem Brett, hinter sich die Weite des Meeres. Die Welle, die er reitet, ist winzig klein, das Meer vollkommen ruhig. Im Vordergrund

29 Bereits in ihrem Konzept verweist Neudörfl darauf, dass in japanischen Schwimmbädern das Wasser nie so tief ist, »daß man untergehen könnte« (Neudörfl 1997: 2). 

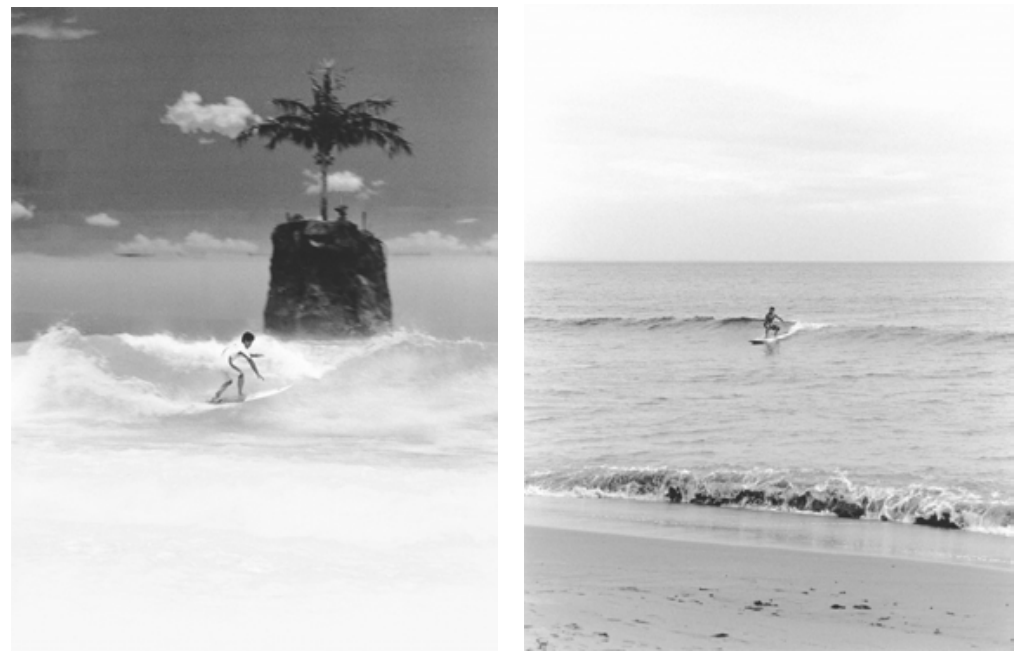

Abb. 39 und 40.

des Bildes ist ein Stück Strand zu sehen und der Himmel ist weiß verschleiert. Der einsame Surfer muss den Strand und das Wasser nicht mit anderen teilen, aber der Spaßfaktor erscheint hier wesentlich geringer. Der künstliche Strand beinhaltet ein höheres Vergnügungspotenzial und ist deshalb wesentlich begehrter als die reale Situation. Damit deutet Neudörfl darauf hin, dass die künstlich gebaute Freizeitwelt Komfort und Sicherheiten bietet, die in der Alltagswelt fehlen.

Durch die Kombination der Skihallen- und Strandbadfotografien verdeutlicht Neudörfl die Gemeinsamkeiten innerhalb dieser künstlich inszenierten Welten, die Sicherheiten für Sport und Freizeit bieten. Auch wenn es mittlerweile in Europa Vergleichbares gibt, zeigt Japan sich hier in der Vorreiterposition und somit als Future World. ${ }^{30}$ Neudörfl betont abermals die Alltäglichkeit der fotografierten Szenerien. Selbst für Japaner sind die Konstruktionen dieser avancierten Freizeitanlagen etwas Besonderes, aber Neudörfls Fotografien betonen nicht das Spezifische der technischen Möglichkeiten, sondern untersuchen deren gewöhnlichen Gebrauch.

In Elisabeth Neudörfls Arbeit bietet dieser Komplex auch aufgrund der Anzahl der Fotografien eine Erweiterung des Themas Sicherheit. Die technische Konstruktion insbesondere der Skihalle greift jedoch auch das Thema der verdichteten Bebauung auf, schließlich sind hier komplexe gebaute Innenraumstrukturen zu sehen, die auf die im Stadtraum fotografierten Konstruktionen des Außenraums verweisen. Die von Neudörfl präsentierten Bildwelten greifen ineinander und verdichten die Arbeit selbst zu einer Einheit. Auch wenn die unterschiedlichen Themenkomplexe vordergründig zuweilen disparat erscheinen, sind sie sowohl inhaltlich als auch gestalterisch zu einem komplexen Ganzen ineinander verwoben. 


\subsection{Menschenbilder}

Einige der bisher in Elisabeth Neudörfls Arbeit Future World analysierten Fotografien zeigen menschenleere Natur- und Architekturdarstellungen, andere integrieren auch Personen als Nutzer der gestalteten Umwelt. Die Darstellung von Menschen markiert einen wichtigen Bereich in Neudörfls Arbeit. Insgesamt achtzehn Porträts bilden Zäsuren im Ablauf des Buches. Hier hebt Neudörfl die Distanz zum Bildgegenstand auf und bildet Köpfe Format füllend $\mathrm{ab}$, weder Ort noch Kleidung geben Aufschluss über ihre Persönlichkeit. Sie sind sich der Präsenz der Kamera bewusst, bleiben aber anonym. Die Betrachtung konzentriert sich auf den Gesichtsausdruck. Die Porträts sind über das gesamte Buch verteilt und stellen die größte Bildgruppe innerhalb der Arbeit dar. Doch Neudörfl porträtiert nicht nur Einzelpersonen. Wiederholt fotografiert sie einen eigenen Zusammenhalt bildende Personengruppen sowie Menschenmengen auf der Straße. Die Gruppenbilder zeichnen sich dadurch aus, dass die abgebildeten Personen im öffentlichen Raum angetroffen und aus einiger Distanz fotografiert werden. Sie sind sich der anwesenden Kamera nicht bewusst. Die anonym bleibenden Personen werden über ihre Gruppenzugehörigkeit definiert. Sie sind in einem sozialen Zusammenhang fotografiert, der ebenso wie der öffentliche, sie umgebende Raum über ihre Beziehung zur Gruppe Aufschluss gibt. Die Individualität der einzelnen Personen wird in den Bildern nicht thematisiert. Die auf der Straße fotografierten Passanten bilden keine eigenständige sozial definierbare Gruppe, vielmehr entsteht im zufälligen Zusammentreffen zahlreicher Individuen eine Menschenmenge. Der einzig erkennbare Zusammenhang besteht in der gleichzeitigen Anwesenheit an einem Ort. Andere Gemeinsamkeiten gibt es nicht.

\subsubsection{Menschengruppen}

Die Gruppenorientierung in der japanischen Gesellschaft gilt, wie in Teil I, Abschnitt 2.3.1. erläutert, als ein gängiges Stereotyp. Die Zugehörigkeit zu einer Gruppe bietet Sicherheit und Geborgenheit und erleichtert es dem Individuum, einen Platz innerhalb der Gesellschaft einzunehmen. Ob dies allein auf die japanische Gesellschaft zutrifft, sei dahingestellt. In einer Abfolge von drei Fotografien zeigt Elisabeth Neudörfl Aspekte einer Gruppenzugehörigkeit von Mädchen im Teenageralter beziehungsweise jungen erwachsenen Frauen, zwei sollen hier vorgestellt werden. Die - wie die beiden folgenden Bilder rechtsseitig angeordnete - Abbildung acht zeigt ein niedriges Haus mit Rauputzfassade und geschlossenen Fensterläden. An der Dachkante ist ein Schriftzug in lateinischen Buchstaben mit dem Wort Hotel zu erkennen. Rechts vor der Fassade steht eine Kiefer mit sehr dünnem Stamm auf einer Grasfläche. Auf der linken Seite schwingt sich eine Treppe mit Betonstufen und Stahlgeländer in einer Kurve links aus dem Bild hinaus. Auf den unteren Stufen sitzen vier junge Frauen in Alltagskleidung zusammen. Eine raucht, zwei schauen ein wenig ins Leere, die vierte hat dem Betrachter den Rücken zugekehrt. Die Fotografie zeigt - aus einiger Distanz aufgenommen - eine unspektakuläre Szenerie. Neudörfl setzt die Beiläufigkeit der Situation zurückhaltend ins Bild. Die Fotografie zeigt die Gruppe junger Frauen, ohne spezifische Klischees zu thematisieren. 

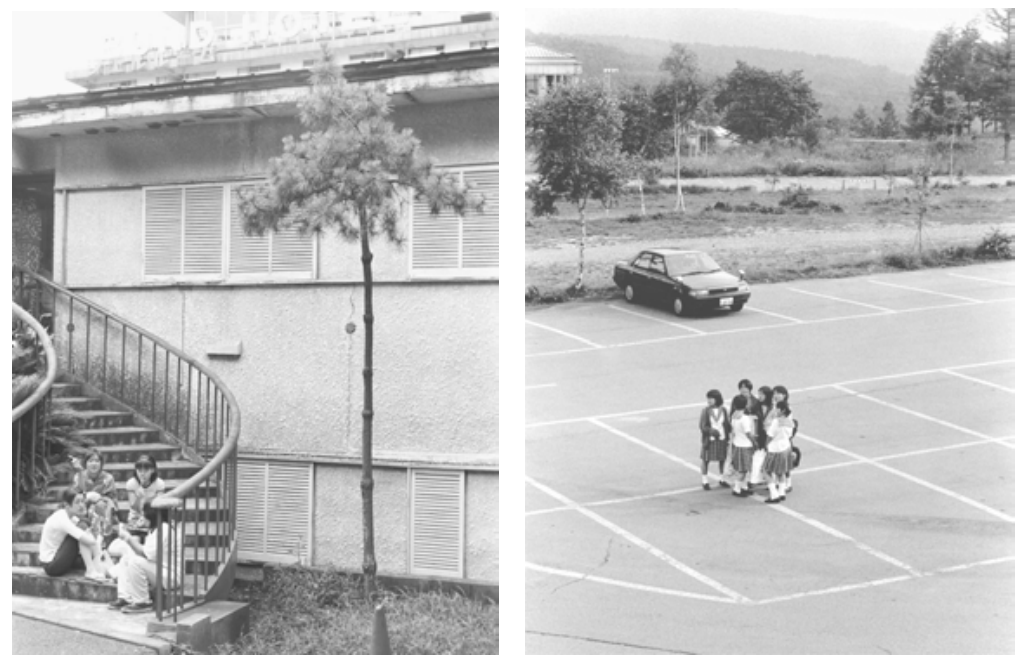

Abb. 8 und 9.

Zentrales Element der folgenden Fotografie ist eine Gruppe von sechs Mädchen, die dicht gedrängt und fast kreisförmig auf einem leeren Parkplatz zusammenstehen (Abb. 9). Auf dem betonierten Boden sind die Stellplätze mit weißen Linien markiert, in der hinteren Reihe ist ein einzelnes Auto geparkt. Hinter dem Parkplatz erstreckt sich eine Art Grünanlage, junge Birken wachsen hier ebenso wie kleinere Sträucher und Gras, das jedoch parallel zur Parkplatzkante einem Trampelpfad gewichen ist. Im Bildhintergrund eröffnet sich eine Landschaft mit bewaldeten Hügeln. Die Mädchen unterhalten sich und scheinen dabei auf etwas zu warten, was durch den Blick der links stehenden Figur aus dem Bild hinaus angedeutet wird. Sie alle tragen Schuluniformen: weiße Blusen mit karierten Kragen, karierte Röcke, weiße Socken und schwarze Schuhe. Zwei Mädchen tragen über der Uniform identische Blazer. Das Alter der Mädchen ist auch aufgrund der Distanz schwer zu schätzen. Da das Tragen einer Schuluniform in Japan jedoch ab der Mittelschule, die die siebte bis neunte Klasse umfasst, Pflicht ist, lässt sich ihr Alter auf diese Altersgruppe eingrenzen (vgl. Gordon 2002b: 442). Bemerkenswert an der Fotografie ist die körperliche Nähe, die die Gruppe trotz des verfügbaren Platzes hält. Zudem versammeln sich die Mädchen wie verabredet genau an einer Schnittstelle zweier Markierungslinien, an der vier Parkplätze aneinander grenzen. Raumaufteilung und grafische Elemente der Fotografie betonen die Homogenität der Gruppe; die Schuluniformen verstärken die Wirkung zusätzlich. Im Gegensatz zu Abbildung acht wird hier ein sehr spezielles Gruppenverhalten porträtiert. Die körperliche Nähe gibt den Mädchen die Sicherheit der Zusammengehörigkeit. Der Parkplatz lässt auf die Situation eines Ausflugs oder einer Reise schließen. Indem die Personen dicht beieinander stehen, wird die Gefahr, zurückgelassen zu werden, eliminiert. Neudörfl zeigt hier eine sehr spezielle Art von Gruppenzusammengehörigkeit, die sich von der in der vorangegangenen Fotografie nachhaltig unterscheidet und eine Anmutung von Fremdheit vermittelt. Sie ist dennoch so beiläufig ins Bild gesetzt, dass nicht explizit wird, ob dieses Verhalten fremd und damit 
spezifisch japanisch ist oder ob ein ähnliches Verhalten auch in Europa beobachtet werden könnte. ${ }^{31}$

Neudörfl schafft durch den inhaltlichen Zusammenhang eine Bildsequenz, die sich mit dem Gruppenverhalten junger Mädchen beschäftigt. Sie betont die Natürlichkeit des Verhaltens innerhalb von Gemeinschaften dieser Altersgruppe. Das in den Fotografien dargestellte Gruppenverhalten kann als soziale Absicherung gegenüber den Unwägbarkeiten einer für Jugendliche in diesem Alter sich ausdehnenden Welt, aber auch als Möglichkeit der Abgrenzung gegenüber anderen begriffen werden. Neudörfl kehrt das Verhalten der Mädchen nicht als spezifisch japanisch hervor, vielmehr entsteht ein Eindruck von Übereinstimmungen und Abweichungen zu uns bekannten Verhaltensweisen. Neudörfls Blick betont abermals die Ambivalenz bezüglich der Kategorien des Eigenen und des Fremden.

Abbildung 33 greift erneut die Thematik des Gruppenverhaltens im Zusammenhang von Schulaktivitäten auf. Auf der rechtsseitig stehenden Fotografie nimmt eine steinige Bergkuppe etwas mehr als die untere Bildhälfte ein. Der Himmel ist grau und lässt die Umgebung hinter einem Dunstschleier unsichtbar werden. Auf dem Gipfel befindet sich ein kleines ShintoHeiligtum, was durch an Pflöcken gespannte Seile begrenzt wird. Links in der Bildmitte führt ein schmaler Steg am Heiligtum vorbei und wieder den Berg hinab. Dort stehen einige Personen in Freizeitkleidung beieinander. Zentrales Element der Fotografie ist jedoch eine sehr große gemischtgeschlechtliche Schülergruppe, die hier offensichtlich anlässlich eines Schulausfluges versammelt ist. ${ }^{32}$ Neudörfl beobachtet sie von einer erhöhten Position aus. Die Schüler tragen alle identische Trainingsanzüge und weiße T-Shirts sowie Rucksäcke auf dem Rücken. Abermals stehen die Schüler recht dicht beieinander, was hier jedoch mit den natürlichen Gegebenheiten des begrenzten Raums zusammenhängt. Dennoch zeugt das Verhalten der Schüler von einem Verantwortungsbewusstsein, das in einer solch großen Gruppe unabdingbar ist. Durch die in der Fotografie eingehaltene Distanz zu den Personen werden Spuren der Individualität gezielt vernachlässigt, was die Homogenität der Gruppe betont. Tatsächlich sehen die Schüler alle sehr ähnlich aus. Diese Fotografie passt erneut in das von Neudörfl beobachtete Konzept des japanischen Sicherheitsbedürfnisses, denn die identische Kleidung ermöglicht die eindeutige Zuordnung zur Gruppe. Bei dieser Gruppengröße kennen die Aufsichtspersonen vermutlich nicht jeden einzelnen Schüler, aber die Uniform bescheinigt die Zugehörigkeit und bietet somit eine gewisse

31 Die japanische Kuratorin Matsumoto sieht in dieser Fotografie Aspekte der japanischen Kultur auf subtile Art repräsentiert. »Das ist eine sehr natürliche Ansicht, andere sagen aber vielleicht, es sei typisch für japanische Frauen, immer zusammen zu sein. Aber es ist aus ihrer [Neudörfls] Sicht nicht so offensichtlich. Vielleicht dachte sie, dies sei eine gute Komposition und verfolgt keine gezielte Absicht mit der Fotografie« (Gespräch mit Matsumoto 2006).

32 Schulausflüge sind zentrales Element des japanischen Schulalltags. Meist fahren alle Schüler eines Jahrgangs gemeinsam, so dass bis zu 500 Schüler zu beaufsichtigen sind. »The excursions serve as a significant opportunity to train students in appropriate public behaviour and etiquette. [...] Maintenance of school reputation is a serious matter for teachers. Students are expected to conduct themselves with dignity« (Gordon 2002a: 440). 

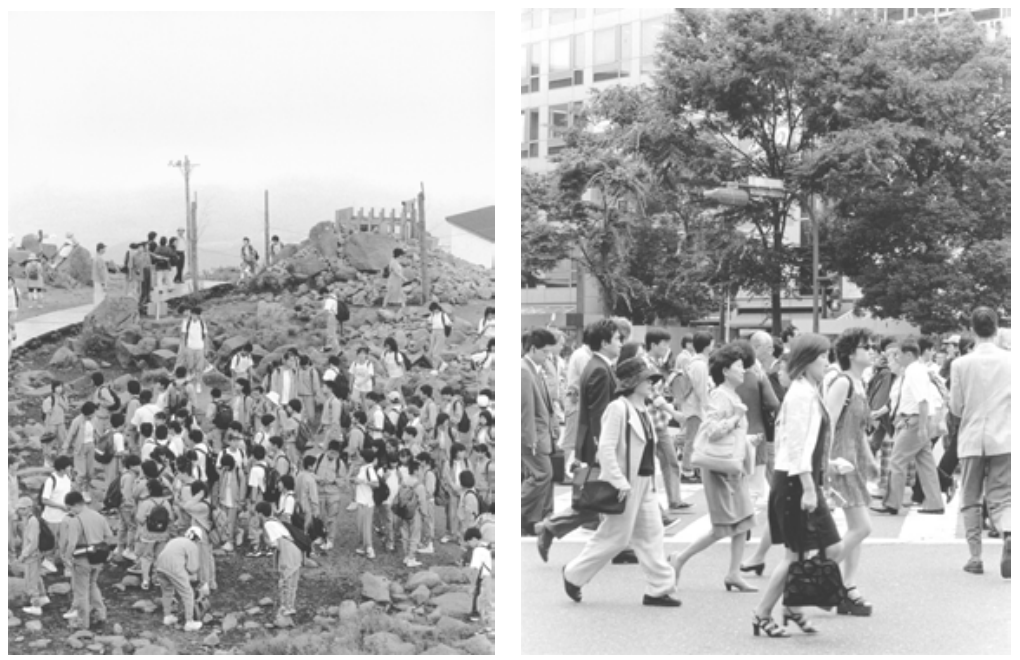

Abb. 33 und 58 .

Sicherheit. ${ }^{33}$ Neudörfl zeigt, dass in Japan Gruppenverhalten und Sicherheit unmittelbar miteinander zusammenhängen. Durch die Verbindung beider Konzepte gelingt es ihr, ein anderes Licht auf das im Westen eher negativ rezipierte japanische Gruppenverhalten zu werfen. Der Kontext ermöglicht es, in der Fotografie eines als typisch angesehenen japanischen Verhaltens, positive Aspekte einer Gruppensozialisation zu entdecken. Fehlende Individualität kann auch als Zeichen Schutz bietender Zugehörigkeit gelesen werden.

Die auf oben genannter Fotografie durch die Gruppengröße entstehende Enge verweist auf die hohe Bevölkerungsdichte, die das urbane Japan kennzeichnet. Elisabeth Neudörfls Future World beinhaltet auch Fotografien, die Menschen nicht im Gruppenzusammenhang, sondern als Teil einer Menschenmenge auf der Straße zeigen. Als Beispiel soll hier die auf der linken Seite gedruckte Fotografie 58 herausgegriffen werden. Viele Passanten überqueren parallel zur unteren Bildkante eine Straße; vorne von links nach rechts, im Hintergrund auch in die entgegengesetzte Richtung. Der etwas unterhalb der Bildmitte gelegene Zebrastreifen verweist auf eine Kreuzungssituation, die sich aus dem Bildausschnitt jedoch nicht erschließt. Im Hintergrund verdecken Bäume höhere Bürogebäude. Aus Augenhöhe fotografiert Neudörfl eine alltäglich wirkende Straßensituation. Das hohe Fußgängeraufkommen verdeutlicht die Bevölkerungsdichte japanischer Städte. Neudörfl lässt einen Zwischenraum zwischen sich und der Menschenmenge entstehen. Obwohl aus der Fußgängerperspektive fotografiert, hebt diese Distanz den Betrachter gezielt von der Masse ab und ermöglicht auch aufgrund der großen Tiefenschärfe die Identifikation einzelner Personen. Die eingehende Betrachtung offenbart ein großes Spektrum an Typen verschiedener Altersstufen:

33 Hier wird ein entscheidender Unterschied westlicher und japanischer Vorstellungen von Sicherheit deutlich. Während auf einem deutschen Schulausflug vermutlich die Anzahl der teilnehmenden Schüler begrenzt würde, ist in Japan gerade eine große Gruppe Garant für adäquates Verhalten und damit für einen problemlosen Ablauf der Exkursion. 
vom Geschäftsmann im Anzug und der elegant gekleideten Frau über Männer in Karohemden und Jeans bis hin zu einer Frau mit kurzem Kleid und Plateauschuhen. Die Vielfalt in dieser Fotografie steht in großem Gegensatz zu der im Bild 33 beobachteten Uniformität der Schülergruppe. Während es auf dem Schulausflug verpflichtend ist, als Teil einer Gruppe wahrgenommen zu werden, sind in Situationen des Alltags andere Entfaltungsmöglichkeiten gegeben. Indem Neudörfl auch diversifizierte Menschenmengen zeigt, erteilt sie dem Stereotyp der ununterscheidbaren Masse eine Absage. Im Zusammenspiel der Fotografien vertieft sich die Aussage, dass verschiedene Situationen unterschiedliche Verhaltensweisen bedingen, weshalb ein bestimmtes Verhalten nicht pauschal als typisch japanisch zu beurteilen ist. Durch ihren zurückgenommenen Blick vermittelt Neudörfl diese Aussage auf subtile Weise. Fragen nach einer spezifischen Individualität lassen sich anhand der Porträtaufnahmen erörtern, die Personen aus nächster Nähe zeigen.

\subsubsection{Porträts}

Von den insgesamt achtzehn Porträts, die über das gesamte Buch verteilt sind, zeigen zehn Fotografien Frauen und acht Männer. Die Köpfe der Personen sind sehr eng ins Format gesetzt, so dass kaum etwas vom Hintergrund zu sehen ist. Damit ist eine ausschließliche Beschäftigung mit den Gesichtern möglich. Die Konzentration auf die Gesichtszüge wird weiterhin dadurch unterstützt, dass die fotografierten Personen nie in die Kamera schauen. Ein Augenkontakt wird vermieden. Der Betrachter der Fotografien wird somit zum Beobachter der porträtierten Personen und nicht zum Partner. Die große räumliche Nähe und der Einsatz des Blitzlichtes verdeutlichen jedoch, dass die Bilder im Wissen und Einverständnis der Fotografierten aufgenommen worden sind. Blitzlicht und Nähe betonen weiterhin die Flächigkeit der Fotografien und heben sie dadurch gezielt von den anderen Bildern aus Future World ab. Zudem sind sie in einem größeren Format im Anschnitt gedruckt. Einige Porträts stehen allein zwischen anderen Fotografien, teilweise folgen auch zwei unmittelbar aufeinander. Die Porträts strahlen eine große Ruhe aus, was ihre Funktion als strukturierendes Element im Buch unterstützt.

Alle Porträtierten sind in einer Weise beschäftigt, die nicht aus den Fotografien heraus ersichtlich ist. Sie scheinen aufmerksam zuzuhören oder sprechen selbst zu Personen, die sich außerhalb des Bildraums befinden. Die nur eingeschränkt sichtbare legere Kleidung der Fotografierten deutet auf eine informelle Aufnahmesituation hin, die nicht extra für das Porträt eingerichtet ist. Elisabeth Neudörfl betont in ihren Fotografien ein kontemplatives und ruhiges Moment und konzentriert sich ausschließlich auf die Gesichtszüge. Gelegentlich kommt eine Hand als gestische Unterstützung des Ausdrucks ins Bild, was das prägende Moment des Gesichtsausdrucks weiter unterstreicht.

Die meist jungen Porträtierten sind vermutlich Studierende, einige der Fotografierten sind aber etwas älter. Es ist jedoch sehr schwer, ihr Alter genau zu bestimmen. Obwohl die Fotografien die Personen in einem eingeschränkten, eingeengten Blickwinkel zeigen, lassen sich dennoch verschiedene Persönlichkeiten unterscheiden. Um einen Überblick über die verschiedenen porträtierten Personentypen zu erhalten, sollen hier exemplarisch drei Porträts betrachtet werden. Alle vorgestellten Bildnisse sind linksseitig angeordnet, was jedoch nicht für die Gesamtheit der Porträts im Buch zutrifft. 

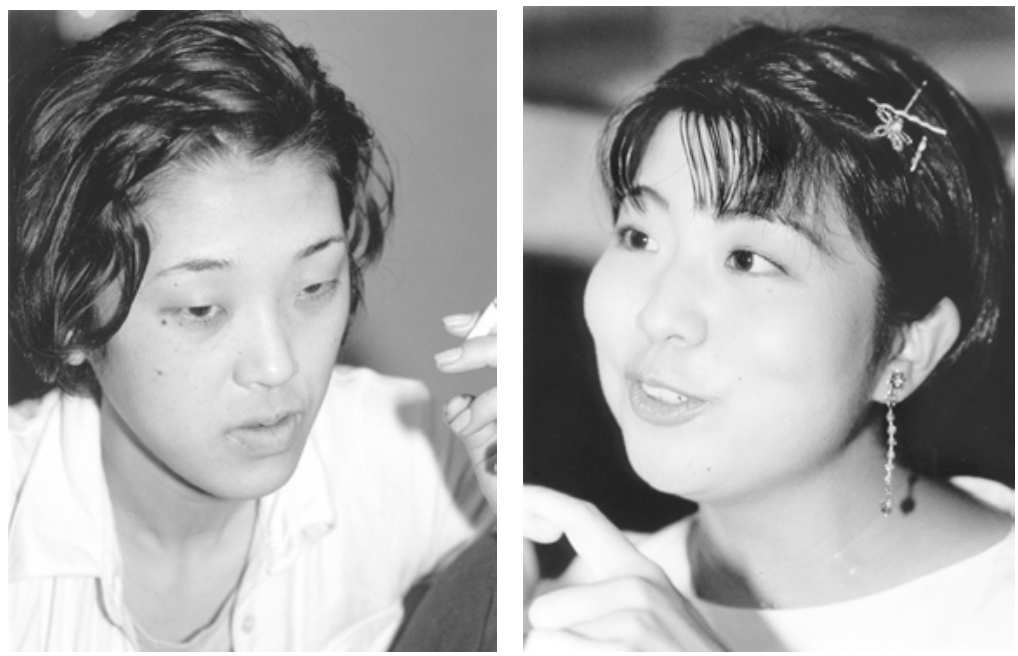

Abb. 64 und 56.

Das erste exemplarisch vorgestellte Bild zeigt das von oben fotografierte Porträt einer jungen Frau (Abb. 64). Sie trägt ein offenes weißes Hemd über einem ebenfalls hellen T-Shirt. Ihr dunkles halblanges Haar hat sie zur Seite aus der Stirn herausgestrichen. An der rechten Bildkante ist ihre linke Hand, in der sie eine Zigarette hält, stark angeschnitten. Der helle Nagellack ihrer Fingernägel löst sich an den Kanten etwas ab. Auf der linken Gesichtshälfte hat sie drei kleine Muttermale, die fast in einer senkrechten Reihe angeordnet scheinen. Durch die Obersicht und die die Augen teilweise verdeckenden Lider ist die Blickrichtung nicht eindeutig zuzuordnen, der Blick scheint jedoch nach unten rechts aus dem Bild heraus zu führen. Weil man die Augen nicht richtig sehen kann, wirkt sie insgesamt eher herb, verschlossen und abweisend. Dazu trägt auch der fehlende Lichtreflex in den Augen bei. Sie bleibt ganz in ihrer Welt und gibt nichts von sich preis.

Die sehr junge Frau von Abbildung 56 ist von rechts im Halbprofil fotografiert, ihr Gesicht ist nach links gewandt. Ihre glatten schwarzen Haare sind an der rechten Seite mit mädchenhaft wirkenden Haarnadeln fixiert, der Pony fällt ihr leicht in die Stirn. Am rechts sichtbaren Ohr trägt sie einen langen Ohrring, eine kleine Halskette verschwindet in der Unschärfe und im Ausschnitt ihres weißen Oberteils. Sie hat ihren Mund leicht gespitzt, weil sie offenbar gerade spricht. Dabei gestikuliert sie mit den Händen, die in der linken unteren Bildecke im Anschnitt zu sehen sind. Ihr wacher Blick führt direkt links aus dem Bild heraus. Sie wirkt freundlich, neugierig und sehr offen. Die beiden jungen Frauen wirken in den Fotografien extrem unterschiedlich. Bedingt durch Kleidung und Accessoires, aber auch durch Mimik und Gestik, entstehen im Bild sehr große Unterschiede und betonen die Differenz der beiden Persönlichkeiten. Trotzdem verweigern sich die Fotografien einer Individualisierung der abgebildeten Personen und treffen keine fixierbare Aussage über deren Charakter.

Das hier als letztes vorgestellte Porträt zeigt einen Mann im mittleren Alter mit einer Kurzhaarfrisur (Abb. 34). Er ist aus leichter Obersicht aufgenommen und hat scheinbar die Augen geschlossen oder aber den Blick so 


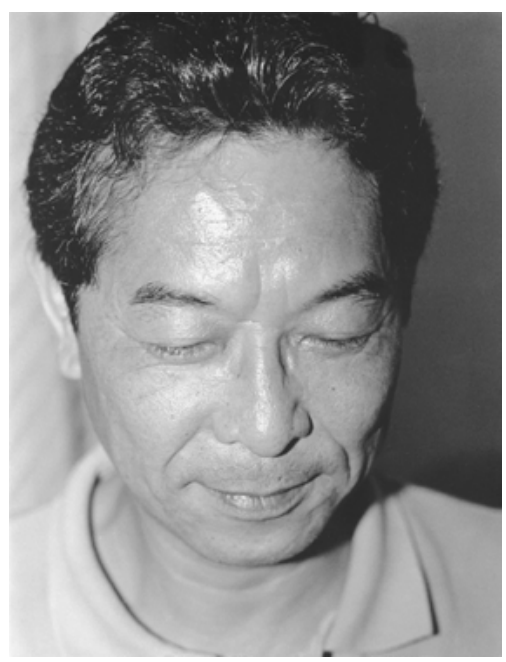

Abb. 34.

weit gesenkt, dass seine Augen nicht sichtbar sind. Er ist glatt rasiert und sein Gesicht zeigt einige Falten. Er trägt ein helles Poloshirt mit offenem Kragen. Allein durch sein Alter und den nicht sichtbaren Blick scheint dieses Porträt aus der Reihe zu fallen, da die Protagonisten der anderen Porträts alle erheblich jünger sind. Dennoch stellt es Elisabeth Neudörfl in eine Reihe mit den anderen Porträts. Durch die formalästhetischen Übereinstimmungen der Aufnahmesituation kann dieses Bildnis als eine Erweiterung des Personenkreises gelesen werden. Neudörfl geht es nicht ausschließlich darum, Personen einer bestimmten Altersgruppe abzubilden, auch wenn sie vorrangig junge Menschen zeigt.

Die Porträts innerhalb der Arbeit Future World suggerieren eine Nähe zu den fotografierten Personen. Diese bleiben aber distanziert, da die Porträts selbst nur sehr wenig über die Persönlichkeiten mitteilen. Die Rolle des Betrachters der Porträts ist vergleichbar mit der des Zuhörers einer fremdsprachigen Konversation, deren Sprache er nur sehr fragmentarisch versteht. $\mathrm{Ab}$ und zu meint der Zuhörer, ein Wort oder einen Satz zu verstehen. Da er aber den Zusammenhang nicht erfasst, entgleitet ihm das Verständnis im Moment des Verstehens. Die Porträts liefern nur vage Anhaltspunkte, die einer weiteren Analyse der Porträtierten im Moment des vermeintlichen Verstehens die Grundlage zu entziehen scheinen. Einerseits besitzen die Personen eine unmittelbare Präsenz, andererseits geben sie nichts von sich preis. Das Bild bleibt Bild und entzieht sich einem intellektuellen und damit verbalisierbaren Verständnis.

Neudörfl nimmt in ihren Porträts keine Bestimmung vor. Sie zeigt durchschnittliche Japanerinnen und Japaner, ohne sie auf eine gesellschaftliche Rolle zu fixieren. Für die Betrachtung stellt Neudörfl lediglich die Gesichtszüge, Mimik und Frisur als Anhaltspunkte zur Verfügung. Ein Verständnis für die Persönlichkeit wird nicht hergestellt. Auch die Ethnizität der Dargestellten ist unbestimmt, sie wird nicht besonders herausgestellt. Es überwiegt die Aufmerksamkeit für den Gesichtsausdruck und eine Suche nach einem Verständnis für die Persönlichkeit selbst. Die Porträtierten werden in ihrer 
Individualität sichtbar, was trotz gleichförmiger Aufnahmesituation einer standardisierten Wahrnehmung widerspricht. In der Ähnlichkeit der Aufnahmesituation entfalten sich die Unterschiede der Fotografierten weit mehr, als es durch individualisierte Porträtsituationen zu erreichen wäre. Besonderheit macht sich nicht am Aufnahmeort, einer exklusiven Kameraführung oder der Kleidung der Porträtierten fest. Ohne dass die Fotografin gezielt eine gesonderte Charakterisierung innerhalb der Porträtsituation betreibt, zeigen die Bildnisse die Vielschichtigkeit innerhalb der porträtierten Gruppe. Die Einbeziehung verschiedener Altersgruppen bestätigt diese Vielfalt zusätzlich.

\subsection{Bewertung}

Elisabeth Neudörfls Future World präsentiert sich als eine Welt, die nicht mit avancierten technischen Neuerungen aufwartet oder utopische Dimensionen eröffnet. Auf zurückhaltende Art werden Aspekte der für den Europäer zwischen Fremdheit und Vertrautheit oszillierenden zeitgenössischen japanischen Gesellschaft verhandelt. Strukturen der Urbanität sowie Grundideen von Sicherheit werden untersucht. Die Porträts zeigen vorrangig junge Einwohner der Future World, die fest in der Gegenwart verankert wirken. Die ausschließliche Verwendung des Hochformats ist inhaltlich auf das Japanthema zugeschnitten. Dieses Stilmittel korrespondiert mit der durch Raummangel erzeugten vertikalen Ausrichtung japanischer Großstädte.

Elisabeth Neudörfls Arbeit liegt eine inhaltliche Konzeption zugrunde. Die konzeptionelle Vorgehensweise ist zunächst nicht offensichtlich, da ihre Fotografien sehr alltäglich wirken und ihr Ansatz Anklänge an eine traditionelle Straßenfotografie aufweist. Die distanzierte Herangehensweise an Motive aus dem Außenraum scheint einer genauen Beobachtung der japanischen Verhältnisse zu entspringen. Neudörfls Fotografien offenbaren jedoch meist nicht auf den ersten Blick, warum sie gemacht worden sind oder welches Element die Fotografin eigentlich zeigen möchte. Die distanzierten Fotografien sind schwer lesbar, weil sie stets als Gesamtkomposition zu betrachten sind und nicht einen Aspekt zur Betrachtung ins Zentrum rücken. Es wird deutlich, dass nicht die Ästhetik des einzelnen Bildes entscheidend ist, sondern die Entwicklung des Themas aus dem Zusammenspiel der Fotografien. Neudörfl sucht nach einem spezifischen Japanbild. Ein Japan der »üblichen bunten Klischeebilder« interessiert sie nicht (Worat 2002). Die Fotografin lässt sich nicht ausschließlich von den Beobachtungen des Außenraums leiten, sondern greift das Thema Sicherheit in ihren konzeptionellen Überlegungen auf. Für die Umsetzung bereist sie unterschiedliche Orte und sucht dort nach Motiven, die sich in ihre Thematik eingliedern lassen. Dabei setzt sie gezielt auf die Auslassung von bestimmten Motiven, die in der Japanfotografie typisch sind.

Elisabeth Neudörfl bewegt sich als scharfsinnige, aber distanzierte Beobachterin durch Japan und etabliert eine zurückhaltende Bildsprache. Die Distanz zum Gegenstand verleiht den Bildern eine sachliche Anmutung. Die weiche, auf harte Kontraste verzichtende Tonalität sowie das Aussparen spektakulärer Ansichten tragen weiterhin dazu bei. Die schwarzweißen Fotografien verweigern sich den bunten Farben des japanischen Alltags, die sich durch Medienberichte in unseren Köpfen eingenistet haben. Der Verzicht auf die Farbe ermöglicht das Sehen von strukturellen Aspekten und leitet den 
Blick in Gefilde jenseits einer bunten Plastikwelt. Die aus der Distanz zum Gegenstand entstehende sachliche Anmutung kann nicht darüber hinwegtäuschen, dass auch Neudörfls Blick eine Subjektivität innewohnt. Sie tritt hauptsächlich in der thematischen Konzentration hervor und drängt sich dem Betrachter nicht auf. Neudörfls Haltung ist ambivalent, sie versucht, das Gezeigte nicht zu werten. Sachlichkeit, Verzicht auf Inszenierung, konzeptionelle Herangehensweise, Offenheit der Fotografien sowie die Bildung eines Kontextes über die große Anzahl von Fotografien im Buch markieren Future World eindeutig als künstlerische Dokumentarfotografie (vgl. Teil I, Abschnitt 4.1.2.).

Die Dokumentation folgt Voraussetzungen konzeptioneller Art. Neudörfl versucht nicht, ein umfassendes Bild der zeitgenössischen japanischen Gesellschaft zu zeichnen. Sie greift sich im Schwerpunkt den Aspekt des japanischen Sicherheitsbedürfnisses heraus, das sie in unterschiedlichen Situationen beobachtet und im Kontext des Alltäglichen visualisiert. Diese inhaltliche Ausrichtung lenkt den Blick des Betrachters und verhilft zu Interpretationen, die in einem anderen Kontext möglicherweise anders ausfielen. Denn die Offenheit der Fotografien ermöglicht verschiedene Sichtweisen und Deutungsmöglichkeiten. Dies wird insbesondere dadurch unterstrichen, dass Neudörfl auf jeglichen Text verzichtet. Sie vertraut in ihrer Arbeit ausschließlich auf die Fotografie und klammert Bildlegenden als Interpretationshilfe aus. Eine Kontextualisierung erfolgt allein durch die Zusammenstellung der Fotografien, was dabei hilft, den Blick gezielt auf bestimmte Aspekte der japanischen Gesellschaft zu fokussieren. Daraus ergibt sich auch die Unmöglichkeit, einzelne Bilder aus dem Kontext herauszulösen und repräsentativ für die Arbeit stehen zu lassen. Erst im facettenreichen Gesamtkontext erreichen die einzelnen Fotografien ihre Gültigkeit. Als Einzelbilder erfüllen sie ästhetische Ansprüche, die jedoch weit hinter denen einer Reise- oder Kunstfotografie zurückbleiben, weil es der Fotografin nicht darauf ankommt, spektakuläre Ansichten Japans zu zeigen. Ihre Wirkung entfalten Neudörfls Fotografien erst im Zusammenspiel, obwohl die meisten Bilder im Buch einzeln angeschaut werden können. Neudörfl arbeitet kaum mit Bildpaarungen und unterstreicht so die Wirkung des Einzelbildes im Gesamtkontext. Nur selten stellt sie Fotografien, die formale oder inhaltliche Korrespondenzen aufweisen, nebeneinander. ${ }^{34}$ Da sie die Abfolge so festlegt, dass Themen eingeführt und an anderer Stelle vertieft werden, entsteht eine zusammenhängende Betrachtungsweise. Die verschiedenen Themenkomplexe sind fest miteinander verwoben.

Neudörfls Fotografien zeigen meist ein weites (weitwinkliges) Blickfeld. Sie erfassen komplexe urbane Situationen, Menschengruppen, Landschaften. Sie klammern zahlreiche Aspekte der japanischen Gesellschaft aus, denn sie verfolgen nicht den Anspruch, ein allgemeingültiges Japanbild aufzuzeigen. Eine Journalistin vermisst beim Presserundgang durch Neudörfls Ausstellung beispielsweise die Darstellung von Geishas und Shintô-Tempeln (vgl. Lockemann 2004: 125). Dies verdeutlicht die Erwartungshaltung, die im Zusam-

34 Der Eindruck in der Ausstellung weicht hier klar von der Buchbetrachtung ab. In der Ausstellung wurden die Fotografien im Format $60 \mathrm{~cm}$ x $40 \mathrm{~cm}$ mit geringem Abstand zueinander in einem Fries an der Wand präsentiert. Die Fotografien säumten umlaufend die Wände eines einzigen Raumes. 
menhang mit Bildern von Japan nach wie vor vorhanden ist. ${ }^{35}$ Neudörfl verzichtet aber nicht nur auf die Darstellung von traditionellen Elementen, sie lässt aus westlicher Sicht spektakulär Scheinendes - und damit vor allem Exotisches - generell aus. Weder fotografiert sie bekannte Hochhausbauten, noch zeigt sie Beispiele absolut außergewöhnlicher Verdichtungen. ${ }^{36}$ Die Fotografien in Future World berücksichtigen zwar auch bekannte Aspekte des modernen Japan. Die Art des Umgangs verweist jedoch darauf, dass Neudörfl kein Interesse an einer Perpetuierung hinlänglich bekannter Klischees hat. Die Auseinandersetzung mit stereotypen Japandarstellungen erfolgt bei Neudörfl auf einer impliziten Ebene. Themenbereiche wie japanisches Gruppenverhalten oder organisiertes Verbrechen werden angesprochen, aber in ihrer Alltäglichkeit unspektakulär ins Bild gesetzt. Im Westen geläufige Japan-Vorstellungen werden aktiviert, aber nicht stereotyp abgebildet.

Elisabeth Neudörfls Distanz zum Gegenstand ermöglicht trotz des verwendeten Kleinbildformats einen Detailreichtum innerhalb der Fotografien, der den Betrachter auf Entdeckungsreise gehen lässt. Die Fotografien sind nicht auf einen Blick zu erfassen. Zunächst offenbaren sich nur die groben Strukturen, weiteres erschließt sich erst nach und nach. Bei einer nur oberflächlichen Betrachtung besteht die Möglichkeit, dass Details unentdeckt bleiben. Es gibt keinen zentralen Bildgegenstand, der sofort sichtbar ist. Erst die Einzelheiten ergeben in der Zusammenschau das ganze Bild. Dies trifft letztendlich generell auf Fotografien zu, doch Fotografien des angewandten Bereichs rücken häufig das für das Bild Ausschlaggebende ins Zentrum. In Neudörfls Fotografien fällt es zuweilen schwer, das zentrale Moment zu bestimmen. So wird der Betrachter dazu angeregt, sich dem Bild zu nähern und dessen Komplexität genau zu untersuchen.

In Elisabeth Neudörfls Fotografien klingt eine Alltäglichkeit an, die Japan gerade nicht als das spektakuläre Fremde und ganz Andere betrachten lässt, sondern als ein Land, das Europa näher ist, als gemeinhin angenommen. ${ }^{37}$ Bereits der Ansatz, in der Form des Buches eine Verbindung zwischen westlicher und japanischer Lesart herzustellen, verdeutlicht Neudörfls Konzentration auf Kulturen verbindende Elemente. Der Übergang zwischen beiden Sehweisen ist fließend. Eine Art der Betrachtung schließt die andere nicht aus. Fremdheit und Vertrautheit durchdringen sich dahingehend, dass der Blick von außen auch Japanern unvertraute Aspekte der eigenen Gesellschaft eröffnen und in westlichen Betrachtern Assoziationen zu Vertrautem auslösen kann. Fremdheit und Vertrautheit werden in Neudörfls Arbeit als relationale Kategorien bestätigt. Das Eigene dient als Folie, vor dem das Fremde wahrgenommen wird. Die Fotografien vermitteln in ihrer Zurückgenommenheit einen interessierten Blick auf ein fremdes Land, ohne das Exotische herauszukehren. Fremdes und Vertrautes stehen nebeneinander. Differentes wird nicht hervorgehoben, es wird vielmehr in die beiläufige Darstellung mit

35 Sie wird auch wiederholt von Presseerzeugnissen geschürt. Das Reisemagazin Merian titelt sowohl 1972 als auch 1992 die Tokio- bzw. Tokio und JapanAusgabe mit dem Bild einer Geisha (vgl. Merian 1972; Merian 1992).

36 Beispiele von Tempeln, die auf Dächer von Wohnanlagen gebaut sind oder Einkaufszentren, auf deren Dächern Autobahnen verlaufen sind auch in Europa bekannt geworden (vgl. z.B. Kaijima/u.a. 2001).

37 »Es kam mir viel normaler vor als gedacht. Im Gesellschaftlichen zum Beispiel, dem Umgang miteinander, finde ich Deutsche und Japaner ähnlicher als Deutsche und Amerikaner« (Worat 2002). 
eingewoben und so fast zu etwas Vertrautem. Neudörfl nivelliert jedoch nicht vorhandene Differenzen. Entscheidend ist, dass sie keine Wertungen vornimmt. Die Betrachter werden nicht überzeugt; sie sollen sich, initiiert durch Neudörfls Fotografien, ein eigenes Bild machen und nicht die Haltung der Fotografin übernehmen. Die ausgewählten Aspekte konfrontieren die Betrachter anlässlich der fotografierten Situationen mit Momenten der Fremdheit. Auf diese Weise vermitteln die Fotografien dem Publikum eine Art von Fremderfahrung, denn sie geben keine Antworten darauf, wie Japan wirklich ist oder worin die japanische Fremdheit besteht. Auch Neudörfls Ansatz zeigt, dass die referentielle Bedeutung nicht der Schlüssel zum Verständnis der Arbeit ist, denn die Bilder schaffen eine neue Bildwirklichkeit, in der sich die Wirkung entfalten kann.

Neudörfl begegnet der Fremde aus der Distanz. Lediglich die Porträts sind in einer nahen Einstellung fotografiert. Weil die Porträtierten aber keinen Blickkontakt zum Betrachter aufnehmen, scheint auch hier der Abstand bestehen zu bleiben. Die Porträtierten erklären sich jedoch mit der Abbildung einverstanden, es findet eine Verständigung zwischen Fotografin und Fotografierten statt. Diese bleibt für den Betrachter unsichtbar. Obwohl sich Neudörfl in der japanischen Gesellschaft bewegt, agiert sie als außen stehende Beobachterin. Der Blick von außen offenbart sich in ihren Fotografien schon aus der gewählten Aufnahmeperspektive heraus. Oft fotografiert Neudörfl von oben und befindet sich allein deshalb auf einer anderen Ebene als der Bildgegenstand. Sie beobachtet das Verhalten der Menschen und dokumentiert es, macht aber deutlich, dass sie nicht direkt dazu gehört. Die fehlende Zugehörigkeit ermöglicht die distanzierte und analytische Sichtweise, was als Zeichen von Fremdheit betrachtet werden kann. Damit knüpft Elisabeth Neudörfl an die Tradition der Street-Photography an, wie sie bereits von Ed van der Elsken in Japan betrieben worden ist (vgl. Teil II, Abschnitt 1.3.). Die Fotografin ist Flaneurin und beobachtet das Geschehen. Sie ist dabei, ohne wirklich Teil des Geschehens zu sein. Gelenkt durch ein thematisches Interesse sucht sie bestimmte Orte auf, um dort gezielt ihre Motive zu finden. Sie gelangt damit zu einer konzentrierten Form der Straßenfotografie, die aus den unendlichen Bildmöglichkeiten diejenigen herausfiltert, die der thematischen Auseinandersetzung ein geschärftes Profil verleihen. Neudörfl bewahrt sich in ihrer Vorgehensweise jedoch immer eine große Offenheit, die sie an die Betrachter weitergibt.

Elisabeth Neudörfls Fotografien machen die Betrachter selbst zu Flaneuren durch eine Future World und fördern die Lust an der Entdeckung. Fremdes und Eigenes durchdringen sich gegenseitig und initiieren so einen Reflexionsprozess über die Wahrnehmung von Japan. Die Offenheit der Darstellung lässt verschiedene Interpretationen zu und löst im Betrachter - abhängig von den eigenen Erfahrungen und dem Vorwissen über Japan - unterschiedliche Assoziationen aus. Somit präsentiert Neudörfl die Zukunftswelt als eine, die als Projektionsfläche Raum für unterschiedliche Erfahrungen des Fremden bietet.

\section{Zusammenfassung:}

Elisabeth Neudörfl verfolgt im Sinne einer weiterentwickelten Straßenfotografie einen konzeptionellen dokumentarfotografischen Ansatz, der sich thematisch auf Aspekte der Sicherheit konzentriert, dabei aber ein sehr zurückhaltendes Bild des japanischen Alltags zeichnet. Sie eröffnet mit ihren 
Fotografien ein ganzes Assoziationsfeld, das sich vieldeutig interpretieren lässt. Ihre Fotografien von urbanen Situationen und Landschaften rücken nicht einen Gegenstand ins Zentrum, sondern entfalten ihre Wirkung in der Gesamtheit des Bildes. Hier beobachtet Neudörfl aus einer Distanz heraus, die sich in ihren Porträts auflöst. Die Porträts der meist jungen Japaner und Japanerinnen zeigen Personen von ganz nah. Dennoch versuchen sie nicht, die einzelne Person psychologisch zu deuten. Vielmehr eröffnen die Porträts die Sicht auf vielfältige Menschentypen, ohne dabei auf gängige Klischees zurückzugreifen. Neudörfls Fotografien wirken subtil, weil sie keine vorgefertigte Meinung anbieten, die sich aus den Bildern herauslesen ließe. Die Bilder machen dem Publikum ein Angebot, durch intensive Betrachtung etwas über Japan zu erfahren. Gleichzeitig wird es mit einem Moment der Fremdheit konfrontiert, das ihm die Möglichkeit eigenständiger Fremdheitserfahrung anhand von Fotografien eröffnet. 


\section{AUSWERTUNG DER GESPRÄCHE MIT JAPANISCHEN FOTOGRAFIE-EXPERTEN}

Die exemplarisch vorgestellten Japanarbeiten von Paul Graham und Elisabeth Neudörfl beschäftigen sich jeweils mit einem Teilaspekt der zeitgenössischen japanischen Kultur und Gesellschaft. Beide beobachten das fremde Land als Ausländer, die sich längere Zeit in Japan aufhalten. Sie suchen nach Möglichkeiten, ihre Wahrnehmungen fotografisch zu visualisieren und einen eigenen Weg in der Japandarstellung zu finden. Einem dokumentarfotografischen Ansatz verpflichtet, bieten sie eine eigenständige Interpretation und präsentieren ihre Ergebnisse im Künstlerbuch. Das Ergebnis legt ihre Sichtweisen offen und präsentiert ihre Haltung gegenüber Japan.

Die Interpretation der beiden Ansätze von Graham und Neudörfl erfolgt in dieser Arbeit aus einem europäischen Blickwinkel heraus. Bislang bleibt aber ungeklärt, wie Japaner diesen Blick von außen einschätzen. Zeigen die Fotografien nach japanischen Maßstäben ein Japanbild, in dem sich Japaner wiederfinden können? Treffen sie Aussagen über Japan, denen Japaner Gültigkeit einräumen können? Der künstlerische Ansatz zeugt von einem eigenwilligen und damit subjektiven Umgang mit dem Thema Japan. Einer subjektiven Darstellung des Fremden wird - wie in Teil I, erstes Kapitel erläutert - mitunter mehr Gültigkeit eingeräumt als Darstellungen, die ihrem selbst gestellten Objektivitätsanspruch kaum genügen können (vgl. Teil I, Abschnitt 1.3.2.). Christoph Jamme äußert die Vermutung, dass künstlerische Repräsentationen möglicherweise zu zutreffenden Darstellungen des Fremden gelangen, weil sie keinen Objektivitätsanspruch erfüllen müssen. Deshalb sieht er in der Kunst einen Ausweg aus der Krise der ethnografischen Repräsentation (vgl. Jamme 2002: 191ff.). Fragen nach der Gültigkeit von Grahams und Neudörfls Darstellungen lassen sich jedoch kaum beantworten, denn wer soll darüber befinden? Weil jede Kultur unendlich viele Facetten aufweist, gibt es nicht ein gültiges Bild. Vielmehr setzt es sich aus zahlreichen möglichen Sichtweisen und Erzählungen zusammen und erlangt Gültigkeit über die Vielfältigkeit der Darstellungen, worauf sich ein Projekt wie European Eyes on Japan gründet. Nicht ein spezifisches Japanbild wird gezeigt; das Japanbild entsteht vielmehr aus der Zusammenschau einer Vielzahl von Ansätzen und Sichtweisen, die sich mit den unterschiedlichen Regionen Japans auseinandersetzen. Dieses Vorgehen zeigt: Japan existiert nicht als einheitlicher Komplex, der sich im Bild fixieren lässt. Die Teilhabe an einer der vielen unterschiedlichen Sub-Kulturen mag die an einer anderen kategorisch ausschließen. Unterschiede finden sich nicht nur innerhalb der vielfältigen Möglichkeiten der Metropolen, sondern auch zwischen Stadt und Land, dem Norden und dem Süden. Eine einzelne fotografische Arbeit kann demzufolge nicht die einzige Sichtweise auf Japan liefern, die alle Teilaspekte berücksichtigt. Weil die Fotografen um diese Unmöglichkeit wissen, beschränken 
sie ihre Beobachtungen gezielt auf Aspekte, die ihnen persönlich besonders auffallen oder ihren Interessen entsprechen.

Die Arbeiten von Graham und Neudörfl schränken ihre Auseinandersetzung thematisch ein, dennoch verhandeln sie in ihren Fotografien verschiedene Elemente der japanischen Kultur, die in der europäischen Rezeption das Japanbild mit beeinflussen. Weil diese fotografischen Arbeiten - gemeinsam mit vielen anderen - das Japanbild in Europa prägen, bleibt die Frage, ob sie in Japan als zutreffend, verzerrend oder stereotyp rezipiert werden. Da eine solche Bewertung nicht aus einer europäischen Perspektive heraus entwickelt werden kann, sollen die Positionen aus einem japanischen Blickwinkel heraus überprüft werden.

Im zweiten Kapitel des ersten Teils wird ausführlich dargelegt, dass sich die Außensicht auf Japan und die Selbstwahrnehmung der Japaner im Laufe der Zeit durchdrungen und miteinander verwoben haben. Insofern ist es unmöglich, Fremd- und Selbstbilder sauber voneinander zu unterscheiden. Zahlreiche von westlichen Ausländern perpetuierte stereotype Annahmen über Japan und die Japaner sind in Japan selbst übernommen worden. Bestimmte Klischeevorstellungen sind ihnen ebenso geläufig wie westlichen Ausländern, andere erscheinen ihnen fremd. Weil die japanische Kultur seit Jahrhunderten Einflüsse von außen in die eigene Kultur integriert, sind die Ursprünge vieler zeitgenössischer Aspekte der japanischen Kultur auch für Japaner kaum auszumachen. Diese Aspekte beeinflussen unter anderen die japanische Sichtweise auf die Fotobücher Empty Heaven von Paul Graham und Future World von Elisabeth Neudörfl.

Während eines dreimonatigen Japanaufenthaltes habe ich im Sinne einer inversen Ethnografie japanische Fotografie-Experten zu den untersuchten Arbeiten befragt. Im Zentrum steht die Frage, ob es Graham und Neudörfl gelingt, ein nach japanischen Maßstäben angemessenes Bild der zeitgenössischen japanischen Gesellschaft zu vermitteln. Dies ist zentral, weil insbesondere in der angewandten Fotografie auch heute zahlreiche stereotype Vorstellungen über Japan wiederholt werden. In der Erwartungshaltung vieler Europäer drückt sich die Sehnsucht nach der Darstellung von Fremdem, wenn nicht gar Exotischem, aus. Nach dieser Prämisse bedeutet »Japan zu sehen« beispielsweise, »die Vernetzung, die Warenwelt, die Disziplin, die Exzentrik, den schrillen Chic, die Reste von Zen« abzubilden. ${ }^{1}$ In Neudörfls Darstellung vermisst eine Journalistin Geishas und Tempel (vgl. Lockemann 2004: 125). Nun gehören all die aufgezählten Dinge ebenso zur japanischen Kultur wie zahlreiche andere. Dies lässt Rückschlüsse auf die vielfältigen möglichen westlichen Sichtweisen zu. Unberührt bleibt davon aber die Wahrnehmung der Arbeiten aus japanischer Sicht, die es zu erkunden gilt.

Eine weitere Frage thematisiert die unterschiedlichen fotografischen Sichtund Darstellungsweisen von japanischer und europäischer Seite. Unterscheidet sich die Außensicht grundlegend von der Selbstsicht? Diese Annahme gründet auf den unterschiedlichen Intentionen, die japanische und europäische Fotografen verfolgen. Weil Fremdheit die Bedingungen der Betrachtung und damit das Ergebnis nachhaltig prägt, kann die Sicht von außen auf eine Thematisierung der Fremdheit kaum verzichten.

In Japan habe ich mit Kuratoren, Fotografen, Fotografie-Professoren und Kritikern über das vermittelte Japanbild in den analysierten Büchern gespro-

1 Dies alles vermisst Erdmann-Ziegler 1996: 90 in Grahams Empty Heaven. 
chen und die Frage erörtert, wie repräsentativ es ist. ${ }^{2}$ Da weder Grahams noch Neudörfls Arbeiten bislang in Japan ausgestellt worden sind, ist der Bekanntheitsgrad beider Arbeiten gering. Während Grahams Buch jedoch teilweise geläufig ist, hatte keiner meiner Gesprächspartner Neudörfls Buch zuvor gesehen.

$\mathrm{Zu}$ Beginn der Gespräche herrscht oft Skepsis, ob es europäischen Fotografen wirklich gelingen kann, ein präzises Bild von Japan zu zeigen. Die meisten sind davon überzeugt, dass Ausländer eher dazu neigen, sich mit den klassischen Themen der Japanfotografie zu beschäftigen und kaum einen tieferen Einblick in die japanische Kultur haben. Man ist der Meinung, dass Europäer einen grundsätzlich anderen Zugang haben als Einheimische. Dennoch lassen sich weder Bildsprache oder Motivwelten immer dezidiert voneinander unterscheiden, wie unten noch ausführlicher erläutert wird.

In der zentralen Frage herrscht ein Konsens unter den Befragten. Es besteht Einigkeit darin, dass es Graham und Neudörfl mit ihren Arbeiten gelingt, einen tiefen und präzisen Einblick in die japanische Gesellschaft und somit ein als adäquat empfundenes Bild des zeitgenössischen Japan zu vermitteln. Die Interviewten stellen klar, dass sie die Positionen als gültige Repräsentationen Japans akzeptieren können, aber dass die Arbeiten einen Ausschnitt aus dem japanischen Alltag zeigen, der insgesamt noch zahlreiche weitere Elemente beinhalte. Man ist sich einig, dass beide Fotografen ein sehr gutes Beobachtungsvermögen besitzen. Sie seien in der Lage, feine Details ins Bild zu setzen und damit nach dem japanischen Selbstverständnis wichtige Aspekte der japanischen Kultur zu vermitteln.

Die Frage, ob es interessant sei, Neudörfls und Grahams Arbeiten in Japan einem japanischen Publikum zu zeigen, wird grundsätzlich bejaht, weil Japaner daran interessiert seien, Fotos von Japan zu sehen (Kikuta). Dennoch herrscht eine gewisse Skepsis vor, weil dem durchschnittlichen Publikum nicht zugetraut wird, die Arbeiten wirklich lesen zu können. »Normale Japa-

2 Insgesamt konnte ich während eines dreimonatigen Japanaufenthaltes vom 1.4. bis zum 30.6.2006 zehn Interviews führen. Die Auswahl meiner Gesprächspartner erfolgte aufgrund von Empfehlungen und vermittelten Kontakten und ist daher eher zufällig zu nennen. Dennoch konnte ich beispielsweise mit Kasahara Michiko, Chefkuratorin des Tokyo Metropolitan Museum of Photography und Kommissarin des japanischen Pavillons auf der Biennale Venedig 2005, eine wichtige Repräsentantin der japanischen Museumslandschaft treffen. Fotografie-Professor Enari Tsuneo ist ein wichtiger Vertreter der künstlerischen Dokumentarfotografie in Japan und hat selbst zahlreiche Bücher zu Themen der japanischen Kriegs- und Nachkriegsgeschichte publiziert. Die meisten Interviews wurden auf Englisch geführt, so dass es den Gesprächspartnern aufgrund mangelnder Sprachkenntnisse manchmal schwer fiel, die passenden Worte zu finden, um ihre Meinung adäquat zum Ausdruck zu bringen. Die Gespräche mit Enari Tsuneo und Saiga Yuji wurden übersetzt. Die Übersetzer waren Studenten, die sowohl Japanisch als auch Englisch sprechen, wobei deren Sprachkenntnisse die Ausdrucksfähigkeit teilweise limitiert haben. Dennoch zeugen die Äußerungen von einer ernsthaften Auseinandersetzung meiner Gesprächspartner mit der Fragestellung. Die direkten Zitate habe ich selbst aus den englischen Texten übersetzt. Die Leitfragen sowie Transkripte der Gespräche finden sich im Anhang, der als pdf von der Verlagswebsite herunter geladen werden kann (http://www.transcript-verlag.de/ts1040/ts1040.php). Weil die Interviews alle im Jahr 2006 geführt worden sind, verzichte ich im Text auf die Angabe der Jahreszahl. Alle Gesprächspartner sind am Ende des Literaturverzeichnisses genannt. 
ner verstehen nicht, wie man Fotografie liest. [...] Deshalb ist es sehr schwierig, solch ein qualitativ hochwertiges Fotobuch [Graham] in Japan zu publizieren. Eine Ausstellung wäre vielleicht eine Möglichkeit« (lizawa). Insgesamt sind sechs der Interviewten der Meinung, für Japaner sei es einfacher, Grahams Arbeit zu verstehen, weil sein Standpunkt Emotionen erzeuge und die Möglichkeit biete, sich damit auseinanderzusetzen (Kikuta; Kasahara; Enari; Yoshihara; Aya; Iizawa). Neudörfls Arbeit hingegen sei zu subtil, als dass sie ohne Erklärung einem japanischen Publikum präsentiert werden könne. »Vielleicht mögen Experten wie Fotohistoriker oder Kuratoren ihre [Neudörfls] Arbeiten, aber es besteht da immer ein grundsätzlicher Unterschied zur allgemeinen Öffentlichkeit« (Kasahara). Zwei Gesprächspartner sind umgekehrter Meinung (Ikeda; Oshima): Sie finden, dass Grahams Arbeit aufgrund der in ihr formulierten Kritik erklärungsbedürftig sei, Neudörfls Arbeit hingegen leicht zu verstehen. Dem japanischen Publikum wird offensichtlich wenig zugetraut, was das Verständnis von Fotografie anbelangt. Die Wichtigkeit, Außensichten auf Japan in Japan zu zeigen, wird aber wiederholt betont, was auf die Relevanz dieser Thematik schließen lässt.

\subsection{Gespräche über Paul Grahams Empty Heaven}

Grundsätzlich sind fast alle Interviewten der Meinung, dass sich die in Japan fotografierten Arbeiten europäischer Fotografen von denen japanischer Fotografen unterscheiden. Die Außensicht bringe eine Distanz mit sich, die es ermögliche, auch alltägliche oder gewöhnliche Dinge zu sehen, die Japanern kaum mehr auffallen. Der Unterschied zu japanischen Arbeiten über Japan finde sich sowohl in der Wahl der Themen als auch in der angewandten Bildsprache. Meine Gesprächspartner finden es sehr schwierig, Elemente zu nennen, die eine westliche von einer japanischen Bildsprache trennen. Insgesamt sei eine pauschale Abgrenzung von Bildsprachen, Stilen oder einer Auswahl bestimmter Motive zwischen westlicher und japanischer Japansicht kaum möglich. Kasahara Michiko, Chefkuratorin des Tokyo Metropolitan Museum of Photography, macht beispielsweise darauf aufmerksam, dass in der gegenseitigen Beeinflussung von Künstlern eine Art Kreislauf entsteht, der schwer $\mathrm{zu}$ entwirren ist. Sie spricht davon, dass zahlreiche in Europa sehr populäre japanische Künstler wie Araki Noboyushi, Murakami Takashi oder Mori Mariko ein exotisches Japanbild vermitteln, das Japan als orientalisch im klassischen Wortsinn zeige. Diese Arbeiten beeinflussen wiederum europäische Fotografen, die sich Japan mit einem solchen Blick nähern. Kasahara sieht in Grahams Arbeit einen starken Einfluss von Araki.

»Diese Art von Bildern formt einen Kreis. Ich denke, Paul Graham ist von Arakis Tokyo beeinflusst und kam hierher, um von Araki beeinflusste Bilder zu machen. Also ist sein Blick japanisch-europäisch, japanisch in einer sehr speziellen Art. Es sieht nicht so sehr nach einem europäischen Blick aus. In einer exotischen Weise ist es ein japanischer oder auch ein europäischer Blick. Sein Blick ist derselbe wie der europäische Blick von denen, die Araki mögen« (Kasahara).

Dennoch findet Kasahara, die Grahams Arbeit sehr schätzt, dass Grahams Blick nicht besonders typisch ist für Europäer, obwohl er typisch japanische 


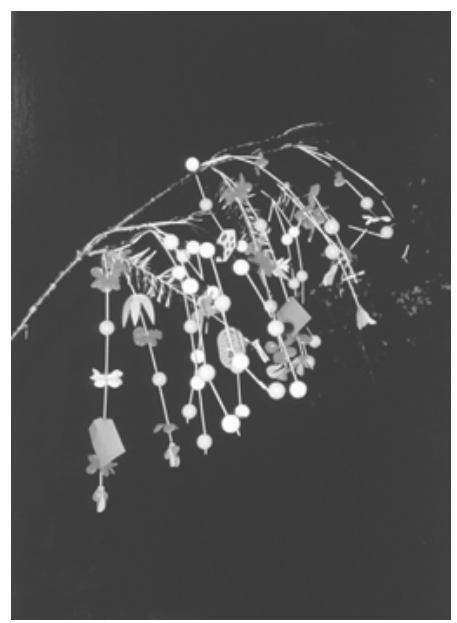

»34. Hanging Decoration, Tokyo 1992«(Graham 1995a: o.S.; Orig. in Farbe).

Elemente mit einbezieht. Sie hält Grahams Arbeit für mehrdeutig und unklar in einer auch von Araki implementierten Weise, was wiederum sehr japanisch sei. Der Fotograf Saiga Yuji erklärt, Graham fotografiere Dinge, die ihn in Japan überraschen, aber er fotografiere sie nach japanischem Geschmack. Weil japanische Fotografen wie Araki oder Moriyama ebenfalls so fotografieren, sei Grahams Sichtweise für Japaner nicht überraschend. Kasahara bemerkt weiterhin, dass japanische Fotografen manchmal eine europäische Sichtweise auf Japan nachahmen, weil sie daran gemessen werden.

Insgesamt die Hälfte meiner Gesprächspartner betont die Bezüge zwischen Araki und Graham und weist auf die wechselseitige Beeinflussung hin, die eine klare Trennung von europäischer und japanischer Sichtweise unmöglich macht. Interessanterweise wählen fast alle Interviewpartner die Fotografie einer Dekoration vor nachtschwarzem Hintergrund, um auf den ArakiBezug aufmerksam zu machen (vgl. Abb. 34: Graham 1995a: o.S.). ${ }^{3}$ Mit der Thematisierung des Bezugs zu Araki wird ein Aspekt der Sichtweisen auf Japan aufgegriffen, der auch schon in Zusammenhang mit den Japandiskursen genannt worden ist: Japanische Selbst- und Fremdbilder durchdringen und beeinflussen sich gegenseitig und machen eine klare Unterscheidung westlicher und japanischer Standpunkte unmöglich (vgl. Teil I, Abschnitt 2.3.1.).

Ein wichtiger Punkt in Grahams Arbeit und damit auch in meinen Gesprächen mit japanischen Fotografie-Experten sind die Bezüge zur jüngeren japanischen Geschichte. Sieht beispielsweise der Fotograf und FotografieProfessor Enari Tsuneo in den Vergangenheitsbezügen eine herausragende Qualität der Arbeit, hatte Kasahara diese vor meinem Hinweis überhaupt nicht wahrgenommen. Kasahara findet Grahams Auseinandersetzung oberflächlich und kann die soziale oder historische Bedeutung nicht entdecken. Vermeintlich ikonische Bilder wie die Fotografie des Kimono Pattern Flash

3 Ein solcher Schmuck wird bei traditionellen Festen (matsuri) üblicherweise an Geschäften angebracht. Es handelt sich also um ein traditionelles Element japanischer Kultur. Die Form, die eine solche Dekoration heute angenommen hat, verweist jedoch auf die süßlich-kitschige Plastikkultur der Gegenwart. 
Burn Photograph bringt sie nicht mit Hiroshima in Verbindung, ähnlich wie andere Gesprächspartner auch (z.B. Yoshihara; vgl. Teil II, Abschnitt 3.3.). Damit offenbart sich ein blinder Fleck, auf den Graham mit seinem Projekt aufmerksam machen möchte. Japans Rolle während des Zweiten Weltkriegs ist bis heute nicht aufgearbeitet. Weder wird sie im japanischen Schulunterricht thematisiert, noch findet ein öffentlicher Diskurs statt. ${ }^{4}$ Insbesondere junge Menschen haben keinen Bezug zu Bildmaterial, das Militärprozessionen im Yasukuni-Schrein, die kaiserliche Armee oder Szenen vom Tag der japanischen Kapitulation zeigt. Die Studenten des Fotografen und Dozenten Saiga Yuji, mit denen ich anlässlich eines Seminars sprechen konnte, verbinden mit Grahams Arbeit unter anderem ein diffuses Gefühl von Krieg, können es aber nicht genau benennen.

Enari sieht in Grahams Arbeit ein herausragendes Beispiel für eine kritische Momentaufnahme aus der Mitte der Periode der bubble economy. Er benennt als Thema Japan nach dem Krieg. Damit ist er einer der wenigen, die in Grahams Arbeit ein spezifisches Thema finden können. Die meisten reagieren auf einzelne Bilder und Bildgruppen, meinen aber, es ginge einfach um das heutige Japan, ohne dies spezifischer formulieren zu können. Enari macht darauf aufmerksam, dass eine direkte Beziehung zwischen der japanischen Kriegsniederlage, der darauf folgenden amerikanischen Besatzung und der heutigen Zeit bestehe. Denn das Interesse an materiellen Gütern und Wohlstand sei seiner Meinung nach durch die Besatzungszeit ausgelöst worden. Die Amerikaner »brachten diese Ideen nach Japan. Und das war der Beginn des modernen Japaners, die Basis für seine Psyche« (Enari). Im veränderten Umgang mit materiellen Gütern bestehe ein wichtiger Unterschied zur japanischen Vorkriegskultur. In Grahams Arbeit sehe er genau diese Zusammenhänge thematisiert. Das Buch »zeigt die moderne Zeit in Japan, die Motoren, die modernen Sachen wie den Kalender. Wenn ich das Buch sehe, verstehe ich, wie Japan wirklich ist. Es ist schön, dies aus einer frischen Perspektive heraus zu sehen. Es beschäftigt sich mit einem wesentlich ernsteren Thema als Ausländer normalerweise in Japan aufnehmen würden « (ebd.). Auch für japanische Fotografen ist - mit wenigen Ausnahmen - die Vergangenheit kein Thema der fotografischen Auseinandersetzung, weil sie darüber nichts wissen oder es sie nicht interessiert. Es sei sehr schwierig, eine kritische Arbeit zu publizieren. »Und wenn man sie publiziert, würde sie keiner anschauen« (ebd.). Damit äußert Enari eine sehr interessante Tatsache, die beispielsweise Ikeda Yuko, Kuratorin am Kyoto National Museum of Modern Art, bestätigt. Eine kritische Auseinandersetzung mit gesellschaftlichen Verhältnissen wird eher mit europäischer als mit japanischer Fotografie assoziiert. Dass sich ein europäischer Fotograf zu japanischen Themen kritisch äußert, wird jedoch nicht von allen Befragten gut geheißen.

Der Fotograf und Dozent Oshima Naruki sieht hierin eine Form des Kolonialismus. Er hat allgemein das Gefühl, dass europäische Fotografen Japan tendenziell von oben herab betrachten. Er wirft Graham vor, dieser konstruiere innerhalb des Buches seine eigenen stereotypen Ideen von Japan. Damit werde er Japan und der japanischen Kultur nicht gerecht. Graham sehe nur

4 Sowohl Enari Tsuneo als auch der Fotograf Saiga Yuji weisen darauf hin, dass von Regierungsseite eine Art Bewusstseinskontrolle über den Sprachgebrauch ausgeübt wird. Jedes Jahr am 15. August wird des Kriegsendes gedacht, aber man spricht nie von Niederlage oder Kapitulation. Diese Begriffe sind tabu. 
das, was er sehen möchte. »Der Fotograf versammelt die Bilder im Buch nach seiner Idee oder der stereotypen europäischen Vorstellung von den Japanern. [...] Die Idee wurzelt möglicherweise im Kolonialismus. Ich frage mich, warum der Fotograf normale Menschen und das alltägliche Leben mit Elementen des Krieges kombiniert« (Oshima). Oshima steht mit diesem Vorwurf allerdings allein da, keiner meiner Gesprächspartner hat sich in entsprechender Weise geäußert. Kikuta Mikiko, Kuratorin des Projekts European Eyes on Japan, sieht zwar Elemente der Konstruktion in Grahams Arbeit, meint aber: "Das ist die Realität dieses Fotografen, aber es ist auch unsere Realität. Wir hatten eine sehr schwere und schlechte Vergangenheit, aber jetzt leben wir mit diesen niedlichen Dingen. Auch das ist unser heutiges Leben« (Kikuta).

Grahams Kritik an der japanischen Gesellschaft wird nicht immer wahrgenommen. Diejenigen, die sie sehen, finden sie aber nicht ungerechtfertigt oder erniedrigend, sondern vielmehr notwendig. Denn einhellig wird die Meinung geäußert, dass Japan ein großes Defizit in der Aufarbeitung seiner Vergangenheit habe, was für das Land selbst nachteilig sei. »Er drückt Aspekte aus, von denen Japaner lieber nichts wissen möchten, « meint die Galeristin Aya. Dass ein europäischer Fotograf auf solche negativen Aspekte der japanischen Kultur hinweist, wird generell als legitim empfunden oder sogar als Chance, da ein solches Thema von Japanern selbst nicht angeschnitten wird. Selbst Oshima kann trotz seiner Kritik an Grahams Umgang mit der japanischen Kultur und Gesellschaft der Arbeit etwas abgewinnen. »Ich habe das Gefühl, die Realität dieser Fotografien wurde vom Fotografen konstruiert. Aber wir haben vor langer Zeit damit begonnen, über unsere Zivilisation anhand von Bildern europäischer Fotografen nachzudenken. Vielleicht präsentiert er diese Bilder, damit wir erneut damit beginnen, über unsere Kultur nachzudenken« (Oshima). Die Beschäftigung mit der eigenen Kultur birgt die Möglichkeit in sich, in einem Prozess der Selbstvergewisserung sich seines Standpunkts bewusst zu werden. Damit ließe sich Grahams Arbeit zwischen andere westliche Äußerungen über die japanische Kultur, wie sie beispielsweise in den Japandiskursen diskutiert werden, einreihen.

Als sehr europäisch wird allgemein die Zusammenstellung der Bilder in Grahams Buch empfunden. »Die meisten Fotografen würden Nahaufnahmen, Ansichten des Alltags und Bilder von jungen Frauen nicht miteinander kombinieren, « meint die Galeristin Aya. ${ }^{5}$ Die Zusammenstellung von sehr unterschiedlichen Motiven wird jedoch als der japanischen Kultur entsprechend angesehen, da hier viele verschiedene Aspekte nebeneinander bestehen. »Weil wir eine sehr durchmischte Kultur mit traditionellen, modernen und zeitgenössischen Dingen nebeneinander haben, sind die Bilder von Japan so verschiedenartig « (Matsumoto). Auch Bildkombinationen wie Candy Wrapper und Kimono Pattern Flash Burn Photograph, mit denen Graham über die Nebeneinanderstellung von einem zeitgenössischem süßlichen Manga-Motiv und der ikonischen Fotografie eines Atombombenopfers Emotionen erzeugen möchte, werden kaum als schockierend wahrgenommen (vgl. Teil II, Abschnitt 3.3.). Dies steht möglicherweise auch in Zusammenhang mit einem vom europäischen abweichenden Geschichtsverständnis in Japan, worauf

5 Diese Aussage ist deshalb verwunderlich, weil viele auf Araki verweisen, der selbst in seinen Büchern sehr unterschiedliche Bildwelten miteinander verbindet. 
Matsumoto Kaoru, Kuratorin am Osaka Contemporary Art Space, aufmerksam macht.

»Ich glaube nicht, dass wir Japaner eine bestimmte Art haben, Geschichte nach konkreten Regeln zu konstruieren. Wir vermischen immer alles und wir vergessen alles. In unserer Gesellschaft bestehen zu jeder Zeit viele Elemente nebeneinander. Ich glaube, die europäische Kultur versucht immer, alles in eine Ordnung zu bringen und daraus die offizielle Geschichte zu machen. [...] In Japan haben wir eine Redensart über das Vergessen: Man wirft Dinge ins Wasser und das Wasser reinigt alles. Nichts ist wirklich feststehend und dazu da, in eine Ordnung gebracht zu werden. [...] In unserer Kultur haben wir eine sehr traditionelle Art zu denken, dementsprechend repräsentiert die Mischung einen Teil dieser Denkweise. Deshalb kann mich so etwas nicht schockieren. Es ist alles Teil unseres Lebens « (Matsumoto). ${ }^{6}$

Oshima weist auf die Tatsache hin, dass es sich bei beiden Fotografien um Reproduktionen von Gedrucktem handelt, weshalb er eine solche Bildkombination ebenfalls kaum als fremd oder schockierend empfindet. Enari betont aber, dass die ungewöhnliche Art der Bildzusammenstellung einen starken Effekt erzeugt und der Arbeit eine gedankliche Tiefe verleiht. Die in Grahams Arbeit formulierte Kritik komme nicht so sehr durch einzelne Bildmotive, sondern vielmehr durch die Zusammenstellungen zustande (vgl. Enari). Der Fotografie-Kritiker und Publizist Iizawa Kôtarô sieht hingegen in Grahams Art der Bildzusammenstellung eher eine Reminiszenz an die japanische Fotografie. Er vermutet, dass Graham sich an Büchern von Araki, Tomatsu Shomei oder Moriyama Daido orientiert hat. »Vielleicht hat Graham diese Art des japanischen Stils genau studiert und benutzt ihn dementsprechend in seinem Buch« (lizawa). Iizawa betont die Mosaikhaftigkeit der japanischen Kultur, der Grahams Bildzusammenstellungen in jedem Fall gerecht werden. ${ }^{7}$

Ein wichtiger Bestandteil von Grahams Arbeit sind die Porträts sowohl von jungen Frauen als auch von Bürokraten. Weil sich Fragen nach stereotyper Darstellung sehr gut anhand von Porträts erläutern lassen, habe ich meine Gesprächspartner konkret danach befragt. Anhand der Frauenporträts lasse sich der Zeitraum von Grahams Arbeit sehr genau einordnen. Alle Gesprächspartner betonen, dass Frauen heute nicht mehr so aussehen. Sie kleiden sich anders, tragen andere Frisuren und seien anders geschminkt. Die porträtierten Frauen wirken wie Relikte aus den 1980er Jahren und seien damit sehr weit von der Gegenwart entfernt. »Alle Frauen sehen ein bisschen altmodisch aus, aber das kommt nicht vom Künstler, sondern von der Zeit« (Ikeda). Da Europäern die modischen Veränderungen in Japan kaum bekannt sind, ist es nur natürlich, dass diese Veränderungen Ausländern kaum auffallen. Auch wenn sich die Moden ändern, ein gewisses Idealbild japanischer

6 Die andere Geschichtsauffassung steht vermutlich im Zusammenhang mit der traditionellen japanischen Zeitrechnung, die auch heute noch gängig ist. Mit jedem Amtsantritt eines Kaisers beginnt eine neue Zeitrechnung. Das Jahr 2006 entspricht Heisei 18, weil Heisei-Tennos (Kaiser Akihitos) Amtszeit nach dem Tod von Showa-Tenno (Kaiser Hirohito) 1989 begonnen hat. 1989 war das Jahr Heisei 1, es folgte auf das Jahr Showa 64.

7 Auch wenn Arakis Bildwelten sich klar von Grahams unterscheiden, ist der Bezug durchaus gerechtfertigt. Auch Araki verbindet in seinen Büchern sehr unterschiedliche Motivwelten miteinander, die im Verlauf eines Buches wiederholt auftauchen. 
Frauen besteht weiterhin. »Viele Frauen wollen einfach so sein: hübsch, entzückend, schön, wohlgestaltet« (Yoshihara). Besonders auffallend ist das auch als Titelbild eingesetzte Porträt Girl with White Face, denn diese Frau bezeichnen meine Interviewpartner als besonders traditionell japanisch (vgl. Teil II, Abschnitt 3.5.1.). Für Japaner wirke sie fast schon stereotyp in ihrem Aussehen. Ihr weißes Gesicht entspreche dem klassischen japanischen Schönheitsideal ebenso wie die speziell ausgesuchte Kleidung sowie die typische Geste der Hand, die zum Mund geführt wird, um die Zähne beim Lachen zu verdecken. Die anderen porträtierten Frauen werden als Durchschnittsjapanerinnen empfunden, die nicht besonders »charakteristisch oder eigentümlich« aussehen (Ikeda). Kasahara kritisiert jedoch Grahams Ansatz, nur junge und keine älteren Frauen auszuwählen. Sie gibt zu bedenken, dass Graham, indem er junge Frauen und alte Männer fotografiere, einen typisch europäischen Blickwinkel einnehme. Iizawa kommentiert die Tatsache, dass die Frauen ausnahmslos nicht in die Kamera schauen:

»Vielleicht interessieren sich westliche Fotografen für die Gesichter japanischer Frauen. Sie sind wie Masken, vielleicht wie Nô-Masken [...], wie eine Oberfläche, ohne einen Ausdruck. Nur mit Schlitzen oder Löchern als Augen; vielleicht ist das die westliche Art des Denkens. Die Augen sind der Eingang zur Seele. Wir können eine Person über ihre Augen verstehen, ihre Seele und ihre innersten Gefühle. Aber japanische Augen sind nur Schlitze, also haben sie [die westlichen Fotografen und das westliche Publikum] keinen Zugang zu ihrem Innern« (Iizawa).

Demzufolge lassen sich die Gesichter der Japanerinnen von Europäern beobachten, ohne die Personen dahinter verstehen zu können. Die Maskenhaftigkeit etabliert - ebenso wie die Gesten - eine Distanz in Grahams Porträts, die auch von Japanern wahrgenommen wird.

Die Gesten der porträtierten Frauen empfinden alle ausnahmslos als sehr typisch japanisch. Iizawa sieht in den Gesten ein defensives Verhalten, was Japanerinnen bereits in der Kindheit vermittelt bekommen, um sich zu schützen. »Japanerinnen werden erzogen, ihre Gefühle oder Meinungen nicht zum Ausdruck zu bringen und so haben sie Probleme, dies auf natürliche Art und Weise zu tun. Sie zögern, um ihre Gefühle mit diesen Gesten auszudrücken« (Iizawa). Laut Matsumoto sind solche Gesten, insbesondere das Bedecken der Zähne, jedoch heute weniger gewöhnlich als noch vor einiger Zeit, weil junge Frauen diese Art des Verhaltens nicht mehr vermittelt bekommen. Die Tatsache, dass Graham sich diesem Element widmet, wird seinem guten Gespür für Details der japanischen Kultur und Gesellschaft zugeschrieben. Solche Gesten gelten vielen Japanern als so selbstverständlich, dass sie ihnen gar nicht mehr auffallen, weswegen japanische Fotografen solche Bilder auch nicht machen können.

Vielen fällt es schwer, sich über die Porträts der Männer zu äußern, weil sie die Intention des Fotografen nicht verstehen können. »Viele Leute sagen, dass Japaner nicht geradlinig sehen, aufrichtig sprechen oder konsequent handeln wollen. Vielleicht ist dies ein Weg des Fotografen, das zu zeigen, « sagt die Kuratorin Yoshihara. Eine solche Lesart entspricht Iizawas Äußerungen zu den Frauenporträts. Ikeda meint, in den Männerporträts abermals Grahams Vorliebe für das Detail zu entdecken. »Er interessiert sich gar nicht für die Person selbst, sondern er interessiert sich für die Brille mit Gesicht, aber nicht für das Gesicht mit Brille« (Ikeda). Einigen Aussagen zufolge seien 
Männer mit Brillen typisch japanisch. Enari meint, dass westliche Fotografen besonders gerne Japaner mit Brillen fotografieren, kann sich aber nicht erklären, warum das so ist. Die Männerporträts werden zumindest nicht als eine Herabsetzung des japanischen Arbeitnehmers gesehen oder als eine stereotypisierende, gleichmachende Art der Fotografie. Auch wenn vielfach nicht klar ist, welchen Zweck die Porträts erfüllen, macht insbesondere Yoshiharas Analyse deutlich, dass auch von japanischer Seite ein Verständnis für die von Graham gewählten fotografischen Ausdrucksmöglichkeiten vorhanden ist.

Insgesamt ist man sich einig, dass Graham sehr genau beobachtet und mit seiner Fokussierung von Details möglicherweise mehr über die japanische Gesellschaft zu vermitteln vermag als Arbeiten, die sich auf die größeren $\mathrm{Zu}-$ sammenhänge im Außenraum konzentrieren. »Er fokussiert immer so kleine Details. In diesem Sinn sind kleinste Räume sein formaler Zugang. Ich denke wirklich, dies repräsentiert die japanische Kultur auf präzise Weise« (Matsumoto). Graham gelinge es, typisch japanische Details ins Bild zu setzen, ohne den Eindruck zu erwecken, seine Arbeit sei stereotyp. Meinen Gesprächspartnern ist diese Unterscheidung immer sehr wichtig. Der Fotograf Saiga Yuji bemerkt, Graham gelinge es, weit unter die Oberfläche zu schauen. »Er hat ein Anliegen und vermittelt seinen Standpunkt, indem er genau hinschaut« (Saiga). Graham zeige Situationen, die wiedererkennbar seien, weshalb auch Ausländer, die Japan nicht kennen, Japanisches in Grahams Fotografien finden könnten (vgl. ebd.).

Japaner finden in Grahams Arbeit zahlreiche Anknüpfungspunkte zu ihrem Alltag. In vielen Gesprächen werden persönliche Assoziationen zu einzelnen Fotografien geäußert. Das verdeutlicht, dass meine Gesprächspartner viele der Details oder der kitschigen Objekte als Teil ihrer Alltagskultur verstehen, die überall in Japan anzutreffen ist. Gerade die Alltäglichkeit hält aber japanische Fotografen davon ab, solche Objekte überhaupt zu sehen. Die Szenerien, auf die Graham seinen Blick richtet, scheinen vielen Japanern zu alltäglich, als dass sie sie als abbildungswürdig erachten würden. Die assoziative Verbindung mit japanischer Fotografie zeigt jedoch, dass auch japanische Fotografen teilweise einzelne von Grahams Motiven auswählen können. Die Zusammenstellung der sehr unterschiedlichen Bilder, insbesondere in der von Graham gewählten kritischen Weise, lässt den Ursprung der Arbeit jedoch ganz offensichtlich als europäisch hervortreten.

Auch wenn Grahams Arbeit als gültige Japandarstellung gesehen wird, stellt Matsumoto klar:

»Wenn Grahams Fotografien die einzige Quelle japanischer Bilder [in Europa] sind, dann ist das ein großes Problem. Es ist wahr, unser alltägliches Leben beinhaltet solche Aspekte. Wir sind selbst starken traditionellen und stereotypen Bildern ausgesetzt, wir sind mit diesen traditionellen Aspekten konfrontiert. [...] Ich sage nicht, dass das alles vorurteilsbehaftet ist. [...] Vielleicht ist es typisch, aber es gibt einfach so viele verschiedene Dinge, die nebeneinander bestehen« (Matsumoto).

Damit benennt Matsumoto noch einmal einen wichtigen Punkt: Eine Position kann von japanischer Seite als gültig akzeptiert werden, wenn sie nicht festschreibt. Weil Grahams Arbeit Leerstellen aufweist, die sich nicht erklären, sondern einer eigenständigen Interpretationsleistung des Publikums bedürfen, formuliert sie ein offenes Angebot. Japan wird durch Grahams Sichtweise nicht als Anderes festgeschrieben. Vielmehr bleibt in den Fotografien die 
Herausforderung des Fremden bestehen, das Fragen aufwirft und keine Antworten bereitstellt. Neben Grahams kann es auch weitere gültige Japandarstellungen geben. Sie existieren nebeneinander und greifen verschiedene Facetten der japanischen Kultur und Gesellschaft auf. Sie überschneiden sich partiell oder zeigen ganz unterschiedliche Elemente.

\subsection{Gespräche über Elisabeth Neudörfls Future World}

So leicht es meinen Gesprächspartnern fällt, über Grahams Arbeit zu sprechen, so schwer tun sie sich damit, Worte für Neudörfls Arbeit zu finden. Die zurückhaltende Herangehensweise, die Alltäglichkeit des Abgebildeten und die weniger offensichtliche Haltung der Fotografin sind als Gründe hierfür anzuführen. »Da sind sehr viele subtile Dinge in den Bildern. Ich kann keinen Weg finden, die Fotografien zu lesen, [...] ich kann in ihrer Arbeit keinen Standpunkt erkennen« (Iizawa). Mit diesen Worten spitzt Foto-Kritiker Iizawa die Probleme zu, die auch andere mit Neudörfls Fotografien haben. Er ist jedoch der einzige, der dem nichts weiter hinzuzufügen weiß, während alle anderen Gesprächspartner nach einiger Zeit Anhaltspunkte finden, über die sich sprechen lässt. Während drei Interviewte finden, dass Neudörfls Arbeit auch von einem japanischen Fotografen fotografiert sein könnte (Kikuta; Kasahara; Enari), meinen die anderen, dass Japaner Japan so gerade nicht abbilden können. »Neudörfl fotografiert Dinge, die Japaner nicht anschauen. Japaner müssten auch so sehen können, sie haben diese Fähigkeit aber verloren, weil das einfach zu alltäglich ist, « sagt der Fotograf Saiga. Wiederholt wird erwähnt, Neudörfl zeige Japan, wie es wirklich ist (Aya; Ikeda; Saiga).

Der Alltag in Neudörfls Fotografien kommt allen sehr bekannt vor. »Die meisten Bilder sind für mich so natürlich, dass ich die ganze Zeit: `kenne ich, kenne ich,« sagen möchte« (Aya). Aber gerade diese Alltäglichkeit führt auch zu Irritationen. Neben der Galeristin Aya, die selbst nicht versteht, warum sie so eigenartig auf die Alltäglichkeit der Abbildungen reagiert, hat beispielsweise Oshima Schwierigkeiten damit, dass es einer Ausländerin gelingt, den japanischen Alltag so treffend ins Bild zu setzen. »Diese Fotografien zeigen Aspekte unseres täglichen Lebens, aber ich finde es sehr merkwürdig, dass diese Bilder von jemandem von außerhalb gemacht worden sind « (Oshima). An anderer Stelle sagt er: »Sie zeigt eine merkwürdige Seite unserer Kultur. Das künstliche Schwimmbad ist lustig, aber es ist auch ganz normal für uns. Vielleicht weiß sie nicht, dass sie diese besondere Seite sieht. [...] Ich empfinde ein frisches Verständnis für unsere Kultur und unseren Alltag« (ebd.).

Aya meint, dass sie vorher nie genau darauf geachtet habe, wie Japaner für Fremde aussehen. Dies führt ihr nun Neudörfls Arbeit vor Augen und beschert ihr zunächst ein Unbehagen. "Wir Japaner achten immer gegenseitig darauf, wie wir aussehen. Aber ich habe noch nie gesehen, was Ausländer für Japaner empfinden. Vielleicht bin ich nicht daran gewöhnt, darüber nachzudenken. Vielleicht habe ich deshalb zunächst ein unbehagliches und befremdliches Gefühl« (Aya). Das Befremden anlässlich Neudörfls Fotografien bedeutet aber nicht, dass das Buch negativ bewertet wird. Im Gegenteil: Die meisten finden gerade die Subtilität und das Ungreifbare spannend und interessieren sich sehr für die Arbeit. Matsumoto meint, Neudörfls Ansatz »versucht, eine Balance zwischen der Ausländerin und der Fotografin zu finden. 
Sie schaut in einer neutralen Weise auf die Szenerie; nicht neutral, aber auf eine gewisse Art objektiv« (Matsumoto). Gerade weil Neudörfl nicht »nach merkwürdigen, besonderen, geheimnisvollen oder exotischen Dingen« (Kikuta) sucht, gelingt es ihr, in ihren Bildern einen Ton zu treffen, der den meisten meiner japanischen Gesprächspartner sehr vertraut ist. Die weiche Tonalität und das Schwarzweiß werden ebenfalls dahingehend wahrgenommen, dass den Fotografien eine gewisse Zeitlosigkeit innewohnt. Zwar könne man in einigen Bildern sehen, dass sie in den 1990er Jahren gemacht seien, der Großteil der Szenerie könne aber heute noch angetroffen werden (vgl. ebd.). In einer Stadt wie Tokyo, die sich in einem permanenten Wandlungsprozess befindet, ist dies keinesfalls selbstverständlich.

Neudörfls Porträtfotografien von meist jungen Japanerinnen und Japanern werden als sehr natürlich empfunden. Die Auswahl der Porträtierten weise auf ganz normale durchschnittliche Japaner, die keine besonderen Eigenheiten besitzen, sondern einen Durchschnitt durch die (jüngere) Bevölkerung bilden, meinen die Interviewten. Kasahara bemerkt, dass die Modelle »nicht von der Fotografin oder von ihrer Art sie anzuschauen, belästigt werden. [...] Ich denke, sie respektieren die Fotografin ebenso, wie die Fotografin sie respektiert. Dies sind sehr natürliche Porträts, in denen die Fotografin nichts zeigt, was die Modelle selbst nicht auch zeigen wollen. Das ist das Wesentliche, denke ich « (Kasahara). Für Kikuta besteht das Besondere der Porträts in der wahrzunehmenden Distanziertheit, da die Personen nicht in die Kamera schauen. Dadurch wird es unmöglich, eine Aussage über die Persönlichkeiten der Porträtierten zu machen. Diese Art der Menschendarstellung findet Aya ungewöhnlich, weil sie in Porträts eher nach der Persönlichkeit der abgebildeten Person sucht. »Vielleicht ist sie [Neudörfl] daran interessiert, den Aspekt der kulturellen Existenz abzubilden« (Aya). Auch Saiga meint, die Porträts erzählen nichts über die Fotografierten. Neudörfl habe sich die Gesichter genau angeschaut, um etwas über Japaner zu erfahren, aber nicht, um eine Aussage über die einzelne Person zu machen. Einer von Saigas Studenten findet, die Fotografin habe möglicherweise zum Ausdruck bringen wollen, dass Japaner keine Gefühle zeigen oder keinen Ausdruck in ihrer Mimik haben (vgl. Saiga). Damit vertritt er eine ähnliche Idee, wie sie Iizawa in seinem Vergleich der europäischen Abbildung japanischer Frauengesichter mit Nô-Masken formuliert (vgl. Abschnitt 5.1.). Ikeda stimmt der Annahme zu, Neudörfl gehe es nicht um die Person als solche, sondern um den Blick auf die Person. Sie findet insbesondere die »schwarzen Köpfe« bei Neudörfls Porträts bildnerisch interessant. Sie seien »so rhythmisch« (Ikeda). Kikuta fallen hingegen insbesondere die Augen der Porträtierten auf, die sie sehr japanisch findet. Die japanischen Gesprächspartner können demzufolge sehr japantypische Details in den Porträts entdecken, finden sie aber sehr natürlich und nicht stereotyp. Vielmehr empfinden sie sie als sehr treffende Darstellungen von ganz normalen Japanern.

Neudörfls Porträts werden oft mit Grahams Frauenporträts verglichen. Erstere gelten als natürlicher, unter anderem, weil sie sehr durchschnittliche Japaner zeigen. Grahams Porträts erinnern meine Gesprächspartner stark an die 1980er Jahre, weshalb sie eine zeitliche Distanz vermitteln. Neudörfls Porträts werden hingegen als eher zeitlos wahrgenommen. Aufgrund des engen Ausschnitts bei Neudörfls Porträts werde deren die Personen betreffende Aussagekraft stark geschmälert. Saiga spitzt den Vergleich dahingehend zu, dass Grahams Porträts Geschichten erzählen und Gefühle zeigen, während 
Neudörfls Porträts nichts erzählen; weshalb sie in jedem Fall mehr als ein Bild benötigt, um ihre Aussage zu treffen. In Grahams Arbeit erzähle bereits ein einzelnes Porträt sehr viel (vgl. Saiga). Dazu passt auch Ikedas Beobachtung über den Gesichtsausdruck der Fotografierten: »Es ist sehr interessant: Die porträtierten Frauen in Grahams Buch versuchen zu sprechen, aber in Neudörfls Buch versuchen die Porträtierten, etwas zu hören« (Ikeda). Während Grahams Porträts durchaus in der Lage sind, etwas mitzuteilen, bleiben Neudörfls Porträts auch für die Befragten passiv und schwer zu entschlüsseln. Die Tatsache, dass auch Japaner nichts über die Persönlichkeiten der Porträtierten aus den Porträts herauslesen können, verdeutlicht, dass dies im Stil der Aufnahmen begründet ist und nicht mit der kulturellen Herkunft der Betrachter zusammenhängt.

Über das Layout äußern sich nur zwei der Gesprächspartner, denen es schwer fällt, die verschiedenen Bildgegenstände zusammenzubringen (vgl. Aya; Oshima). Sie finden es nicht besonders verständlich, warum Landschaften, Stadtlandschaften und Porträts im Layout miteinander verbunden werden. Aya meint: »Wenn japanische Fotografen ihre Bilder layouten, unterscheiden sie Objekte wie Landschaft und Porträt voneinander und bringen sie nicht zusammen. Sie würden Stadtlandschaft und andere Landschaft durch Kapitel voneinander trennen« (Aya). ${ }^{8}$ Aya sieht hier Parallelen zwischen Neudörfls und Grahams Arbeit. Die Parallelen erschöpfen sich jedoch in der in beiden Arbeiten fehlenden Unterteilung in Kapitel, denn viele Gesprächspartner sind der Meinung, dass Graham mittels der Bildzusammenstellung seiner Arbeit eine Schärfe und Kontur verleiht, die Neudörfls Arbeit fehlt.

Neudörfls Bildgestaltung wird nur selten thematisiert. Auffallend sei die eher ungewöhnliche ausschließliche Wahl des Hochformats. Die Bildaufteilung gilt wiederum als europäisch. »Ich denke, das ist eine sehr deutsche Art, die Szenerie auszuschneiden. [...] Sie konzentriert sich auf die Formen. Indem sie sie ausschneidet, wird wirklich eine Ordnung der Dinge und eine Struktur in der Unordnung vermittelt " (Matsumoto). Matsumoto ist aber der Meinung, dass japanische Fotografen viel von dieser Art der Bildgestaltung gelernt haben, so dass sie ihr sehr vertraut vorkomme. Ikeda sieht Neudörfls Bildgestaltung insbesondere von der Fotografie der Moderne beeinflusst. »Wenn man die moderne Fotografie in Deutschland der 1920er und 30er Jahre gut kennt, dann kann man eine solche Essenz ganz einfach aus ihren Fotografien herauslesen« (Ikeda). Mit der 〉Essenz« bezieht sich Ikeda auf die von ihr formulierte Vorliebe Neudörfls für »Strukturen und konstruktive Kombinationen mit den unterschiedlichen alltäglichen Motiven. Deshalb kann ich sagen, dass ihre Fotos sehr ästhetisch aussehen« (ebd.). In diesem Zusammenhang erwähnt Ikeda auch das Element der japanischen Schriftzeichen, die wiederholt in Neudörfls Fotografien zu sehen sind. "Das ist ein bisschen spielerisch, weil da der Bauhausstil mit den japanischen Zeichen kombiniert wird. [...] Aber auch wenn man Japanisch nicht versteht, spielt es für das

8 Dass Ayas Aussage nicht vollständig den japanischen Gepflogenheiten gerecht wird, macht auch Iizawas bereits zitierter Vergleich zwischen Arakis und Grahams Buch deutlich. Arakis Bücher leben gerade davon, sehr diverse Themenkomplexe unmittelbar miteinander zu kombinieren. Nach den Aussagen der Interviewten $\mathrm{zu}$ beurteilen, ist Arakis Art der Bildkombination jedoch nicht typisch für japanische Fotobücher. 
Verständnis der Bilder keine Rolle. Das ist mehr so ein Gestaltungselement« (ebd.). Mit dem Verweis auf den `Bauhausstil« spielt Ikeda auf die Sachlichkeit in Neudörfls Fotografien an, die durch den Einsatz der japanischen Schriftzeichen gebrochen werde, weil diese ihr als weniger sachlich gelten. Mit moderner Klarheit bringt Ikeda eher lateinische Buchstaben in Verbindung. Iizawa sieht in der Präsenz der japanischen Schriftzeichen einen Kontrast zwischen dem zeitgenössischen und dem traditionellen Japan (vgl. Iizawa). Die Architekturen muten für ihn eher westlich an, während die japanischen Zeichen klar das Japanische betonen. Trotzdem hilft ihm diese Beobachtung nicht weiter, ein Verständnis für die Arbeit zu entwickeln. Ein Kontrast zwischen alt und neu wird sonst von niemandem in Neudörfls Arbeit gesehen. Das liegt vermutlich daran, dass die japanischen Schriftzeichen ebenso zur zeitgenössischen japanischen Kultur gehören wie nichttraditionelle Architekturen, die Neudörfl vorrangig fotografiert.

Größere Verständnisschwierigkeiten ergeben sich aus der Wahl des Titels Future World. Einige fragen, ob Neudörfl in Japan die Zukunft gefunden habe (z.B. Kikuta). Unter Zukunft verstehen fast alle etwas anderes, sie können nichts Zukünftiges in den Fotografien entdecken, weshalb sie der Titel irritiert. Iizawa bewertet dies als Ironie, »weil sie die Zukunft nicht zeigt« (Iizawa). Dies entspricht wohl am ehesten der oben formulierten Annahme, dass Neudörfl sich die europäischen Ideen Japans als Land der Zukunft aneignet, um sie in ihrer Japandarstellung zu durchbrechen und eben gerade nichts vermeintlich Zukünftiges zu zeigen, womit ein Element gängiger Japandarstellungen hinterfragt wird (vgl. Teil II, Abschnitt 4.1.). Neben Iizawa formuliert Saiga als einziger ein Verständnis für Neudörfls Wahl des Titels. »Die Welt, die Neudörfl fotografiert, ist so alltäglich, dass der Titel Future World zu sagen scheint, dass es auch in der Zukunft so weitergehen wird. Die Arbeit vermittelt, dass es wenig aufregende Dinge gibt im alltäglichen Leben. Der Begriff Future World ist abstrakt und eher weich, was sehr gut zu den Fotografien passt« (Saiga). Aya hingegen findet das Buch sehr interessant, »aber der Titel [...] ist unpassend gewählt« (Aya). Diese Reaktion ist sehr verständlich, denn woher sollen Japaner wissen, dass man in Europa die japanische Gegenwart für europäische Zukunft hält? Für Japaner ist ihre Gegenwart Gegenwart, weshalb sie die technologische Avanciertheit ihrer Gesellschaft und deren Rezeption in anderen Erdteilen nicht wahrnehmen können. Das ist nur aus einer Außensicht heraus möglich. Deshalb wird durch den Titel klar, dass es sich nicht um das Buch eines japanischen Fotografen handeln kann. ${ }^{9}$

Neudörfls Arbeit gilt meinen japanischen Gesprächspartnern als eine sehr adäquate Darstellung des zeitgenössischen japanischen Alltags. Die Alltäglichkeit und damit einhergehende Banalität wird teilweise jedoch als verstörend empfunden, weil die Intention der Fotografin daraus nicht abzulesen sei. Auf ihre zurückgenommene Weise verkörpere Neudörfls Fotografie jedoch etwas sehr Vertrautes. "Ich empfinde etwas sehr Japanisches, vielleicht eine gewisse Schüchternheit« (Kikuta). Dieses Gefühl von Schüchternheit ist vermutlich auf die feinfühlige und zurückhaltende Art zurückzuführen, mit der Neudörfl Themen aufgreift. »Sie nimmt sich eine Szene vor, die etwas vermittelt, aber sie macht das nicht auf eine vordergründige Art. Ihre Herangehensweise ist sehr zurückhaltend und vorsichtig. Man muss selbst heraus- 
finden, was sie in der Szene gefunden hat « (Matsumoto). Aya meint dann auch: »Möglicherweise entspricht ihr empfindsamer Ausdruck japanischen Gefühlen« (Aya). Unabhängig davon, mit welchen Begriffen Neudörfls Ausdrucksweise belegt wird, verdeutlichen die verschiedenen Beschreibungsversuche, dass es Neudörfl gelingt, eine fotografische Arbeit zu entwickeln, die Japanern sehr Vertrautes zeigt. »Neudörfl befindet sich in der Mitte zwischen Europa und Japan. [...] Möglicherweise weiß sie, dass sie nicht auf eine japanische Art sehen kann. Dennoch ist sie eine Europäerin, die vermutlich etwas von Japan versteht, es mag und etwas für Japan empfindet« (Kikuta). Auch wenn es für die japanischen Fotografie-Experten nicht ganz einfach ist, sich direkt zu Neudörfls Arbeit zu äußern, wird im Laufe der Gespräche deutlich, dass die Qualität von Neudörfls Japandarstellung durchaus hervortritt und ein Interesse zu erzeugen vermag. Dass Neudörfl für Japan typische Aspekte aufgreift, sie aber nicht stereotyp sondern sehr feinfühlig und zurückhaltend verhandelt, ist Konsens. Damit bestätigen meine japanischen Gesprächspartner die Annahme, dass sowohl Neudörfls als auch Grahams Arbeiten einen interessanten Zugang zur japanischen Kultur bieten, der sich von anderen Außendarstellungen Japans unterscheidet. »Bevor ich Sie getroffen und bevor ich diese Bilder gesehen habe, war ich mir nicht sicher, ob ein Ausländer Japan wirklich sehen könne, wie es ist. Heute, wo ich diese Bücher gesehen habe, denke ich, dass die jüngere Generation sich im Vergleich zur vorhergehenden, die hauptsächlich hübsche Blumen, Geisha, Berge und all das zeigt, wirklich geändert hat« (Enari).

\section{Zusammenfassung:}

In Gesprächen über die analysierten Arbeiten von Paul Graham und Elisabeth Neudörfl bestätigen japanische Fotografie-Experten die Annahme, dass beiden eine adäquate und präzise Darstellung der zeitgenössischen japanischen Gesellschaft gelingt. Sie machen aber deutlich, dass es sich bei den Darstellungen lediglich um Teilaspekte der sehr komplexen japanischen Realität handelt. Der genauen Beobachtung Neudörfls und Grahams sei es zuzuschreiben, dass sie Aspekte der japanischen Kultur und Gesellschaft aufgreifen, die japanische Fotografen aufgrund der Alltäglichkeit so nicht zu zeigen vermögen. Auch neigen japanische Fotografen dazu, von einer kritischen Betrachtung wie sie Graham betreibt, Abstand zu nehmen. Beide Arbeiten lassen sich klar als europäische Darstellungen Japans erkennen, die jedoch eine wesentlich andere Sichtweise etablieren, als es allgemein von westlicher Japanfotografie erwartet wird. 



\section{SCHLUSSBEMERKUNG}

Die Untersuchung der Arbeiten Empty Heaven von Paul Graham und Future World von Elisabeth Neudörfl verdeutlicht, dass es möglich ist, mit Mitteln der künstlerischen Dokumentarfotografie eine über die üblichen Klischees und Stereotype hinausweisende Darstellung einer fremden Gesellschaft oder Kultur zu erzielen. Die Reaktionen der befragten japanischen FotografieExperten geben darüber letzte Sicherheit, denn sie bestätigen, dass Grahams und Neudörfls Arbeiten sich von dem abheben, was gemeinhin von europäischen Fotografen, die in Japan fotografieren, erwartet wird. Es wird deutlich, dass es den beiden Fotografen gelingt, kulturelle Eigenheiten in ihrer alltäglichen Ausprägung ins Bild zu setzen und die japanische Kultur damit nicht allein als different und anders zu präsentieren. So zeigen beide im Detail untersuchten Arbeiten selbst für Japaner interessante und überraschende Aspekte des eigenen Landes. Vor dem Hintergrund der Schwierigkeiten, mit denen die Fotografie konfrontiert ist, wenn sie sich um authentische oder objektive Darstellungen bemüht, ist dies eine umso höher zu bewertende Leistung.

Graham und Neudörfl fragen nicht, was das Fremde ist oder worin die Fremdheit besteht, mit der wir in Japan notwendigerweise konfrontiert sind. Vielmehr nehmen sie das Fremde als Herausforderung an, als das, »worauf wir antworten, « um mit Waldenfels zu sprechen (Waldenfels 1997: 109; Hervorhebung im Original). Sie suchen gerade nicht nach dem was oder wozu von Fremdheit, sondern sie wenden sich der Fremdheit zu, ohne sie benennen oder fixieren $\mathrm{zu}$ wollen. Ihre Fotografien geben keine Antworten, die das Publikum nur aufzunehmen braucht, um etwas über Japan zu erfahren. Vielmehr geben sie Fragen an die Betrachter weiter, die mit Assoziationen und eigenem Vorwissen selbst aktiv werden müssen, um Bedeutung zu finden. Bedeutung ist in den Bildern zwar angelegt, aber nicht festgelegt. Die Fotografien sind vielschichtig und fordern - so wie das Fremde selbst - zu okkasionell abweichender Rezeption heraus: sie beginnen zu schillern.

Es zeigt sich auch, dass die Fotografie für eine solch differenzierte Sichtweise auf das Fremde nicht neu erfunden werden muss. Sowohl Graham als auch Neudörfl entwickeln vorhandene Linien der Dokumentarfotografie weiter. Sie spitzen sie zu und nutzen sie für eine konzeptionelle Form der künstlerischen Dokumentarfotografie. Finden diese Arbeiten Interesse und Verständnis des Publikums, kann es ihnen im besten Fall gelingen, neue Einsichten zu bewirken. Diese bestehen in dem Verständnis, dass das Fremde nicht ausschließlich das vom Eigenen Abweichende ist, sondern dass im Fremden selbst auch Parallelen zum Eigenen und Elemente von Alltäglichem entdeckt werden können. 
Besonders geeignet, Japan darzustellen, scheinen Grahams und Neudörfls Ansätze auch deshalb, weil sie Parallelen zur japanischen Fotografie aufweisen. Im Jahr 1974 schreibt der japanische Kurator Yamagishi Shoji:

»Japanische Fotografen vervollständigen ein Projekt normalerweise in Buchform, sie stellen eine Anzahl Fotografien in Serien zusammen, die durch einen gemeinsamen Gegenstand, ein Thema oder eine Idee verbunden sind. Der ganze Wert oder die vollständige Auswirkung solcher Arbeiten kann nicht verstanden werden, wenn einzelne Bilder für eine Ausstellung an der Museumswand aus der Serie herausgelöst werden. Dies zu tun, beraubt die Fotografien der ihnen zugedachten Verbindung zu den vorhergehenden oder nachfolgenden Bildern in der Serie« (Yamagishi 1974: o.S.).

Diese Aussage lässt sich ebenfalls auf Grahams und Neudörfls Japanprojekte anwenden. Denn auch ihre Arbeiten überzeugen im Zusammenspiel der Fotografien. In den Einzelausstellungen, anlässlich derer die beiden Künstlerbücher erschienen sind, waren die vollständigen Arbeiten zu sehen. Die Buchform erweist sich dementsprechend nicht nur für die beiden Arbeiten als adäquat, sondern für das Japanthema insgesamt.

Bewusst oder unbewusst haben sich beide Fotografen für eine Annäherung an Japan entschieden, die der britische Kurator Mark Holborn 1986 in einem Ausstellungskatalog über japanische Fotografie beschreibt:

»Zwei Herausforderungen sind vorherrschend. Der Fotograf kann das visuelle Chaos der urbanen Dichte wie der von Shinjuku konfrontieren und eine durchsetzungsfähige Strategie entwickeln, um es in der Ausgestaltung seiner Fotografien zu verwenden. Alternativ kann der Fotograf daran arbeiten, die Fassade zu durchdringen, um einen Themenbereich zu finden, der das Chaos transzendiert. Diese Arbeit beinhaltet eine metaphorische Reise zum flüchtigen Herzstück der japanischen Erfahrung, auf der einen Seite begrenzt von einer mythischen Geschichte sowie einem nationalen traumatischen Erlebnis und auf der anderen Seite von einem verstärkten Bewusstsein für die Zukunft« (Holborn 1986: 9).

Mit der urbanen Dichte und Schichtung, die Holborn nicht nur in Shinjuku, sondern in jeder japanischen Großstadt von Hokkaido bis Okinawa wiederholt sieht, setzt sich Neudörfl intensiv auseinander. Diese Art der Beobachtung des urbanen Raums markiert einen konstitutiven Aspekt ihrer Arbeit Future World, in der sie die Idee des wrapping aufgreift und sinnfällig in ihren Fotografien des urbanen Raums umsetzt. Paul Graham zeichnet einerseits die Oberflächen auf, die Holborn als entscheidendes Element in der japanischen Kultur beschreibt (vgl. ebd.: 6), durchdringt sie aber mittels metaphorischer Betrachtungen und Bildkombinationen und bezieht auch Historisches mit ein. Oberflächen und ihre Durchdringung stellen ein wichtiges Element in Grahams Arbeit dar. Zudem kann seine Arbeit auf einer metaphorischen Ebene gelesen werden, wodurch sie ihre komplexe Wirkung entfaltet. Schichtung (wrapping), Oberflächen (veneer) und das Durchdringen der Oberflächen markieren wesentliche Bestandteile der japanischen Erfahrung, die in Neudörfls und Grahams Arbeiten zum Tragen kommt. Somit treffen die beiden Fotografen Bereiche, die maßgeblich sind für eine Fremdheitserfahrung, die den japanischen Alltag und die japanische Gegenwart berücksichtigt. 
Die Dokumentarfotografie beschäftigt sich mit der Wiedergabe von Sichtbarem, im vorliegenden Fall handelt es sich dabei um Japanisches, das aus europäischer Perspektive fremd anmutet. Für das abbildende Medium Fotografie sind die Oberflächen der Dinge von großer Bedeutung, denn ihnen kann man sich mit der Kamera nähern. Weil Fremdheit jedoch keine kategoriale Eigenschaft ist, lässt sich das, was an den Gegenständen fremd ist, nicht auf eindeutig festlegende Weise darstellen. Versuche, sich dem Fremden abbildend beziehungsweise bestimmend zu nähern, können das Fremde als Fremdes kaum treffen, weil das Fremde als das, was uns herausfordert, nicht objektivierend beschreibbar ist. Die Fotografie, die sich mit dem Fremden beschäftigt, kann versuchen, es zu erklären. Doch dabei besteht die Gefahr, dass objektiviert, festgeschrieben oder stereotypisiert wird.

Die Arbeiten von Graham und Neudörfl versuchen deshalb, Fremdheit zu transzendieren und die Erfahrung des Fremden an die Betrachter weiterzuleiten. Dem Publikum wird in den untersuchten Fotografien Fremdheit gerade nicht als Klischee vermittelt, das die Behauptung eines: so ist es! aufstellt. Vielmehr macht die thematische Fülle und Offenheit der Bilder den Betrachtern das Angebot, Aspekte der japanischen Gegenwart jenseits von Klischees zu erfahren. Die Arbeiten ermöglichen den Betrachtern selbst ein Stück Fremderfahrung, denn in den Fotografien tritt die Herausforderung des Fremden in Form von unbeantworteten Fragen und gezielt eingesetzten Irritationen hervor. Irritationen und Unbestimmtheitsstellen, die auf etwas verweisen, was die Fotografien selbst nicht eindeutig beantworten können, lassen die Arbeiten zu Projektionsflächen werden, auf die das Publikum individuelle und subjektive Assoziationen projizieren kann. Die Rezeption ist dementsprechend individualisiert. Es besteht zwar eine Grundlage des Verständnisses, doch in der individuellen Ausprägung wird es variieren. Auch damit unterscheidet sich eine künstlerische Dokumentarfotografie von anderen dokumentarfotografischen Gebrauchsweisen. In der Reise- oder der journalistischen Fotografie wird generell eher auf die Erzielung eines Konsenses in der Rezeption gesetzt. Deshalb sind deren Bilder mitunter leichter zugänglich und einfacher zu verstehen.

Ein Grund hierfür ist in der Art der Repräsentation der Bilder zu suchen. Grahams und Neudörfls Fotografien sind Abbilder von etwas, sie zeigen beispielsweise eine Person, eine architektonische Konstellation, ein kleines Ensemble im Innenraum. Doch es geht nicht ausschließlich darum, ein Verständnis für das Abgebildete zu erzeugen. Die Fotografien von Graham und Neudörfl gehen über den repräsentierten Gegenstand hinaus. Sie agieren als Bilder im Kontext der Zusammenstellung im Buch und entfalten nur so ihre volle Wirkung. Das Abgebildete steht nicht allein für die Fotografie. Die Art der Abbildung, die Intention des Fotografierenden und der Kontext lassen die einzelne Fotografie über den repräsentierten Gegenstand hinausweisen. Diese Art des Umgangs mit dokumentarfotografischen Mitteln lässt sich als künstlerische Repräsentation beschreiben, die über die objektive Repräsentation, die in ihrer konstruktiven Form tendenziell fixiert, hinausgeht.

Elemente der Konstruktion sind insbesondere in Grahams Arbeit Empty Heaven $\mathrm{zu}$ beobachten, die in der Umsetzung wesentlich radikaler und ausschnitthafter ist als Neudörfls Future World. Nicht von ungefähr richten sich daher die von japanischer Seite vereinzelt geäußerten Vorwürfe der Konstruktion einer spezifisch gesuchten Sichtweise auch gegen Grahams, nicht aber gegen Neudörfls Arbeit. Grahams konstruierender Ansatz stellt ein 
Mittel dar, seine Aussagen zu präzisieren und zu verstärken. Er ist einerseits Teil einzelner Bilder, was beispielsweise in den Frauen- und Bürokratenporträts sehr deutlich zum Ausdruck kommt, aber auch Teil des Gesamtkomplexes der Arbeit in Form von Bildpaarungen und Tableaus. Auch wenn seine Arbeit insgesamt wesentlich festgelegter ist als Neudörfls und die Aussage wesentlich präziser auf den Punkt gebracht wird, bleibt dennoch ein großer Bereich an Offenheit in der Arbeit bestehen. So kann hier die Konstruktion als fotografisches Mittel gesehen werden, das den Gegenstand zu präzisieren, jedoch nicht im Sinne einer objektiven Repräsentation festzulegen sucht.

Beide Arbeiten zeigen, dass künstlerische Repräsentationen das Fremde als Fremdes erfahrbar machen können. Damit sind Empty Heaven und Future World Kunstwerke, die der von Jamme geäußerten Idee positiver Repräsentationen des Fremden entsprechen: »Deutlicher als Philosophie und Ethnologie offenbart die Kunst die politischen und pädagogischen Dimensionen jedes Fremdverstehens, weil sie das existentiell-praktische Gefordertsein in der Begegnung mit dem Fremden unübersehbar in den Mittelpunkt rückt« (Jamme 2002: 207).

Die künstlerische Dokumentarfotografie ist offensichtlich besonders geeignet, sich Aspekten des Fremden zuzuwenden und diese zu vermitteln. Als Dokumentarfotografie ist sie dem Gegenstand verpflichtet; die Fotografen wissen aber um die Unmöglichkeit, Wahrheit oder Authentizität über Fotografien auszudrücken. Weil es unmöglich ist, die fremde Kultur als Ganzes in objektiver Weise darzustellen, rücken sie mittels einer Konzeption einen Teilaspekt der fremden Kultur ins Zentrum des Interesses. Die einzelnen Fotografien sind nicht abhängig von der Ästhetik der zu fotografierenden $\mathrm{Ob}$ jekte. Denn alles ist abbildungswürdig, was mit dem zugrunde liegenden Konzept in Einklang gebracht werden kann und dieses unterstützt. Es geht gerade nicht darum, besonders ästhetische oder aus exotischen Gründen interessant scheinende Gegenstände zu fotografieren. Es zeigt sich, dass eine gewisse Alltäglichkeit, die das Eigene und Vertraute in den Fotografien des Fremden mit thematisiert, dem Fremden besonders gerecht wird. Denn das Fremde als Fremdes verweigert sich einer trennscharfen Abgrenzung vom Eigenen, weil es immer nur vor dem Hintergrund und in Abhängigkeit zum Eigenen rezipiert werden kann. Ansonsten wird es lediglich zum Anderen, das als Anderes eine Differenz markiert, die festschreibt. Die Repräsentation des Fremden als Anderes - nach der in der vorliegenden Arbeit entwickelten Begrifflichkeit - bewegt sich in stereotypen Kategorien und lässt damit keine Flexibilität in der Darstellung des Fremden zu. Auf diese Weise werden Stereotypen perpetuiert.

Die Absage an das Einzelbild ist ein entscheidender Faktor, mit dem innerhalb der künstlerischen Dokumentarfotografie gearbeitet wird. In der Anordnung von Serien, Sequenzen und Tableaus entfaltet sich die volle Wirkung der Fotografien - in denen einzelne Aussagen bereits angelegt sind erst im Zusammenspiel der Bilder. Auf diese Weise können Aussagen verstärkt, zurückgenommen, modifiziert oder präzisiert werden. In der linearen Folge einer großen Anzahl von Bildern stellen Graham und Neudörfl einen Kontext her. Der Verzicht auf eine textliche Einordnung der Fotografien, die Richtungen der Rezeption vorgibt und damit die Wirkung der Bilder als Bilder einschränkt, ermöglicht eine weitergehende Offenheit. Denn im Unterschied $\mathrm{zu}$ beschreibenden Annäherungen an einen Gegenstand, die schnell Bedeutungen festschreiben, beinhalten die Fotografien im Stil einer künstlerischen 
Dokumentarfotografie eine Unvoreingenommenheit, die auf individuelle Weise unter Einbeziehung der Assoziationen der Betrachter gelesen werden kann. Die künstlerische Dokumentarfotografie spielt mit der Vielschichtigkeit von Bedeutungsebenen im Bild, ein Hinzufügen von Text wäre geradezu kontraproduktiv. Gleichzeitig ist damit das Risiko eines möglichen Missverständnisses verbunden, wie mitunter in den Gesprächen mit japanischen Fotografie-Experten aufscheint. ${ }^{1}$ Dennoch ist die in den Fotografien angelegte Offenheit nicht zu groß, dass sie zu vieldeutig und damit nichtssagend werden könnte. Die thematische Konzentration sowie die Anordnung der Fotografien im Buch eröffnen den Betrachtern Interpretationsmöglichkeiten, die abhängig vom eigenen Wissen variieren mögen. Damit binden die Fotografen die Betrachter aktiv in den Prozess der Bedeutungskonstitution mit ein.

Je mehr über den Hintergrund des Fotografierten bekannt ist, desto größer wird der Rahmen der Interpretationsmöglichkeiten, die sich aus dem Zusammenspiel von eingebrachtem Wissen und den Fotografien selbst entwickeln. Mit dem Wissen um den Hintergrund der langjährigen Beziehungen zwischen Japan und Europa und der daraus resultierenden Bewertungen Japans lassen sich manche Vor-Urteile und Einschätzungen leichter einordnen. Zudem ermöglicht dieses Wissen eine differenzierte Betrachtung der in den Fotografien thematisierten stereotypen Vorstellungen und der Kritik daran. So eröffnet beispielsweise die genaue Analyse japanischen Gruppenverhaltens einen vielschichtigen Blick auf dieses Thema, der auch positive Deutungen zulässt und nicht auf einer im Stereotyp eher negativen Bewertung verharrt.

Das Wissen um die Funktionsweisen und Methoden der Dokumentarfotografie kann das Verständnis weiterhin vertiefen. Die Untersuchung der Darstellungsmöglichkeiten innerhalb der Dokumentarfotografie zeigt, dass verschiedene Intentionen und Ansätze zu unterschiedlichen Bildwelten führen. Der Begriff des Dokumentarischen fasst zahlreiche Unterbereiche zusammen, die - wie dargelegt - sehr differente Ziele verfolgen. Wo mitunter ästhetisierend oder illustrativ gearbeitet wird, ist die Entwicklung eines tiefgehenden Verständnisses für den Gegenstand - die fremde Kultur - kaum zu erreichen, weil hier oft das Fremde als Anderes dargestellt wird.

Die künstlerische Dokumentarfotografie besitzt den weitesten Spielraum. Sie ist - wie alle Dokumentarfotografie - ihrem Gegenstand verpflichtet. Aber weil sie weder etwas illustrieren, noch auf redaktionell gewünschte Erkenntnisse eingehen oder das Schöne und Besondere zeigen muss, können sich künstlerische Dokumentarfotografen im eigenen Auftrag Themen suchen, Ideen umreißen, sich Ziele setzen. Die fotografische Arbeit entwickelt sich also entlang der subjektiven Ideen und Annahmen der Künstler, die damit im Zentrum stehen. ${ }^{2}$ Die Ideen, nicht aber die Künstler stehen im Mittelpunkt: In einer gelungenen Umsetzung wird nicht das persönliche Erleben oder die Befindlichkeit der Künstler im Fokus der Arbeit stehen, sondern de-

1 Beispielsweise wird die historische Dimension in Grahams Arbeit nicht erkannt (vgl. Kasahara 2006) oder Neudörfls Arbeit stößt auf Verständnislosigkeit (vgl. Iizawa 2006).

2 Mit dem Konflikt zwischen seiner Rolle als Auftrags- oder künstlerischer Fotograf ist beispielsweise Walker Evans' frühzeitiges Aussteigen aus der FSA zu erklären. Seine Rolle als Auftragsfotograf kollidierte mit seiner unabhängigen Haltung, wodurch der ständig schwelende Konflikt mit Koordinator Roy Stryker 1937 schließlich zum Bruch führte (vgl. Trachtenberg 1990: Kap. 5; Hurley 1977: 60ff.; 74f.). 
ren Rezeption der Welt. Wie die Untersuchung zeigt, kann jedoch auch eine subjektiv geprägte Sichtweise zu einer interessanten und gültigen Darstellung von Welt führen, die ihrem Gegenstand gerecht wird und ihn nicht im Sinne eines subjektivistischen und damit eines allzu konstruktiven Ansatzes verbiegt.

Die Krise der ethnografischen Repräsentation ist nach Christoph Jamme mitunter durch die Erkenntnis ausgelöst, dass eine Trennung von Selbst- und Fremderfahrung als Grundvoraussetzung zur objektiven Beschreibung des Fremden nicht leistbar ist. Denn der Beobachter ist immer selbst - auch emotional - von der Fremdheit betroffen. Grahams und Neudörfls Arbeiten transportieren einen Eindruck davon, dass sich die Fotografen selbst vor Ort mit der Fremdheitserfahrung konfrontiert haben, um diese in Fotografien umzusetzen, sie in Bilder zu übersetzen. Denn um die Erfahrung der Fremdheit auch für andere erfahrbar zu machen, bedarf es einer Übersetzung. »Jedes Verstehen [...] ist ein Prozeß einer solchen Über-Setzung, der Übersetzung nämlich eines Symbolsystems in ein anderes. [...] Kunst macht Ernst mit der Einsicht, daß Fremd- und Selbsterfahrung nicht zu trennen sind « (Jamme 2002: 200). Hier wird deutlich, dass Subjektivität gerade im künstlerischen Umgang mit Fremdheit und der Vermittlung des Fremden ein entscheidender Faktor ist.

Erst seit Walker Evans' Gebrauch der Dokumentarfotografie wird dieser fotografischen Form ebenfalls ein subjektives Potential zuerkannt. Der Fotograf wird zum Autor, der in seiner individuellen Sicht gerade die Differenz zwischen Welt und Bildwirklichkeit betont. Der Autor greift die Herausforderungen unserer Zeit auf und positioniert sich zu ihnen, indem er - thematisch konzentriert - eine Haltung entwickelt. Mögliche Antworten auf die Herausforderung des Fremden sind die Arbeiten von Paul Graham und Elisabeth Neudörfl. Hier scheint Japans Fremdheit auf, ohne in eine subjektive Weltsicht abzugleiten.

Weil die künstlerische Dokumentarfotografie als Kunstform einen großen Freiraum genießt, muss sie nicht bestimmte Vorgaben beherzigen, um sich ihrem Gegenstand zu nähern. Sie muss einzig und allein die von den Künstlern ersonnene Konzeption transportieren, mit der die Künstler sich selbst ein Terrain abstecken, auf dem sie arbeiten möchten. Dieser konzeptionelle Rahmen ist sehr entscheidend für die Entwicklung von Arbeiten einer künstlerischen Dokumentarfotografie. Denn er ermöglicht eine Konzentration auf das, was den Künstlern wichtig ist, was sie in ihren Fotografien transportieren möchten. Die Konzeption lenkt die Wahrnehmung während des Prozesses des Fotografierens und soll verhindern, dass sich der Fotograf ausschließlich dem Differenten und Besonderen widmet. Gleichzeitig ermöglicht eine Konzeption dem Fotografierenden aber, sich auf das zu konzentrieren, was er finden und fotografieren möchte. Sie dient also dazu, die Aufmerksamkeit zu lenken: weg vom vordergründig Unbekannten hin zu den mithin unauffälligen Details, die die vielschichtigen Unterschiede von Fremdem und Eigenem konstituieren. Die Konzeption soll eine Offenheit gegenüber dem Fremden ermöglichen.

In unserer globalisierten Welt werden kulturelle oder nationale Unterschiede tendenziell nivelliert, um Grundlagen für ein Handeln auf internationaler Ebene zu schaffen. Dennoch bedeutet das nicht, dass kulturelle Differenzen verschwinden. Vielmehr scheint es notwendig, ein neues Bewusstsein sowohl für kulturelle Abweichungen als auch für Parallelen zu entwickeln; 
dafür ist es nötig, ein Verständnis für Fremdes herauszubilden, das nicht im Stereotyp festlegt und dauerhaft trennt, sondern das Verbindungen schafft und Klischees zu überwinden vermag. Dazu kann auch eine Fotografie beitragen, die das Fremde nicht in Form eines Anderen vom Eigenen abgrenzt, sondern Fremdes als Fremdes sichtbar macht - als Hintergrund des Eigenen und Alltäglichen. Die Untersuchung von Grahams und Neudörfls Japanarbeiten zeigt, dass innerhalb einer differenzierten Auseinandersetzung mit der fremden Kultur sowie einem selbstreflexiven Gebrauch des Mediums ein Bild entstehen kann, das Wahrnehmungen verändert und Klischees überwindet. Dies kann aber nur in einer Zusammenarbeit zwischen Künstlern und Betrachtern geschehen, denn letztere müssen sich auf diese anspruchsvolle Form von Bildlichkeit einlassen. Obwohl wir in einer Welt leben, die auf unendlich vielen visuellen Reizen gründet, in der mediale Bildproduktion ein wichtiger Faktor unserer alltäglichen Lebenswelt ist, scheint das Interesse an Bildern, die mit Offenheit arbeiten und den Betrachter herausfordern, nach wie vor begrenzt. Es ist ja auch viel bequemer, sich mit Bildern zu konfrontieren, die einem mitteilen, wie etwas zu sehen ist, die Antworten geben. Viel schwieriger ist es, Differenzierungen vorzunehmen und solche auch zu akzeptieren beziehungsweise ein Verständnis dafür zu entwickeln, dass fremde Kulturen nicht nur aus Differentem bestehen, sondern auch dort eine Alltäglichkeit herrscht, die Schnittstellen zum Eigenen aufweist.

Für die zukünftige Betrachtung des Fremden weisen Grahams und Neudörfls Arbeiten den Weg in eine Richtung, die Fremdes differenziert zu sehen und darzustellen vermag. Trotz ihrer mitunter problematischen Beziehung zur Realität ist die Fotografie, insbesondere die künstlerische Dokumentarfotografie, durchaus in der Lage, sich der Welt als Spannungsfeld von Fremdheit in vermeintlich Bekanntem, Alltäglichem und Vertrautheit, die im Fremden zu entdecken ist, auf verständnisvolle, differenzierte und offene Art zu nähern. 



\section{LITERATURVERZEICHNIS}

Adam, Hans Christian (1979): »Photographie auf Forschungsreise. Reisende Photographen im 19. Jahrhundert«. In: In unnachahmlicher Treue, hg. v. Heinz Langholz, Köln, 115-128.

Agee, James/Evans, Walker (1941): Let Us Now Praise Famous Men. Three Tenant Families, Boston.

Albert, Pierre/Feyel, Gilles (1998): »Fotografie und Medien. Die Veränderungen der illustrierten Presse«. In: Neue Geschichte der Fotografie, hg. v. Michel Frizot, Köln (franz. Orig. 1994), 358-369.

Allport, Gordon W. (1958): The Nature of Prejudice, New York.

Allport, Gordon W. (2000): »The Nature of Prejudice«. In: Stereotypes and Prejudice: Essential Readings, hg. v. Charles Stangor, Philadelphia 2000 (Orig.: Cambridge, Mass. 1954), 20-48.

Antoni, Klaus (1993): »Das japanische Paradigma. Stereotypen und Klischees in der Deutung des japanischen Wirtschaftserfolges«. In: Münchner japanischer Anzeiger, Vol 2, 3-22.

Antoni, Klaus (1999): »Japans schwerer Weg nach Asien - Geistesgeschichtliche Anmerkungen zu einer aktuellen Debatte«. In: Überwindung der Moderne? Japan am Ende des zwanzigsten Jahrhunderts, hg. v. Irmela Hijiya-Kirschnereit, Frankfurt a.M., 123-145.

Aoki, Tamotsu (1996): Der Japandiskurs im historischen Wandel. Zur Kultur und Identität einer Nation, München.

Arago, Dominique François (1980): »Bericht über den Daguerreotyp (1839)«. In: Theorie der Fotografie I. 1839-1912, hg. v. Wolfgang Kemp, München, 51-55.

Asmus, Gesine (1983): »Aus der Ferne aus der Nähe. Bilder vom Mittelmeerraum vor und nach der Erfindung der Fotografie«. In: Ansichten der Ferne. Reisephotographie 1850 - heute, hg. v. Klaus Pohl, Kat. (Deutscher Werkbund, Hessisches Landesmuseum Darmstadt), Giessen, 7-57.

Atsushi, Tanaka (1993): »Yôga - Malerei im westlichen Stil. 1868-1912«. In: Japan und Europa: 1543-1929, hg. v. Doris Croissant/Lothar Ledderose/ u.a., Kat. (Martin-Gropius-Bau Berlin), Berlin, 178-188.

Banta, Melissa/Hinsley, Curtis M. (1986a): »Foreword: From Site to Sight «. In: From Site to Sight. Anthropology, Photography, and the Power of Imagery, hg. v. Melissa Banta/Curtis M. Hinsley, Kat. (Peabody Museum of Archaeology and Ethnology), Cambridge, Mass., 7-10.

Banta, Melissa/Hinsley, Curtis M. (1986b): »Nineteenth-Century Visions of the Exotic: Travel and Expeditionary Photography«. In: From Site to Sight. Anthropology, Photography, and the Power of Imagery, hg. v. Melissa Banta/Curtis M. Hinsley, Kat. (Peabody Museum of Archaeology and Ethnology), Cambridge, Mass., 39-48. 
Banta, Melissa/Hinsley, Curtis M. (1986c): »Social and Cultural Anthropology: Responses and the Responsibility in the Photographic Encounter«. In: From Site to Sight. Anthropology, Photography, and the Power of Imagery, hg. v. Melissa Banta/Curtis M. Hinsley, Kat. (Peabody Museum of Archaeology and Ethnology), Cambridge, Mass., 101-126.

Banta, Melissa (1988): „Life of a Photograph: Nineteenth-Century Photographs of Japan from the Peabody Museum and Wellesley College Museum«. In: A Timely Encounter. Nineteenth-Century Photographs of Japan, hg. v. Melissa Banta/Susan Taylor, Kat. (Peabody Museum of Archaeology and Ethnology and the Wellesley College Museum), Cambridge, Mass. 1988, 11-21.

Barthes, Roland (1983): Elemente der Semiologie. Frankfurt a.M. (franz. Orig. 1964).

Barthes, Roland (1985): Die Helle Kammer. Bemerkungen zur Photographie. Frankfurt a.M. (franz. Orig. 1980).

Barthes, Roland (1990): »Die Fotografie als Botschaft «. In: Der entgegenkommende und der stumpfe Sinn. Kritische Essays III, Roland Barthes, Frankfurt a.M. (franz. Orig. 1961), 11-27.

Baumuk, Bodo (1993): »Japan auf den Weltausstellungen 1862-1933«. In: Japan und Europa: 1543-1929. Essays, hg. v. Berliner Festspiele GmbH, Essayband zur Ausstellung (Martin-Gropius-Bau Berlin), Berlin, 44-49.

Bauret, Gabriel (2000): »European Eyes on Japan«. In: European Eyes on Japan. Japan Today, Vol. 1, hg. v. EU-Japan Fest Japan Committee, Tokyo, 6-7.

Bausinger, Herrmann (1988): »Stereotypie und Wirklichkeit«. In: Jahrbuch für Deutsch als Fremdsprache, 14/1988, München, 157-170.

Becker, Howard (1978): »Do photographs tell the truth?« In: Afterimage 02/1978, Vol. 5, No. 8, hg. v. Visual Studies Workshop, Rochester, 1978, 9-13.

Befu, Harumi (1992): »Introduction. Framework of Analysis«. In: Othernesses of Japan. Historical and Cultural Influences of Japanese Studies in Ten Countries, hg. v. Harumi Befu/Josef Kreiner, München, 15-35.

Befu, Harumi (1994): »Japan as Other. Merits and Demerits of Overseas Japanese Studies«. In: Japan in Global Context. Papers presented on the Occasion of the fifth Anniversary of the German Institute for Japanese Studies, Tokyo, hg. v. Josef Kreiner, München, 33-45.

Benedict, Ruth (1967): The Chrysanthemum and the Sword. Patterns of Japanese Culture, 2. Auflage, London (1946).

Benjamin, Walter (1963): »Kleine Geschichte der Photographie«. In: Das Kunstwerk im Zeitalter seiner technischen Reproduzierbarkeit. Drei Studien zur Kunstsoziologie, Walter Benjamin, Frankfurt a.M. (1931), 65-94.

Bennett, Terry (1991): »Chronologie - die Verbreitung der Photographie in Japan im 19. Jahrhundert«. In: Felice Beato in Japan. Photographien zum Ende der Feudalzeit 1863-1873, Claudia G. Philipp/Dietmar Siegert/ Rainer Wick, Heidelberg, 24-25.

Berg, Eberhard/Fuchs, Martin (Hg.) (1995): Kultur, soziale Praxis, Text. Die Krise der ethnografischen Repräsentation, 2. Auflage, Frankfurt a.M. (1993).

Berger, John (1984): »Erscheinungen«. In: Eine andere Art zu erzählen, hg. v. John Berger/Jean Mohr, München/Wien, 81-129. 
Bergler, R./Six, B. (1972): »Stereotype und Vorurteile«. In: Handbuch der Psychologie 7/2: Sozialpsychologie, hg. v. C.F. Graumann, Göttingen, 1371-1432.

Benge, Harvey (2006): You are here, Köln.

Bhabha, Homi K. (2000): Die Verortung der Kultur, Tübingen (engl. Orig. 1994).

Billig, Michael (1995): Banal Nationalism, London.

Binder, Kurt (1984): Japan, Luzern.

Bischof, Marco (Hg.) (1990): Werner Bischof. 1916-1954. Leben und Werk, Bern.

Bischof, Werner (1955): Japan, Zürich. [Englischsprachige Ausgabe unter dem selben Titel: New York].

Blessing, Jennifer (2004): Speaking with hands: Photographs from the Buhl Collection, Kat. (Solomon R. Guggenheim Museum New York), New York.

Boehm, Gottfried (2001): »Die Wiederkehr der Bilder«. In: Was ist ein Bild?, hg. v. Gottfried Boehm, 3. Auflage, München (1994), 11-38.

Böhme, Gernot (1999): Theorie des Bildes, München.

Boltanski, Luc (1981): »Die Rhetorik des Bildes«. In: Eine illegitime Kunst. Die sozialen Gebrauchsweisen der Fotografie, hg. v. Pierre Bourdieu, Frankfurt a.M. (franz. Orig. 1965), 137-163.

Borhan, Pierre (2002): »Destiny and Determination«. In: Dorothea Lange. The Heart and Mind of a Photographer, hg. v. Pierre Borhan, Boston/ New York/London, 6-26.

Bosse, Friederike (1997): »Wirtschaftliche Strukturen«. In: Informationen zur politischen Bildung Nr. 255/1997, 32-45.

Boulding, Kenneth (1987): The Image. Knowledge in Life and Society, 17. Auflage, Ann Arbor (1961).

Bourdieu, Pierre (1981): »Die gesellschaftliche Definition der Photographie«. In: Eine illegitime Kunst. Die sozialen Gebrauchsweisen der Photographie, hg. v. Pierre Bourdieu, Frankfurt a.M. (franz. Orig. 1965), 85-109.

Brandwein, Mary Lu (2000): Playing Honkyoku; Praying Honkyoku, http://www.shakuhachi.org/HONKYOKU.html, 17.07.2008.

Braun, Peter (2002): »Fotografie«. In: Metzler-Lexikon Medientheorie - Medienwissenschaft: Ansätze - Personen - Grundbegriffe, hg. v. Helmut Schanze, Stuttgart/Weimar, 119-122.

Breger, Rosemary Anne (1990): Myth and Stereotye. Images of Japan in the German Press and in Japanese Self-Presentation, Frankfurt a.M./u.a. 1990.

Breitwieser, Sabine (Hg.): Allan Sekula. Performance under Working Conditions, Kat. (Generali Foundation, Wien), Ostfildern-Ruit.

Broadbent, Kaye (2002): »Gender and Work«. In: Encyclopedia of Contemporary Japanese Culture, hg. v. Sandra Buckley, London/New York, 168169.

Buchloh, Benjamin (1995): »Allan Sekula: Photography between Discourse and Document«. In: Fish Story. Allan Sekula, Kat. (Witte de With, Center for Contemporary Art, Rotterdam), Rotterdam, 189-200.

Buckley, Sandra (2002a): »Housewife«. In: Encyclopedia of Contemporary Japanese Culture, hg. v. Sandra Buckley, London/New York, 201-203.

Buckley, Sandra (2002b): »Manga«. In: Encyclopedia of Contemporary Japanese Culture, hg. v. Sandra Buckley, London/New York, 295-298. 
Buckley, Sandra (2002c): »Pink Salons «. In: Encyclopedia of Contemporary Japanese Culture, hg. v. Sandra Buckley, London/New York, 392.

Budde, Hendrik (1993a): »Japanische Farbholzschnitte und europäische Kunst: Maler und Sammler im 19. Jahrhundert«. In: Japan und Europa: 1543-1929, hg. v. Doris Croissant/Lothar Ledderose/u.a., Kat. (MartinGropius-Bau Berlin), Berlin, 164-177.

Budde, Hendrik (1993b): »Japanmode in Europa«. In: Japan und Europa: 1543-1929, hg. v. Doris Croissant/Lothar Ledderose/u.a., Kat. (MartinGropius-Bau Berlin), Berlin, 425-426.

Bunnell, Peter C. (1998): »Für eine moderne Fotografie. Die Erneuerung des Piktoralismus«. In: Neue Geschichte der Fotografie, hg. v. Michel Frizot, Köln (franz. Orig. 1994), 310-326.

Clifford, James (1995): »Über ethnographische Autorität«. In: Kultur, soziale Praxis, Text. Die Krise der ethnografischen Repräsentation, 2. Auflage, Frankfurt a.M. (1993), 109-157.

Coaldrake, William H. (1996): Architecture and Authority in Japan, London/ New York.

Cooper, Michael (1993): »Frühe europäische Berichte aus Japan«. In: Japan und Europa: 1543-1929, hg. v. Doris Croissant/Lothar Ledderose/u.a., Kat. (Martin-Gropius-Bau Berlin), Berlin, 46-55.

Coulmas, Florian (2005a): Die Kultur Japans. Tradition und Moderne, München (2003).

Coulmas, Florian (2005b): Hiroshima. Geschichte und Nachgeschichte, München.

Creighton, Millie R. (1996): »Marriage, Motherhood, and Career Management in a Japanese >Counter Culture «. In: Re-Imaging Japanese Women, hg. v. Anne E. Imamura, Berkely/u.a., 192-220.

Croissant, Doris (1993): »Yôga - Malerei und Graphik. 1868-1912«. In: Japan und Europa: 1543-1929, hg. v. Doris Croissant/Lothar Ledderose/ u.a., Kat. (Martin-Gropius-Bau Berlin), Berlin, 533-534.

Därmann, Iris (2002): »Fremderfahrung und Repräsentation«. In: Fremderfahrung und Repräsentation, hg. v. Iris Därmann/Christoph Jamme, Weilerswist, 7-46.

Därmann, Iris (2005a): »Der Fremde im Widerstand gegen das Verstehen oder: Hermeneutik und Ethnologie auf dem Prüfstand erneuter Kritik«. In: Philosophische Rundschau. Eine Zeitschrift für philosophische Kritik, 52. Jg., Bd. 1, März 2005, 21-39.

Därmann, Iris (2005b): »Ethnologie«. In: Bildwissenschaft. Disziplinen, Themen, Methoden, hg. v. Klaus Sachs-Hombach, Frankfurt a.M., 174184.

Danto, Arthur C. (2001): »Abbildung und Beschreibung«. In: Was ist ein Bild?, hg. v. Gottfried Boehm, 3. Auflage, München (1994), 125-147.

Dasgupta, Romit (2002): »Sarariiman«. In: Encyclopedia of Contemporary Japanese Culture, hg. v. Sandra Buckley, London/New York, 434-435.

Delank, Claudia (1996): Das imaginäre Japan in der Kunst. >Japanbilder vom Jugendstil bis zum Bauhaus, München.

Delank, Claudia (2000): »Japanbilder - Bilder aus Japan. YokohamaPhotographie in der ostasiatischen und europäischen Bildtradition des 19. Jahrhunderts«. In: Ostasienrezeption zwischen Klischee und Innovation, hg. v. Walter Gebhard, München, 255-275. 
Delank, Claudia (2003): »Fotografien in Japan«. In: Japan Forum, Vol. 100, Juli 2003, 1-2.

Dewitz, Bodo von/Lebeck, Robert (Hg.) (2001): Kiosk. Eine Geschichte der Fotoreportage 1839-1973, Kat. (Museum Ludwig, Köln), Göttingen.

Dewitz, Bodo von (2007): »Vom Wesen der Photographie. August Sanders Porträtwerk Menschen des 20. Jahrhunderts. Dokumente zu seiner Geschichte«. In: Künstler \& Fotografien. 1959 - 2007. Museum Ludwig Köln, hg. v. Barbara Engelbach, Köln, 48-63.

Dixon, Daniel (Hg.) (1952): Modern Photography, Bd. 16 (12/1952), 68-77; 138-142.

Domenig, Aya (1997): »Streifzüge durch das alte Japan - ein Fotoalbum«. In: Ans Licht geholt. Frühe Fotografien aus dem Archiv des Völkerkundemuseums, Kat. (Völkerkundemuseum der Universität Zürich), Zürich, 43-49.

Donahue, Ray T. (1998): Japanese Culture and Communication. Critical Cultural Analysis, Lanham/New York/Oxford.

Dower, John (1999): Embracing Defeat. Japan in the Wake of World War II, New York/London.

Drosdowski, Günther (Hg.) (1989): Duden, Etymologie. Herkunftswörterbuch der deutschen Sprache, 2., völlig neu bearbeitete und erweiterte Auflage, Mannheim/Wien/Zürich.

Drosdowski, Günther (Hg.) (1990): Duden Fremdwörterbuch, Bd. 5, 5. neu bearb. u. erw. Auflage, Mannheim/Wien/Zürich.

Dyer, Richard (1980): Gays and Film, London (1977).

Dyer, Richard (1993): Matter of Images. Essays on Representations, London/New York.

Edwards, Elizabeth (1992): »Introduction: Anthropology and Photography«. In: Anthropology and Photography 1860-1920, hg. v. Elizabeth Edwards, New Haven/London, 3-17.

Edwards, Elisabeth (1997): »Beyond the boundary: a consideration of the expressive in photography and anthropology«. In: Rethinking Visual Anthropology, hg. v. Marcus Banks/Howard Morphy, New Haven/ London, 53-80.

Eggers, Katja (2002): »No risk - but fun!« In: Schädelspalter. Hannovers Stadtillustrierte, Nr. 07/2002, Hannover, 80.

Ehrlich, S.G. (1967): Photographic Evidence. The Preparation and Use of Photography in Civil and Criminal Cases, London.

Ellemers, Naomi/Knippenberg, Ad van (1997): »Stereotyping in Social Context«, in: The Social Psychology of Stereotyping and Group Life, hg. v. Russell Spears et al., Oxford, 208-235.

Elsken, Ed van der (1988): De Ontdekking van Japan, Amsterdam.

Elsken, Ed van der (2000): Fotografie + Film 1949-1990, Kat. (Kunstmuseum Wolfsburg), Ostfildern-Ruit.

Embree, John F. (1939): Suye Mura. A Japanese Village, Chicago.

Erdmann-Ziegler, Ulf (1996): »Aber Shishi: Paul Graham«. In: Magische Allianzen. Fotografie und Kunst, Ulf Erdmann-Ziegler, Regensburg 1996, 89-91 (Erstabdruck: die tageszeitung, 7./8.10.1995, 14).

Eskildsen, Ute (1985): Fotografie in deutschen Zeitschriften 1946-1984, Kat. (Institut für Auslandsbeziehungen Stuttgart), Stuttgart.

Evans, Walker (1988): American Photographs, New York (1938). 
Evans, Walker (2000): »The Reappearance of Photography«. In: Unclassified. A Walker Evans Anthology. Selections from the Walker Evans Archive, hg. v. Jeff L. Rosenheim/Douglas Eklund, Zürich/Berlin/New York (engl. Orig 1931), 80-84.

Fabian, Johannes (1995): »Präsenz und Repräsentation. Die anderen und das anthropologische Schreiben«. In: Kultur, soziale Praxis, Text. Die Krise der ethnografischen Repräsentation, 2. Auflage, Frankfurt a.M. (1993), 335-364.

Featherstone, David (1984): »Preface«. In: Observations. Essays on Documentary Photography, hg. v. David Featherstone, Untitled Bd. 35, Carmel, vii-viii.

Felix, Zdenek (Hg.) (1994): Andreas Gursky. Fotografien 1984 - 1993, Kat. (Deichtorhallen Hamburg), München.

Fleischmann, Anja (1999): Das Japanbild in England vom 16. bis 20. Jahrhundert, München.

Freund, Gisèle (1976): Photographie und Gesellschaft, München.

Friedenthal, Richard (1965): »Vorwort«. In: Tokio, William Klein, Hamburg, o.S.

Friese, Eberhard (1990): »Philipp Franz von Siebold (1796-1866) und sein Japanwerk heute«. In: Kulturvermittler zwischen Japan und Deutschland. Biographische Skizzen aus vier Jahrhunderten, hg. v. Japanisches Kulturinstitut Köln, Frankfurt a.M/New York, 31-49.

Frisinghelli, Christine (2003): »To the Distant Observer«. In: European Eyes on Japan. Japan Today. Vol. 5, hg. v. The EU-Japan Fest Japan Committee, Tokyo, 103.

Fritsch, Gustav (1875): »Praktische Gesichtspunkte für die Verwendung zweier dem Reisenden wichtigen technischen Hülfsmittel: das Mikroskop und der photographische Apparat«, in: Georg von Neumayer (Hg.), Anleitung zu wissenschaftlichen Beobachtungen auf Reisen, Berlin, 591-625.

Frizot, Michel (Hg.) (1998a): Neue Geschichte der Fotografie, Köln (franz. Orig. 1994).

Frizot, Michel (1998b): »Hippolyte Bayard: Der Ertrunkene«. In: Neue Geschichte der Fotografie, hg. v. Michel Frizot, Köln (franz. Orig. 1994), 30.

Frizot, Michel (1998c): »Eine andere Fotografie. Neue Perspektiven des Blicks«. In: Neue Geschichte der Fotografie, hg. v. Michel Frizot, Köln (franz. Orig. 1994), 387-397.

Fuchs, Martin/Berg, Eberhard (1995): »Phänomenologie der Differenz. Reflexionsstufen ethnographischer Repräsentation«. In: Kultur, soziale Praxis, Text. Die Krise der ethnografischen Repräsentation, hg. v. Eberhard Berg/Martin Fuchs, 2. Auflage, Frankfurt a.M. (1993), 11-108.

Fuse, Hideto (2006): »Notes on the Color Pink in Japanese Art«. In: Pink. The Exposed Color in Contemporary Art and Culture, hg. v. Barbara Nemitz, Ostfildern-Ruit, 54-63.

Gautrand, Jean-Claude (1998a): »Die Ausrüstung des Reisefotografen«. In: Neue Geschichte der Fotografie, hg. v. Michel Frizot, Köln (franz. Orig. 1994), 158.

Gautrand, Jean-Claude (1998b): »Die piktoralistischen Techniken«. In: Neue Geschichte der Fotografie, hg. v. Michel Frizot, Köln (franz. Orig. 1994), 300 .

Geertz, Clifford (1984): »Distinguished Lecture: Anti-Anti-Relativism«. In: American Anthropologist, Vol. 86, Nr. 2, Juni 1984, 263-278. 
Geiger, Wolfgang (1995): »Victor Segalens Exotismuskonzeption und ihre Bedeutung für die heutige Forschung«. In: Mein Bild in deinem Auge: Exotismus und Moderne. Deutschland - China im 20. Jahrhundert, hg. v. Wolfgang Kubin, Darmstadt, 43-82.

Gelfert, Hans-Dieter (2000): Was ist Kitsch?, Göttigen.

Geo Spezial (2006): Japan, Nr. 6, Dezember 2006/Januar 2007, Hamburg.

Gidal, Tim N. (1993): Chronisten des Lebens. Die moderne Fotoreportage, Berlin.

Gierstberg, Frits (1998): »Dismal Science. An Interview with Allan Sekula«. In: Allan Sekula: Dead Letter Office, Kat. (Nederlands Foto Instituut, Rotterdam), Einleger: (Palais des Beaux Arts de Bruxelles), Brüssel, 1-9.

Gilman, Sander (1985): Difference and Pathology, Ithaca.

Göltz, Klaus E./Immisch, Theo/u.a. (Hg.) (1991): Hans Finsler. Neue Wege der Photographie, Kat. (Staatliche Galerie Moritzburg Halle), Leipzig.

Gössmann, Elisabeth (1990): »Am Anfang war die Frau die Sonne. Frauen im alten Japan«. In: Nippons neue Frauen, hg. v. Ruth Linhart/Fleur Wöss, Reinbek, 14-31.

Goldsmith, Arthur (1985): »Einführung. Bearbeitet von Bernhard W. Wette«. In: Die internationale Bibliothek der Photographie. Photojournalismus, Zürich, 7-14.

Gollwitzer, Heinz (1962): Die gelbe Gefahr. Geschichte eines Schlagworts. Studien zum imperialistischen Denken, Göttingen.

Goodman, Nelson (1990): Weisen der Welterzeugung, Frankfurt a.M. (engl. Orig. 1978).

Goodman, Nelson (1995): Sprachen der Kunst. Entwurf einer Symboltheorie, Frankfurt a.M. (engl. Orig. 1976).

Gordon, June A. (2002a): »School Excursions«. In: Encyclopedia of Contemporary Japanese Culture, hg. v. Sandra Buckley, London/New York, 440.

Gordon, June A. (2002b): »School Uniforms«. In: Encyclopedia of Contemporary Japanese Culture, hg. v. Sandra Buckley, London/New York, 442.

Gorz, André (2000): Arbeit zwischen Misere und Utopie, Frankfurt a.M. (franz. Orig. 1997).

Gräff, Werner (1929): Es kommt der neue Fotograf!, Berlin.

Graham, Paul (1983): A1. The Great North Road, London.

Graham, Paul (1986): Beyond Caring, London.

Graham, Paul (1987): Troubled Land, London.

Graham, Paul (1990): In Umbra Res, Kat. (National Museum of Photography, Film and Television, Bradford), Manchester.

Graham, Paul (1993): New Europe, Kat. (Fotomuseum Winterthur), Manchester.

Graham, Paul (1995a): Empty Heaven. Photographs from Japan 1989-1995, Kat. (Kunstmuseum Wolfsburg), Zürich/Berlin/New York.

Graham, Paul (1995b): »Die Uhr des Kaisers. Ein Gespräch zwischen Paul Graham und Uta Grosenick«. Einleger in: Empty Heaven. Photographs from Japan 1989-1995, Paul Graham, Kat. (Kunstmuseum Wolfsburg), Zürich/Berlin/New York.

Graham, Paul (1999): End of an Age, Zürich/Berlin/New York.

Graham, Paul (2003): American Night, Kat. (PS1/MoMA, New York), Göttingen.

Graham, Paul (2007): A Shimmer of Possibility, Göttingen. 
Grames, Eberhard (1979): Japan, Luzern.

Grierson, John/Forsyth, Hardy (1947): Grierson und der Dokumentarfilm, Gütersloh.

Grierson, John (1998): »Grundsätze des Dokumentarfilms«. In: Bilder des Wirklichen. Texte zur Theorie des Dokumentarfilms, hg. v. Eva Hohenberger, Berlin (engl. Orig. 1933), 100-113.

Griesecke, Birgit (2001): Japan dicht beschreiben. Produktive Fiktionalität in der ethnographischen Forschung, München.

Guillain, Robert (1955): »Japan«. In: Japan, Werner Bischof, Zürich, VIIXXXI.

Gunning, Tom (1995): »Vor dem Dokumentarfilm«. In: Kintop 4. Jahrbuch zur Erforschung des frühen Films, hg. v. Frank Kessler/Sabine Lenk/ Martin Loiperdinger, Frankfurt a.M., 111-121.

Haberland, Detlef (1990): »Engelbert Kaempfer. Arzt, Reisender und `Entdecker« Japans«. In: Kulturvermittler zwischen Japan und Deutschland. Biographische Skizzen aus vier Jahrhunderten, hg. v. Japanisches Kulturinstitut Köln, Frankfurt a.M./New York, 9-30.

Haberland, Detlef (1993): »Zwischen Wunderkammer und Forschungsbericht - Engelbert Kaempfers Beitrag zum europäischen Japanild«. In: Japan und Europa: 1543-1929, hg. v. Doris Croissant/Lothar Ledderose/u.a., Kat. (Martin-Gropius-Bau Berlin), Berlin, 83-93.

Hall, Stuart (1999): »Die zwei Paradigmen der Cultural Studies«. In: Widerspenstige Kulturen. Cultural Studies als Herausforderung, hg. v. Karl H. Hörning/Rainer Winter, Frankfurt a.M., 13-42.

Hall, Stuart (2002): »The Work of Representation«. In: Representation: Cultural Representations and Signifying Practices, hg. v. Stuart Hall, 5. Auflage, London/Thousand Oaks/New Delhi (1997), 13-64.

Hammond, Anne (1998): »Naturalismus und Symbolismus. Die piktoralistische Fotografie«. In: Neue Geschichte der Fotografie, hg. v. Michel Frizot, Köln (franz. Orig. 1994), 292-309.

Handy, Ellen (1988): »Tradition, Novelty, and Invention: Portrait and Landscape Photography in Japan, 1860s-1880s«. In: A Timely Encounter. Nineteenth-Century Photographs of Japan, hg. v. Melissa Banta/Susan Taylor, Kat. (Peabody Museum of Archaeology and Ethnology and the Wellesley College Museum), Cambridge, Mass., 53-71.

Hansen, Klaus P. (2000): Kultur und Kulturwissenschaft. Eine Einführung, Zweite, vollständig überarbeitete und erweiterte Auflage, Tübingen/Basel.

Hardach-Pinke, Irene (o.J.): »Die Entstehung des modernen Japan und seine Wahrnehmung durch den Westen«. In: Japan: Eine andere Moderne, hg. v. Irene Hardach-Pinke, Tübingen, 11-36.

Hardt, Michael/Negri, Antonio (2002): Empire. Die neue Weltordnung, Frankfurt a.M. (engl. Orig. 2000).

Harpprecht, Klaus (1992): »Oh, Tokio«. In: Merian, Tokio und Japan, Heft $12 / 45,36-50$.

Haslam, S. Alexander (1997): »Stereotyping and Social Influence: Foundations of Stereotype Consensus«. In: The Social Psychology of Stereotyping and Group Life, hg. v. Russell Spears/et al., Oxford, 119-143.

Hausmann, Raoul/Gräff, Werner (1979): »Wie sieht der Fotograf? Gespräch zwischen Raoul Hausmann und Werner Gräff (1933)«. In: Theorie der Fotografie II. 1912-1945, hg. v. Wolfgang Kemp, München, 171-179. 
Heilbrun, Françoise (1998): »Die Reise um die Welt. Forscher und Touristen«. In: Neue Geschichte der Fotografie, hg. v. Michel Frizot, Köln (franz. Orig. 1994), 148-166.

Hendry, Joy (1993): Wrapping Culture. Politeness, Presentation and Power in Japan and Other Societies, Oxford.

Hendry, Joy (1999): An Anthropologist in Japan. Glimpses of life in the field, London/New York.

Hendry, Joy (2004): Understanding Japanese Society, 3. überarbeitete Auflage, London (1987).

Henle, Fritz (1937): Das ist Japan. Volk und Landschaft, mit einem Text von Takayasu Senzoku, Harzburg.

Herbert, Wolfgang (2002): Japan nach Sonnenuntergang. Unter Gangstern, Illegalen und Tagelöhnern, Berlin.

Herrmann, Th. (1992): »Schema, Schematismus«. In: Historisches Wörterbuch der Philosophie. Völlig neubearbeitete Ausgabe des >Wörterbuchs der philosophischen Begriffe` von Rudolf Eisler, hg. v. Joachim Ritter/Karlfried Gründer, Bd. 8, Darmstadt, Sp.1261-1263.

Herzogenrath, Wulf (Hg.) (1992a): Distanz und Nähe, Kat. (Ausstellung des Instituts für Auslandsbeziehungen), Ostfildern.

Herzogenrath, Wulf (1992b): »Distanz und Nähe«. In: Distanz und Nähe, Kat. (Ausstellung des Instituts für Auslandsbeziehungen), Ostfildern, 6-21.

Hijiya-Kirschnereit, Irmela (1988): Das Ende der Exotik. Zur japanischen Kultur und Gesellschaft der Gegenwart, Frankfurt a.M.

Hillier, Bill/Hanson, Julienne (1984): The social logic of space, Cambridge/u.a.

Hils, Claudio (1999): Tokyo Urban Space, Kat. (Suermondt-LudwigMuseum Aachen), Aachen.

Höfer, Candida (2001): Douze - Twelve, Kat. (Musee des Beaux Arts et de la Dentelle, Calais), Calais.

Hogrebe, Wolfram (1993): »Die Epistemische Bedeutung des Fremden«. In: Kulturthema Fremdheit. Leitbegriffe und Problemfelder kulturwissenschaftlicher Fremdheitsforschung, hg. v. Alois Wierlacher, München, 355-369.

Hohenberger, Eva (1998): »Dokumentarfilmtheorie«. In: Bilder des Wirklichen. Texte zur Theorie des Dokumentarfilms, hg. v. Eva Hohenberger, Berlin, 8-34.

Holborn, Mark (1986): Black Sun: The Eyes of Four. Roots and Innovation in Japanese Photography (Eikoh Hosoe, Shomei Tomatsu, Masahisa Fukase, Daido Moriyama), Kat. (Museum of Modern Art, Oxford, England), New York.

Holschbach, Susanne (2004): »Im Zweifel für die Wirklichkeit - zu Begriff und Geschichte dokumentarischer Fotografie«. In: Wirklich wahr! Realitätsversprechen von Fotografien, hg. v. Siegrid Schneider/Stefanie Grebe, Kat. (Ruhrlandmuseum Essen), Ostfildern-Ruit, 23-30.

Honnef, Klaus (1978): »Ein Mann mit der Kamera. Bemerkungen zum fotografischen Werk von Eugène Atget«. In: Eugène Atget. Das alte Paris, hg. v. Rheinisches Landesmuseum Bonn, Kat. (Rheinisches Landesmuseum Bonn), Bonn, 17-34.

Honnef, Klaus (1979): »Es kommt der Autorenfotograf. Materialien und Gedanken zu einer neuen Ansicht über die Fotografie«. In: In Deutschland. Aspekte gegenwärtiger Dokumentarfotografie, hg. v. Klaus Honnef/ 
Wilhelm Schürmann, Kat. (Rheinisches Landesmuseum Bonn), Bonn, 832.

Honnef, Klaus (1983): »Thesen zur Autorenfotografie (1979)«. In: Theorie der Fotografie III. 1945-1980, hg. v. Wolfgang Kemp, München, 204-210.

Honnef, Klaus (2004): »Die Intensität der Malerei wider die glitzerhafte Fotografie. Ein Gespräch mit Heinz-Norbert Jocks«. In: Kunstforum International, Bd. 171 (Juli-August 2004), Ruppichteroth, 143-157.

Honold, Alexander (2006): »Das Fremde. Anmerkungen zu seinem Auftritt in Kultur und Wissenschaft«. In: Der Orient, die Fremde. Positionen zeitgenössischer Kunst und Literatur, hg. v. Regina Gödecke/Alexandra Karentzos, Bielefeld, 21-38.

Hornby, A.S. (Hg.) (1986): Oxford Advanced Learner's Dictionary of Current English, 24. überarbeiteter Abdruck der 3. Auflage, Oxford (1974).

Howe, Peter (2001): »Photojournalism at a crossroads«. In: Nieman Reports, Vol. 55, Nr. 3, Cambridge, Proquest Database.

Huber, Hans Dieter (2004): Bild Beobachter Milieu. Entwurf einer allgemeinen Bildwissenschaft, Ostfildern-Ruit.

Hügli, Anton/Lübcke Poul (Hg.) (1997): Philosophie-Lexikon, vollständig überarbeitete und erweiterte Neuausgabe, Reinbek bei Hamburg.

Hurley, Forrest Jack (1974): Portrait of a Decade. Roy Stryker and the Development of Documentary Photography in the Thirties, New York.

Husserl, Edmund (1987): Cartesianische Meditationen. Eine Einleitung in die Phänomenologie, hg., eingeleitet und mit Registern versehen von Elisabeth Ströker, Hamburg.

Husserl Edmund (2006): Phantasie und Bildbewusstsein, hg. und eingeleitet von Eduard Marbach, Hamburg.

Imdahl, Max (1996): »Giotto. Zur Frage der ikonischen Sinnstruktur«. In: Reflektion, Theorie, Methoden, Max Imdahl, Gesammelte Schriften, Bd. 3, Frankfurt a.M., 424-455.

Imdahl, Max (2001): »Ikonik. Bilder und ihre Anschauung«. In: Was ist ein Bild?, hg. v. Gottfried Boehm, 3. Auflage, München (1994), 300-324.

Impey, Oliver (1993): »Japanisches Exportkunsthandwerk und seine Auswirkungen auf die europäische Kunst des 17. und 18. Jahrhunderts«. In: Japan und Europa: 1543-1929, hg. v. Doris Croissant/Lothar Ledderose/u.a., Kat. (Martin-Gropius-Bau Berlin), Berlin, 147-163.

Ishii, Ayako/Iizawa, Kôtarô (2003): »Chronology. Übersetzt und bearbeitet von John Junkerman und Matsuda Takako«. In: The History of Japanese Photography, hg. v. Anne Wilkes Tucker, Kat. (The Museum of Fine Arts, Houston), Houston, 312-333.

Iwasaki, Haruko (1988): »Western Images, Japanese Identities: Cultural Dialogue between East and West in Yokohama Photography«. In: A Timely Encounter. Nineteenth-Century Photographs of Japan, hg. v. Melissa Banta/Susan Taylor, Kat. (Peabody Museum of Archaeology and Ethnology and the Wellesley College Museum), Cambridge, Mass., 23-37.

Jacobi, Tom/Siemens, Jochen (1999): »Generation Konfus. Japans Kinder und die Spaßgesellschaft«. In: Stern, Jg. 52, Heft 26, Hamburg, 68-78.

Jäger, Gottfried (2005): »Bildsystem Fotografie«. In: Bildwissenschaft. Disziplinen, Themen, Methoden, hg. v. Klaus Sachs-Hombach, Frankfurt a.M., 349-364. 
Jäkel, Lutz (2007): »Starfotograf Ara Güler. Das scharfe Auge des alten Istanbul«. In: Spiegel-Online vom 7.5.2007, http://www.spiegel.de/reise/ fernweh/0,1518,476927,00.html.

Jamme, Christoph (2002): »Gibt es eine Wissenschaft des Fremden? Zur aktuellen Theoriedebatte zwischen Philosophie und Ethnologie«. In: Fremderfahrung und Repräsentation, hg. v. Iris Därmann/Christoph Jamme, Weilerswist, 183-208.

Jarman, Francis (1998): The Perception of Asia. Japan and the West, Hildesheim.

Jocks, Heinz-Norbert (2004): »Der Gebrauch der Fotografie. Ein Versuch über die Fotologie«. In: Kunstforum International, Bd. 171 (Juli-August 2004), Ruppichteroth, 37-79.

Jonas, Hans (2001): »Homo Pictor: Von der Freiheit des Bildens«. In: Was ist ein Bild?, hg. v. Gottfried Boehm, 3. Aufl., München, 105-124.

Jouffroy, Alain (1982): »La Torre di Babele di William Klein«. In: I Grandi Fotografi: William Klein, hg. v. Gruppo editoriale Fabbri, Mailand, 4-8.

Kaempfer, Engelbert (1964): Geschichte und Beschreibung Japans. Aus den Originalhandschriften des Verfassers hg. von Christian Wilhelm Dohm, unveränderter Neudruck des 1777-79 im Verlag der Meyerschen Buchhandlung in Lemgo erschienenen Originalwerks mit einer Einführung von Hanno Beck, Stuttgart.

Kaijima, Momoyo/Kuroda, Junzo/Tsukamoto, Yoshiharu (2001): Made in Tokyo, Tokyo.

Kaneko, Ryuichi (2003): »Realism and Propaganda. The Photographer's Eye Trained on Society«. In: The History of Japanese Photography, hg. v. Anne Wilkes Tucker, Kat. (The Museum of Fine Arts, Houston), Houston, 184-207.

Kapitza, Peter (2001): Engelbert Kaempfer und die Europäische Aufklärung. Dem Andenken des Lemgoer Reisenden aus Anlaß seines 350. Geburtstags am 16. September 2001, München.

Karl Baedecker GmbH (Hg.) (1993): Japan, Ostfildern-Kemnat.

Kaufhold, Enno (1994): »Reisen zum Menschen. Der Fotograf Fritz Henle«. In: Fritz Henle 1909 - 1993. Die Quadratur der Schönheit. Retrospektive für den Fotografen Fritz Henle, hg. v. Museum für Kunst und Kulturgeschichte der Stadt Dortmund, Kat. (Museum für Kunst und Kulturgeschichte der Stadt Dortmund), Heidelberg, 10-21.

Kaufhold, Enno (2000): »Ed van der Elsken, Fotograf, das bin ich. Fotojournalismus als Individualismus«. In: Fotografie + Film 1949-1990, Kat. (Kunstmuseum Wolfsburg), Ostfildern-Ruit, 22-25.

Kemp, Wolfgang (Hg.) (1980): Theorie der Fotografie I. 1839-1912, München.

Kemp, Wolfgang (Hg.) (1979): Theorie der Fotografie II. 1912-1945, München.

Kemp Wolfgang (Hg.) (1983): Theorie der Fotografie III. 1945-1980, München.

Kinoshita, Naoyuki (2003): »The Early Years of Japanese Photography«. In: The History of Japanese Photography, hg. v. Anne Wilkes Tucker, Kat. (The Museum of Fine Arts, Houston), Houston, 16-35.

Klein, William (1956): Life is Good and Good for you in New York: Trance Witness Revels, Paris/u.a.

Klein, William (1965): Tokio, Hamburg.

Klein, William (1989): Close Up, Heidelberg.

Kobayashi, Audrey (2002): »Cherry Blossoms«. In: Encyclopedia of Contemporary Japanese Culture, hg. v. Sandra Buckley, London/New York, 63. 
Koenig, Thilo (1998): »Die andere Seite der Gesellschaft. Die Erforschung des Sozialen«. In: Neue Geschichte der Fotografie, hg. v. Michel Frizot, Köln (franz. Orig. 1994), 346-357.

Kohl, Karl-Heinz (1993): Ethnologie - die Wissenschaft vom kulturell Fremden. Eine Einführung, München.

Koithahn, Corinna (2000): Manga - der japanische Comic, http://www. linse.uni-due.de/Projekte/comicsprache/manga_akira/manga01.htm, 17.07.2008.

Koller, Jörg (2001): Fordismus und Schichtarbeit, http://www.uni-muenster. de/PeaCon/kapzeit/Fordismus.htm, 17.07.2008.

Kracauer, Siegfried (1964): Theorie des Films. Die Errettung der äußeren Wirklichkeit, hg. v. Karsten Witte, Frankfurt a.M.

Krase, Andreas (1995a): »Die Ferne aus der Nähe. Die Japanbilder des Barons von Stillfried-Rathenicz«, in: NBK, Nr. 4/5, 48-51.

Krase, Andreas (1995b): »Paul Graham - Fotografien aus Japan 1989-1995«, in: NBK, Nr. 4/5, 52-53.

Krebs, Gerhard (2002): »Japan und Preußen. Zur Einführung«. In: Japan und Preußen, hg. v. Gerhard Krebs, München, 11-15.

Krech, Hartmut (1984): »Lichtbilder vom Menschen. Vom Typenbild zur anthropologischen Fotografie«. In: Fotogeschichte, Jg. 4, Heft 14, hg. v. Timm Starl, 3-15.

Kreiner, Josef (1993): »Vom paradiesischen Zipangu zum zurückgebliebenen Schwellenland - das europäische Japanbild vom 16. bis zum 19. Jahrhundert«. In: Japan und Europa: 1543-1929. Essays, hg. v. Berliner Festspiele GmbH, Essayband zur Ausstellung (Martin-Gropius-Bau Berlin), Berlin, 18-26.

Kreiner, Josef (1994): »Some Personal Reflections on Japanese Studies«. In: Japan in Global Context. Papers presented on the Occasion of the fifth Anniversary of the German Institute for Japanese Studies, Tokyo, hg. v. Josef Kreiner, München, 47-54.

Kreiner, Josef/Ölschleger, Hans Dieter (1996): »Preface«. In: Japanese Culture and Society. Models of Interpretation, hg. v. Josef Kreiner/Hans Dieter Ölschleger, München, 7-15.

Kristeva, Julia (1990): Fremde sind wir uns selbst, Frankfurt a.M. 1990.

Krusche, Dietrich (1973): Japan. Konkrete Fremde. Eine Kritik der Modalitäten europäischer Erfahrung von Fremde, München.

Kulessa, Detlef (1989): Vision und Dokumentation. Sozial-dokumentarische Photographie der 30er Jahre in den USA: eine ikonologische Betrachtung, Frankfurt a.M.

Lampe, Gerhard (2002): »Dokumentarfilm«. In: Metzler-Lexikon Medientheorie - Medienwissenschaft: Ansätze - Personen -Grundbegriffe, hg. v. Helmut Schanze, Stuttgart/Weimar, 68-72.

Landmann, Michael (1975): »Das Fremde und die Entfremdung«. In: Entfremdung, hg. v. Heinz-Horst Schrey, Darmstadt.

Landsberg, Mitchell (o.J.): Fifty Years Later, Iwo Jima Photographer Fights His Own Battle, http://www.ap.org/pages/about/pulitzer/rosenthal.html, 17.07.2008.

Langford, Mike (1991): Japan, Oxford.

Lebeck, Robert (2006): »Neugierig auf die Welt. Ein Gespräch mit HeinzNorbert Jocks«. In: Kunstforum International, Bd. 181 (Juli-September 2006), Ruppichteroth, 155-177. 
Lewin, Bruno (1967): Kleines Wörterbuch der Japanologie, Wiesbaden.

Linhart, Ruth (1990): »Der Traum vom Glück. Liebe, Sex und Partnerschaft«. In: Nippons neue Frauen, hg. v. Ruth Linhart/Fleur Wöss, Reinbek, 54-68

Lippmann, Walter (1964): Die öffentliche Meinung, München (engl. Orig. 1922).

Lockemann, Bettina (2004): »Das Fremde sehen. Der Blick auf Japan in Paul Grahams Künstlerbuch >Empty Heaven««. In: Printed Matter: Fotografie im/und Buch, hg. v. Barbara Lange, Leipzig, 125-135.

Lockemann, Bettina/Neudörfl, Elisabeth (1999): Plan, hg. v. Institut für Buchkunst Leipzig, Leipzig.

Low, Morris (2002): »Just-in-Time-Delivery«. In: Encyclopedia of Contemporary Japanese Culture, hg. v. Sandra Buckley, London/New York, $241 \mathrm{f}$

Lüscher, Ingeborg (1996): Japanische Glückszettel, Frankfurt a.M.

Luhmann, Niklas (1996): Die Realität der Massenmedien, 2., erweiterte Auflage, Opladen (1995).

Luig, Klaus (1990): »Rudolf von Gneist (1816-1895) und die japanische Verfassung von 1889«. In: Kulturvermittler zwischen Japan und Deutschland. Biographische Skizzen aus vier Jahrhunderten, hg. v. Japanisches Kulturinstitut Köln, Frankfurt a.M./New York, 50-77.

Mae, Michiko (2001): »Transkulturalität als neues Paradigma für die kulturund sozialwissenschaftliche Japanforschung«. In: Jahrbuch der Heinrich Heine Universität Düsseldorf, hg. v. Gert Kaiser, Düsseldorf, 258-265.

Mathias-Pauer, Regine (1984): »Deutsche Meinungen zu Japan. Von der Reichsgründung bis zum Dritten Reich«. In: Deutschland und Japan. Historische Kontakte, hg. v. Josef Kreiner, Bonn, 121-132.

Malinowski, Bronislaw (1979): Argonauten des westlichen Pazifik. Ein Bericht über Unternehmungen und Abenteuer der Eingeborenen in den Inselwelten von Melanesisch-Neuguinea, Schriften Bd.1, hg. von F. Kramer, Frankfurt a.M. (engl. Orig. 1922).

Malinowski, Bronislaw (1986): Ein Tagebuch im strikten Sinn des Wortes. Neuguinea 1914-1918. Schriften Bd. 4/1, hg. von F. Kramer, Frankfurt a.M. (engl. Orig. 1967).

Manz, Wolfgang (1968): Das Stereotyp. Zur Operationalisierung eines sozialwissenschaftlichen Begriffs, Meisenheim.

Martinez, Romeo E. (1978): »Eugène Atget 1857-1927«. In: Eugène Atget. Das alte Paris, hg. v. Rheinisches Landesmuseum Bonn, Kat. (Rheinisches Landesmuseum Bonn), Bonn, 9-13.

Matz, Reinhard (1981): »Gegen einen naiven Begriff der Dokumentarfotografie«, in: European Photography, Nr. 6, Vol. 2, April/May/June 1981, Göttingen, 6-12.

Martin, Bernd (2002): »Die preußische Ostasienexpedition und der Vertrag über Freundschaft, Handel und Schiffahrt mit Japan (24. Januar 1861)«. In: Japan und Preußen, hg. v. Gerhard Krebs, München, 77-101.

Matsumoto, David (2002): The New Japan. Debunking Seven Cultural Stereotypes, Yarmouth/London.

McGrane, Bernard (1989): Beyond Anthropology. Society and the Other, New York.

McNight, Anne (2002): »Pink Films«. In: Encyclopedia of Contemporary Japanese Culture, hg. v. Sandra Buckley, London/New York, 391. 
Meckel, Andreas (1990): »Jacob Meckel (1842-1906), Instrukteur der japanischen Armee - ein Leben im preußischen Zeitgeist«. In: Kulturvermittler zwischen Japan und Deutschland. Biographische Skizzen aus vier Jahrhunderten, hg. v. Japanisches Kulturinstitut Köln, Frankfurt a.M./New York, 78-98.

Meene, Hellen van (2006): Tokyo Girls, hg. v. Yusaku Imamura, Kat. (Tokyo Wonder Site Shibuya), Tokyo.

Mehl, Heinrich (1994): »Das wahre Gesicht Japans? - Das Japan-Bild in deutschen illustrierten Zeitschriften der letzten 150 Jahre«. In: Vertraute Fremde: Anmerkungen zu Kultur, Politik und Pädagogik in Japan und Deutschland, Festschrift Satoru Kurisaki, hg. v. Heinrich Mehl/Hansjörg Meyer, München, 29-59.

Meinhardt, H. (1971): »Andersheit, Anderssein«. In: Historisches Wörterbuch der Philosophie. Völlig neubearbeitete Ausgabe des >Wörterbuchs der philosophischen Begriffe` von Rudolf Eisler, hg. v. Joachim Ritter/ Karlfried Gründer, Bd. 1, Darmstadt, Sp. 297-300.

Menne, A. (1972): »Fremd, Fremdheit«. In: Historisches Wörterbuch der Philosophie. Völlig neubearbeitete Ausgabe des $>$ Wörterbuchs der philosophischen Begriffer von Rudolf Eisler, hg. v. Joachim Ritter/ Karlfried Gründer, Bd. 1, Darmstadt, Sp. 1102.

Merian (1972): Tokio, Heft 2, 25. Jahrgang, Hamburg.

Merian (1992): Tokio und Japan, Heft 12, 45. Jahrgang, Hamburg.

Metz, Christian (2003): »Foto, Fetisch«. In: Diskurse der Fotografie. Fotokritik am Ende des fotografischen Zeitalters, hg. v. Herta Wolf, Frankfurt a.M. (engl. Orig. 1985), 215-225.

Meyer, Hansjörg (1994): »Vermittelte Fremde - Notizen zu Lafcadio Hearn«. In: Vertraute Fremde: Anmerkungen zu Kultur, Politik und Pädagogik in Japan und Deutschland, Festschrift Satoru Kurisaki, hg. v. Heinrich Mehl/Hansjörg Meyer, München, 60-90.

Meyers Taschenlexikon in 10 Bänden (1985): »Konfuzianismus«. In: Band 5, Mannheim, 269.

Meyers Taschenlexikon in 24 Bänden (1990): »Entropie«. In: Band 6, 3. aktualisierte Auflage, Mannheim, 170.

Minato, Chihiro (1998): »Japan und die Fotografie. Die Begegnung mit dem anderen«. In: Neue Geschichte der Fotografie, hg. v. Michel Frizot, Köln (franz. Orig. 1994), 686-693.

Mohanty, J.N. (1998): »Epilogue: Culture Theory and Practice«. In: Cultural Otherness and Beyond, hg. v. Chhandra Gupta/D.P. Chattopadhyaya, Leiden/u.a., 239-245.

Morphy, Howard/Banks, Marcus (1997): »Introduction: Rethinking Visual Anthropology«. In: Rethinking Visual Anthropology, hg. v. Marcus Banks/Howard Morphy, New Haven/London 1997, 1-35.

Murakami Haruki (1995): Hard-boiled wonderland und das Ende der Welt, Frankfurt a.M.

Nagai, Paul Takashi (1962): Die Glocken von Nagasaki. Geschichte der Atombombe, 8. Auflage, München (1955).

Nakai, Akio (2002): »Das japanische Preußen-Bild in historischer Perspektive«. In: Japan und Preußen, hg. v. Gerhard Krebs, München, 17-30.

Natori, Younosuke (1942): Groß-Japan. Dai Nippon, mit einer Einleitung von Dr. F. Rumpf, 2. Auflage, Starnberger See (1937). 
Nemitz, Barbara (Hg.) (2006): Pink. The Exposed Color in Contemporary Art and Culture, Ostfildern-Ruit.

Neudörfl, Elisabeth (1993a): Burn Warehouse Burn, unveröffentlichtes Künstlerbuch (Unikat).

Neudörfl, Elisabeth (1993b): o.T. (Japan-Buch), unveröffentlichtes Künstlerbuch (Unikat).

Neudörfl, Elisabeth (1994): venceremos, unveröffentlichtes Künstlerbuch (Unikat).

Neudörfl, Elisabeth (1997): Konzept. Künstliche Welten - Fotoprojekt über das Sicherheitsbedürfnis in Japan, unveröffentlichtes Konzeptpapier.

Neudörfl, Elisabeth (2002): Future World, Kat. (Sprengel Museum Hannover), Hannover.

Neudörfl, Elisabeth (2006): Super Pussy Bangkok, hg. v. Institut für Buchkunst Leipzig, Leipzig.

Neudörfl, Elisabeth (2007): »der Stadt (1998)«. In: Set 4. Wege zur Selbstverständlichkeit, Kat. (Fotomuseum Winterthur), Winterthur, 19.

Neumann, Pia (1996): Metaphern des Misslingens. Amerikanische Dokumentarfotografie der sechziger und siebziger Jahre zwischen Konzeptkunst und Gesellschaftskritik, Frankfurt a.M.

Newhall, Beaumont (1984a): Geschichte der Photographie, München.

Newhall, Beaumont (1984b): »A Backward Glance at Documentary«. In: Observations. Essays on Documentary Photography, hg. v. David Featherstone, Untitled Bd. 35, Carmel, 1-6.

Noble, Gregory W. (2002): »Auto Industry«. In: Encyclopedia of Contemporary Japanese Culture, hg. v. Sandra Buckley, London/New York, 36-38.

Nohara, Komakichi (1935): Das wahre Gesicht Japans. Ein Japaner über Japan, Dresden.

Oakes, Penelope J./Reynolds, Katherine J. (1997): »Asking the Accuracy Question: Is Measurement the Answer?« In: The Social Psychology of Stereotyping and Group Life, hg. v. Russell Spears/et al., Oxford, 51-71.

Ölschleger, Hans Dieter (1996): »The Tumbling Walls of the Ivory Tower: Cultral Anthropology Meets the Japanese«. In: Japanese Culture and Society. Model of Interpretation, hg. v. Josef Kreiner/Hans Dieter Ölschleger München, 81-107.

Osborne, Peter D. (2000): Travelling Light. Photography and Visual Culture, Manchester/New York.

Pekar, Thomas (2000): »Der Japan-Diskurs um 1900. Ein Skizzierungsversuch«. In: Ostasienrezeption zwischen Klischee und Innovation, hg. v. Walter Gebhard, München, 227-254.

Peress, Gilles (1994): Farewell to Bosnia, Zürich.

Peters, Kathrin (2001): Netzgespräch: Wirklichkeitsfotografie. Mit Susanne Holschbach, Christine Karallus, Kathrin Peters, Maren Polte, Inka Schube, Fabian Stech, http://nachdemfilm.de/no2/wir01dts.html, 17.07.2008.

Pfab, Rupert (2001): Studien zur Düsseldorfer Photographie. Die frühen Akademieschüler von Bernd Becher, Weimar.

Philipp, Claudia Gabriele (1991): »Ein west-östlicher Dialog«. In: Felice Beato in Japan. Photographien zum Ende der Feudalzeit 1863-1873, hg. v. Claudia G. Philipp/Dietmar Siegert/Rainer Wick, Heidelberg, 6-10.

Philipp, Claudia G./Siegert, Dietmar/Wick, Rainer (Hg.) (1991): Felice Beato in Japan. Photographien zum Ende der Feudalzeit 1863-1873, Heidelberg. 
Phillips, Sandra S. (2004): »Currents in Photography in Postwar Japan«. In: Shomei Tomatsu. Skin of the Nation, hg. v. Leo Rubinfien/Sandra S. Phillips, Kat. (San Francisco Museum of Modern Art), New Haven/ London, 42-57.

Pickering, Michael (2001): Stereotyping. The Politics of Representation, New York.

Pink, Sarah (2001): Doing Visual Ethnography. Images, Media and Representation in Research, London/u.a.

Pinney, Christopher (1992): »The Parallel Histories of Anthropology and Photography«. In: Anthropology and Photography 1860-1920, hg. v. Elizabeth Edwards, New Haven/London, 74-95.

Platinum Print (1915): »An Advertisement Pictured with the Struss Pictorial Lense«. In: Platinum Print, Bd. II, Nr. 1/1915, 16.

Plessner, Helmuth (1953): »Mit anderen Augen«. In: Zwischen Philosophie und Gesellschaft. Ausgewählte Abhandlungen und Vorträge, hg. v. Helmuth Plessner, Bern.

Plumpe, Gerhard (1990): Der tote Blick. Zum Diskurs der Photographie in der Zeit des Realismus, München.

Pohl, Klaus (1983a): »Ansichten der Ferne: Vorwort«. In: Ansichten der Ferne. Reisephotographie 1850 - heute, hg. v. Klaus Pohl, Kat. (Deutscher Werkbund, Hessisches Landesmuseum Darmstadt), Giessen, 4-6.

Pohl, Klaus (1983b): »Die Welt für Jedermann. Reisephotographie in deutschen Illustrierten der zwanziger und dreißiger Jahre«. In: Ansichten der Ferne. Reisephotographie 1850 - heute, hg. v. Klaus Pohl, Kat. (Deutscher Werkbund, Hessisches Landesmuseum Darmstadt), Giessen, 96-127.

Pohl, Manfred (1997a): »Deutsch-japanische Beziehungen«. In: Informationen zur politischen Bildung, Nr. 255/1997, 52-53.

Pohl, Manfred (1997b): »Glossar«. In: Informationen zur politischen Bildung, Nr. 255/1997, 54-56.

Pohl, Manfred (2002): Geschichte Japans, München.

Poignant, Roslyn (1992): »Surveying the Field of View: The Making of the RAI Photographic Collection«. In: Anthropology and Photography 18601920, hg. v. Elizabeth Edwards, New Haven/London, 42-73.

Pompe, Hedwig (2003): »Eine Handreichung zum Thema«. In: Manus Loquens. Medium der Geste - Gesten der Medien, hg. v. Matthias Bickenbach/Annina Klappert/Hedwig Pompe, Köln, 8-25.

Porra, Véronique (2000): »Die fiktionale Verarbeitung der >Gelben Gefahr als Artikulation frankozentrischer Diskurse. Das Beispiel von Danrits L'Invasion jaune (1905-1909)«. In: Ostasienrezeption zwischen Klischee und Innovation, hg. v. Walter Gebhard, München, 185-207.

Pountney, H. (1971): Police Photography, London.

Pratt, Mary Louise (1992): Imperial Eyes. Travel Writing and Transculturation, London.

Pultz, John (1998): »Strenge und Klarheit. Die Neue Fotografie in den Vereinigten Staaten, 1920-1940«. In: Neue Geschichte der Fotografie, hg. v. Michel Frizot, Köln 1998 (franz. Orig. 1994), 476-493.

Raphael, Kurt (1933): »Das soziale Motiv und seine Gestaltung«. In: Deutscher Kamera-Almanach, 1933.

Reese, Heinz-Dieter (o.J.): Zu den Aufnahmen. (3) Kokû (Leerer Himmel), http://www.traurigetropen.de/reiher02.htm, 17.07.2008. 
Rehkämper, Klaus (2005): »Ist der Begriff der bildhaften Ähnlichkeit wirklich undefinierbar?« In: Bildwissenschaft zwischen Reflexion und Anwendung, hg. v. Klaus Sachs-Hombach, Köln, 242-250.

Reicher, Stephen/Hopkins, Nick/Condor, Susan (1997): »Stereotype Construction as a Strategy of Influence«. In: The Social Psychology of Stereotyping and Group Life, hg. v. Russell Spears/et al., Oxford, 94-118.

Reichert, Folker E. (1993): »Zipangu - Japans Entdeckung im Mittelalter«. In: Japan und Europa: 1543-1929, hg. v. Doris Croissant/Lothar Ledderose/u.a., Kat. (Martin-Gropius-Bau Berlin), Berlin, 25-36.

Reinfried, Heinrich (1996): »Anpassung und Widerstand in der Rezeption der europäischen Kultur im Japan des 19. Jahrhunderts«. In: Die Begegnung mit dem Fremden. Wertungen und Wirkungen in Hochkulturen vom Altertum bis zur Gegenwart, hg. v. Meinhard Schuster, Stuttgart/Leipzig, 184-203.

Ritchin, Fred (1998): »Zeitzeugen. Das Engagement des Fotojournalisten«. In: Neue Geschichte der Fotografie, hg. v. Michel Frizot (Hg.), Köln (franz. Orig. 1994), 590-611.

Rohde, Miriam (1997): »Grundlagen der Außenpolitik«. In: Informationen zur politischen Bildung, Nr. 255/1997, 46-51.

Rosenberger, Nancy R. (1996): »Fragile Resistance, Signs of Status. Women between State and Media in Japan«. In: Re-Imaging Japanese Women, hg. v. Anne E. Imamura, Berkeley/u.a., 12-45.

Rosler, Martha (1999): »Drinnen, Drumherum und nachträgliche Gedanken (zur Dokumentarfotografie)«. In: Martha Rosler. Positionen in der Lebenswelt, hg. v. Sabine Breitwieser, Wien/Köln (engl. Orig. 1981), 105-148.

Roth, Gerhard (1998): Das Gehirn und seine Wirklichkeit. Kognitive Neurobiologie und ihre philosophischen Konsequenzen, Frankfurt a.M.

Roth, Klaus (1998): »»Bilder in den Köpfen`. Stereotypen, Mythen und Identitäten aus ethnologischer Sicht«. In: Das Bild vom Anderen: Identitäten, Mentalitäten, Mythen und Stereotypen in multiethnischen europäischen Regionen, hg. v. Valeria Heuberger/Arnold Suppan/Elisabeth Vyslonzil, Frankfurt a.M./u.a., 21-44.

Rothstein, Arthur (1986): Documentary Photography, Boston/London.

Rumpf, Marianne (1990): »Emil Orlik (1870-1932) und Fritz Rumpf (18881949) - Deutsche Künstler reisen nach Japan«. In: Kulturvermittler zwischen Japan und Deutschland: biographische Skizzen aus vier Jahrhunderten, hg. v. Japanisches Kulturinstitut Köln, Frankfurt a.M./New York, 178-193.

Rupp, Katherine (2003): Gift-Giving in Japan. Cash, Connections, Cosmologies, Stanford.

Sachs-Hombach, Klaus (2006): Das Bild als kommunikatives Medium. Elemente einer allgemeinen Bildwissenschaft, Köln.

Sachsse, Rolf (1983): »Heimat als Reiseland«. In: Ansichten der Ferne. Reisephotographie 1850 - heute, hg. v. Klaus Pohl, Kat. (Deutscher Werkbund, Hessisches Landesmuseum Darmstadt), Giessen, 129-150.

Sachsse, Rolf (2003): Fotografie. Vom technischen Bildmittel zur Krise der Repräsentation, Köln.

Said, Edward W. (1995): Orientalism. Western Conceptions of the Orient, Neudruck mit neuem Nachwort, London (1978).

Salgado, Sebastiao (1993): Workers, New York. 
Salmon, Naomi Tereza (2000): »Japan tomography«. In: European Eyes on Japan. Japan Today. Vol. 1, hg. v. The EU-Japan Fest Japan Committee, Tokyo, 70-87.

Saure, Gabriele (1992): »Eine neue Künstlergilde? Serielle Bildformen in der illustrierten Presse 1925 bis 1944«. In: Photo-Sequenzen. Reportagen. Bildergeschichten. Serien aus dem Ullstein-Bilderdienst von 1925 bis 1944, hg. v. Thomas Kempas/Gabriele Saure, Kat. (Haus am Waldsee, Berlin), Berlin, 19-38.

Scheerer, E./et al. (1992): »Repräsentation«. In: Historisches Wörterbuch der Philosophie. Völlig neubearbeitete Ausgabe des >Wörterbuchs der philosophischen Begriffe $<$ von Rudolf Eisler, hg. v. Joachim Ritter/Karlfried Gründer, Bd. 8, Darmstadt, Sp.790-853.

Schwabe, Alexander (2007): »Bilderkrieg. Islamisten drohen preisgekröntem Fotografen mit dem Tod«. In: Spiegel Online vom 26. Januar 2007, http://www.spiegel.de/politik/ausland/0,1518,462052,00.html, 17.07.2008.

Schwindt, Martin/Hammitzsch, Horst (Hg.) (1974): Bernhardus Varenius: Descriptio Regni Japoniae cum quibusdam affinis materiae: Ex variis auctoribus collecta et in ordinem redacta per Bernhardum Varenium: Beschreibung des japanischen Reiches: Amsterdam 1649, übers. von F.-C. Volkmann, Darmstadt.

Schilling, Heiner (2000): »The Entropic Forest. Photographs«. In: The Entropic Forest, Heiner Schilling/Hiroo Yamagata, Kat. (Yokohama Museum of Art), Yokohama.

Schindlbeck, Markus (1989): »Die ethnographische Photographie in der Berliner Gesellschaft für Anthropologie, Ethnologie und Urgeschichte«. In: Die ethnographische Linse. Photographien aus dem Museum für Völkerkunde Berlin, hg. v. Markus Schindlbeck, Kat. (Museum für Völkerkunde Berlin), Berlin, 17-19.

Schliemann, Heinrich (1984): Reise durch China und Japan im Jahre 1865, Konstanz (franz. Orig. 1867).

Schneider, Roland (1990): »Karl Florenz, der Begründer der deutschen Japanologie«. In: Kulturvermittler zwischen Japan und Deutschland: biographische Skizzen aus vier Jahrhunderten, hg. v. Japanisches Kulturinstitut Köln, Frankfurt a.M./New York, 149-161.

Schneider, Ruth (o.J.): Shôjo Manga. Japanische Mädchencomics, http://www.japanlink.de/mk/mk_manga_shojo.shtml, 17.07.2008.

Schlieper, Andreas (1997): Die Nähe fremder Kulturen. Parallelen zwischen Japan und Deutschland, Franfurt a.M./New York.

Schönpflug, U. (1998): »Stereotyp«. In: Historisches Wörterbuch der Philosophie. Völlig neubearbeitete Ausgabe des >Wörterbuchs der philosophischen Begriffeく von Rudolf Eisler, hg. v. Joachim Ritter/Karlfried Gründer, Bd. 10, Darmstadt, Sp.135-139.

Schube, Inka (2002): Elisabeth Neudörfl. Future World, Begleittext zur Ausstellung, Sprengel Museum Hannover.

Screech, Timon (1993): »Rezeption und Interpretation der westlichen Perspektive im Japan des 18. Jahrhunderts«. In: Japan und Europa: 15431929, hg. v. Doris Croissant/Lothar Ledderose/u.a., Kat. (MartinGropius-Bau Berlin), Berlin, 128-137.

Segalen, Victor (1994): Die Ästhetik des Diversen. Versuch über den Exotismus, Frankfurt a.M. (dt. Erstausgabe 1983). 
Sekula, Allan (2000): »Den Modernismus demontieren, das Dokumentarische neu erfinden. Bemerkungen zur Politik der Repräsentation«. In: Theorie der Fotografie IV. 1980-1995, hg. v. Hubertus von Amelunxen, München 2000 (engl. Orig. 1976),120-129.

Shibata, Toshio (1999): The Quintessence of Japan, Kat. (Sprengel Museum Hannover), Hannover.

Shimada, Shingo (1994): Grenzgänge - Fremdgänge. Japan und Europa im Kulturvergleich, Frankfurt a.M./New York.

Shin'ichi, Miyajima (2003): »Die zwei Gesichter der japanischen Kunst«. In: Japans Schönheit, Japans Seele. Meisterwerke aus dem Tokyo National Museum. Die großen Sammlungen, hg. v. Kunst- und Ausstellungshalle der Bundesrepublik Deutschland, Kat. (Kunst- und Ausstellungshalle der Bundesrepublik Deutschland, Bonn), Bonn, 33-48.

Siebold, Philipp Franz von (1832-1858): Nippon: Archiv zur Beschreibung von Japan und dessen Neben und Schutzländern Jezo mit den südlichen Kurilen, Sachalin, Korea und den Liukiu-Inseln, Leiden.

Siegert, Dietmar (1991): »Felice Beaton in Japan«. In: Felice Beato in Japan. Photographien zum Ende der Feudalzeit 1863-1873, hg. v. Claudia G. Philipp/Dietmar Siegert/Rainer Wick, Heidelberg, 11-16.

Sloan, William J. (1974): »Documentary Film«. In: The Encyclopedia of Photography, hg. v. Willard D. Morgan, Vol. 7, New York/u.a., 1162-1170.

Solomon-Godeau, Abigail (2003): »Wer spricht so? Einige Fragen zur Dokumentarfotografie«. In: Diskurse der Fotografie. Fotokritik am Ende des fotografischen Zeitalters, hg. v. Herta Wolf (Hg.), Frankfurt a.M. (engl. Orig. 1991), 53-74.

Sontag, Susan (1991): Über Fotografie, Frankfurt a.M. (engl. Orig. 1977).

Sorensen, André (2002): The Making of Urban Japan. Cities and planning from Edo to the twenty-first century, London/New York.

Stahr, Henrick (2004): Fotojournalismus zwischen Exotismus und Rassismus. Darstellungen von Schwarzen und Indianern in Foto-Text-Artikeln deutscher Wochenillustrierter 1919-1939, Hamburg.

Stallybrass, O. (1977): Stereotype, London.

Stangor, Charles/Schaller, Mark (2000): »Stereotypes as Individual and Collective Representations «. In: Stereotypes and Prejudice, hg. v. Charles Stangor, Ann Arbor, 64-82.

Starl, Timm (2002): »Dokumentarische Fotografie«. In: DuMonts Begriffslexikon zur zeitgenössischen Kunst, hg. v. Hubertus Butin, Köln, 73-77.

Steinorth, Karl (1992): »Der Weg zum Fotoessay«. In: Photo-Sequenzen. Reportagen. Bildergeschichten. Serien aus dem Ullstein-Bilderdienst von 1925 bis 1944, hg. v. Thomas Kempas/Gabriele Saure, Kat. (Haus am Waldsee, Berlin), Berlin, 13-18.

Struth, Thomas (2002): Thomas Struth 1977-2002, Kat. (Dallas Museum of Art), Dallas.

Stryker, Roy E. (1974): »Documentary Photography«. In: The Encyclopedia of Photography, hg. v. Willard D. Morgan, Vol. 7, New York/u.a., 11791183.

Sugimoto, Yoshio (2002): »Japan in Comparison. Stocktaking and Future Agenda«. In: Japan im Vergleich, hg. v. Wolfgang Seifert/Claudia Weber, München, 23-29. 
Suhrbier, Mona B. (1995): »Fremde. Die Herausforderung des Anderen. Eine Einführung«. In: Fremde. Die Herausforderung des Anderen, hg. v. Mona Suhrbier, Kat. (Museum für Völkerkunde), Frankfurt a.M., 7-19.

Sullivan, Gerald (1999): Margaret Mead, Gregory Bateson, and Highland Bali: fieldwork photographs of Bayung Gedé, 1936-1939, Chicago.

Suppan, Arnold (1998): »Einleitung. Identitäten und Stereotypen in multiethnischen europäischen Regionen«. In: Das Bild vom Anderen: Identitäten, Mentalitäten, Mythen und Stereotypen in multiethnischen europäischen Regionen, hg. v. Valeria Heuberger/Arnold Suppan/Elisabeth Vyslonzil, Frankfurt a.M./u.a., 9-20.

Szarkowski, John (1985): »Annäherungen an Atget«. In: Eugène Atget 18571927. IV. Das neue Jahrhundert, hg. v. John Szarkowski/Maria Morris Hambourg, München, 9-33.

Tadashi, Yoshida (1993): »Rangaku - Die Holländischen Wissenschaften«. In: Japan und Europa: 1543-1929, hg. v. DorisCroissant/Lothar Ledderose/u.a., Kat. (Martin-Gropius-Bau Berlin), Berlin, 94-106.

Tagg, John (1988): The Burden of Representation. Essays on Photographs and Histories, Minneapolis.

Tajfel, Henri (1981): Human Groups and Social Categories, Cambridge.

Tajfel, Henri/Forgas, Joseph P. (2000), »Social Categorization: Cognitions, Values and Groups«. In: Stereotypes and Prejudice: Essential Readings, hg. v. Charles Stangor, Philadelphia (Orig. 1981), 49-63.

Tajima, Noriyuki (1996): Tokio. Ein Führer zur zeitgenössischen Architektur, Köln.

Tajima, Noriyuki/Powell, Catherine (1997): Tokyo. Labyrinth City, Köln.

Taylor, Charles (1995): Negative Freiheit? Zur Kritik des neuzeitlichen Individualismus, 2. Auflage, Frankfurt a.M. 1995 (engl. Orig. 1985).

The Estate of Walker Evans (Hg.) (1982): Walker Evans at Work, New York.

The EU-Japan Fest Japan Committee (Hg.) (2000a): European Eyes on Japan. Japan Today. Vol. 1, Tokyo.

The EU-Japan Fest Japan Committee (Hg.) (2000b): European Eyes on Japan. Japan Today. Vol. 2, Tokyo.

The EU-Japan Fest Japan Committee (Hg.) (2002): European Eyes on Japan. Japan Today. Vol. 4, Tokyo.

The EU-Japan Fest Japan Committee (Hg.) (2003): European Eyes on Japan. Japan Today. Vol. 5, Tokyo.

The EU-Japan Fest Japan Committee (Hg.) (2005): European Eyes on Japan. Japan Today. Vol. 7, Tokyo.

Theunissen, M. (1971): »Andere (der)«. In: Historisches Wörterbuch der Philosophie. Völlig neubearbeitete Ausgabe des $>$ Wörterbuchs der philosophischen Begriffe< von Rudolf Eisler, hg. v. Joachim Ritter/Karlfried Gründer, Bd. 1, Darmstadt, Sp.296-297.

Theye, Thomas (1983): »Ferne Länder - fremde Bilder. Das Bild Asiens in der Photographie des 19. Jahrhunderts«. In: Ansichten der Ferne. Reisephotographie 1850 - heute, hg. v. Klaus Pohl, Kat. (Deutscher Werkbund, Hessisches Landesmuseum Darmstadt), Giessen, 59-95.

Theye, Thomas (1989a): »Der geraubte Schatten: Einführung«. In: Der geraubte Schatten. Photographie als ethnographisches Dokument, hg. v. Thomas Theye, Kat. (Münchner Stadtmuseum), München/Luzern, 8-59.

Theye, Thomas (1989b): »Wir wollen nicht glauben, sondern schauen. Zur Geschichte der ethnographischen Fotografie im deutschsprachigen Raum 
im 19. Jahrhundert«. In: Der geraubte Schatten. Photographie als ethnographisches Dokument, hg. v. Thomas Theye, Kat. (Münchner Stadtmuseum), München/Luzern, 60-119.

Thompson, Jerry L. (1982): „Walker Evans: Some Notes on His Way of Working«. In: Walker Evans at Work, hg. v. The Estate of Walker Evans, New York, 9-17.

Timmerberg, Helge (1992): »Yakuza. Japans Mafia im Stress«. In: Merian, Tokio und Japan, Heft 12/45, 74-82.

Trachtenberg, Alan (1990): Reading American Photographs. Images as History. Mathew Brady to Walker Evans, New York.

Trauzettel, Rolf (1995): »Exotismus als intellektuelle Haltung«. In: Mein Bild in deinem Auge: Exotismus und Moderne; Deutschland - China im 20. Jahrhundert, hg. v. Wolfgang Kubin, Darmstadt, 1-16.

Tucker, Anne Wilkes (1984): »Photographic Facts and Thirties America«. In: Observations. Essays on Documentary Photography, hg. v. David Featherstone, Untitled Bd. 35, Carmel, 40-55.

Tucker, Anne Wilkes (2003): »The History of Japanese Photography: Introduction«. In: The History of Japanese Photography, hg. v. Anne Wilkes Tucker, Kat. (The Museum of Fine Arts, Houston), Houston, 2-13.

Turner, Judith (1995): Tokyo Marine Oyama Training Center, Tokyo.

Tyler, Stephen A. (1991): Das Unaussprechliche. Ethnographie, Diskurs und Rhetorik in der postmodernen Welt, München.

Tylor, E.B. (1871): Primitive Culture: Researches into the Development of Mythology, Philosophy, Language, Art and Custom, London.

Vianden, Heinz (1990): »Erwin Bälz (1849-1913) und die deutsche Medizin in Japan«. In: Kulturvermittler zwischen Japan und Deutschland. Biographische Skizzen aus vier Jahrhunderten, hg. v. Japanisches Kulturinstitut Köln, Frankfurt a.M./New York, 99-121.

Vos, Ken (1993): »Dejima und die Handelsbeziehungen zwischen den Niederlanden und dem vormodernen Japan«. In: Japan und Europa: $1543-$ 1929, hg. v. Doris Croissant/Lothar Ledderose/u.a., Kat. (MartinGropius-Bau Berlin), Berlin, 72-82.

Waldenfels, Bernhard (1989): »Erfahrungen des Fremden in Husserls Phänomenologie«. In: Profile der Phänomenologie. Zum 50. Todestag von Edmund Husserl, Phänomenologische Forschungen, Nr. 22, hg. v. Ernst Wolfgang Orth, München, 39-62.

Waldenfels, Bernhard (1997): Topographie des Fremden, Frankfurt a.M.

Waldenfels, Bernhard (2002): »Paradoxien ethnographischer Fremddarstellung«. In: Fremderfahrung und Repräsentation, hg. v. Iris Därmann/ Christoph Jamme, Weilerswist, 151-182.

Waplington, Nick (1997): Safety in Numbers, London.

Watanabe, Hiroshi (2001): The Architecture of Tôkyô, Stuttgart/London.

Weber, Claudia (1990): »Chancengleichheit per Gesetz«. In: Nippons neue Frauen, hg. v. Ruth Linhart/Fleur Wöss, Reinbek, 104-126.

Weber, Claudia (2002): »Der Gesellschaftsvergleich in der Soziologie«. In: Japan im Vergleich, hg. v. Wolfgang Seifert/Claudia Weber, München, 30-54.

Wenders, Wim/Wenders, Donata (2006): Journey to Onomichi, Kat. (Omotesando Hills, Tokyo), Tokyo. 
Werneburg, Brigitte (1996): »Für einen reflexiven Begriff der Dokumentarfotografie«. In: Dokumentarfotografie Förderpreise 1994/1995, hg. v. Wüstenrot Stiftung, Ludwigsburg, 74-79.

Weski, Thomas (2003): »Grausam und zärtlich«. In: Cruel and Tender. Zärtlich und grausam - Fotografie und das Wirkliche, hg. v. Thomas Weski/ Emma Dexter, Kat. (Museum Ludwig, Köln), Ostfildern-Ruit, 23-27.

Weski, Thomas (2004): »Feldarbeit«. In: Heinrich Riebesehl. Fotografische Serien 1963-2001, hg. v. Ulrike Schneider, Kat. (Sprengel Museum Hannover), Ostfildern-Ruit, 38-42.

Wiener, Michael (1990): Ikonographie des Wilden. Menschen-Bilder in Ethnographie und Photographie zwischen 1850 und 1918, München.

Wierlacher, Alois (1993): »Kulturwissenschaftliche Xenologie. Ausgangslage, Leitbegriffe und Problemfelder«. In: Kulturthema Fremdheit. Leitbegriffe und Problemfelder kulturwissenschaftlicher Fremdheitsforschung, hg. v. Alois Wierlacher, München, 19-114.

Wiesing, Lambert (2000): Phänomene im Bild, München.

Wiesing, Lambert (2005): Artifizielle Präsenz. Studien zur Philosophie des Bildes, Frankfurt a.M.

Wilkinson, Endymion (1982): Japan ist ganz anders. Geschichte eines großen Mißverständnisses, Königstein Ts.

Wilson, Andrew (1996): »History and the >Thinking« Photograph«. In: Paul Graham, hg. v. Phaidon Press Ltd., London, 38-103.

Winkel, Margarita (1991): Souvenirs from Japan. Japanese Photography at the Turn of the Century, London/Leiden.

Wittgenstein, Ludwig (1984): »Philosophische Untersuchungen«. In: Ludwig Wittgenstein, Werkausgabe Band I, Frankfurt a.M. (1953), 225-580.

Worat, Jörg (2002): »Ein anderer Fotoblick auf Japans Metropole«, in: Neue Presse, Hannover, 03.07.2002.

Wortmann, Volker (2004): »Die Magie der Oberfläche. Zum Wirklichkeitsversprechen der Fotografie«. In: Wirklich wahr! Realitätsversprechen von Fotografien, hg. v. Siegrid Schneider/Stefanie Grebe, Kat. (Ruhrlandmuseum Essen), Ostfildern-Ruit, 11-21.

Yamagata, Hiroo (2000): »The Entropic Forest. Text«. In: The Entropic Forest, Heiner Schilling/Hiroo Yamagata, Kat. (Yokohama Museum of Art), Yokohama.

Yamagishi, Shoji (1974): New Japanese Photography, hg. von John Szarkowski/Shoji Yamagishi, Kat. (Museum of Modern Art), New York.

Yokoe, Fuminori (2000): »Eine zeitlose Botschaft«. In: Ed van der Elsken, Fotografie + Film 1949-1990, Kat. (Kunstmuseum Wolfsburg), Ostfildern-Ruit, 159.

Yzerbyt, Vincent/Rocher, Steve/Schadron, Georges (1997): »Stereotypes as Explanations: A Subjective Essentialistic View of Group Perception«. In: The Social Psychology of Stereotyping and Group Life, hg. v. Russell Spears/et al., Oxford, 20-50. 


\section{Gespräche mit japanischen Fotografie-Experten}

Aya, Tomoka (2006): Gespräch zwischen Aya Tomoka, Galeristin der Third Gallery Aya in Osaka, und der Autorin am 31.5.2006 in Osaka. (Gespräch auf Englisch).

Enari, Tsuneo (2006): Gespräch zwischen Enari Tsuneo, Fotograf und Professor an der Kyushu Sangyo University, und der Autorin am 23.5.2006 in Fukuoka (Gespräch auf Japanisch mit englischer Übersetzung von Aron Browne).

Iizawa, Kôtarô (2006): Gespräch zwischen Iizawa Kôtarô, Foto-Kritiker und Publizist sowie Dozent am Tokyo College of Photography, und der Autorin am 26.6.2006 in Tokyo (Gespräch auf Englisch).

Ikeda, Yuko (2006): Gespräch zwischen Ikeda Yuko, Kuratorin am Kyoto National Museum of Modern Art, und der Autorin am 1.6.2006 in Kyoto (Gespräch auf Deutsch).

Kasahara, Michiko (2006): Gespräch zwischen Kasahara Michiko, Chefkuratorin des Tokyo Metropolitan Museum of Photography, und der Autorin am 12.5.2006 in Tokyo (Gespräch auf Englisch).

Kikuta, Mikiko (2006): Gespräch zwischen Kikuta Mikiko, Kuratorin des Projekts European Eyes on Japan, und der Autorin am 3.5.2006 in Tokyo (Gespräch auf Englisch).

Matsumoto, Kaoru (2006), Gespräch zwischen Matsumoto Kaoru, Kuratorin am Osaka Contemporary Art Space, und der Autorin am 31.5.2006 in Osaka (Gespräch auf Englisch).

Oshima, Naruki (2006): Gespräch zwischen Oshima Naruki, Fotograf und Dozent an der Kyoto Saiga University of Arts, und der Autorin am 2.6.2006 in Kyoto (Gespräch auf Englisch).

Saiga, Yuji (2006): Gespräch im Rahmen eines Privatseminars zwischen Saiga Yuji, Fotograf und Dozent am Tokyo College of Photography, und der Autorin sowie fünf Studierenden am 25.6.2006 in Tokyo (Gespräch auf Japanisch mit englischer Übersetzung von Hinohara Yuta).

Yoshihara, Mieko (2006), Gespräch zwischen Yoshihara Mieko, Kuratorin am Tokushima Modern Art Museum, und der Autorin am 29.5.2006 in Tokushima (Gespräch auf Englisch). 


\section{ZfK - Zeitschrift für Kulturwissenschaften}

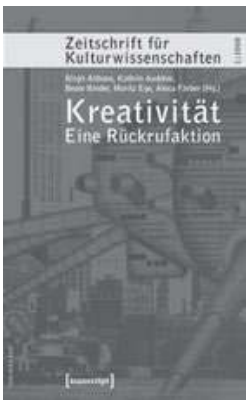

Birgit Althans, Kathrin Audem, Beate Binder, Moritz Ege, Alexa Färber (Hg.)

\section{Kreativität. Eine Rückrufaktion}

Zeitschrift für Kulturwissenschaften, Heft 1/2008

März 2008, 138 Seiten, kart., $8,50 €$

ISSN 9783-9331

\section{ZFK - Zeitschrift für Kulturwissenschaften}

Der Befund zu aktuellen Konzepten kulturwissenschaftlicher Analyse und Synthese ist ambivalent: Neben innovativen und qualitativ hochwertigen Ansätzen besonders jüngerer Forscher und Forscherinnen steht eine Masse oberflächlicher Antragsprosa und zeitgeistiger Wissensproduktion zugleich ist das Werk einer ganzen Generation interdisziplinärer Pioniere noch wenig erschlossen.

In dieser Situation soll die Zeitschrift für Kulturwissenschaften eine Plattform für Diskussion und Kontroverse über Kultur und die Kulturwissenschaften bieten. Die Gegenwart braucht mehr denn je reflektierte Kultur, historisch situiertes und sozial verantwortetes Wissen. Aus den Einzelwissenschaften heraus kann so mit klugen interdisziplinären Forschungsansätzen fruchtbar über die Rolle von Geschichte und Gedächtnis, von Erneuerung und Verstetigung, von Selbststeuerung und ökonomischer Umwälzung im Bereich der Kulturproduktion und der naturwissenschaftlichen Produktion von Wissen diskutiert werden.

Die Zeitschrift für Kulturwissenschaften lässt gerade auch jüngere Wissenschaftler und Wissenschaftlerinnen zu Wort kommen, die aktuelle fächerübergreifende Ansätze entwickeln.

\section{Lust auf mehr?}

Die Zeitschrift für Kulturwissenschaften erscheint zweimal jährlich in Themenheften. Bisher liegen die Ausgaben Fremde Dinge (1/2007), Filmwissenschaft als Kulturwissenschaft (2/2007) und Kreativität. Eine Rückrufaktion (1/2008) vor.

Die Zeitschrift für Kulturwissenschaften kann auch im Abonnement für den Preis von 8,50 € je Ausgabe bezogen werden.

Bestellung per E-Mail unter: bestellung.zfk@transcript-verlag.de 


\section{Kultur- und Medientheorie}

Alma-Elisa Kittner

Visuelle Autobiographien

Sammeln als Selbstentwurf bei Hannah Höch, Sophie Calle und Annette Messager

Dezember 2008, ca. 300 Seiten, kart., zahlr. Abb., ca. 29,80 €, ISBN: 978-3-89942-872-8

Christian Kassung (Hg.) Die Unordnung der Dinge Eine Wissens- und Mediengeschichte des Unfalls

Dezember 2008, ca. 400 Seiten, kart., zahlr. Abb., ca. 33,80 €, ISBN: 978-3-89942-721-9

Sandra Poppe,

Thorsten Schüller, Sascha Seiler (Hg.) 9/11 als kulturelle Zäsur Repräsentationen des 11. September 2001 in kulturellen

Diskursen, Literatur und visuellen Medien

Dezember 2008, ca. 294 Seiten, kart., ca. $28,80 €$,

ISBN: 978-3-8376-1016-1

Erika Fischer-Lichte, Kristiane Hasselmann, Alma-Elisa Kittner (Hg.) Kampf der Künste! Kultur im Zeichen von Medienkonkurrenz und Eventstrategien

Dezember 2008, ca. 300 Seiten, kart., zahlr. Abb., ca. 28,80 €, ISBN: 978-3-89942-873-5
Kathrin Ackermann, Christopher F. Laferl (Hg.) Transpositionen des Televisiven Fernsehen in Literatur und Film

Dezember 2008, ca. 200 Seiten, kart., zahlr. Abb., ca. 25,80 €, ISBN: 978-3-89942-938-1

Susanne Regener

Visuelle Gewalt

Menschenbilder aus

der Psychiatrie

des 20. Jahrhunderts

Dezember 2008, ca. 220 Seiten, kart., zahlr. Abb., ca. 25,80 €, ISBN: $978-3-89942-420-1$

Gerald Kapfhammer, Friederike Wille (Hg.)

"Grenzgänger"

Mittelalterliche

Jenseitsreisen

in Text und Bild

Dezember 2008, ca. 300 Seiten, kart., zahlr. Abb., ca. 31,80€, ISBN: 978-3-89942-888-9

Ulrike Haß,

Nikolaus Müller-Schöll (Hg.) Was ist eine Universität?

Schlaglichter auf eine ruinierte Institution Dezember 2008, ca. 16o Seiten, kart., ca. $12,80 €$, ISBN: 978-3-89942-907-7

Özkan Ezli, Dorothee Kimmich, Annette Werberger (Hg.) Wider den Kulturenzwang Migration, Kulturalisierung und Weltliteratur

November 2008, ca. 290 Seiten, kart., ca. $28,80 €$, ISBN: 978-3-89942-987-9

Leseproben und weitere Informationen finden Sie unter: www.transcript-verlag.de 


\section{Kultur- und Medientheorie}

Christian Pundt

Medien und Diskurs

Zur Skandalisierung

von Privatheit

in der Geschichte

des Fernsehens

November 2008, ca. 400 Seiten,

kart., ca. $36,80 €$,

ISBN: 978-3-89942-994-7

Doris Kolesch, Vito Pinto, Jenny Schrödl (Hg.)

\section{Stimm-Welten}

Philosophische,

medientheoretische und

ästhetische Perspektiven

November 2008, 232 Seiten,

kart., ca. $24,80 €$,

ISBN: 978-3-89942-904-6

Daniel Gethmann,

Susanne Hauser (Hg.)

Kulturtechnik Entwerfen

Praktiken, Konzepte

und Medien in Architektur und Design Science

November 2008, 300 Seiten,

kart., zahlr. Abb., ca. 29,80 €,

ISBN: 978-3-89942-901-5

York Kautt

Image

Zur Genealogie eines

Kommunikationscodes

der Massenmedien

November 2008, 370 Seiten,

kart., zahlr. Abb., 29,80 €,

ISBN: 978-3-89942-826-1

Kristiane Hasselmann

Die Rituale der Freimaurer

Zur Konstitution eines

bürgerlichen Habitus im

England des 18. Jahrhunderts

November 2008, ca. 300 Seiten,

kart., zahlr. Abb., ca. 29,80 €,

ISBN: 978-3-89942-803-2
Ines Kappert

Der Mann in der Krise oder: Kapitalismuskritik in der Mainstreamkultur

Oktober 2008, 250 Seiten, kart., $24,80 €$,

ISBN: 978-3-89942-897-1

Susanne von Falkenhausen

KugelbauVisionen

Kulturgeschichte

einer Bauform von der

Französischen Revolution

bis zum Medienzeitalter

Oktober 2008, 214 Seiten, kart., zahlr. Abb., 24,80 €, ISBN: 978-3-89942-945-9

Annette Bitsch

Diskrete Gespenster

Die Genealogie des

Unbewussten aus der

Medientheorie und

Philosophie

der Zeit

Oktober 2008, 552 Seiten, kart., $42,80 €$,

ISBN: 978-3-89942-958-9

Uwe Seifert, Jin Hyun Kim,

Anthony Moore (eds.)

Paradoxes of Interactivity

Perspectives for Media Theory,

Human-Computer Interaction, and Artistic Investigations

Oktober 2008, 344 Seiten,

kart., zahlr. Abb., 35,80 €,

ISBN: 978-3-89942-842-1

Ramón Reichert

Amateure im Netz

Selbstmanagement und

Wissenstechnik im Web 2.0

Oktober 2008, 246 Seiten,

kart., zahlr. z.T. farb. Abb., 24,80 €, ISBN: 978-3-89942-861-2

Leseproben und weitere Informationen finden Sie unter: www.transcript-verlag.de 


\section{Kultur- und Medientheorie}

Dorothee Kimmich,

Wolfgang Matzat (Hg.)

Der gepflegte Umgang

Interkulturelle Aspekte

der Höflichkeit in Literatur

und Sprache

Oktober 2008, 226 Seiten,

kart., 22,80 €

ISBN: 978-3-89942-820-9

Henri Schoenmakers,

Stefan Bläske,

Kay Kirchmann,

Jens Ruchatz (Hg.)

Theater und Medien/

Theatre and the Media

Grundlagen - Analysen -

Perspektiven.

Eine Bestandsaufnahme

September 2008, 584 Seiten,

kart., zahlr. z.T. farb. Abb., 19,80 €,

ISBN: 978-3-8376-1064-2

Gunther Gebhard,

Oliver Geisler,

Steffen Schröter (Hg.)

StreitKulturen

Polemische und

antagonistische

Konstellationen

in Geschichte

und Gegenwart

September 2008, 236 Seiten,

kart., 25,80 €,

ISBN: 978-3-89942-919-o

Michael Schetsche,

Martin Engelbrecht (Hg.)

Von Menschen und

Außerirdischen

Transterrestrische

Begegnungen im Spiegel

der Kulturwissenschaft

August 2008, 286 Seiten,

kart., 27,80 €

ISBN: $978-3-89942-855-1$
Christa Sommerer,

Laurent Mignonneau,

Dorothée King (eds.)

Interface Cultures

Artistic Aspects

of Interaction

August 2008, 348 Seiten, kart., zahlr. Abb., 34,80 €, ISBN: 978-3-89942-884-1

\section{Geert Lovink}

\section{Zero Comments}

Elemente einer kritischen Internetkultur

August 2008, 332 Seiten, kart., $28,80 €$,

ISBN: 978-3-89942-804-9

\section{Simone Loleit}

Wahrheit, Lüge, Fiktion:

Das Bad in der deutsch-

sprachigen Literatur

des 16. Jahrhunderts

Juli 2008, 390 Seiten,

kart., $41,80 €$,

ISBN: 978-3-89942-666-3

Antonia Wunderlich

Der Philosoph im Museum

Die Ausstellung

"Les Immatériaux" von

Jean François Lyotard

Juli 2008, 264 Seiten,

kart., zahlr. Abb., $28,80 €$,

ISBN: $978-3-89942-937-4$

Claudia Lillge,

Anne-Rose Meyer (Hg.)

Interkulturelle Mahlzeiten

Kulinarische Begegnungen und

Kommunikation in der Literatur

Juni 2008, 370 Seiten,

kart., $30,80 €$,

ISBN: $978-3-89942-881-0$

Leseproben und weitere Informationen finden Sie unter: www.transcript-verlag.de 
